\author{
UNIVERSIDADE DE SÃO PAULO \\ FACULDADE DE FILOSOFIA, LETRAS E CIÊNCIAS HUMANAS \\ DEPARTAMENTO DE GEOGRAFIA
}

\title{
ANÁLISE ESTATÍSTICA DE UMA SÉRIE HISTÓRICA DE PRECIPITAÇÃO HORÁRIA NA CIDADE DE SÃO PAULO (1970 A 2009)
}

Versão Corrigida

DANIEL MENDES 


\title{
UNIVERSIDADE DE SÃO PAULO \\ FACULDADE DE FILOSOFIA, LETRAS E CIÊNCIAS HUMANAS \\ DEPARTAMENTO DE GEOGRAFIA
}

\section{ANÁLISE ESTATÍSTICA DE UMA SÉRIE HISTÓRICA DE PRECIPITAÇÃO HORÁRIA NA CIDADE DE SÃO PAULO (1970-2009)}

\author{
Versão Corrigida
}

DANIEL MENDES

\author{
Dissertação submetida ao Programa de Pós- \\ Graduação em Geografia Física da Universidade de \\ São Paulo, Faculdade de Filosofia, Letras e Ciências \\ Humanas, para a obtenção do titulo de Mestre. \\ Área de concentração: Estudos teóricos aplicados em \\ Climatologia.
}

Orientadora: Prof $^{a}$. Dr ${ }^{a}$. Maria Elisa Siqueira Silva

SÃO PAULO 
De acordo com a Resolução CoPGr 6018, de 13/10/2011, eu, Dra. Maria Elisa Siqueira Silva, na qualidade de orientadora, declaro que o aluno de mestrado Daniel Mendes cumpriu com as normas estabelecidas e realizou a revisão na forma legal da resolução vigente através de uma versão corrigida. 
Catalogação na Publicação

Serviço de Biblioteca e Documentação

Faculdade de Filosofia, Letras e Ciências Humanas da Universidade de São Paulo

\section{Mendes, Daniel \\ M538a ANÁLISE ESTATÍSTICA DE UMA SÉRIE HISTÓRICA DE PRECIPITAÇÃO HORÁRIA NA CIDADE DE SÃO PAULO (1970- 2009) / Daniel Mendes; orientadora Maria Elisa Siqueira Silva. São Paulo, 2013.} $250 \mathrm{f}$.

Dissertação (Mestrado)- Faculdade de Filosofia, Letras e Ciências Humanas da Universidade de São Paulo. Departamento de Geografia. Área de concentração: Geografia Física.

1. precipitação horária. 2. cidade de São Paulo. 3. tendência linear . 4. ENOS. I. Silva, Maria Elisa Siqueira, orient.

II. Título. 
COMISSÃO EXAMINADORA

Prof. Dr. Emerson Galvani

Prof. Dra. Michelle Simões Reboita

Profa. Dra. Maria Elisa Siqueira Silva

Daniel Mendes

São Paulo, 4 de Outubro de 2013.

Aprovado

Resultado 


\section{AGRADECIMENTOS}

O meu agradecimento é dedicado exclusivamente aos meus pais, Pedro Paulo Mendes e Maria Imaculada de Lima Mendes, na intenção de valorizar os seus esforços na educação de um ser humano que revele no seu caráter o principio de que a humildade, o respeito, a solidariedade e a responsabilidade precisam estar acima de qualquer vaidade, egoísmo ou hipocrisia. Agradeço a minha formação intelectual original ao pequeno e seletivo colégio Magister, principalmente, em função do estímulo da criatividade. Aprendemos a diferença de um ser inteligente de um sábio através de uma reflexão que dizia: "Não procure somente o conhecimento, porém faça do mesmo um objeto de sua abstração e alcance a sabedoria". O inteligente reproduz de maneira passiva e obediente, se torna arrogante e imagina ser o dono da verdade, por outro lado, o sábio é ao mesmo tempo crítico e reflexivo, onde, inclusive, questiona a sua própria inteligência, o que $\circ$ deixa humilde e aberto a entender o seu próprio erro, na intenção, exclusiva, de buscar uma solução para uma hipótese. 
"Não basta ensinar ao homem uma especialidade, porque se tornará assim uma máquina utilizável e não uma personalidade. É necessário que adquira um sentimento, um senso prático daquilo que vale a pena ser empreendido, do que é belo e moralmente correto."

Por trás de um grande físico havia um grande humanista, Albert Einstein (1 4 de Março 1879 - 18 de Abril 1955). 


\section{SUMÁRIO}

I - INTRODUÇÃO

II - REFERENCIAL TEÓRICO

III - MÉTODOS, TÉCNICAS E MATERIAIS

3.1- O Domínio Temporal. 40

3.2- Definição dos Tipos de Chuva. 41

3.3- Agrupamento de Amostras de Chuvas. 48

3.4- Procedimentos Estatísticos Elementares. 49

3.5- Tendência Linear ao Longo da Série Temporal 51

3.6- Manipulação do Banco de Dados. 52

3.7- O Modelo de Regressão e o Ajuste Linear. 56

3.8- Coeficiente de Correlação Linear de Pearson. 59

3.9- Modelo Cíclico ou Sazonal 59

3.10- El Niño - Oscilação Sul - ENOS 60

3.11- Procedimento Final de Análise 1 62

3.12- Procedimento Final de Análise 2. 66

3.13- Oscilação Decadal do Pacífico. 71

IV - RESULTADOS E DISCUSSÕES 
4.2.1.3- Variação Cíclica de Chuva Muito Fraca 87

4.2.1.4- Análise da Correlação Cíclica. 88

4.2.1.5- Análise Específica do Ciclo de Chuva - MFA 89

4.2.1.6- Hipótese Inicial e Conclusão Final - MFA I 90

4.2.2- Análise Trimestral 92

4.2.2.1 - Frequência Trimestral de Chuva Muito Fraca 92

4.2.2.2- Variação Cíclica Trimestral de Chuva - MFA 97

4.2.2.3- Análise da Correlação Cíclica Trimestral 98

4.2.2.4- Análise Específica das Fases Trimestrais 100

4.2.2.5- A Hipótese Inicial e a Conclusão Final - MFA II. 103

4.3- Chuva Fraca - 0,25 a 1,0 mm h-1

4.3.1 - Análise Anual. 105

4.3.1.1 - Frequência Anual de Chuva Fraca 105

4.3.1.2- Análise do Ajuste Linear 105

4.3.1.3- Variação Cíclica de Chuva Fraca. 108

4.3.1.4- Análise da Correlação Cíclica. 108

4.3.1.5- Análise Específica do Ciclo de Chuva - FA 108

4.3.1.6- A Hipótese Inicial e a Conclusão Final - FA I 109

4.3.2- Análise Trimestral 110

4.3.2.1 - Frequência Trimestral de Chuva Fraca

4.3.2.2- Variação Cíclica Trimestral de Chuva - FA

4.3.2.3- Análise da Correlação Cíclica Trimestral.

4.3.2.4- Análise Específica das Fases Trimestrais

4.3.2.5 - A Hipótese Inicial e a Conclusão Final - FA II...

4.4- Chuva Moderada - 1,0 a 4,0 mm h-1 
4.4.1.2- Análise do Ajuste Linear

4.4.1.3- Variação Cíclica de Chuva Moderada 126

4.4.1.4- Análise da Correlação Cíclica 126

4.4.1.5- Análise Específica do Ciclo de Chuva - MO 127

4.4.1.6- A Hipótese Inicial e a Conclusão Final - MO I. 128

4.4.2-Análise Trimestral 129

4.4.2.1 - Frequência Trimestral de Chuva Moderada 130

4.4.2.2 - Variação Cíclica Trimestral de Chuva - MO 135

4.4.2.3- Análise da Correlação Cíclica Trimestral 136

4.4.2.4- Análise Específica das Fases Trimestrais. 137

4.4.2.5 - A Hipótese Inicial e a Conclusão Final - MO II 141

4.5 - Chuva Forte - 4,0 a 16,0 mm h-1

4.5.1-Análise Anual

4.5.1.1 - Frequência Anual de Chuva Forte

4.5.1.2-Análise do Ajuste Linear

4.5.1.3-Variação Cíclica de Chuva Forte.

4.5.1.4-Análise da Correlação Cíclica 146

4.5.1.5-Análise Específica do Ciclo de Chuva - FO _ 146

4.5.1.6-Hipótese Inicial e a Conclusão Final - FO I 147

4.5.2-Análise Trimestral 148

4.5.2.1 - Frequência Trimestral de Chuva Forte 149

4.5.2.2- Variação Cíclica Trimestral de Chuva - FO 154

4.5.2.3- Análise da Correlação Cíclica Trimestral. 155

4.5.2.4- Análise Específica das Fases Trimestrais 156

4.5.2.5 - A Hipótese Inicial e a Conclusão Final - FO II. 159

4.6- Chuva Muito Forte - 16,0 a 50,0 $\mathrm{mm} \mathrm{h}^{-1}$ 
4.6.1.2- Análise do Ajuste Linear

4.6.1.3- Variação Cíclica de Chuva Muito Forte.

4.6.1.4- Análise da Correlação Cíclica.

4.6.1.5- Análise Específica do Ciclo de Chuva - MFO 165

4.6.1.6- A Hipótese Inicial e a Conclusão Final - MFO I. 166

4.6.2- Análise Trimestral 167

4.6.2.1 - Frequência Trimestral de Chuva Muito Forte 168

4.6.2.2- Variação Cíclica Trimestral de Chuva - MFO 173

4.6.2.3- Análise da Correlação Cíclica Trimestral 174

4.6.2.4- Análise Específica das Fases Trimestrais 176

4.6.2.5- A Hipótese Inicial e a Conclusão Final - MFO

4.7- Chuva Intensa

4.7.1 - Análise Anual.

4.7.1.1 - Frequência Anual de Chuva Intensa

4.7.1.2- Análise do Ajuste Linear

4.7.1.3- Variação Cíclica de Chuva Intensa. 183

4.7.1.4- Análise da Correlação Cíclica.

4.7.1.5- Análise Específica do Ciclo de Chuva Intensa 184

4.7.1.6- A Hipótese Inicial e a Conclusão Final - Cl I 184

4.7.2- Análise Trimestral 186

4.7.2.1 - A Frequência Trimestral de Chuva Intensa 186

4.7.2.2- Variação Cíclica Trimestral de Chuva Intensa 190

4.7.2.3- Análise da Correlação Cíclica Trimestral.

4.7.2.5- A Hipótese Inicial e a Conclusão Final - Cl II 
4.8.1 - Análise Anual.

4.8.1.1 - Análise do Ajuste Linear 197

4.8.1.2- Variação Cíclica da Amostra A10 199

4.8.1.3- Análise Específica do Ciclo de Chuva - A 10 200

4.8.1.4- A Hipótese Inicial e a Conclusão Final - A 10 I 201

4.8.2- Análise Trimestral 202

4.8.2.1 - Variação Cíclica Trimestral de Chuva - A10 205

4.8.2.2- Análise Específica das Fases Trimestrais 206

4.8.2.3- A Hipótese Inicial e a Conclusão Final - A10 II. 208

4.9- Amostra de Chuva $\geq 20 \mathrm{~mm} \mathrm{~h}^{-1}$

4.9.1-Análise Anual 209

4.9.1.1 - Análise do Ajuste Linear

4.9.1.2- Variação Cíclica da Amostra A20

4.9.1.3- Análise Específica do Ciclo de Chuva - A20

4.9.1.4- A Hipótese Inicial e a Conclusão Final - A20 I

4.9.2-Análise Trimestral

4.9.2.1 - Variação Cíclica Trimestral

4.9.2.2- Análise Específica das Fases Trimestrais 
4.10.2.2-Análise Específica das Fases Trimestrais

4.11.1 - Frequência Anual e a os Limites Extremos.

4.11.2- Frequência Trimestral. 


\section{LISTA DE FIGURAS}

Figura 1 - As Variações de Temperatura na Superfície da Terra, nos últimos 140 anos. 24

Figura 2 - As Principais Características de um Sistema de Monção na América do Sul. 30

Figura 3 - Estação Meteorológica do IAG/USP. 37

Figura 4 - Mapa do Município de São Paulo-SP 38

Figura 5 - Pluviógrafo de Hellmann. 39

Figura 6 - O Pluviógrafo de Bóia e um recorte de pluviograma para o período de $70 \mathrm{~min}$. 40

Figura 7 - A Região Niño3.4 52

Figura 8 - Variação Explicada e Não Explicada pela Reta de Regressão. 58

Figura 9 - Impacto Climático Trimestral Associado a Eventos El Niño e La Niña. 62

Figura 10 - Organograma Referente ao $1^{\circ}$ Procedimento da Análise 1. 65

Figura 11 - Organograma Referente ao $2^{\circ}$ Procedimento da Análise 1. 65

Figura 12 - Organograma Referente ao $3^{\circ}$ Procedimento da Análise 1. 66

Figura 13 - Organograma Referente ao $1^{\circ}$ Procedimento da Análise 2. 68

Figura 14 - Organograma Referente ao $2^{\circ}$ Procedimento da Análise 2. 69

Figura 15 - Organograma Referente ao $3^{\circ}$ Procedimento da Análise 2. 70

Figura 16 - Fase Quente da ODP e ENSO.

Figura 17 - Valor Anual de Oceanic Niño Index entre (1970-2009). 74

Figura 18 - Ajuste Linear da Série Temporal do ONI Anual, entre 1970 e 2009. 75

Figura 19 - Ajuste Linear dos Anos com Fases (a) Neutra, (b), ENOS, (c), El Niño e (d) La Niña. 76

Figura 20 - Índice Anual da Oscilação Decadal do Pacífico entre 1970-2009. 76

Figura 21 - ONI de cada Estação do Ano entre 1970-2009. 77

Figura 22 - Ajuste Linear do Valor Trimestral do ONI para Cada Estação do Ano. 78

Figura 23 - Ajuste Linear do Valor Trimestral do ONI durante o Verão 79

Figura 24 - Ajuste Linear do Valor Trimestral do ONI durante o Outono 80

Figura 25 - Ajuste Linear do Valor Trimestral do ONI durante o Inverno 81

Figura 26 - Ajuste Linear do Valor Trimestral do ONI durante a Primavera 82

Figura 27 - Índice da ODP para cada Estação do Ano 83

Figura 28 - Frequência Anual de Chuva Muito Fraca entre 1970-2009. 85 
Figura 29 - Ajuste Linear da Frequência Anual de Chuva Muito Fraca entre 1970-2009. 86

Figura 30 - Tendência Linear da Frequência Anual de Chuva Muito Fraca 87

Figura 31 - Variação Cíclica Anual da Frequência de Chuva Muito Fraca entre 1970 e 2009. 87

Figura 32 - Variação Cíclica Anual de Chuva Muito Fraca. 88

Figura 33 - Variações Cíclicas Anuais da Fase EL Niño e da Frequência de Chuva Muito Fraca 88

Figura 34 - Fases Específicas do Ciclo Anual de Chuva Muito Fraca 90

Figura 35 - Fases Específicas do Ciclo Anual de Chuva MFA durante a Série Temporal de EN. 91

Figura 36 - Frequência Trimestral de Chuva Muito Fraca. 93

Figura 37 - Ajuste Linear Trimestral de Chuva Muito Fraca. 93

Figura 38 - Ajuste Linear Trimestral de Chuva Muito Fraca para as Estações de Verão, Outono, Inverno e Primavera durante a fase Neutra.

Figura 39 - Ajuste Linear Trimestral de Chuva Muito Fraca para as Estações de Verão, Outono, Inverno e Primavera durante a fase ENOS.

Figura 40 - Ajuste Linear Trimestral de Chuva Muito Fraca para as Estações de Verão, Outono, Inverno e Primavera durante a fase El Niño.

Figura 41 - Ajuste Linear Trimestral de Chuva Muito Fraca para as Estações de Outono e Inverno durante a fase La Niña. 96

Figura 42 - Variação Cíclica Trimestral de Chuva Muito Fraca, entre 1970 e 2009. 98

Figura 43 - Variação Cíclica de Chuva MFA, no Outono, entre 1970 e 2009. 99

Figura 44 - Variação Cíclica de Chuva MFA, na Primavera, entre 1970 e 2009. 99

Figura 45 - Variação Cíclica de Chuva MFA, na Primavera, durante a Fase Neutra. 99

Figura 46 - Variação Cíclica de Chuva MFA, na Primavera, durante a Fase ENOS. 99

Figura 47 - Fases Específicas do Ciclo Trimestral de Chuva Muito Fraca. 102

Figura 48 - Frequência Anual de Chuva Fraca entre 1970-2009.. 105

Figura 49 - Ajuste Linear da Frequência Anual de Chuva Fraca entre 1970-2009._. 106

Figura 50 - Tendência Linear da Frequência Anual de Chuva Fraca. 107

Figura 51 - Variação Cíclica Anual da Frequência de Chuva Fraca entre 1970 e 2009. 108

Figura 52 - Fases Específicas do Ciclo Anual de Chuva Fraca. 109

Figura 53 - Frequência Trimestral de Chuva Fraca.

Figura 54 - Ajuste Linear Trimestral de Chuva Fraca

Figura 55 - Ajuste Linear Trimestral de Chuva Fraca para as Estações de Outono, Inverno e Primavera durante a fase Neutra. 
Figura 56 - Ajuste Linear Trimestral de Chuva Fraca para as Estações de Outono e Inverno durante a fase ENOS.

Figura 57 - Ajuste Linear Trimestral de Chuva Fraca para as Estações de Verão e Inverno durante a fase El Niño.

Figura 58 - Ajuste Linear Trimestral de Chuva Fraca para as Estações de Verão, Inverno e Primavera durante a fase La Niña.

Figura 59 - Variação Cíclica Trimestral de Chuva Fraca, entre 1970 e 2009.

Figura 60 - Variação Cíclica de Chuva FA, na Primavera, entre 1970 e 2009.

Figura 61 - Variação Cíclica de Chuva FA, no Verão, durante a Fase La Niña.

Figura 62 - Variação Cíclica de Chuva FA, no Outono, durante a Fase ENOS.

Figura 63 - Fases Específicas do Ciclo Trimestral de Chuva Fraca

Figura 64 - Frequência Anual de Chuva Moderada entre 1970-2009.

Figura 65 - Ajuste Linear da Frequência Anual de Chuva Moderada entre 1970-2009.

Figura 66 - Tendência Linear da Frequência Anual de Chuva Moderada

Figura 67 - Variação Cíclica Anual da Frequência de Chuva Moderada entre 1970 e 2009.

Figura 68 - Variações Cíclicas Anuais da Fase EL Niño e de Frequência de Chuva Moderada.

Figura 69 - Fases Específicas do Ciclo Anual de Chuva Moderada.

Figura 70 - Fases Específicas do Ciclo Anual de Chuva MO durante a Série Temporal de EN.

Figura 71 - Frequência Trimestral de Chuva Moderada

Figura 72 - Ajuste Linear Trimestral de Chuva Moderada

Figura 73 - Ajuste Linear Trimestral de Chuva Moderada para as Estações de Outono, Inverno e

Primavera durante a fase Neutra.

Figura 74 - Ajuste Linear Trimestral de Chuva Moderada para as Estações de Outono e Primavera durante a fase ENOS.

Figura 75 - Ajuste Linear Trimestral de Chuva Moderada para a Estação de Verão durante a fase El Niño.

Figura 76 - Ajuste Linear Trimestral de Chuva Fraca para as Estações de Outono e Primavera durante a fase La Niña.

Figura 77 - Variação Cíclica Trimestral de Chuva Moderada, entre 1970 e 2009.

Figura 78 - Variação Cíclica de Chuva MO, no Verão, entre 1970 e 2009.

Figura 79 - Variação Cíclica de Chuva MO, no Outono, entre 1970 e 2009.

Figura 80 - Variação Cíclica de Chuva MO, no Verão, durante a Fase La Niña. 
Figura 81 - Variação Cíclica de Chuva MO, no Outono, durante a Fase ENOS.

Figura 82 - Fases Específicas do Ciclo Trimestral de Chuva Moderada. 140

Figura 83 - Frequência Anual de Chuva Forte entre 1970-2009. 143

Figura 84 - Ajuste Linear da Frequência Anual de Chuva Forte entre 1970-2009. 144

Figura 85 - Tendência Linear da Frequência Anual de Chuva Forte. 145

Figura 86 - Variação Cíclica Anual da Frequência de Chuva Forte entre 1970 e 2009. 145

Figura 87 - Variações Cíclicas Anuais da Frequência de Chuva Forte, durante a Fase EN. 146

Figura 88 - Fases Específicas do Ciclo Anual de Chuva Forte 147

Figura 89 - Frequência Trimestral de Chuva Forte. 150

Figura 90 - Ajuste Linear Trimestral de Chuva Forte 150

Figura 91 - Ajuste Linear Trimestral de Chuva Forte para as Estações de Outono e Inverno durante a fase Neutra.

Figura 92 - Ajuste Linear Trimestral de Chuva Forte para a Estação de Inverno durante a fase ENOS

Figura 93 - Ajuste Linear Trimestral de Chuva Forte para as Estações de Verão, Outono e Inverno durante a fase El Niño.

Figura 94 - Ajuste Linear Trimestral de Chuva Forte para as Estações de Outono, Inverno e Primavera durante a fase La Niña. 153

Figura 95 - Variação Cíclica Trimestral de Chuva Forte, entre 1970 e 2009. 154

Figura 96 - Variação Cíclica de Chuva FO, no Outono, entre 1970 e 2009. 155

Figura 97 - Variação Cíclica de Chuva FO, no Verão, durante a Fase La Niña. 156

Figura 98 - Variação Cíclica de Chuva FO, no Outono, durante a Fase ENOS. 156

Figura 99 - Variação Cíclica de Chuva FO, na Primavera, durante a Fase Neutra. 156

Figura 100 - Fases Específicas do Ciclo Trimestral de Chuva Forte. 158

Figura 101 - Frequência Anual de Chuva Muito Forte entre 1970-2009. 161

Figura 102 - Ajuste Linear da Frequência Anual de Chuva Muito Forte entre 1970-2009. 162

Figura 103 - Tendência Linear da Frequência Anual de Chuva Muito Forte.

Figura 104 - Variação Cíclica Anual da Frequência de Chuva Muito Forte entre 1970 e 2009. 164

Figura 105 - Variações Cíclicas Anuais da Fase EL Niño e de Frequência de Chuva Muito Forte 165

Figura 106 - Fases Específicas do Ciclo Anual de Chuva Muito Forte 165

Figura 107 - Fases Específicas do Ciclo Anual de Chuva MFO durante a Série Temporal de EN. 
Figura 108 - Frequência Trimestral de Chuva Muito Forte 168

Figura 109 - Ajuste Linear Trimestral de Chuva Muito Forte. 169

Figura 110 - Ajuste Linear Trimestral de Chuva Muito Forte para a Estação de Inverno durante a fase Neutra.

Figura 111 - Ajuste Linear Trimestral de Chuva Muito Forte para as Estações de Verão, Outono, Inverno e Primavera durante a fase ENOS.

Figura 112 - Ajuste Linear Trimestral de Chuva Muito Forte para as Estações de Outono e Inverno durante a fase El Niño.

Figura 113 - Ajuste Linear Trimestral de Chuva Muito Forte para as Estações de Verão e Primavera durante a fase La Niña.

Figura 114 - Variação Cíclica Trimestral de Chuva Muito Forte, entre 1970 e 2009.

Figura 115 - Variação Cíclica de Chuva MFO, no Outono, durante a Fase El Niño. 175

Figura 116 - Variação Cíclica de Chuva MFO, no Inverno, durante a Fase El Niño. 175

Figura 117 - Variação Cíclica de Chuva MFO, na Primavera, durante a Fase Neutra. 176

Figura 118 - Fases Específicas do Ciclo Trimestral de Chuva Muito Forte 178

Figura 119 - Frequência Anual de Chuvas Intensas entre 1970-2009. 181

Figura 120 - Ajuste Linear da Frequência Anual de Chuva Intensa entre 1970-2009. 182

Figura 121 - Tendência Linear da Frequência Anual de Chuva Intensa. 182

Figura 122 - Variação Cíclica Anual da Frequência de Chuva Intensa entre 1970 e 2009. 183

Figura 123 - Fases Específicas do Ciclo Anual de Chuva Intensa 184

Figura 124 - Frequência Trimestral de Chuva Intensa 187

Figura 125 - Ajuste Linear Trimestral de Chuva Intensa.

Figura 126 - Ajuste Linear Trimestral de Chuva Intensa para a Estação de Verão durante a fase Neutra

Figura 127 - Ajuste Linear Trimestral de Chuva Intensa para as Estações de Outono, Inverno e

Primavera durante a fase ENOS.

Figura 128 - Ajuste Linear Trimestral de Chuva Intensa para as Estações de Outono, Inverno e Primavera durante a fase EI Niño.

Figura 129 - Ajuste Linear Trimestral de Chuva Intensa para as Estações de Outono e Inverno durante a fase La Niña.

Figura 130 - Variação Cíclica Trimestral de Chuva Intensa, entre 1970 e 2009.

Figura 131 - Variação Cíclica de Chuva Intensa, na Primavera, entre 1970 e 2009. 
Figura 132 - Variação Cíclica de Chuva Intensa, na Primavera, durante a Fase Neutra.

Figura 133 - Variação Cíclica de Chuva Intensa, no Outono, durante a Fase El Niño. 192

Figura 134 - Fases Específicas do Ciclo Trimestral de Chuva Intensa 194

Figura 135 - Frequência Anual de Chuva $\geq 10 \mathrm{~mm} \mathrm{~h}^{-1}$ entre 1970-2009. 197

Figura 137 - Tendência Linear da Frequência Anual de Chuva $\geq 10 \mathrm{~mm} \mathrm{~h}^{-1}$. 199

Figura 138 - Variação Cíclica Anual da Frequência de chuva A10 entre 1970 e 2009. 200

Figura 139 - Fases Específicas do Ciclo Anual de Chuva A10 200

Figura 140 - Frequência Trimestral de chuva A10 202

Figura 141 - Ajuste Linear Trimestral de chuva A10. 203

Figura 142 - Ajuste Linear Trimestral de chuva A10 para a Estação de Verão, durante a Fase Neutra.

Figura 143 - Ajuste Linear Trimestral de chuva A10 para a Estação de Primavera, durante a Fase ENOS.

Figura 144 - Ajuste Linear Trimestral de chuva A10 para as Estações de Verão e Primavera, durante a Fase EN. 204

Figura 145 - Ajuste Linear Trimestral de chuva A10 para a Estação de Primavera, durante a Fase $L N$.

Figura 146 - Variação Cíclica Trimestral de Chuva A 10, entre 1970 e 2009. 205

Figura 147 - Variação Cíclica de Chuva A 10, na Primavera, durante a Fase ENOS. 206

Figura 148 - Fases Específicas do Ciclo Trimestral de Chuva A10. 207

Figura 149 - Frequência Anual de Chuva $\geq 20$ mm h-1 entre 1970-2009.

Figura 151 - Tendência Linear da Frequência Anual de Chuva $\geq 20$ mm h-1

Figura 152 - Variação Cíclica Anual da Frequência de chuva A20 entre 1970 e 2009.

Figura 153 - Fases Específicas do Ciclo Anual de Chuva A20. 213

Figura 154 - Frequência Trimestral de chuva A20.

Figura 155 - Ajuste Linear Trimestral de chuva A20.

Figura 156 - Ajuste Linear Trimestral de chuva A20 para a Estação da Primavera, durante a Fase Neutra.

Figura 157 - Ajuste Linear Trimestral de chuva A20 para as Estações de Verão e Primavera, durante a Fase ENOS.

Figura 158 - Ajuste Linear Trimestral de chuva A20 para a Estação de Primavera, durante a Fase EN. 
Figura 159 - Ajuste Linear Trimestral de chuva A20 para a Estação de Verão, durante a Fase LN...217

Figura 160 - Variação Cíclica Trimestral de Chuva A20, entre 1970 e 2009.

Figura 161 - Variação Cíclica de Chuva A20, na Primavera, entre 1970 e 2009.

Figura 162 - Variação Cíclica de Chuva A20, na Primavera, durante a Fase El Niño.

Figura 163 - Fases Específicas do Ciclo Trimestral de Chuva A20.

Figura 164 - Frequência Anual de Chuva $\geq 30 \mathrm{~mm} \mathrm{~h}^{-1}$ entre 1970-2009.

Figura 166 - Tendência Linear da Frequência Anual de Chuva $\geq 30 \mathrm{~mm} \mathrm{~h}-1$.

Figura 167 - Variação Cíclica Anual da Frequência de chuva A30 entre 1970 e 2009.

Figura 168 - Variações Cíclicas Anuais do ONI e da Frequência de chuva A30

Figura 169 - Variações Cíclicas Anuais da Frequência de chuva A30, durante a Fase Neutra. 226

Figura 170 - Variações Cíclicas Anuais da Frequência de chuva A30, durante a Fase EN. 226

Figura 171 - Fases Específicas do Ciclo Anual de Chuva A30

Figura 172 - Frequência Trimestral de chuva A30

Figura 173 - Ajuste Linear Trimestral de chuva A30.

Figura 174 - Ajuste Linear Trimestral de chuva A30 para as Estações de Verão e Primavera, durante a Fase Neutra.

Figura 175 - Ajuste Linear Trimestral de chuva A30 para a Estação de Verão, durante a Fase ENOS.

Figura 176 - Ajuste Linear Trimestral de chuva A30 para a Estação de Primavera, durante a Fase EN.

Figura 177 - Ajuste Linear Trimestral de chuva A30 para a Estação de Verão e Primavera, durante a Fase LN.

Figura 178 - Variação Cíclica Trimestral de Chuva A30, entre 1970 e 2009.

Figura 179 - Fases Específicas do Ciclo Trimestral de Chuva A30.

Figura 180 - Frequência Anual de Chuva Extrema e os Limites Máximos (mm)

Figura 181 - Frequência Mensal de Chuva Extrema e os Índices de Verão da ODP e ONI 238

Figura 182 - Cronologia de Episódios de Chuva Extrema no Período de 1970 a 2009.

Figura 183 - Variação Cíclica da ODP e da ONI durante o Mês de Janeiro 239

Figura 184 - Variação Cíclica da ODP e da ONI durante o Mês de Fevereiro. 240

Figura 185 - Variação Cíclica da ODP e da ONI durante o Mês de Dezembro. 241 


\section{LISTA DE TABELAS}

Tabela 1 - Classificação da Intensidade das Chuvas adotada neste estudo. 43

Tabela 2 - Limites Mínimos de Intensidade, em mm, para Chuva Intensa. $\quad 47$

Tabela 3 - Agrupamento de Amostras de Chuva.

Tabela 4 - Classificação do Oceanic Niño Index. $\quad 52$

Tabela 5 - Modelo de Planilha Utilizada no Armazenamento da Frequência Anual da Precipitação Horária 53

Tabela 6 - Valores Utilizados na Reclassificação do Oceanic Niño Index

Tabela 7 - Resultado da Reclassificação da ONI. $\quad 54$

Tabela 8 - Variação Cíclica Anual com Tendência Linear. $\quad$ _ 55

Tabela 9 - Estimativa Anual das Variáveis Consideradas no Estudo pelo Ajuste Linear Simples. $\quad 56$

Tabela 10 - Estimativa Anual do Valor da Frequência de Precipitação.

Tabela 11 - Os Coeficientes Linear e Angular da Reta de Regressão. $\quad 57$

Tabela 12 - Equação de Correlação Linear de Pearson (r) e a Classificação dos Valores. _ 59

Tabela 13 - As Equações da Média Periódica e da Sazonal no Período. $\quad 60$

Tabela 14 - A Distribuição t-Student, segundo Beiguelman (1996). _ _ _ 64

Tabela 15 - Demográfica Decadal da RMSP e do Distrito de Cursino, de 1970 a 2010

Tabela 16 - Tendência Linear Anual de Chuva Muito Fraca e do ONI. _ 87

Tabela 17 - Correlação Linear entre a Anomalia de ONI e da Frequência Anual de Chuva Muito

Fraca entre 1970 e 2009, sem Tendência Linear (Série Cíclica). _ _ 88

Tabela 18 - Correlação Anual em Fases Específicas _ 91

Tabela 19 - Correlação Linear Trimestral entre a Tendência Linear Trimestral de Chuva Muito Fraca e a Tendência Linear Trimestral do ONI, incluindo as Fases, Neutra, ENOS, EN e LN. 96

Tabela 20 - Correlação Cíclica entre a Frequência de Chuva Muito Fraca observada na Estação do IAG e os Valores de ONI para Cada Estação do Ano.

Tabela 21 - Correlação Linear entre a Frequência de Chuva Muito Fraca observada na Estação do IAG e os Valores de ONI para Cada Estação do Ano 102

Tabela 22 - Tendência Linear Anual de Chuva Fraca e do ONI para o Período de 1970 a 2009 _... 107 Tabela 23 - Correlação Linear entre a Anomalia de ONI e da Frequência Anual de Chuva Fraca entre 1970 e 2009, sem Tendência Linear (Série Cíclica). 
Tabela 24 - Correlação Anual em Fases Específicas

Tabela 25 - Correlação Linear Trimestral entre a Tendência Linear Trimestral de Chuva Fraca e a

Tendência Linear Trimestral do ONI incluindo as Fases, Neutra, ENOS, EN e LN..

Tabela 26 - Correlação Cíclica entre a Frequência de Chuva Fraca observada na Estação do IAG e os Valores de ONI para Cada Estação do Ano.

Tabela 27 - Correlação Linear entre a Frequência de Chuva Fraca observada na Estação do IAG e os Valores de ONI para Cada Estação do Ano.

Tabela 28 - Tendência Linear Anual de Chuva Moderada e do ONI.

Tabela 29 - Correlação Linear entre a Anomalia de ONI e da Frequência Anual de Chuva Moderada entre 1970 e 2009, sem Tendência Linear (Série Cíclica).

Tabela 30 - Correlação Anual em Fases Específicas.

Tabela 31 - Correlação Linear Trimestral entre a Tendência Linear Trimestral de Chuva Moderada e a Tendência Linear Trimestral do ONI incluindo as Fases, Neutra, ENOS, EN e LN.

Tabela 32 - Correlação Cíclica entre a Frequência de Chuva Moderada observada na Estação do IAG e os Valores de ONI para Cada Estação do Ano).

Tabela 33 - Correlação Linear entre a Frequência de Chuva Moderada observada na Estação do IAG e os Valores de ONI para Cada Estação do Ano.

Tabela 34 - Tendência Linear Anual de Chuva Forte e do ONI para o Período de 1970 a $2009 \quad 145$

Tabela 35 - Correlação Linear entre a Anomalia de ONI e da Frequência Anual de Chuva Forte entre 1970 e 2009, sem Tendência Linear (Série Cíclica).

Tabela 36 - Correlação Anual em Fases Específicas.

Tabela 37 - Correlação Linear Trimestral entre a Tendência Linear Trimestral de Chuva Forte e a Tendência Linear Trimestral do ONI incluindo as Fases, Neutra, ENOS, EN e LN.

Tabela 38 - Correlação Cíclica entre a Frequência de Chuva Forte observada na Estação do IAG e os Valores de ONI para Cada Estação do Ano

Tabela 39 - Correlação Linear entre a Frequência de Chuva Forte observada na Estação do IAG e os Valores de ONI para Cada Estação do Ano

Tabela 40 - Tendência Linear Anual de Chuva Muito Forte e do ONI

Tabela 41 - Correlação Linear entre a Anomalia de ONI e da Frequência Anual de Chuva Muito Forte entre 1970 e 2009, sem Tendência Linear (Série Cíclica).

Tabela 42 - Correlação Anual em Fases Específicas.

Tabela 43 - Correlação Linear Trimestral entre a Tendência Linear Trimestral de Chuva Muito Forte e a Tendência Linear Trimestral do ONI incluindo as Fases, Neutra, ENOS, EN e LN. 
Tabela 44 - Correlação Cíclica entre a Frequência de Chuva Muito Forte observada na Estação do IAG e os Valores de ONI para Cada Estação do Ano.

Tabela 45 - Correlação Linear entre a Frequência de Chuva Muito Forte observada na Estação do IAG e os Valores de ONI para Cada Estação do Ano.

Tabela 46 - Tendência Linear Anual de Chuva Intensa e do ONI

Tabela 47 - Correlação Linear entre a Anomalia de ONI e da Frequência Anual de Chuva Intensa entre 1970 e 2009, sem Tendência Linear (Série Cíclica).

Tabela 48 - Correlação Anual em Fases Específicas.

Tabela 49 - Correlação Linear Trimestral entre a Tendência Linear Trimestral de Chuva Intensa e a Tendência Linear Trimestral do ONI, incluindo as Fases, Neutra, ENOS, EN e LN.

Tabela 50 - Correlação Cíclica entre a Frequência de Chuva Intensa observada na Estação do IAG e os Valores de ONI para Cada Estação do Ano

Tabela 51 - Correlação Linear entre a Frequência de Chuva Muito Fraca observada na Estação do

IAG e os Valores de ONI para Cada Estação do Ano. 195

Tabela 52 - Tendência Linear Anual de Chuva A10 e do ONI 199

Tabela 53 - Correlação Linear entre a Anomalia de ONI e da Frequência Anual de chuva A10 entre 1970 e 2009, sem Tendência Linear (Série Cíclica).

Tabela 54 - Correlação Anual em Fases Específicas.

Tabela 55 - Correlação Linear Trimestral entre a Tendência Linear Trimestral de Chuva A10 e a

Tendência Linear Trimestral do ONI incluindo as Fases, Neutra, ENOS, EN e LN

Tabela 56 - Correlação Cíclica entre a Frequência de Chuva A20 observada na Estação do IAG e os Valores de ONI para Cada Estação do Ano

Tabela 57 - Correlação Linear entre a Frequência de Chuva A10 observada na Estação do IAG e os

Valores de ONI para Cada Estação do Ano

Tabela 58 - Tendência Linear Anual de Chuva A20 e do ONI

Tabela 59 - Correlação Linear entre a Anomalia de ONI e da Frequência Anual de chuva A20 entre 1970 e 2009, sem Tendência Linear (Série Cíclica).

Tabela 60 - Correlação Anual em Fases Específicas.

Tabela 61 - Correlação Cíclica Trimestral entre a Tendência Linear Trimestral de Chuva A20 e a

Tendência Linear Trimestral do ONI incluindo as Fases, Neutra, ENOS, EN e LN.

Tabela 62 - Correlação Linear entre a Frequência de Chuva A20 observada na Estação do IAG e os Valores de ONI para Cada Estação do Ano

Tabela 63 - Correlação Linear entre a Frequência de Chuva A20 observada na Estação do IAG e os Valores de ONI para Cada Estação do Ano. 
Tabela 64 - Tendência Linear Anual de Chuva A30 e do ONI para o Período de 1970 a 2009

Tabela 65 - Correlação Linear entre a Anomalia de ONI e da Frequência Anual de chuva A30 entre 1970 e 2009, sem Tendência Linear (Série Cíclica).

Tabela 66 - Correlação Anual em Fases Específicas.

Tabela 67 - Correlação Linear Trimestral entre a Tendência Linear Trimestral de Chuva A30 e a

Tendência Linear Trimestral do ONI incluindo as Fases, Neutra, ENOS, EN e LN.

Tabela 68 - Correlação Cíclica entre a Frequência de Chuva A30 observada na Estação do IAG e os Valores de ONI para Cada Estação do Ano 233

Tabela 69 - Correlação Linear entre a Frequência de Chuva A30 observada na Estação do IAG e os Valores de ONI para Cada Estação do Ano 234

Tabela 70 - Cronologia de Episódios de Chuva Extrema no Período de 1970 a 2009. 238 


\section{RESUMO}

A complexidade de compreensão durante a observação realizada a partir da identificação de um possível quadro de evolução em um sistema climático marcado por uma série temporal longa de uma determinada variável ambiental deve-se ao fato do ambiente sofrer múltiplas interações físico-químicas que naturalmente ocorrem nas escalas global, regional e local. $\mathrm{Na}$ intenção de compreender alguns elementos dessa dinâmica foram analisadas algumas hipóteses que podem nos aproximar de possíveis explicações a respeito do contexto que emerge a partir da realidade observada. Neste contexto foi analisada a hipótese de que o ambiente fisicamente alterado pelo homem possa estar influenciado no número de episódios de chuvas nas suas diversas intensidades durante o intervalo de uma hora. A segunda hipótese analisou a possibilidade das alterações em grandes escalas envolvendo às flutuações de temperatura observadas na superfície do mar (TSM) de uma região específica (Niño3.4) localizada no pacífico equatorial possam estar influenciando e/ou intensificando os episódios de chuva em escala local. No entanto, a partir dessas possibilidades o objetivo foi a de analisar através do uso de métodos estatísticos, a partir da aplicação de ajustes e correlações lineares, a identificação de tendências positivas ou negativas, no quadro de cada tipo de chuva e, posteriormente, no quadro das variações de TSM, da região Niño3.4. O segundo procedimento adotado avaliou de uma maneira qualitativa a possibilidade de haver correlações positivas entre os dois ajustes lineares analisados. Os resultados indicaram que a variabilidade climática anual da região Niño3.4 durante a série completa (1970-2009) apresentou um quadro de aquecimento (ajuste positivo). Por outro lado, também foi observado o aquecimento da TSM durante séries específicas da série completa identificadas como fase Neutra, ENOS e La Niña. No entanto, a série especifica relativa à fase El Niño apresentou um comportamento inverso, no caso, um resfriamento na TSM durante o período analisado. Neste caso, foi constatado que o aquecimento anual da TSM da região Niño3.4 ocorre em função do aquecimento observado durante as anomalias negativas (La Niña). O quadro dos ajustes lineares de cada tipo de chuva revelou uma diminuição horária na frequência de chuvas muito fracas (nevoeiros e neblinas), de chuvas fracas (chuviscos e garoas) e de chuvas moderadas (tempestades leves oriundas de nimbostratus). Por outro lado, o quadro de ajustes lineares para chuvas mais intensas foram positivas, como no caso, de chuvas fortes (tempestades ordinárias) e muito fortes (tempestades severas).

Palavras chave: precipitação horária, cidade de São Paulo, tendência linear, ENOS 


\section{ABSTRACT}

The complexity of understanding during the observation carried out from the identification of a possible behavior of evolution in a climatic system marked by a series storm long of a determined environmental variable is due to the fact of the environment suffer multiple interactions chemical-physically what naturally take place in the global, regional and local scales. In the intention of understanding some elements of this dynamic one there were analyzed some hypotheses that can bring near us of possible explanations as to the context that surfaces from the observed reality. In this context it was analyzed the hypothesis of which the environment physically altered by the man could be influenced the number of episodes of rains in his several intensities during the interval of an hour. The second hypothesis analyzed the possibility of the alterations in great scales wrapping to the fluctuations of temperature observed in the surface of the sea (TSM) of a specific region (Niño3.4) located in the Pacific Ocean be able to be influencing and / or intensifying the episodes of rain in local scale. However, from these means the objective was it of analyzing through the use of statistical methods, from the application of agreements and linear correlations, the identification of positive or negative tendencies, in the picture of each type of rain and, subsequently, in the picture of the variations of TSM, of the region Niño3.4. The second adopted proceeding valued in a qualitative way the possibility to be positive correlations between two linear analyzed agreements. The results indicated that the climatic annual variability of the region Niño3.4 during the complete series (1970-2009) presented a picture of heating (positive agreement). On the other side, also the heating of the TSM was observed during specific series, of the complete series, identified like phases Neuter, ENOS and La Niña. However, the series specify relative to the phase El Niño he presented a reverse behavior, in the case, a cooling in the TSM during the analyzed period. In this case, it was noted that the annual heating of the TSM of the region Niño3.4 takes place in function of the heating observed during the negative anomalies (La Niña). The picture of the linear agreements of each type of rain revealed a reduction hourly in the frequency of very weak rains (thick fogs and fogs), of weak rains (drizzles and drizzles) and of moderate rains (light originating storms of nimbostratus). On the other side, the picture of linear agreements for more intense rains they were positive, since in the case, of strong rains (ordinary storms) and very strong (severe storms).

Keywords: hourly precipitation, city of Sao Paulo, linear trend, ENOS. 


\section{I - INTRODUÇÃO}

A complexidade de compreensão da evolução de um sistema climático, caracterizado por uma série temporal longa de uma determinada variável ambiental, deve-se ao fato do ambiente sofrer múltiplas interações físico-químicas que, naturalmente são observadas nas escalas global, regional e local. A busca da compreensão de alguns elementos dessa dinâmica requer a consideração de assumir hipóteses que podem nos aproximar de possíveis explicações a respeito do contexto que emerge a partir da realidade observada. $O$ aquecimento, a mudança ou apenas as variações ambientais, periódicas ou quase periódicas, dos aspectos climáticos devem ser analisadas de maneira criteriosa e responsável e, desta forma não faltar com a verdade científica. Neste estudo, o principal foco é diagnosticar o comportamento de episódios de chuva observados na estação meteorológica, instalada no Parque CIENTEC, bairro Água Funda, no município de São Paulo. O diagnóstico é feito levando-se em consideração a tendência linear de longo prazo e, as alterações periódicas ou quase periódicas dos dados de precipitação. Nesse sentido, porém de maneira mais específica, o estudo analisou através dos resultados, as possíveis anomalias que podem ocorrer em função de um comportamento linear, seja ele, positivo ou negativo, durante as suas respectivas variações cíclicas identificadas ao longo da série ou em determinados períodos que particularmente também foram analisados. A possível combinação envolvendo a presença da componente linear e ao mesmo tempo da componente cíclica permite analisar a possibilidade de estar ocorrendo uma intensificação no ritmo climático a partir de um aumento nas amplitudes dos seus respectivos ciclos.

No aspecto linear, foi estimada a tendência de longo prazo para todas as intensidades de chuvas a serem analisadas. No aspecto cíclico, a intenção é verificar a possível existência de associações, realizadas a partir dados obtidos, de uma localidade específica, da cidade de São Paulo, envolvendo a variabilidade de precipitação e os índices que caracterizam o fenômeno El Niño-South Oscillation. 
A importância em realizar estudos focados neste tipo de proposta de análise é a de contribuir a partir do ponto de vista da climatologia na busca de soluções atreladas aos acidentes físicos que proporcionam desastres naturais e consequentemente prejuízos matérias e perdas humanas. No entanto é compreensível que os deslizamentos e enchentes ocorram quando tais fatores climáticos tendem a interagir de uma maneira natural ao estabelecer uma reação com a superfície a partir da percolação e da infiltração decorrentes dos aspectos geomorfológicos e pedológicos. A constatação de um diagnóstico positivo na qual aponta um aumento na intensidade de chuva em qualquer ponto que esteja localizado na região sudeste deve também ser analisado em função de uma possível correlação com o aumento linear da população que quando associadas ao descaso das políticas públicas tendem a proporcionar o aumento na frequência e na intensidade da chuva como um fator que pode variar em um nível hipotético, de importante a decisivo, no aumento de casos de tragédias.

O aspecto geral e conclusivo a ser considerado nesta introdução relativa à análise estatística aplicada nas variadas intensidades de chuvas observadas no intervalo horário, observadas na cidade de São Paulo, no período de 1970-2009, revelou uma diminuição na frequência de chuvas menos intensas (muito fraca, fraca e moderada) e, por outro lado, o aumento na frequência de chuvas mais intensas (forte e muito forte). O segundo aspecto observado foi o aquecimento da TSM da região Niño3.4 estarem associadas ao aumento de temperatura durante as anomalias negativa, no caso, La Niña.

O contexto da aplicação dos métodos foi considerado na intenção de refletir a relação fundamental existente entre as interações elementares que ocorrem entre a atmosfera é a superfície na qual o estudo está inserido. Tendo em vista que a Geografia é uma ciência culturalmente rica e que apresenta inúmeras possibilidades de reflexão, não seria inteligente restringir ou mesmo ignorar tal possibilidade de enriquecer as análises através destes preciosos conhecimentos adquiridos. A Geografia antes de ser física, ela é essencialmente humana. Neste caso a ideia de chuva e os processos nas quais envolvem as interações entre a atmosfera e a superfície fazem parte das reações física e químicas elementares que ocorrem 
a partir dos quatros elementos que inicialmente foram considerados como sendo fundamentais para a existência de vida no planeta. Assim os ritmos das interações entre ar, da atmosfera, o fogo, do aquecimento térmico, a terra, da superfície e, a água, da chuva determinarão as condições naturais que farão parte do dia a dia do ser humano. Neste sentido, o tempo tende a evoluir cronologicamente, $\bigcirc$ espaço fisicamente e $\circ$ ar instantaneamente. A água pode atingir mais de um estado (liquido, gasoso e sólido) e interferir nas atividades humanas de diversas formas e em diversos espaços físicos, o aquecimento expõe o nível da agitação das moléculas, o ar é o meio de propagação dos fatos e dos fenômenos e, por fim, a terra é o palco dos resultados das transformações. Neste contexto é importante mencionar que o estudo parte de uma consciência na qual a chuva nada mais é do que o resultado de uma transformação de um processo de interações de reagentes invisíveis analisadas a partir dos dados finais observados e armazenados através de estações meteorológicas. Não há uma resposta determinística neste estudo envolvendo uma caracterização climática. A intenção foi a de demonstrar nos resultados o reflexo da interação destes processos no comportamento das frequências de cada intensidade de chuva analisada. 


\section{II - REFERENCIAL TEÓRICO}

Atualmente, no ambiente acadêmico, cientistas renomados e com alta capacidade intelectual, aprimorada a partir de uma vasta experiência adquirida pela busca de soluções para hipóteses acerca de processos ambientais ao longo de sua vida discutem a respeito do assunto fundamental: a tendência da temperatura global no decorrer do último século.

A temperatura média global, da superfície, ou seja, a temperatura média do ar próxima da superfície da terra e, da temperatura da superfície do mar, vem aumentando desde 1861 (IPCC, 2001). Durante o século XX, o aumento foi de $0,6 \pm 0,2^{\circ} \mathrm{C}^{5,6}$ (Figura 1).

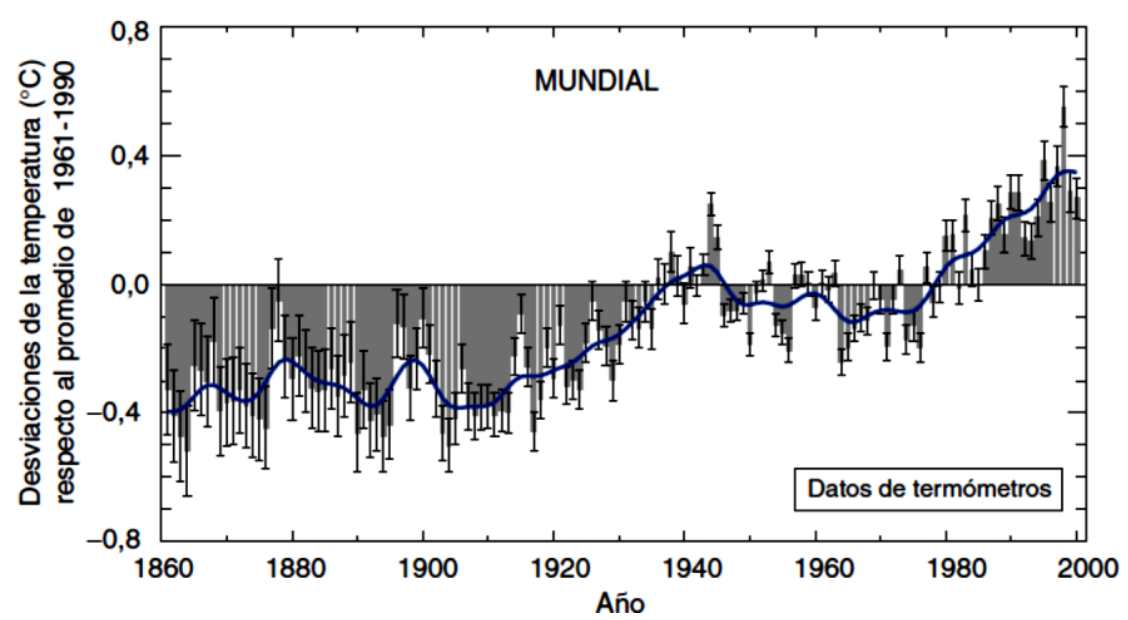

Figura 1 - As Variações de Temperatura na Superfície da Terra nos últimos 140 anos. Fonte: http://www.ipcc.ch/

A presença deste assunto, no início da apresentação, do referencial teórico, deve-se a uma reflexão realizada a partir das hipóteses estabelecidas neste estudo. Tais hipóteses estão diretamente correlacionadas, na forma de feedbacks que, naturalmente fazem parte deste contexto, mais amplo, de anomalias climáticas. Desta forma é preciso estabelecer a partir de referências intelectuais, no assunto, uma linha de raciocínio que seja ao mesmo tempo original e, suficientemente bem argumentada. A priori, é possível analisar, através de um processo de reflexão, realizada a partir dos conhecimentos adquiridos, ao longo de uma 
carreira acadêmica que, a existência de um provável aquecimento, no globo terrestre, não seria o início de mudanças climáticas e, sim o fim de um processo físico. Dentre estes processos, às anomalias de temperatura, da superfície do mar, farão parte deste estudo. Assumindo tal ponto de vista que, será mais especificamente argumentado no final deste estudo, a partir das considerações finais, justifica-se, neste momento, a linha de raciocínio, utilizada, na pirâmide de intelectuais formada neste referencial teórico. Neste sentido, é importante assumir que $\circ$ fato de negar a existência de um possível aquecimento global, pode ser mais que um ato de irresponsabilidade social, mas também em faltar com essência do pensamento cientifico que se fundamenta através da busca da verdade. Não se deve subestimar ou reduzir as inúmeras e desconhecidas interações atmosféricas que, ocorrem em um espaço relativo, de acordo com a visão de Einstein sobre o espaço, ao mesmo tempo em que, não se deve restringir-se a base de argumentações em conceitos ultrapassadas, ligadas a visão de espaço absoluto, como na visão de Newton.

A referência inicial parte da concepção de análise sobre o ambiente urbano realizado por Carlos Augusto de Figueiredo Monteiro. Monteiro (1976), em "Teoria e Clima Urbano", já havia feito uma definição do que seria o clima urbano. Conforme Monteiro, "Assim como a própria definição ou tomada de consciência de que o fato urbano emergiu do contraste com o campo, onde através dessa dicotomia e dos contrastes entre eles que $\circ$ homem tomou consciência de que a própria atmosfera sobre a cidade era sensivelmente diferente daquela do campo. Surgiram as primeiras preocupações do que se chamaria hoje de clima urbano, antes mesmo, da eclosão da revolução industrial no universo urbano". De acordo com Monteiro (1976) pode-se notar que, às vezes, a diferença é gritante, tal como em casos em que as noites da cidade são muito mais quentes do que as noites das áreas periféricas rurais. Outras vezes, a diferença é sutil, quando uma camada de nevoeiro ou, neblina cobre a cidade e, até mesmo quando o clima, de uma área relativamente pequena, torna-se modificado pela luz e, calor de uma lâmpada de rua, da cidade. Desta forma, a cidade gera um clima próprio, o clima urbano, como sendo o resultado, da interferência, de 
todos os fatores que se processam sobre a camada de limite urbano, agindo no sentido de alterar o clima, em escala local. O professor Monteiro, dentre todos os seus méritos científicos, destacaria o seu caráter esclarecedor que infelizmente no geral foi reproduzido como sendo apenas uma prática metódica excepcional em função da incompreensão intelectual do seu ponto de vista reflexivo que não se limitou apenas aos métodos, mas sim em uma demonstração de um pensamento que remete a liberdade essencial proporcionada pelo conhecimento. No entanto, a sua referência no contexto deste estudo se reduz ao fato de sua teoria apresentar um esclarecimento a respeito de uma alteração no comportamento físico que ocorreu em função da reconstituição de elementos geográficos de num determinado espaço que no caso é a urbe. Tal comportamento significa que Monteiro (1976) fez uma demonstração, do que seria considerado pela física, como sendo um processo de intensificação, da transferência de calor, por condução que, seriam proporcionadas pela constituição de uma atmosfera específica, formada por uma composição química, de partículas suspensas que, estariam muito próximas de serem homogêneas, caracterizando um ambiente ideal para a transferência de calor, de partícula, para partícula. Neste caso, pode ser compreensível que, Monteiro (1976), tenha descrito o início de um processo físico, através do pensamento racional, na qual representaria a identificação do que seria ○ "Aquecimento Global". Desta forma, pode-se imaginar a possibilidade, das mudanças climáticas ser a origem do processo de aquecimento global e, não o contrário.

O próximo encarte, em nível de escala, possui o enfoque regional que, parte da consideração, a respeito do relatório do Intergovernmental Panel on Climate Change (2001) que possui um tópico específico, a respeito deste quadro para a América Latina, onde McCarthy (2001) afirma que há uma grande evidência, de variabilidade climática, na região, na escala temporal intrasazonal que, podem atingir até períodos mais longos. Em muitas subregiões, do continente, como no noroeste do Peru e, no nordeste do Brasil, McCarthy (2001) aponta que a variabilidade no clima, normalmente está associada, a fenômenos, que produzem fortes impactos sociais e, ambientais que, podem ser intensificados, pelo 
aquecimento global e, pelas alterações associadas, ao tempo e ao clima. No mesmo relatório, é apresentada a seguinte observação: "As variações na precipitação e, as suas respectivas repercussões dependem, ainda, dos aspectos geográficos, de cada sub-região". Por outro lado, no relatório também consta que, as variações médias dependem da origem e, da qualidade dos dados, assim como dos períodos de registros e, das análises matemáticas empregadas e, desta forma, não se deve apenas ser atribuída responsabilidade às mudanças climáticas. Ainda neste relatório, McCarthy (2001) destaca o fenômeno da El Niño-Oscilação Sul ou ENOS (Southern Oscillation) como sendo o processo responsável, pela maior parte da variabilidade climática, em escalas temporais interanuais, na América Latina. Nesse sentido, a região é mencionada como sendo vulnerável ao ENOS que, normalmente, proporciona distintos impactos, por todo continente. McCarthy (2001) relata que, o El Niño está associado, com as condições secas, no nordeste brasileiro, no norte da Amazônia, no altiplano, Peruboliviano e, na costa do Pacífico, da América Central. O sul do Brasil e o noroeste peruano, exibem anomalias úmidas durante o mesmo período. Por outro lado, os eventos, de La Niña, estão mais associados, a períodos de secas, no sul do Brasil. A conclusão de McCarthy (2001) presume que, se o El Niño e a La Niña tendem a intensificar, no decorrer do tempo, a América Latina poderia estar exposta a condições climáticas, extremas, com mais frequência. Os demais relatórios do IPCC não serão descritos na intenção de não distanciar do foco principal do estudo e assim evitar prolongamentos úteis, porém não muito objetivos.

A partir do reconhecimento do relatório de McCarthy (2001) é necessário focar esse panorama, genérico, na especificidade do estudo realizado. O estudo realizado por Grimm et al (1999) provê a análise da "Variabilidade Climática na América do Sul Austral (ASA) associada com eventos de El Niño e La Niña". A América do Sul Austral, definida neste estudo, corresponde à porção sul do Brasil, Argentina, Chile, Uruguai e Paraguai. Tal região é considerada, como sendo uma das mais afetadas, por eventos de El Niño (EN) e, La Niña (LN). De fato, muitas áreas, na ASA, têm sido destacadas, no que diz respeito, a forte variabilidade, interanual, de precipitação, associada com esses eventos Grimm et al (1999). 
Ainda, neste estudo, Grimm et al (1999) indicaram as correlações entre as anomalias de temperatura da superfície do mar (TSM) na região do pacífico equatorial e as anomalias de precipitação na ASA. Os resultados consistentes de Grimm et al (1999), principalmente em função do seu amplo banco de dados, de precipitações mensais, permitiram concluir que, toda a região da ASA apresentava anomalias, de precipitação, associadas com eventos de EN e LN, ou seja, as variações de precipitação ocorriam positivamente (correlação positiva), de acordo com as alterações periódicas, de EN e LN. Os dados de precipitação mensal foram obtidos de 134 estações meteorológicas que foram selecionadas, dentre os países que compõem a ASA. O período das anomalias de precipitação modifica-se em todas as partes da ASA, levando à identificação, de oito regiões coerentes, para os casos de EN e, de 6 para os casos de LN. De um modo geral, todas essas regiões apresentaram uma resposta significativa, para algum período de cada evento. $O$ sul do Brasil foi indicado como sendo a região com o sinal mais forte, durante os episódios de EN, considerando, toda a região da ASA. As principais regiões coerentes, para os casos de EN e LN são basicamente as mesmas, exceto, por pequenas diferenças. De um modo geral, é possível notar, vetores que, no caso, foram utilizados para indicar o nível de correlação (de acordo com o seu tamanho), distribuído, num mapa representando a ASA e, especificamente, neste caso, os vetores apresentavam sentidos opostos, para os casos de anomalias de precipitação, observado nos períodos de $E N$ e $L N$, especialmente até a fase madura. Este resultado é coerente com a simetria, das anomalias, de circulação sobre a ASA e, nos oceanos contíguos, durante esses eventos, embora sejam observados, pequenos desvios no tempo e espaço. A simetria das precipitações fica bem destacada no Oceano Pacífico e, indica o alto grau de linearidade, de sua resposta, sobre ASA, durante estes eventos. Algumas características das anomalias de precipitação, durante o evento de EN, são bastante semelhantes na região.

Por outro lado, Grimm et. al (1999) destacam que as características, mais notáveis, nas anomalias de circulação atmosférica são praticamente equivalentes a um modelo de dipolo barotrópico, ou seja, campos de função de corrente que apresentaram um padrão 
clássico de dipolo vortical, com vórtices ciclônico e, anticiclônico posicionados em lados opostos, ao eixo da corrente, conforme a definição de Pereira (2009) que, no caso, ocorre sobre os oceanos Pacífico e Atlântico, com a polaridade invertida. Este modelo contribui para o fortalecimento (enfraquecimento), dos ventos de oeste, sobre o oceano Pacífico oriental, nas regiões subtropicais e, sobre o Atlântico ocidental, nas latitudes médias, causando uma curvatura ciclônica (anticiclônica), anômala, a oeste da ASA. Grimm et al (1999) nos revelam, contudo, que podem ocorrer situações, em que a correlação entre os campos das latitudes médias, das anomalias sazonais, a uma determinada altura geopotencial, se equivalem a uma aproximação de ordem nula, ou seja, inexistência de correlação, uma vez que os eventos de precipitação, podem estar mais bem correlacionados, com as perturbações transientes e, com aos padrões de escala local, da circulação atmosférica, segundo Grimm et al (1999).

\footnotetext{
Esses padrões transientes são transportados pelo escoamento médio, contribuindo para as anomalias sazonais, e são modulados através da macroescala pelos padrões de circulação de baixa frequência desencadeados por eventos de EN ou LN, favorecendo ou suprimindo a precipitação. (Grimm et al (1999). Climate Variability Southern South American Associated with EI Niño and La Niña Events, J. Climate, 13, 35-58)
}

De um modo geral, Grimm et al (1999), permite deduzir que, os possíveis reflexos na região sudeste, ocorreriam indiretamente, como sendo frutos de interações que, poderiam acontecer, em função dos padrões de macroescala (EN e LN). Nesse sentido, tais padrões proporcionariam um aumento (diminuição), na frequência da circulação, que ora favorece ou, suprimi a precipitação. Contudo, Grimm et al (1999) comenta que é importante mencionar que, há diferenças intrasazonais, no impacto, dos eventos EN (LN) e, neste caso, se faz necessário realizar uma análise mensal, durante certas fases, dos ciclos destes eventos.

A variabilidade de precipitação pode ainda estar associada à circulação de monção. A respeito desse assunto, Zilli (2007) comenta que a circulação de monção na América do Sul é um importante fator para a determinação do padrão climático regional e, 
de sua variabilidade durante a primavera e o verão da América do Sul. A circulação atmosférica, da região mais próxima do equador é abastecida, por uma fonte de calor e umidade, da floresta amazônica que, compõe em baixos níveis, o ambiente necessário, para o estabelecimento da circulação monçônica. $O$ escoamento monçônico, de baixos níveis que, ocorre durante a primavera e verão, pode ser considerado, como um desvio da circulação em relação à média anual. Esse escoamento, anômalo, origina-se nas regiões de alta pressão, dos Açores, no hemisfério norte (HN) que, estão sob as condições de inverno, Zilli (2007). As condições de inverno, no $\mathrm{HN}$, fortalecem os ventos alísios, de nordeste que, cruzam o equador, no noroeste, da África e, realiza movimentos ciclônicos, sobre a baixa continental, estabelecida na superfície, do continente sul-americano durante o hemisfério de verão, na Baixa do Chaco, indicado pelo número 3, da Figura 2, conforme Zilli (2007).

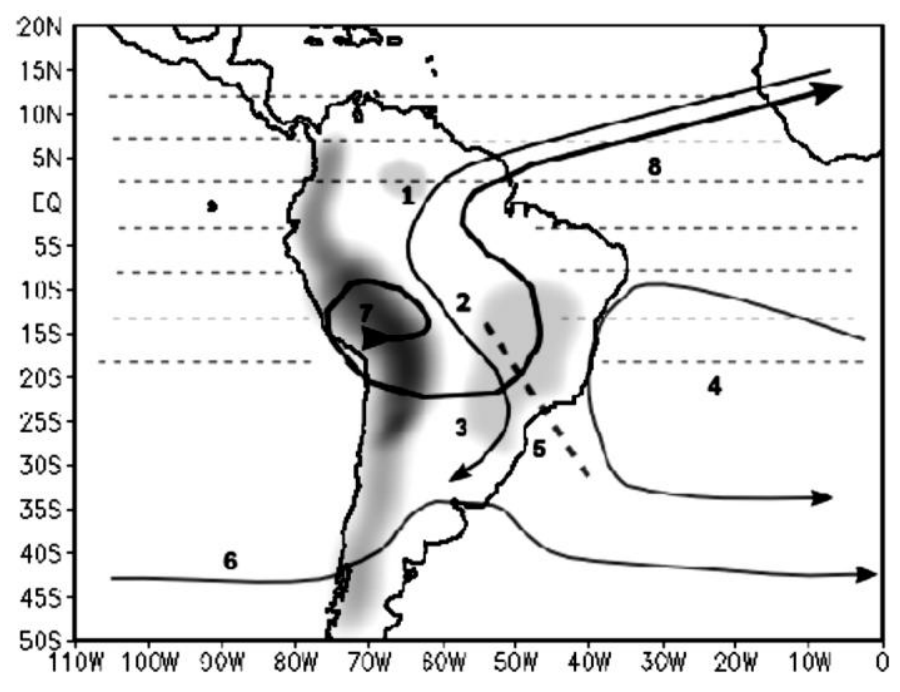

Figura 2 - As Principais Características de um Sistema de Monção na América do Sul.

As áreas sombreadas representam a topografia. As regiões onde os ventos alísios prevalecem estão indicadas por finas linhas tracejadas. (1) fluxos trans-equatoriais em baixos níveis; (2) ventos de noroeste; (3) baixa do Chaco; (4) alta subtropical; (5) ZCAS; (6) ventos de oeste em latitudes médias; (7) Alta da Bolívia; e (8) fluxo de retorno em altos níveis (Adaptado de Zilli, 2007).

Em altos níveis, Zilli (2007) comenta que, as monções são caracterizadas, por uma circulação anticiclônica, sobre os planaltos, na região oeste, do continente (alta da Bolívia), produzindo fluxos de retorno que, cruzam o equador, na direção oposta, aos de baixos níveis. 
Por fim, Zilli (2007) descreve que, em praticamente todo o Brasil, excluindo a região Sul, o ciclo anual da precipitação é caracterizado por duas estações bem definidas: uma seca, durante o inverno, relacionada à manutenção de áreas, com alta pressão, em níveis baixos, sobre boa parte do continente e, outra úmida que, se estende da primavera, até o fim do verão, relacionada à baixa térmica, estabelecida na região central, da América do Sul.

As regiões norte e sudeste, da América do Sul, apresentam, respectivamente, falta e excesso precipitação durante eventos El Niño. Em anos de La Niña, o sinal das anomalias de precipitação se inverte, tal como indicado em Silva e Silva (2010). De uma maneira geral, os valores absolutos, de correlação linear, entre índices de ENSO (TSM do Niño3) e, a precipitação mensal, nas regiões norte/nordeste e sudeste da América do Sul variam entre 0,2 e 0,3. A precipitação mensal, observada na região sudeste, do Brasil, apresenta baixa correlação linear, igual ou inferior a 0,2, com a TSM do Niño3. Ou seja, a ocorrência de eventos ENSO, não está significativamente associada, a um padrão característico de precipitação, no sudeste do Brasil, Silva e Silva (2010). A variabilidade climática, da região sudeste, do Brasil, possivelmente está relacionada a influências, tanto tropicais, como extratropicais, o que dificulta a identificação dos processos determinantes. Com a dificuldade de se definir a influência, de eventos ENOS, na precipitação, do sudeste do Brasil, foi proposto neste estudo associar dados filtrados, da precipitação mensal, observada em São Paulo, com os eventos de aquecimento e, resfriamento do Pacífico Equatorial.

A respeito de trabalhos trimestrais que avaliaram a relação entre intensidade dos eventos El Niño e La Niña e as médias das anomalias de precipitação acumulada durante os respectivos períodos, Coelho et al (1999) analisou tal comportamento numa escala nacional. Aproximando os seus resultados para informações que possam convergir para a cidade de São Paulo através da observação dos seus mapas pluviométricos nota-se que durante o inverno não foram identificadas significativas correlações com El Niño. Por outro lado, nota-se que independente da intensidade da La Niña ocorre uma variação positiva de aproximadamente de $50 \mathrm{~mm}$. No outono, durante o El Niño nota-se uma anomalia positiva de 
$50 \mathrm{~mm}$, porém mais intensa quando comparado ao seu período forte a moderado. Em relação a La Niña nota-se que no seu período fraco, a anomalia variou positivamente em torno de $100 \mathrm{~mm}$. Na primavera, nota-se que durante o El Niño não houve significativas alterações nas anomalias de precipitação. Por outro lado, durante as La Niñas mais intensas, nota-se uma anomalia negativa de aproximadamente $50 \mathrm{~mm}$ e durante as La Niñas de intensidade fraca uma anomalia próxima de $50 \mathrm{~mm}$. No mesmo artigo publicado, não foi publicado o mapa relativo à estação de verão. No entanto, é importante comentar que o trabalho realizado por Coelho et al (1999) não esteve focado na cidade de São Paulo e, desta forma, as observações realizadas através dos seus mapas são meras e subjetivas aproximações que fazem uso de sua referência como parâmetros necessários para as análises, inclusive em função da composição de sua série temporal ser equivalente ao período de 1965 a 1998.

No trabalho realizado por Sugahara et al (2008) a análise diária de chuva extrema na cidade de São Paulo, no período de 1933 a 2005, fez uso de modelagem estatística através do método dos quantis para estimar valores pluviométricos a serem identificados como extremos no intervalo temporal diário. Neste estudo, fazendo uso da projeção da regressão linear, Sugahara et al (2008) separou a série temporal em três classes de análise. Na classe anual, de Janeiro a Dezembro, nota-se que houve um aumento em torno de $40 \mathrm{~mm}$ de chuva no período de 1933 a 2005. Na classe definida como úmida, Outubro a Março, e seca, Abril a Setembro, nota-se que o aumento identificado acerca de $40 \mathrm{~mm}$ variou no eixo y no intervalo úmido de 100 a $140 \mathrm{~mm}$ e seco de 80 a $120 \mathrm{~mm}$.

A análise do clima urbano, conforme discutem Tarifa e Armani (2000), deve considerar, além dos aspectos físicos, relacionados à atmosfera, do município de São Paulo, os aspectos urbanos e sociais. As correlações estabelecidas com a consideração do uso e ocupação do solo, desastres ambientais e fatores biogeográficos fazem com que, o estudo forneça um quadro mais realístico, envolvendo a integração de vários fatores, na reorganização dos espaços climáticos, do município. Estes espaços, denominados de Unidades Climáticas Urbanas por Tarifa e Armani (2000), no nível de clima local, fornecem informações 
necessárias que, podem ser úteis, para a análise do ambiente, da área de estudo e, para o planejamento urbano e defesa civil.

No que se diz respeito ao assunto "Chuva", muitos estudos foram realizados, em diversas áreas do conhecimento, envolvendo este tema. Inúmeras poderiam ser as referências, no entanto serão destacadas, apenas algumas que, ressaltem, principalmente, o caráter interdisciplinar que, envolve este assunto. A respeito da ocorrência espacial, da chuva, Azevedo (1996) realizou uma investigação, de caráter empírico, na cidade de São Paulo, na qual esteve focada, em reproduzir, a repercussão espacial da chuva, na intenção de analisar, de maneira mais próximo possível, do local de ocorrência. Nesse sentido, Azevedo (1996) faz considerações, a respeito dos aspectos dinâmicos e, quantitativos, relativos às repercussões das chuvas. Tais considerações podem ser notadas, por meio de suas reflexões, como através da hipótese de existência, de um enorme pluviômetro, com a capacidade de cobrir uma área, com muitos quilômetros quadrados, onde uma precipitação qualquer, teria sido completamente, interceptada por este. No que diz respeito, especificamente, a essa colocação é fato que, muito se comenta sobre a variação espaço-temporal, da precipitação, no entanto, Azevedo (1996) induz o pensamento do leitor ao aspecto da heterogeneidade dos sistemas atmosféricos precipitantes e, a sua eventual observação imprecisa. $O$ autor também menciona a respeito da imprecisão, na escala temporal de observação, uma vez que, as observações, de chuva são feitas, em muitos casos, a cada hora, impossibilitando qualquer análise, de evento com duração menor que este intervalo de tempo. Neste sentido, Azevedo (1996) demonstra a importância, da realização, de observações que, estejam muito próximas da realidade, para análise de eventos, de curta duração. Azevedo (1996) destaca a importância dos experimentos empíricos, no reconhecimento, mais próximo possível, das condições nas quais os dados obtidos estão inseridos na realidade. As constatações da variabilidade espacial da precipitação, mesmo na ocorrência de sistemas atmosféricos mais complexos que, possuem um regime, pluviométrico, mais regular e homogêneo, necessitam de um 
monitoramento adequado, para que se compreenda o comportamento de sua repercussão espaço-temporal.

No aspecto que envolve estudos das frequências absolutas, Cabral (2002) analisou a variabilidade e, a tendência do fenômeno pluvial, na região metropolitana de São Paulo. O ponto relevante, a ser observado, neste estudo é relativo à hipótese do processo de urbanização ter afetado o comportamento, dos níveis pluviométricos, gerando, consequentemente, o aumento de episódios, de chuvas torrenciais e, a diminuição de chuvas, mais leves (inclusive a garoa). Cabral (2002) levou em consideração, as causas de origem regional e, global que, também pudessem ter um papel importante, na distribuição espaçotemporal, das chuvas. Neste sentido, conforme os resultados obtidos, pelo autor, podemos notar que, a hipótese foi confirmada com sucesso. A segunda abordagem deste estudo esteve focada na análise, espaço-temporal, porém, não sob o aspecto intuitivo, de uma abordagem dinâmica, assim como fez Azevedo (1996). Nunes (1997) também realizou um estudo, voltado para a variabilidade, espacial e temporal da chuva que, foi avaliada em uma dimensão física, maior do que a apresentada por Cabral (2012), no caso, para o estado de São Paulo. Nunes (1997) enfoca na variabilidade anual e sazonal, da precipitação, no estado de São Paulo, estabelecendo uma correlação, com as atuações, de eventos ENOS. Os resultados de Nunes (1997) revelam que o aumento da variabilidade dos elementos do clima seria um dos indícios mais fortes relacionados às mudanças climáticas globais. Suas análises demonstram que, de fato, ocorrem alterações, na tendência de chuva, no estado de São Paulo, nos anos mais recentes, as quais foram mais nítidas nos períodos de inverno e de outono. No entanto, a autora descreve que, deve haver outras variáveis ambientais que influenciam os resultados.

Ambrizzi e Dufek (2007) analisaram a variabilidade, de chuvas extremas, no estado de São Paulo. Os dados observados foram de precipitações diárias. No caso, foram feitos mapas, envolvendo a projeção linear, da tendência, para 59 estações pluviométricas. 0 período analisado foi o intervalo de 1950-1999 e, posteriormente, 1990-1999. No caso, os autores notaram um significativo aumento, de dias com precipitação extrema que, foi 
observado em mais de $45 \%$ das estações pluviométricas. $O$ teste de Mann-Kendall utilizado, neste estudo, apontou uma tendência positiva, na precipitação total anual, de chuvas extremas, na qual avaliou episódios de chuvas, iguais e superiores a $20 \mathrm{~mm}$, durante seis anos. Desta forma, os resultados sugeriram que ocorreram alterações na intensidade de precipitação.

O trabalho realizado por Xavier e Pereira Filho (2007) envolve a análise, das medições e, observações meteorológico-climáticas, de superfície, onde o aspecto mais importante foi na demonstração de uma definição, estatística, para a caraterização de intervalos temporais, significativos, a serem utilizados nas análises pluviométricas.

Por último, é importante mencionar a origem dos quantitativos, utilizados neste estudo, através da definição exata, realizada através de cálculos que, definiram matematicamente, os valores de precipitação que correspondem a um episódio de Chuvas Intensas, de Pfafstetter (1957) e Wilken (1978). O engenheiro Pfafstetter (1957) é referência nacional no estudo de chuvas intensas. Seus cálculos servem de base para a definição de chuva intensa, em 98 postos pluviométricos, espalhados pelo Brasil. Sua obra denominada de "Chuvas Intensas no Brasil", produzida em 1957, atende a um amplo leque de pesquisadores interessados no assunto. Apesar dessas informações, devido a propósito deste estudo, não será feito uso dos cálculos específicos relativos à precipitação, duração e, tempo de recorrência, pois não é a intenção deste trabalho. Os cálculos de Pfafstetter (1957) apresentam finalidades específicas, relacionadas, em especial, a obras de drenagem urbana. Para a climatologia, Pfafstetter (1957) faz uma definição matemática, partindo de constatações empíricas, a respeito dos limites mínimos para os episódios de chuvas, considerados como intensas no Brasil. Este cálculo foi reanalisado e, complementado posteriormente por Wilken (1978).

A menção honrosa, deste trabalho, ao mérito pessoal de Ary França. França (1945) em sua tese de doutorado, apresentada à cadeira de Geografia Humana em 1945, apresenta um estudo específico sobre o clima da bacia de São Paulo, na qual um dos 
elementos do clima analisado foi o de precipitação. França (1945) traçou um perfil pluviométrico, de chuvas anuais, relacionando em um mesmo gráfico, suas respectivas correlações qualitativas, com ○ perfil topográfico que acompanha ○ meridiano, a partir da serra da Cantareira até o oceano, através da cidade de São Paulo. França (1945) não apenas analisa os elementos do clima, de maneira isolada, como também inserem, nesse contexto, os aspectos relativos aos seus respectivos comportamentos, em função do relevo e, da localização espacial na distribuição dos fenômenos climáticos.

As zonas da várzea, que é a parte mais baixa da bacia de São Paulo e área contígua, ao sul, mais acidentada e elevada, revela um mínimo de pluviosidade, de acordo com os registros de 1888 a 1940, na estação da Luz (1326,3 mm), de 1889 a 1923, na Praça da República (1303,3 mm), de 1903 a 1934, na Avenida Paulista $(1341,3 \mathrm{~mm})$ e, principalmente, do período de 1933 a 1941, no Instituto Astronômico e Geofísico (1262,7mm). (França (1999). Estudo Sobre o Clima da Bacia de São Paulo, Tese de Doutorado, p21)

O trabalho a ser apresentado, a partir das referências teóricas está focado em apresentar um resultado que, constate ou não, a partir de novas informações, a influência provocada pelo espaço urbano, nas condições atmosféricas, através do aumento na frequência de episódios de chuvas. Neste contexto serão avaliadas, conjuntamente, as alterações em grandes escalas, relacionadas às flutuações de temperatura, na superfície do mar (TSM), da região do Oceano Pacífico Equatorial. Por último, analisar a possibilidade, do processo de urbanização, durante o período de 1970 a 2009, quando combinado, com as variações cíclicas naturais da TSM, tende a provocar um aumento (diminuição), nos episódios, de cada tipo de chuva, na cidade de São Paulo. 


\section{III - MÉTODOS, TÉCNICAS E MATERIAIS}

A origem de todas as informações quantitativas parte do conjunto de dados de precipitação horária, obtida pela Estação Meteorológica do Instituto de Astronomia, Geofísica

e Ciências Atmosféricas da Universidade de São Paulo (EM-IAG/USP), para o período de 1970 a 2009. De acordo com Xavier e Filho (2007), a instalação desta estação meteorológica tem sido praticamente a mesma, desde o início de suas atividades, no dia 22 de novembro de 1932.

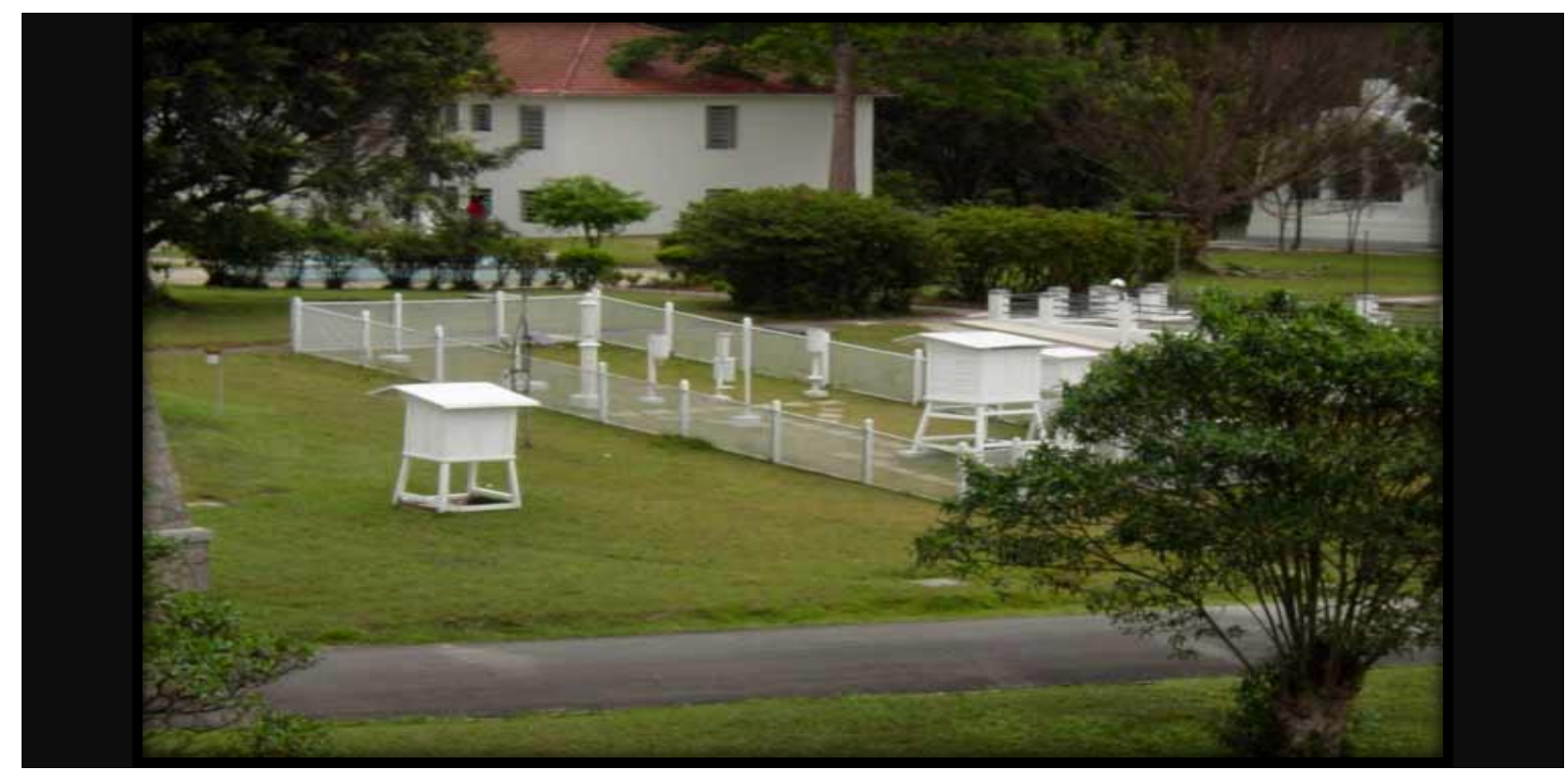

Figura 3 - Estação Meteorológica do IAG/USP, foto tirada em 2008.

Fonte: http://www.dca.iag.usp.br/www/estacao/Instrumentos.htm

Em termos cartográficos, tanto o cercado, quanto $\circ$ edifício onde trabalham os técnicos em meteorologia encontram-se nos arredores de um marco, correspondente à latitude $23^{\circ} 39^{\prime} \mathrm{S}$ e à longitude $46^{\circ} 37^{\prime} \mathrm{W}$. A estação está situada a 799,2 metros de altitude acima do nível médio do mar (NMM), no Parque Estadual das Fontes do Ipiranga, no bairro Água Funda, Zona Sudeste - Distrito de Cursino, na capital de São Paulo. A localização geográfica, da estação meteorológica no município de São Paulo está ilustrada na Figura 4. 


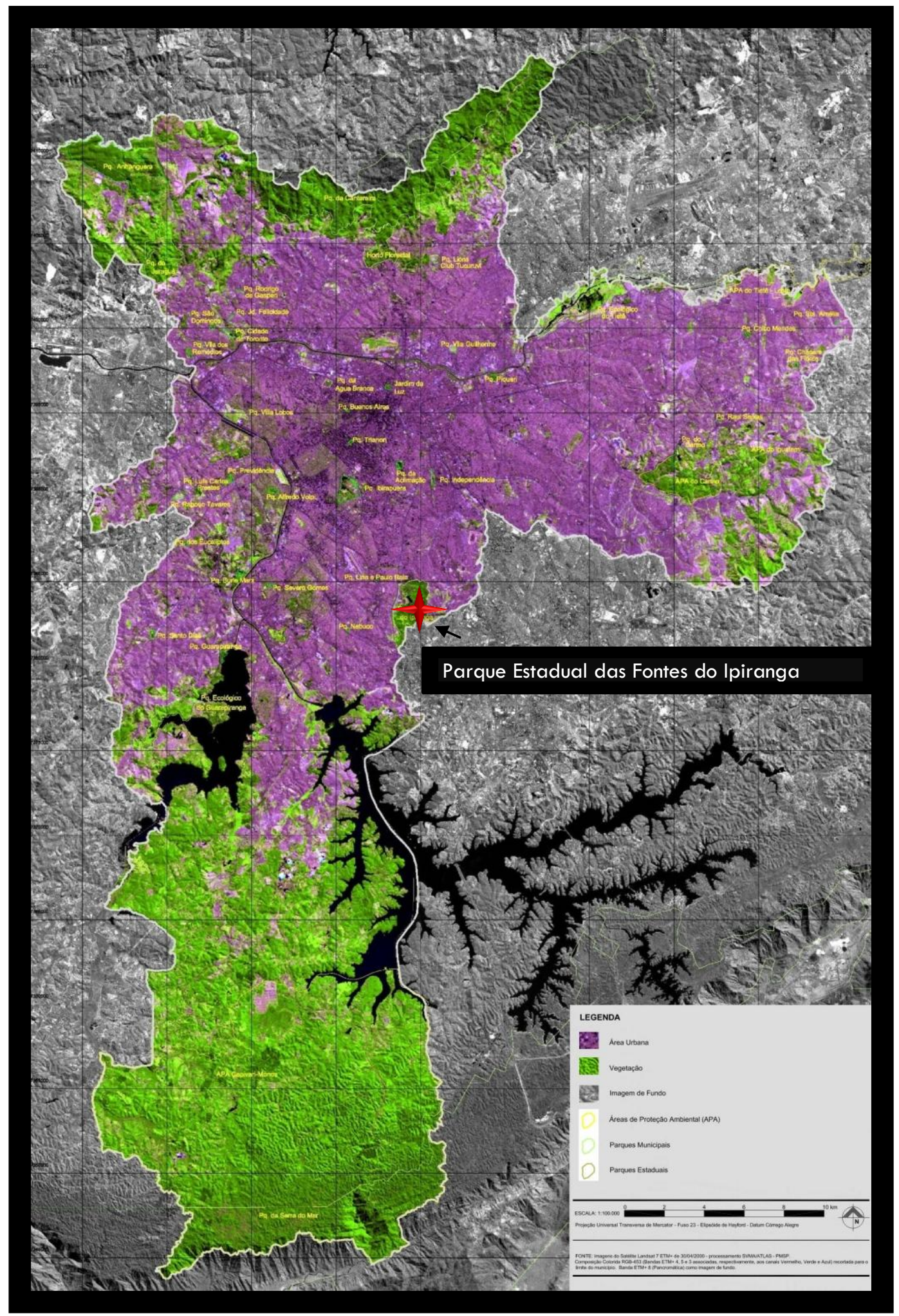

Figura 4 - Mapa do Município de São Paulo-SP com a Localização do Parque Estadual das Fontes do Ipiranga (cruz vermelha), onde está instalada a Estação Meteorológica do IAG-USP (Imagem de Satélite do Landsat 7 ETM+, 2000).

Fonte: $\underline{\text { http://smdu.prefeitura.sp.gov.br/historico demografico/. }}$ 
O aparelho mecânico utilizado no registro da altura pluviométrica na Estação Meteorológica do IAG-USP é o pluviógrafo de Hellmann, ilustrada na Figura 5. Este aparelho possui uma rotação diária, que registra os dados continuamente, durante as 24 horas do dia. A partir de 2009, as observações coletadas pelos observadores meteorológicos e, as registradas pelos instrumentos automáticos são arquivadas digitalmente em planilhas eletrônicas e, instantaneamente transferidas para o banco de dados e para o portal da internet, no endereço: www.estacao.iag.usp.br. No dia seguinte às leituras, os dados coletadas são confirmadas com base na verificação com dados registrados na folha de observação e, nos registradores automáticos. Posteriormente, as medições são inseridas nas folhas durante a madrugada, de uma às seis horas. É importante ressaltar que a Estação Meteorológica, não adota o horário de verão e, sim o tempo universal coordenado (TMC) ou tempo médio de Greenwich (TMG), durante todo ano, para esta localização geográfica, na qual o horário local corresponde ao TMG de menos 3 horas.

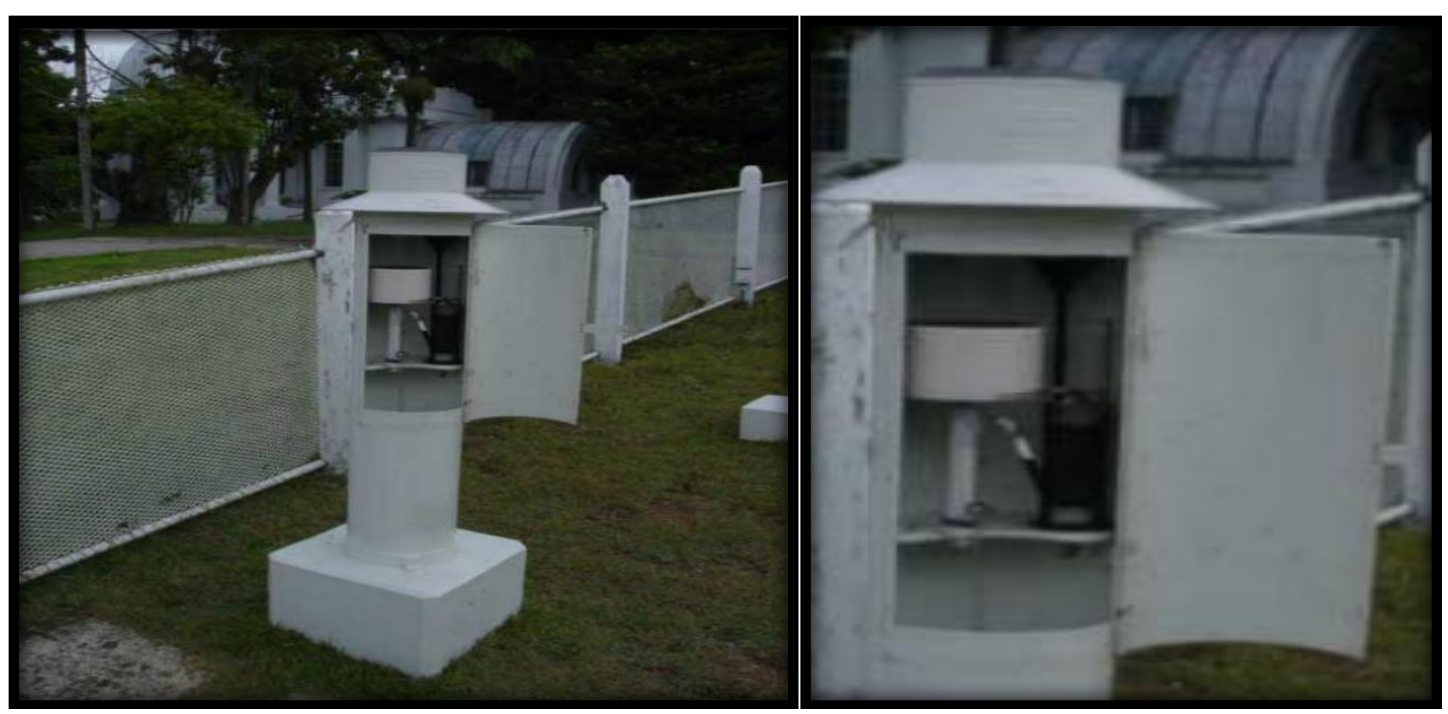

Figura 5 - Pluviógrafo de Hellmann, instalado no cercado Meteorológico, da Estação Meteorológica do IAG-USP, São Paulo-SP.

Fonte: http://www.estacao.iag.usp.br/

Os dados pluviográficos, em geral, são registrados em pluviogramas, cujo comprimento e altura, correspondem, respectivamente, à escala temporal e à escala de registro da precipitação. A cada 10 milímetros de precipitação acumulada, o recipiente do 
pluviômetro é esvaziado, levando ao início de um novo registro. O registro do volume pluviométrico é feito a cada 10 minutos. Alguns detalhes estruturais, do pluviógrafo e um recorte de pluviograma estão ilustrados na Figura 6. Neste caso, foi registrado um volume de 16 milímetros, de precipitação, em 60 minutos.
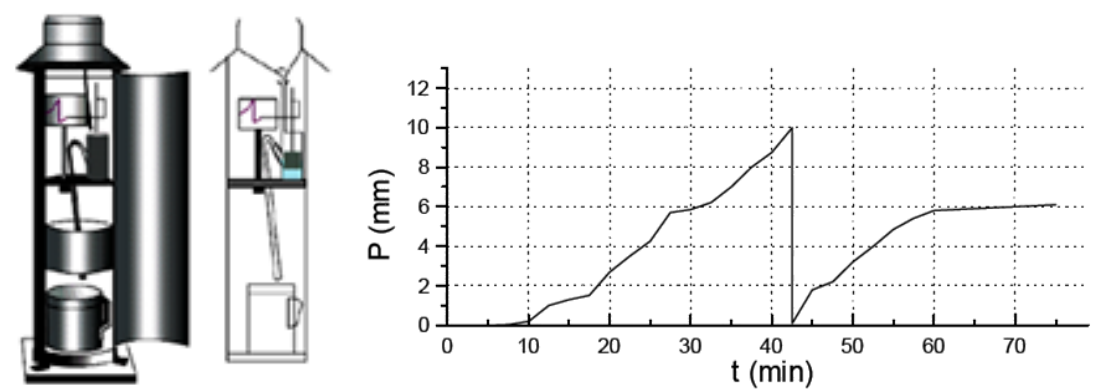

Figura 6 - O Pluviógrafo de Bóia e um recorte de pluviograma para o período de 70 min. Fonte: Varejão-Silva (2001)

No recorte do pluviograma, a linha vertical, em $42 \mathrm{~min}$, corresponde a uma sifonagem. Na parte inferior, no eixo das abscissas, estão às escalas temporais, em minutos e, no eixo das ordenadas, está à gradação da altura pluviométrica, em milímetros.

Na sequência serão apresentadas seções distintas que correspondem os detalhes específicos, de cada etapa realizada, durante os procedimentos metodológicos adotados.

\section{1 - O Domínio Temporal}

Tal como indicado pela Organização Mundial de Meteorologia (OMM), um série de dados climaticamente consistente deve apresentar minimamente 30 anos. A OMM define a caracterização de clima com base no conjunto de fenômenos meteorológicos que representem - estado médio da atmosfera de uma dada região durante este período de tempo. Com as mudanças globais atualmente observadas durante as últimas décadas, ou durante o último século, tornou-se mais complexo, o estabelecimento do tamanho que deve ter uma série 
temporal, para que represente o clima de determinada região. O intervalo de 1970 a 2009 , adotado neste trabalho, contribui para que a análise tenha um caráter climático. A longevidade da série favorece a consistência estatística dos cálculos e, sustenta a adoção de modelos específicos, como os modelos lineares e cíclicos, aplicados em nível local. No entanto, esse não é o único propósito, do uso, de uma série temporal extensa. A segunda razão é motivada pela possibilidade de identificar, ao longo desta série temporal, um número representativo de fases ENOS. De acordo com os registros do Climate Prediction Center (NCEP), no período de 1970 a 2009, foram identificados 13 anos de El Niño, 14 anos de La Niña, que oscilaram entre os 13 anos de Fase Neutra, na região Niño 3.4, do Pacífico Equatorial. Entende-se quanto maior a quantidade de dados disponíveis, melhor é a confiabilidade estatística a cerca do objeto analisado.

\section{2- Definição dos Tipos de Chuva}

O esclarecimento da base teórica, utilizada na definição dos tipos de chuvas, neste estudo, é fundamental para a compreensão do que exatamente é o foco da análise, ou seja, a apresentação teórica inicial que, antecipa as especificações dos procedimentos a serem adotados para análise dos dados. É importante destacar que os dados de precipitação foram obtidos na escala horária, sendo agrupadas e analisadas nas escalas mensal, sazonal e anual. As análises são feitas a partir de um valor absoluto da precipitação, na qual a respectiva contagem, de suas frequências, foi incluída valores iguais e superiores a estes limites. Considerando a definição de "chuva" como a água precipitada na superfície pelo processo total de um evento precipitante e, precipitação como parte da chuva que ocorreu em um intervalo de tempo, pode-se dizer que este estudo baseia-se na investigação, do comportamento de precipitação horária, observada na Estação Meteorológica do IAG.

Neste contexto, o dispositivo científico básico a ser utilizado faz uso do conhecimento estatístico que inicialmente é introduzido na contagem da frequência absoluta de episódios de 
precipitação horária com limiares pré-definidos. Neste caso, a precipitação horária tende a estar associada à potencialidade do episódio neste intervalo de tempo que definirá cada tipo de chuva de acordo com os padrões internacionais (haverá uma seção específica para esta explicação). O cômputo da abrangência, de precipitação, em um intervalo de tempo maior, por exemplo, durante um dia, refere-se a outro tipo de consideração física. Nesse sentido, é importante mencionar que o fato de chover foi interpretado como sendo um processo que está associado à evolução espaço-temporal da precipitação que, de fato ocorre num determinado espaço geográfico. Por outro lado, entende-se a precipitação como sendo uma parte mensurável da chuva, obtida em um determinado intervalo de tempo que, pode ser definido cronologicamente. No contexto acadêmico, a análise horária poderá fornecer novas informações às análises anuais, realizados por Cabral (2002) e, as análises mensais, realizadas por Machado (1993). Neste sentido, ao estabelecer comparações entre as escalas temporais de estudo, notamos que o cálculo de regressão, quando aplicados no intervalo horário, aproxima a informação da realidade, do acontecimento do fato que, no caso é a precipitação. $O$ argumento matemático que justifica tal colocação deve-se ao fato que, neste caso, temos 24 intervalos de uma hora, em um dia que, remetem à contagem de 24 possíveis eventos de chuva em cada dia, num total máximo de 744 eventos, em um mês. Supondo uma escala diária é possível alcançar a possibilidade, de registro, de um evento por dia, num total de 30 dias. Dessa forma, o número total máximo de eventos poderia ser igual a 30 . Por outro lado, é notável que ocorra episódios com durações superiores ou inferiores a uma hora, porém essas análises envolvem estudos mais específicos e com outros objetivos. A relevância da argumentação deve-se ao fato de que estamos considerando que possam ocorrer, mais que um episódio de chuva, em um mesmo dia.

Após o esclarecimento sobre a importância da escala temporal a ser utilizada é, também importante acrescentarmos que o estudo adotará limiares técnicos e científicos, de convenções internacionais e, estudos específicos realizados para dados observados no Brasil. Desta forma, as próximas informações, apresentadas nesta seção, estão focadas, na 
fundamentação teórica, dos procedimentos realizados, para a classificação de chuva.

As Classificações de Chuvas foram baseadas, a partir das definições estabelecidas pela American Meteorological Society (AMS) e pela Met Office (UK). Neste sentido é importante mencionar que, o instrumento básico empregado, nos registros de chuva, considera como sendo a unidade métrica o nível de água em milímetros por hora $\left(\mathrm{mm} \mathrm{h}^{-1}\right)$ de precipitação efetiva, registrada pelo pluviógrafo. A partir dessa observação, os organismos internacionais, mencionados anteriormente, classificam as chuvas, em muito fraca, fraca, moderada, forte e muito forte. No entanto, foram feitas algumas adaptações nos valores numéricos deste modelo, em função deste estudo, por também levar em consideração os estudos realizados no Brasil, nos campos da Hidrologia, Biologia e Agronomia. A intenção ao realizar tais ajustes é possibilitar a aproximação da realidade climática do ambiente de estudo. A classificação realizada, a partir do trabalho interdisciplinar, realizado por Leite et al (2011), envolvendo análises de precipitação em Ponta Grossa, no estado do Paraná, contribuiu para a definição da classificação que foi definitivamente adotada neste estudo. A tal classificação adotada neste estudo é apresentada na Tabela 1.

Tabela 1 - Classificação da Intensidade das Chuvas adotada neste estudo.

\begin{tabular}{cc}
\hline CLASSIFICAÇÃO & $\left(\mathrm{mm} \mathrm{h}^{-1}\right)$ \\
\hline Muito Fraca (MFA) & $<0,25$ \\
\hline Fraca (FA) & $0,25 I-1,0$ \\
\hline Moderada (MO) & $1,01-4,0$ \\
\hline Forte (FO) & $4,01-16,0$ \\
\hline Muito Forte (MFO) & $16,01-50,0$ \\
\hline
\end{tabular}


A definição quantitativa da precipitação horária, em geral, não permite inferir o tipo de sistema atmosférico associado. Os cálculos estatísticos, quando realizados isoladamente do contexto dinâmico, do processo de formação de chuvas, principalmente, no que diz respeito à sua classificação em intensidades, podem não fazer muito sentido. Nas latitudes subtropicais, região de estudo, há dois processos importantes responsáveis pela formação de nebulosidade e, consequentemente, de chuvas: as formações ciclônicas (Chuvas ciclônicas) ou Frontais e as Chuvas Convectivas ou, por aquecimento local, Galvani (2012). De um modo geral, as chuvas frontais são responsáveis por intensidades médias e baixas de precipitação, por um longo período de duração e estão associadas a sistemas atmosféricos que cobrem grandes áreas. Estes sistemas podem ser constituídos por formas distintas, de nuvens estratiformes e/ou cumuliformes, que podem ser extensas, horizontalmente e, profundas, verticalmente. Por outro lado, as chuvas de origem convectiva, que, nas latitudes tropicais, também podem ser chamadas de chuvas de verão, apresentam grandes intensidades, durações mais curtas e, estão associadas a sistemas de menor abrangência horizontal. Este tipo de chuva é formado predominantemente por nuvens cumuliformes que, apresentam um intenso desenvolvimento vertical. Por outro lado, sistemas atmosféricos responsáveis por chuviscos e garoas normalmente são originários de nuvens estratiformes. Os episódios de chuvisco ou garoa podem eventualmente se intensificar com o aumento da concentração de material particulado suspensos na atmosfera, decorrentes do processo de urbanização.

Tendo em vista, os esclarecimentos anteriores, podem-se identificar qualitativamente as condições de tempo associadas a cada tipo de chuva. Neste caso, fazendo uso dos estudos realizados por Frediani (2012), as Chuvas Muito Fracas (MFA), podem estar originárias de neblinas e nevoeiros ("mist" e "fog"), as Chuvas Fracas (FA), de Chuviscos e Garoas ("Drizzle"), as Chuvas Moderadas (MO), de tempestades leves ("light thunderstorms") formadas por Nimbostratus, Chuvas Fortes (FO), de "tempestades ordinárias" e, por último, Chuvas Muito Fortes (MFO), de "tempestades severas" formadas por "Supercélulas". Particularmente, neste 
contexto, também serão acrescidos, mais dois tipos de chuvas, as Chuvas Intensas e as Chuvas Extremas, durante as respectivas análises a serem aplicadas.

As Chuvas Intensas foram particularmente definidas de acordo com exposição teórico-quantitativa realizada por Pfafstetter (1957). Dessa forma, o conceito de Chuvas Intensas parte de uma medida correspondente à altura de água precipitada num intervalo de tempo que, pode ser expressa em $\mathrm{mm} \mathrm{h}^{-1}$ ou $\mathrm{mm} \mathrm{min}^{-1}$. Nesse sentido, um milímetro por minuto de chuva corresponde a uma vazão de um litro por minuto afluindo em uma área de um metro quadrado. O tipo de chuva definido como intensa, está associada ao quociente entre o volume de água precipitada e o intervalo de tempo em que este volume é observado, tal como definido por Pfafstetter (1957) e Wilken (1978). Os resultas destes cálculos fornecem os valores que identificam quando um determinado tipo de precipitação pode ser considerado como intensa.

A partir das análises dos pluviogramas, Pfafstetter (1957) identificou as respectivas alturas $(e \mathrm{~mm})$ e as intensidades médias $\left(e \mathrm{~mm} \mathrm{~h}^{-1}\right.$ ) de precipitação para qualquer intervalo de tempo, entre cinco minutos e 24 horas. Para encontrar o período de maior intensidade de um determinado evento de chuva, Pfafstetter (1957), procurou a parte mais inclinada da curva formada pelos registros de chuva, ou, o trecho de curva que apresenta a maior diferença de precipitações para intervalos constantes. Desta forma, o autor constatou que $\circ$ início ou o final da parte mais intensa da chuva não coincidia necessariamente a em intervalos de diferentes durações. Neste aspecto, especificamente técnico, observa-se que, involuntariamente, ○ gráfico atinge várias vezes o limite do papel, no sentido vertical, onde corresponde aos sifonamentos do aparelho registrador, e partir desse comportamento, se contou uma dezena de milímetros de precipitação, para cada dente do gráfico no intervalo considerado. Como os pontos mais altos e mais baixos, dos dentes nos gráficos, não coincidem, exatamente, com as marcações de dez e zero milímetros, respectivamente, Pfafstetter (1957), teve que realizar uma correção na precipitação total, que corresponde à diferença entre as leituras nas extremidades dos dentes e aquelas marcações. Assim, foi definido como correção 
negativa, quando o dente não atinge aquelas marcações. Neste caso, Pfafstetter (1957), observou que os dados de precipitação máxima, registrados em intervalos de cinco minutos a 48 horas, formavam uma progressão geométrica, com razão dois, o que permitiu, com certa facilidade, a projeção de uma curva, a partir dos resultados marcados em papel de graduação logarítmica. O limite mínimo de cinco minutos representa o menor intervalo que se podem ler, com precisão adequada, os registros pluviográficos. O limite máximo foi fixado em 48 horas, porque para durações maiores, os dados de pluviômetros são mais vantajosos, em função de apresentarem uma suficiente precisão aliada com uma maior facilidade de manuseio. Assim, a duração de 14 horas, representa a média de 16 h e 12 h, que se obtém, respectivamente, com a progressão de razão dois, das durações de 1 h e 24 h, que devem ser mantidas por conveniência. A razão três entre as durações de 5 min e 15 min não prejudica a definição da curva, nesta parte.

No entanto, dentre os estudos realizados Pfafstetter (1957), a solução referente aos limites mínimos de intensidade, é o objeto analisado a partir dos procedimentos metodológicos. A base dessa solução foi realizada com os dados de precipitações que foram escolhidos, de modo que, em cada posto e para cada duração, se tivesse, em média, aproximadamente, três eventos de chuva por ano. Pfafstetter (1957) realizou o cálculo do limite de precipitação, para diversas cidades no Brasil, onde uma de suas aplicações corresponde a Estação Meteorológica do IAG. Desta forma, o autor observou que, quando intensas, as precipitações não excedem, em todas as durações, os limites mínimos fixados que na média, foram anotados, aproximadamente, dez eventos de chuva, por ano de observação, para cada posto. Por fim, Pfafstetter (1957) define que uma chuva pode ser considerada como intensa desde que, para qualquer duração, tenha ocorrido uma precipitação superior ao limite por ele fixado. A partir de tais limites, o foco do procedimento utilizado neste estudo é de apenas determinar as Chuvas Intensas sob o ponto de vista climatológico. A Tabela 2 apresenta os limites acima dos quais, a chuva é considerada "intensa". 
Tabela 2 - Limites Mínimos de Intensidade, em mm, para Chuva Intensa, segundo Pfafstetter (1957), Wilken (1978) e o adotado neste estudo.

\begin{tabular}{|c|c|c|c|}
\hline Tempo (min) & Pfafstetter (1957) & Wilken (1978) & $\begin{array}{l}\text { Valores adotados } \\
\qquad(\mathrm{mm})\end{array}$ \\
\hline 5 & 8 & 10 & 8 \\
\hline 10 & & 12 & 12 \\
\hline 15 & 15 & 15 & 15 \\
\hline 20 & & & 16,7 \\
\hline 25 & & & 18,4 \\
\hline 30 & 20 & 20 & 20 \\
\hline 35 & & & 21 \\
\hline 40 & & & 22 \\
\hline 45 & & 23 & 23 \\
\hline 50 & & & 23,7 \\
\hline 55 & & & 24,3 \\
\hline 60 & 25 & 25 & 25 \\
\hline
\end{tabular}

Por último, a definição de Chuvas Extremas. Tais chuvas originam-se muitas vezes de tempestades severas associadas a sistemas atmosféricos do tipo "Multicélula", conforme Frediani (2012). O nível extremo é um estágio que uma precipitação pode alcançar em função de sua intensidade extrapolar o limite de $50 \mathrm{~mm} \mathrm{~h}^{-1}$. Este limite é adotado pelo Met Office e pela AMS. Os episódios de Chuvas Extremas estão associados às chuvas torrenciais, que se caracterizam pela precipitação de grande quantidade de água, de forma abrupta, durante um curto, médio ou longo período de tempo. $O$ índice foi definido devido à força do impacto da precipitação e à incapacidade de absorção da água pela superfície, que, por consequência, está associada à ocorrência de enchentes, inundações e deslizamentos de terra. Na questão que envolve a discussão de causa e efeito definida pela associação entre a intensidade de um evento de chuva e desastres ambientais, é importante destacar que os valores definidos na Tabela 2 não se aplicam em todos os casos. Notam-se casos de enchentes proporcionadas por intensidades de chuvas muito menores que podem ser potencializadas, em função de inúmeros componentes diferenciados, na qual a superfície pode estar estruturada. Da mesma forma, podem ser analisados os casos de deslizamento de terra, em áreas de risco que, dependendo da cobertura vegetal ou mesmo do tipo de solo, podem amenizar ou intensificar o fator erosivo. 


\section{3- Agrupamento de Amostras de Chuvas}

O procedimento metodológico aplicado para a definição do agrupamento de intensidades distintas de precipitação correspondeu a uma organização da classificação de chuvas, considerada anteriormente, em grupos que apresentassem, ao mesmo tempo, uma significância e representatividade dentro da amostragem estatística. Por meio deste procedimento foi possível diagnosticar diferentes tipos de chuvas, em apenas um grupo e, assim obter novos resultados a partir de valores (níveis pluviométricos) que fossem mais significativos dentro da amostra. Neste contexto, foram pré-identificados, três grupos representativos, para a amostra analisada. A amostra analisada corresponde ao banco de dados de precipitação horária e mensal para o intervalo de 1970 a 2009. Os tais grupos representativos foram definidos com limites iguais e superiores a 10, 20 e 30 milímetros. A definição dos limites destes grupos foi definida através do cálculo realizado a partir das somas das frequências absolutas acumuladas, de classes com altas frequências absolutas simples mensais, para cada ano da série analisada. Desta forma, os resultados revelaram que os intervalos de $10 \mathrm{Ol}-20,20 \mathrm{l}-30$ e $30 \mathrm{l}-40 \mathrm{~mm}$, apresentaram $87 \%$ da precipitação da amostra. A amostra, por sua vez, foi selecionada com base nos meses com maior precipitação acumulada em cada ano. A partir desses meses foram retiradas as precipitações acumuladas horárias totais. Dos valores horários foram desprezados os menores que $10 \mathrm{~mm}$, equivalentes a chuvas inferiores a precipitação moderada. Assim, foi construída uma amostra a partir do valor mínimo de precipitação igual a $10 \mathrm{~mm}$. Os intervalos foram definidos fazendo uso do cálculo do limite inferior e superior de classe, que constituem as maiores frequências da série analisada. Assim, por exemplo, a classe $10 \mathrm{l}-20 \mathrm{~mm}$ apresenta limite inferior igual a $10 \mathrm{~mm}$ e, limite superior igual a $20 \mathrm{~mm}$. Excluindo a classe de valores menores que $10 \mathrm{~mm}$, a primeira classe, $10 \mathrm{l}-20 \mathrm{~mm}$, foi constituída por $52 \%$ dos valores da amostra, a segunda classe, $20 \mathrm{l}-$ $30 \mathrm{~mm}$, por $22 \%$ dos dados da amostra e, terceira classe, $30 \mathrm{l}-40 \mathrm{~mm}$, por $12 \%$ dos dados da amostra. Esses limiares são suficientes para definirmos os intervalos de classes 
representativos a serem adotados, em estudo específico, que aborde o acúmulo de tipos de chuvas em classes diferentes da classe das chuvas fracas e chuviscos. A organização em grupos representativos distintos, quando projetados no contexto da hipótese deste estudo, possivelmente proporcionará diagnósticos distintos daqueles realizados para a classificação de chuvas. Neste sentido, Xavier e Filho (2007) explicam que a adoção de classes, para analisar a observação da precipitação, permite distinguir causas distintas, que possam estar associadas a chuvas mais intensas e mais brandas. A Tabela 3 apresenta 0 agrupamento dos tipos de chuva adotado para a série temporal de precipitação horária.

Tabela 3 - Agrupamento de Amostras de Chuva.

CLASSIFICAÇÃO $\left(\mathrm{mm} \mathrm{h}^{-1}\right)$

Moderada $(\mathrm{MO})$ + Forte $(\mathrm{FO})+$ Muito Forte (MFO) + Chuvas Extremas (Ce)

Forte (FO) + Muito Forte (MFO) + Chuvas Extremas (Ce)

\section{4- Procedimentos Estatísticos Elementares}

Os procedimentos estatísticos elementares referem-se à identificação da frequência absoluta $\left(f_{i}\right)$ e da frequência absoluta acumulada $\left(F_{i}\right)$ nos intervalos temporais equivalentes a escala diária, mensal e anual. Para realizar tal contagem foram programados códigos em FORTRAN (Force 3.0 b3 plus) e, fórmulas automáticas, disponíveis no Microsoft Office Excel 2010. Também foram utilizados, complementarmente, os softwares Minitab 15 (Statistical Software) e IBM SPSS Statistics. O estudo toma por base estes valores armazenados em banco de dados, individualizados para cada aplicação. A base teórica constitui-se pelo material de estatística inferencial escrita por Santos (2012), publicado pelo Instituto de Matemática e 
Estatística (IME), da Universidade de São Paulo e, no material de Farias (2008), publicado pelo Departamento de Estatística da Universidade Federal Fluminense (UFF).

A Contagem da Frequência Absoluta Simples, $f_{i}$, representa $\circ$ número de repetições de um valor individual encontrado em uma mesma classe de valores da variável. Este procedimento, quando aplicado na contagem da precipitação horária, proporcionou quantificar o número de vezes que a variável, de um determinado tipo de chuva, foi identificado, na amostra. Para realizar tal procedimento foi empregada a seguinte equação:

$$
f_{i}=\sum_{k=1}^{K} n, i=1, \ldots, k
$$

$\mathrm{Na}$ equação anterior, $f_{i}$ representa a frequência absoluta simples, para cada classe $i ; K$, o número total de eventos, em uma mesma classe $\mathrm{i}, \mathrm{k}$ é o contador de eventos dentro de uma mesma classe, e n, o número de vezes de ocorrência do evento dentro de uma mesma classe i.

Os resultados dessa contagem, realizada para todos os tipos de chuva e, incluindo as amostras iguais e maiores a 10, 20 e 30 milímetros, foram organizados a partir de um banco de dados, em classes mensais, trimestrais e anuais.

A contagem da Frequência Absoluta Acumulada, $F_{i}$, representa 0 total das frequências absolutas simples obtidas em cada classe. Em geral, a composição da contagem deste tipo de frequência segue a ordem das classes pré-estabelecidas. Desta forma, a equação matriz para a realização deste cálculo pode ser escrita da seguinte forma:

$$
F_{i}=\sum_{i=1}^{J} f_{i}
$$

Na equação anterior, $F_{i}$ representa a frequência absoluta acumulada para todas as classes consideradas; $f_{i}$, a frequência absoluta simples relativa a cada classe; $i$, o contador de classes e J, o número total de classes que se considera. 
Os valores da contagem da frequência absoluta acumulada, assim como no procedimento de contagem anterior, foram organizados e armazenados em um banco de dados que contém agrupamentos mensais, trimestrais e anuais para todos os tipos de chuva considerados e para os casos específicos de chuvas, representados pela amostragem de valores iguais e maiores a 10, 20 e 30 milímetros horários. Todos os procedimentos adotados nos cálculos estatísticos elementares, realizados a partir da contagem da frequência absoluta, simples e acumulada, foram realizados de acordo com a AMS, Met Office e Pfafstetter.

\section{5- Tendência Linear ao Longo da Série Temporal}

Os procedimentos adotados neste estudo após a contagem elementar das frequências de precipitação horária em classes distintas estão focados nos cálculos básicos relativos à identificação de suas respectivas tendências lineares e possíveis correlações cíclicas com eventos de aquecimento no Oceano Pacífico, ao longo da série temporal analisada. Tendo em vista, as duas hipóteses iniciais do estudo, onde a primeira delas parte de uma reflexão sobre a possibilidade do aquecimento (resfriamento) das águas superficiais, do Oceano Pacífico Equatorial, na região definida como sendo a Niño3.4, estar provocando o aumento (diminuição) nas frequências de chuvas na cidade de São Paulo. Desta forma, neste momento será analisado apenas o aspecto envolvendo o comportamento linear da série temporal, envolvendo os dados do Oceanic Niño Index e das frequências absolutas de chuvas, com a intenção inicial de definirmos o plano de sua inclinação, quando positivo (negativo) e, posteriormente estabelecer ○ grau de correlação. O Oceanic Niño Index (ONI) é utilizado pela NOAA para identificar a ocorrência de eventos de El Niño (quente) e La Niña (fria), no Pacífico Equatorial. $O$ índice é calculado a partir da média obtida de 3 meses de anomalias na TSM, na região Niño3.4 (Figura 7), definidas pelas coordenadas $5^{\circ} \mathrm{N}-5^{\circ} \mathrm{S}, 120^{\circ}-170^{\circ} \mathrm{O}$. 
Nino3.4 region

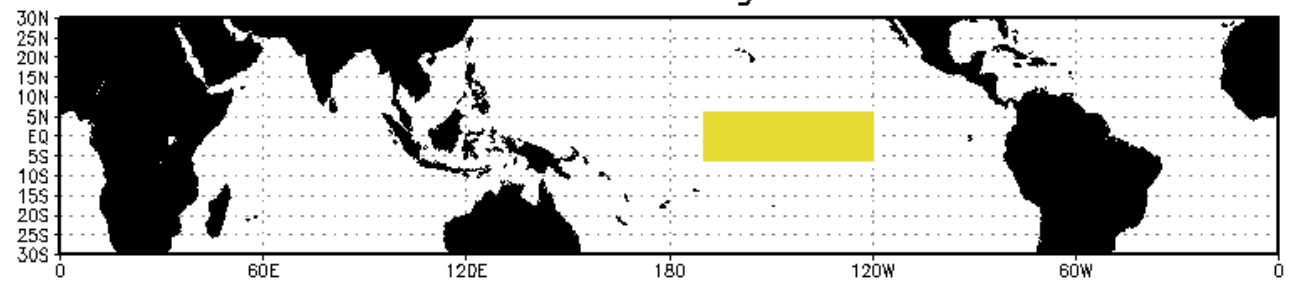

Figura 7 - A Região Niño3.4 - Faixa Amarela - no Oceano Pacífico Equatorial. Fonte: http://www.esrl.noaa.gov/psd/forecasts/sstlim/forlgl.html

A classificação de um evento quente ou frio no Pacífico pelo ONI obedece ao critério de manutenção da anomalia de TSM na região de Niño3.4 por, pelo menos cinco meses consecutivos, sendo que a anomalia deve ser igual ou superior a $+0,5^{\circ} \mathrm{C}$, para a caracterização de eventos quentes (El Niño) e, inferior a $-0,5$, para a caraterização de eventos frios (La Niña). O intervalo de variação da TSM é ainda dividido em classes que designem evento neutro, fraco, moderado e forte, de acordo com o indicado na Tabela 4.

Tabela 4 - Classificação do Oceanic Niño Index como evento Neutro, Fraco, Moderado e Forte, segundo o Climate Prediction Center (NOAA).

$\begin{array}{cccc}\text { ELENINO } & \text { Positivo }(+) & \text { LANINA } & \text { Negativo }(-) \\ \text { FRACO } & 0,5 \mid-0,9 & \text { FRACO } & 0,5 \mid-0,9 \\ \text { MODERADO } & 1,0 \mid-1,4 & \text { MODERADO } & 1,0 \mid-1,4 \\ \text { FORTE } & \geq 1,5 & \text { FORTE } & \geq 1,5 \\ \text { NEUTRO } & 0,4 & \text { NEUTRO } & -0,4\end{array}$

\section{6- Manipulação do Banco de Dados}

A explicação do procedimento envolvendo a manipulação do banco de dados é fundamental para a demonstração da matriz de dados, que foram levados em consideração, durante as análises realizadas, a partir do ajuste linear e da correlação cíclica. Desta forma, forão utilizados o banco de dados resultante da contagem das frequências de chuvas e da National Oceanic and Atmospheric Administration (NOAA), relativo ao Oceanic Niño Index (ONI). O primeiro procedimento adotado neste contexto foi a manipulação dos dados anuais 
da série, formado pelos dados anuais de frequências de chuvas horárias e pelos dados anuais da ONI. De uma maneira geral, a frequência anual de chuva foi inicialmente organizada, em uma tabela de contagem anual a partir do cálculo da frequência absoluta acumulada, envolvendo as respectivas classificações de chuvas, incluvive as classificações por amostragem. Na Tabela 5 está demonstrada uma parte do modelo adotado em todos os procedimentos iniciais. Nela é possivel observar, além da contagem, o total e a média de cada variável ao longo da série de 40 anos.

Tabela 5 - Modelo de Planilha Utilizada no Armazenamento da Frequência Anual da Precipitação Horária.

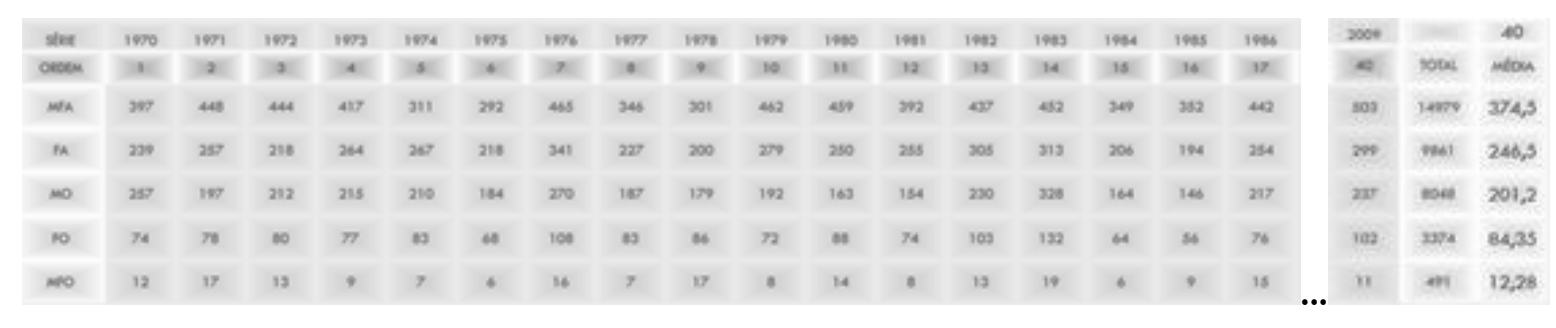

O mesmo procedimento, tal como o apresentado na Tabela 5 foi adotado na montagem da tabela dos indices da ONI. No entanto, se faz necessário realizar algumas explicações a respeito de determinadas especificações empregadas nos cálculos. A primeira especificação parte da necessidade de calcular a média anual a partir dos índices mensais do ONI. Desta forma, apesar de ser simples, é importante apresentar o procedimento para a melhor comprrenssão dos próximos passos que foram realizados. A etapa realizada que precede a elaboração da tabela constitui de uma classificação básica dos índices da ONI, como sendo um recurso matemático utilizado, para a eliminação dos números imaginários. A explicação deste raciocínio, parte da consideração da inexistencia de frequências de chuvas negativas, que possam ser introduzidas num modelo de correlação, envolvendo temperaturas negativas. É importante aproveitar este momento para explicar que os modelos mencionados constituem de modelos de análise e não de previsão. A próxima Tabela 6 apresenta uma 
parte demonstrativa da reclassificação da ONI. Onde as cores azvis são as anomalias negativas e a cores vervelhas, as anomalias positivas.

Tabela 6 - Valores Utilizados na Reclassificação do Oceanic Niño Index segundo a intensidade do evento ENOS.

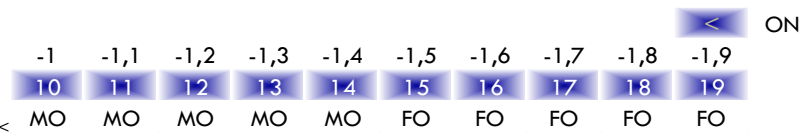

\begin{tabular}{|c|c|c|c|c|c|c|c|c|c|}
\hline 0,1 & 0,2 & 0,3 & 0,4 & 0,5 & 0,6 & 0,7 & 0,8 & 0,9 & 1 \\
\hline 20 & 21 & 22 & 23 & 24 & 25 & 26 & 27 & 28 & 29 \\
\hline $\mathrm{N}$ & $\mathrm{N}$ & $\mathrm{N}$ & $\mathrm{N}$ & $\mathrm{FA}$ & $\mathrm{FA}$ & $\mathrm{FA}$ & $\mathrm{FA}$ & $\mathrm{FA}$ & $\mathrm{MO}$ \\
\hline
\end{tabular}

Na Tabela 7 apresentamos o resultado final do produto da classificação adotada, para o valor da ONI anual obtida pela média da ONI mensal, com o respectivo valor total e a respectiva média aritimética.

Tabela 7 - Resultado da Reclassificação da ONI.

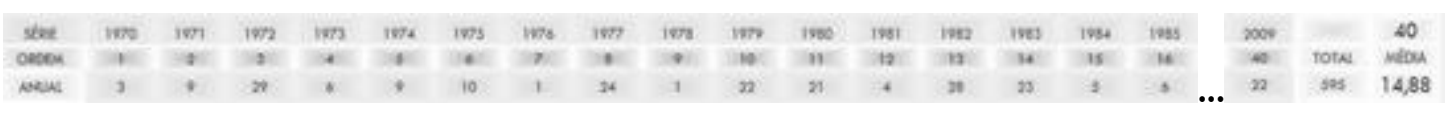

O mesmo procedimento é adotado na elaboração das planilhas específicas relativas às fases neutras, ENOS, La Niña e El Niño.

No segundo procedimento foram elaboradas tabelas de acordo com o modelo multiplicativo, representado pela função $Y=T \times S$ e $C \times I=0$. Através dessa função, estão sendo apresentadas, as componentes que foram calculadas. $O$ primeiro resultado apresenta $\circ$ produto parcial do cálculo, ou seja, $Y=T \times S$, como sendo parte de uma sequência lógica, marcada por etapas a serem seguidas. Desta maneira, a partir do cálculo da média periódica envolvendo as frequências (amostras) de um determinado tipo de chuva, foi possível obter a variação anual ou sazonal com a componente de tendência incluída. Essa técnica permitiu realizar uma ponderação das frequências absolutas anuais ou trimestrais, onde geram novos valores, que oscilam dentro de um plano médio estatístico, realtivo as possiveis variações cíclicas. O plano médio é equivalente a um e, quando mais afastados estiverem às oscilações desta referência, mais significativa são consideradas as variações cíclicas. Neste 
contexto, é importante mencionar que os valores obtidos a partir da ponderação, ao longo da série, mantiveram a componente linear, onde foi possível calcular e projetar, as respectivas tendencias. Dessa forma, foi possível substituir, a realização dos mesmos cálculos e projeções, que naturalmente partiriam dos dados brutos das frequências absolutas. A realização desse procedimento foi importante em função de ter tornado possível à identificação do comportamento linear que naturalmente seria obtido a partir das frequências, porém com 0 acréscimo de informação relativa à sua respectiva oscilação ao longo do plano médio (1) de uma possível variação cíclica. Tal procedimento precede o cálculo da variação cíclica com a componente linear removida (processo de remoção da tendência). No entanto, a adoção deste procedimento é relevante. O resultado do procedimento adotado está ilustrado na Tabela 8, que também foi utilizado para o Oceanic Niño Index.

Tabela 8 - Variação Cíclica Anual com Tendência Linear

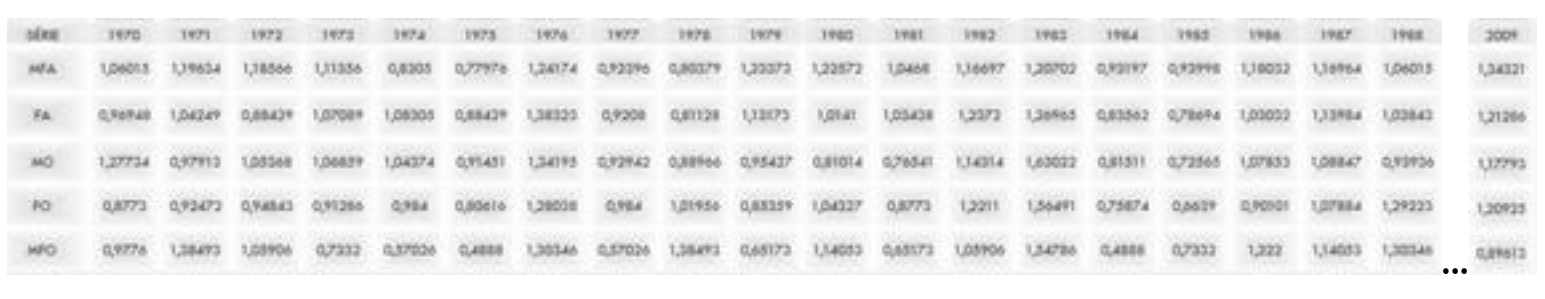

O terceiro procedimento adotado relaciona-se ao cálculo da tendência linear das frequências de precipitação horária para os vários limiares e para ○ ONI. A partir deste resultado, foi realizada a última etapa do procedimento. Neste caso, foi aplicada a equação da reta a partir das estimativas do coeficiente linear e angular. A explicação do equacionamento matemático está esclarescida em um tópico posterior específico. No momento, o destaque é apenas a manipulação do banco de dados. A estimativa anual de cada variável de precipitação de acordo com o ajuste linear está ilustrada na Tabela 9. Para os dados de ONI, também foi calculada a estimativa segundo a regressão linear dos dados em relação aos anos. 
Tabela 9 - Estimativa Anual das Variáveis Consideradas no Estudo pelo Ajuste Linear Simples

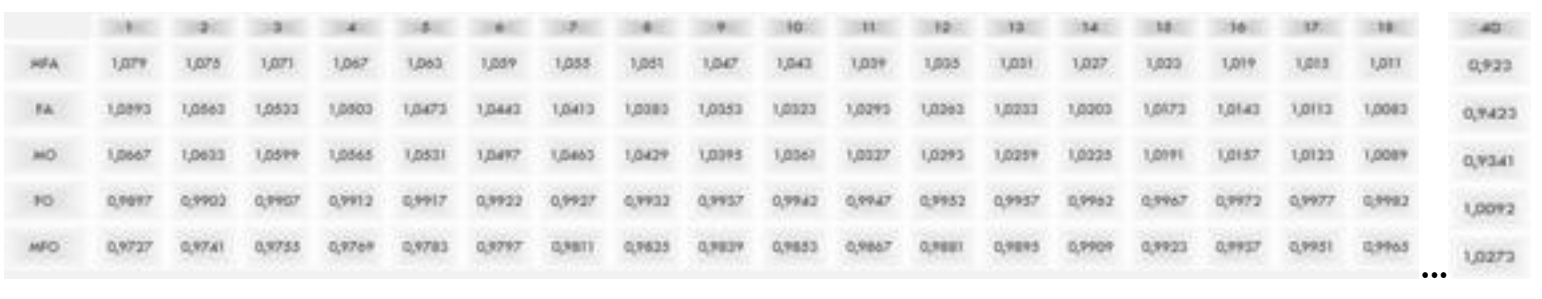

O quarto e último procedimento adotado é a elaboração de uma tabela contendo o produto do cálculo elementar de remoção da tendência linear dos dados originais. É importante mencionar que a remoção da tendência linear foi aplicada tanto às frequências ponderadas de chuva, quanto ao ONI. A remoção de ambas tendencias proporcionou que os valores oscilassem em torno 0 para as duas variações cíclicas a serem analisadas. 0 mesmo procedimento será realizado inclusive em análises periódicas, como no caso das fases neutras, ENOS, El Niño e La Niña. Um recorte dos resultados obtidos com este último procedimento encontra-se ilustrado na Tabela 10.

Tabela 10 - Estimativa Anual do Valor da Frequência de Precipitação Segundo a Regressão Linear (recorte).

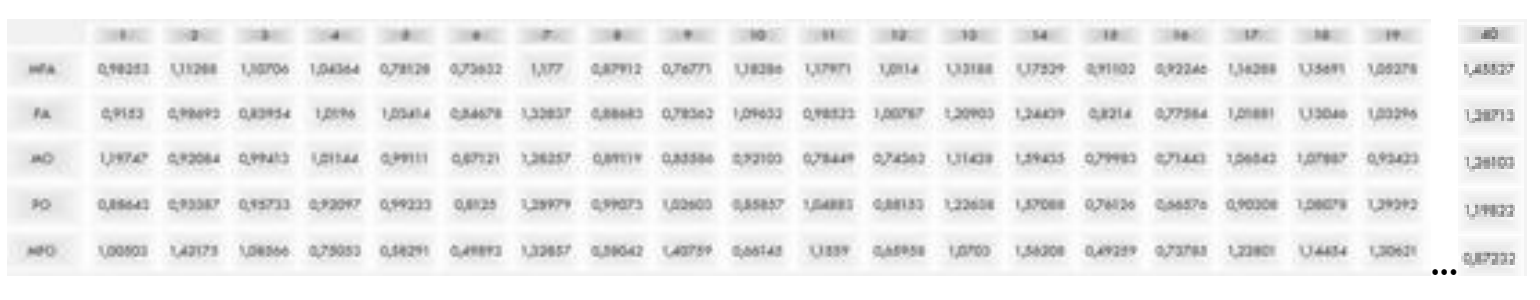

\section{7- O Modelo de Regressão e o Ajuste Linear}

De um modo geral, as análises de regressão, quando aplicadas nos estudos envolvendo a climatologia, possuem a finalidade de modelar o comportamento de alguma variável, em relação a outra(s), permitindo, em muitos casos, a verificação da tendência de evolução de determinada variável. O ajuste de valores de uma variável em termos de outra variável ou outras variáveis proporciona verificar adicionalmente a possibilidade de relação de causa e efeito entre as variáveis. É importante destacar que a análise da regressão 
apenas indica a associação matemática existente entre uma variável dependente e outra(s) independente(s). No contexto deste estudo, a análise de regressão linear simples entre a precipitação e o tempo cronológico da observação realizada em todas as classificações pluviométricas - Classificação de Chuvas, Chuvas Intensas e Chuvas Extremas - acrescentadas de análises de casos específicos, com valores iguais e superiores a 10, 20 e $30 \mathrm{~mm}$.

A análise específica da equação e da significância de seus parâmetros parte da compreensão de alguns elementos que a constitui. $O$ coeficiente angular indica a tendência linear da variável em relação ao tempo. O coeficiente linear indica o valor estimado da variável no tempo inicial da série temporal. O coeficiente de determinação ou de explicação, $r^{2}$, indica a qualidade do ajuste linear, ou seja, a porcentagem da variância associada à variável dependente estimada, explicada pela(s) variável(is) independente(s), neste caso ○ tempo. O coeficiente de determinação assume valores entre 0 e 1 . A equação da reta de regressão pode ser definida como $\hat{Y}=\alpha+\beta X$, sendo $\hat{Y}$ a variável estimada, $\alpha$ o coeficiente linear, $\beta$ o coeficiente angular e, por último, $X$ a variável independente, neste caso o tempo cronológico. O método mais usado para ajustar uma reta a um conjunto de pontos $(x, y)$, é conhecido como método dos mínimos quadrados. Este método supõe que o erro quadrático médio entre os valores estimados e os observados seja mínimo, tal que $\sum_{i=1}^{i=N}(\widehat{Y}-Y)^{2}=$ mínimo. A partir deste método é possível calcular os coeficientes $\alpha$ e $\beta$ da reta de regressão, como indicado na Tabela 1 1, sendo que $\mathbf{n}$ constitui o número de observações, para x e y.

Tabela 11 - Os Coeficientes Linear e Angular da Reta de Regressão.

$$
\hat{\alpha}=\frac{\sum y}{n}-b \frac{\sum x}{n} \quad \hat{\beta}=\frac{n \sum(x y)-\sum x-\sum y}{n \sum x^{2}-\left(\sum x\right)^{2}}
$$

Uma reta de regressão, em geral, não coincide com os dados observados. A diferença entre os valores estimados pela reta de regressão e os valores observados pode 
ser expressa como erro médio associado à estimativa. Quanto maior a diferença entre o valor observado e o estimado, maior o erro médio da regressão. Na Figura 8,0 índice $i$ refere-se à observação, o asterisco, a média das variáveis observadas e $Y^{\prime}$ ou $\hat{Y}$ indica à variável estimada.

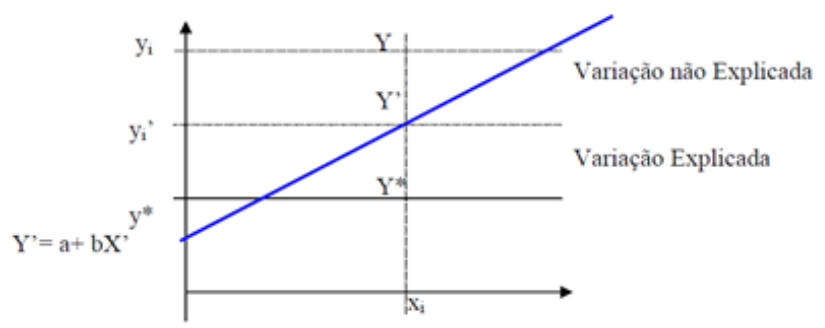

Figura 8 - Variação Explicada e Não Explicada pela Reta de Regressão.

Ao se analisar o exemplo de reta de regressão da Figura 6, observamos que o ponto $y_{i}$, observado no tempo $x_{i}$, está localizado acima do valor estimado $Y^{\prime}$ ou $\hat{Y}$. A média das observações é expressa por $Y^{*}$. A diferença entre o valor observado, $y_{i}$, e o valor médio, $Y^{*}$ constitui o desvio entre a observação e a sua média. A diferença entre os valores estimados $Y^{\prime}$ ou $\hat{Y}$ e a média, $Y^{*}$, constitui o desvio entre a estimativa de $y_{i}$, e a média. A soma dos desvios quadráticos de todos os valores observados em relação a média de $Y$, SQT, é chamada de Variação Total e, pode ser expressa por $\Sigma\left(Y-Y^{*}\right)^{2}$. A soma dos desvios quadráticos de todos os valores estimados em relação à média de $Y, \mathrm{SQE}$, é chamada de Variação Não Explicada pela reta de regressão e, pode ser expressa por $\Sigma\left(Y-Y^{\prime}\right)^{2}$. Assim, o coeficiente de determinação relacionado a uma reta de regressão é expresso por $R^{2}=1$ (SQE/SQT) e indica a qualidade da regressão. A diferença entre o valor de um ponto $Y$ ( $x i$, yi) e seu valor estimado $Y^{\prime}\left(x_{i}^{\prime}, y_{i}^{\prime}\right)$, isto é, a distância entre o ponto $Y$ e a reta de regressão, é chamada de Variação Não Explicada pela reta de regressão, ou seja, $\Sigma\left(Y-Y^{\prime}\right)^{2}$. Por último, a diferença entre o valor $Y^{\prime}$ (estimativa de $Y$ ) situado sobre a reta de regressão e o valor médio de $Y^{*}$ (situado sobre a reta paralela ao eixo $\mathrm{x}$ ) é conhecida como Variação Explicada pela reta de regressão, ou seja, $\Sigma\left(Y^{\prime}-Y^{*}\right)^{2}$. 


\section{8- Coeficiente de Correlação Linear de Pearson}

O procedimento adotado na análise de correlação, parte do conceito matemático que possibilita descrever, de forma compacta através de um valor, a existência de alguma associação entre duas variáveis, ou ainda, constitui um modelo utilizado para avaliar duas amostras de dados, com a intenção de se comprovar a explicação de uma das variáveis pela outra. O coeficiente de correlação linear Pearson e as suas respectivas intensidades de correlação estão expressos na Tabela 12.

Tabela 12 - Equação de Correlação Linear de Pearson (r) e a Classificação dos Valores, segundo Shimakura e Junior (2004).

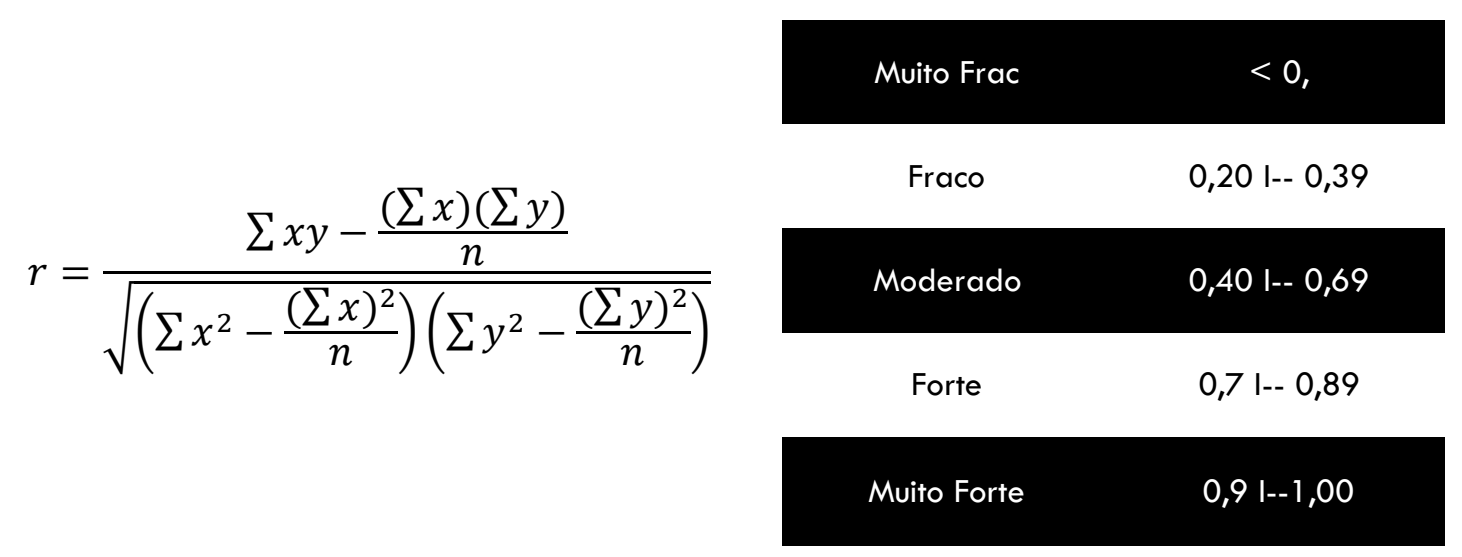

\section{9- Modelo Cíclico ou Sazonal}

Na análise geral do modelo cíclico, em termos conceituais, Júnior (2010) explica que normalmente as variações cíclicas são avaliadas em conjunto, que tem por finalidade analisar variações de um determinado período cronológico. A realização de tal modelo, parte do modelo multiplicativo, onde geralmente as variações cíclicas e irregulares são avaliadas em conjunto. As variações cíclicas e irregulares são obtidas através da remoção das componentes, tendência linear e sazonalidade, esta última apenas se os dados apresentam escala menor do que a anual. A sazonalidade de uma determinada variável climatológica constitui um sinal 
forte e, em geral, bem conhecido. Assim, a retirada da sazonalidade de uma série temporal permite verificar a variabilidade de intensidade de uma determinada variável para as mesmas estações do ano, ou para os mesmos meses do ano, dentre anos distintos. Existem mais de um método para a solução deste problema. No entanto, foi adotado o Modelo Multiplicativo, em função de ser praticamente um padrão utilizado na climatologia e pela sua coerência matemática relativa ao propósito do estudo.

A primeira equação apresentada na Tabela 13, relativa à média periódica, expressa a razão entre o produto do somatório das frequências simples anuais, de toda série analisada e, o número total de anos $\left(n_{i}\right)$ que neste caso é igual a 40 . A segunda equação indica a razão entre a frequência de precipitação, em cada estação do ano e, a média das frequências para os 40 anos considerados. Este cálculo foi realizado para todas variáveis dependentes consideradas no estudo.

Tabela 13 - As Equações da Média Periódica e da Sazonal no Período.

Eq. 1. Média Periódica $(\overline{\boldsymbol{y}})$

Eq. 2. Sazonal no Período (S)

$$
\overline{\mathbf{y}}_{\mathbf{j}}=\frac{\sum_{\mathbf{i}} \mathbf{y}_{\mathbf{i}, \mathbf{j}}}{\mathbf{n}_{\mathbf{i}}} \quad \mathrm{S}_{\mathrm{i}, \mathrm{j}}=\frac{\mathrm{y}_{\mathrm{i}, \mathrm{j}}}{\overline{\mathrm{y}}_{\mathrm{i}, \mathrm{j}}}
$$

\subsection{0- El Niño - Oscilação Sul - ENOS}

Os eventos de El Niño e La Niña caracterizam-se, respectivamente, pelo aquecimento e resfriamento anômalo das águas superficiais do Oceano Pacífico Tropical central e leste. A gangorra barométrica entre o setor sul do Pacífico Central e Oeste, chamado de Oscilação Sul, tal como comenta Ambrizzi (2011) está associada ao aquecimento e esfriamento do Pacífico Equatorial. A interação entre as anomalias de temperatura da superfície do mar, no Pacífico Tropical e, a atmosférica sobrejacente, decorrente do aquecimento anômalo, constitui 
- fenômeno de interação oceano-atmosfera chamada, na literatura científica, de ENOS - El Niño Oscilação Sul. O El Niño tem por característica, conforme Ambrizzi (2011), duração típica de 12 a 18 meses, de forma que normalmente reaparece em intervalos de dois a sete anos. Normalmente, sua evolução ocorre a partir do começo do ano, em abril-maio, atingindo sua máxima intensidade em dezembro ou janeiro do próximo ano e, na metade do ano seguinte a seu início, já se encontra bastante enfraquecido. A respeito da repercussão desses episódios no clima de regiões remotas, Ambrizzi (2011), ao fazer uma observação específica para o Brasil, menciona que eventos El Niño tendem a provocar secas no nordeste e enchentes no sul e sudeste. Apesar dessa última observação, o autor comenta que, especificamente sobre a região sudeste do Brasil, ainda não foi identificado um padrão característico da TSM no Pacífico Tropical relacionado diretamente à perturbação da chuva. Os padrões climáticos globais relativos à temperatura do ar observada em observados em dezembro-fevereiro e junho-agosto estão ilustrados na Figura 9. Por meio desta figura é possível verificar que ocorre aquecimento do ar nos dois períodos considerados, na região sudeste do Brasil. Eventos de La Niña, caracterizados pelo resfriamento anormal das águas do Pacífico Equatorial centro-leste, estão associados a anomalias negativas de temperatura do ar no sudeste do Brasil durante o trimestre dezembro-fevereiro, tal como indicado na Figura 9. Entre junho e agosto, não há sinal significativo de associação entre a ocorrência de eventos $L N$ e a temperatura do ar na região sudeste. Durante os episódios de La Niña, os ventos alísios no Pacífico Tropical são mais intensos que a média climatológica. $O$ índice de Oscilação Sul (indicador atmosférico que expressa a diferença entre as anomalias de pressão atmosférica na superfície entre o Pacífico Ocidental e o Pacífico Oriental) apresenta valores positivos em situações de LN, o que indica a intensificação da pressão atmosférica no Pacífico Central e Oriental em relação à anomalia de pressão no Pacífico Ocidental. Em geral, o episódio começa a se desenvolver em meados do ano e atinge sua intensidade máxima no final do próprio ano de início e dissipa-se cerca de seis meses depois do período de máxima intensidade. Geralmente, as anomalias climáticas associadas ao fenômeno La Niña 
apresentam sinal invertido àquelas observadas durante os períodos de El Niño. Por outro lado, sabemos que as fases do fenômeno não apresentam associações estritamente lineares, tal como comenta Marengo (2007).

As repercussões, no Brasil, de situações de LN, estão associadas, segundo Ambrizzi (2011), à diminuição de chuva sobre a Região Sul, durante o verão e, ao seu aumento na Região Nordeste e no setor leste da Amazônia. Em geral, os eventos de La Niña começam a se desenvolver no início do ano, atingem sua intensidade máxima no final desse mesmo ano e dissipam-se em meados do ano seguinte, segundo Ambrizzi (2011).

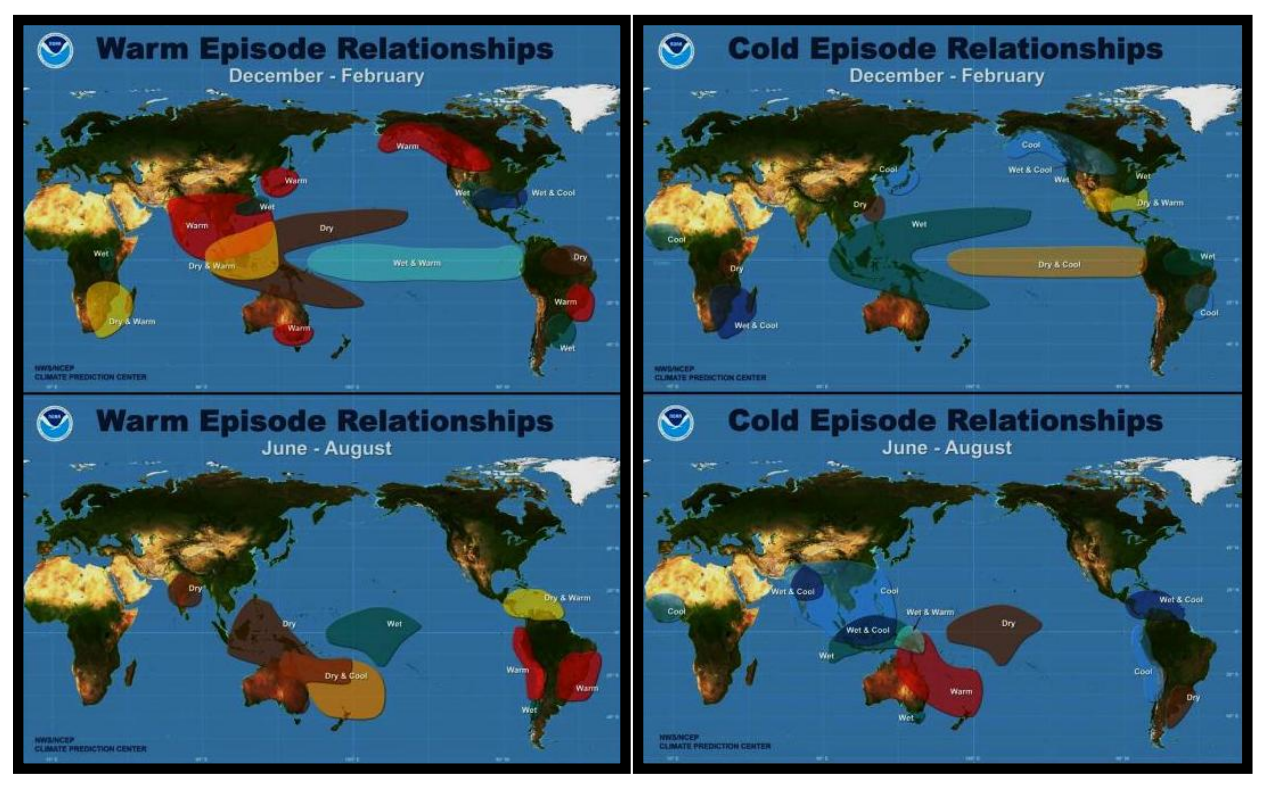

Figura 9 - Impacto Climático Trimestral Associado a Eventos El Niño e La Niña. Fonte: www.cpc.ncep.noaa.gov.

\subsection{1- Procedimento Final de Análise 1}

Os tópicos anteriores apresentaram os procedimentos básicos relativos às particularidades envolvendo cada parte do processo a ser realizado, incluindo os respectivos cálculos aplicados que fizeram parte de uma estrutura científica adotada. O Procedimento Final de Análise I representa a primeira parte do aspecto final desta estrutura articulada. Tal procedimento foi a base da organização a ser observada nos resultados. 
O Procedimento Final de Análise I partiu de uma generalização onde procurou analisar o ajuste linear de cada tipo de chuva (exceto as Chuvas Extremas) e, das respectivas fases da ONI. A partir dos resultados dessas análises, foram estabelecidas correlações entre os ajustes lineares de chuvas horárias e da ONI incluíndo as suas respectivas fases. Analisando, especificamente, a significância do ajuste linear entende-se que o seu resultado peocurou apenas revelar a posição da reta de sua inclinação, ou seja, quando positiva e negativa. O nível de significância é visto como um resultado relativo e, não absoluto que, em determinados períodos da série podem ser mais ou menos significativos em função de anomalias específicas que, podem ou não estarem correlacionadas com as alterações da TSM na região Niño 3.4 .

Na segunda análise deste procedimento foi analisado o comportamento cíclico de cada tipo de chuva (exceto as Chuvas Extremas), através da identificação de períodos específicos que oscilaram com valores abaixo e acima da média. A partir desses resultados foi possível definir os períodos em que as variações oscilaram mais positivamente e mais negativamente. Posteriormente a essa identificação estabelecemos correlações para diferentes escalas temporais formadas pela série integral (1970-2009), relativa (ENOS, El Niño e La Niña) e específica (Fases altas e baixas da oscilação cíclica). Neste caso, é importante comentar que as correlações foram denominadas de cíclicas, pelo fato de correlacionar variações cíclicas de episódios de chuvas e do Oceanic Niño Index.

De modo geral, as correlações lineares foram calculadas entre a variável dependente, chuva e, a variável independente, ONI. A partir desses resultados, foi calculado - grau de correlação, entre as variações cíclicas das frequências de cada tipo de chuva e o índice ONI. O teste t-Student foi aplicado para avaliar a significância do resultado de correlação linear. O teste de significância permite verificar se o valor de correlação linear tem significado estatístico, ou seja, se a correlação linear indicada é estatisticamente válida, por meio do Teste T unicaudal. Neste teste, o valor calculado de $t$ é comparado com os valores críticos, $t_{c}$, relativo à distribuição t-Student, de acordo com a Tabela 14. Com base no 
teste de hipótese descrito em Sales (2012) quando $t$ calculado é maior que $t_{c}$, podemos rejeitar a hipótese nula $\left(\mathrm{H}_{0}: \mathrm{r}=0\right)$ e, desta forma, aceitar a hipótese alternativa $\left(\mathrm{H}_{a}\right)$, ou seja, a presença de correlação linear entre as variáveis. Para o caso de significância estatística igual a $95 \%$ e $n=40$, o valor de $t_{c}$ é igual a 2,021 (tal como apresentado na Tabela 14). Assim, neste exemplo, valores de t maiores que 2,021 levam à conclusão de que a correlação linear é significativamente a um nível de $95 \%$. O valor de $t$ pode ser calculado, segundo Sales (2012), com base em:

$$
t=r \sqrt{\frac{n-2}{1-r^{2}}}
$$

em que $r$ indica a correlação linear e $n$, o número total de observações. Utilizamos $(n-2)$ graus de liberdade. No caso, foram aceitos como estatisticamente significativos, o nível de $80 \%$ para coeficientes de correlação envolvendo ONI, 90\% para Fase Neutra e ENOS e 95\% para EL Niño e La Niña.

Tabela 14 - A Distribuição t-Student, segundo Beiguelman (1996). P indica o Valor de $\alpha$ e gl, - Grau de Liberdade da Série Temporal Considerada.

\begin{tabular}{|c|c|c|c|}
\hline $\mathbf{g l} \backslash \backslash \mathbf{P}$ & 0,20 & 0,10 & 0,05 \\
\hline 01 & 3,078 & 6,314 & 12,706 \\
\hline 03 & 1,638 & 2,353 & 3,182 \\
\hline 05 & 1,476 & 2,015 & 2,571 \\
\hline 07 & 1,415 & 1,895 & 2,365 \\
\hline 09 & 1,383 & 1,833 & 2,262 \\
\hline 11 & 1,363 & 1,796 & 2,201 \\
\hline 13 & 1,350 & 1,771 & 2,160 \\
\hline 15 & 1,341 & 1,753 & 2,131 \\
\hline 17 & 1,333 & 1,740 & 2,110 \\
\hline 19 & 1,328 & 1,729 & 2,093 \\
\hline 21 & 1,323 & 1,721 & 2,080 \\
\hline 23 & 1,319 & 1,714 & 2,069 \\
\hline 25 & 1,316 & 1,708 & 2,060 \\
\hline 27 & 1,314 & 1,703 & 2,052 \\
\hline 28 & 1,313 & 1,701 & 2,048 \\
\hline 29 & 1,311 & 1,699 & 2,045 \\
\hline 30 & 1,310 & 1,697 & 2,042 \\
\hline 40 & 1,303 & 1,684 & 2,021 \\
\hline
\end{tabular}


A Figura 10 ilustra a estrutura do $1^{\circ}$ procedimento - 0 ajuste linear. Na análise individual "A" realizou-se o ajuste linear de cada tipo de chuva no intervalo temporal integral de 1970 a 2009. Na análise individual "B" realizamos o ajuste linear para o índice ONI no intervalo temporal integral e relativo (ENOS, Neutra, EI Niño e La Niña). O resultado de cada análise individual apresentou duas opções: tendência positiva ou negativa.

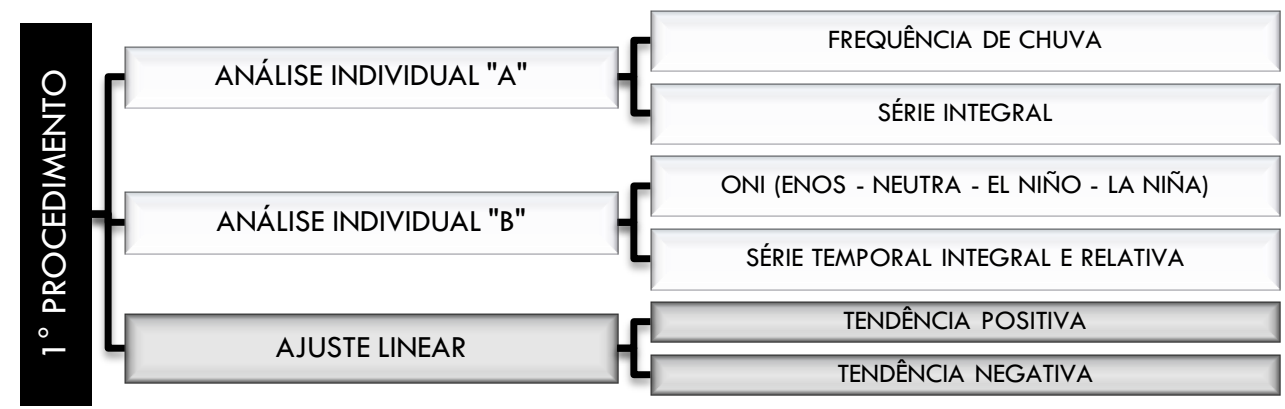

Figura 10 - Organograma Referente ao $1^{\circ}$ Procedimento da Análise 1.

A Figura 11 apresenta a estrutura do $2^{\circ}$ procedimento - a correlação linear. $\mathrm{Na}$ análise agrupada "A"+"B" realizamos a correlação linear entre cada tipos de chuva e cada fase da ONI dentro dos limítes das respectivas escalas temporais. O resultado da correlação foi qualitativo na intenção de verificar se o ajuste linear "A" concidia com o ajuste linear "B".

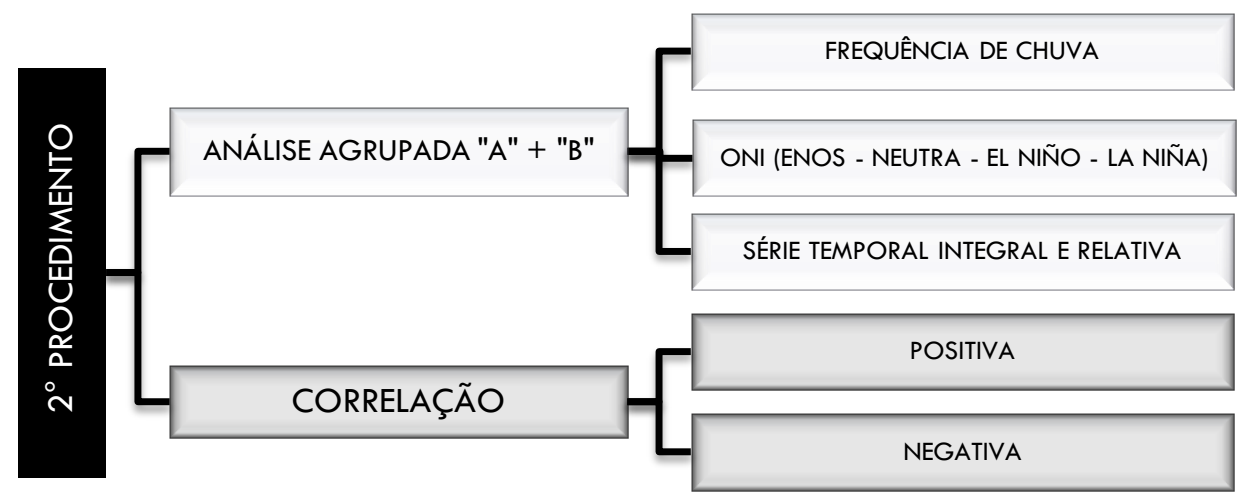

Figura 11 - Organograma Referente ao $2^{\circ}$ Procedimento da Análise 1.

A Figura 12 apresenta a estrutura do $3^{\circ}$ procedimento - a correlação específica. $\mathrm{Na}$ análise específica "A"+"B" realizamos a correlação de cada fase alta (baixa) da variação 
cíclica de cada tipo de chuva, com as respectivas fases da ONI, dentro dos limítes das escalas temporais. $O$ resultado da correlação linear apontou quando houve correlação positiva ou negativa.

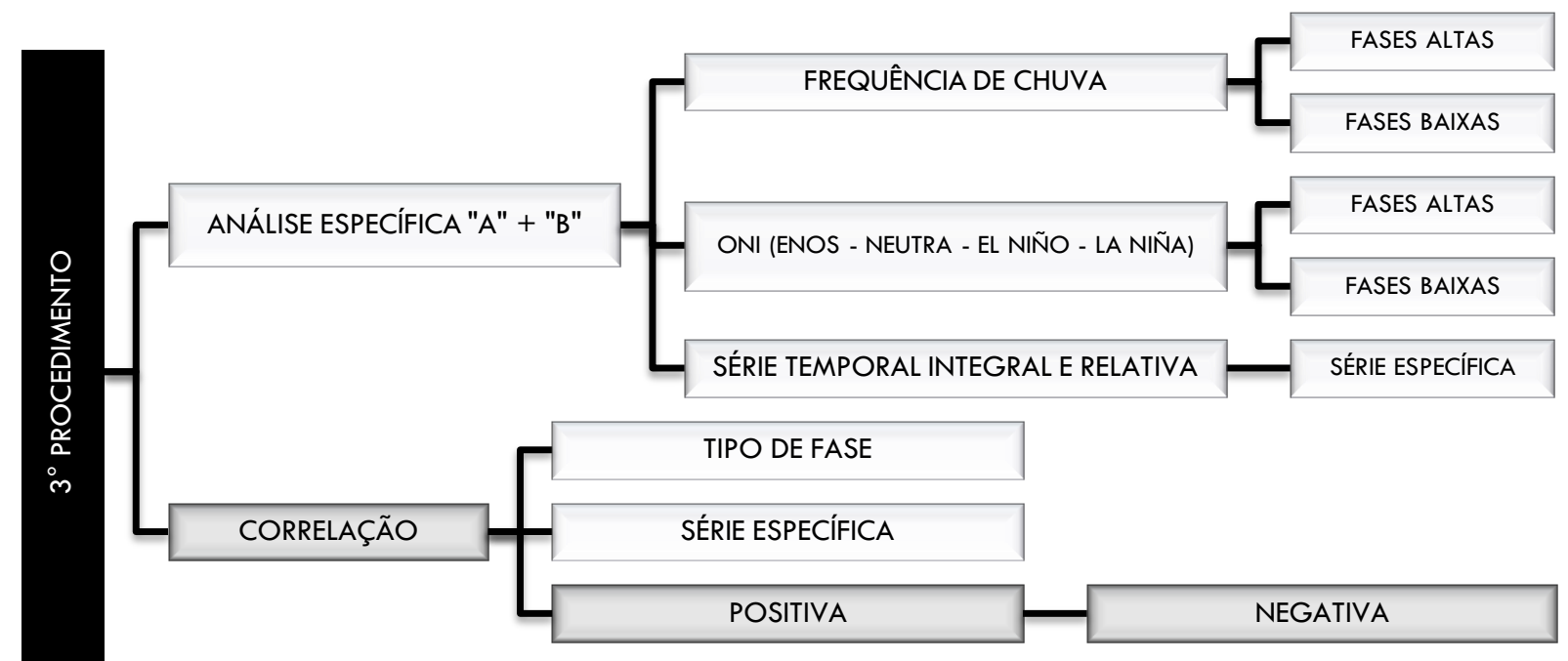

Figura 12 - Organograma Referente ao $3^{\circ}$ Procedimento da Análise 1.

\subsection{2- Procedimento Final de Análise 2}

O primeiro procedimento final de análise teve a função de apresentar uma generalização da metodologia aplicada, por meio da ausência dos conceitos teóricos fundamentais da climatologia, relacionada aos El Niños e as La Niñas. Dessa forma, o procedimento final de análise 2 , tem como finalidade, apresentar de maneira clara e organizada, as considerações e as deduções (sugestões), que foram realizadas durante o processo de análise a ser apresentada durante os resultados. Neste contexto, é importante apresentar a base teórica empregada e, posteriormente, enquadrá-las nas articulações dos procedimentos de análise, realizados anteriormente. Em geral, todas as informações quantitativas partem dos valores disponíveis pela NOAA, que por sua vez, estão baseados nos índices denominados de Oceanic Niño Index. Este indice, como já apresentado anteriormente, possui a função de identificar os períodos anômalos, relativos ao monitoramento da temperatura da superfície do mar, de uma região localizada do Pacífico 
Equatorial, definida como sendo a Niño3.4. A partir desses dados é possivel estabelecer o primeiro ajuste linear, através de uma linha que represente a sua evolução ao longo da série e, avaliar qualitativamente (a partir do método dedutivo), o seu comportamento, em relação ao ajuste linear de um determinado tipo de chuva. Este procedimento possui a função de avaliar se as variáveis estão coerentemente relacionadas, de acordo com a base conceitual, estabelecida principalmente pela NOAA. Desta forma, se faz necessário assumir as respectivas coerências que foram adotadas.

A análise da inclinação da termoclima, na região do Pacífico Equatorial proporciona avaliar o comportamento de três condições climáticas básicas associadas as suas respectivas oscilações térmicas que, possivelmente provocariam mais ou menos frequências de um determinado tipo de chuva. Primeiramente foi sugerido que o aquecimento observado a partir dos índices da ONI proporcionaria convecções mais profundas e, consequentemente, poderia proporcionar aumento na frequência de um determinado tipo de chuva, porém com uma possibilidade menor, do que uma condição de El Niño. Nesse sentido, uma possível tendência linear positiva (negativa), observada para $\circ \mathrm{ONI}$, provavelmente estaria associada a uma tendência linear também positiva (negativa), para as frequências de chuvas. É possível também encontrar a falta de correlação linear entre a frequência de chuva e o ONI, ou seja, as alterações registradas pelo índice oceânico niño não estariam associadas à frequência de chuva. Neste contexto, o nível de correlação poderá ser determinante quando apresentarem o mesmo sinal (positivo ou negativo), ou seja, quando mais bem correlacionado, maiores poderão ser as chances, da ONI, ter influenciado na frequência de um determinado tipo de chuva. A possibilidade de associação entre o aumento do ONI estar associada ao aumento da frequência de chuva é complexa. Supõe-se que existe uma associação, a explicação físicodinâmica deve ser elaborada em outra análise. Os passos seguintes fazem parte do procedimento empregado na análise 2. A Figura 13 apresenta $\circ$ primeiro procedimento da análise 2 baseado nas análises individuais "A" e "B". 


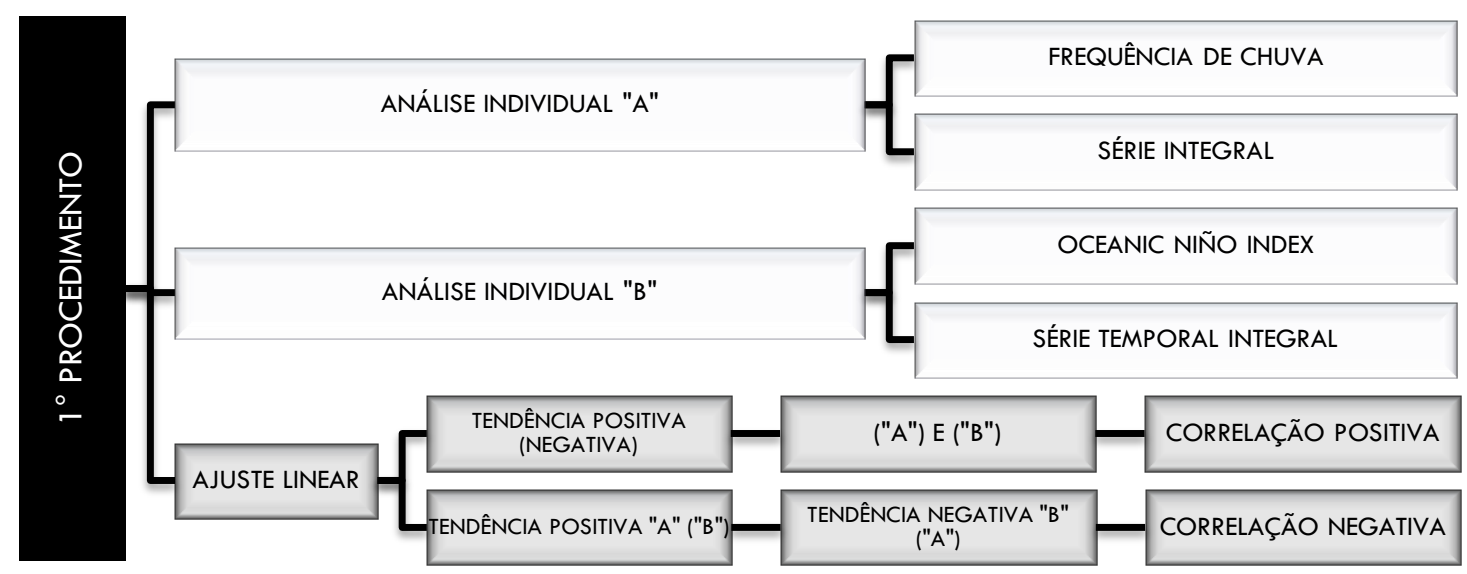

Figura 13 - Organograma Referente ao $1^{\circ}$ Procedimento da Análise 2.

O $2^{\circ}$ procedimento, da análise 2 , esteve focado na realização de análises das fases específicas e dos períodos relativos. As fases específicas, em questão, correspondem às fases altas e/ou cristas das oscilações da série e, os períodos relativos, tratam-se dos anos correspondentes a estas fases. A série de 1970-2009 foi dividida em categorias ou séries temporais relativas, conhecidas como ONI, ENOS, Fase Neutra, El Niño e La Niña. Dessa forma, "conceitualizando" e "contextualizando", os termos utilizados no primeiro procedimento, foi possível elaborar a articulação definitiva do segundo procedimento. A Figura 13 apresenta tal articulação aplicada à série temporal representada pela ONI. Neste caso, foram avaliados os respectivos ajustes lineares, a partir das análises individuais definidas como "A" e "B". Desta forma, a partir da referência dessa articulação será possível observar dois resultados. O primeiro é o comportamento linear ao longo da série, tanto das frequências de chuvas, quanto dos indices da ONI. O segundo resultado, parte da análise de correlação, envolvendo as duas variáveias do primeiro resultado. A intenção ao ter realizado tal correlação, foi a de verificar se as projeções lineares obtidas se correspondem, ou seja, analisar a possibilidade de um feedback entre o aquecimento (resfriamento) da ONI e o aumento (diminuição) nas frequências de chuvas. $\bigcirc 2^{\circ}$ procedimento, da análise 2 , representado pela articulação da Figura 14 apresenta as etapas desta análise. 


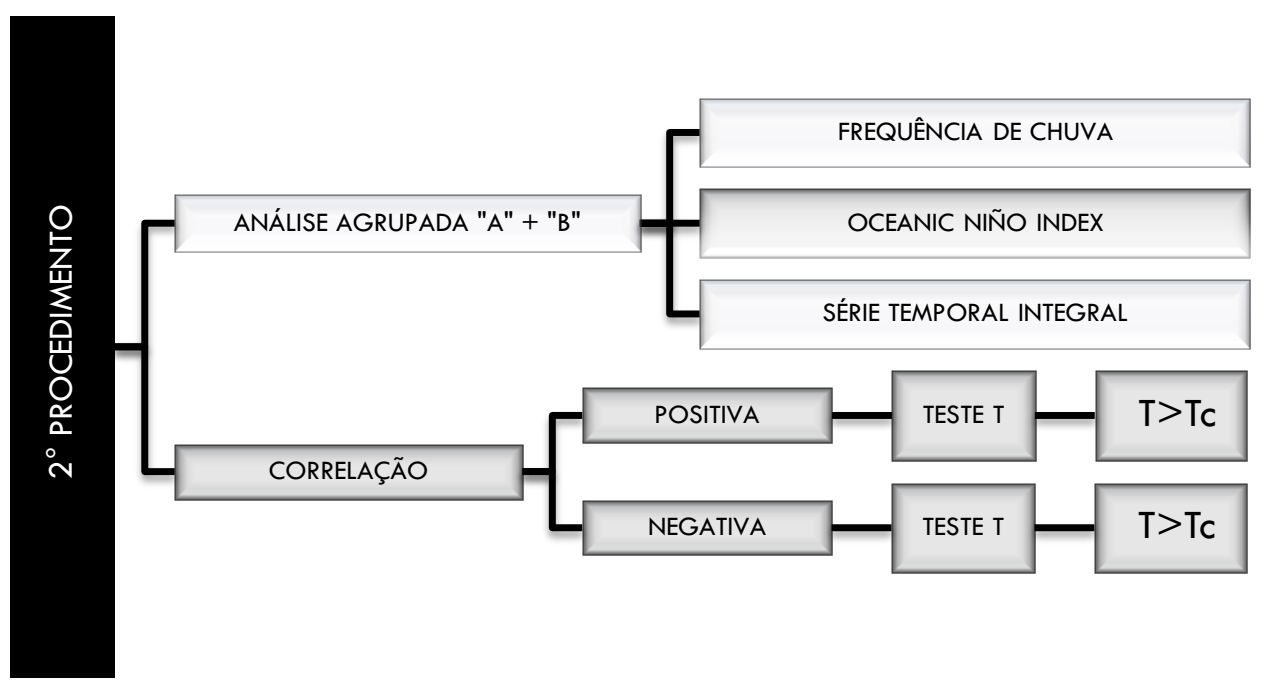

Figura 14 - Organograma Referente ao $2^{\circ}$ Procedimento da Análise 2.

A partir dessa segunda articulação foi possível, ao mesmo tempo, obter um terceiro resultado e, um ponto de partida para uma dedução, ou seja, a hipótese de uma correlação linear positiva (observado a partir do segundo resultado da primeira articulação) e uma correlação cíclica positiva (observado neste terceiro resultado) nos sugere que, tanto linearmento, quanto ciclicamente, estiveram correlacionados (nota-se também que é possível verificar de acordo com os coeficientes de correlação, se estes, estiveram mais bem correlacionados linearmente ou ciclicamente). A dedução, parte da hipótese de ter ocorrido uma possível correlação linear, negativa ou positiva e, por outro lado, ocorrer uma possivel correlação cíclica negativa. Neste caso, presumimos que ocorram apenas correlações lineares.

A terceira e última articulação, Figura 15 , relativo ao $3^{\circ}$ procedimento, da análise 2 , esteve focado nas analises das fases específicas, ou seja, nas fases altas e baixas da variação cíclica. A correlação aplicada, neste caso, possui um caráter qualitativo, entre o período de um determinado tipo de fase (alta ou baixa) e os indices do ONI para o mesmo período. A justificativa para o uso do termo qualitativo, para tal correlação, se deve ao fato do grupo amostral ser insuficiente para a definição de resultados estatisticamente significativos. No entanto, a intenção foi a de verificar a sensibilidade da oscilação, em 
relação a sua resposta diante do comportamento envolvendo as duas variáveis em períodos específicos e, sugerir em função deste resultado a probabilidade de estarem correlacionados.

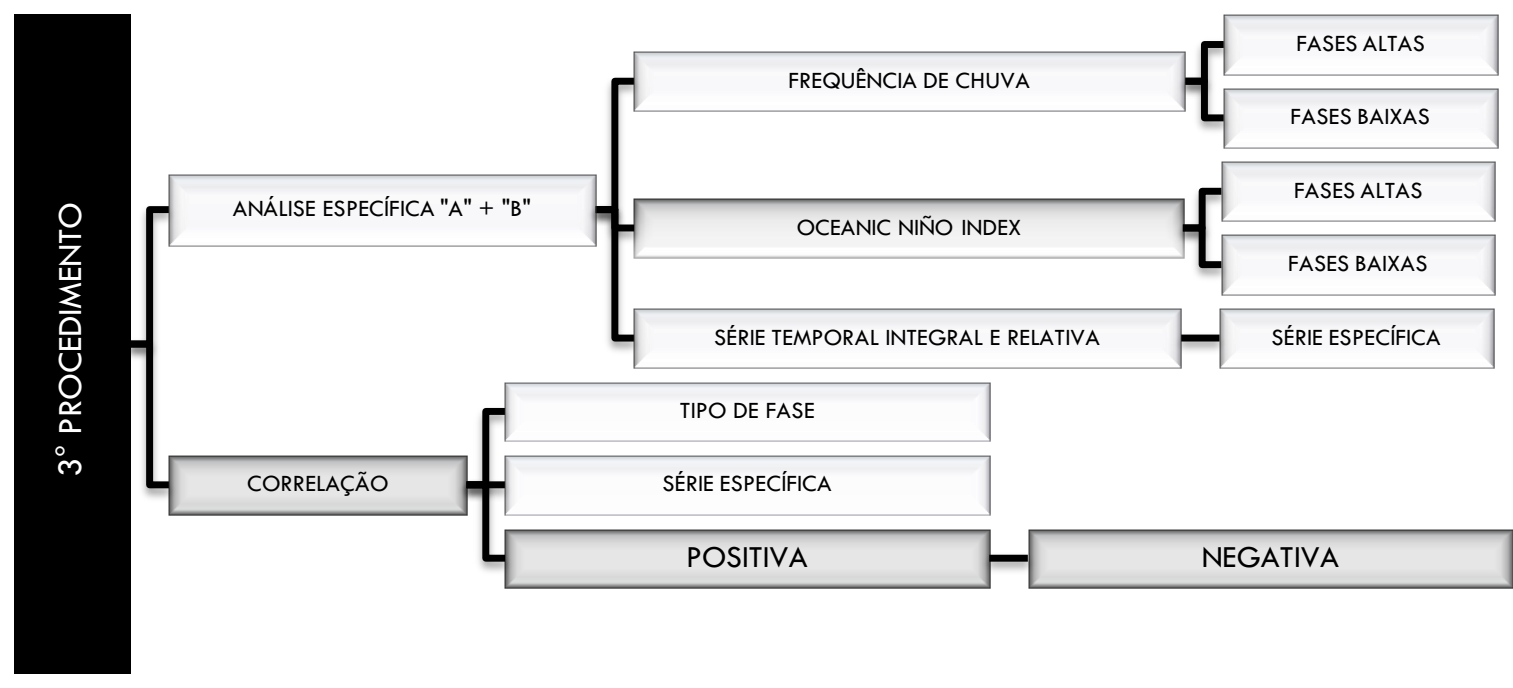

Figura 15 - Organograma Referente ao $3^{\circ}$ Procedimento da Análise 2.

A partir da compreensão desta última articulação, é possível entender como foi obtido o quarto resultado e mais um ponto de reflexão. Desta forma, este resultado revela um comportamento particular de uma variação cíclica. No caso, é possível que ocorra, a possibilidade, de haver uma correlação entre as fases específicas de chuvas e dos indices do ONI. Mais precisamente, foi diagnosticado em que fases as duas varáveis estiveram correlacionas, ou seja, apesar de não haver correlação durante todo ciclo é possível que tenha ocorrido correlações em determinadas fases. $O$ segundo ponto de reflexão, neste caso, partir do dignóstico deste resultado, nos sugere que apesar de não haver, num campo hipotético, uma correlação linear e uma correlação cíclica, é possivel que ocorra correlações envolvendo fases específicas.

Os três procedimentos da análise 2 apresentaram os níveis de cada diagnósticos, através das articulações, envolvendo a variável chuva e a variável ONI. A intenção foi a de demonstrar os níveis de organização, a partir de uma exposição detalhada, do estudo realizado. Nesse sentido, o aquecimento ou resfriamento observado pela linearidade (ajuste 
linear) forneceu o quadro inicial de possíveis alterações, e as correlações posteriormente estabelecidas, procuraram definir os seus possíveis reflexos, numa escala temporal que variou entre a série integral, relativa e específica. As séries revelam através de três niveis de análise, a possível existência de uma correlação, em algum momento do limíte temporal, seja ela, no período integral, relativo e específico. Desta forma, foi possível sugerir de maneira precisa, o nível de uma possível influência, deduzido a partir da hipótese, envolvendo o aquecimento (resfriamento) das águas superficias do Pacífico Equatorial e, a frequência de chuva horária na cidade de São Paulo.

Tendo em vista os esclarecimentos anteriores e retornando aos procedimentos adotados nas articulações, cabe esclarecer que não serão apresentadas as demais articulações para as demais categorias (ENOS, Fase Neutra, El Niño e La Niña), por serem consideradas como redundantes.

\subsection{3- Oscilação Decadal do Pacífico}

A lembrança da Oscilação Decadal do Pacífico no contexto deste estudo ocorre devido aos resultados obtidos sobre sua periodicidade e possíveis associações às chuvas observadas na América do Sul, tal como comentam Robertson e Mechoso (2000). De modo geral, foi considerado que a ODP possui uma variabilidade significativa na escala decadal, com periodicidade aproximada em intervalos de 20 a 30 anos, conforme Molion (2007). Sua fase quente (fria) é caracterizada por anomalias positivas (negativas) de TSM no Pacífico Tropical centro-leste, e, por anomalias negativas (positivas), nas áreas extratropicais da bacia do Pacífico, nos setores mais a oeste. A Figura 16 ilustra bem o campo espacial das anomalias de TSM na bacia do Pacífico nas fases quentes e fria, definido pela primeira componente principal associada aos valores de TSM. 


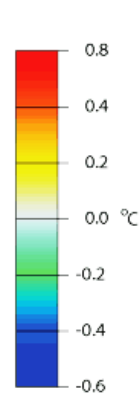

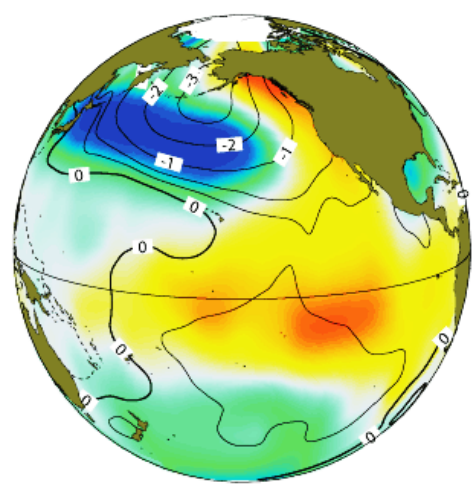

Warm Phase PDO

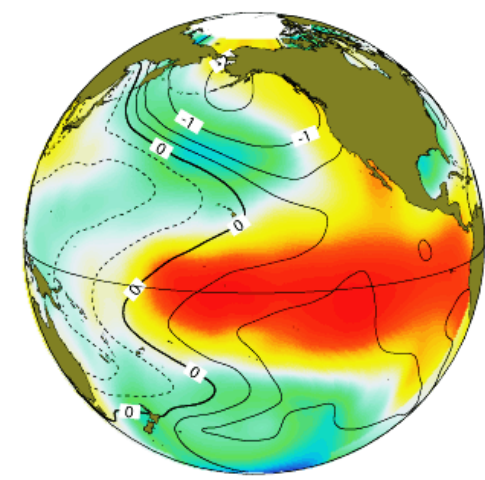

Warm Phase ENSO

Figura 16 - Fase Quente da ODP e ENSO. O Padrão Espacial das Anomalias de Temperatura da Superfície do Mar (sombreamento, graus Celsius) e Pressão ao Nível do Mar (contornos) associado com a Fase Quente da ODP para o período 1900-1992.

Fonte: http://cses.washington.edu/.

O fator ODP, por meio de suas fases quentes e frias, pode auxiliar na compreensão da existência de El Niños (La Niñas) mais bem correlacionada com as possíveis alterações no campo das frequências de chuvas. Desta forma, a ODP no contexto dos procedimentos adotados foi apenas mais um dispositivo utilizado para argumentar na análise de uma determinada situação observada durante os resultados. 


\section{IV - RESULTADOS E DISCUSSÕES}

A introdução dos resultados e discussões apresenta uma breve consideração a respeito do contexto histórico-geográfico, da cidade de São Paulo e do distrito de Cursino, no período de 1970 a 2009. Nesse sentido, é importante mencionar que, este estudo, não esteve alienado aos processos intrínsecos, relativos à (re)produção do espaço geográfico motivada pela aceleração dos processos produtivos (industrias) e, a sua consequente contribuição para o aumento populacional ao longo dos anos. Desta forma, diante deste contexto, não podemos ignorar que a reorganização física do espaço proporcionou a inserção de novos compostos químicos, altamente reagentes na atmosfera que, possivelmente refletiram de alguma forma na frequência de cada tipo de chuva. A Tabela 15 apresenta o histórico demográfico da Região Metropolitana de São Paulo e do Distrito de Cursino. Os dados fazem parte do acervo histórico da Prefeitura de São Paulo e dos dados fornecidos pelo Instituto Brasileiro de Geografia e Estatística (IBGE).

Tabela 15 - Demográfia decadal da RMSP e do distrito de Cursino, de 1970 a 2010. Dados obtidos da Prefeitura de São Paulo e do IBGE (2013).

\begin{tabular}{|cccccc|}
\hline & \multicolumn{5}{c|}{ História Demográfica Decadal da RMSP e do Distrito de Cursino } \\
\hline POPULAÇÃO & 1970 & 1980 & 1990 & 2000 & 2010 \\
\hline RMSP & 8.139 .730 & 12.588 .725 & 15.444 .941 & 17.878 .703 & 19.683 .975 \\
\hline$\%$ & - & 4,5 & 1,9 & 1,6 & 1,0 \\
\hline CURSINO & 90.462 & 116.473 & 110.435 & 102.089 & 92.895 \\
\hline$\%$ & - & 2,6 & $-0,5$ & $-0,8$ & $-0,8$ \\
\hline
\end{tabular}

Os dados da Tabela 15 revelam que o crescimento populacional da RMSP vem aumentando, a taxas (\%) decrescentes, ao longo das últimas décadas. O Distrito de Cursino, região onde está localizada a estação meteorológica do IAG-USP, apresentou no intervalo de 1970 a 1980, aumento da população. De 1990 a 2010 tem apresentado redução da população. 


\section{1- ONI e ODP entre 1970 e 2009}

Os resultados preliminares constam de projeções gráficas e valores numéricos que foram utilizados em todas as análises com a intenção de evitar constantes repetições. Nesse sentido, todos os resultados que serão utilizados durante as análises relacionadas às correlações estatísticas, a serem utilizadas em todos os tipos de chuvas e, em todas as séries temporais definidas a partir dos índices do Oceanic Niño Index. Neste caso, diferente do que ocorre com os resultados das frequências, para cada tipo de chuva, os resultados das categorias do ONI serão sempre os mesmos. A partir desse esclarecimento, nos cabe neste momento, apresentar os resultados das respectivas séries temporais da ONI.

A tendência linear e a variação cíclica do ONI, ao longo da série de 1970 a 2009, são apresentadas nesta seção. Nota-se, com base na Figura 18, que os valores de ONI apresentam tendência linear positiva ao longo da série considerada. Da variação cíclica (série temporal sem tendência linear), ilustrada na Figura 17, nota-se a ocorrência de oito períodos distintos caracterizados por EN (cor vermelha do gráfico), com ONI superiores a 0,5 e, dez por LN (cor azul do gráfico), com ONI inferiores a -0,5.

O primeiro resultado é a variação anual da ONI e o seu respectivo comportamento linear ao longo da série (1970-2009).

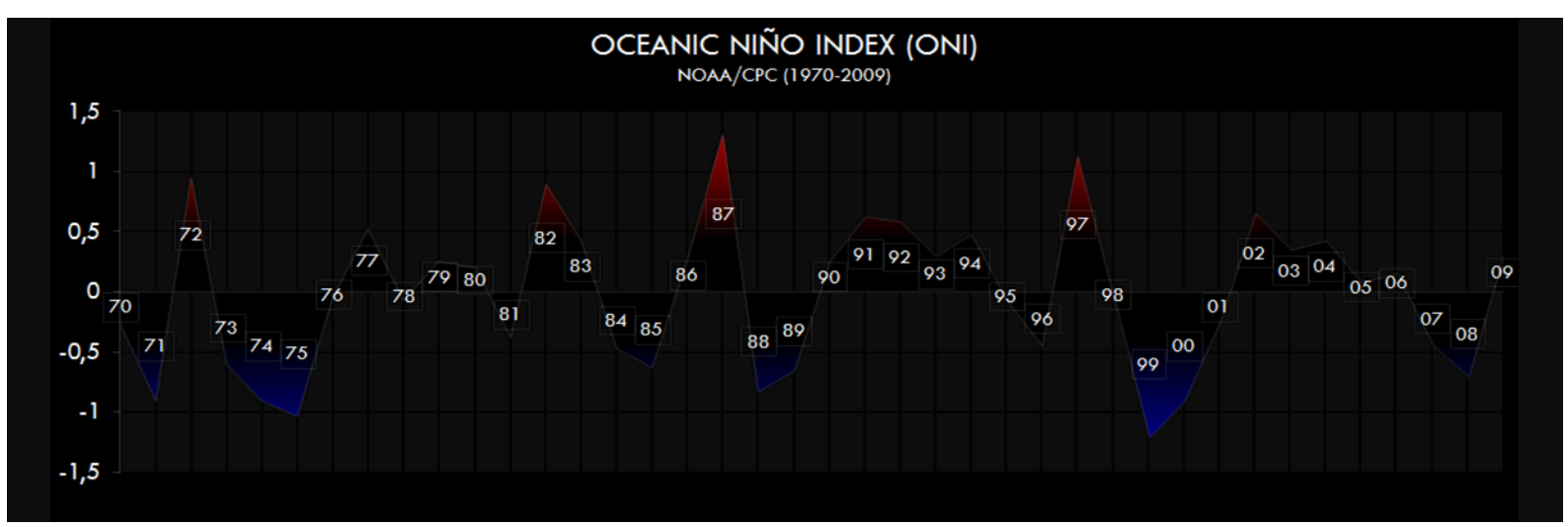

Figura 17 - Valor Anual de Oceanic Niño Index entre (1970-2009). As Cores Vermelhas e Azuis indicam, Respectivamente, a Ocorrência de Eventos EN e LN.

Fonte: www.cpc.ncep.noaa.gov. 


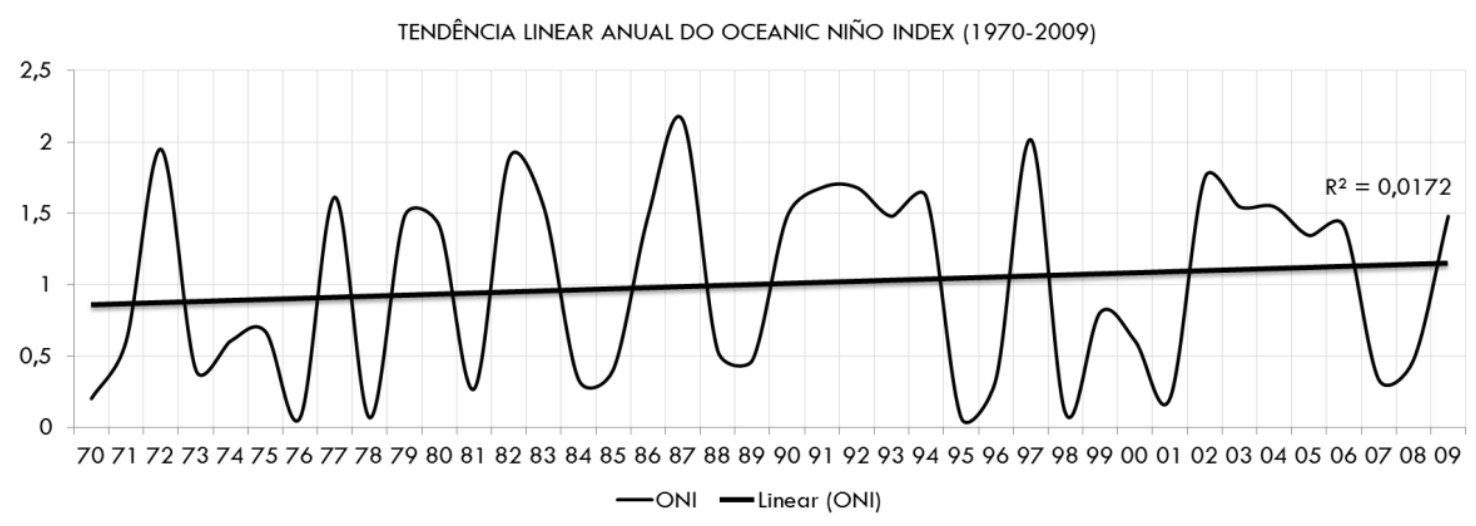

Figura 18 - Ajuste Linear da Série Temporal do ONI Anual, entre 1970 e 2009.

A separação dos valores de ONI em eventos neutros e eventos de EN e LN juntos, conforme ilustrado na Figura 19, indica que os valores absolutos de ONI têm aumentado. Ou seja, os eventos têm ficado mais intensos. Desta forma é possível notar que houve um aquecimento na TSM durante a série integral (1970-2009) e, durante as respectivas séries relativas (ENOS, Neutra e La Niña). A única exceção foi à série relativa à fase de El Niño.

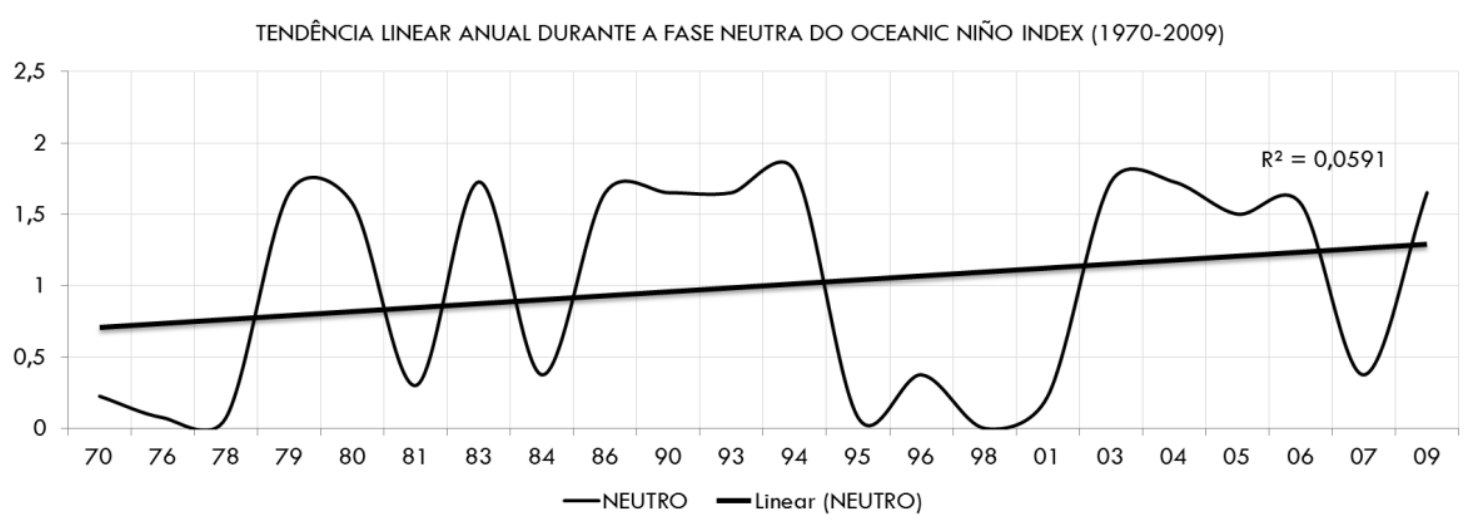

A

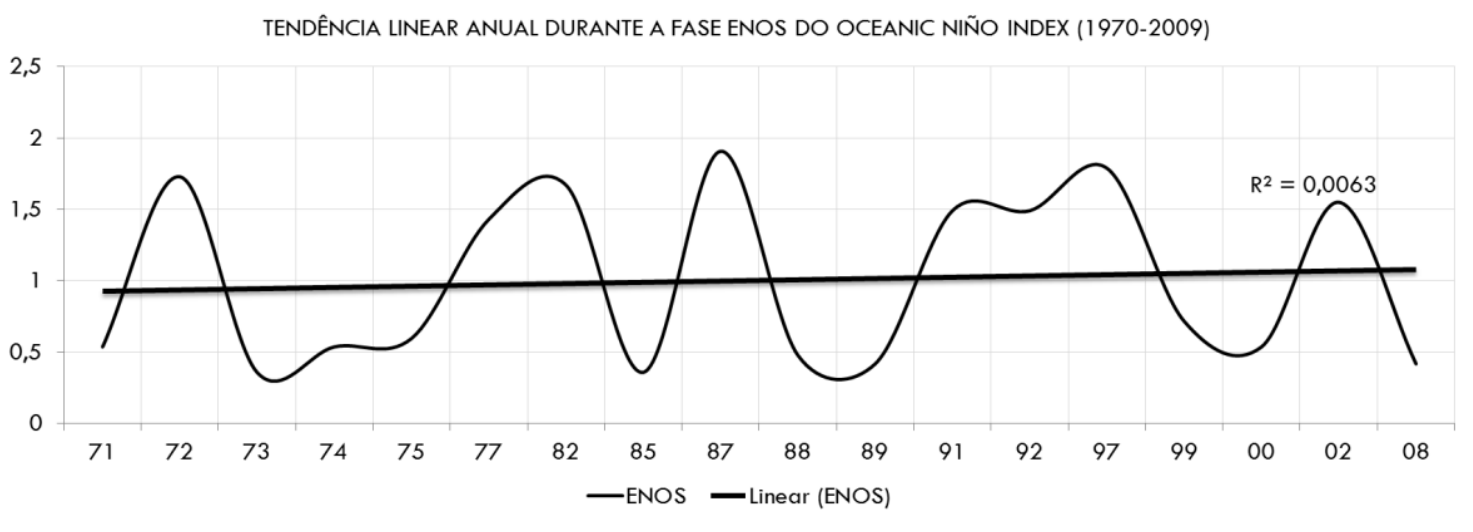



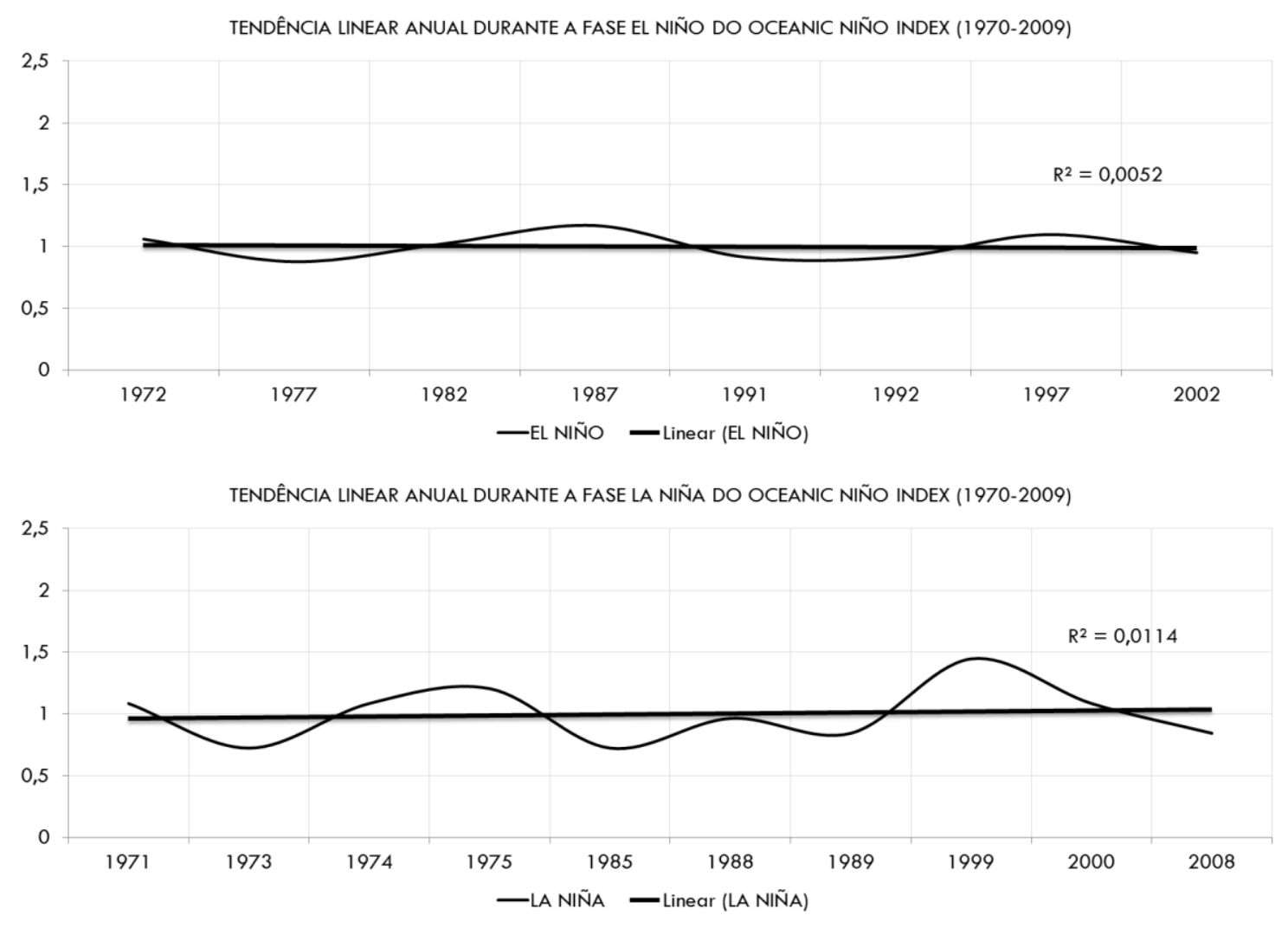

Figura 19 - Ajuste Linear dos Anos com Fases (A) Neutra, (B), ENOS, (C), El Niño e (D) La Niña.

A comparação entre os dados do índice ODP (Figura 20) e os de ONI (Figura 17), nota-se que os eventos de El Niños mais intensos (área vermelha do gráfico da Figura 17), observados nos anos de 1972, 1982, 1987 e 1997, apenas os eventos de 1987 e 1997 coincidiram com os valores intensos e positivos da ODP. Os eventos de La Niña mais intensos (área azul do gráfico da Figura 17), observadas nos anos de 1971, 1974, 1975, 1988, 1999, 2000 e 2008, coincidiram, com exceção de 1974 e 1988, com os intensos valores negativos da ODP.

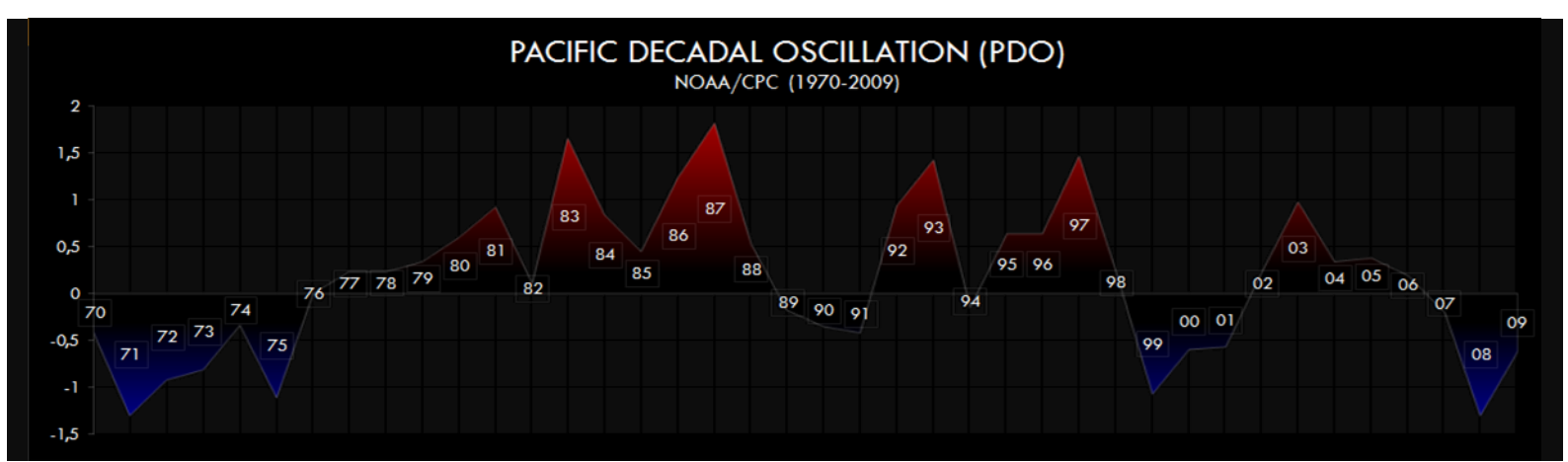

Figura 20 - Índice Anual da Oscilação Decadal do Pacífico entre 1970-2009. 
Os valores sazonais ou trimestrais da ONI, tal como ilustrado na Figura 21, apresentam os resultados obtidos para cada estação do ano, verão, outono, inverno e primavera, entre 1970 e 2009.

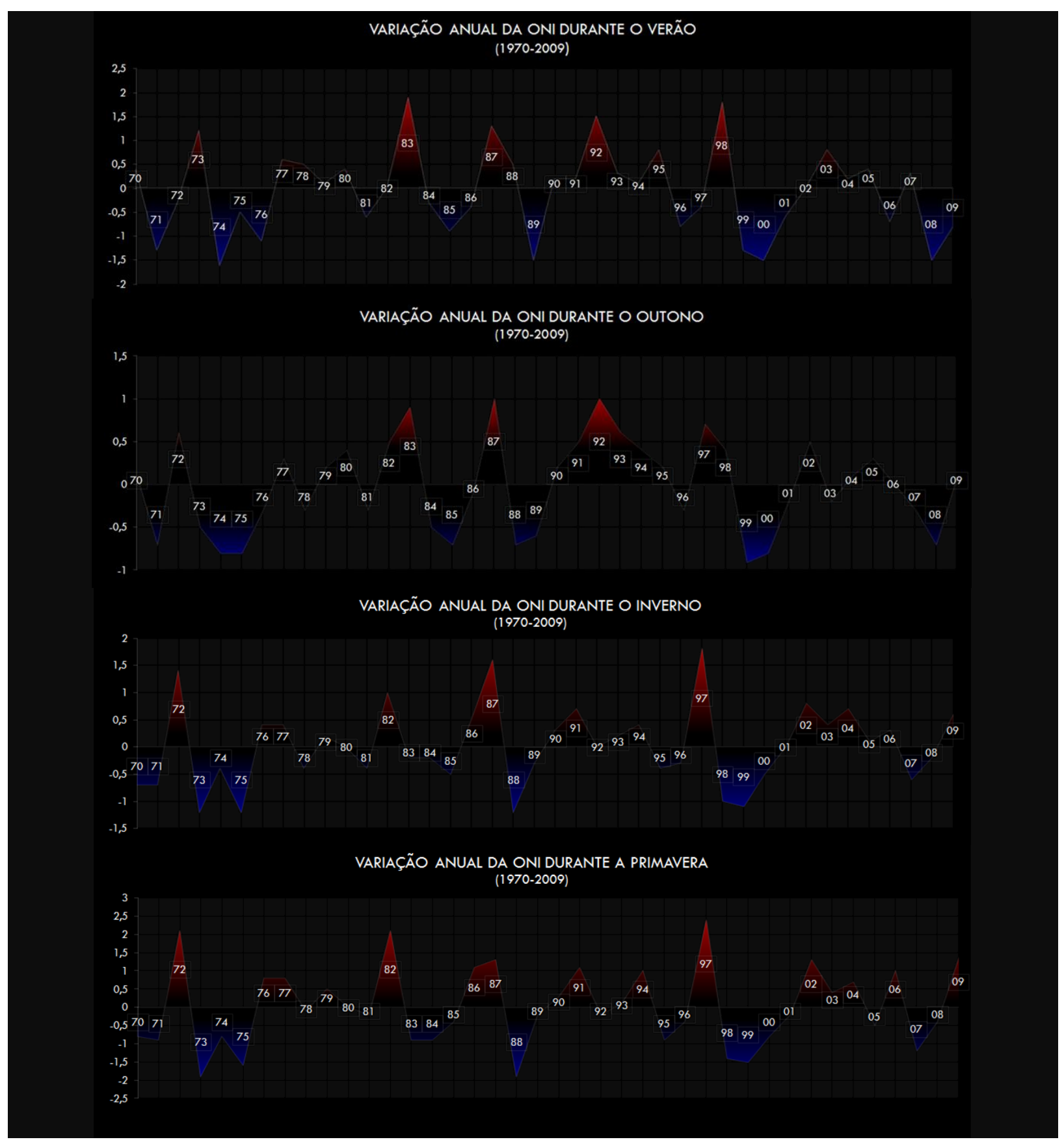

Figura 21 - ONI de cada Estação do Ano entre 1970-2009.

Apesar da pouca quantidade de eventos de EN e LN na série temporal considerada, de 1970 a 2009, é possível verificar que durante as estações de outono e verão, os valores 
78

de ONI estiveram estáveis, enquanto que nas estações de inverno e primavera estes valores aumentam, tal como ilustrado na Figura 22.

TENDÊNCIA LINEAR TRIMESTRAL DO OCEANIC NIÑO INDEX - VERĂO (1970-2009)

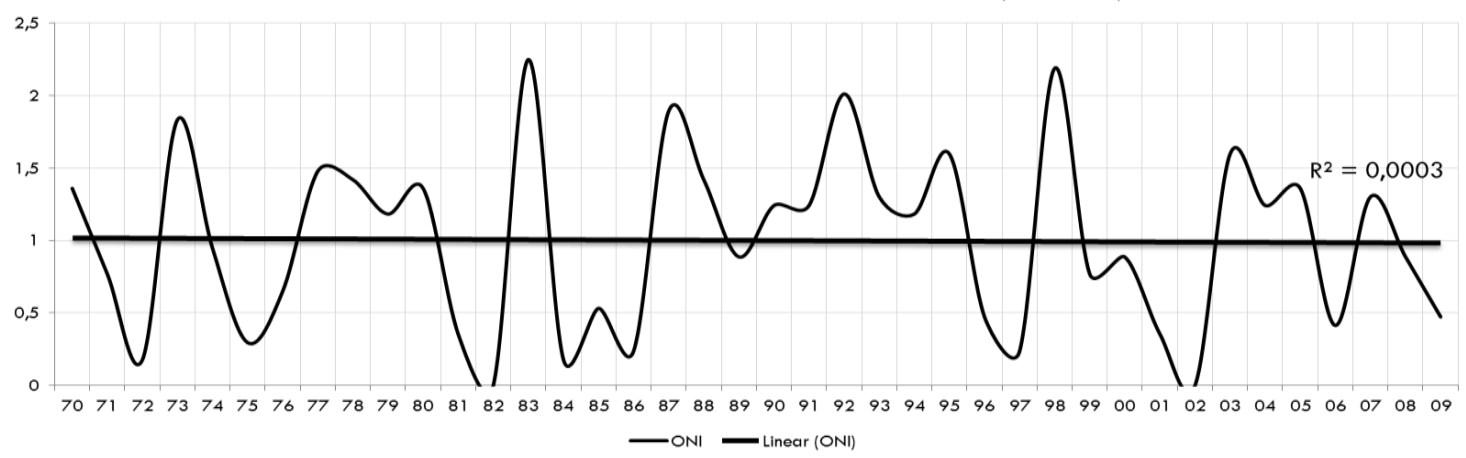

A

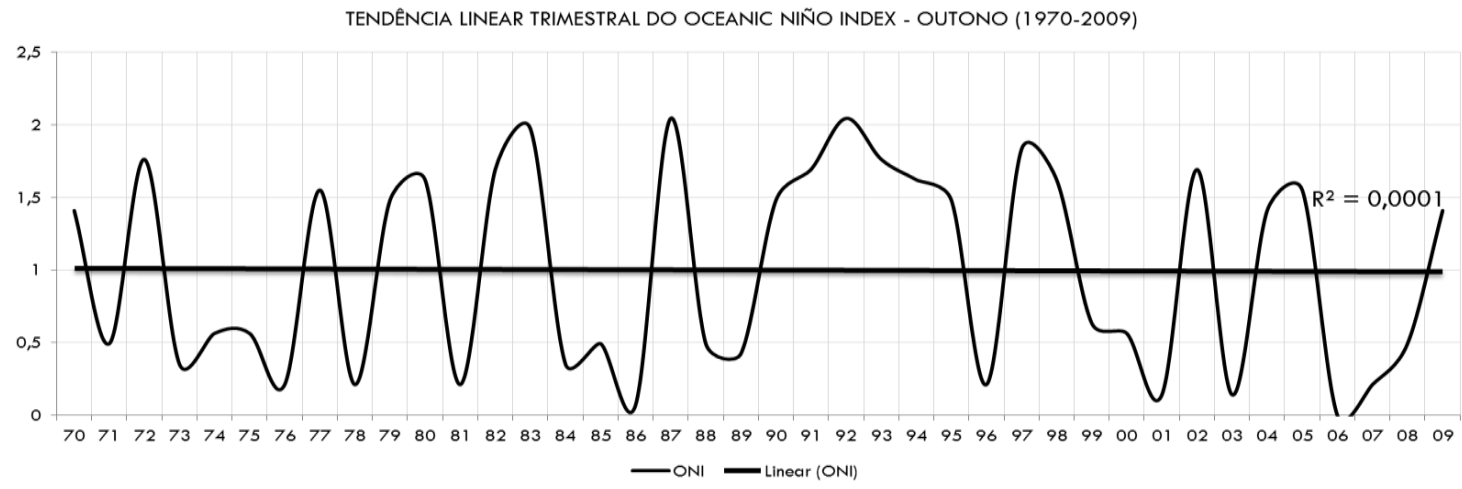

B

TENDÊNCIA LINEAR TRIMESTRAL DO OCEANIC NIÑO INDEX - INVERNO (1970-2009)

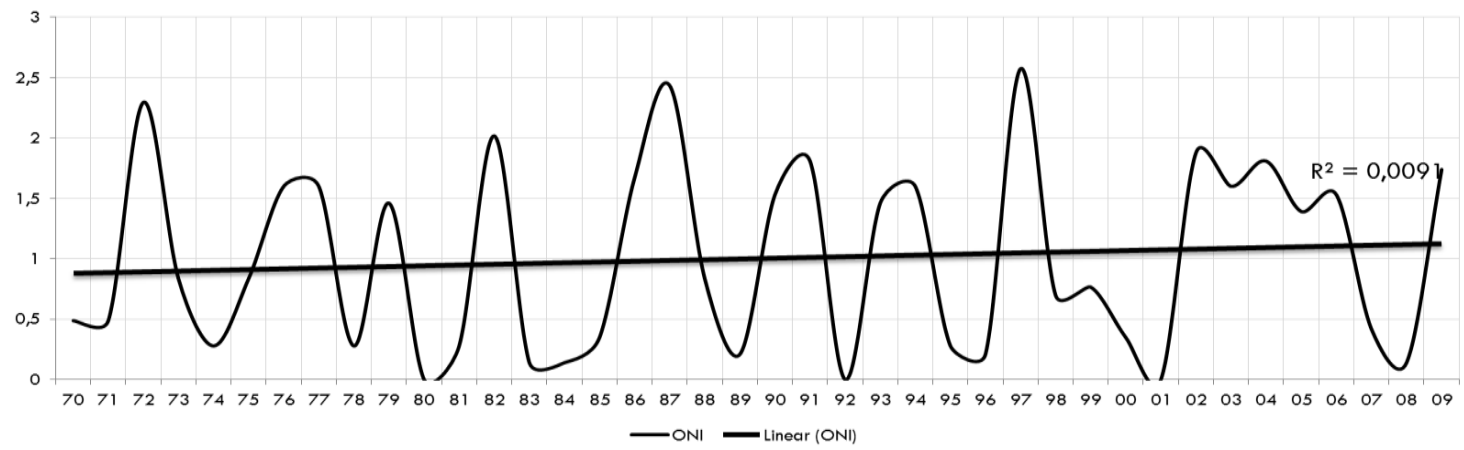

C

TENDÊNCIA LINEAR TRIMESTRAL DO OCEANIC NIÑO INDEX - PRIMAVERA (1970-2009)

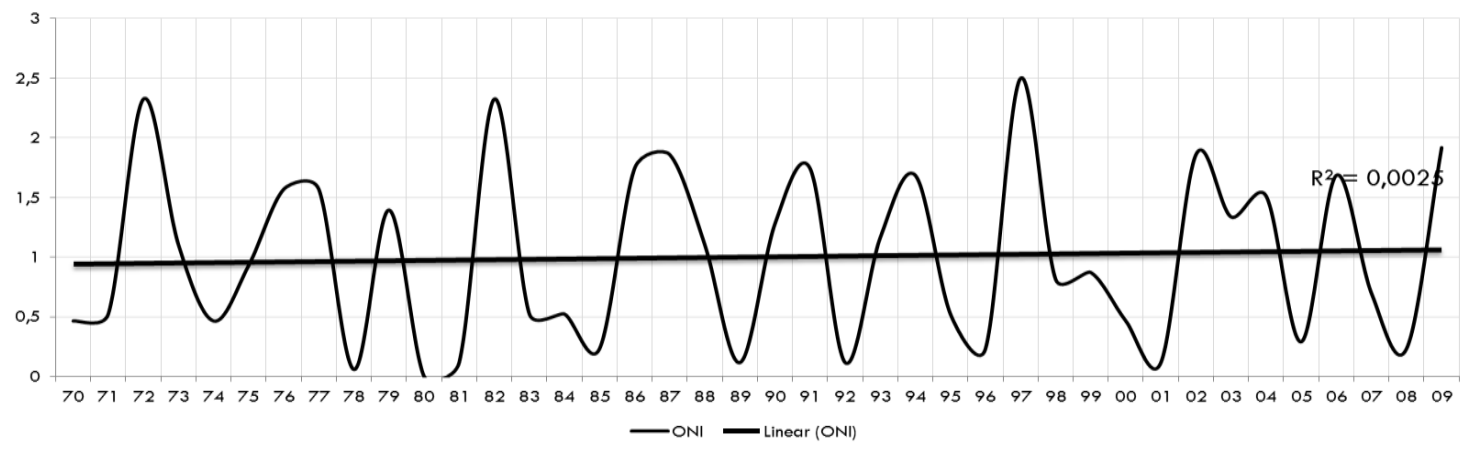

D

Figura 22 - Ajuste Linear do Valor Trimestral do ONI para Cada Estação do Ano, verão (a), outono (b), inverno (c) e primavera (d), entre 1970 e 2009. 
O valor trimestral do ONI para a estação climática de verão apresentou tendências lineares positivas, observadas durante a fase neutra e El Niño. Por outro lado, as fases ENOS e La Niña apresentaram tendências lineares negativas. A Figura 23 apresenta tais resultados.
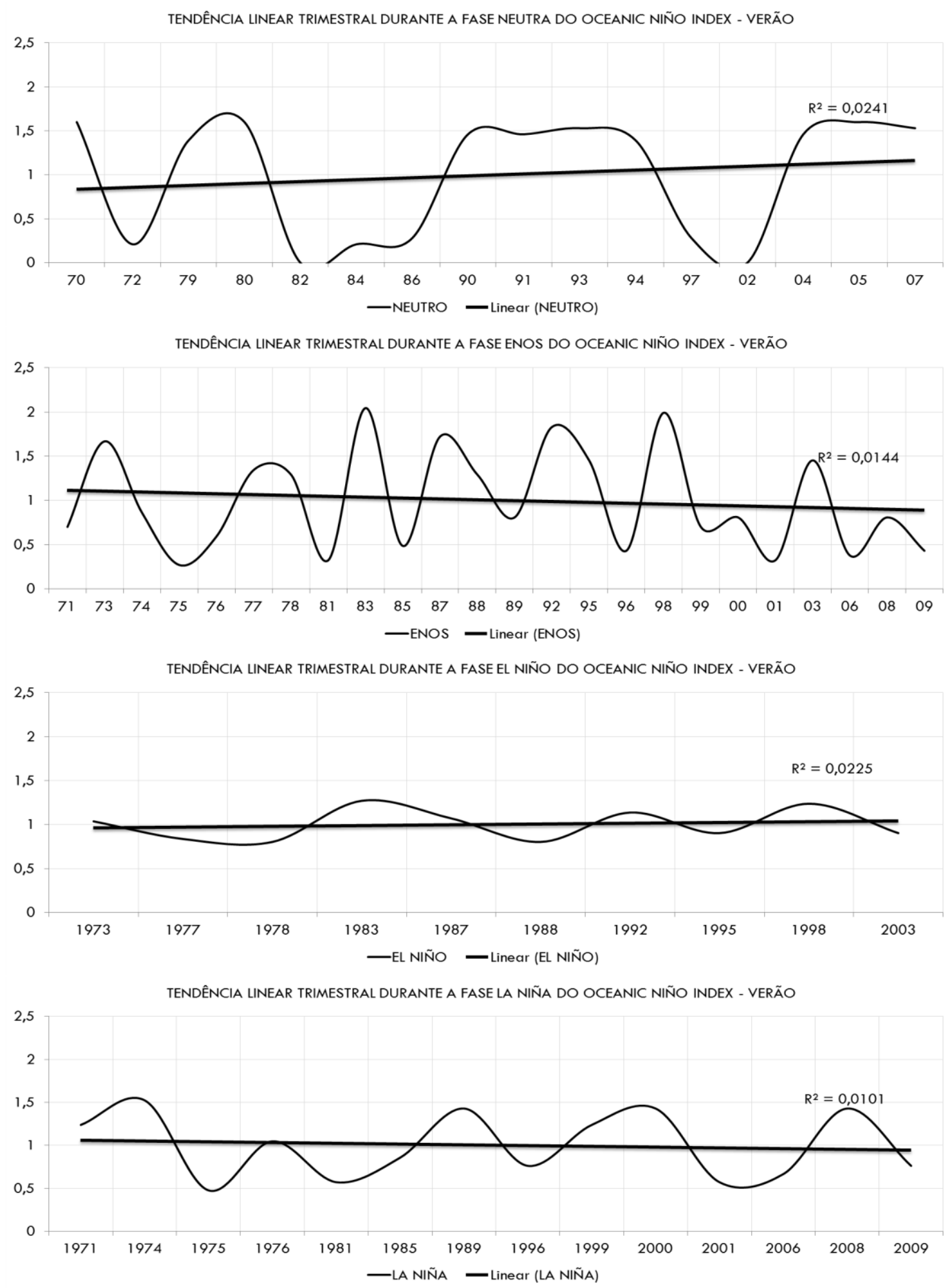

Figura 23 - Ajuste Linear do Valor Trimestral do ONI durante o Verão para as Fases, Neutra, ENOS, El Niño e La Niña. 
O valor trimestral do ONI para a estação climática de outono apresentou tendências lineares positivas, observadas durante a sua fase ENOS e La Niña. Por outro lado, a fase neutra apresentou tendência linear negativa e, para El Niño não houve alteração. A Figura 24 apresenta tais resultados.
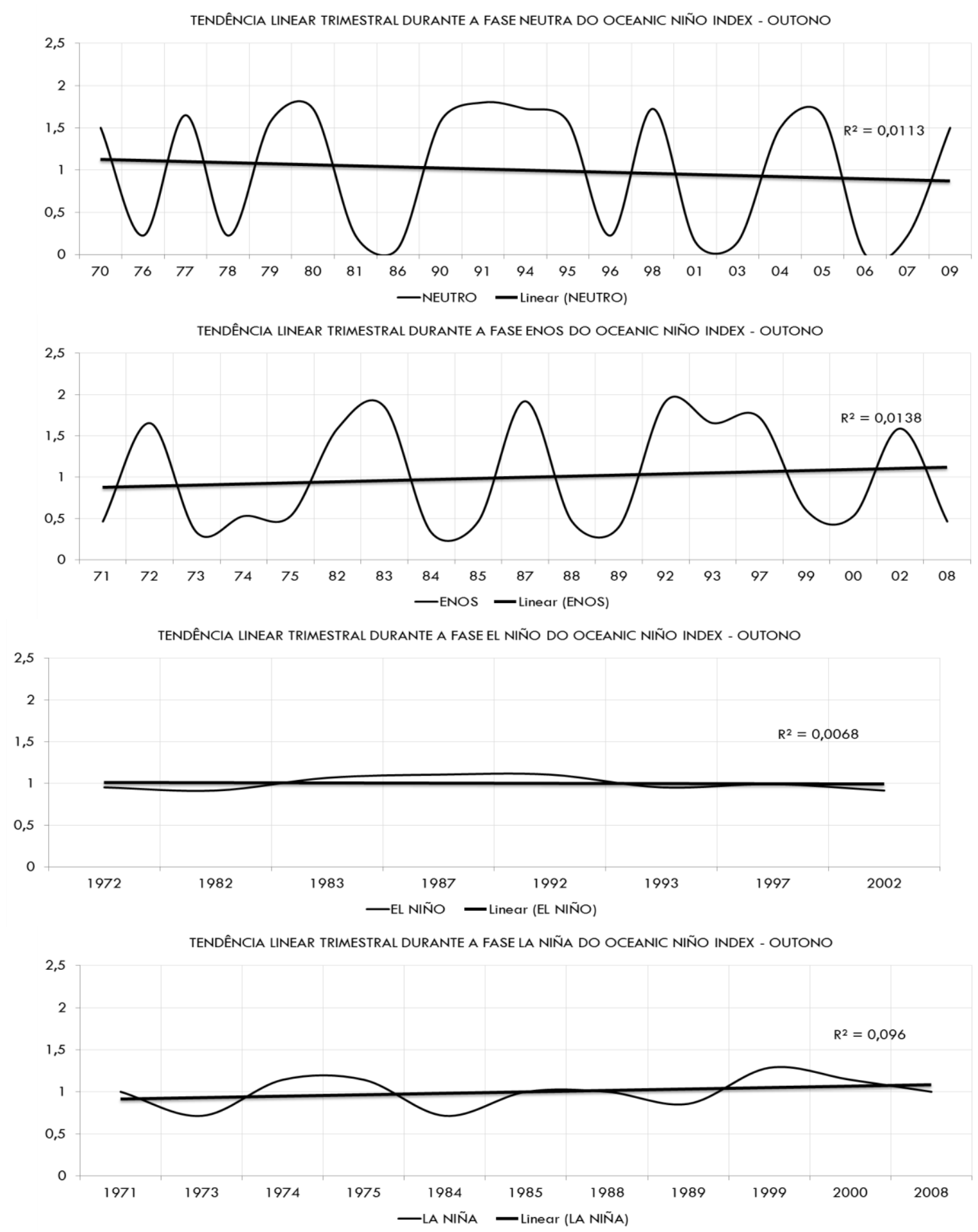

Figura 24 - Ajuste Linear do Valor Trimestral do ONI durante o Outono para as Fases, Neutra, ENOS, El Niño e La Niña. 
O valor trimestral do ONI para a estação climática de inverno apresentou tendências lineares positivas, observadas durante a sua fase neutra e ENOS. Por outro lado, a fase EI Niño e La Niña apresentaram tendências lineares negativas. A Figura 25 apresenta tais resultados.
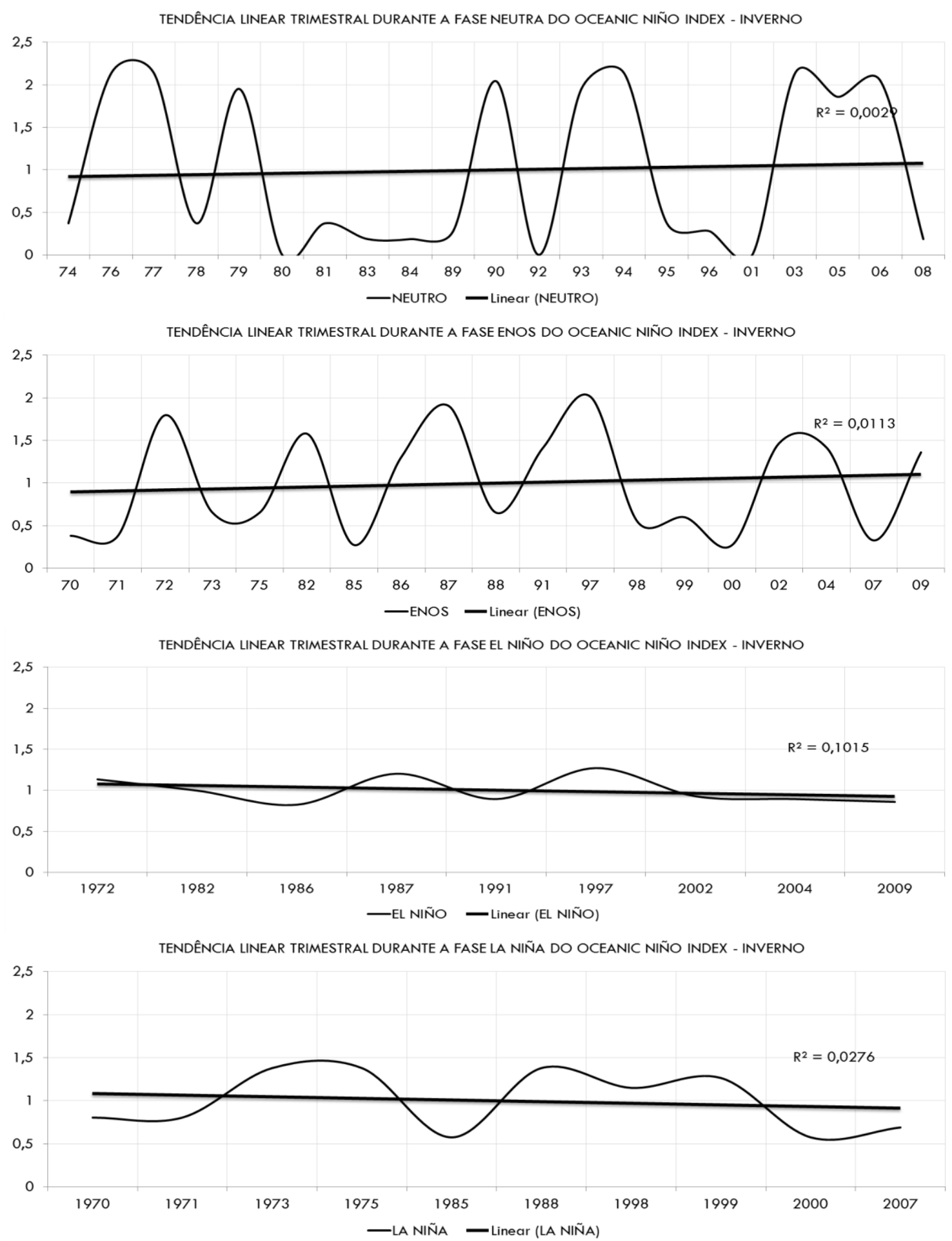

Figura 25 - Ajuste Linear do Valor Trimestral do ONI durante o Inverno para as Fases, Neutra, ENOS, El Niño e La Niña. 
O valor trimestral do ONI para a estação climática de primavera apresentou tendências lineares positivas, observadas durante a fase neutra e ENOS. Por outro lado, a fase La Niña apresentou tendência linear negativa e a fase El Niño apresentou estabilidade (tendência linear negativa nula). A Figura 26 apresenta tais resultados.
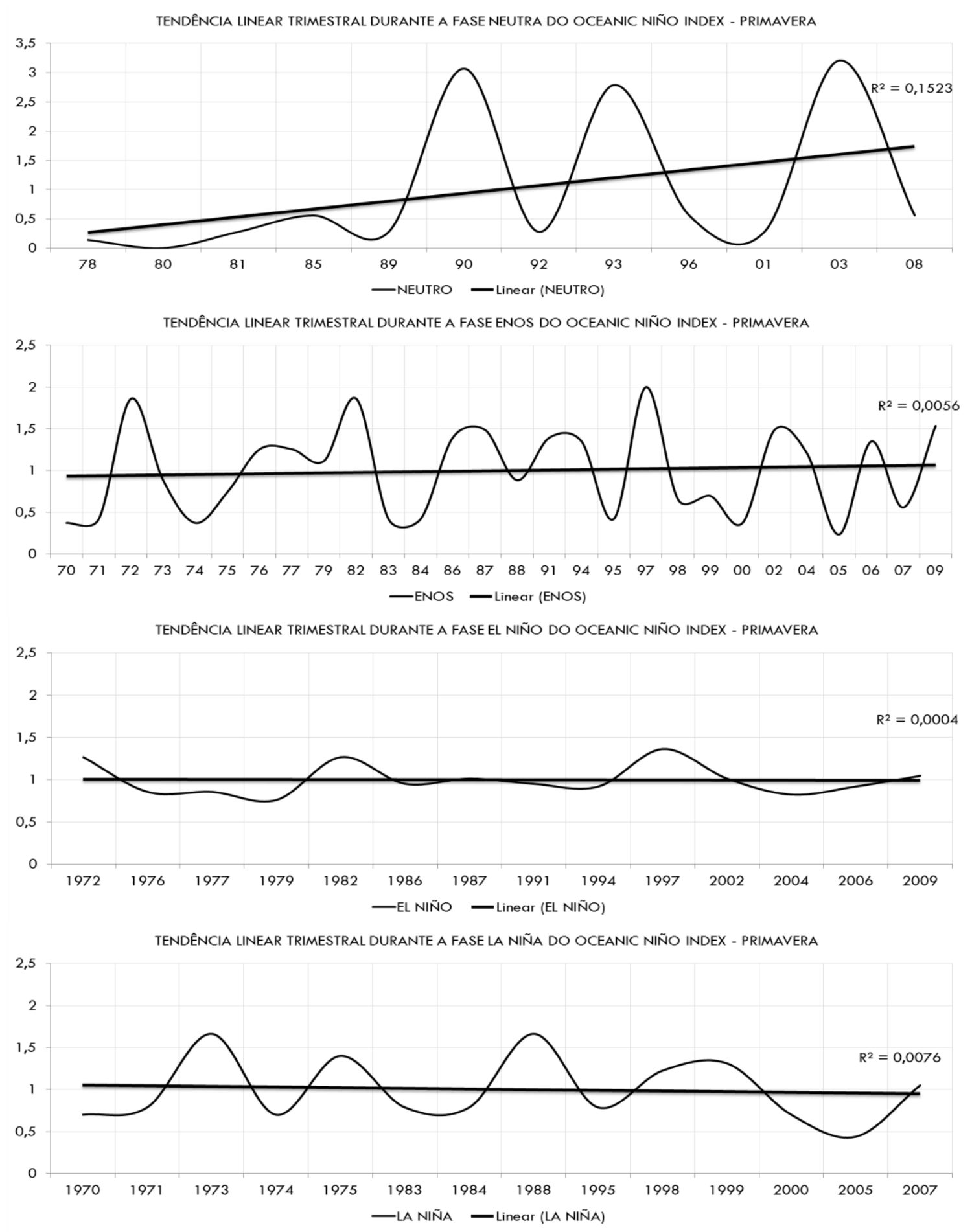

Figura 26 - Ajuste Linear do Valor Trimestral do ONI durante a Primavera para as Fases, Neutra, ENOS, El Niño e La Niña. 
Analisando os gráficos do ONI e posteriormente correlacionando com os da ODP (Figura 27) nota-se que coincidiram as anomalias entre os anos com mesmo sinal durante o período de 1970 a 2010.

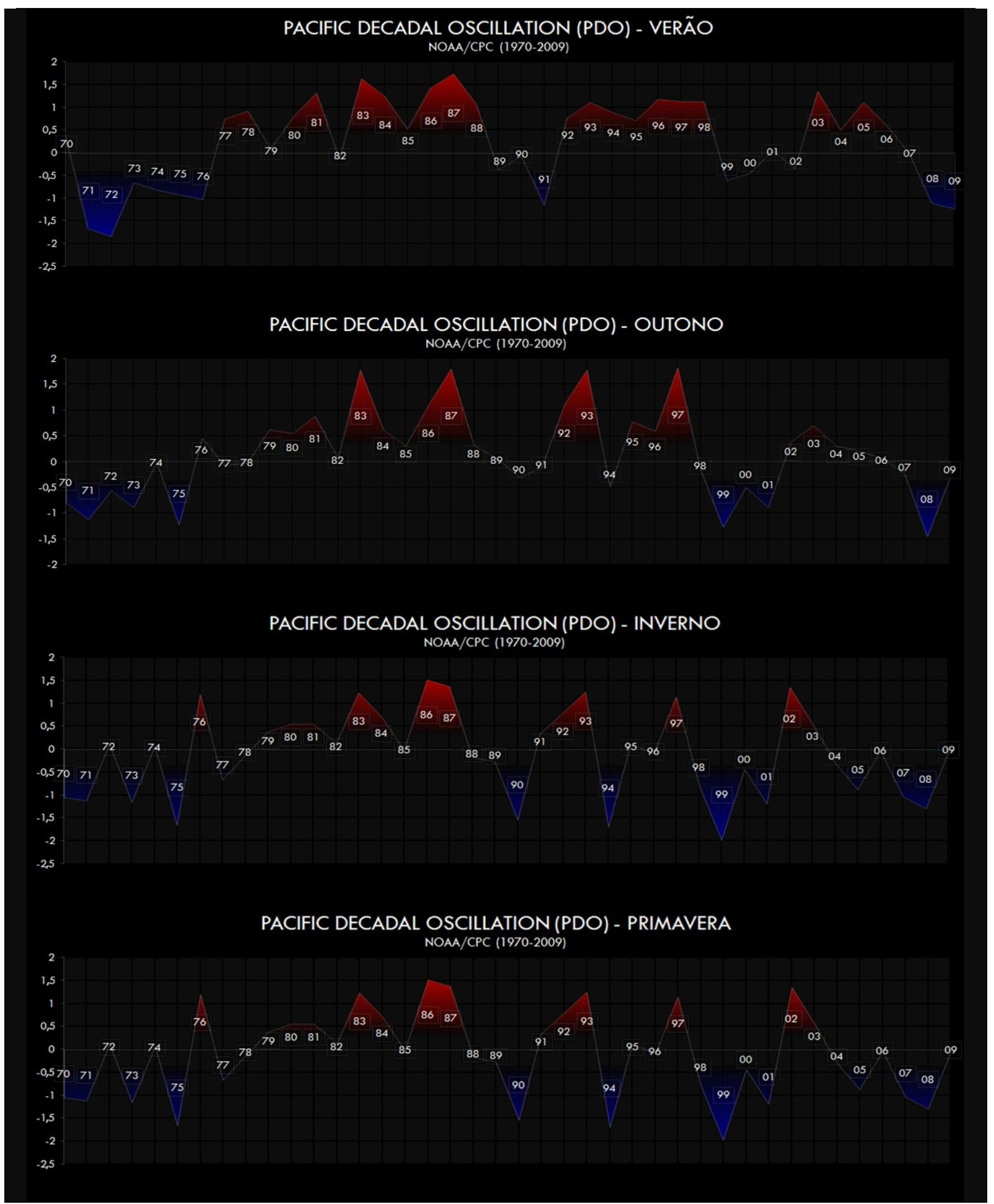

Figura 27 - Índice da ODP para cada Estação do Ano, Verão, Outono, Inverno e Primavera, entre 1970-2009. 


\section{2- Chuva Muito Fraca - 0,1 a 0,25 mm h-1}

As chuvas definidas como sendo muito fracas e, que possivelmente estão associadas as "neblinas e nevoeiros" atingem níveis pluviométricos equivalentes a 0,1 $-0,25 \mathrm{~mm} \mathrm{~h}{ }^{-1}$. A partir da hipótese inicial deste estudo, a intenção ao analisar este tipo de chuva, é a de concluir para a série temporal de 1970-2009 a existência ou não de um nível de correlação aceitável, envolvendo o comportamento de sua frequência e as variações registradas na temperatura da superfície do mar na região Niño3.4. De acordo com tal hipótese, o estudo estabelece uma reflexão com base em três possibilidades, que podem ou não atuar em conjunto. A reflexão teórica e quantitativa analisa a possibilidade de uma possível correlação, que pode ser ou não, isoladamente linear, cíclica e/ou especificamente por fases, ou seja, possíveis correlações identificadas durante as fases altas ou baixas das variações cíclicas. A cronologia das escalas de análise foi dividida em anuais e trimestrais. A intenção desta reflexão científica é a de presumir a partir dos resultados, a possibilidade de ter ocorrido uma intensificação ou enfraquecimento, nos quadros evolutivos das variações cíclicas de Chuva Muito Fraca, a partir do aumento ou da diminuição das amplitudes dos seus respectivos ciclos, em função do aquecimento ou resfriamento, diagnosticado através dos registros da TSM, na região Niño3.4.

\subsection{1 - Análise Anual}

A análise anual possui a finalidade de apresentar uma conclusão obtida a partir da identificação do tipo de correlação existente na intenção de sugerir a possibilidade de haver uma relação anual envolvendo a Chuva Muito Fraca (MFA) e o Oceanic Niño Index. Neste caso, também estão inclusos os resultados das correlações realizadas para as fases ENOS, Neutra, El Niño e La Niña. 


\subsubsection{1 - Frequência Anual de Chuva Muito Fraca}

A partir da frequência anual de Chuva Muito Fraca $\left(0,1\right.$ a $\left.0,25 \mathrm{~mm} \mathrm{~h}-{ }^{1}\right)$, representada no gráfico da Figura 28, é possível identificar que a frequência máxima ocorreu no ano de 2009, relativo à contagem de 503 casos horários.

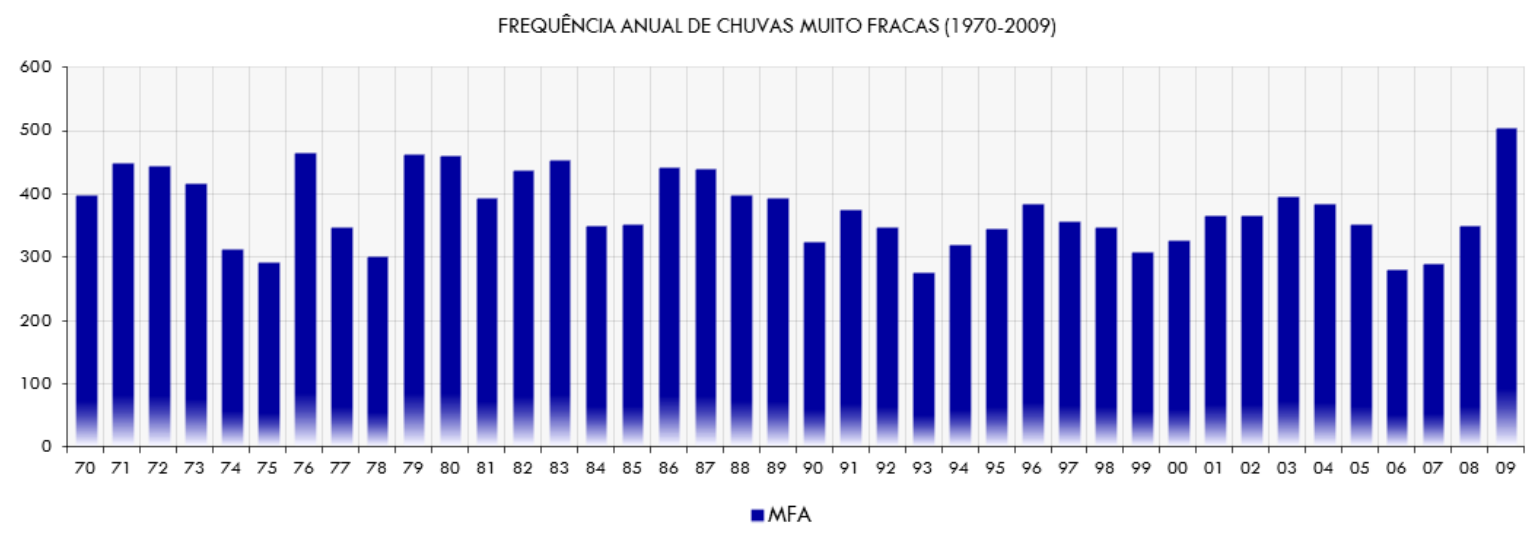

Figura 28 - Frequência Anual de Chuva Muito Fraca entre 1970-2009.

\subsubsection{2- Análise do Ajuste Linear}

O ajuste linear da frequência anual de Chuva Muito Fraca no município de São Paulo indica a diminuição desta frequência ao longo da série temporal analisada, de 1970 a 2009, tal como ilustrada na Figura 29. A análise realizada para as fases, neutra, ENOS, El Niño e La Niña, separadamente, mostra que, em todos os casos, a frequência anual de Chuva Muito Fraca diminui com o tempo (Figura 30). A comparação entre a tendência linear da frequência de Chuva Muito Fraca e do ONI indica que enquanto o ONI assume valores cada vez mais intensos, no decorrer da série temporal, a frequência de Chuva Muito Fraca diminui, tal como indicado na Tabela 16. A exceção ocorre no caso de eventos de EN que apresenta tendência negativa nula (estabilidade) de TSM, ao longo do período analisado, concomitantemente à tendência negativa de frequência de Chuva Muito Fraca (ver tabela 16, linha 4). 


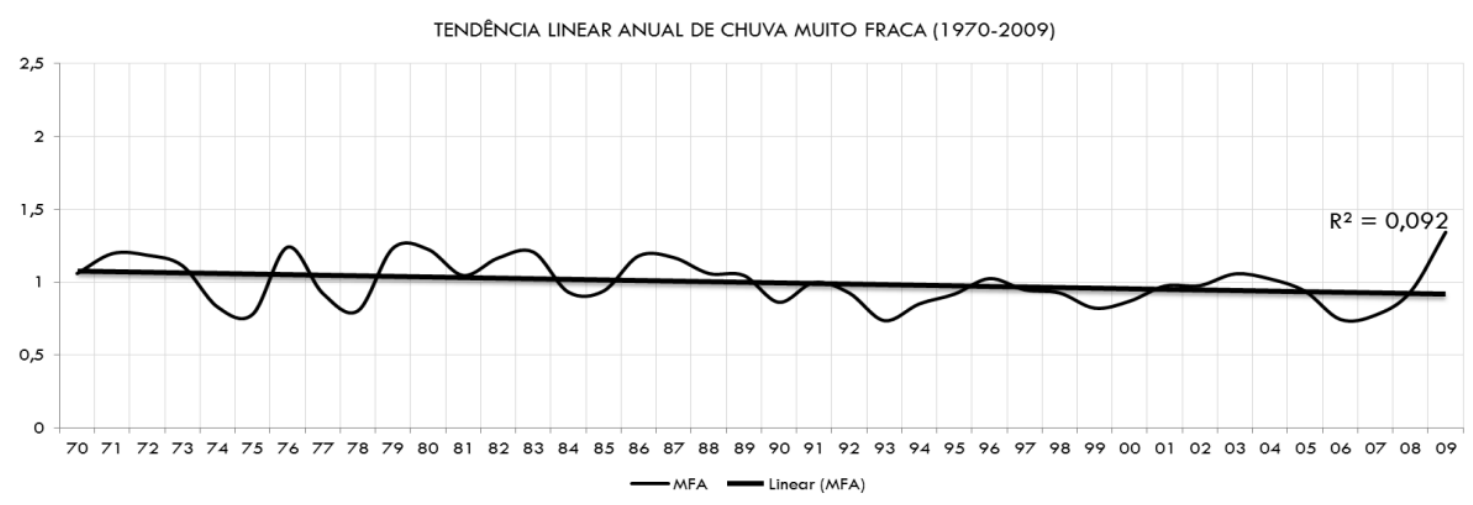

Figura 29 - Ajuste Linear da Frequência Anual de Chuva Muito Fraca entre 1970-2009.
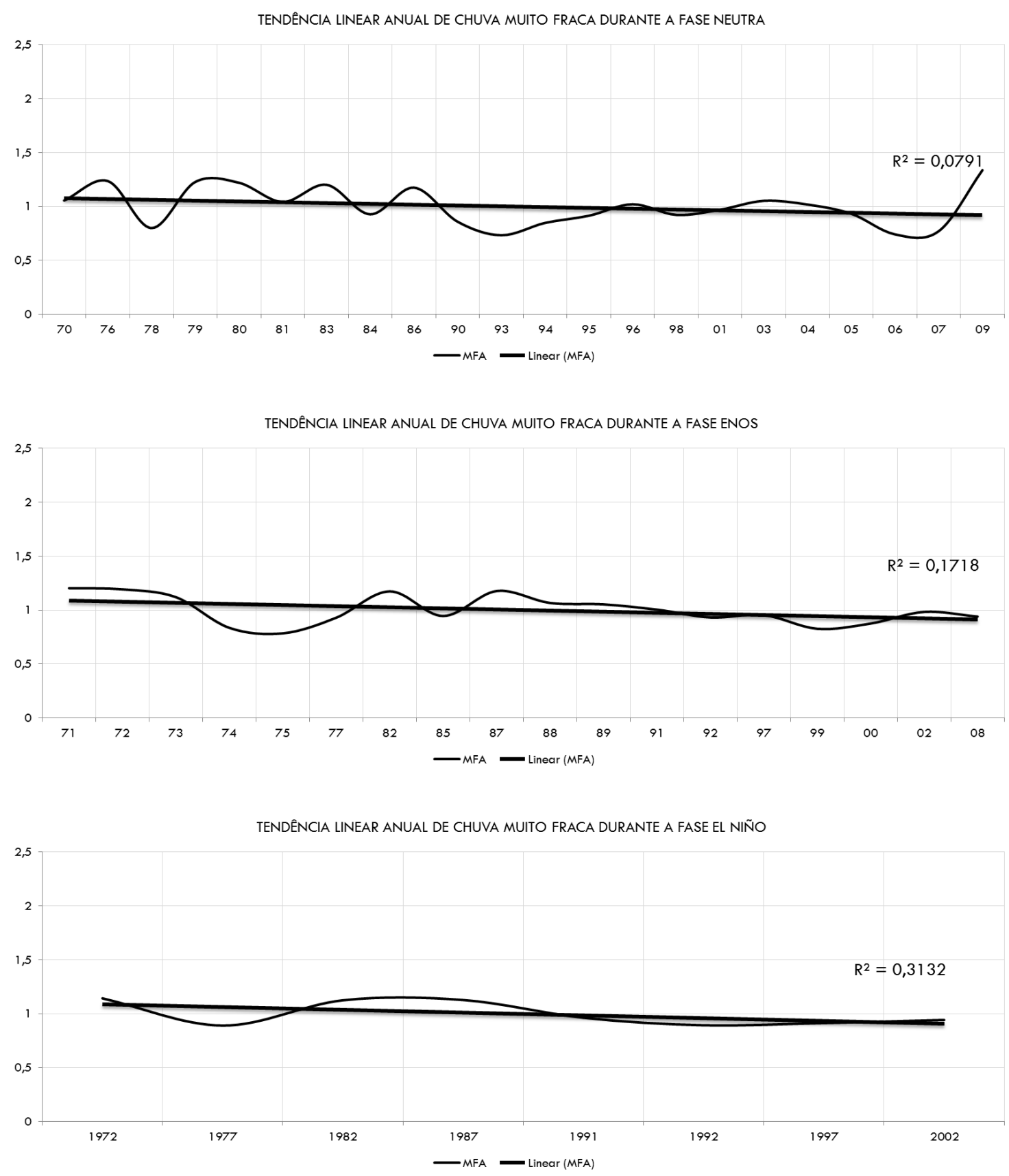


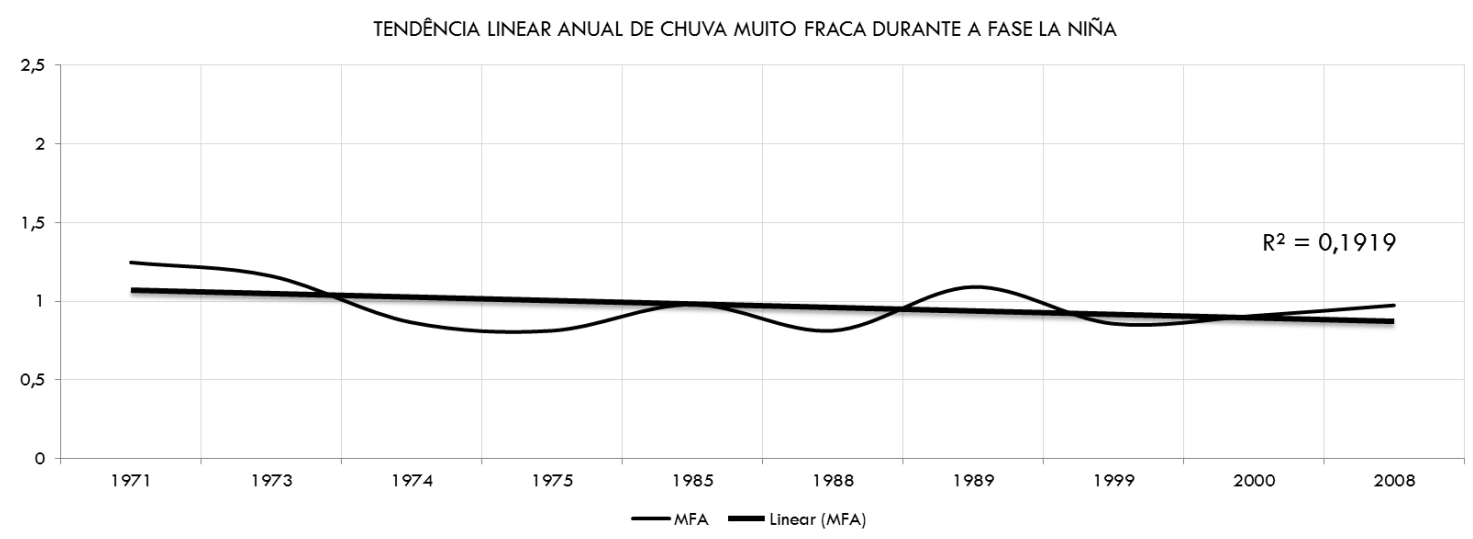

Figura 30 - Tendência Linear da Frequência Anual de Chuva Muito Fraca para a Fase, Neutra, ENOS, EN e LN, entre 1970-2009.

Os resultados observados através dos ajustes lineares negativos para a série anual revelam que as frequências analisadas no intervalo horário refletiram positivamente com os resultados das análises diárias realizadas por Cabral (2002).

Tabela 16 - Tendência Linear Anual de Chuva Muito Fraca e do ONI para o Período de 1970 a 2009. A Primeira Linha da Tabela indica a Tendência Linear de Todos os Dados Anuais e, as Demais Linhas indicam a Tendência Linear para cada Fase do ONI.

\begin{tabular}{|c|c|c|c|c|c|c|}
\hline${ }^{\circ} A^{*}$ & TIPO DE CHUVA & TENDENCIA UNEAR & "B" & CATEGORIA & TENDENCIA UNEAR & CORRELAÇĀO UINEAR \\
\hline Al & MFA & NEGATIVA & B1 & ONI & POSITIVA & NEGATIVA \\
\hline A2 & MFA & NEGATIVA & B2 & NEUTRO & POSITIVA & NEGATIVA \\
\hline A3 & MFA & NEGATIVA & B3 & ENOS & POSITIVA & NEGATIVA \\
\hline A4 & MFA & NEGATIVA & B4 & EL NIÑO & NEGATIVA & POSIIIVA \\
\hline A5 & MFA & NEGATIVA & B5 & LA NIÑA & POSITIVA & NEGATIVA \\
\hline
\end{tabular}

\subsubsection{3- Variação Cíclica de Chuva Muito Fraca}

A variação cíclica anual de Chuva Muito Fraca pode ser observada na Figura 31 . É possível notar que a oscilção presente na série temporal completa de 1970 a 2009 variou entre 21 fases altas (esferas vermelhas) e 19 fases baixas (esferas azuis).

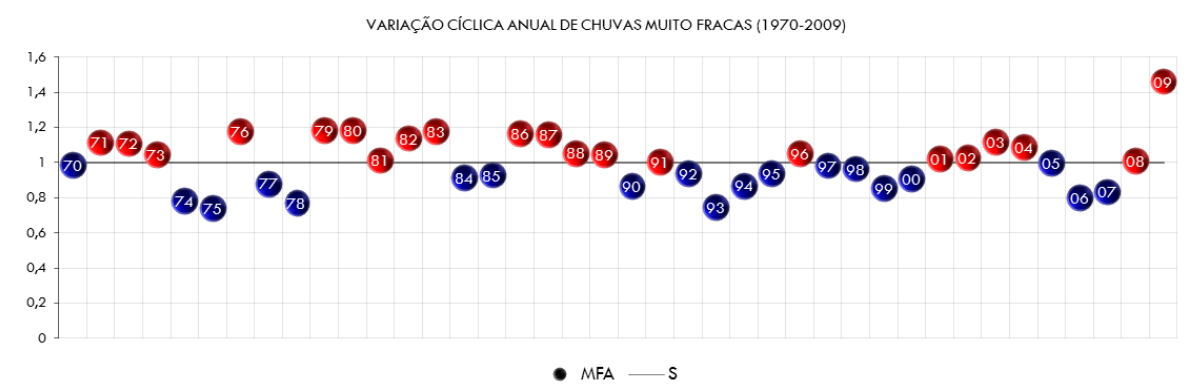

Figura 31 - Variação Cíclica Anual da Frequência de Chuva Muito Fraca entre 1970 e 2009. 


\subsubsection{4- Análise da Correlação Cíclica}

A partir dos resultados do teste de significância - t-"Student" - notamos que os resultados do cálculo de correlação linear, para as séries cíclicas, entre $\mathrm{ONI}$ e a frequência anual de Chuva Muito Fraca, nas fases, Neutra, ENOS e La Niña não foram significativos (Tabela 17). Por outro lado, observamos que o ONI e a fase de EN (Tabela 17, linhas 1 e 4) apresentaram correlações lineares significativas (Figuras 32 e 33).

Tabela 17 - Correlação Linear entre a Anomalia de ONI e da Frequência Anual de Chuva Muito Fraca entre 1970 e 2009, sem Tendência Linear (Série Cíclica).

\begin{tabular}{|c|c|c|c|c|c|}
\hline & $\mathrm{CIClO}$ "A" & & Cicio "B" & CORRELAÇĀO CICUICA & TESTE T-STUDENT \\
\hline Al & MFA & B1 & ONI & 0,265 & SIGNIFICATIVO \\
\hline A2 & MFA & B2 & NEUTRA & 0,261 & NÄO SIGNIFICATIVO \\
\hline A3 & MFA & B3 & ENOS & 0,383 & NÃO SIGNIFICATIVO \\
\hline A4 & MFA & B4 & EL NIÑ̃O & 0,745 & SIGNIFICATIVO \\
\hline A5 & MFA & B5 & LA NIÑA & 0,344 & NÃO SIGNIFICATIVO \\
\hline
\end{tabular}

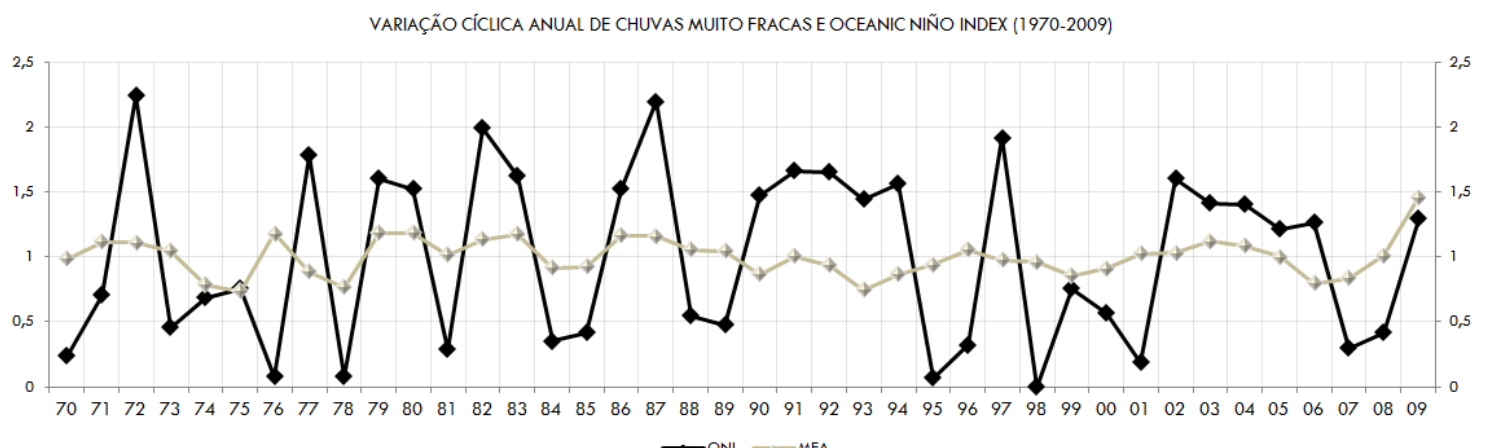

Figura 32 - Variação Cíclica Anual de Chuva Muito Fraca (Linha Branca) e do Oceanic Niño Index (Linha Preta) entre 1970 e 2009.

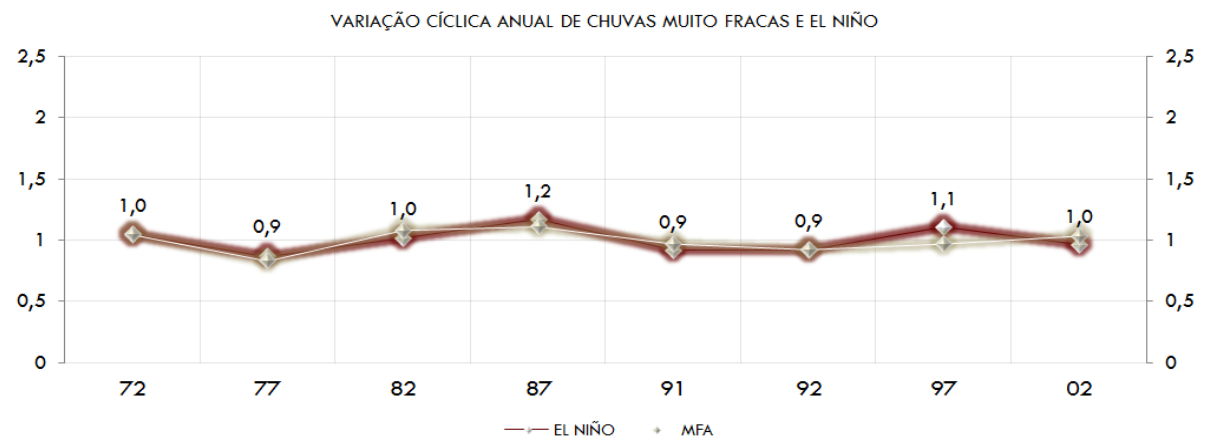

Figura 33 - Variações Cíclicas Anuais da Fase EL Niño e da Frequência de Chuva Muito Fraca, entre 1970 e 2009. 
Mesmo considernado a baixa correlação linear obtida entre a série temporal de ONI e da frequência anual de Chuva Muito Fraca, observamos, pela Figura 32 que, as anomalias positivas (negativas) de $\mathrm{ONI}$ ocorrem em períodos similares às anomalias positivas (negativas) de frequência de Chuva Muito Fraca. No entanto, notamos que a correspondência é muito mais significativa durante os períodos quentes da $\mathrm{ONI}$ do que os frios.

\subsubsection{5- Análise Específica do Ciclo de Chuva - MFA}

Os resultados de tal análise revelam as possíveis correlações existentes entre as fases altas e baixas da frequência de Chuva Muito Fraca e do ONI. Neste caso, identificamos a série específica através das fases altas $(\bar{x}>1)$ e baixas $(\bar{x}<1)$ da variação cíclica da frequência de chuva MFA. Na Figura 34 observamos um gráfico delimitado por fases (F1, F2, F3...) e, uma tabela, à direita, que identifica o tipo de fase (fase alta em vermelho e fase baixa em azul). Na tabela, nas linhas logo abaixo de cada tipo de fase estão os resultados das correlações entre as fases específicas de Chuva Muito Fraca e o índice do ONI.

A variação cíclica anual de Chuva Muito Fraca no período de 1970 a 2009 foi composta por 16 fases específicas (altas e baixas). No entanto, a partir do resultado negativo da correlação linear entre a tendência negativa de Chuva Muito Fraca e a tendência positiva da ONI, foram particularmente analisadas as fases da oscilação que possivelmente estiveram associadas a tal comportamento. Neste caso, as fases baixas estariam correlacionadas com a Chuva Muito Fraca e, as fases altas correlacionadas com o ONI. A partir dessa probabilidade foram identificadas três fases baixas, significativamente e positivamente correlacionadas, nos anos 1970, 1977, 1978, 1984 e 1985. Por outro lado, foram identificadas quatro fases altas, significativamente e positivamente correlacionadas, nos anos de 1971, 1972, 1973, 1979, 1980, 1981, 1982, 1983, 1986, 1987, 1988, 1989, 2008 e 2009. 


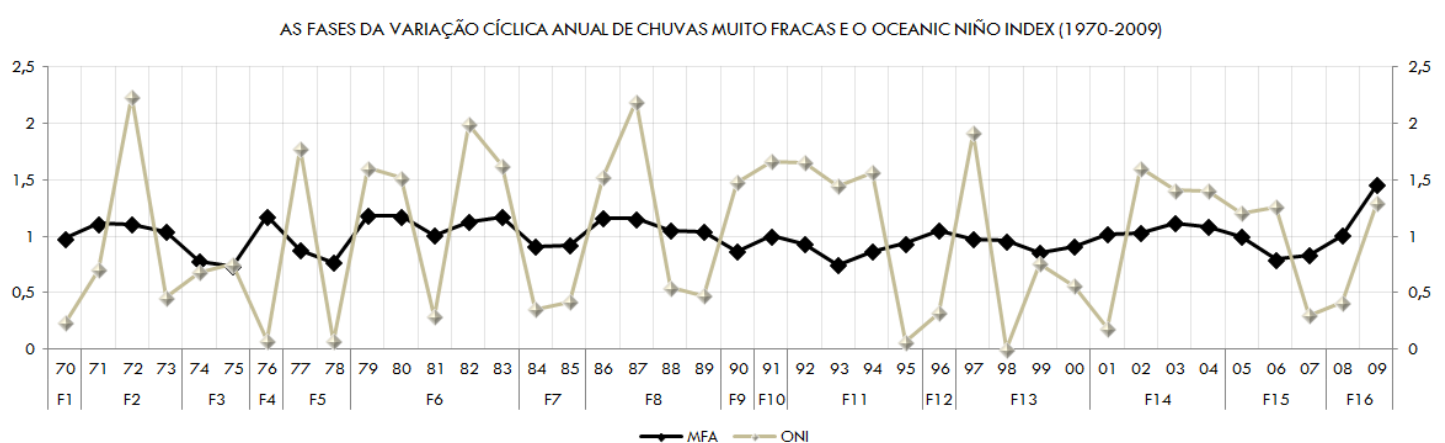

Figura 34 - Fases Específicas do Ciclo Anual de Chuva Muito Fraca. A linha Branca corresponde à variação cíclica do ONI e a linha Preta de Chuva MFA, para o Período de 1970-2009.

\subsubsection{6- Hipótese Inicial e Conclusão Final - MFA I}

A conclusão final para análise anual de Chuva Muito Fraca foi baseada a partir dos resultados envolvendo os três procedimentos aplicados. De modo geral, durante este período, os resultados indicam que o aquecimento observado na região Niño3.4 não coincidiu com o aumento na frequência de Chuva Muito Fraca, com exceção da fase El Niño. Nesta fase foi possível observar que o resfriamento na TSM coincidiu com a diminuição na frequência deste tipo de chuva. A respeito dos resultados das correlações cíclicas foi possível notar que o ciclo da ONI e da fase El Niño estiveram significativamente correlacionados. Ou seja, ocorre a explicação da variância de Chuva Muito Fraca em função da ONI e do El Niño.

Por último, é possível sugerir que os reflexos do resultado do ajuste linear possam ter ocorrido pontualmente em fases e anos específicos. Desta forma, para os quatros casos de correlação linear negativa (ONI, Fase Neutra, ENOS e La Niña) é provável que as fases altas quando significativamente e positivamente correlacionados estivessem associadas a tais ajustes lineares. Por outro lado, é também possível sugerir que as fases baixas quando significativamente e positivamente correlacionados estivessem associadas as Chuva Muito Fraca. Nesta situação, o resultado da significância da correlação cíclica, especificamente, para a ONI reforçaria a justificativa de ter ocorrido a tal possibilidade. A respeito da exceção observada, para o caso de correlação envolvendo a fase El Niño observamos que ocorreu concomitantemente uma correlação linear e cíclica. Em função desse resultado é 
possível concluir para este caso que muito provavelmente ocorreu um enfraquecimento durante a variação cíclica de Chuva Muito Fraca caracterizado pela diminuição de suas respectivas amplitudes, ao longo da série, em função do resfriamento observado na TSM, na região Niño3.4. Neste caso, é possível identificar consonância com a expectativa de Grimm et al (1999), ou seja, nota-se a influência de padrões de macroescala alterando a frequência de circulação, que neste caso diminui suprimindo a precipitação. Desta forma identificamos na Figura 35 que as fases de baixa $(\bar{x}<1)$, como a F2 (1977) e a F4 (1991, 1992 e 1997) foram os períodos mais prováveis de terem ocorrido tal reflexo em função do nível de correlação específica (observe a fase F2 e F4, da Figura 35, em azul e, posteriormente observe na tabela a direita, o nível de correlação específica).

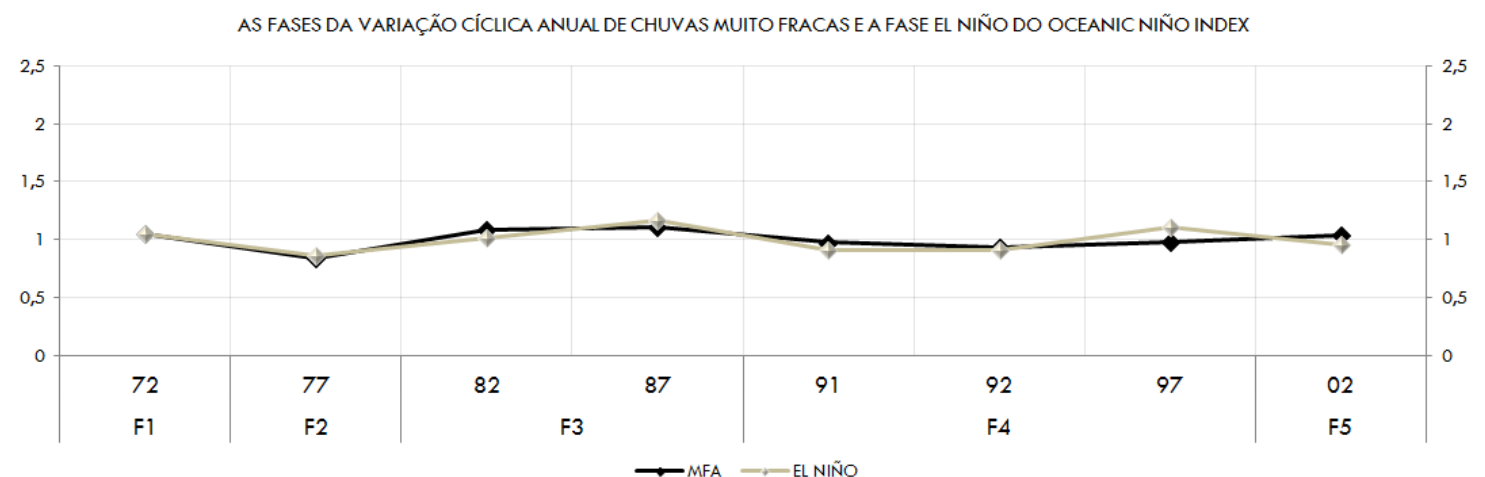

Figura 35 - Fases Específicas do Ciclo Anual de Chuva MFA durante a Série Temporal de EN. A linha branca corresponde à variação cíclica do EN e a linha cinza de Chuva MFA.

A Tabela 18 apresenta uma síntese dos resultados finais da correlação por fases específicas entre a frequência de Chuva Muito Fraca e o ONI, entre 1970 e 2009.

Tabela 18 - Correlação Anual em Fases Específicas. A Coluna "A" indica o Ajuste Linear da Chuva MFA nas Séries Temporais "B" correspondente o ONI e suas Fases. A Última Coluna aponta os Possíveis Anos que estiveram Correlacionados com o Resultado da Correlação Linear do Ajuste "A" e "B".

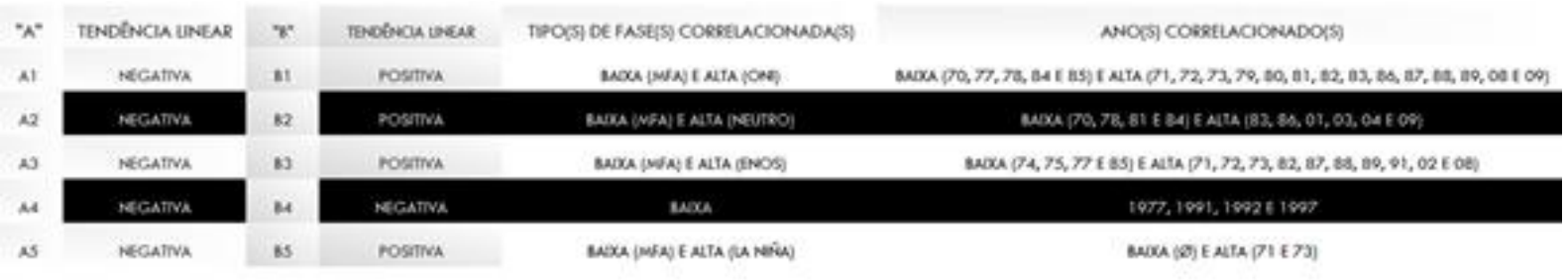




\subsection{2- Análise Trimestral}

A segunda análise envolve a relação trimestral entre a Chuva Muito Fraca e o Oceanic Niño Index. Nestas análises estão incluídas as séries temporais, definidas como relativas, ou seja, períodos específicos da série integral, classificadas como ENOS, fase Neutra, El Niño e La Niña. Trata-se de uma análise individualizada, envolvendo os três procedimentos elementares adotados, que foram aplicados para as quatro estações climáticas do ano, ou seja, verão, outono, inverno e primavera.

\subsubsection{1 - Frequência Trimestral de Chuva Muito Fraca}

Os resultados das frequências trimestrais de Chuva Muito Fraca $\left(0,1\right.$ a $\left.0,25 \mathrm{~mm} \mathrm{~h}^{-1}\right)$ podem ser observados a partir da Figura 36. No outono e inverno, a tendência linear de chuva MFA é negativa durante o período de 1970 a 2009 (Figuras 36 e 37). Por outro lado, a tendência linear deste tipo de chuva para o verão e primavera pode ser considerada como sendo nulas ou estáveis.

FREQUÊNCIA TRIMESTRAL DE CHUVAS MUITO FRACAS - VERÃO (1970-2009)

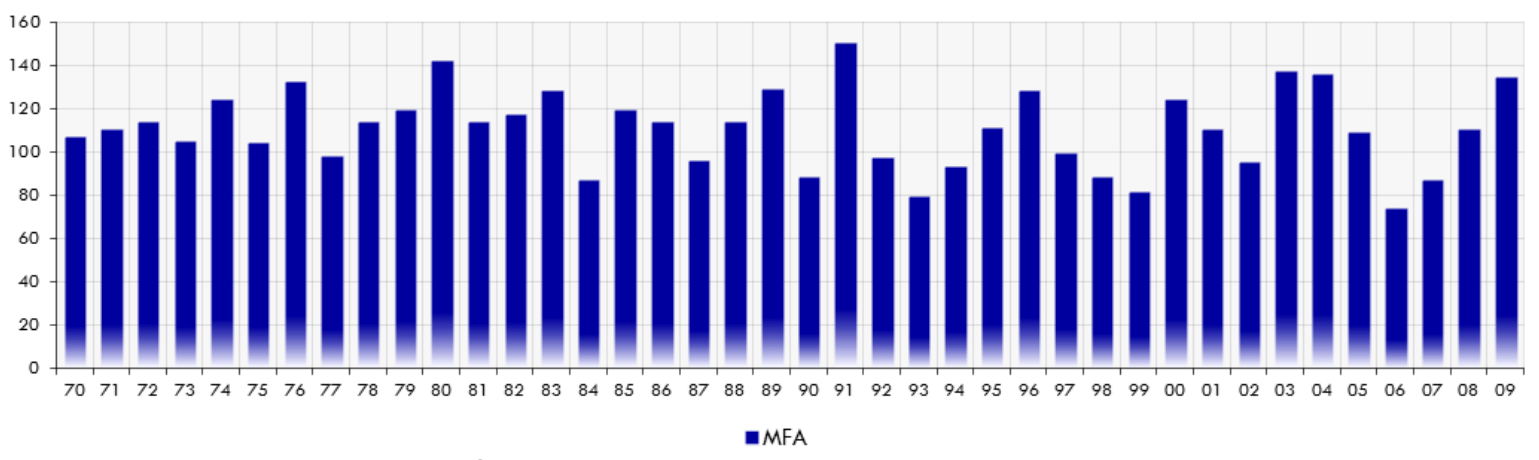

FREQUÊNCIA TRIMESTRAL DE CHUVAS MUITO FRACAS - OUTONO (1970-2009)

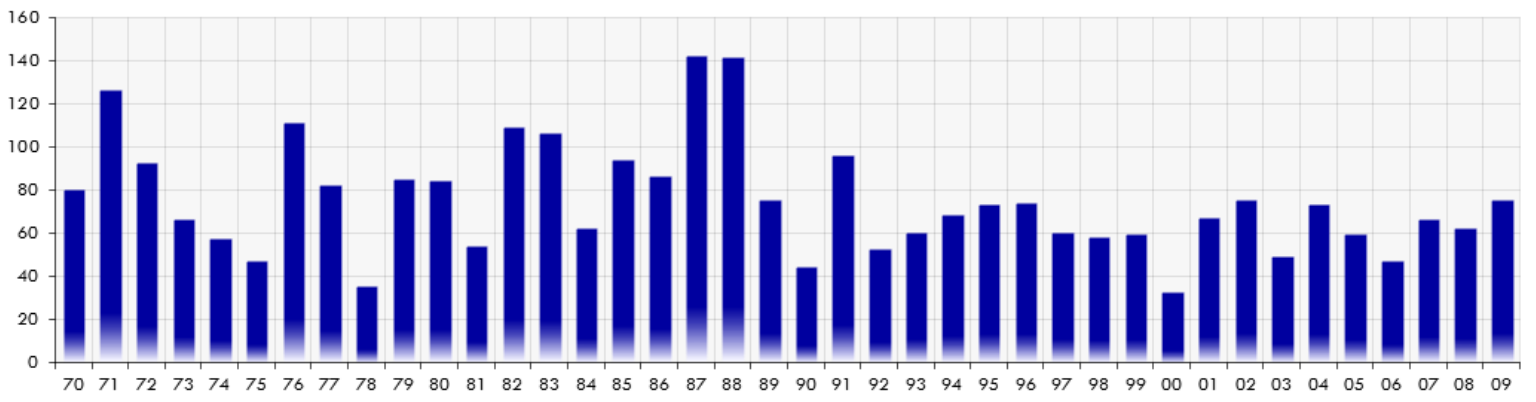

-MFA 
FREQUÊNCIA TRIMESTRAL DE CHUVAS MUITO FRACAS - INVERNO (1970-2009)

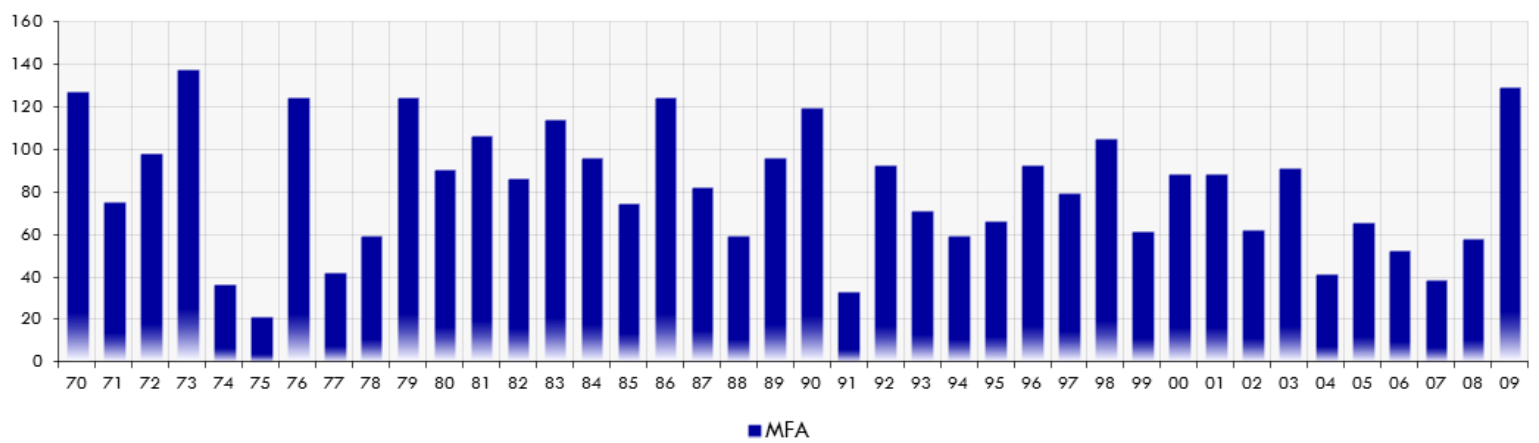

FREQUÊNCIA TRIMESTRAL DE CHUVAS MUITO FRACAS -PRIMAVERA (1970-2009)

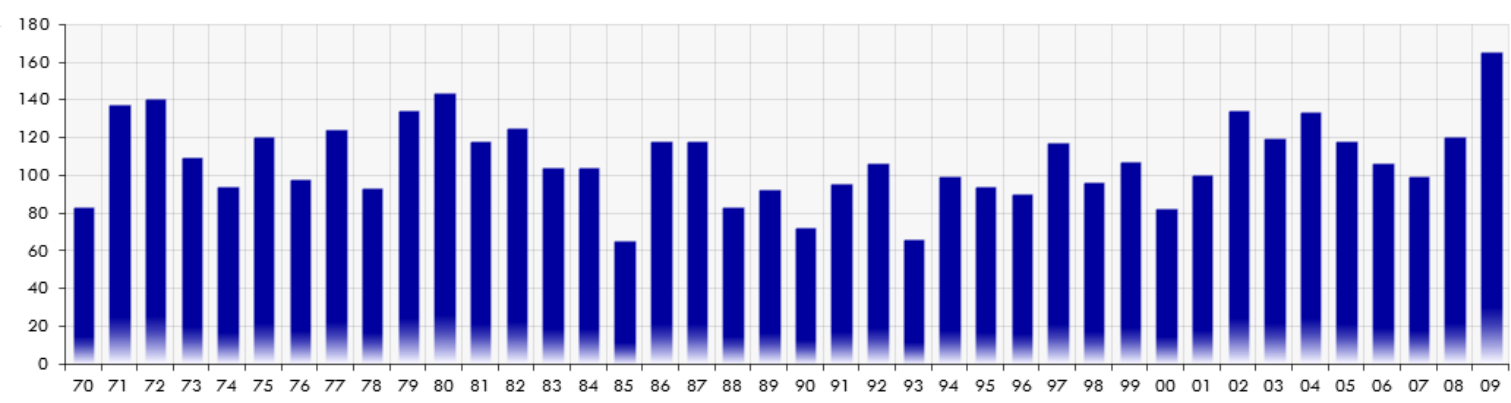

-MFA

Figura 36 - Frequência Trimestral de Chuva Muito Fraca na Estação do IAG-USP durante o Verão, Outono, Inverno e Primavera para o Período de 1970 a 2009.

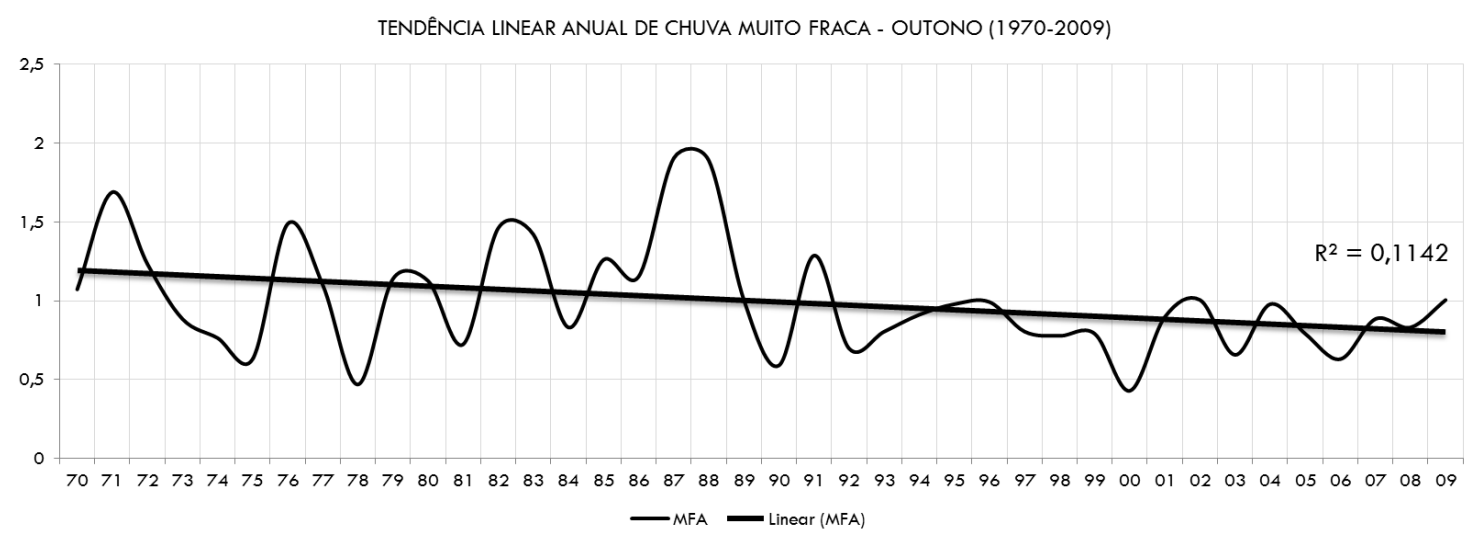

TENDÊNCIA LINEAR ANUAL DE CHUVA MUITO FRACA - INVERNO (1970-2009)

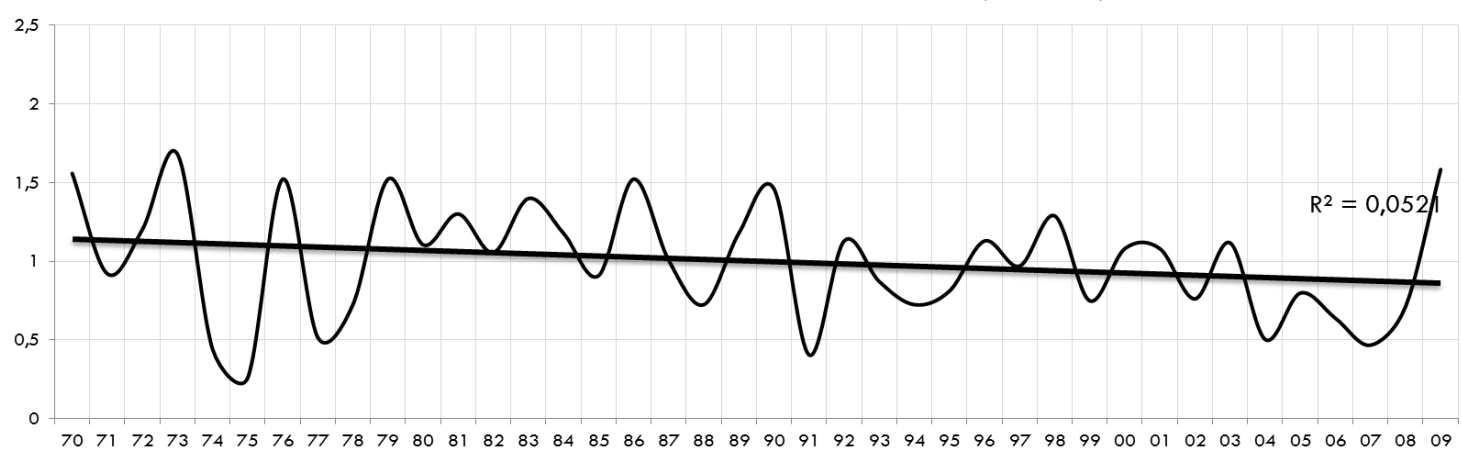

—MFA - Linear (MFA)

Figura 37 - Ajuste Linear Trimestral de Chuva Muito Fraca para as Estações de Outono e Inverno, no Período de 1970 a 2009. 
Todas as séries temporais do ONI apresentaram tendência linear negativa, neste caso incluímos os ajustes lineares mais significativos nas Figuras 38-41. Nestas figuras observamos que durante a fase neutra, os ajustes negativos foram encontrados no verão, outono e inverno (Figura 38). Nas demais fases, ENOS, El Niño e La Niña, os ajustes negativos foram encontrados no outono e inverno (Figuras 39-41).
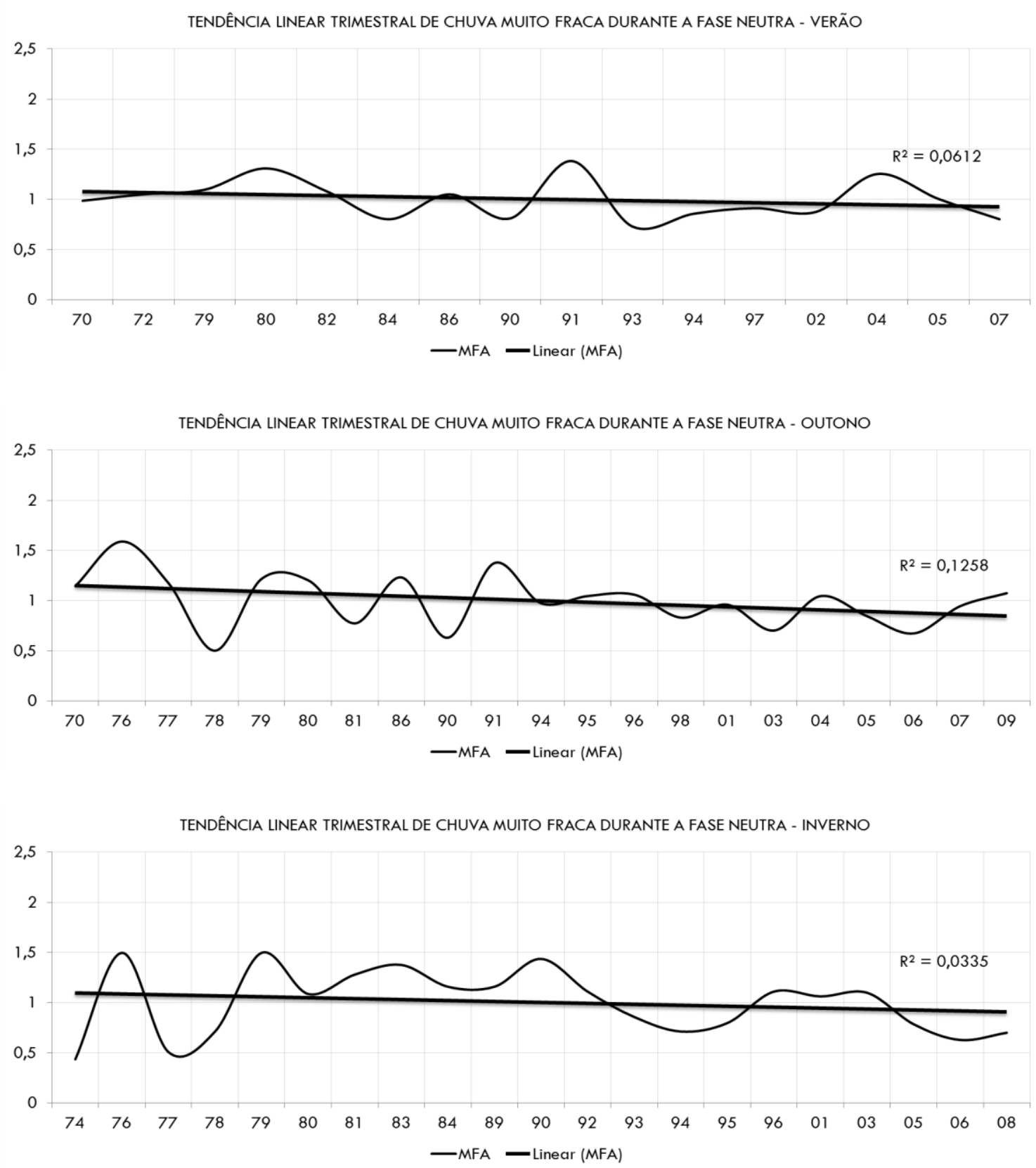

Figura 38 - Ajuste Linear Trimestral de Chuva Muito Fraca para as Estações de Verão, Outono e Inverno durante a fase Neutra. 

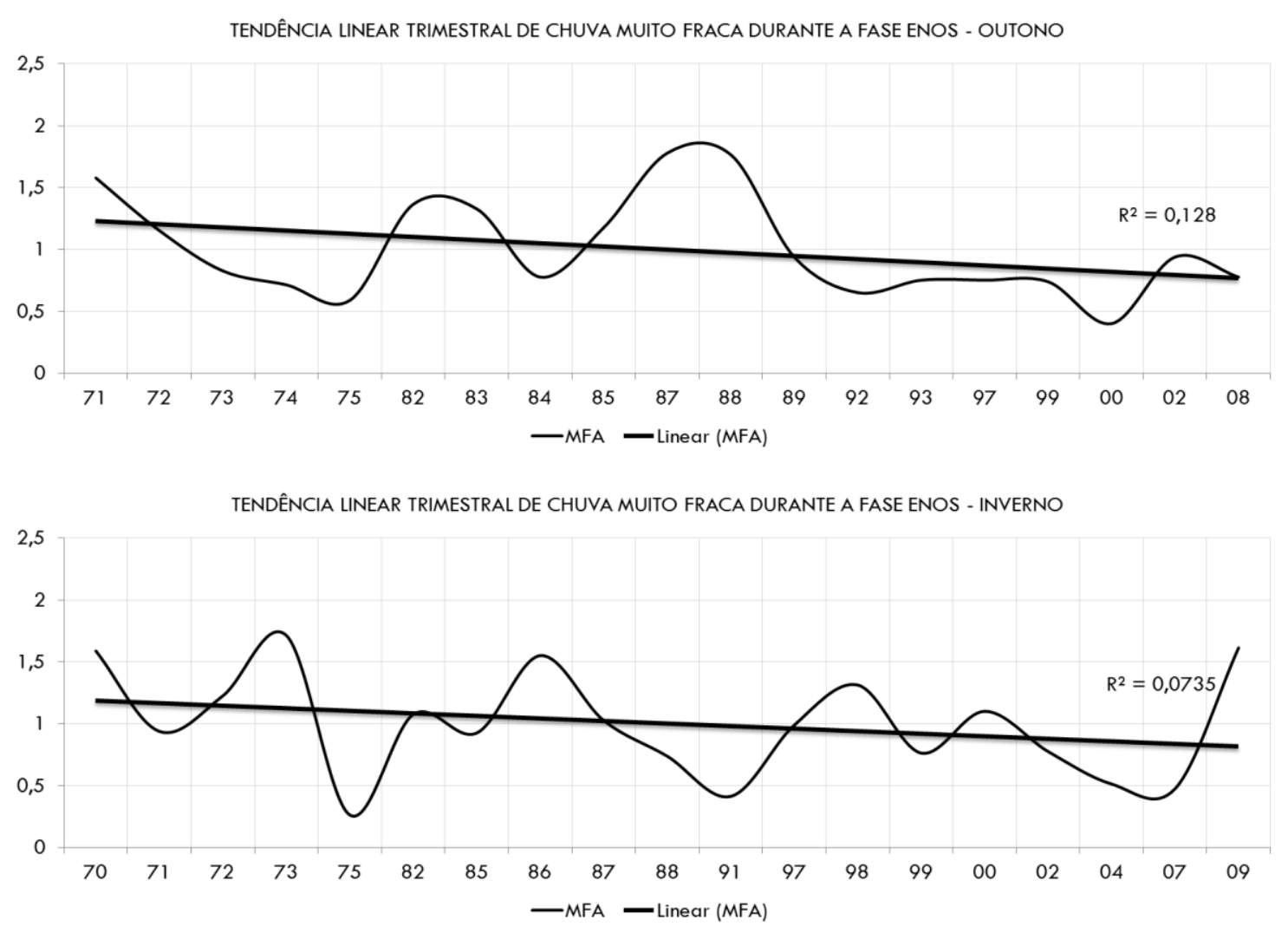

Figura 39 - Ajuste Linear Trimestral de Chuva Muito Fraca para as Estações de Outono e Inverno durante a fase ENOS.
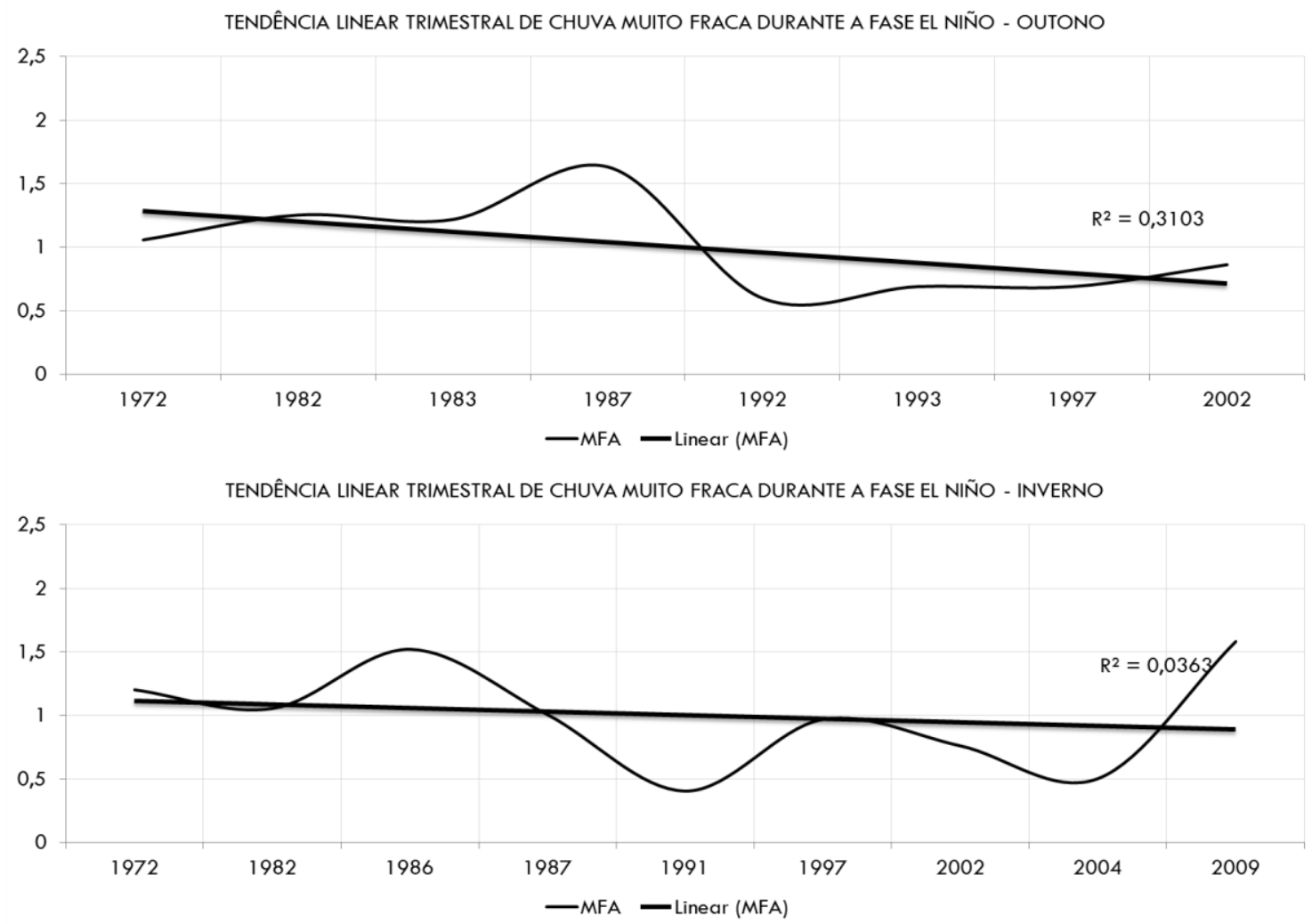

Figura 40 - Ajuste Linear Trimestral de Chuva Muito Fraca para as Estações de Outono e Inverno durante a fase El Niño. 

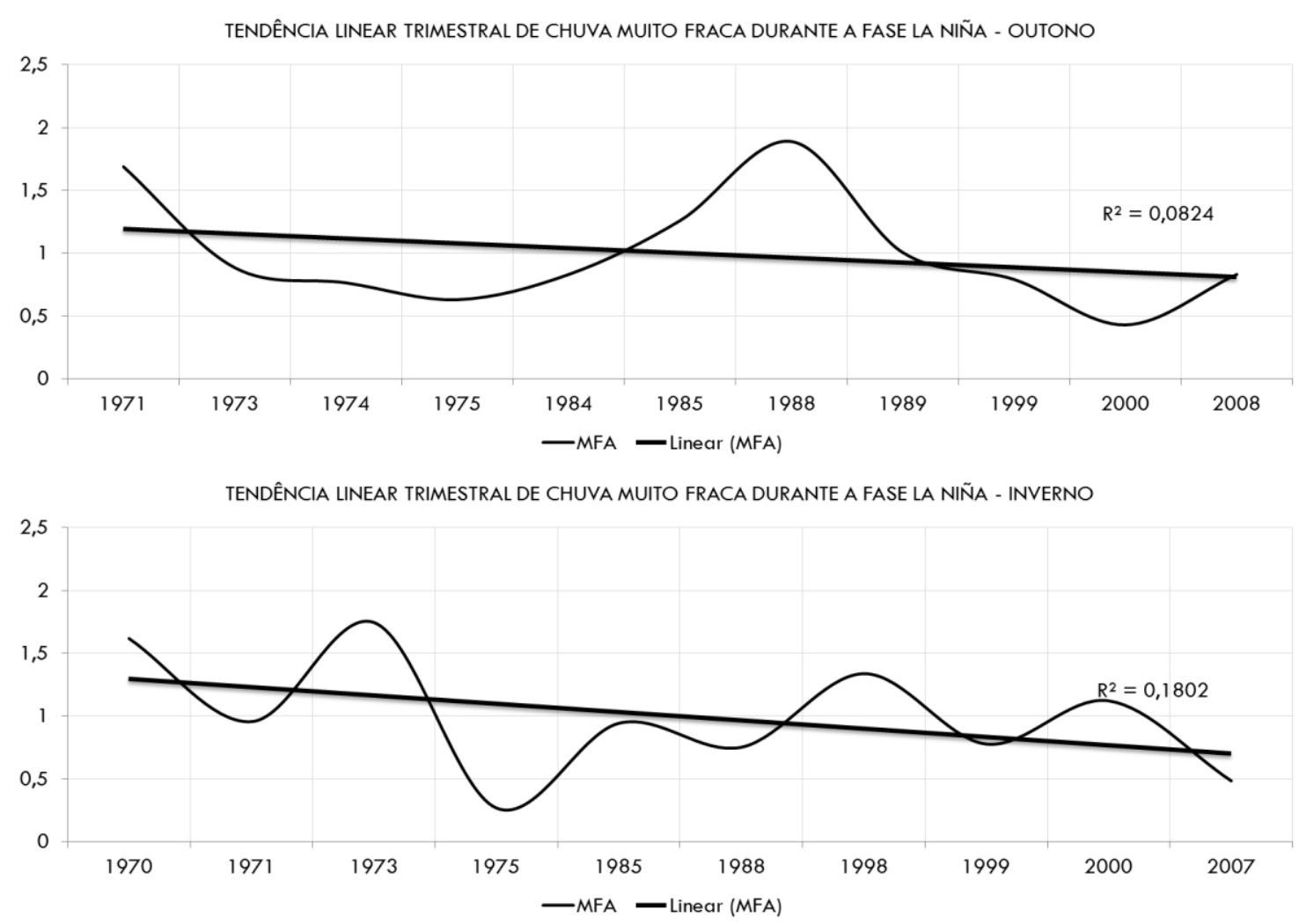

Figura 41 - Ajuste Linear Trimestral de Chuva Muito Fraca para as Estações de Outono e Inverno durante a fase La Niña.

Os resultados trimestrais por fases também coincidem com os resultados identificados no trabalho de Cabral (2002). Ou seja, mesmo em séries temporais específicas o padrão de diminuição da frequência de chuvas mais leves se manteve. De modo geral, a Tabela 19 indica que na maioria dos casos envolvendo correlações lineares entre a chuva MFA e ONI foram positivas $(+)$. No total foram 13 correlações positivas que apresentaram haver uma correlação estatística, em todas as estações climáticas do ano, entre as chuvas MFA e a série temporal integral (ONI) e as séries temporais relativas (neutra, ENOS, EN e LN). As correlações lineares ocorreram com mais frequência durante o verão e a primavera.

Tabela 19 - Correlação Linear Trimestral entre a Tendência Linear Trimestral de Chuva Muito Fraca e a Tendência Linear Trimestral do ONI, incluindo as Fases, Neutra, ENOS, EN e LN.

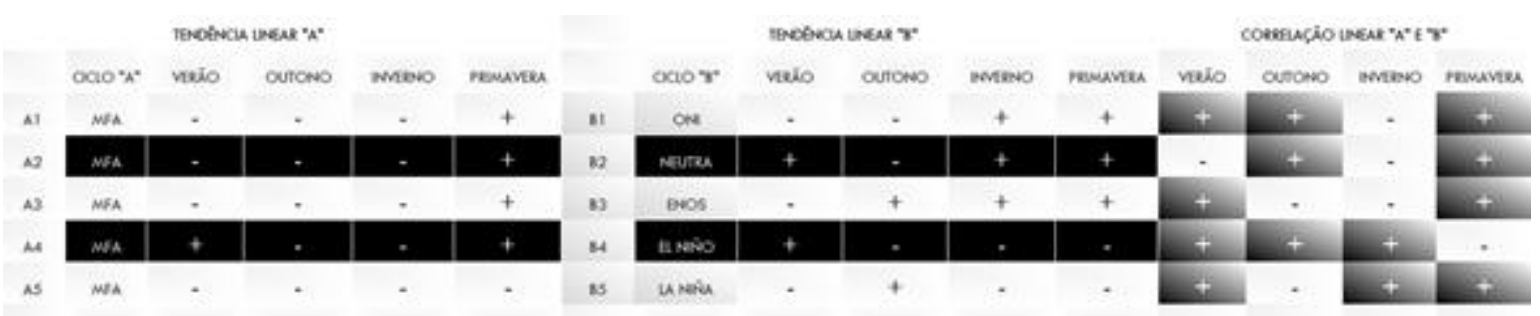


A frequência da chuva MFA, durante o verão, diminui em todos os casos, exceto para a série temporal constituída por eventos de EN. Durante o inverno e outono, a frequência da chuva MFA diminui em todos os casos. Para a estação da primavera, a frequência da chuva MFA aumenta, exceto nos períodos de La Niña, em que observamos tendência negativa da frequência de chuva MFA (Figuras $38-41$ e Tabela 19). Contudo, considerando todas as estações climáticas, no período de 1970 a 2009, verificamos que a frequência de chuva MFA diminui no decorrer do tempo, exceto na primavera onde a tendência linear positiva não é significativa (Figura 37 e Tabela 19).

\subsubsection{2- Variação Cíclica Trimestral de Chuva - MFA}

A variação das anomalias da frequência de chuva MFA para o período de 1970 a 2009, para as quatro estações do ano está ilustrada na Figura 42.

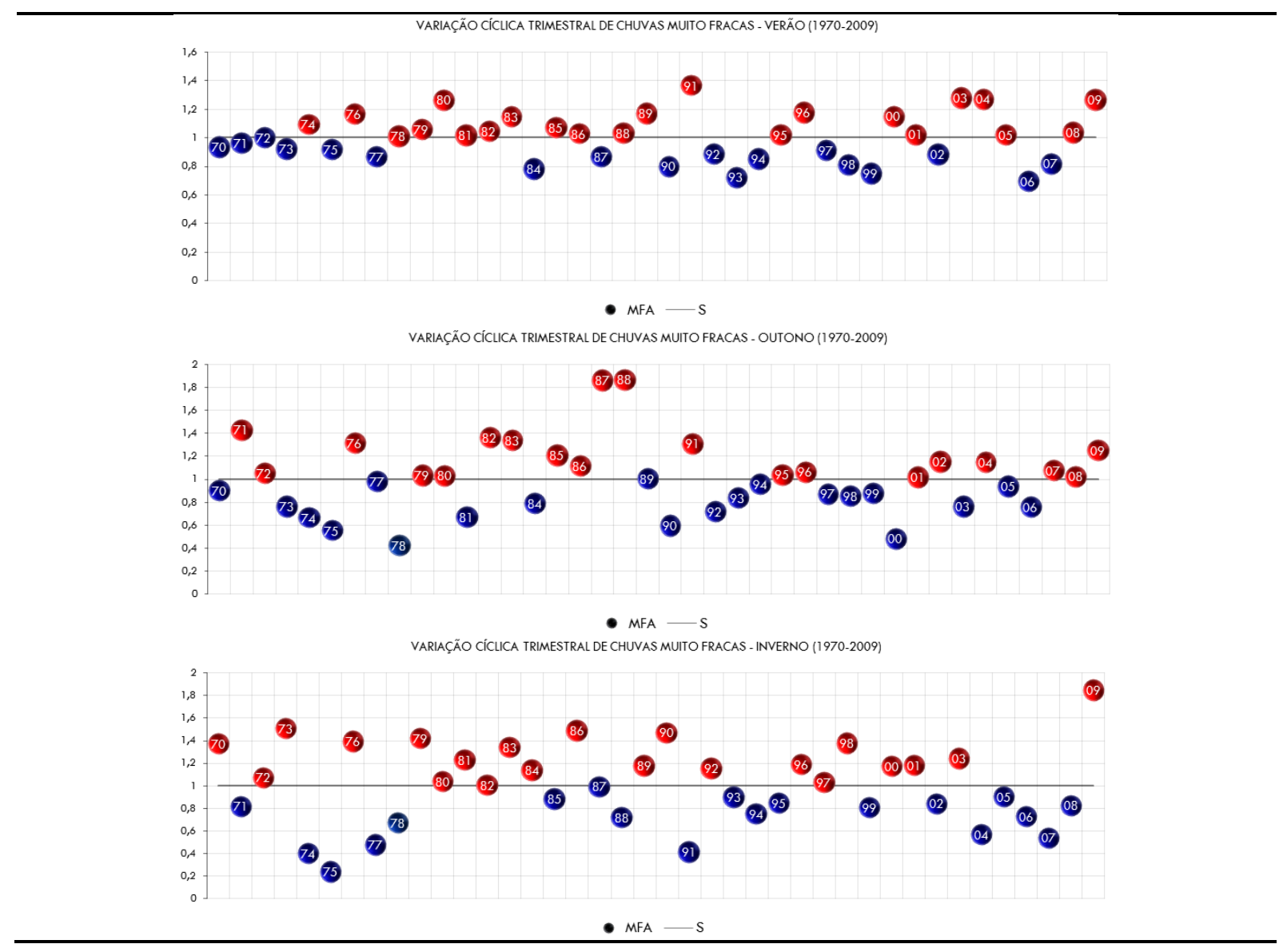




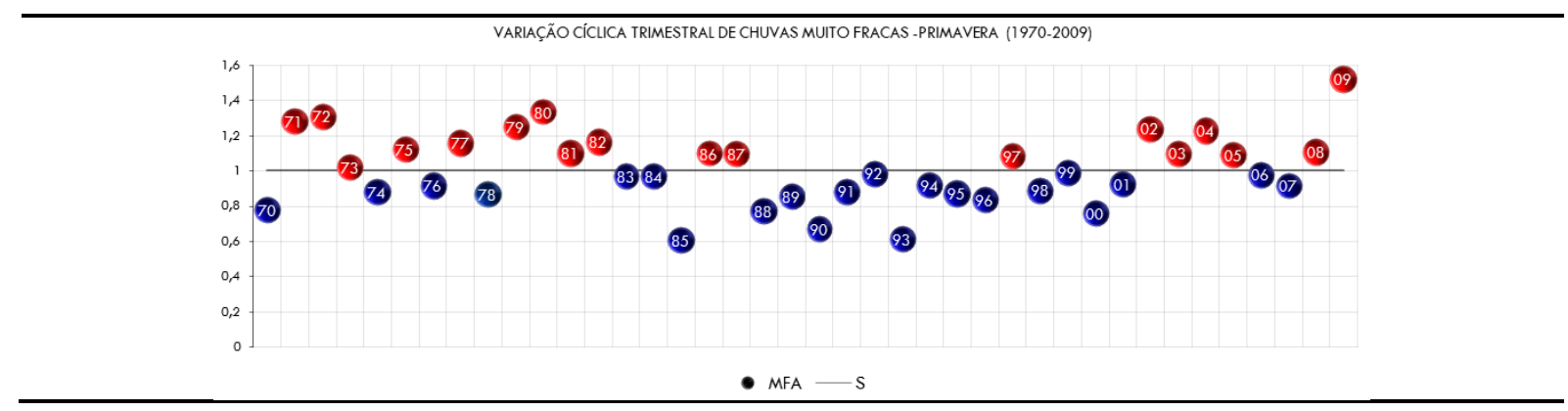

Figura 42 - Variação Cíclica Trimestral de Chuva Muito Fraca, entre 1970 e 2009.

\subsubsection{3- Análise da Correlação Cíclica Trimestral}

De forma geral, separando a série temporal em estações do ano, observamos que a correlação linear entre as séries de ONI e frequência de chuva MFA é positiva e significativa para o outono $(r=0,23)$, Figura 43 e, na primavera $(r=0,36)$, Figura 44 . Ou seja, a frequência de chuva MFA pode estar associada fisicamente aos valores de ONI durante o outono e primavera. A separação das séries temporais em eventos distintos quanto à TSM na região do Niño3.4 permitiu verificar que durante a primavera, nos casos de eventos neutros e ENOS, a correlação linear entre estas duas variáveis continua significativa, embora negativa durante a fase neutra $(r=-0,57)$, Figura 45 e, positiva durante a fase de de ENOS $(r=0,49)$, Figura 46. Todos os demais resultados podem ser observados a partir da Tabela 20.

Tabela 20 - Correlação Cíclica entre a Frequência de Chuva Muito Fraca observada na Estação do IAG e os Valores de ONI para Cada Estação do Ano e, para Cada Condição de Anomalia na Região de Niño3.4 (Eventos Neutros, ENOS, EN e LN).

\begin{tabular}{|c|c|c|c|c|c|c|c|}
\hline VERĀO & OUTONO & INVERNO & PRIMAVERA & VERĀo & OUTONO & INVERNO & PRIMAVERA \\
\hline Al & A1 & AT & A) & one & one & one & ore \\
\hline$\Delta 2$ & $\Delta 2$ & $\Delta 2$ & $\Delta 2$ & NEUTRO & NAUTRO & NeUTRO & NEUTRO \\
\hline A & A3 & as & A & Evos & evos & evos & evos: \\
\hline AA & 24 & A4 & As & a néso & a neiso & E T TESO & E Nếo \\
\hline \multirow[t]{2}{*}{ AS } & As & As & As & la neia & LA Neí & La NeIIA & LA ReÉLA \\
\hline & \multicolumn{2}{|c|}{ CORRELAÇÃO CICLICA } & & \multicolumn{4}{|c|}{ TESTE T - STUDENT } \\
\hline VERÃO & OUTONO & INVERNO & PrLMAVErea & VERÃO & OUTONO & INVERNO & PRIMAVERA \\
\hline 0,007 & $0,2 n$ & Q.01 & 0,35 & MÜo sigrencativo & sonericativo & NÜo socencatrvo & sonercativo \\
\hline 0,19 & 0,22 & $-0,01$ & $-0,50$ & Niso socincativo & Nḯ sockencativo & Nǘ socencatro & sonencativo \\
\hline$-0,13$ & 0,25 & $0, \infty$ & 0,49 & NÄO sarencativo & Mio sorencativo & Nüo sonencatrvo & Sonencatmo \\
\hline$-0,22$ & 0,14 & $-0,00$ & 0,21 & NÄO SUCNEACATIVO & Mä́ Sognencativo & NÄO SOGEACATIVO & NÄO SOCHEACATIVO \\
\hline 0,17 & $-0,11$ & $-0,15$ & $-0,00$ & NÄO STCTEACATIVO & NÄO SEGTEACATVO & NäO SCOEFCATVO & NÄO SOCNEACATNO \\
\hline
\end{tabular}


99

VARIAÇÃO CÍCLICA TRIMESTRAL DE CHUVAS MUITO FRACAS E OCEANIC NIÑO INDEX - OUTONO (1970-2009)

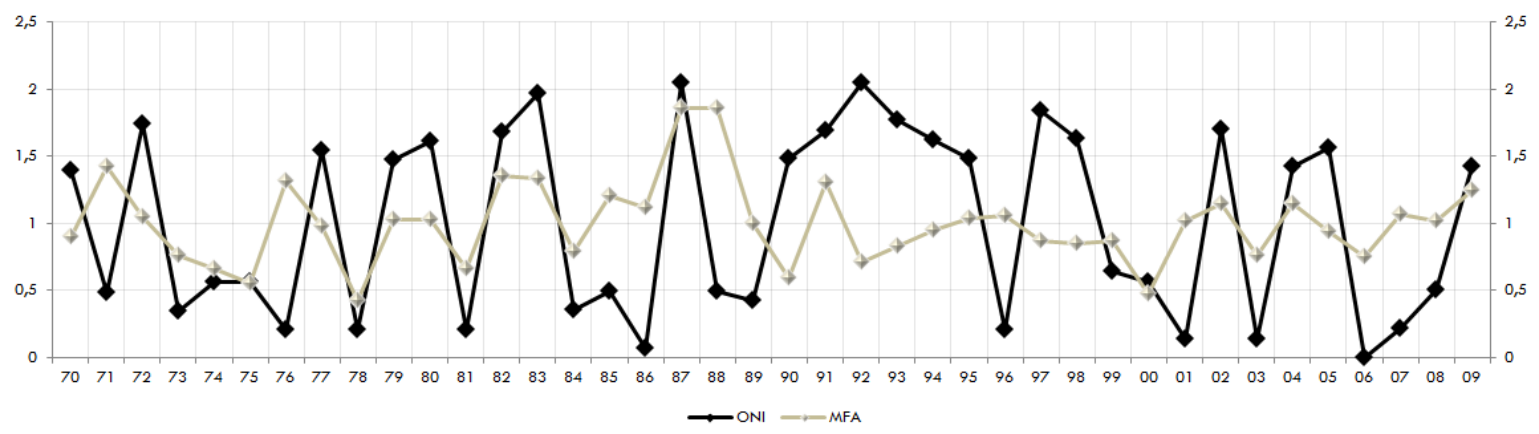

Figura 43 - Variação Cíclica de Chuva MFA, no Outono, entre 1970 e 2009.

VARIAÇÃO CíCLICA TRIMESTRAL DE CHUVAS MUITO FRACAS E OCEANIC NIÑO INDEX - PRIMAVERA (1970-2009)

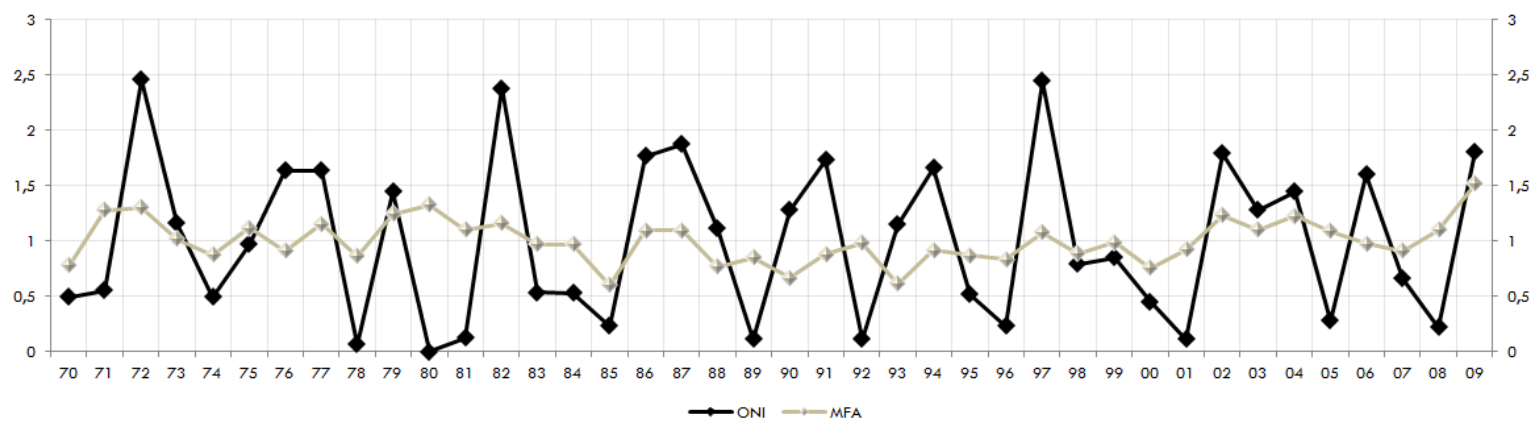

Figura 44 - Variação Cíclica de Chuva MFA, na Primavera, entre 1970 e 2009.

VARIAÇÃO CÍCLICA TRIMESTRAL DE CHUVAS MUITO FRACAS E A FASE NEUTRA DO OCEANIC NIÑO INDEX - PRIMAVERA

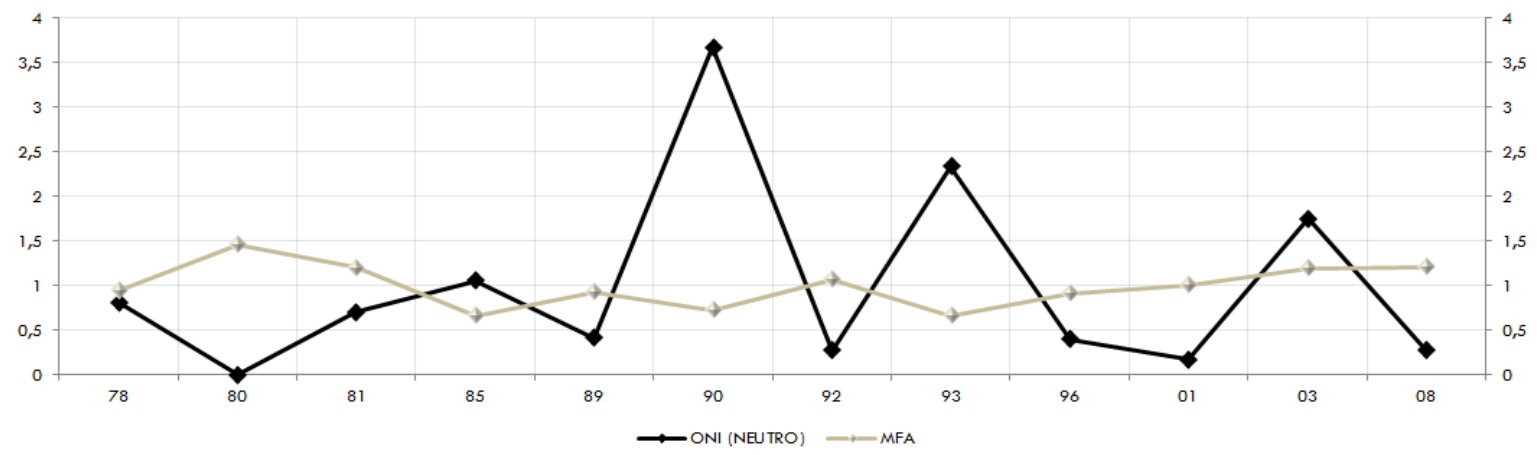

Figura 45 - Variação Cíclica de Chuva MFA, na Primavera, durante a Fase Neutra.

VARIAÇÃO CÍCLICA TRIMESTRAL DE CHUVAS MUITO FRACAS E ENOS - PRIMAVERA

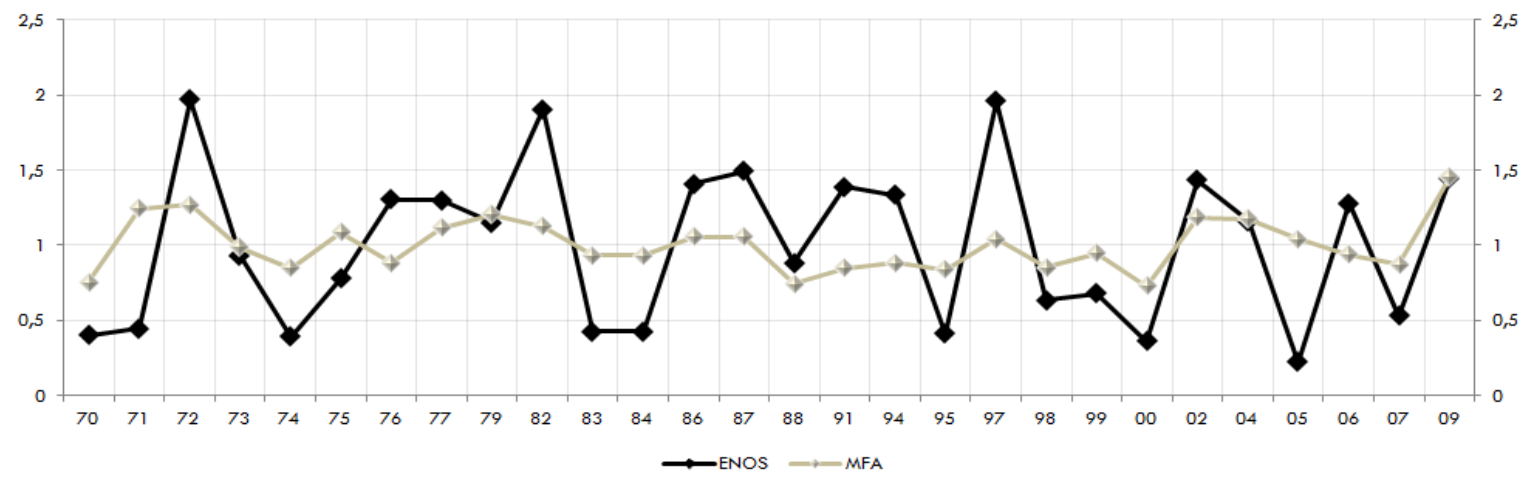

Figura 46 - Variação Cíclica de Chuva MFA, na Primavera, durante a Fase ENOS. 


\subsubsection{4- Análise Específica das Fases Trimestrais}

Os resultados de tal análise revelam as possíveis correlações existentes entre as fases altas e baixas da frequência de Chuva Muito Fraca e do ONI. Neste caso, identificamos a série específica através das fases altas $(\bar{x}>1)$ e baixas $(\bar{x}<1)$ da variação cíclica da frequência trimestral de chuva MFA. A variação cíclica de chuva MFA no período de 1970 a 2009 durante a estação de verão foi composta por 20 fases específicas. A partir do resultado positivo da correlação linear entre a tendência negativa de chuva MFA e a tendência negativa do ONI, procuramos identificar as fases da oscilação que possivelmente estiveram associadas a tal comportamento. Neste caso, deduzimos que somente as fases baixas estariam correlacionadas (Figura 47). Em função dessa probabilidade, identificamos nos anos $75,84,92,93,94,06$ e 07 as fases baixas que estariam significativamente e positivamente correlacionadas com a correlação positiva entre a chuva MFA e o ONI (Tabela 21). A variação cíclica de chuva MFA no período de 1970 a 2009 durante a estação de outono foi composta por 20 fases específicas. A partir do resultado positivo da correlação linear entre a tendência negativa de chuva MFA e a tendência negativa do ONI, procuramos identificar as fases da oscilação que possivelmente estiveram associadas a tal comportamento. Neste caso, deduzimos que somente as fases baixas estariam correlacionadas (Figura 47). Em função dessa probabilidade, identificamos nos anos $97,78,81,84,97,98,99,00,03,05$ e 06 as fases baixas que estariam significativamente e positivamente correlacionadas com a correlação positiva entre a chuva MFA e o ONI (Tabela 21). A variação cíclica de chuva MFA no período de 1970 a 2009 durante a estação de inverno foi composta por 21 fases específicas. A partir do resultado negativo da correlação linear entre a tendência negativa de chuva MFA e a tendência positiva da ONI, procuramos identificar as fases da oscilação que possivelmente estiveram associadas a tal comportamento. Neste caso, as fases baixas estariam correlacionadas com a chuva MFA e, as fases altas correlacionadas com $\circ$ ONI (Figura 47). Em função dessa probabilidade, identificamos nos anos 71, 85, 87, 88 e 99 as 
fases baixas que estariam significativamente e positivamente correlacionadas com a chuva MFA. Por outro lado, identificamos nos anos $76,86,89,90,03$ e 09 as fases altas que estariam significativamente e positivamente correlacionadas com o ONI (Tabela 21). A variação cíclica de chuva MFA no período de 1970 a 2009 durante a estação de primavera foi composta por 16 fases específicas. A partir do resultado positivo da correlação linear entre a tendência positiva de chuva MFA e a tendência positiva do ONI, foram identificadas as fases da oscilação que possivelmente estiveram associadas a tal comportamento. Neste caso, deduzimos que somente as fases altas estariam correlacionadas (Figura 47). Em função dessa probabilidade, identificamos nos anos $77,97,02,03,04,05,08$ e 09 as fases altas que estariam significativamente e positivamente correlacionadas com a correlação positiva entre a chuva MFA e o ONI (Tabela 21).
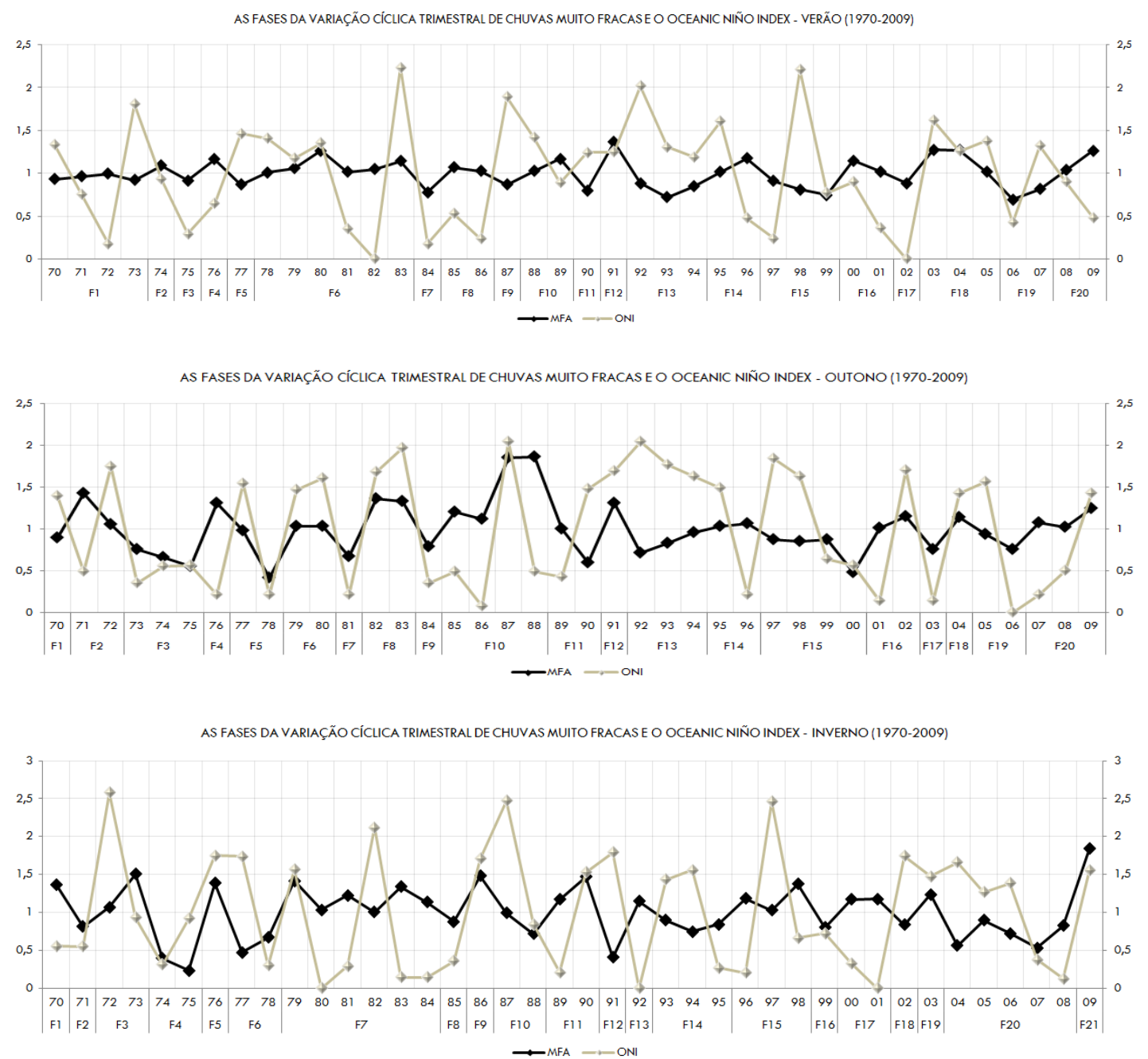


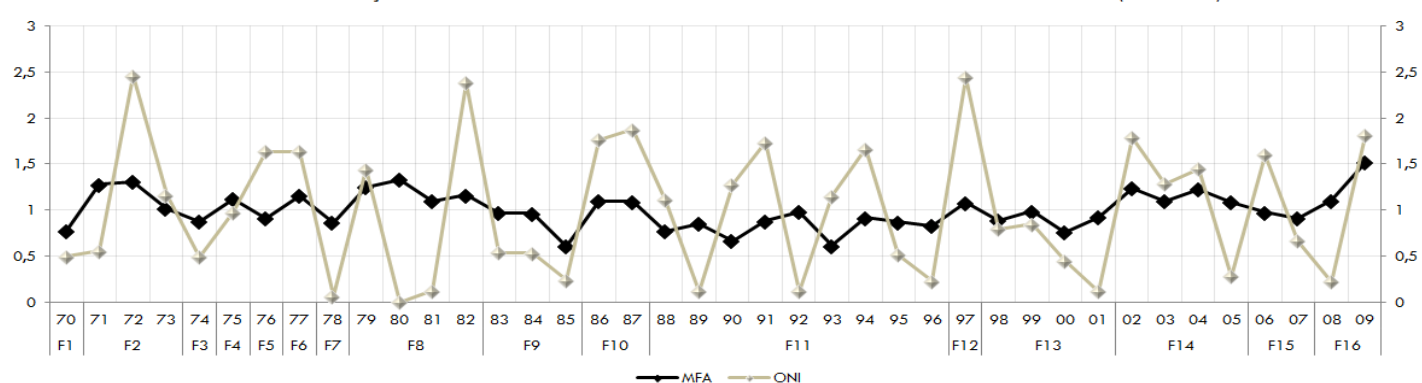

Figura 47 - Fases Específicas do Ciclo Trimestral de Chuva Muito Fraca, Verão, Outono, Inverno e Primavera. A linha Branca corresponde à variação cíclica do ONI e a linha Preta de Chuva MFA, para o Período de 1970-2009.

Tabela 21 - Correlação Linear entre a Frequência de Chuva Muito Fraca observada na Estação do IAG e os Valores de ONI para Cada Estação do Ano e, para Cada Condição de Anomalia na Região de Niño3.4 (Eventos Neutros, ENOS, EN e LN). "A" representa as Séries Temporais de Chuva MFA relativa às Séries Temporais do ONI "B". Assim, B1 (ONI), B2 (Neutro), B3 (ENOS), B4 (EN) e B5 (LN). Correlação "A" são os Tipos Fases Correlacionadas com a Chuva MFA e Correlação "B" são os Tipos Fases Correlacionadas com o ONI.

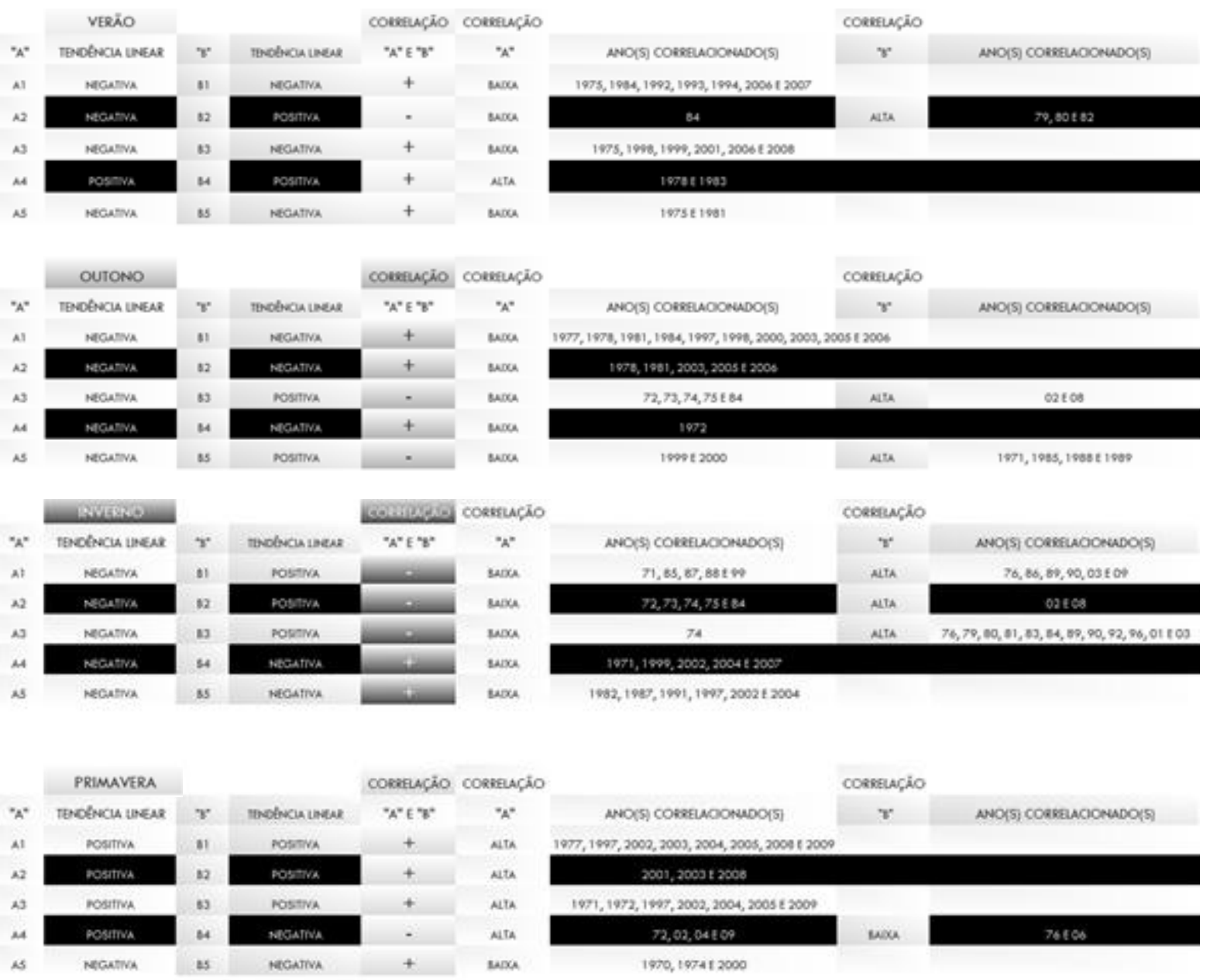




\subsubsection{5- A Hipótese Inicial e a Conclusão Final - MFA II}

A conclusão final para análise trimestral de Chuva Muito Fraca parte das distintas correlações identificadas, para cada estação climática, envolvendo o ajuste linear dos índices do ONI na região Niño3.4 e a frequência de chuva MFA. De modo geral, no verão e no outono, observamos que o ajuste linear negativo do ONI coincidiu positivamente com o ajuste negativo de chuva MFA. O mesmo ocorreu durante a primavera, no entanto, neste período a correlação positiva ocorreu em função dos ajustes lineares positivos do ONI e da chuva MFA. A exceção ocorreu durante o inverno, onde ocorreu correlação negativa em função do ajuste linear positivo da ONI e do ajuste linear negativo da chuva MFA. A Tabela 21 apresenta os resultados das demais correlações realizadas para as séries temporais do ONI em cada estação climática do ano. Após identificarmos as respectivas correlações lineares trimestrais entre a chuva MFA e o ONI, analisamos os resultados das correlações cíclicas trimestrais. Neste caso, encontramos apenas quatro correlações cíclicas significativas de acordo com a Tabela 20. A primeira e segunda correlação significativa e positiva foi identificada no outono e na primavera, durante a série temporal integral do ONI. A terceira correlação significativa foi negativa, identificada na primavera, durante a fase neutra. A quarta correlação significativa e positiva foi identificada na primavera, durante a fase ENOS.

A partir da combinação dos resultados observados durante o outono relativo à identificação de correlação positiva envolvendo ajustes negativos e a identificação de uma significativa de correlação cíclica, analisamos por dedução e correlação que seja muito provável que tenha ocorrido um enfraquecimento das variações cíclicas de chuva MFA em função da diminuição das amplitudes dos seus ciclos ao longo do período de 1970 a 2009. Neste caso, é possível identificar consonância com a expectativa de Grimm et al (1999), ou seja, nota-se a influência de padrões de macroescala alterando a frequência de circulação, que neste caso diminui suprimindo a precipitação. Na primavera, observamos que ocorreu a mesma situação, porém envolvendo ajustes positivos de chuva MFA e ONI. Neste caso, 
analisamos que seja muito provável que tenha ocorrido uma intensificação das variações cíclicas de chuva MFA em função do aumento das amplitudes dos seus ciclos ao longo do período de 1970 a 2009. Na primavera também foi identificado à correlação positiva entre a chuva MFA e a série temporal ENOS envolvendo ajustes positivos. Dessa forma, analisamos que também seja muito provável que tenha ocorrido uma intensificação das variações cíclicas de chuva MFA em função do aumento das amplitudes dos seus ciclos ao longo do período da fase ENOS. Ainda, podemos identificar os possíveis reflexos das combinações observadas, em fases específicas, que podem ser visualizados através dos anos que estiveram correlacionados, de acordo com a Tabela 21.

\section{3- Chuva Fraca - 0,25 a 1,0 mm h-1}

As chuvas definidas como sendo fracas e, que possivelmente estão associadas aos "Chuviscos e Garoas" atingem níveis pluviométricos equivalentes a 0,25 - 1,0 mm h-1. A partir da hipótese inicial deste estudo, a intenção ao analisar este tipo de chuva, é a de concluir para a série temporal de 1970-2009 a existência ou não de um nível de correlação aceitável, envolvendo o comportamento de sua frequência e as variações registradas na temperatura da superfície do mar na região Niño3.4. De acordo com tal hipótese, o estudo estabelece uma reflexão a partir três possibilidades, que podem ou não atuar em conjunto. A reflexão teórica e quantitativa analisa a possibilidade de uma possível correlação, que pode ser ou não, isoladamente linear, cíclica e/ou especificamente por fases altas ou baixas da variação cíclica. A cronologia das escalas de análise foi dividida em anuais e trimestrais. A intenção desta reflexão científica é a de presumir a partir dos resultados, a possibilidade de ter ocorrido uma intensificação ou enfraquecimento, nos quadros evolutivos das variações cíclicas de Chuva Fraca, a partir do aumento ou da diminuição das amplitudes dos seus respectivos ciclos, em função do aquecimento ou resfriamento, diagnosticado através dos registros da TSM, na região Niño3.4. 


\subsection{1 - Análise Anual}

A análise anual possui a finalidade de apresentar uma conclusão obtida a partir da identificação do tipo de correlação existente na intenção de sugerir a possibilidade de haver uma relação anual envolvendo a Chuva Fraca (FA) e o Oceanic Niño Index. Neste caso, também estão inclusos os resultados das correlações realizadas para as fases ENOS, Neutra, El Niño e La Niña.

\subsubsection{1 - Frequência Anual de Chuva Fraca}

A partir da frequência anual de Chuva Fraca $\left(0,25\right.$ a 1,0 $\left.\mathrm{mm} \mathrm{h}^{-1}\right)$, representada no gráfico da Figura 48, é possível identificar que a frequência máxima ocorreu no ano de 1976, relativo à contagem de 341 casos horários.

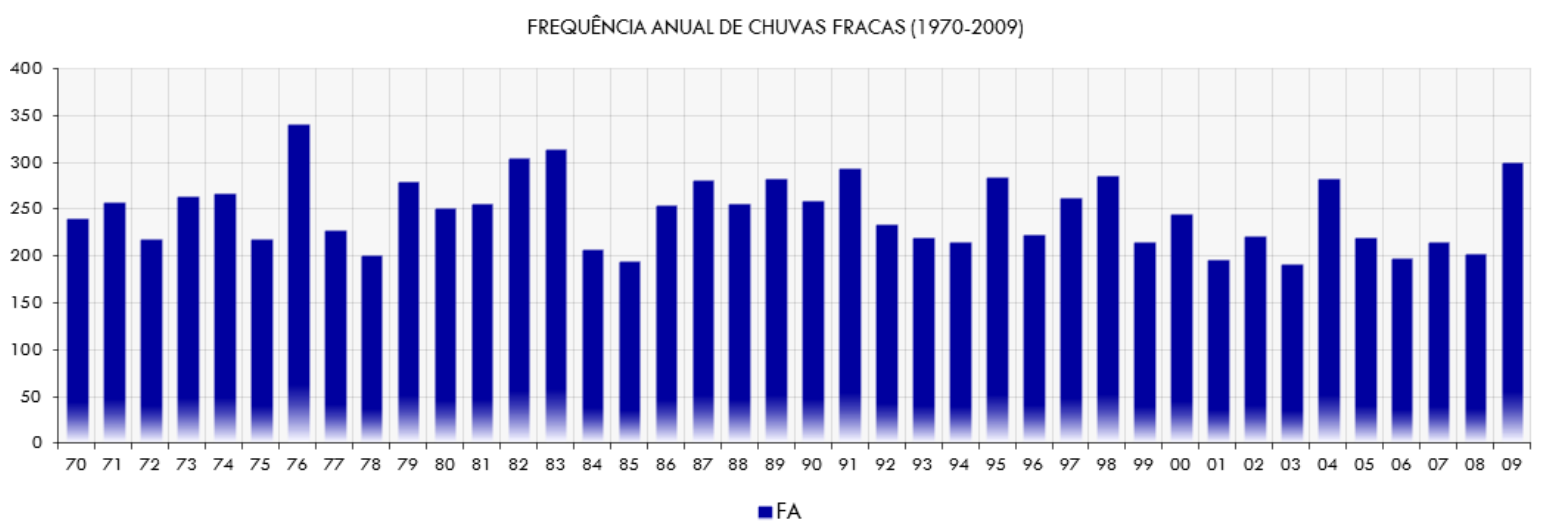

Figura 48 - Frequência Anual de Chuva Fraca entre 1970-2009.

\subsubsection{2- Análise do Ajuste Linear}

O ajuste linear da frequência anual de Chuva Fraca no município de São Paulo indica a diminuição desta frequência ao longo da série temporal analisada, de 1970 a 2009, tal como ilustrada na Figura 49. A análise realizada para as fases, neutra, ENOS, El Niño e La Niña, separadamente, mostra que, em todos os casos, a frequência anual de Chuva Fraca diminui com o tempo, exceto para o caso de El Niño que se mantêm estável (Figura 50). A 
comparação entre a tendência linear da frequência de Chuva Fraca e do ONI indica que enquanto o ONI assume valores cada vez mais intensos, no decorrer da série temporal, a frequência de Chuva Fraca diminui, tal como indicado na Tabela 22. A exceção ocorre no caso de eventos de EN que apresenta tendência negativa nula de TSM, ao longo do período analisado, concomitantemente à tendência negativa nula de frequência de Chuva Fraca (ver tabela 22, linha 4).

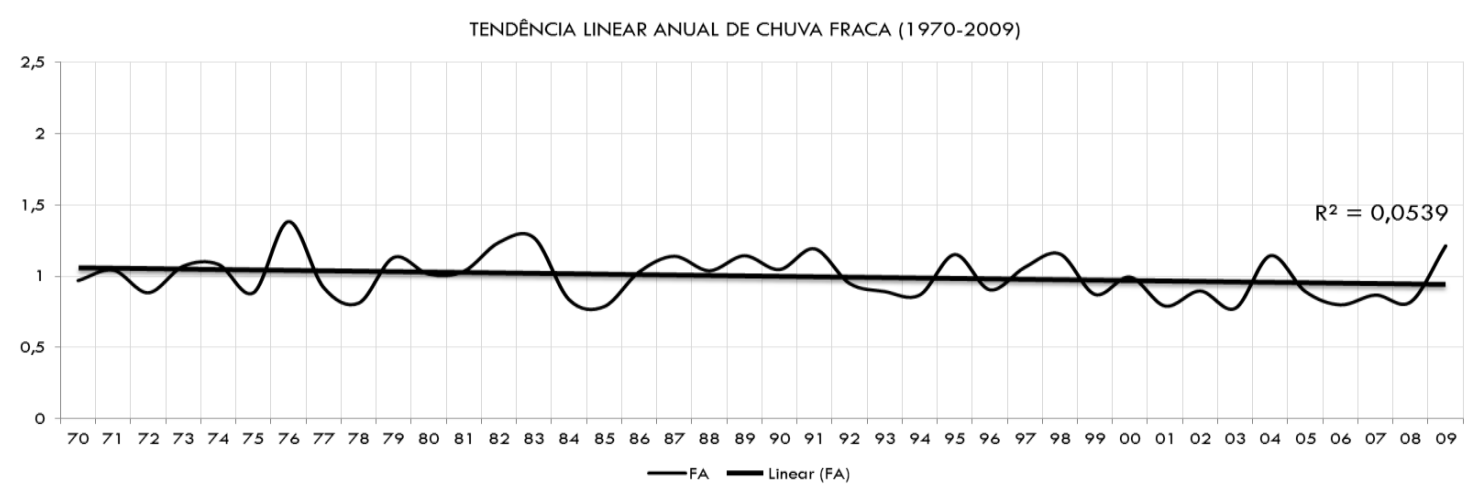

Figura 49 - Ajuste Linear da Frequência Anual de Chuva Fraca entre 1970-2009.
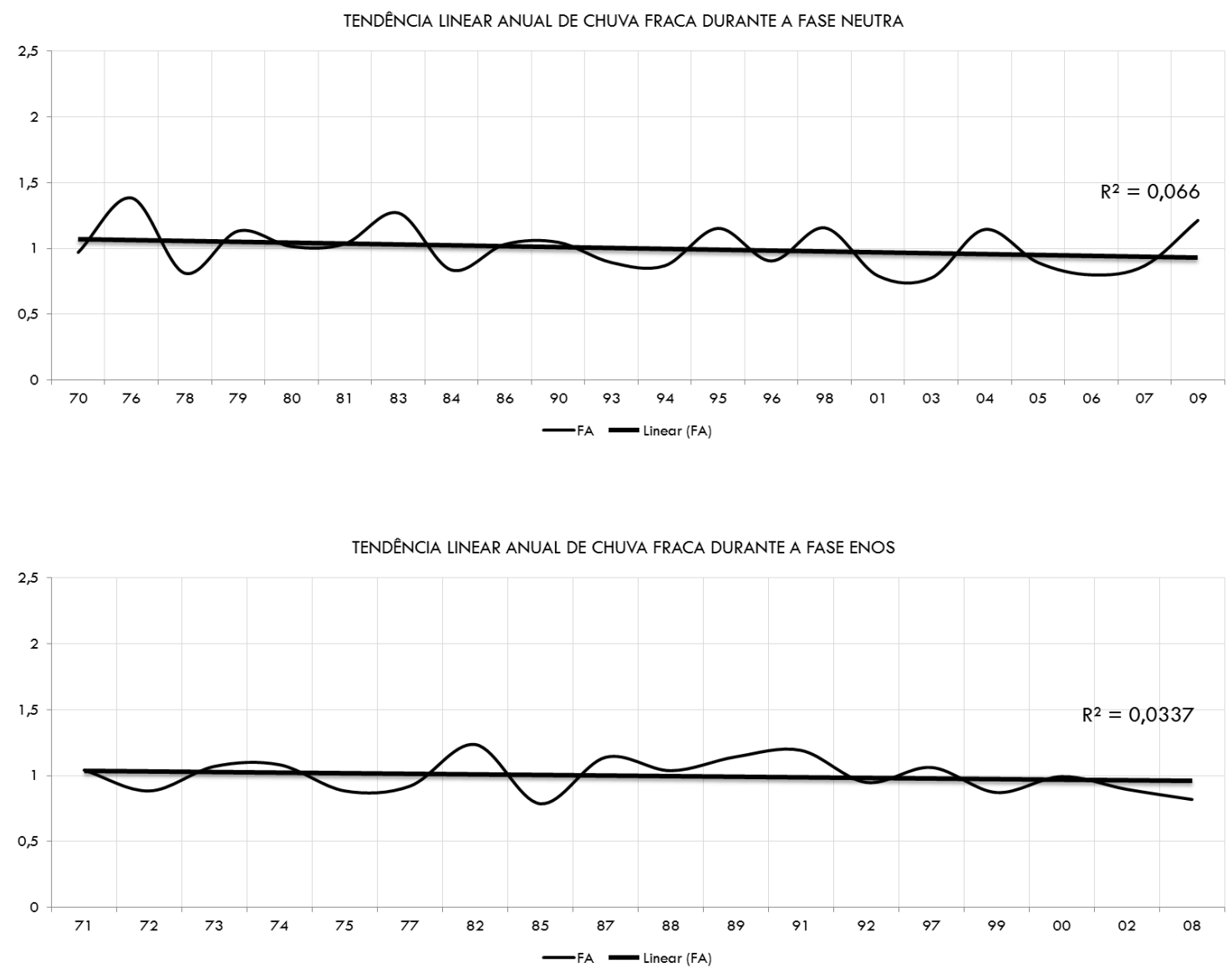

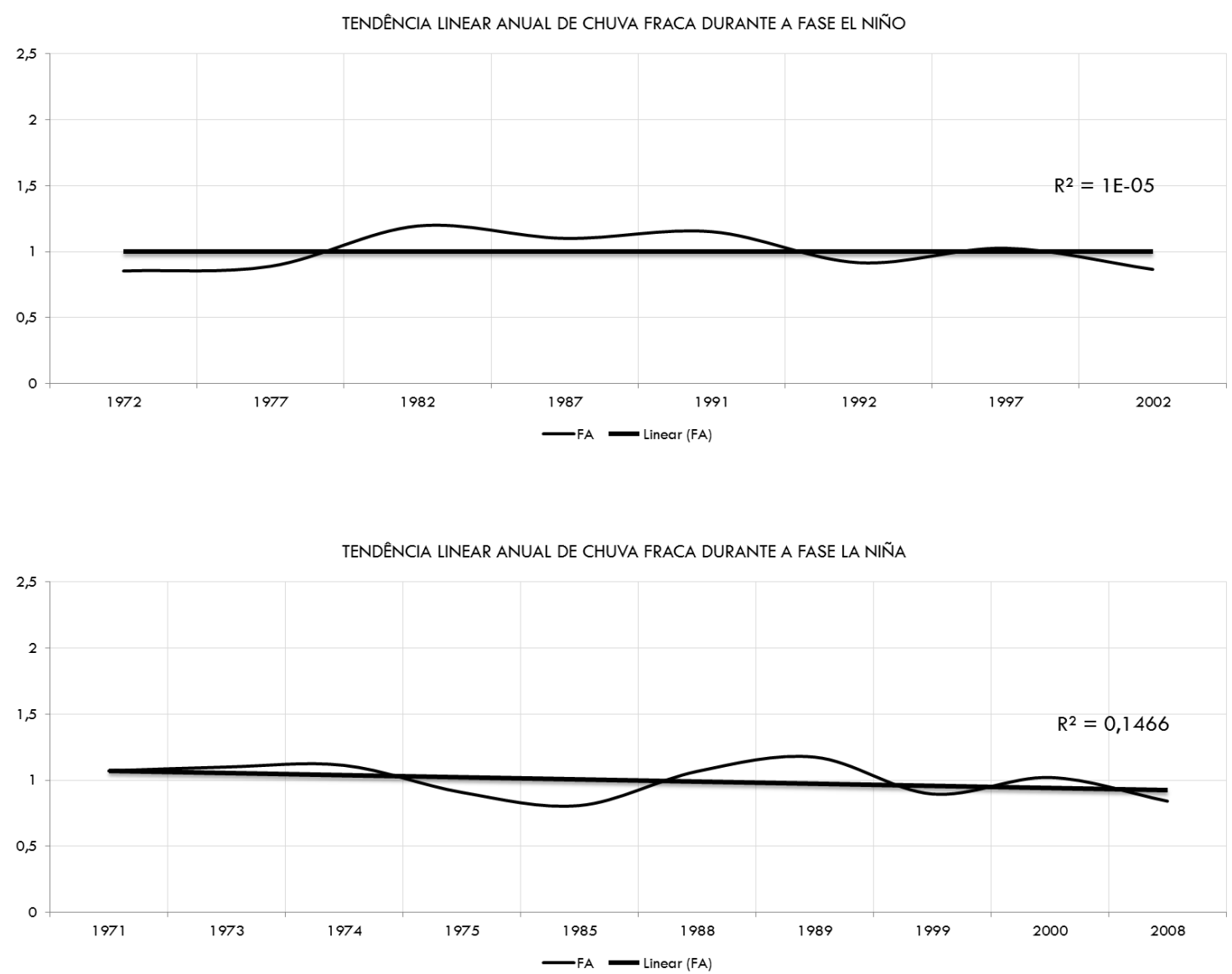

Figura 50 - Tendência Linear da Frequência Anual de Chuva Fraca para a Fase Neutra, ENOS, EN e LN, entre 1970-2009.

Os resultados observados através dos ajustes lineares negativos para a série anual revelam que as frequências analisadas no intervalo horário refletiram positivamente com os resultados das análises diárias realizadas por Cabral (2002).

Tabela 22 - Tendência Linear Anual de Chuva Fraca e do ONI para o Período de 1970 a 2009. A Primeira Linha da Tabela indica a Tendência Linear de Todos os Dados Anuais e, as Demais Linhas indicam a Tendência Linear para cada Fase do ONI.

\begin{tabular}{lc|c|c|c|c|c}
\hline "A" & TIPO DE CHUVA & TENDENCIA LINEAR & "B" & CATEGORIA & TENDENCIA LINEAR & CORRELAÇÃO LINEAR \\
\cline { 2 - 3 } A1 & FA & NEGATIVA & B1 & ONI & POSITIVA & NEGATIVA \\
A2 & FA & NEGATIVA & B2 & NEUTRO & POSITIVA & NEGATIVA \\
A3 & FA & NEGATIVA & B3 & ENOS & POSITIVA & NEGATIVA \\
A4 & FA & NEGATIVA & B4 & EL NIÑO & NEGATIVA & POSITIVA \\
\hline A5 & FA & NEGATIVA & B5 & LA NIÑA & POSITIVA & NEGATIVA
\end{tabular}




\subsubsection{3- Variação Cíclica de Chuva Fraca}

A variação cíclica anual de Chuva Fraca pode ser observada na Figura 51. É possível notarmos a oscilção presente na série temporal completa, de 1970 a 2009, formada por 19 fases altas (esferas vermelhas) e 21 fases baixas (esferas azuis).

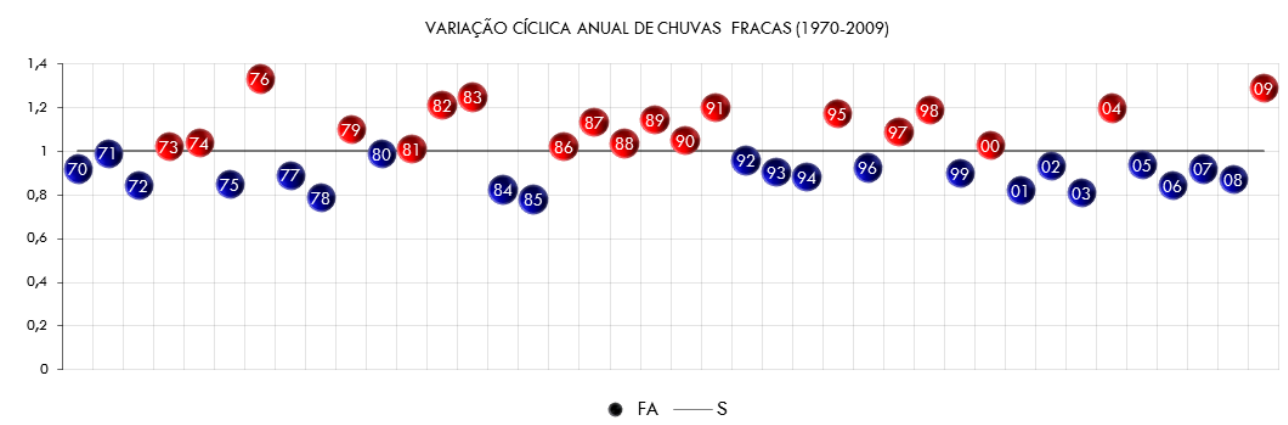

Figura 51 - Variação Cíclica Anual da Frequência de Chuva Fraca entre 1970 e 2009.

\subsubsection{4- Análise da Correlação Cíclica}

A partir dos resultados do teste de significância - t-"Student" - notamos que os resultados do cálculo de correlação linear, para as séries cíclicas, entre ONI e a frequência anual de Chuva Fraca, não foram significativos (Tabela 23).

Tabela 23 - Correlação Linear entre a Anomalia de ONI e da Frequência Anual de Chuva Fraca entre 1970 e 2009, sem Tendência Linear (Série Cíclica).

\begin{tabular}{|c|c|c|c|c|c|}
\hline & CIClO "A" & & Ciclo " $B$ " & CORRELAÇĀO CICUCA & TESTE T-STUDENT \\
\hline A1 & FA & B1 & ONI & 0,129 & NÄO SIGNIFICATIVO \\
\hline A.2 & FA & B2 & NEUTRA & 0,07 & NÄO SIGNIFICATIVO \\
\hline $\mathrm{A} 3$ & FA & 83 & ENOS & 0,276 & NÄO SIGNIFICATIVO \\
\hline A4 & FA & B4 & EL NIÑO & 0,303 & NÄO SIGNIFICATIVO \\
\hline A5 & FA & B5 & LA NINA & 0,358 & NÄO SIGNIFICATIVO \\
\hline
\end{tabular}

\subsubsection{5- Análise Específica do Ciclo de Chuva - FA}

Os resultados de tal análise revelam as possíveis correlações existentes entre as fases altas e baixas da frequência de Chuva Fraca e do ONI. Neste caso, na Figura 52 
identificamos a série específica através das fases altas $(\bar{x}>1)$ e baixas $(\bar{x}<1)$ da variação cíclica da frequência de chuva FA.

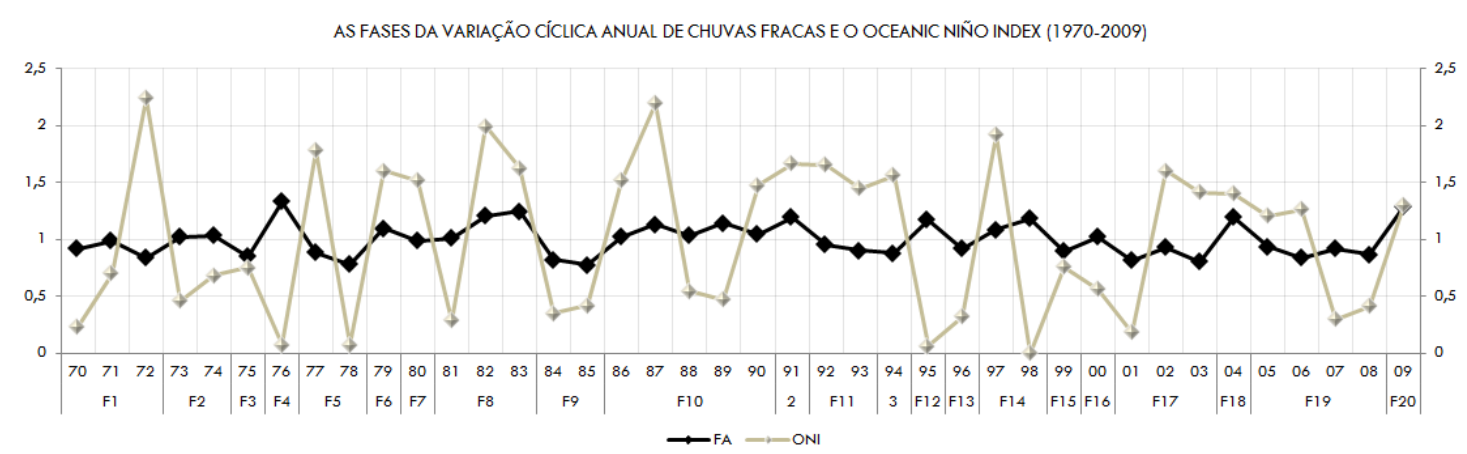

Figura 52 - Fases Específicas do Ciclo Anual de Chuva Fraca. A linha Branca corresponde à variação cíclica do ONI e a linha Preta de Chuva FA, para o Período de 1970-2009.

A variação cíclica anual de Chuva Fraca no período de 1970 a 2009 foi composta por 20 fases específicas (altas e baixas). No entanto, a partir do resultado negativo da correlação linear entre a tendência negativa de Chuva Fraca e a tendência positiva da ONI, procuramos identificar as fases da oscilação que possivelmente estiveram associadas a tal comportamento. Neste caso, as fases baixas estariam correlacionadas com a Chuva Fraca e, as fases altas correlacionadas com o ONI. A partir dessa probabilidade foram identificadas 6 fases baixas, significativamente e positivamente correlacionadas, nos anos de 1975, 1977, 1978, 1992, 1993, 1994, 1996, 1999, 2001, 2002 e 2003. Por outro lado, foram identificadas 5 fases altas, significativamente e positivamente correlacionadas, nos anos de $1973,1974,1979,1981,1982,1983,2004$ e 2009.

\subsubsection{6- A Hipótese Inicial e a Conclusão Final - FA I}

A conclusão final para análise anual de Chuvas Fracas foi baseada a partir dos resultados envolvendo os três procedimentos aplicados. De modo geral, durante este período, os resultados sugerem que o aquecimento observado na região Niño3.4, não coincidiu com o aumento na frequência de Chuvas Fracas, com exceção da fase El Niño. Nesta fase, foi 
possível observar que o resfriamento na TSM, coincidiu com a diminuição na frequência deste tipo de chuva. A respeito dos resultados das correlações cíclicas, não foi identificado nenhuma fase significativamente correlacionada. Por último, é possível sugerir que os reflexos do resultado do ajuste linear possam ter ocorrido, pontualmente, em fases e anos específicos. Desta forma, para os quatros casos de correlação linear negativa (ONI, Fase Neutra, ENOS e La Niña) é provável que as fases altas, quando significativamente e positivamente correlacionados, estivessem associadas a tais ajustes lineares. Por outro lado, é também possível sugerir que as fases baixas, quando significativamente e positivamente correlacionados, estivessem associadas às Chuvas Fracas. A exceção observada foi o caso de correlação envolvendo a fase El Niño, na qual é possível notar que apenas ocorreu uma correlação linear. A partir deste resultado presume-se que somente seja possível identificar os reflexos da correlação linear a partir das fases baixas. De acordo com essa conclusão, é possível identificar pontualmente nas fases de baixa - quando elas estiverem significativamente e positivamente correlacionadas - os anos que estiveram associados. A Tabela 24 apresenta todos os detalhes específicos relacionados com conclusão realizada.

Tabela 24 - Correlação Anual em Fases Específicas. A Coluna "A" indica o Ajuste Linear da Chuva FA nas Séries Temporais "B" correspondente o ONI e suas Fases. A Última Coluna aponta os Possíveis Anos que estiveram Correlacionados com o Resultado da Correlação Linear do Ajuste "A" e "B".

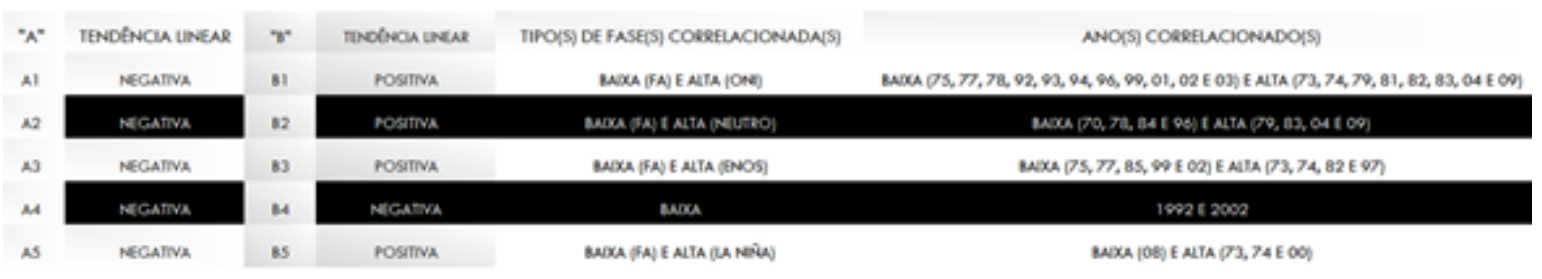

\subsection{2- Análise Trimestral}

A segunda análise envolve a relação trimestral entre a Chuva Fraca e o Oceanic Niño Index. Nestas análises estão incluídas as séries temporais, definidas como relativas em função de se tratar de períodos específicos da série integral, definidos como ENOS, Fase 
Neutra, El Niño e La Niña. Trata-se de uma análise individualizada, envolvendo os três procedimentos elementares adotados, que foram aplicados para as quatro estações climáticas do ano, ou seja, verão, outono, inverno e primavera.

\subsubsection{1 - Frequência Trimestral de Chuva Fraca}

Os resultados das frequências trimestrais de Chuva Fraca $\left(0,25\right.$ a $\left.1,0 \mathrm{~mm} \mathrm{~h}-{ }^{1}\right)$ podem ser observados a partir da Figura 53. No outono, inverno e primavera, a tendência linear de chuva FA, durante o período de 1970 a 2009, é negativa (Figuras 54). Por outro lado, a tendência linear, deste tipo de chuva, para o verão, pode ser considerada como sendo nula ou estável.

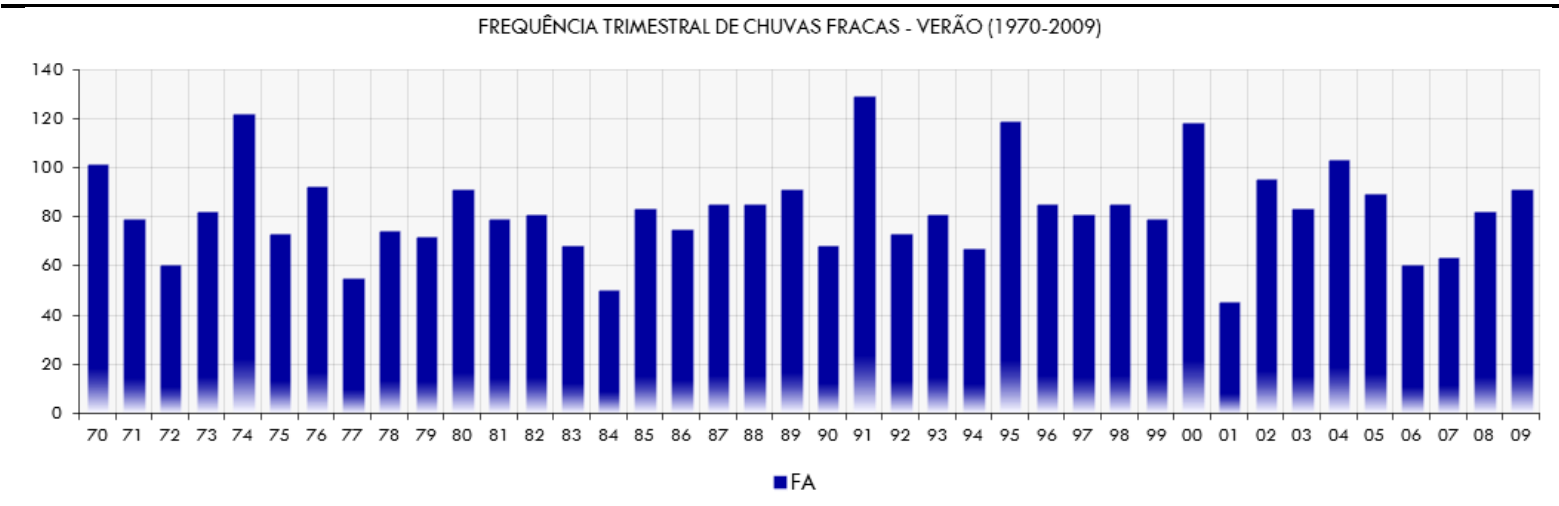

FREQUÊNCIA TRIMESTRAL DE CHUVAS FRACAS - OUTONO (1970-2009)

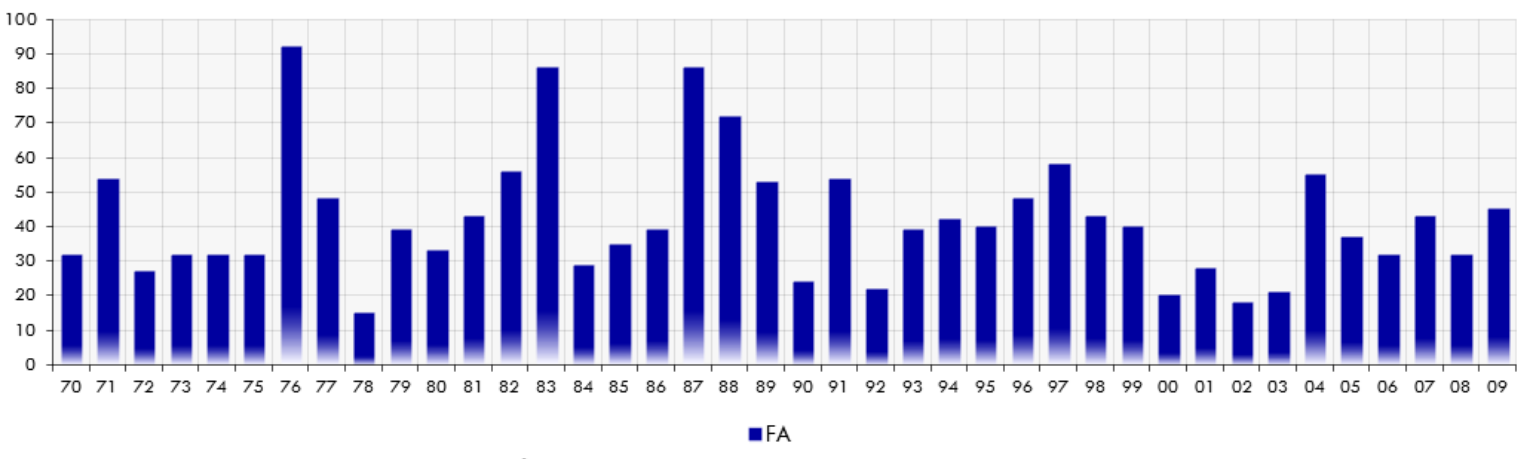

FREQUÊNCIA TRIMESTRAL DE CHUVAS FRACAS - INVERNO (1970-2009)

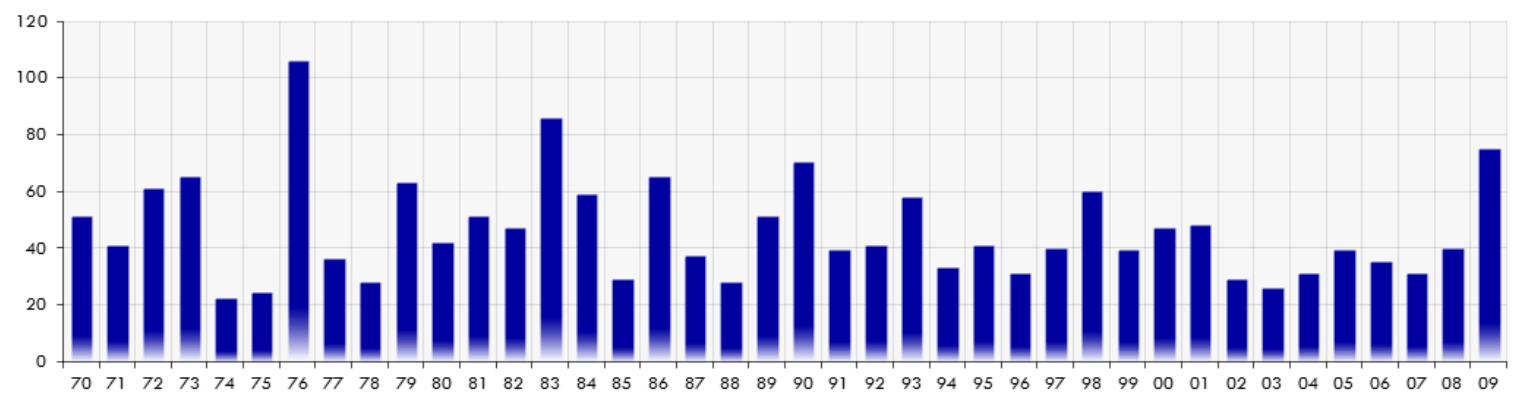


FREQUÊNCIA TRIMESTRAL DE CHUVAS FRACAS -PRIMAVERA (1970-2009)

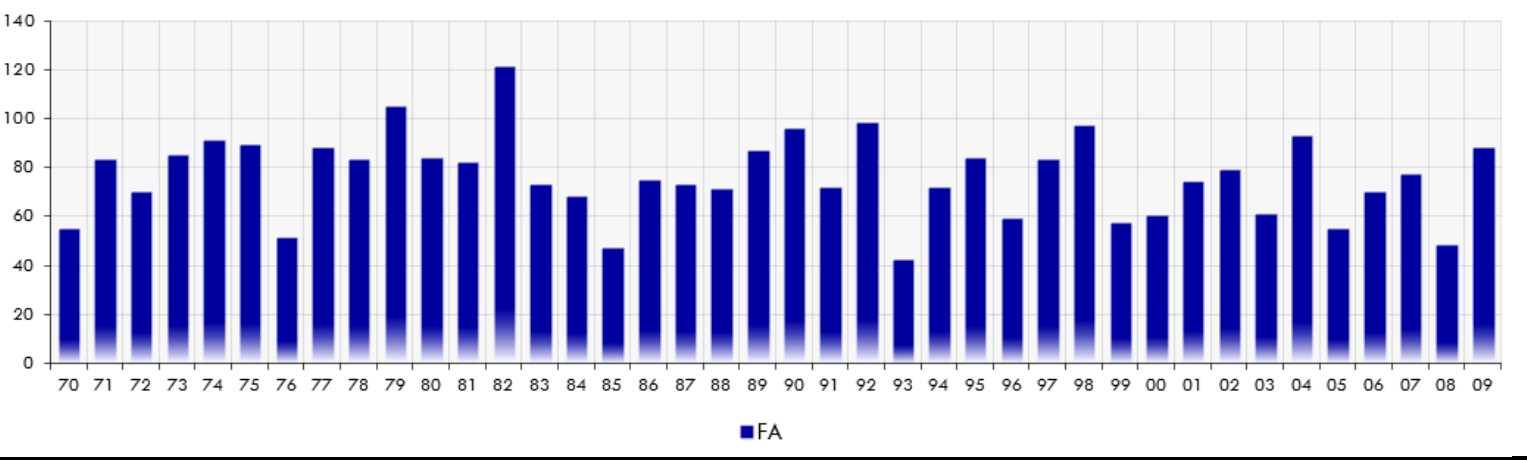

Figura 53 - Frequência Trimestral de Chuva Fraca na Estação do IAG-USP durante o Verão, Outono, Inverno e Primavera para o Período de 1970 a 2009.
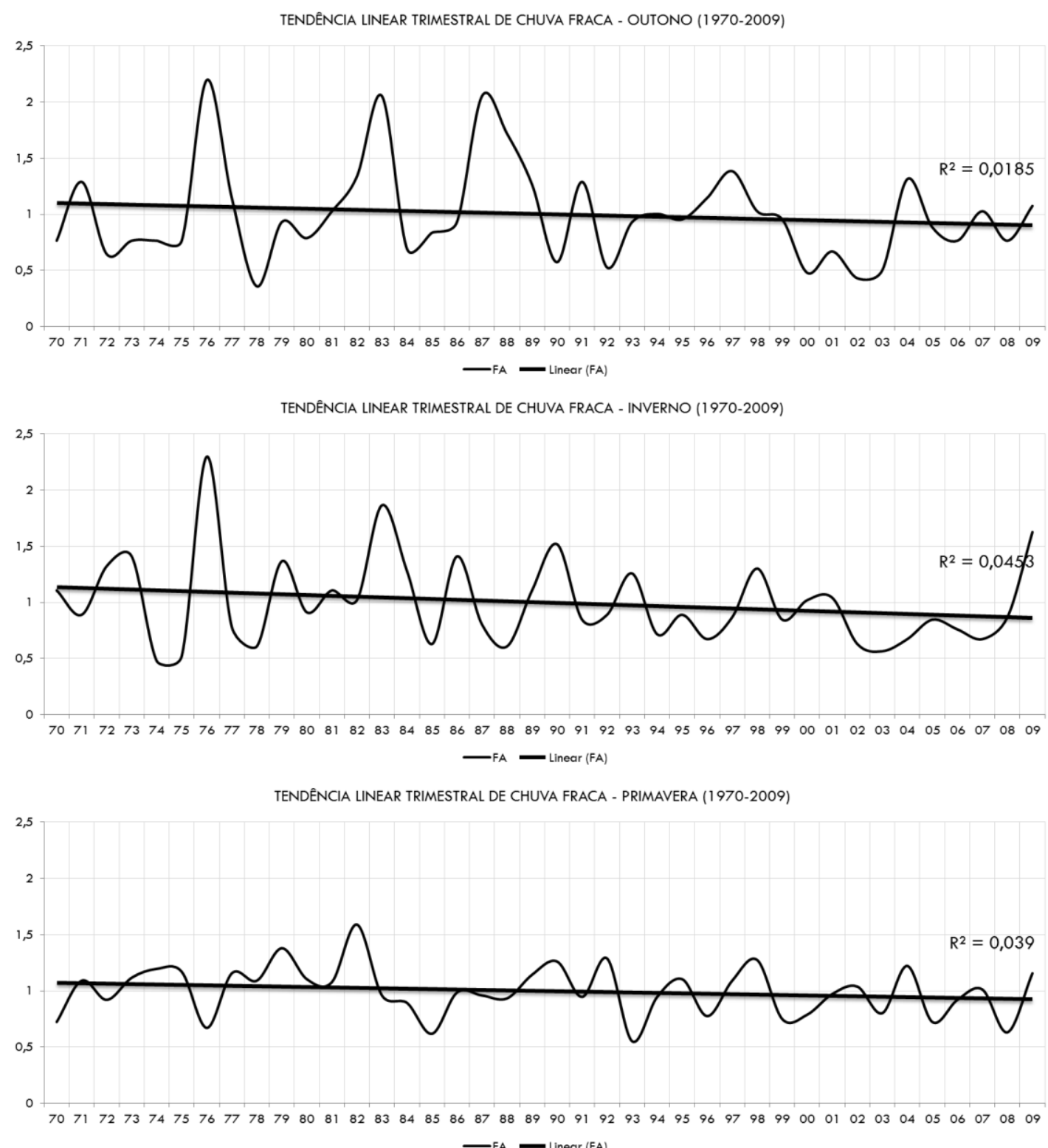

Figura 54 - Ajuste Linear Trimestral de Chuva Fraca para as Estações de Outono, Inverno e Primavera, no Período de 1970 a 2009. 
A maioria das séries temporais do ONI apresentarm tendência linear negativa, neste caso incluímos os ajustes lineares mais significativos nas Figuras 55-58. A excessão encontrada foi à tendência linear positiva da fase El Niño durante o verão. Nestas figuras observamos que durante a fase neutra, os ajustes negativos foram identificados no outono, inverno e primavera (Figura 55). Na fase ENOS, os ajustes negativos foram identificados no outono e no inverno (Figura 56). Na fase EN, o único ajuste negativo foi identificado no inverno (Figura 57). Na fase $L N$, os ajustes negativos foram identificados no verão, inverno e primavera (Figura 58).
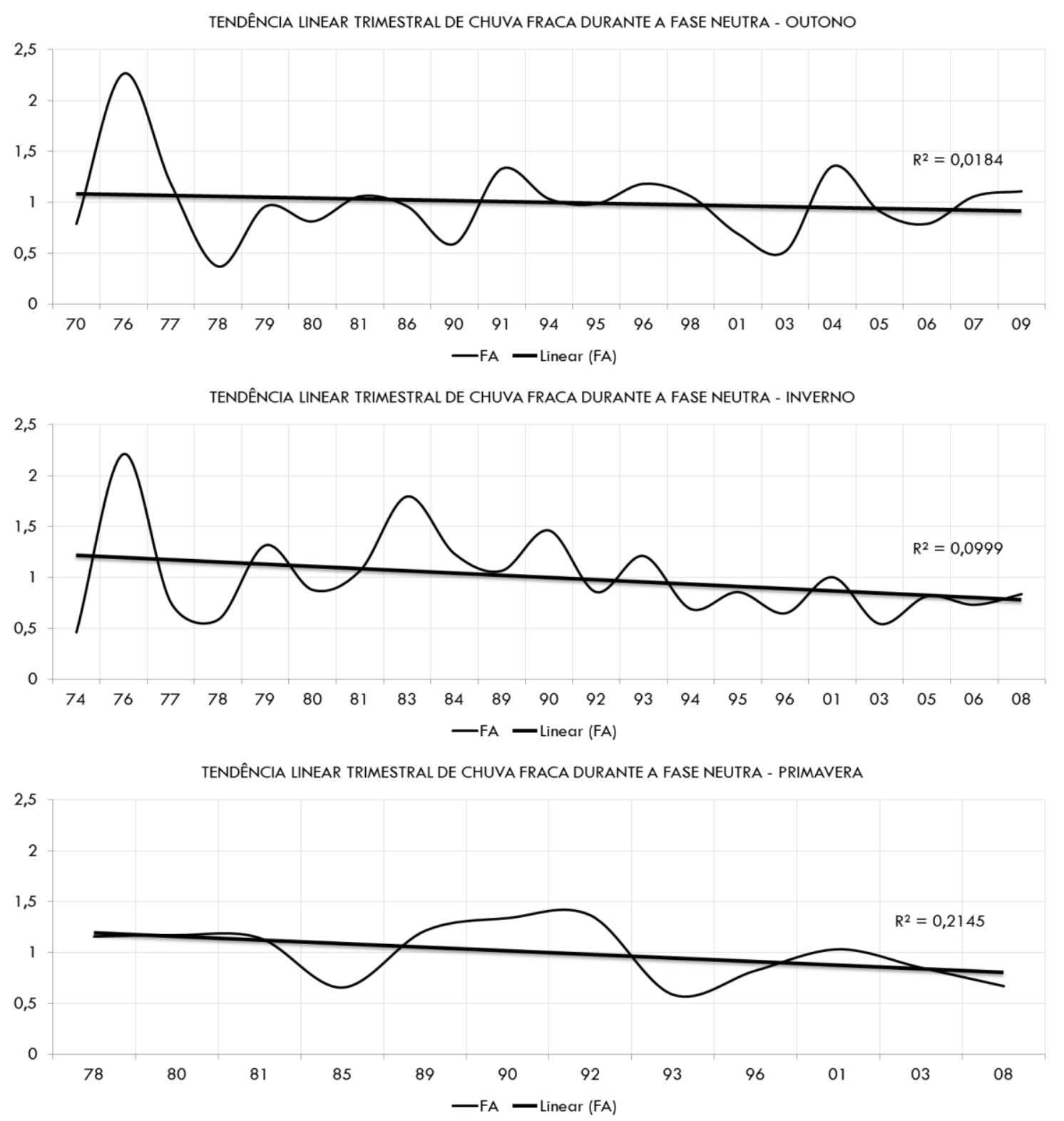

Figura 55 - Ajuste Linear Trimestral de Chuva Fraca para as Estações de Outono, Inverno e Primavera durante a fase Neutra. 

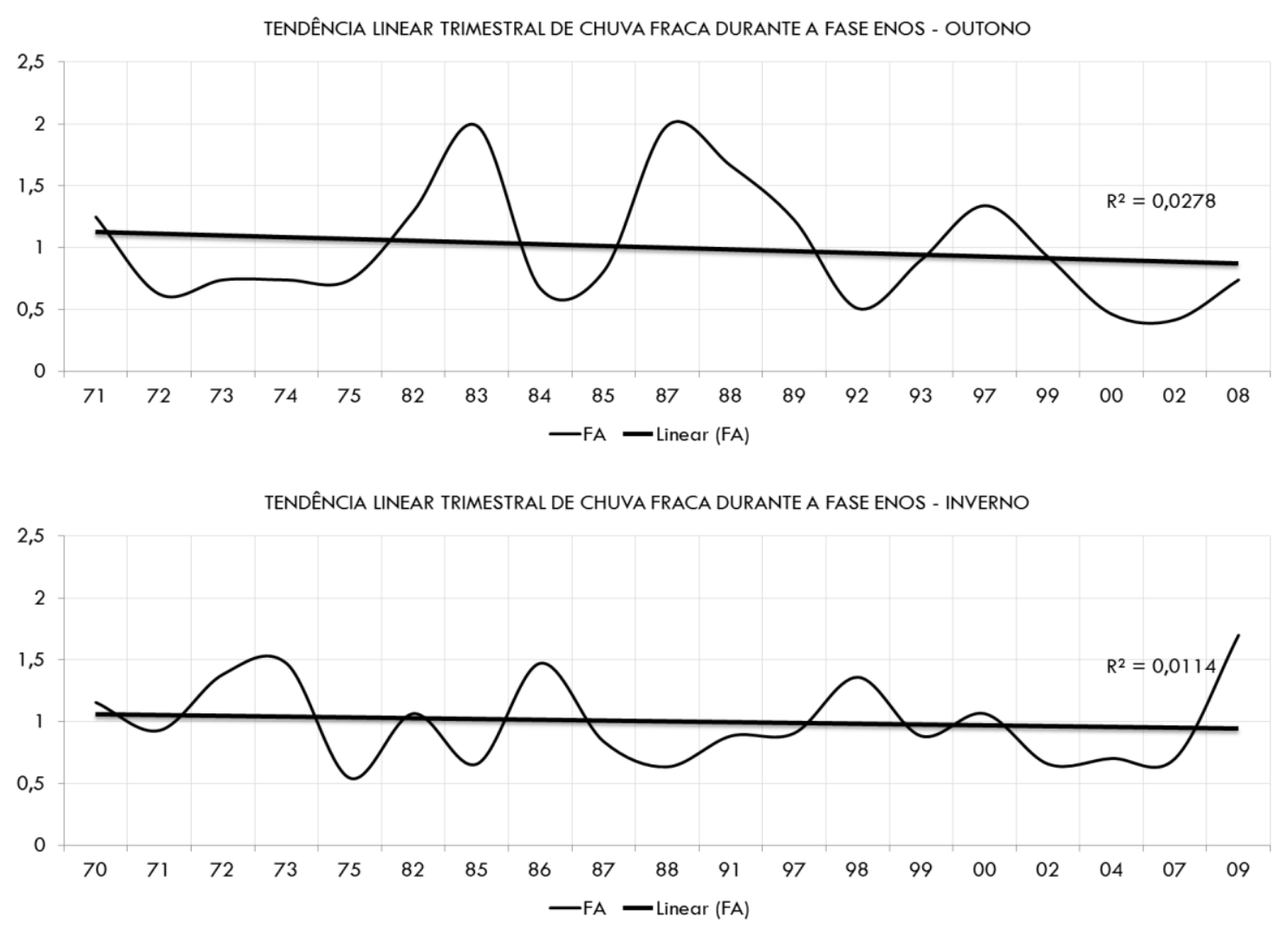

Figura 56 - Ajuste Linear Trimestral de Chuva Fraca para as Estações de Outono e Inverno durante a fase ENOS.
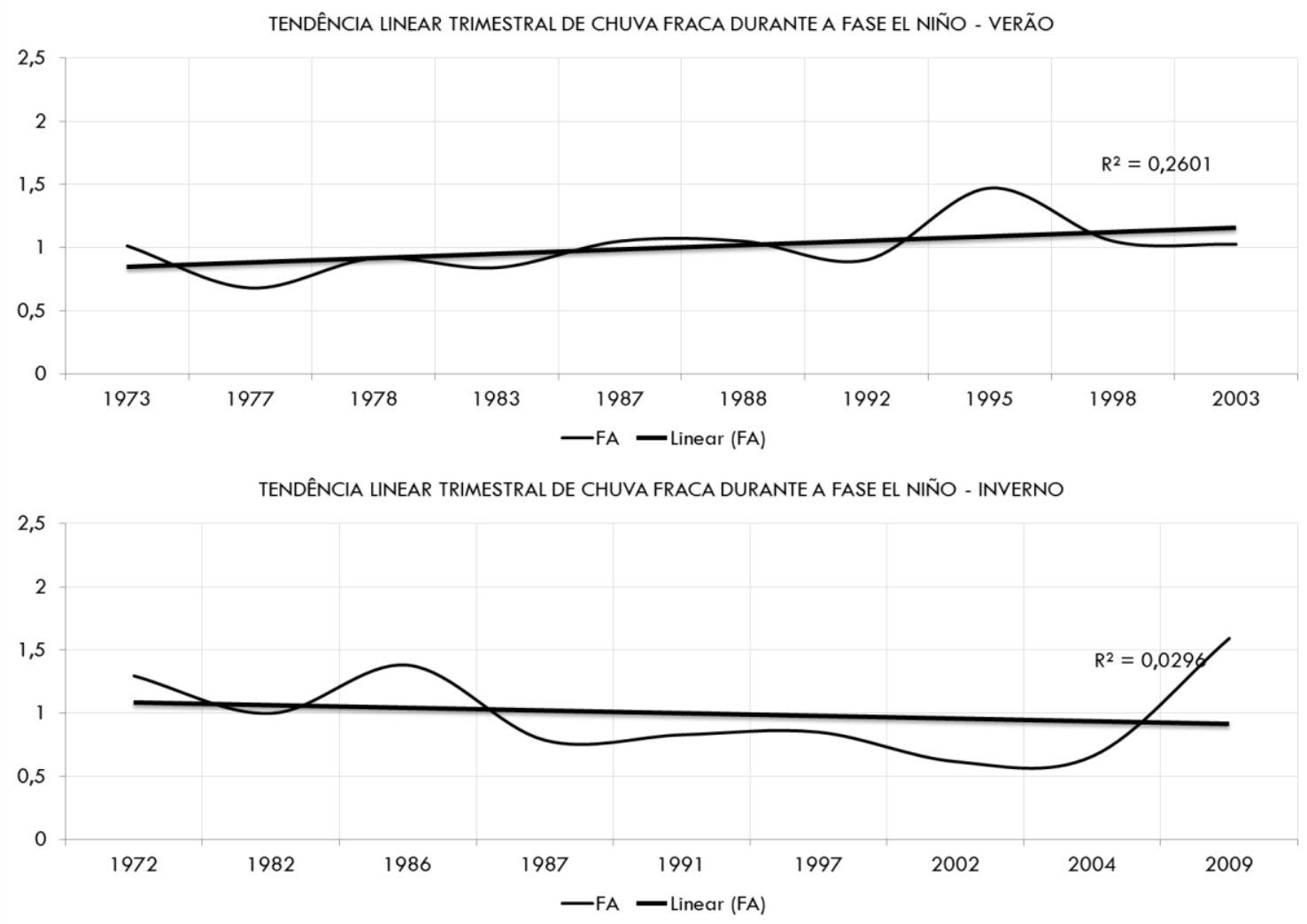

Figura 57 - Ajuste Linear Trimestral de Chuva Fraca para as Estações de Verão e Inverno durante a fase El Niño. 

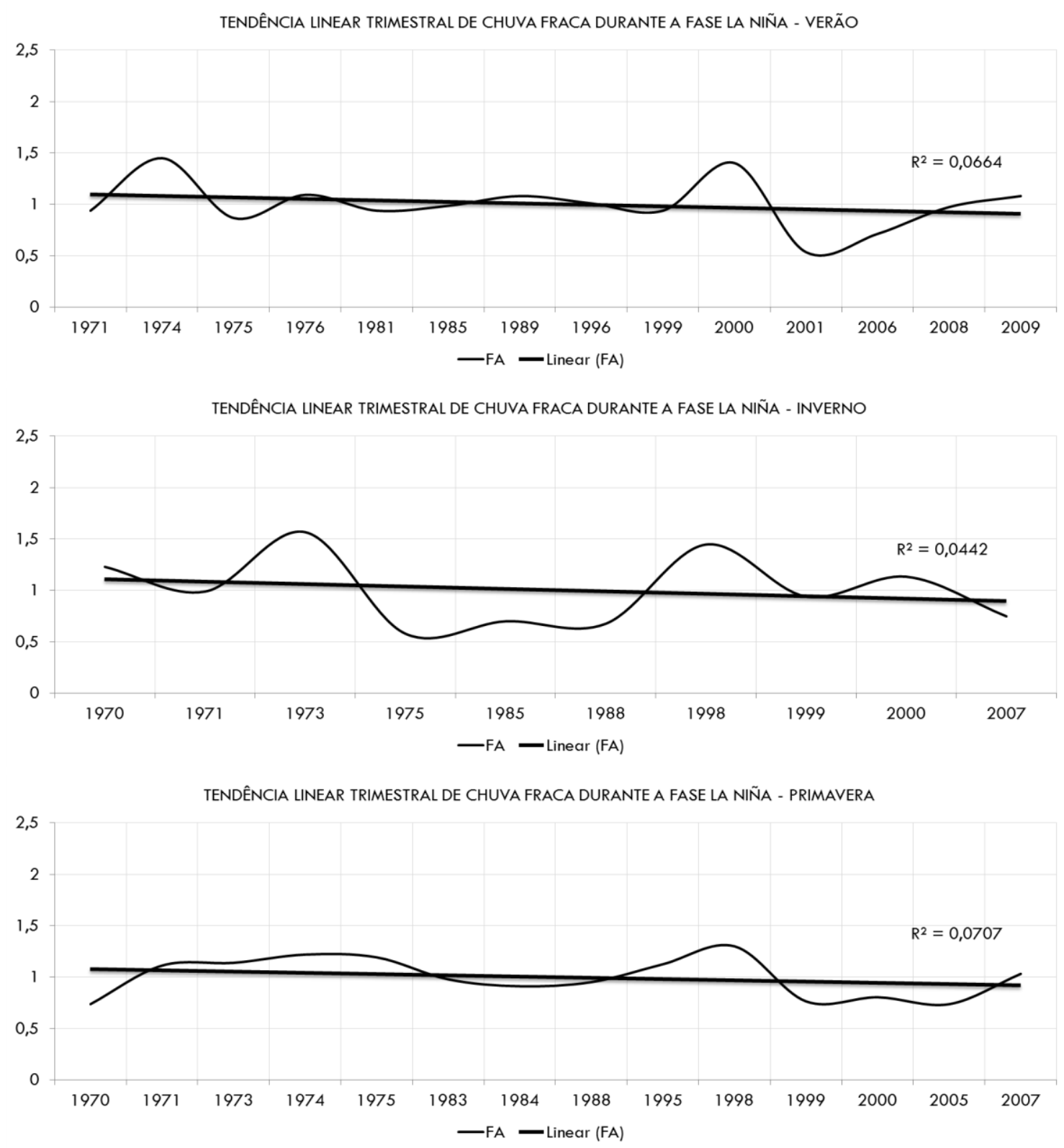

Figura 58 - Ajuste Linear Trimestral de Chuva Fraca para as Estações de Verão, Inverno e Primavera durante a fase La Niña.

Os resultados trimestrais por fases também coincidem com os resultados identificados no trabalho de Cabral (2002). Ou seja, mesmo em séries temporais específicas o padrão de diminuição da frequência de chuvas mais leves se manteve. No entanto, a análise detalhada estabelecida neste estudo, permiti observar que na fase específica em relação à fase El Niño - resultado se apresenta de maneira contrária ao comportamento geral observado por Cabral (2002). De modo geral, a Tabela 25 indica que a metade dos casos envolvendo 
correlações lineares entre a chuva FA e ONI foram positivas (+). No total foram 10 correlações positivas que apresentaram haver uma correlação estatística, em todas as estações climáticas do ano, entre as chuvas FA e a série temporal integral (ONI) e as séries temporais relativas (neutra, ENOS, EN e LN). As correlações lineares ocorreram com mais frequência durante o verão e o outono.

Tabela 25 - Correlação Linear Trimestral entre a Tendência Linear Trimestral de Chuva Fraca e a Tendência Linear Trimestral do ONI incluindo as Fases, Neutra, ENOS, EN e LN.

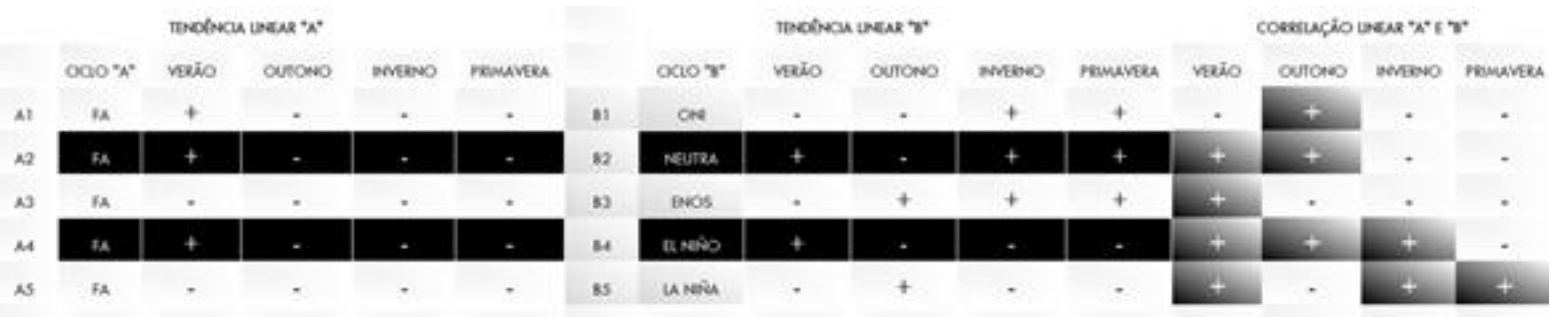

A frequência da chuva FA, durante o verão, diminui durante a fase ENOS e $L N$ e, aumenta durante $\circ$ ONI, fase Neutra e EN. Durante o outono, inverno e primavera, a frequência da chuva MFA diminui em todos os casos (Tabela 25). Contudo, considerando todas as estações climáticas, no período de 1970 a 2009, verificamos que a frequência de chuva FA diminui no decorrer do tempo, exceto no verão onde a tendência linear positiva não é significativa (Tabela 25).

\subsubsection{2- Variação Cíclica Trimestral de Chuva - FA}

A variação das anomalias da frequência de chuva FA para o período de 1970 a 2009, para as quatro estações do ano está ilustrada na Figura 59.

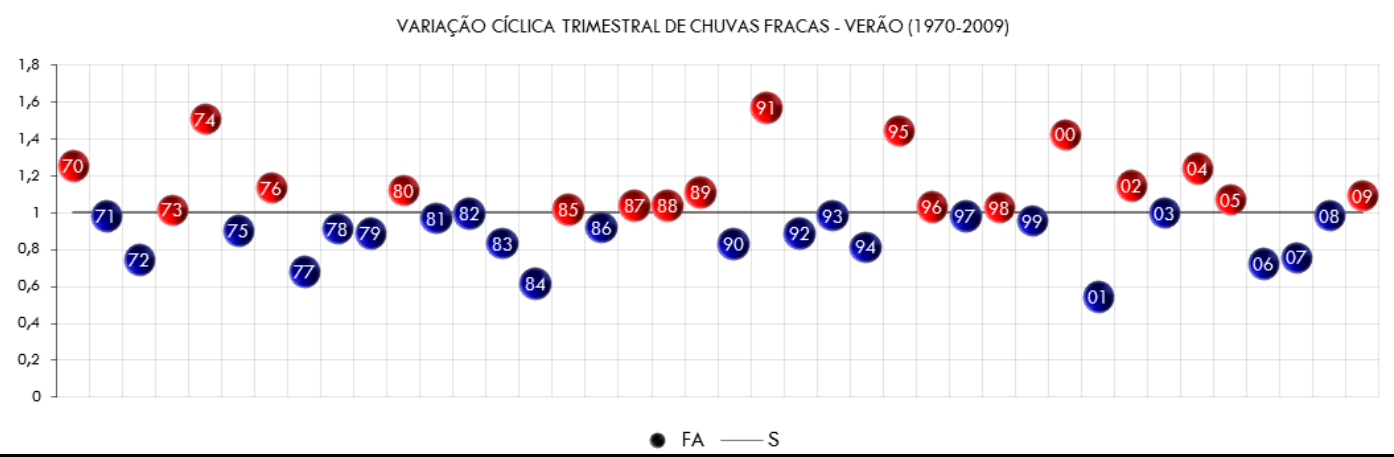




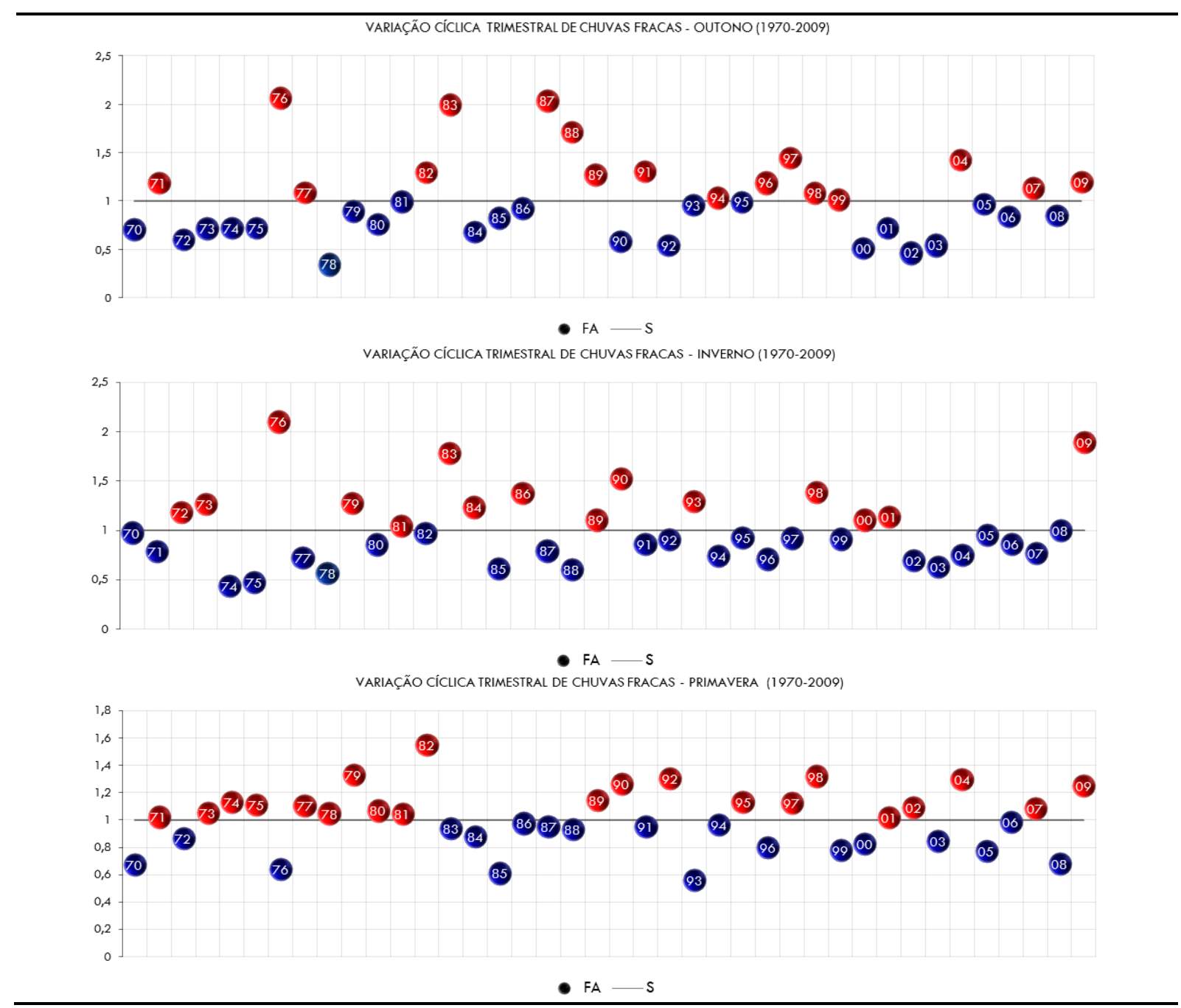

Figura 59 - Variação Cíclica Trimestral de Chuva Fraca, entre 1970 e 2009.

\subsubsection{3- Análise da Correlação Cíclica Trimestral}

De forma geral, separando a série temporal em estações do ano, observamos que a correlação linear entre as séries de ONI e frequência de chuva FA é positiva e significativa somente para a primavera $(r=0,22)$, Figura 60 . Ou seja, a frequência de chuva FA pode estar associada fisicamente aos valores de ONI durante a primavera. A separação das séries temporais em eventos distintos quanto à TSM na região do Niño3.4 permitiu verificar que durante o verão, na fase $L N$, a correlação linear entre estas duas variáveis foi positiva e significativa $(r=0,74)$, Figura 61. A segunda correlação linear, significativa e positiva foi identificada no outono, na fase ENOS $(r=0,30)$, Figura 62. Todos os demais resultados podem ser observados a partir da Tabela 26. 
Tabela 26 - Correlação Cíclica entre a Frequência de Chuva Fraca observada na Estação do IAG e os Valores de ONI para Cada Estação do Ano e, para Cada Condição de Anomalia na Região de Niño3.4 (Eventos Neutros, ENOS, EN e LN).

\begin{tabular}{|c|c|c|c|c|c|c|c|}
\hline VERÄO & OUTONO & INVERNO & PRCMUVERA & VERÃO & OUTONO & INVERENO & PRIMAVERA \\
\hline A) & A) & Al & A1 & ONI & ONA & ONI & One \\
\hline$A^{2}$ & N2 & $A^{2}$ & $A^{2}$ & NEUT:O & NEUTRO & NEUTRO & NEUTRO \\
\hline A3 & N 3 & N & $A 3$ & ENOS & ENOS & ENOS & ENOS \\
\hline MA & M & M4 & M & E. NINAOO & EL NAROO & E MEÑO & EL NEÑO \\
\hline As & As & NS & N & UNERA & LA NERTA & UNENA & Lanetu \\
\hline \multicolumn{4}{|c|}{ CORRELAÇÄO CICLCA } & \multicolumn{4}{|c|}{ TESTE T - STUDENT } \\
\hline VERÄO & OUTONO & INVERNO & Pranavera & VERR̆O & OUTONO & INVERANO & PRIMAVERA \\
\hline 0,158 & 0.191 & 0,121 & 0,227 & NĨO SEGNETCATINO & NḮ SIGNaACATINO & NİO SAGNEACATINO & SGGACATNO \\
\hline 0,343 & 0.087 & 0,162 & $-0,008$ & NL̈O SIGNEFCATINO & Nï SIGNIFACATIVO & NG̈O SUGNAFCATIVO & NIOO SIGNAFACATVO \\
\hline 0,067 & 0,308 & 0,154 & 0,302 & NÜO SSCAUFACAINO & SUCNEFCAINO & NÄO SSCAEFCAIVOO & NÄO SIGNEFCATMO \\
\hline $.0,16$ & 0,4 & $-0,317$ & 0.181 & NİO SEGNEKATINO & NïO SAGNEFCATIVO & NḦo SEGNEACATINO & NİO SIGNERCATIVO \\
\hline $0>07$ & $-0,025$ & 0,043 & 0,329 & SGENACATIVO & NËO SIGNIACATINO & NÄO SUGNIFCATINO & NH̃O SICNAACATIVO \\
\hline
\end{tabular}

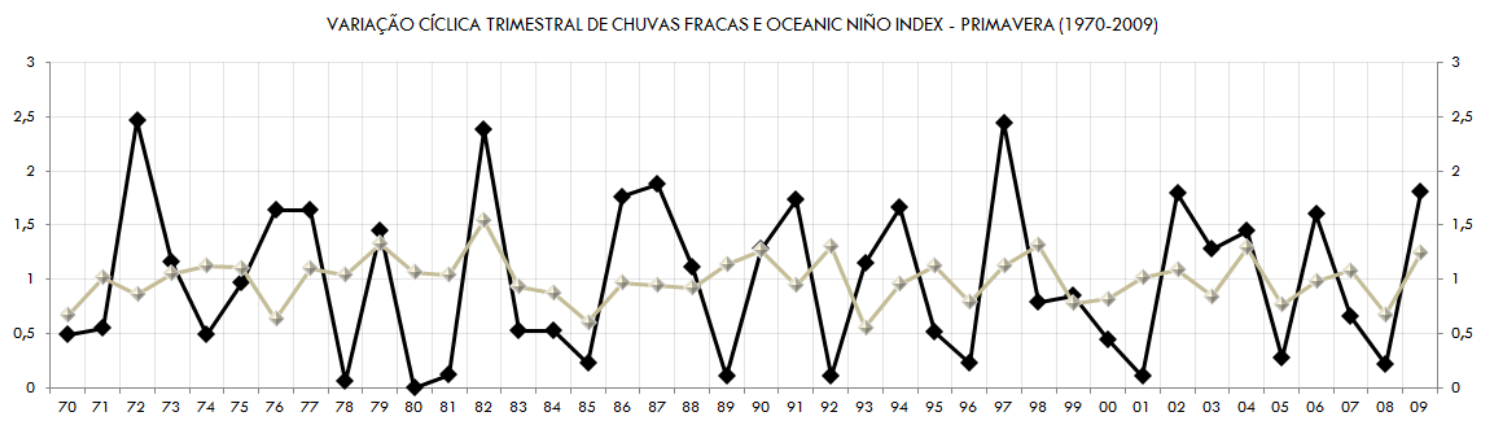

Figura 60 - Variação Cíclica de Chuva FA, na Primavera, entre 1970 e 2009.

VARIAÇÃO CÍCLICA TRIMESTRAL DE CHUVAS FRACAS E LA NIÑ̃ - VERÃO

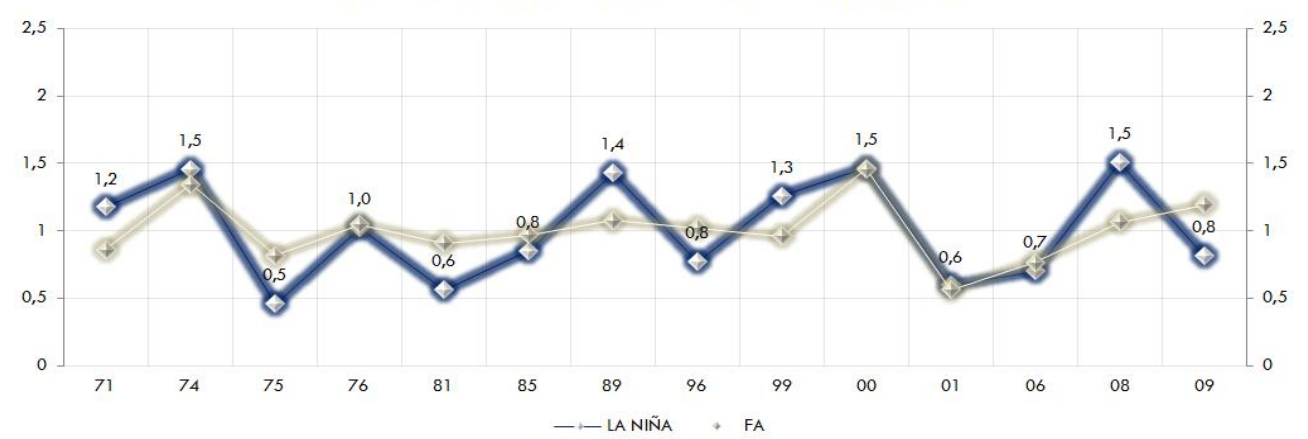

Figura 61 - Variação Cíclica de Chuva FA, no Verão, durante a Fase La Niña.

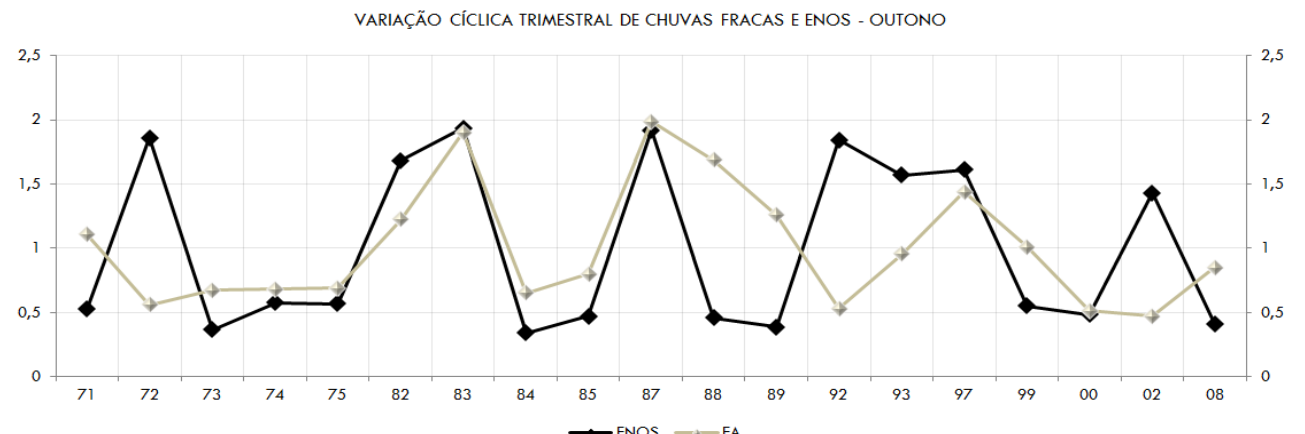

Figura 62 - Variação Cíclica de Chuva FA, no Outono, durante a Fase ENOS. 


\subsubsection{4- Análise Específica das Fases Trimestrais}

Os resultados de tal análise revelam as possíveis correlações existentes entre as fases altas e baixas da frequência de Chuva Fraca e do ONI. Neste caso, identificamos a série específica através das fases altas $(\bar{x}>1)$ e baixas $(\bar{x}<1)$ da variação cíclica da frequência trimestral de chuva FA. A variação cíclica de Chuva Fraca no período de 1970 a 2009 durante a estação de verão foi composta por 25 fases específicas. A partir do resultado negativo da correlação linear entre a tendência positiva de Chuva Fraca e a tendência negativa da ONI, procuramos identificar as fases da oscilação que possivelmente estiveram associadas a tal comportamento. Neste caso, as fases altas estariam correlacionadas com a Chuva Fraca e, as fases baixas correlacionadas com ○ ONI (Figura 63). Em função dessa probabilidade, identificamos nos anos de 1970, 1980, 1991, 1995, 1996 e 1998 as fases altas que estariam significativamente e positivamente correlacionadas com a chuva FA. Por outro lado, identificamos nos anos de 1971, 1972, 1975, 1986, 1997, 1999 e 2001 as fases baixas que estariam significativamente e positivamente correlacionadas com o ONI (Tabela 27). A variação cíclica de Chuva Fraca no período de 1970 a 2009 durante a estação de outono foi composta por 20 fases específicas. A partir do resultado positivo da correlação linear entre a tendência negativa de Chuva Fraca e a tendência negativa da ONI, procuramos identificar as fases da oscilação que possivelmente estiveram associadas a tal comportamento. Neste caso, deduzimos que somente as fases baixas estariam correlacionadas (Figura 63). Em função dessa probabilidade, identificamos nos anos de 2005, 2006 e 2008 as fases baixas que estariam significativamente e positivamente correlacionadas com a correlação positiva entre a chuva FA e o ONI (Tabela 27). A variação cíclica de Chuva Fraca no período de 1970 a 2009 durante a estação de inverno foi composta por 22 fases específicas. A partir do resultado negativo da correlação linear entre a tendência negativa de Chuva Fraca e a tendência positiva da ONI, procurou-se identificar as fases da oscilação que possivelmente estiveram associadas a tal comportamento. 
Neste caso, as fases baixas estariam correlacionadas com a Chuva Fraca e, as fases altas correlacionadas com ○ ONI (Figura 63). Em função dessa probabilidade, identificamos nos anos de 1970, 1971, 1974, 1975, 1977, 1978, 1985, 1987, 1988 e 1999 as fases baixas que estariam significativamente e positivamente correlacionadas com a chuva FA. Por outro lado, identificamos nos anos de 1976, 1979, 1983, 1984, 1986, 1989, 1990, 1993 e 2009 as fases altas que estariam significativamente e positivamente correlacionadas com $\circ$ ONI (Tabela 27). A variação cíclica de Chuva Fraca no período de 1970 a 2009 durante a estação de primavera foi composta por 22 fases específicas. A partir do resultado negativo da correlação linear entre a tendência negativa de Chuva Fraca e a tendência positiva da ONI, procuramos identificar as fases da oscilação que possivelmente estiveram associadas a tal comportamento. Neste caso, as fases baixas estariam correlacionadas com a Chuva Fraca e, as fases altas correlacionadas com o ONI (Figura 63). Em função dessa probabilidade, identificamos nos anos de 1970, 1983, 1984, 1985, 1986, 1987, 1988, 1992, 1994, 1996, 2005, 2006 e 2008 as fases baixas que estariam significativamente e positivamente correlacionadas com a chuva FA. Por outro lado, identificamos nos anos de 1977, 1978, 1979, 1980, 1981, 1982, 1989, 1990, 2001, 2002, 2004 e 2009 as fases altas que estariam significativamente e positivamente correlacionadas com o ONI (Tabela 27).
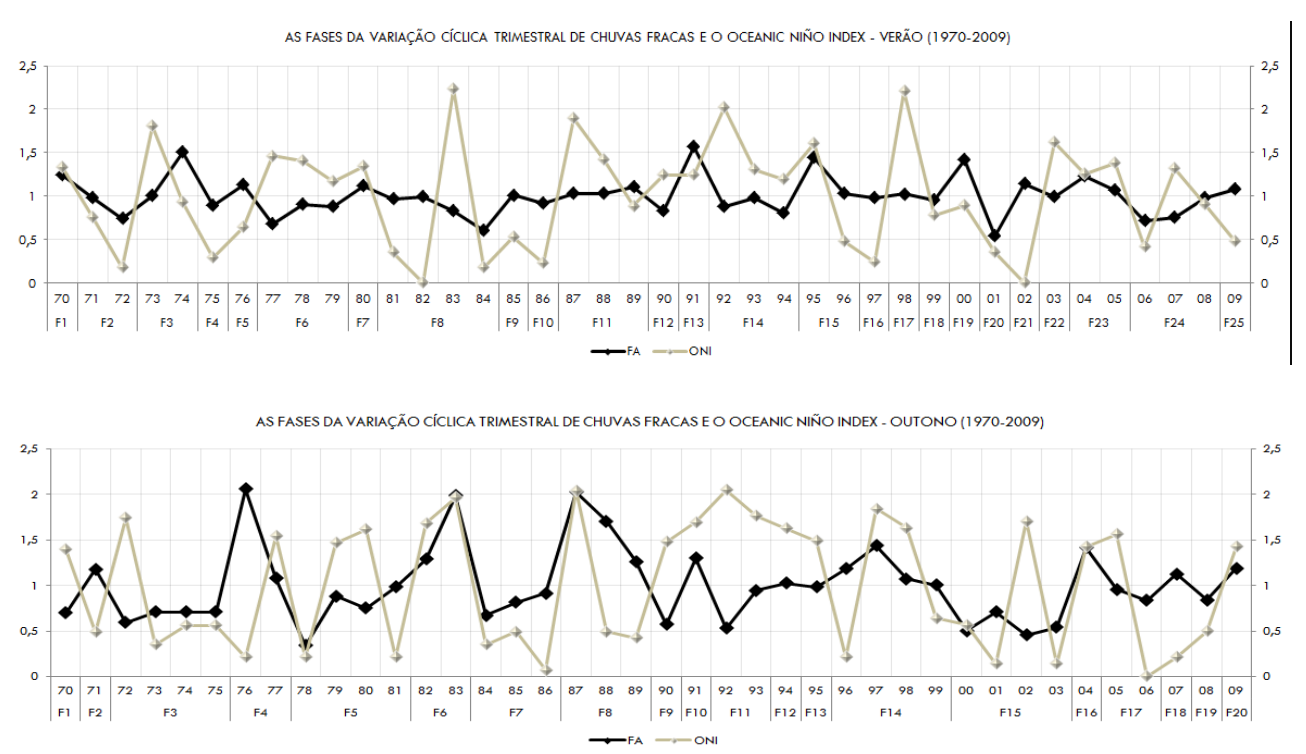

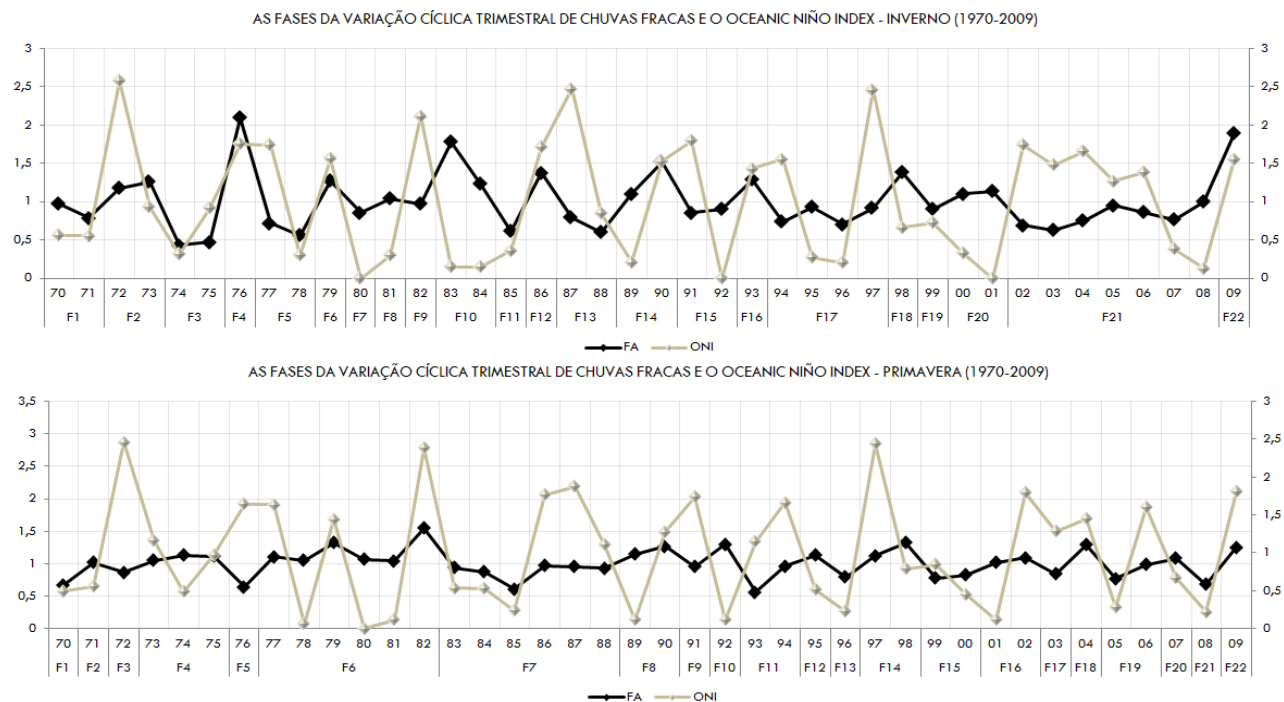

Figura 63 - Fases Específicas do Ciclo Trimestral de Chuva Fraca, Verão, Outono, Inverno e Primavera. A linha Branca corresponde à variação cíclica do ONI e a linha Preta de Chuva FA, para o Período de 1970-2009.

Tabela 27 - Correlação Linear entre a Frequência de Chuva Fraca observada na Estação do IAG e os Valores de ONI para Cada Estação do Ano e, para Cada Condição de Anomalia na Região de Niño3.4 (Eventos Neutros, ENOS, EN e LN). "A" representa as Séries Temporais de Chuva FA relativa às Séries Temporais do ONI "B". Assim, B1 (ONI), B2 (Neutro), B3 (ENOS), B4 (EN) e B5 (LN). Correlação "A" são os Tipos Fases Correlacionadas com a Chuva FA e Correlação "B" são os Tipos Fases Correlacionadas com o ONI.

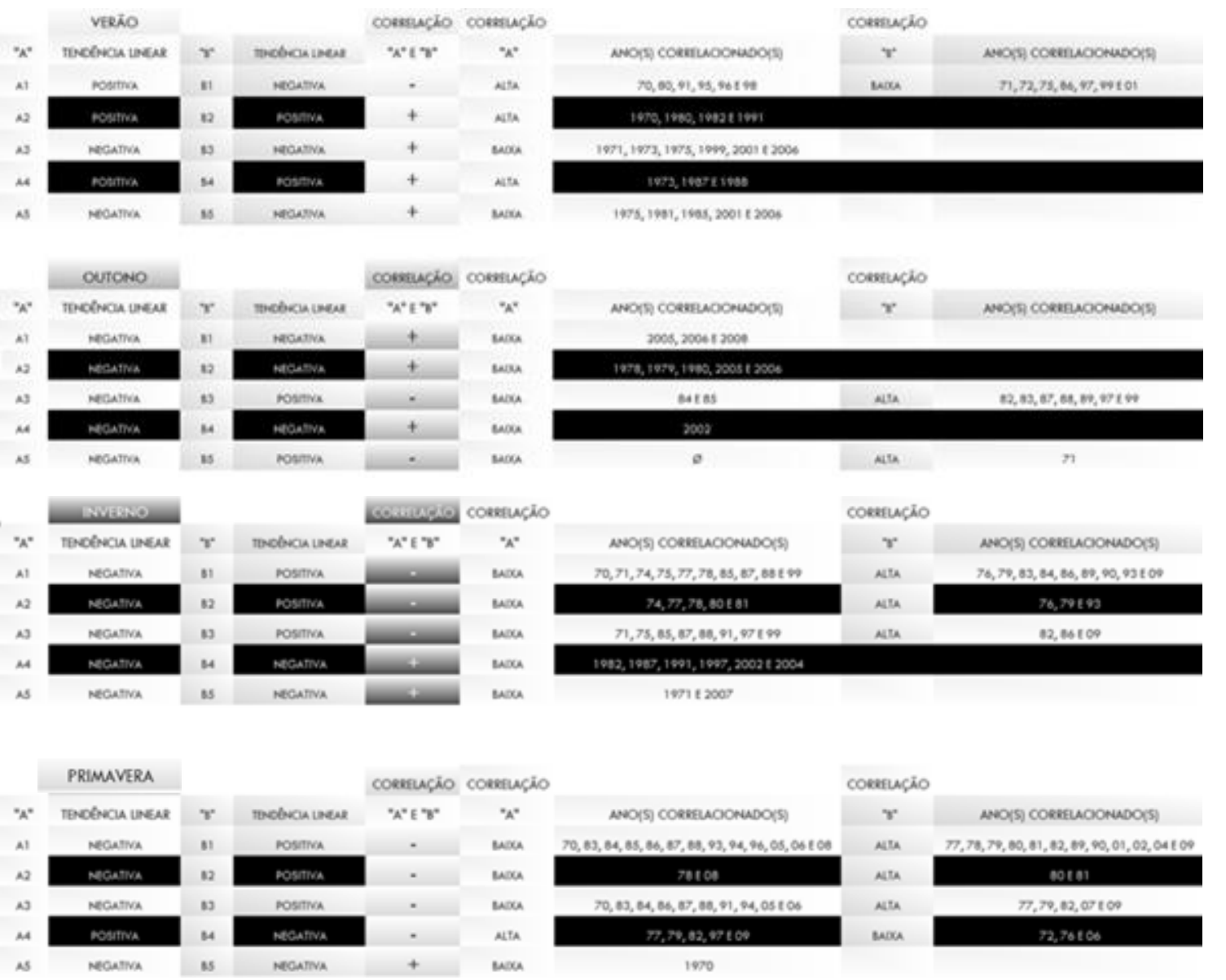




\subsubsection{5- A Hipótese Inicial e a Conclusão Final - FA II}

A conclusão final para análise trimestral de Chuva Fraca parte das distintas correlações identificadas, para cada estação climática, envolvendo o ajuste linear dos índices do ONI na região Niño3.4 e a frequência de chuva FA. De modo geral, no verão, inverno e primavera observamos que o ajuste linear negativo (positivo) do ONI não coincidiu positivamente com o ajuste de chuva FA. A exceção observada ocorreu na estação de outono, onde o ajuste linear negativo de chuva FA coincidiu positivamente com $\circ$ ajuste linear negativo do ONI. A Tabela 27 apresenta os resultados das demais correlações realizadas para as séries temporais do ONI em cada estação climática do ano. Após identificarmos as respectivas correlações lineares trimestrais entre a chuva FA e o ONI, analisamos os resultados das correlações cíclicas trimestrais. Neste caso, encontramos apenas três correlações cíclicas positivas e significativas (Tabela 26). A primeira foi identificada no verão, durante a fase $L N$. A segunda foi identificada no outono, durante a fase ENOS. A terceira foi identificada na primavera, durante o ONI.

A partir da combinação dos resultados observados durante a fase $L N$, na estação de verão, onde identificamos uma correlação positiva envolvendo ajustes lineares negativos e uma correlação cíclica significativa, analisamos por dedução e correlação que seja muito provável que tenha ocorrido um enfraquecimento das variações cíclicas de chuva FA em função da diminuição das amplitudes dos seus ciclos ao longo do período da fase La Niña. Ainda, podemos identificar o possível reflexo da combinação observada, em fases específicas, que podem ser visualizados através dos anos que estiveram correlacionados, de acordo com a Tabela 27.

\section{4- Chuva Moderada - 1,0 a 4,0 mm h-1}

As chuvas definidas como sendo moderadas e, que possivelmente estão associadas as "tempestades leves" atingem níveis pluviométricos equivalentes a $1,0-4,0 \mathrm{~mm} \mathrm{h-1.} \mathrm{A} \mathrm{partir}$ 
da hipótese inicial deste estudo, a intenção ao analisar este tipo de chuva, é a de concluir para a série temporal de 1970-2009, a existência ou não de um nível de correlação aceitável, envolvendo o comportamento de sua frequência e as variações registradas na temperatura da superfície do mar na região Niño3.4. De acordo com tal hipótese, o estudo estabelece uma reflexão a partir três possibilidades, que podem ou não atuar em conjunto. A reflexão teórica e quantitativa analisa a possibilidade de uma possível correlação, que pode ser ou não, isoladamente linear, cíclica e/ou especificamente por fases, altas ou baixas da variação cíclica. A cronologia das escalas de análise foi dividida em anuais e trimestrais. A intenção desta reflexão científica é a de presumir a partir dos resultados, a possibilidade de ter ocorrido uma intensificação ou enfraquecimento, nos quadros evolutivos das variações cíclicas de Chuva Moderada, a partir do aumento ou da diminuição das amplitudes dos seus respectivos ciclos, em função do aquecimento ou resfriamento, diagnosticado através dos registros da TSM, na região Niño3.4.

\subsection{1 - Análise Anual}

A análise anual possui a finalidade de apresentar uma conclusão obtida a partir da identificação do tipo de correlação existente na intenção de sugerir a possibilidade de haver uma relação anual envolvendo a Chuva Moderada (MO) e o Oceanic Niño Index. Neste caso, também estão inclusos, os resultados das correlações realizadas para as fases ENOS, Neutra, El Niño e La Niña.

\subsubsection{1 - Frequência Anual de Chuva Moderada}

A partir da frequência anual de Chuva Moderada ( 1,0 a 4,0 mm h-1), representada no gráfico da Figura 64, é possível identificar que a frequência máxima ocorreu no ano de 1983, relativo à contagem de 328 casos horários. 


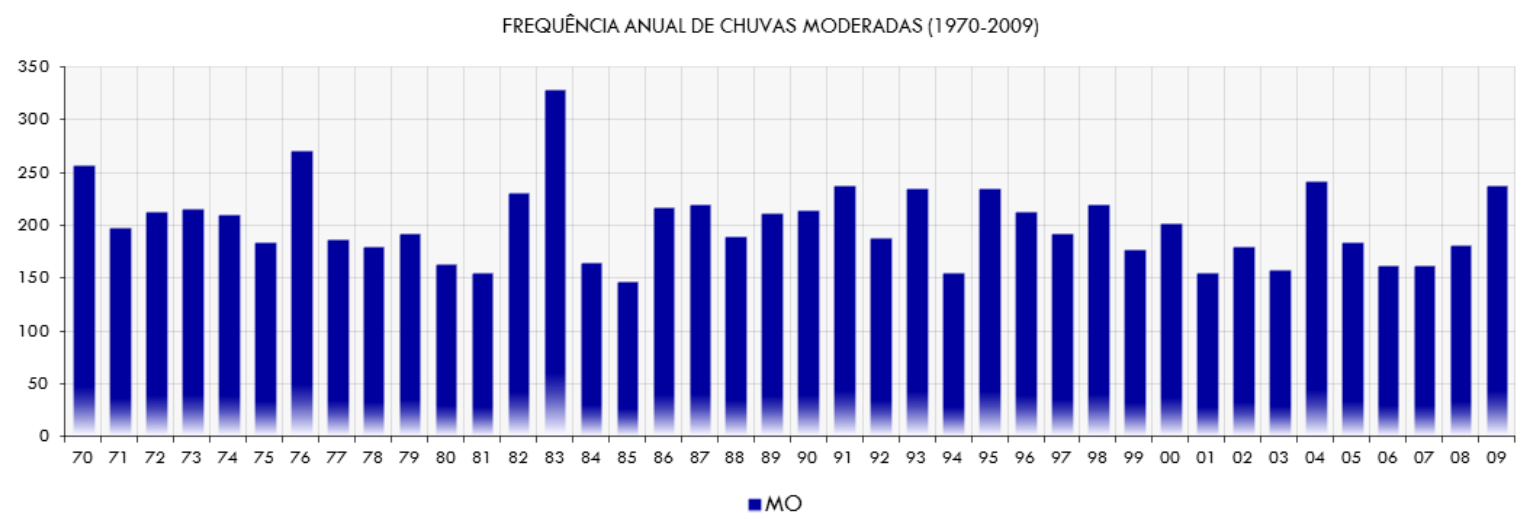

Figura 64 - Frequência Anual de Chuva Moderada entre 1970-2009.

\subsubsection{2- Análise do Ajuste Linear}

O ajuste linear da frequência anual de Chuva Moderada no município de São Paulo indica a diminuição desta frequência ao longo da série temporal analisada, de 1970 a 2009, tal como ilustrada na Figura 65. A análise realizada para as fases, neutra, ENOS, El Niño e La Niña, separadamente, mostra que, em todos os casos, a frequência anual de Chuva Moderada diminui com o tempo (Figura 66). A comparação entre a tendência linear da frequência de Chuva Moderada e do ONI indica que enquanto o ONI assume valores cada vez mais intensos, no decorrer da série temporal, a frequência de Chuva Moderada diminui, tal como indicado na Tabela 28. A exceção ocorre no caso de eventos de EN que apresenta tendência negativa nula de TSM, ao longo do período analisado, concomitantemente à tendência negativa de frequência de Chuva Moderada (ver tabela 28, linha 4).

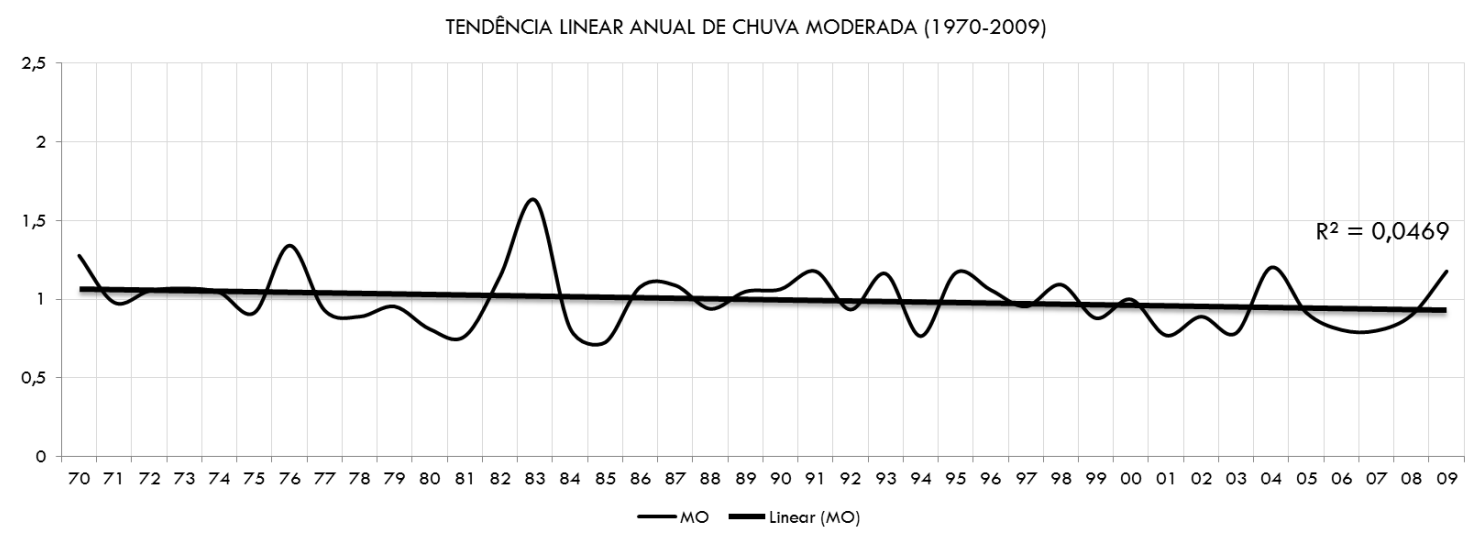

Figura 65 - Ajuste Linear da Frequência Anual de Chuva Moderada entre 1970-2009. 

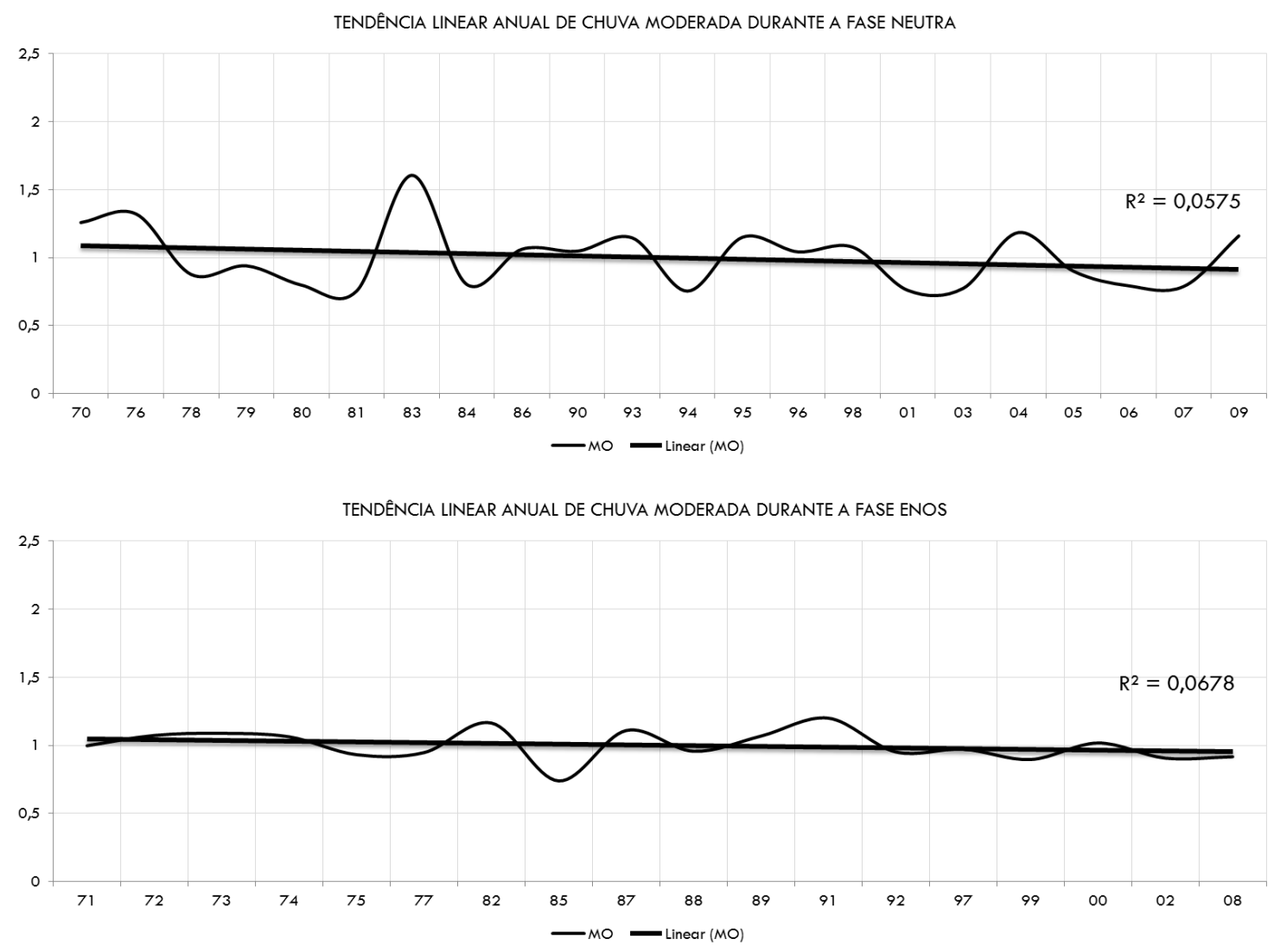

TENDÊNCIA LINEAR ANUAL DE CHUVA MODERADA DURANTE A FASE EL NIÑO

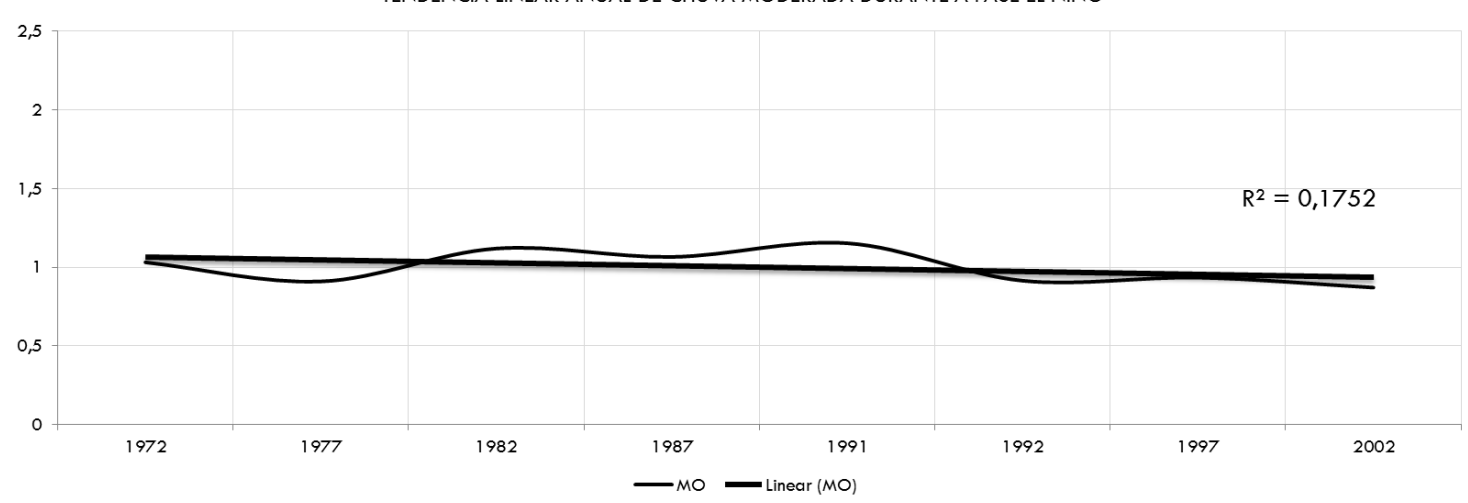

TENDÊNCIA LINEAR ANUAL DE CHUVA MODERADA DURANTE A FASE LA NIÑA

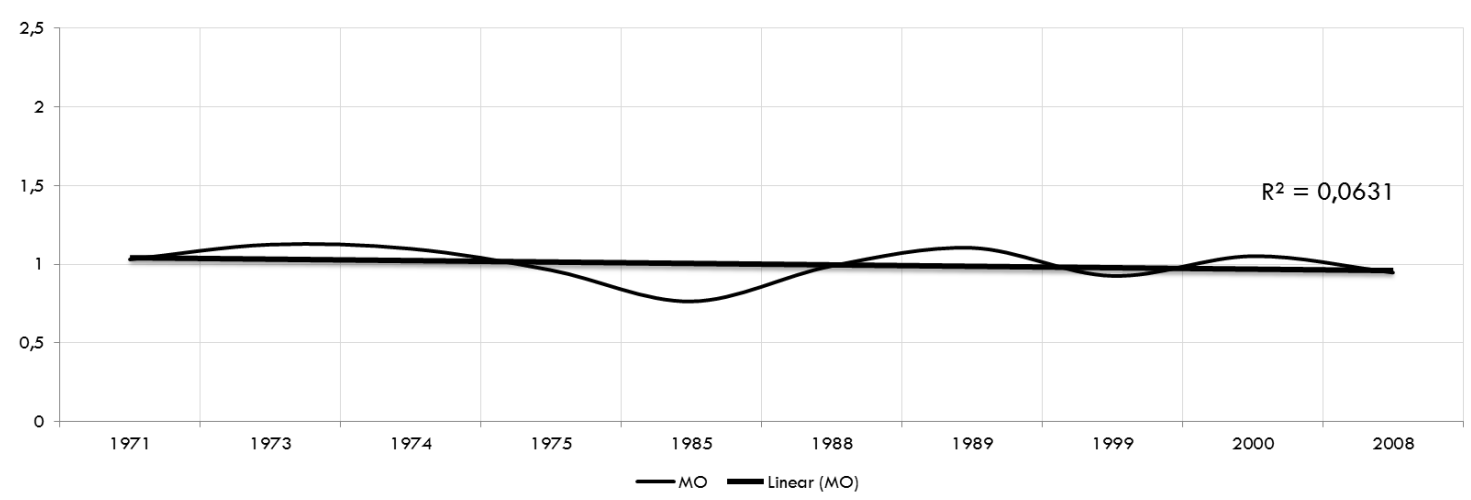

Figura 66 - Tendência Linear da Frequência Anual de Chuva Moderada para a Fase, Neutra, ENOS, EN e LN, entre 1970-2009. 
Os resultados observados através dos ajustes lineares negativos para a série anual revelam que as frequências analisadas no intervalo horário refletiram positivamente com os resultados das análises diárias realizadas por Cabral (2002).

Tabela 28 - Tendência Linear Anual de Chuva Moderada e do ONI para o Período de 1970 a 2009. A Primeira Linha da Tabela indica a Tendência Linear de Todos os Dados Anuais e, as Demais Linhas indicam a Tendência Linear para cada Fase do ONI.

\begin{tabular}{cc|c|c|c|c|c}
\hline "A" & TIPO DE CHUVA & TENDENCIA UINEAR & "B" & CATEGORIA & TENDENCIA UINEAR & CORRELAÇÄO UINEAR \\
\cline { 2 - 3 } A1 & MO & NEGATIVA & B1 & ONI & POSITIVA & NEGATIVA \\
A2 & MO & NEGATIVA & B2 & NEUTRO & POSITIVA & NEGATIVA \\
A3 & MO & NEGATIVA & B3 & ENOS & POSITIVA & NEGATIVA \\
A4 & MO & NEGATIVA & B4 & EL NIÑO & NEGATIVA & POSITIVA \\
\hline A5 & MO & NEGATIVA & B5 & LA NIÑA & POSITIVA & NEGATIVA
\end{tabular}

\subsubsection{3- Variação Cíclica de Chuva Moderada}

A variação cíclica anual de Chuva Moderada pode ser observada na Figura 67. É possível notarmos a oscilção presente na série temporal completa, de 1970 a 2009, formada por 17 fases altas (esferas vermelhas) e 23 fases baixas (esferas azuis).

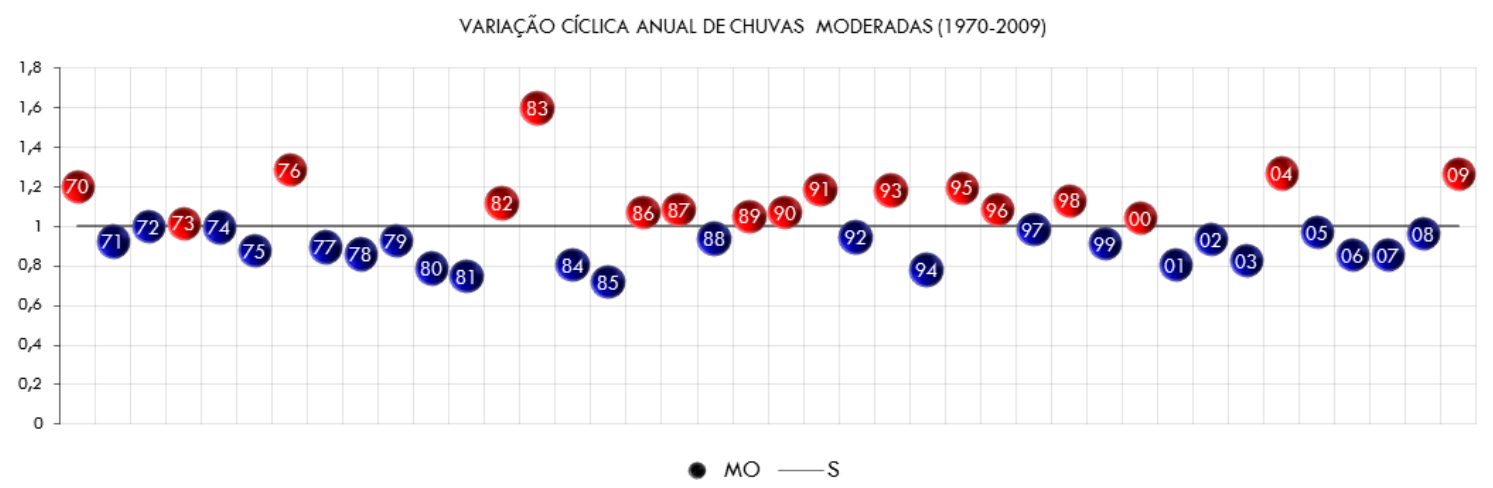

Figura 67 - Variação Cíclica Anual da Frequência de Chuva Moderada entre 1970 e 2009.

\subsubsection{4- Análise da Correlação Cíclica}

A partir dos resultados do teste de significância - t-"Student" - notamos que os resultados do cálculo de correlação linear, para as séries cíclicas, entre ONI e a frequência 
anual de Chuva Moderada, nas fases, Neutra, ENOS e La Niña não foram significativos (Tabela 29). Por outro lado, observamos que a fase de EN (Tabela 29, linha 4) apresentou correlação linear significativa (Figura 68).

Tabela 29 - Correlação Linear entre a Anomalia de ONI e da Frequência Anual de Chuva Moderada entre 1970 e 2009, sem Tendência Linear (Série Cíclica).

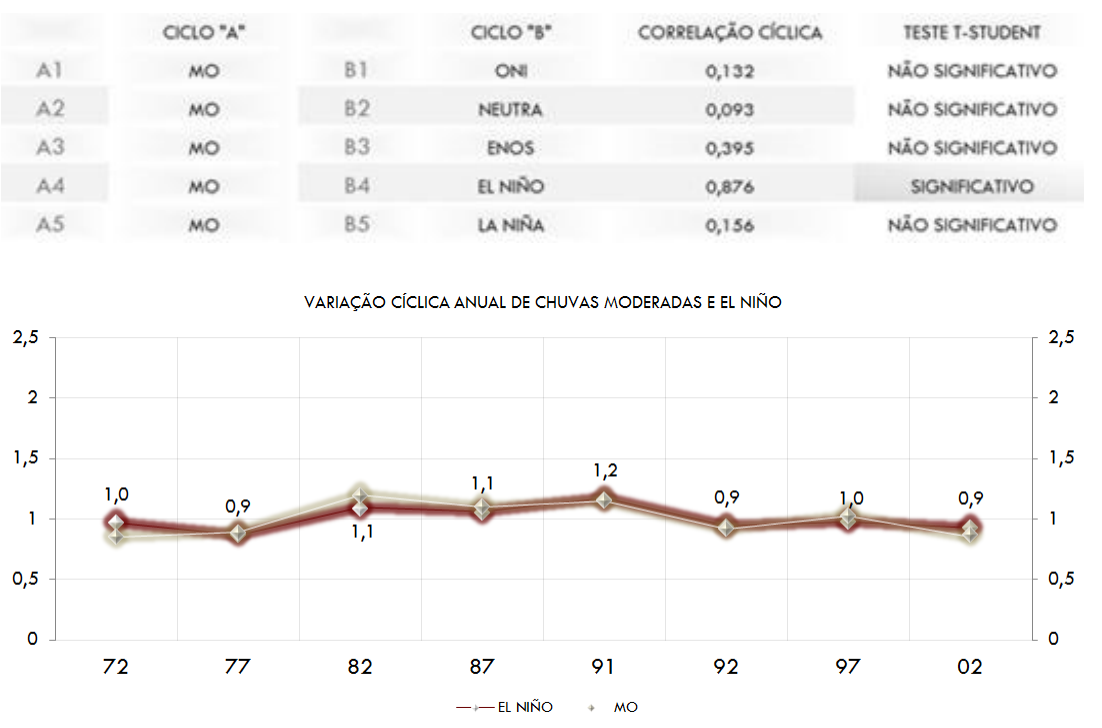

Figura 68 - Variações Cíclicas Anuais da Fase EL Niño e de Frequência de Chuva Moderada, entre 1970 e 2009.

\subsubsection{5- Análise Específica do Ciclo de Chuva - MO}

Os resultados de tal análise revelam as possíveis correlações existentes entre as fases altas e baixas da frequência de Chuva Moderada e do ONI. Neste caso, na Figura 69 identificamos a série específica através das fases altas $(\bar{x}>1)$ e baixas $(\bar{x}<1)$ da variação cíclica da frequência de chuva MO.

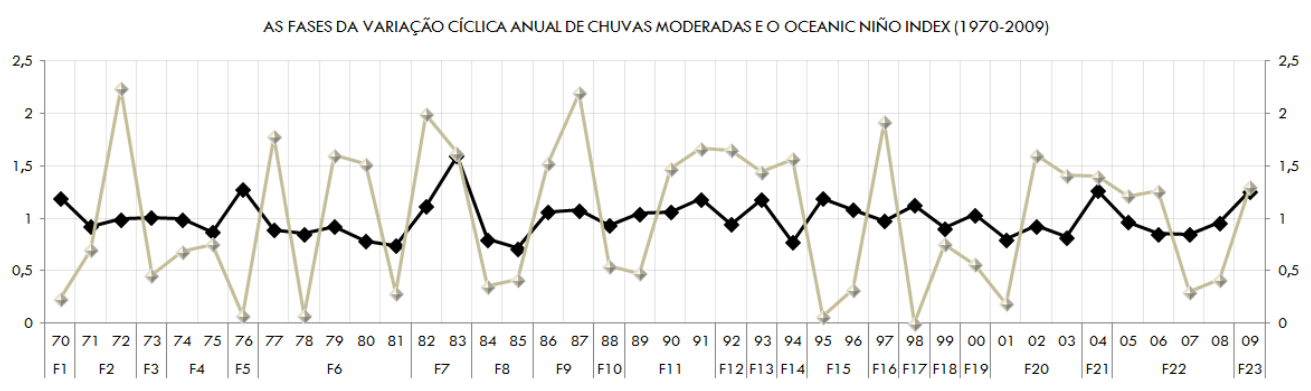

Figura 69 - Fases Específicas do Ciclo Anual de Chuva Moderada. A linha Branca corresponde à variação cíclica do ONI e a linha Preta de Chuva MO, para o Período de 1970-2009. 
A variação cíclica anual de Chuva Moderada no período de 1970 a 2009 foi composta por 23 fases específicas (altas e baixas). No entanto, a partir do resultado negativo da correlação linear entre a tendência negativa de Chuva Moderada e a tendência positiva da ONI, procuramos identificar as fases da oscilação que possivelmente estiveram associadas a tal comportamento. Neste caso, as fases baixas estariam correlacionadas com a Chuva Moderada e, as fases altas correlacionadas com o ONI. A partir dessa probabilidade foram identificadas 4 fases baixas, significativamente e positivamente correlacionadas, nos anos de $1971,1972,1988,1999,2001,2002$ e 2003. Por outro lado, foram identificadas 5 fases altas, significativamente e positivamente correlacionadas, nos anos de 1986, 1987, 1989, 1990, 1991, 1993, 2004 e 2009.

\subsubsection{6- A Hipótese Inicial e a Conclusão Final - MO I}

A conclusão final para análise anual de Chuva Moderada foi baseada a partir dos resultados envolvendo os três procedimentos aplicados. De modo geral, durante este período, os resultados sugerem que o aquecimento observado na região Niño3.4, não coincidiu com o aumento na frequência deste tipo de chuva, com exceção da fase El Niño. Nesta fase, foi possível observar que o resfriamento na TSM coincidiu com a diminuição na frequência deste tipo de chuva. A respeito dos resultados das correlações cíclicas, apenas a série El Niño, esteve significativamente correlacionada. Por último, é possível sugerir que os reflexos do resultado do ajuste linear possam ter ocorrido, pontualmente, em fases e anos específicos. Desta forma, para os quatros casos de correlação linear negativa (ONI, Fase Neutra, ENOS e La Niña) é provável que as fases altas, quando significativamente e positivamente correlacionados, estivessem associadas a tais ajustes lineares positivos. Por outro lado, é também possível sugerir que as fases baixas, quando significativamente e positivamente correlacionados, estivessem associadas à Chuva Moderada. A respeito da exceção, observada para o caso de correlação envolvendo a fase El Niño foi possível notar que além 
uma positiva correlação linear também ocorreu uma significativa correlação cíclica. A partir desse resultado, identificamos que neste caso, provavelmente, ocorreu um enfraquecimento das variações cíclicas, em função da diminuição de suas respectivas amplitudes ao longo da série. Neste caso, é possível identificar uma consonância com a expectativa de Grimm et al (1999), ou seja, nota-se a influência de padrões de macroescala alterando a frequência de circulação, que neste caso diminui suprimindo a precipitação. Neste caso, podem-se identificar os reflexos dessa combinação a partir das fases baixas na Figura 70.

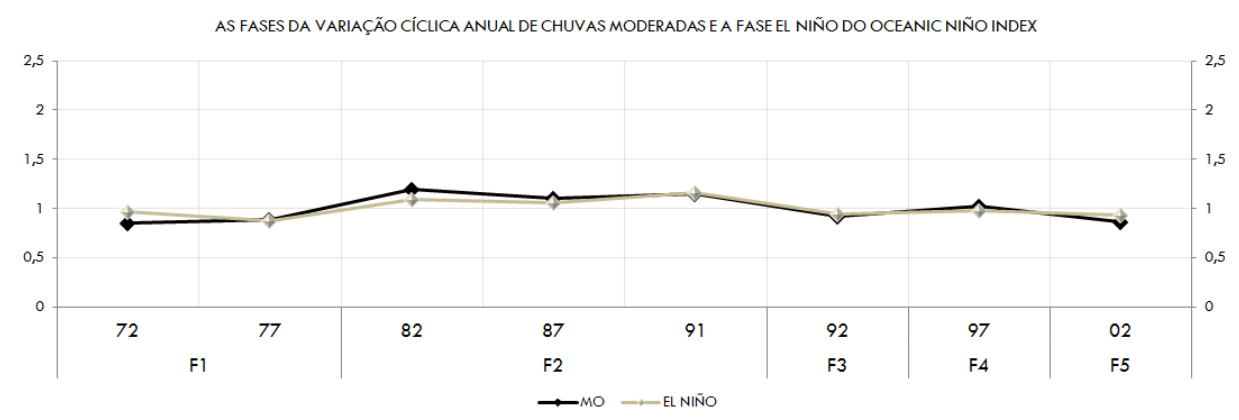

Figura 70 - Fases Específicas do Ciclo Anual de Chuva MO durante a Série Temporal de EN. A linha branca corresponde à variação cíclica do EN e a linha cinza de Chuva MO.

A Tabela 30 apresenta uma síntese dos resultados finais da correlação por fases específicas entre a frequência de Chuva Moderada e o ONI, entre 1970 e 2009.

Tabela 30 - Correlação Anual em Fases Específicas. A Coluna "A" indica ○ Ajuste Linear da Chuva MO nas Séries Temporais "B" correspondente o ONI e suas Fases. A Última Coluna aponta os Possíveis Anos que estiveram Correlacionados com o Resultado da Correlação Linear do Ajuste "A" e "B".

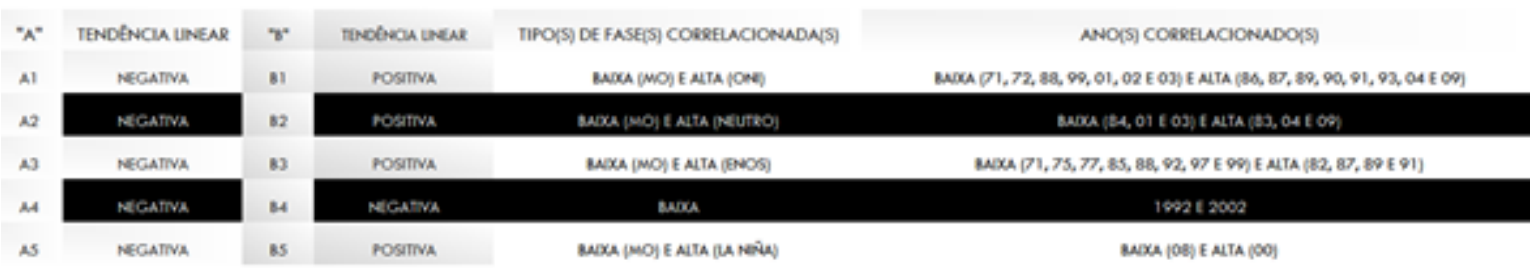

\subsection{2- Análise Trimestral}

A segunda análise envolve a relação trimestral entre a Chuva Moderada e o Oceanic Niño Index. Nestas análises estão incluídas as séries temporais, definidas como 
relativas, ou seja, períodos específicos da série integral, classificadas como ENOS, fase Neutra, El Niño e La Niña. Trata-se de uma análise individualizada, envolvendo os três procedimentos elementares adotados, que foram aplicados para as quatro estações climáticas do ano, ou seja, verão, outono, inverno e primavera.

\subsubsection{1 - Frequência Trimestral de Chuva Moderada}

Os resultados das frequências trimestrais de Chuva Moderada (1,0 a 4,0 $\left.\mathrm{mm} \mathrm{h}^{-1}\right)$ podem ser observados a partir da Figura 71. No outono, inverno e primavera, a tendência linear de chuva MO, durante o período de 1970 a 2009, é negativa (Figura 72). Por outro lado, a tendência linear, deste tipo de chuva, para o verão, pode ser considerada como sendo nula ou estável.

FREQUÊNCIA TRIMESTRAL DE CHUVAS MODERADAS - VERÃO (1970-2009)

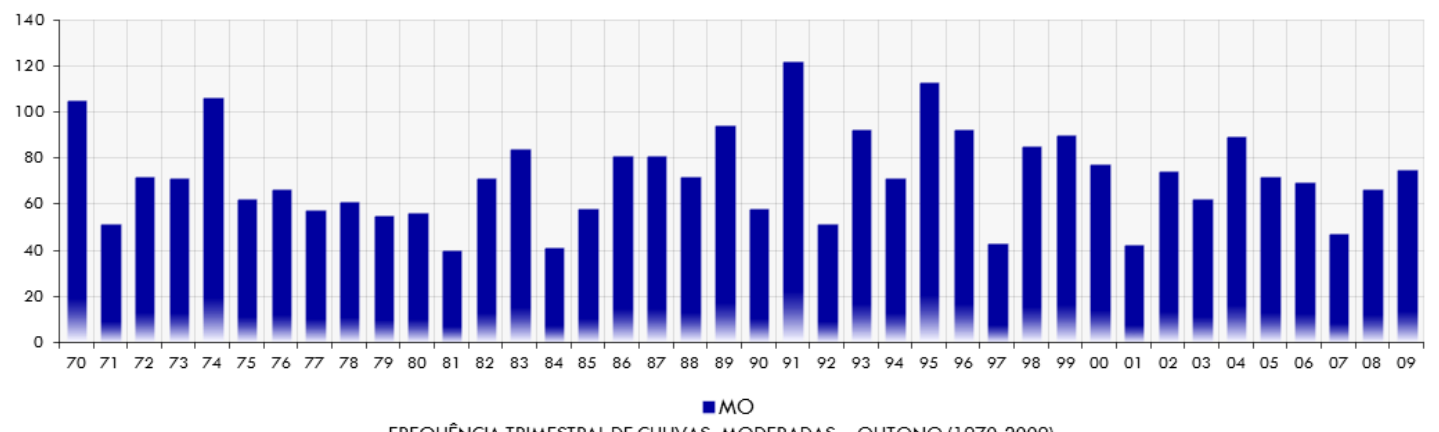

FREQUÊNCIA TRIMESTRAL DE CHUVAS MODERADAS - OUTONO (1970-2009)

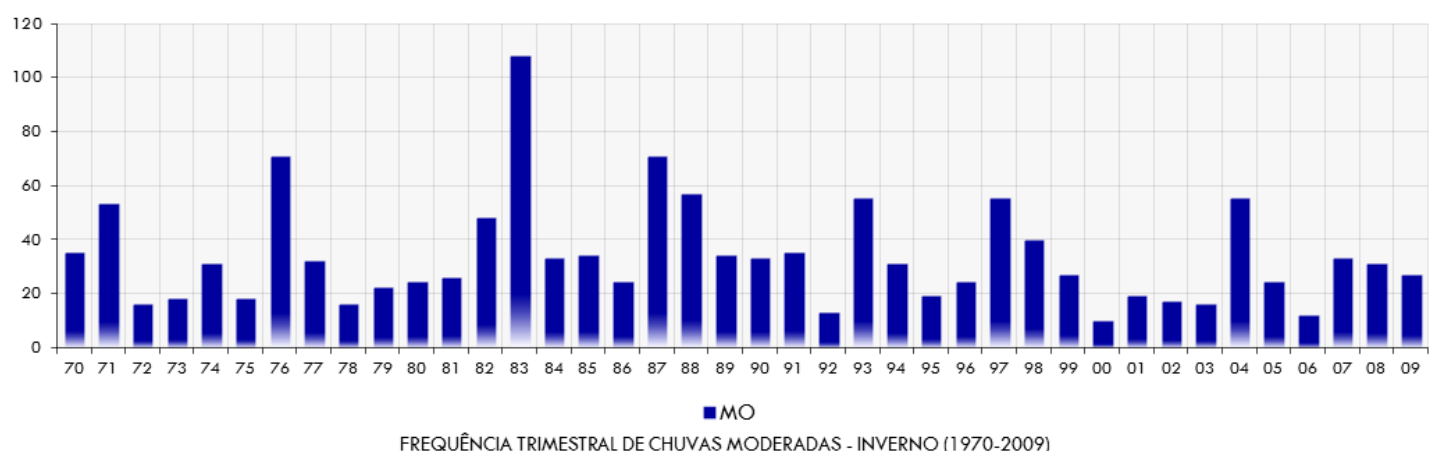

FREQUÊNCIA TRIMESTRAL DE CHUVAS MODERADAS - INVERNO (1970-2009)

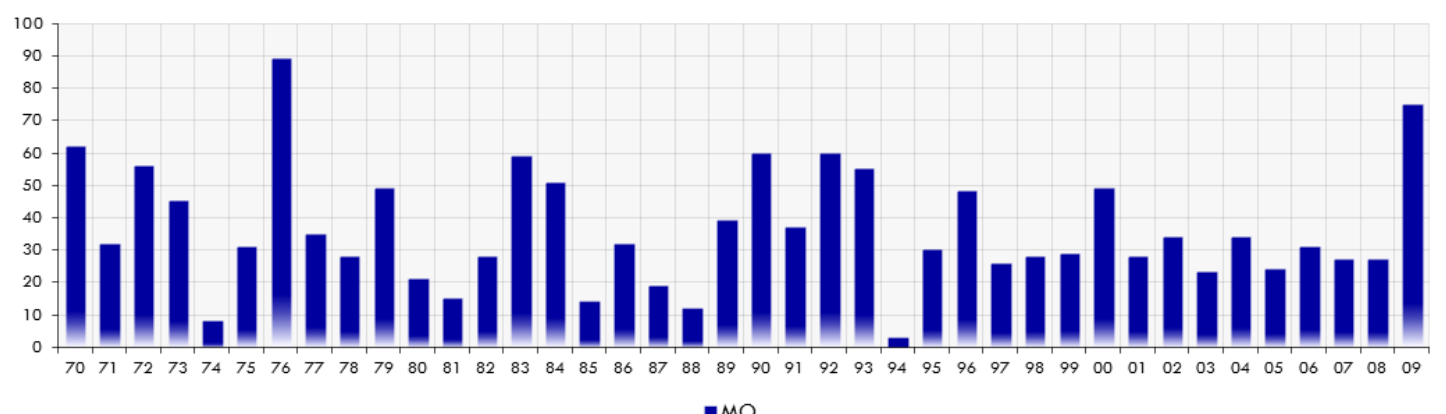




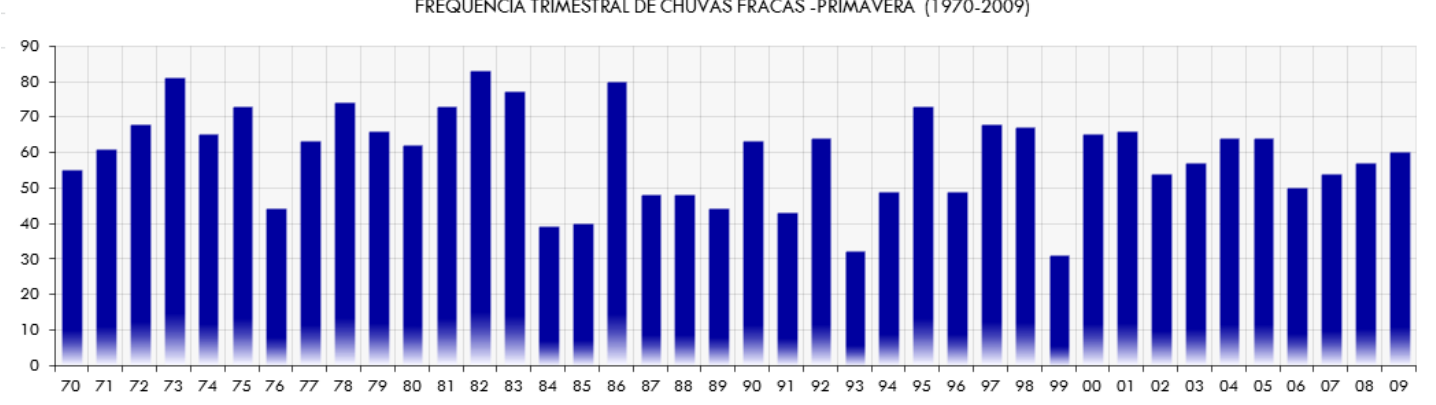
- MO

Figura 71 - Frequência Trimestral de Chuva Moderada na Estação do IAG-USP durante o Verão, Outono, Inverno e Primavera para o Período de 1970 a 2009.
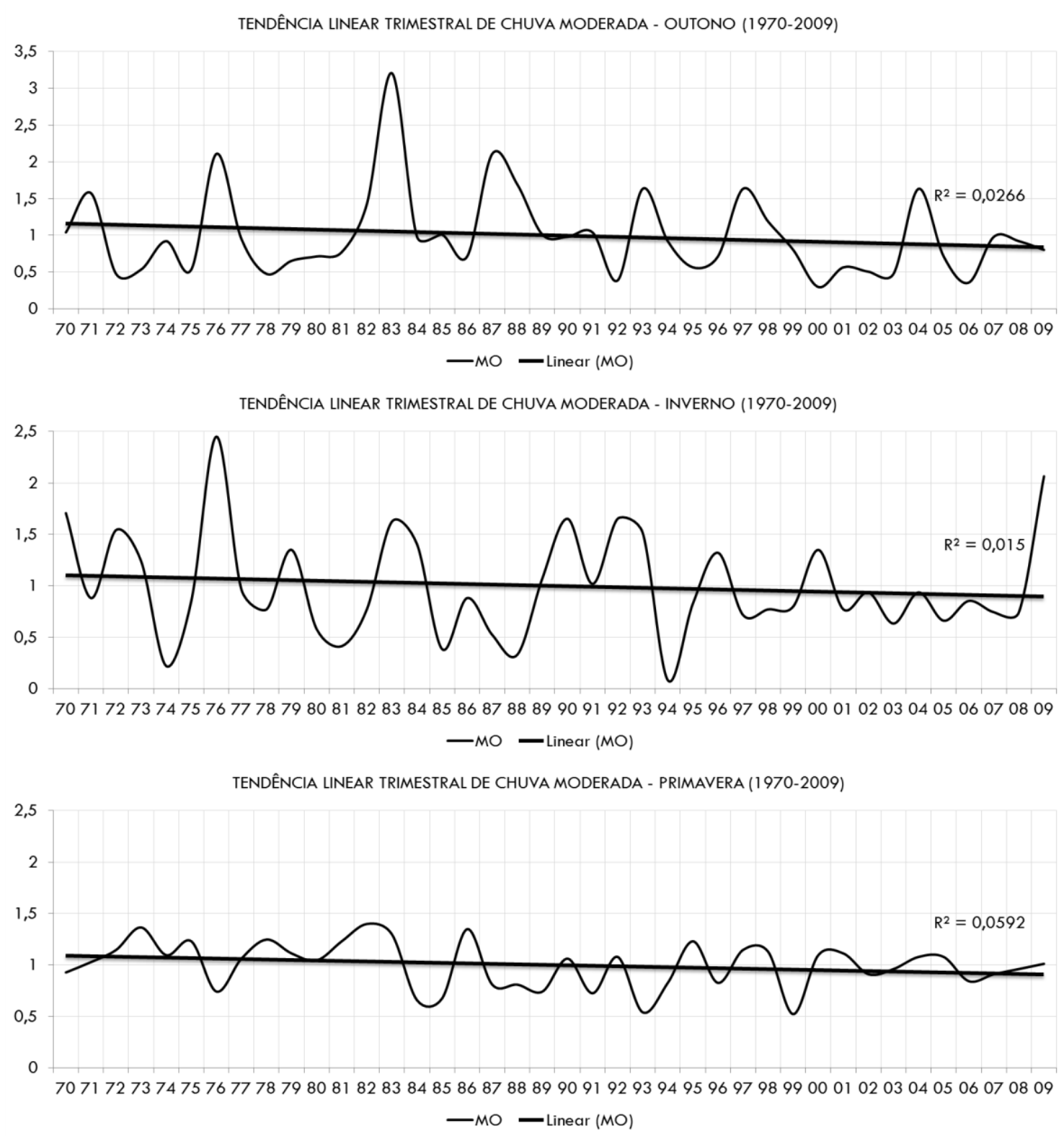

Figura 72 - Ajuste Linear Trimestral de Chuva Moderada para as Estações de Outono, Inverno e Primavera, no Período de 1970 a 2009. 
A maioria das séries temporais do ONI apresentarm tendência linear negativa, neste caso incluímos os ajustes lineares mais significativos nas Figuras 73-76. A excessão encontrada foi à tendência linear positiva da fase El Niño durante o verão (Figura 75). Nestas figuras observamos que durante a fase neutra, os ajustes negativos foram identificados no outono, inverno e primavera (Figura 73). Na fase ENOS, os ajustes negativos foram identificados no outono e na primavera (Figura 74). Na fase $L N$, os ajustes negativos foram identificados no outono e na primavera (Figura 76).
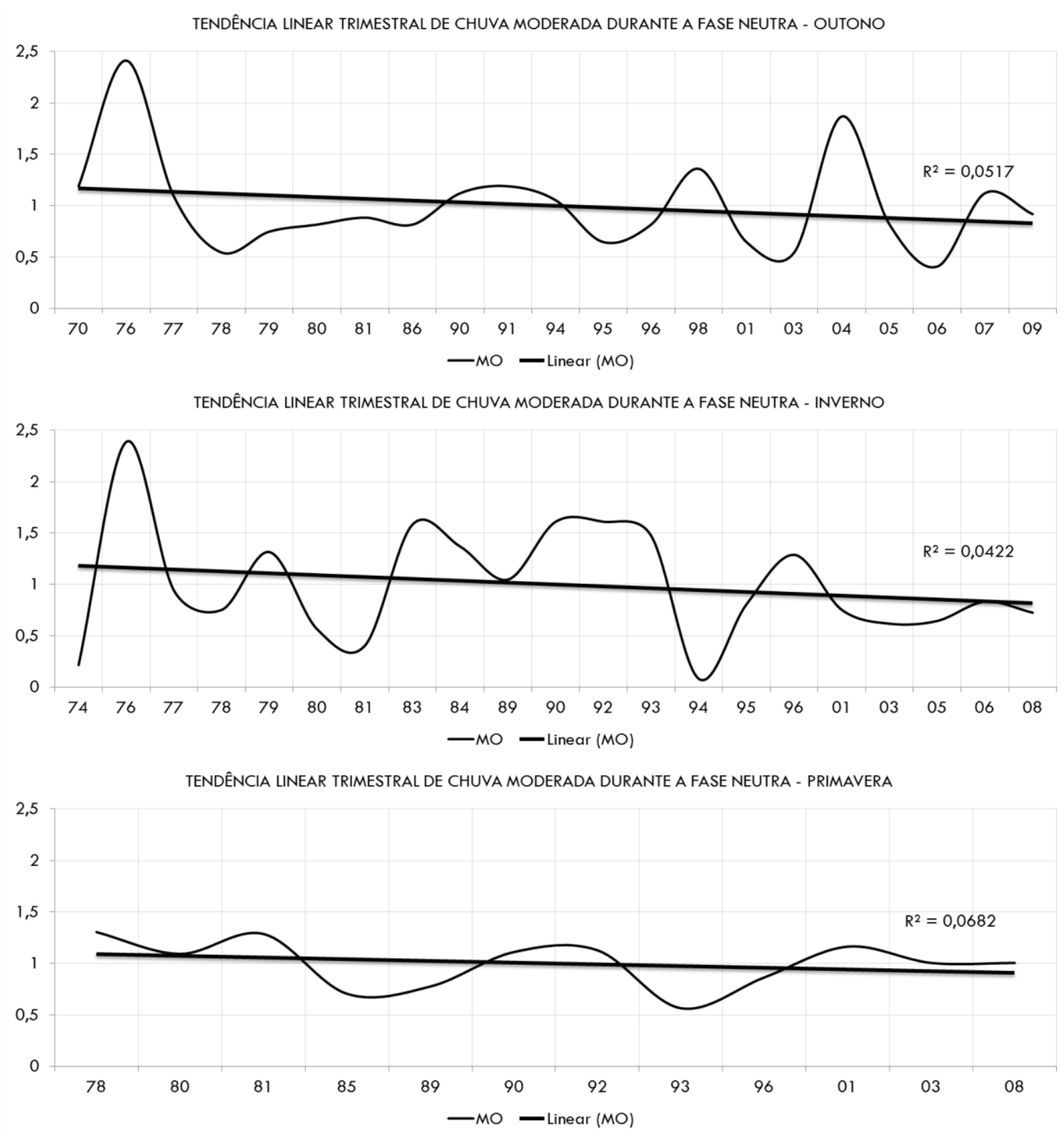

Figura 73 - Ajuste Linear Trimestral de Chuva Moderada para as Estações de Outono, Inverno e Primavera durante a fase Neutra. 

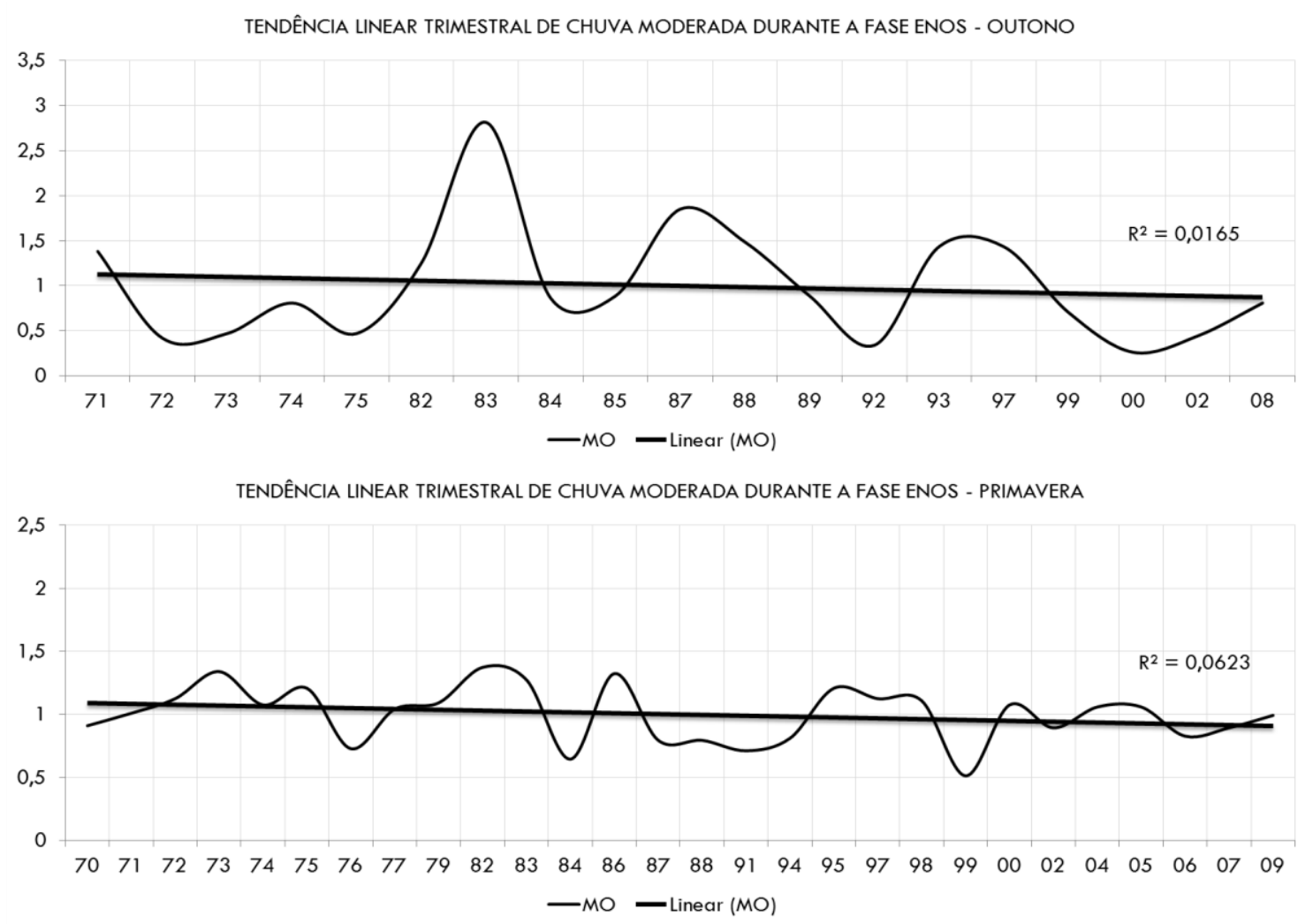

Figura 74 - Ajuste Linear Trimestral de Chuva Moderada para as Estações de Outono e Primavera durante a fase ENOS.

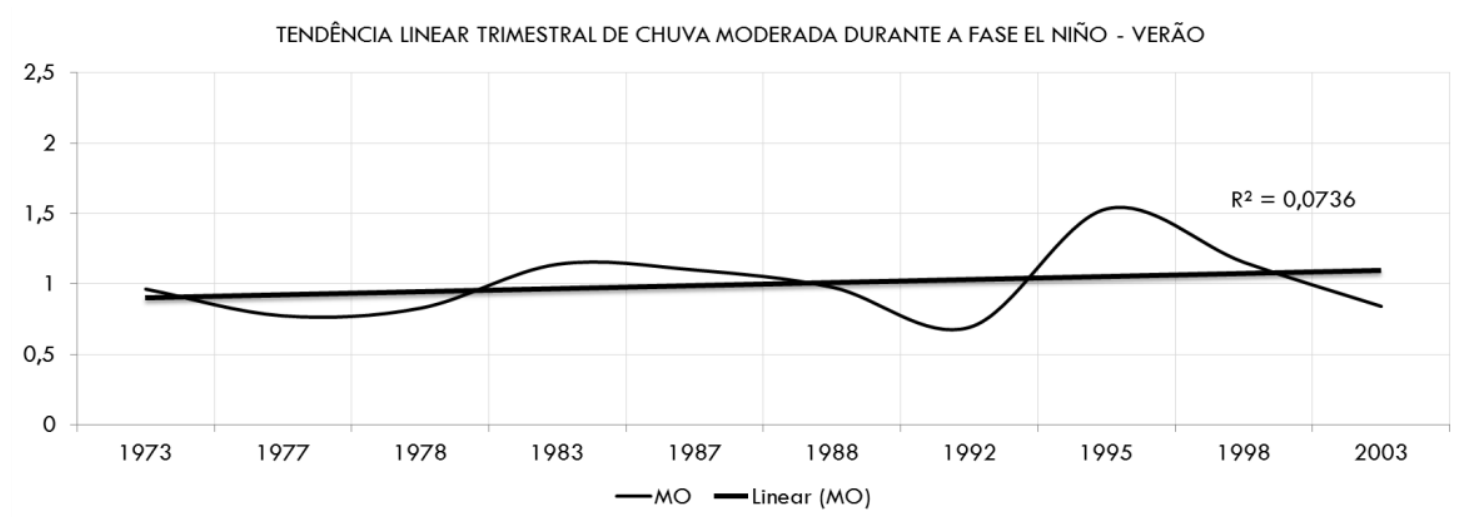

Figura 75 - Ajuste Linear Trimestral de Chuva Moderada para a Estação de Verão durante a fase El Niño.

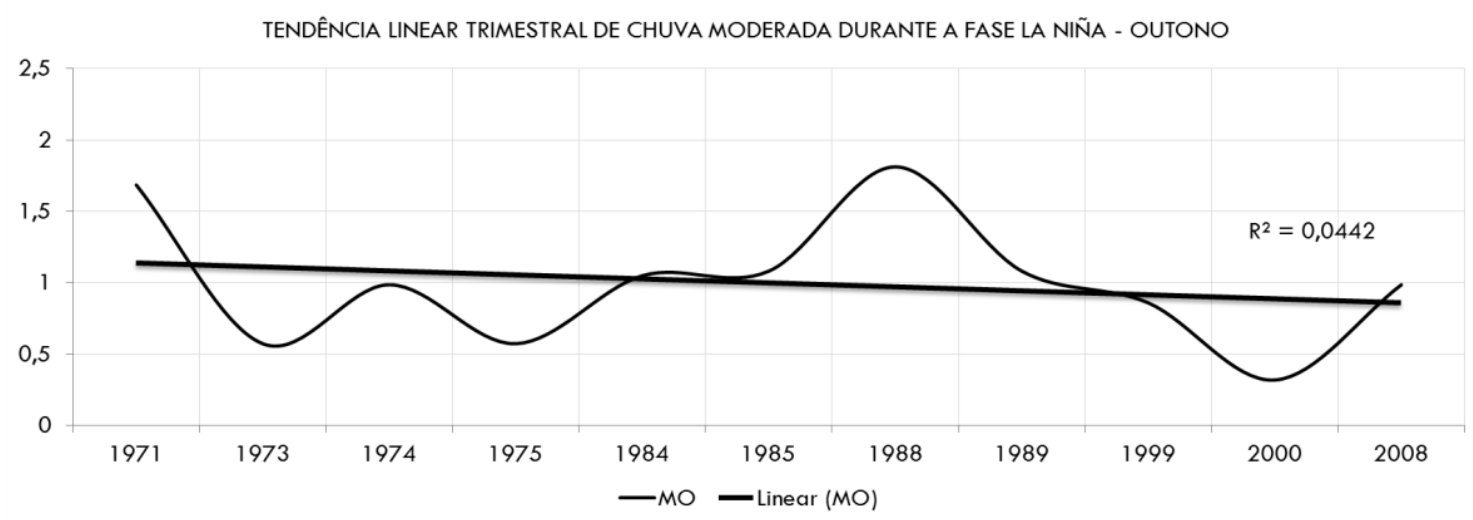




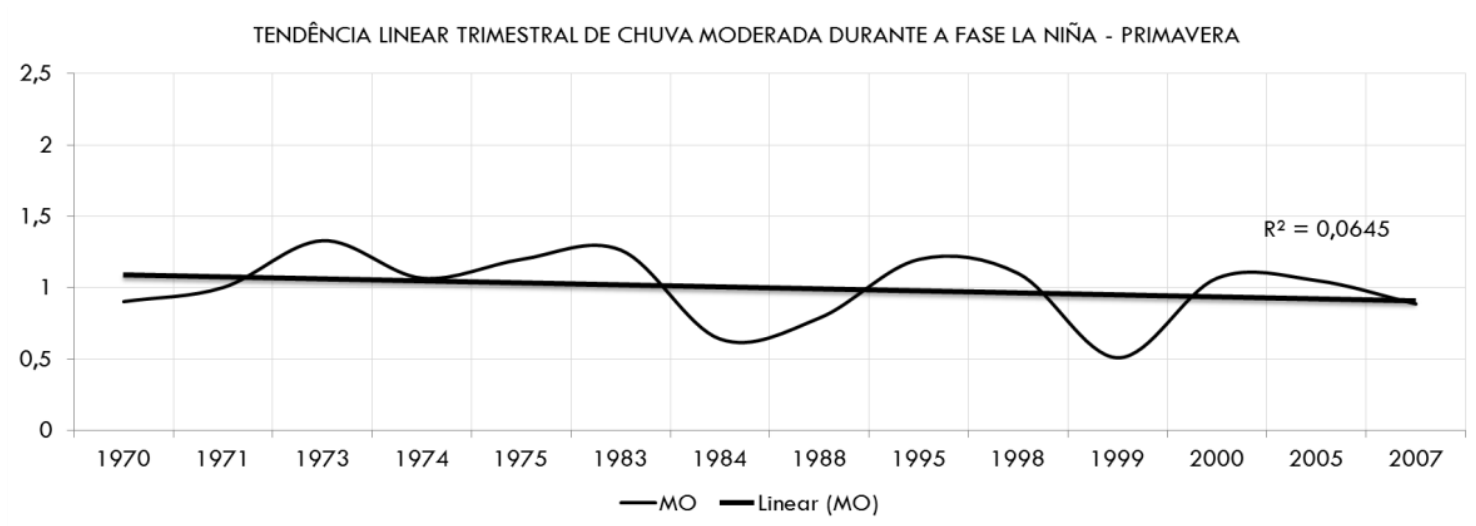

Figura 76 - Ajuste Linear Trimestral de Chuva Fraca para as Estações de Outono e Primavera durante a fase La Niña.

Os resultados trimestrais por fases também coincidem com os resultados identificados no trabalho de Cabral (2002). Ou seja, mesmo em séries temporais específicas o padrão de diminuição da frequência de chuvas mais leves se manteve. No entanto, a fase específica correspondente a de El Niño, novamente, contrariou a espectativa. De modo geral, a Tabela 31 indica que menos da metade dos casos envolvendo correlações lineares entre a chuva MO e ONI foram positivas (+). No total foram 7 correlações positivas que apresentaram haver uma correlação estatística, em todas as estações climáticas do ano, entre as chuvas $M O$ e a série temporal integral (ONI) e as séries temporais relativas (neutra, ENOS, EN e LN). As correlações lineares ocorreram com mais frequência durante o outono e a primavera. $O$ destaque é a fase de EN que apresentou correlações positivas em todas as estações.

Tabela 31 - Correlação Linear Trimestral entre a Tendência Linear Trimestral de Chuva Moderada e a Tendência Linear Trimestral do ONI incluindo as Fases, Neutra, ENOS, EN e LN.

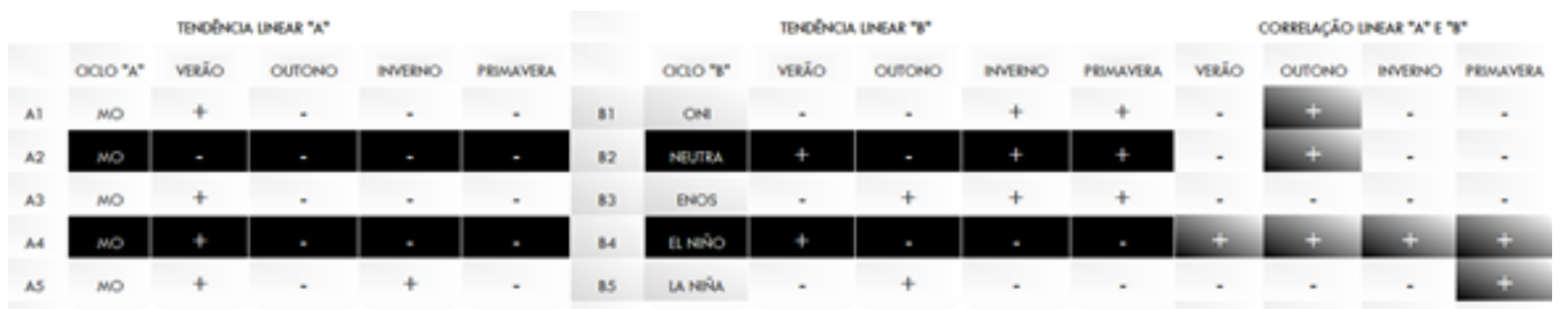

A frequência da chuva $M O$, durante o verão, diminui apenas durante a fase Neutra.

Durante o outono e a primavera, a frequência da chuva MO diminui em todos os casos 
(Tabela 31). No inverno, a frequência da chuva MO aumenta somente na fase LN. Contudo, considerando todas as estações climáticas, no período de 1970 a 2009, verificamos que a frequência de chuva MO diminui no decorrer do tempo, exceto no verão onde a tendência linear positiva não é significativa (Tabela 31).

\subsubsection{2- Variação Cíclica Trimestral de Chuva - MO}

A variação das anomalias da frequência de chuva MO para o período de 1970 a 2009, para as quatro estações do ano está ilustrada na Figura 77.

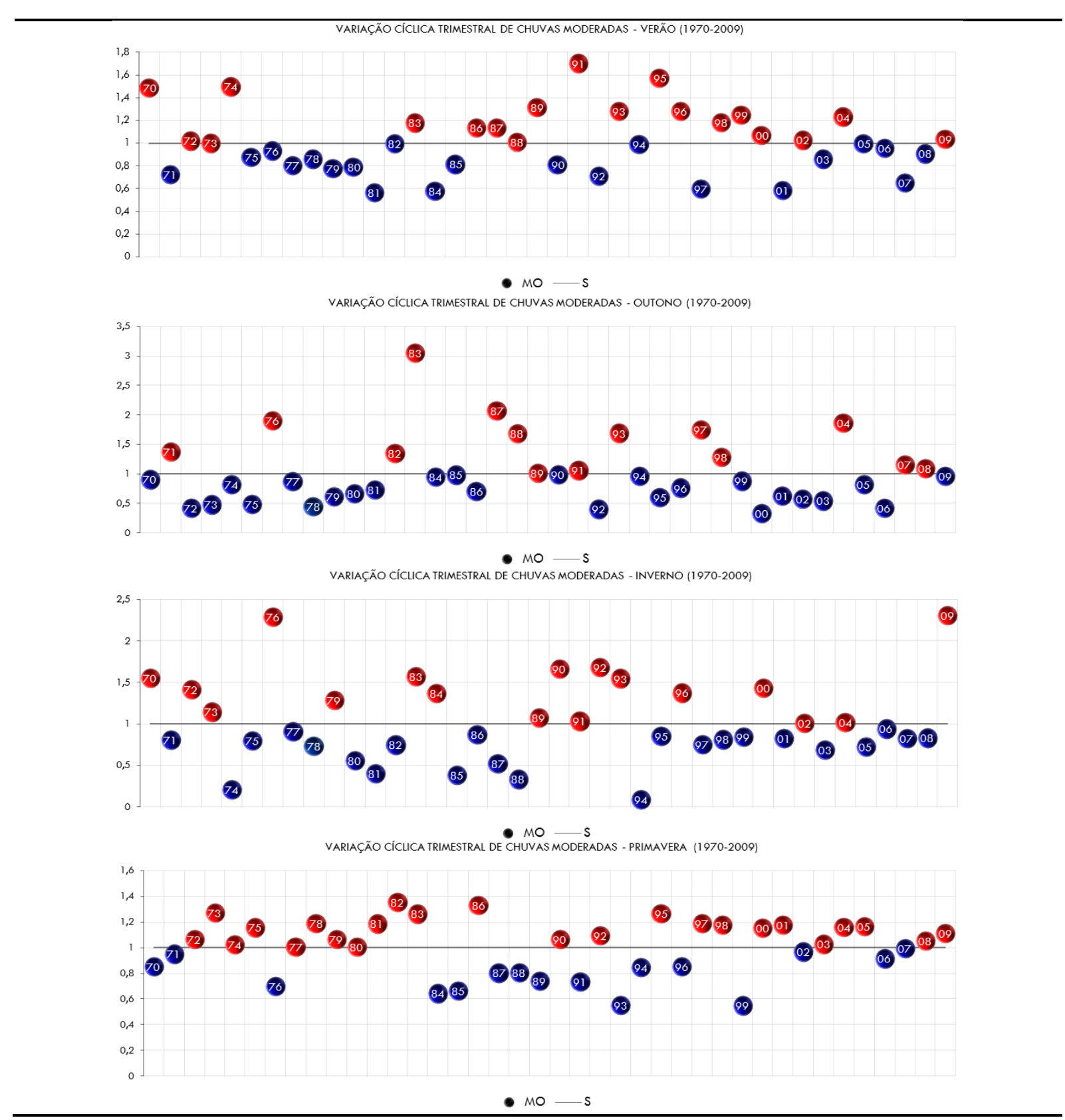

Figura 77 - Variação Cíclica Trimestral de Chuva Moderada, entre 1970 e 2009. 


\subsubsection{3- Análise da Correlação Cíclica Trimestral}

De forma geral, separando a série temporal em estações do ano, observamos que a correlação linear entre as séries de $\mathrm{ONI}$ e frequência de chuva $M O$ é positiva e significativa para o verão $(r=0,24)$, Figura 78 e, no outono $(r=0,32)$, Figura 79 . Ou seja, a frequência de chuva MO pode estar associada fisicamente aos valores de ONI durante o verão e outono. A separação das séries temporais em eventos distintos quanto à TSM na região do Niño3.4 permitiu verificar que durante o verão, na fase $L N$, a correlação linear entre estas duas variáveis foi positiva e significativa $(r=0,56)$, Figura 80. A segunda correlação linear, significativa e positiva foi identificada no outono, na fase ENOS $(r=0,39)$, Figura 81 . Todos os demais resultados podem ser observados a partir da Tabela 32.

Tabela 32 - Correlação Cíclica entre a Frequência de Chuva Moderada observada na Estação do IAG e os Valores de ONI para Cada Estação do Ano e, para Cada Condição de Anomalia na Região de Niño3.4 (Eventos Neutros, ENOS, EN e LN).

\begin{tabular}{|c|c|c|c|c|c|c|c|}
\hline VERÃO & OUTONO & NVERNO & PRIMAVERA & VERĀO & OUTONO & INVERNOO & PEIMAVERA \\
\hline A) & AI & A) & A1 & ONel & Coe & ore & ONe \\
\hline$A^{2}$ & $\mathrm{~N}^{2}$ & $N 2$ & 12 & NEUROO & NEUTRO & NEUTRO & neutio \\
\hline A3 & 1.3 & A3 & $A^{3}$ & ENOS & ENOS & Evos & ENOS \\
\hline as & MA & MA & $\wedge 4$ & ta Ne⿻上丨 & I NENOO & A NENOO & E NeNO \\
\hline As & NS & As & NS & LANERA & UNeNA & UANAR & UNARA \\
\hline \multicolumn{4}{|c|}{ CORRELAÇÄO CICUICA } & \multicolumn{4}{|c|}{ TESTE T - STUDENT } \\
\hline VERĀO & OUTONO & INVERNO & PRIMAVERA & VERĀO & OUIONO & INVERNO & PRLMAVERA \\
\hline 0.20 & 0,321 & 0,008 & 0.056 & SGGNICATINO & SEGNACATIVO & NR̈O SIGNEICATINO & Nío somencativo \\
\hline 0.29 & 0,200 & 0,129 & 0.2 & MÜo sucreficatwo & MR̈O SGGERCA & NüO SNCNEACATIVO & NïO SIGeERCATVO \\
\hline 0.251 & 0,37 & oosi & 0,075 & NÜO SIGEAFCATINO & SECNERCATIVO & NÜO SACNERCAITVO & NIOO SIGEefCATINO \\
\hline 0.19 & 0,33 & 0,286 & OA15. & NIOO SYGAFACATWO & NİO SICNEFCATMO & NÄO SICNEFCAINO & NÜO SICEUFCATIVO \\
\hline 0,567 & 0,079 & $-0,20$ & 0,106 & SLONEFCATINO & NÜO SICAEFICATIVO & NÄO SICNAFICATIVO & NÄO SIONERCATIVO \\
\hline
\end{tabular}

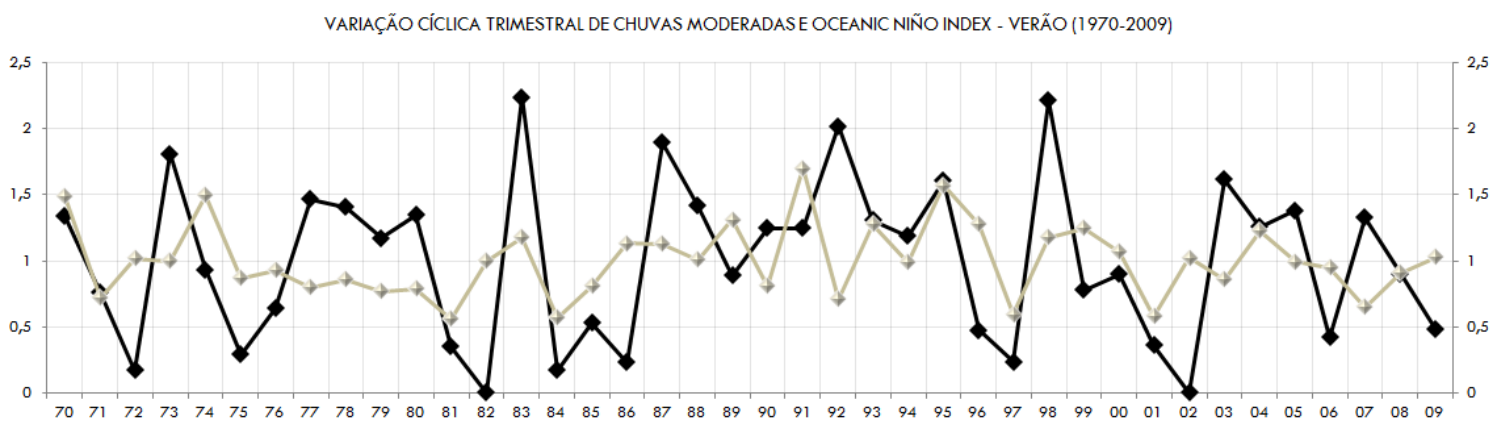

Figura 78 - Variação Cíclica de Chuva MO, no Verão, entre 1970 e 2009. 
VARIAÇÃO CÍCLICA TRIMESTRAL DE CHUVAS MODERADASE OCEANIC NIÑO INDEX - OUTONO (1970-2009)

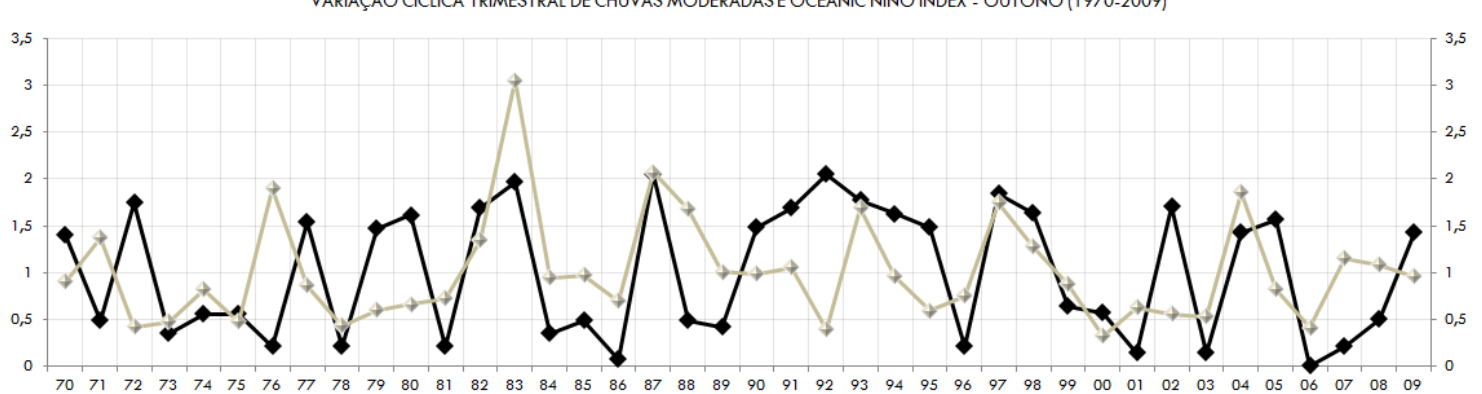

$\rightarrow$ ONI $\longrightarrow$ MO

Figura 79 - Variação Cíclica de Chuva MO, no Outono, entre 1970 e 2009.

VARIAÇÃO CÍCLICA TRIMESTRAL DE CHUVAS MODERADAS E LA NIÑA - VERÃO

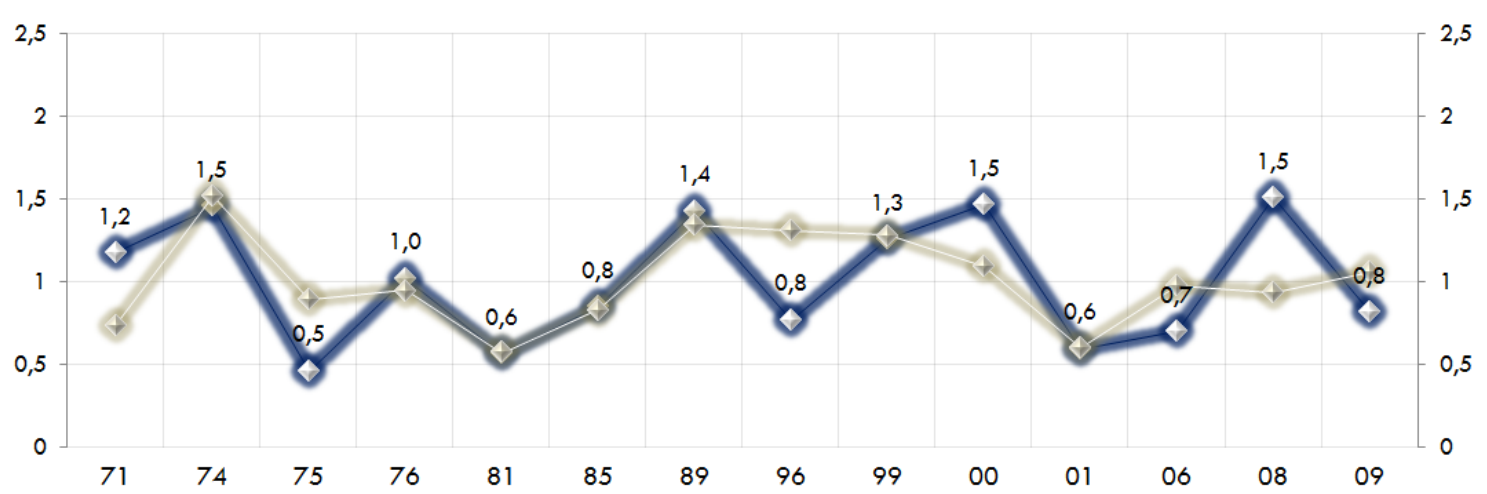

- - LA NIÑA * MO

Figura 80 - Variação Cíclica de Chuva MO, no Verão, durante a Fase La Niña.

VARIAÇÃO CÍCLICA TRIMESTRAL DE CHUVAS MODERADAS E ENOS - OUTONO

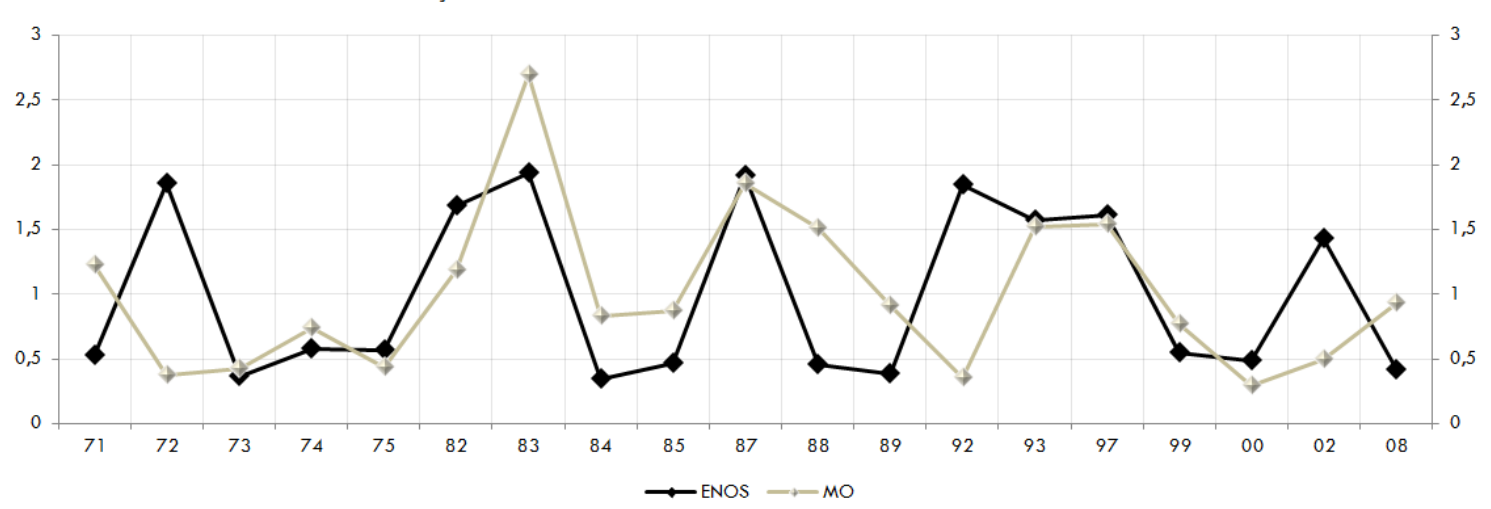

Figura 81 - Variação Cíclica de Chuva MO, no Outono, durante a Fase ENOS.

\subsubsection{4- Análise Específica das Fases Trimestrais}

Os resultados de tal análise revelam as possíveis correlações existentes entre as fases altas e baixas da frequência de Chuva Moderada e do ONI. Neste caso, identificamos a série específica através das fases altas $(\bar{x}>1)$ e baixas $(\bar{x}<1)$ da variação cíclica da 
frequência trimestral de chuva MO. A variação cíclica de chuva MO no período de 1970 a 2009 durante a estação de verão foi composta por 21 fases específicas. A partir do resultado negativo da correlação linear entre a tendência positiva de chuva $M O$ e a tendência negativa do ONI, procuramos identificar as fases da oscilação que possivelmente estiveram associadas a tal comportamento. Neste caso, as fases altas estariam correlacionadas com a chuva MO e, as fases baixas correlacionadas com o ONI (Figura 82). Em função dessa probabilidade, identificamos nos anos 70, 83, 91, 93, 95, 96 e 04 as fases altas que estariam significativamente e positivamente correlacionadas com a chuva MO. Por outro lado, identificamos nos anos $71,84,85,97$ e 01 as fases baixas que estariam significativamente e positivamente correlacionadas com o ONI (Tabela 33). A variação cíclica de chuva MO no período de 1970 a 2009 durante a estação de outono foi composta por 19 fases específicas. A partir do resultado positivo da correlação linear entre a tendência negativa de chuva MO e a tendência negativa do ONI, procuramos identificar as fases da oscilação que possivelmente estiveram associadas a tal comportamento. Neste caso, deduzimos que somente as fases baixas estariam correlacionadas (Figura 82). Em função dessa probabilidade, identificamos nos anos $84,85,86,05$ e 06 as fases baixas que estariam significativamente e positivamente correlacionadas com a correlação positiva entre a chuva MO e o ONI (Tabela 33). A variação cíclica de chuva MO no período de 1970 a 2009 durante a estação de inverno foi composta por 21 fases específicas. A partir do resultado negativo da correlação linear entre a tendência negativa de chuva $M O$ e a tendência positiva da ONI, procuramos identificar as fases da oscilação que possivelmente estiveram associadas a tal comportamento. Neste caso, as fases baixas estariam correlacionadas com a chuva MO e, as fases altas correlacionadas com o ONI (Figura 82). Em função dessa probabilidade, identificamos nos anos $71,74,75,77,78,80,81,82,85,86,87$ e 88 as fases baixas que estariam significativamente e positivamente correlacionadas com a chuva MO. Por outro lado, identificamos nos anos $72,73,76,79,83,84,02,04$ e 09 as fases altas que estariam significativamente e positivamente correlacionadas com o ONI (Tabela 33). A variação cíclica 
de chuva MO no período de 1970 a 2009 durante a estação de primavera foi composta por 20 fases específicas. A partir do resultado negativo da correlação linear entre a tendência negativa de chuva MO e a tendência positiva da ONI, procuramos identificar as fases da oscilação que possivelmente estiveram associadas a tal comportamento. Neste caso, as fases baixas estariam correlacionadas com a chuva $M O$ e, as fases altas correlacionadas com 0 ONI (Figura 82). Em função dessa probabilidade, identificamos nos anos 70, 71, 87, 88, 89, 93, 94,96 e 99 as fases baixas que estariam significativamente e positivamente correlacionadas com a chuva MO. Por outro lado, identificamos nos anos $86,90,97,98,08$ e 09 as fases altas que estariam significativamente e positivamente correlacionadas com o ONI (Tabela 33).
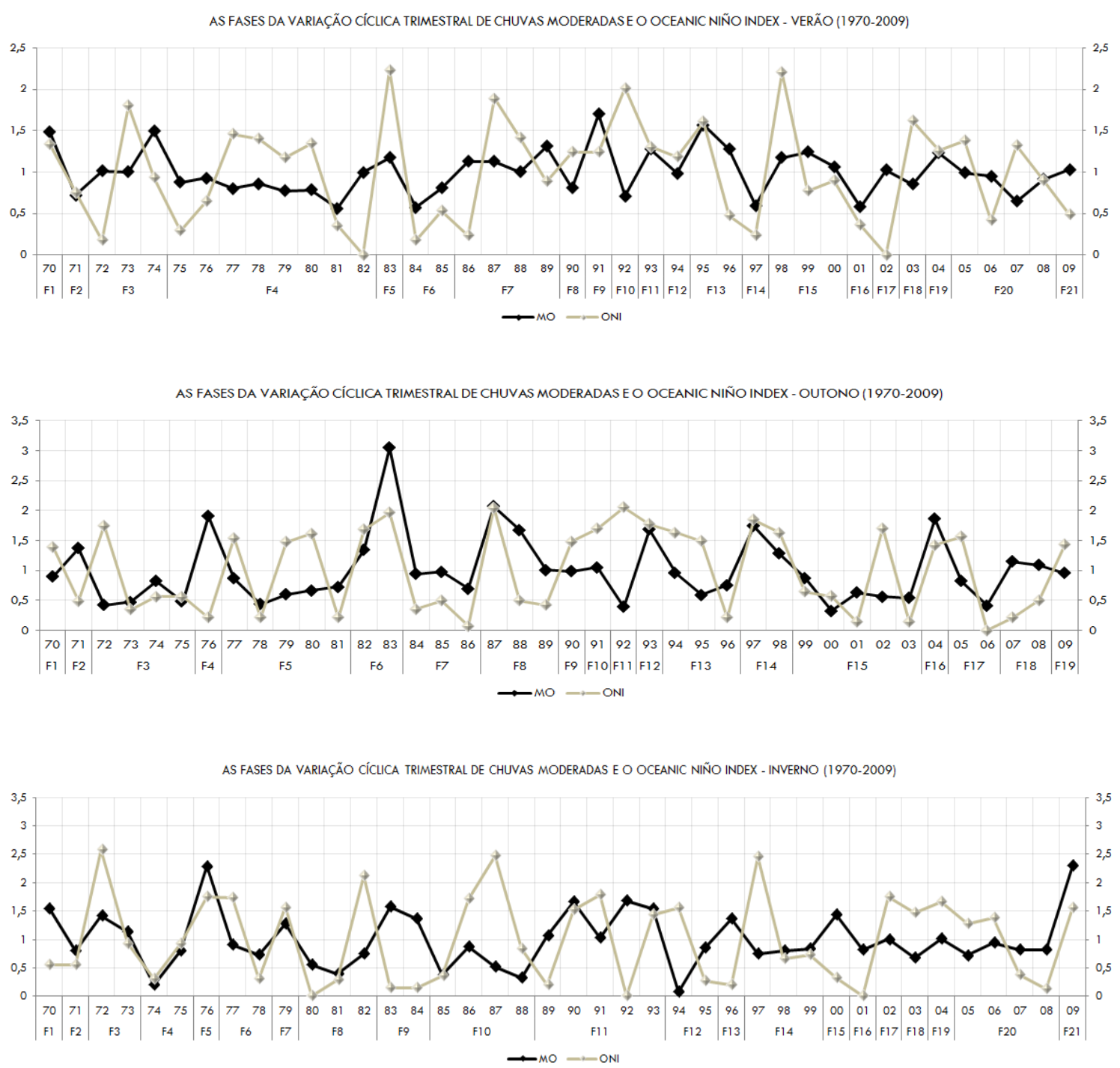
AS FASES DA VARIAÇÃO CÍCLICA TRIMESTRAL DE CHUVAS MODERADAS E O OCEANIC NIÑO INDEX - PRIMAVERA (1970-2009)

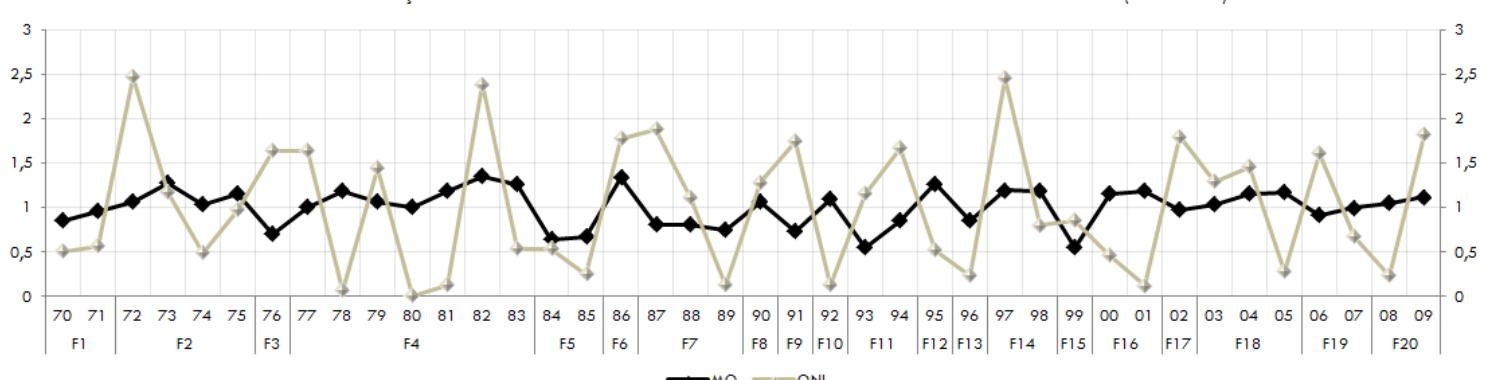

Figura 82 - Fases Específicas do Ciclo Trimestral de Chuva Moderada, Verão, Outono, Inverno e Primavera. A linha Branca corresponde à variação cíclica do ONI e a linha Preta de Chuva MO, para o Período de 1970-2009.

Tabela 33 - Correlação Linear entre a Frequência de Chuva Moderada observada na Estação do IAG e os Valores de ONI para Cada Estação do Ano e, para Cada Condição de Anomalia na Região de Niño3.4 (Eventos Neutros, ENOS, EN e LN). "A" representa as Séries Temporais de Chuva MO relativa às Séries Temporais do ONI "B". Assim, B1 (ONI), B2 (Neutro), B3 (ENOS), B4 (EN) e B5 (LN). Correlação "A" são os Tipos Fases Correlacionadas com a Chuva MO e Correlação "B" são os Tipos Fases Correlacionadas com o ONI.

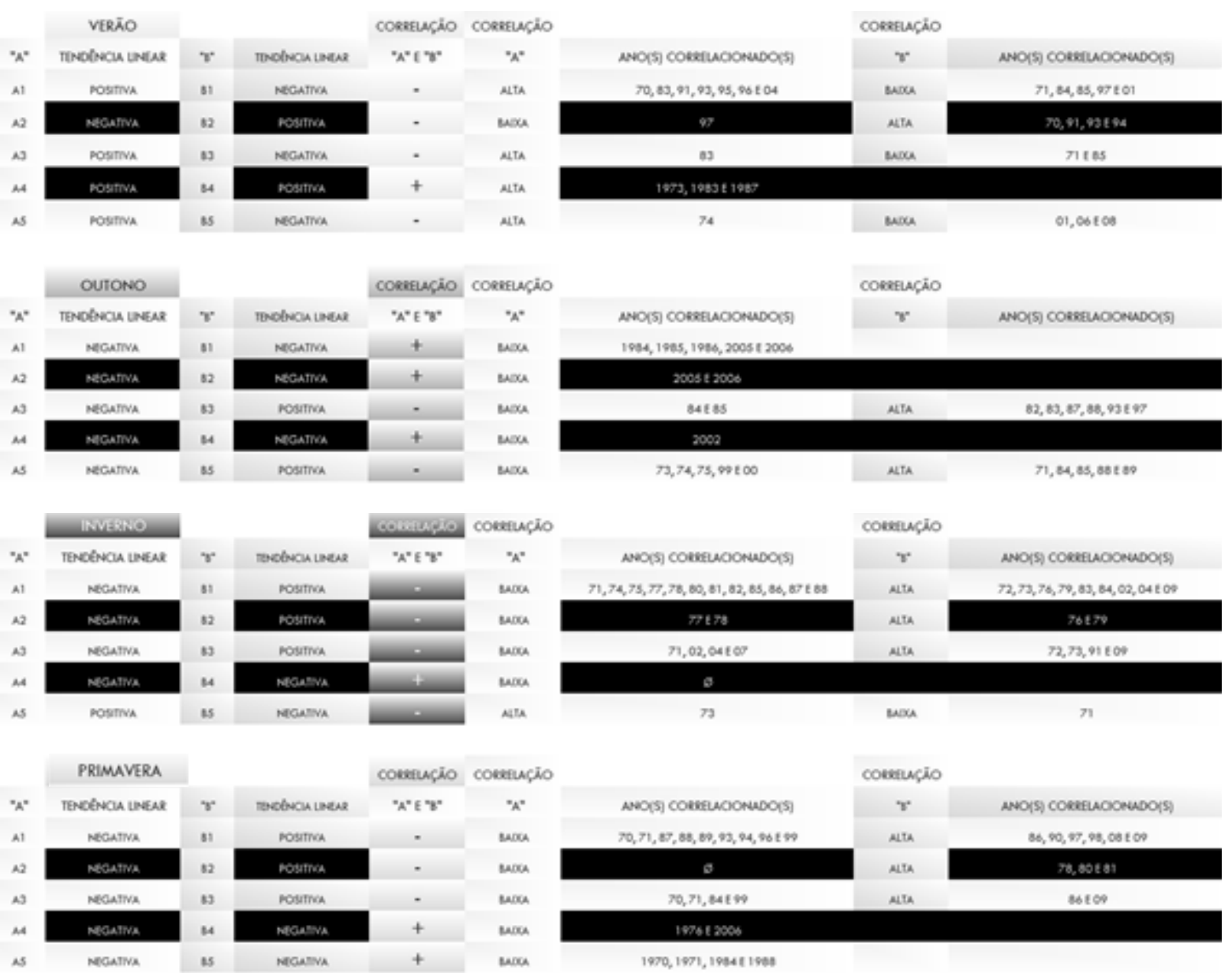




\subsubsection{5 - A Hipótese Inicial e a Conclusão Final - MO II}

A conclusão final para análise trimestral de Chuva Moderada parte das distintas correlações identificadas, para cada estação climática, envolvendo o ajuste linear dos índices do ONI na região Niño3.4 e a frequência de chuva MO. De modo geral, no verão, inverno e primavera observamos que $\circ$ ajuste linear positivo (negativo) do ONI não coincidiu positivamente com $\circ$ ajuste de chuva MO. A exceção observada ocorreu na estação de outono, onde o ajuste linear negativo de chuva MO coincidiu positivamente com o ajuste linear negativo do ONI. A Tabela XX apresenta os resultados das demais correlações realizadas para as séries temporais do ONI em cada estação climática do ano. Após identificarmos as respectivas correlações lineares trimestrais entre a chuva $M O$ e $\circ \mathrm{ONI}$, analisamos os resultados das correlações cíclicas trimestrais. Neste caso, encontramos apenas quatro correlações cíclicas positivas e significativas (Tabela 32). A primeira e a segunda foram identificadas no verão, durante o ONI e a fase $L N$. A terceira e a quarta foram identificadas no outono, durante o ONI e a fase ENOS.

A partir da combinação dos resultados observados durante a série temporal do ONI, na estação de outono, onde identificamos uma correlação positiva envolvendo ajustes lineares negativos e uma correlação cíclica significativa, analisamos por dedução e correlação que seja muito provável que tenha ocorrido um enfraquecimento das variações cíclicas de chuva MO em função da diminuição das amplitudes dos seus ciclos ao longo do período de 1970 a 2009. Neste caso, é possível identificar consonância com a expectativa de Grimm et al (1999), ou seja, nota-se a influência de padrões de macroescala alterando a frequência de circulação, que neste caso diminui suprimindo a precipitação. Ainda, podemos identificar o possível reflexo da combinação observada, em fases específicas, que podem ser visualizados através dos anos que estiveram correlacionados, de acordo com a Tabela 33. 


\section{5 - Chuva Forte $-4,0$ a $16,0 \mathrm{~mm} \mathrm{~h}{ }^{-1}$}

As chuvas definidas como sendo fortes e, que possivelmente estão associadas as "tempestades ordinárias" atingem níveis pluviométricos equivalentes a 4,0 - 16,0 mm h-1. A partir da hipótese inicial deste estudo, a intenção ao analisar este tipo de chuva é a de concluir para a série temporal de 1970-2009, a existência, ou não, de um nível de correlação aceitável, envolvendo o comportamento de sua frequência e as variações registradas na temperatura da superfície do mar na região Niño3.4. De acordo com tal hipótese, o estudo estabelece uma reflexão a partir três possibilidades, que podem ou não atuar em conjunto. A reflexão teórica e quantitativa analisa a possibilidade de uma possível correlação, que pode ser ou não, isoladamente linear, cíclica e/ou especificamente por fases, altas ou baixas da variação cíclica. A cronologia das escalas de análise foi dividida em anuais e trimestrais. A intenção desta reflexão científica é a de presumir a partir dos resultados, a possibilidade de ter ocorrido uma intensificação ou enfraquecimento, nos quadros evolutivos das variações cíclicas de Chuva Forte, a partir do aumento ou da diminuição das amplitudes dos seus respectivos ciclos, em função do aquecimento ou resfriamento, diagnosticado através dos registros da TSM, na região Niño3.4.

\subsection{1 - Análise Anual}

A análise anual possui a finalidade de apresentar uma conclusão obtida a partir da identificação do tipo de correlação existente na intenção de sugerir a possibilidade de haver uma relação anual envolvendo a Chuva Forte (FO) e o Oceanic Niño Index. Neste caso, também estão inclusos os resultados das correlações realizadas para as fases ENOS, Neutra, El Niño e La Niña. 


\subsubsection{1 - Frequência Anual de Chuva Forte}

A partir da frequência anual de Chuva Forte $\left(4,0\right.$ a $\left.16,0 \mathrm{~mm} \mathrm{~h}-{ }^{-1}\right)$, representada no gráfico da Figura 83, é possível identificar que a frequência máxima ocorreu no ano de 1983, relativo à contagem de 132 casos horários.

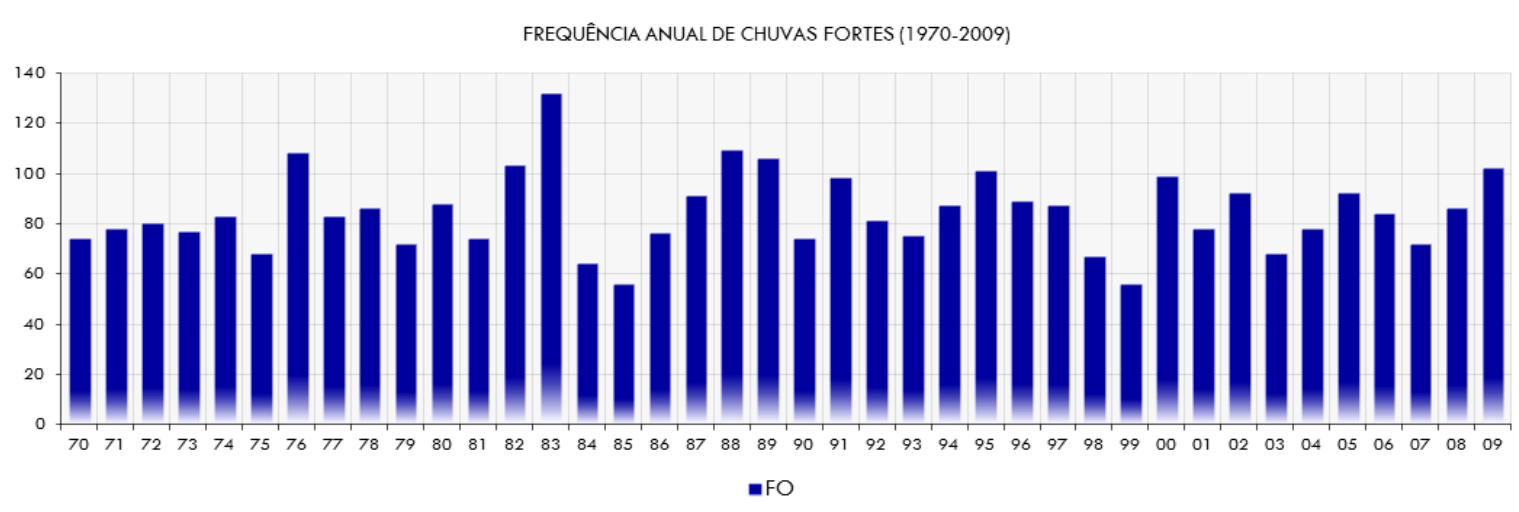

Figura 83 - Frequência Anual de Chuva Forte entre 1970-2009.

\subsubsection{2- Análise do Ajuste Linear}

O ajuste linear da frequência anual de Chuva Forte no município de São Paulo indica estabilidade desta frequência ao longo da série temporal analisada, de 1970 a 2009, tal como ilustrada na Figura 84. A análise realizada para as fases, neutra, ENOS, El Niño e La Niña, separadamente, mostra que, em todos os casos, a frequência anual de Chuva Forte aumenta com o tempo, exceto na fase Neutra (Figura 85). A comparação entre a tendência linear da frequência de Chuva Forte e do ONI indica que enquanto ○ ONI assume valores cada vez mais intensos, no decorrer da série temporal, a frequência de Chuva Forte aumenta, tal como indicado na Tabela 34. A exceção ocorre no caso de eventos de EN que apresenta tendência negativa nula de TSM, ao longo do período analisado, sensivelmente contraria a tendência positiva nula de frequência de Chuva Forte (ver tabela 34, linha 4). 
TENDÊNCIA LINEAR ANUAL DE CHUVA FORTE (1970-2009)

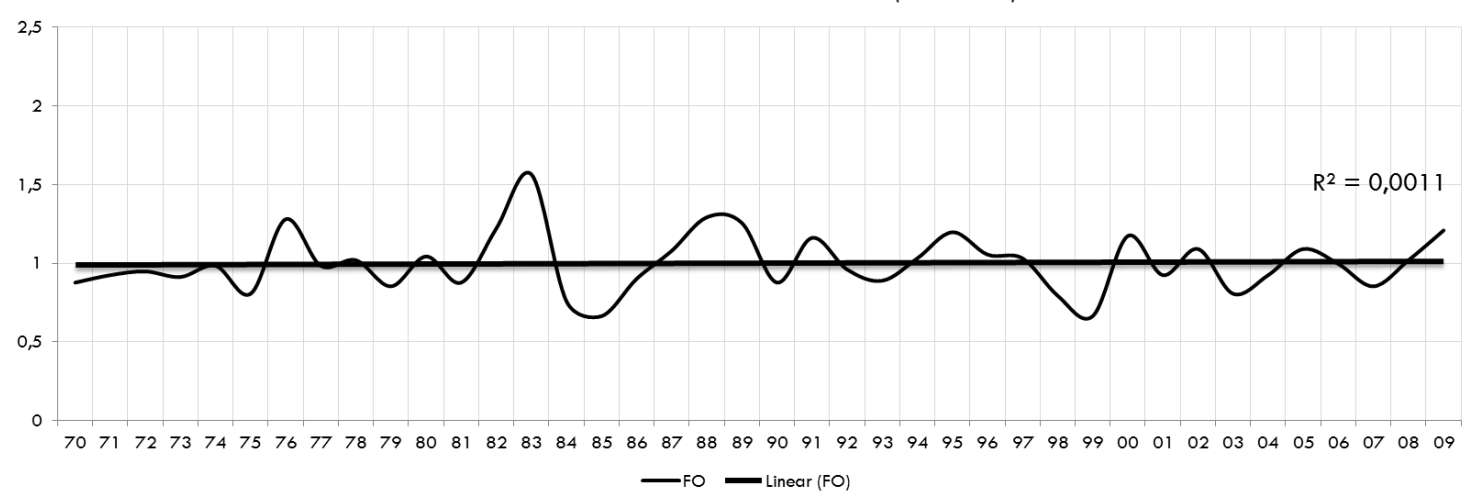

Figura 84 - Ajuste Linear da Frequência Anual de Chuva Forte entre 1970-2009.
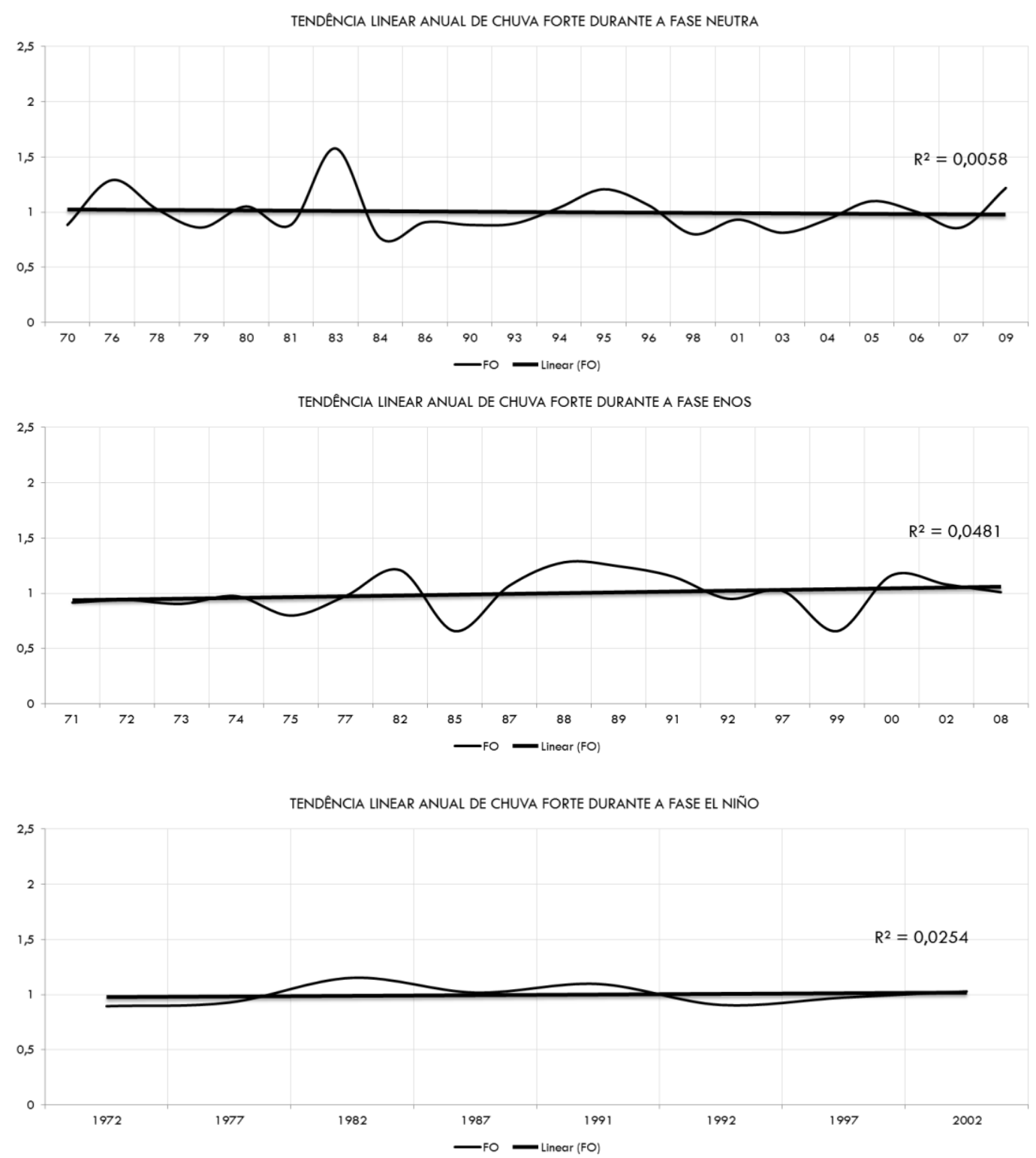


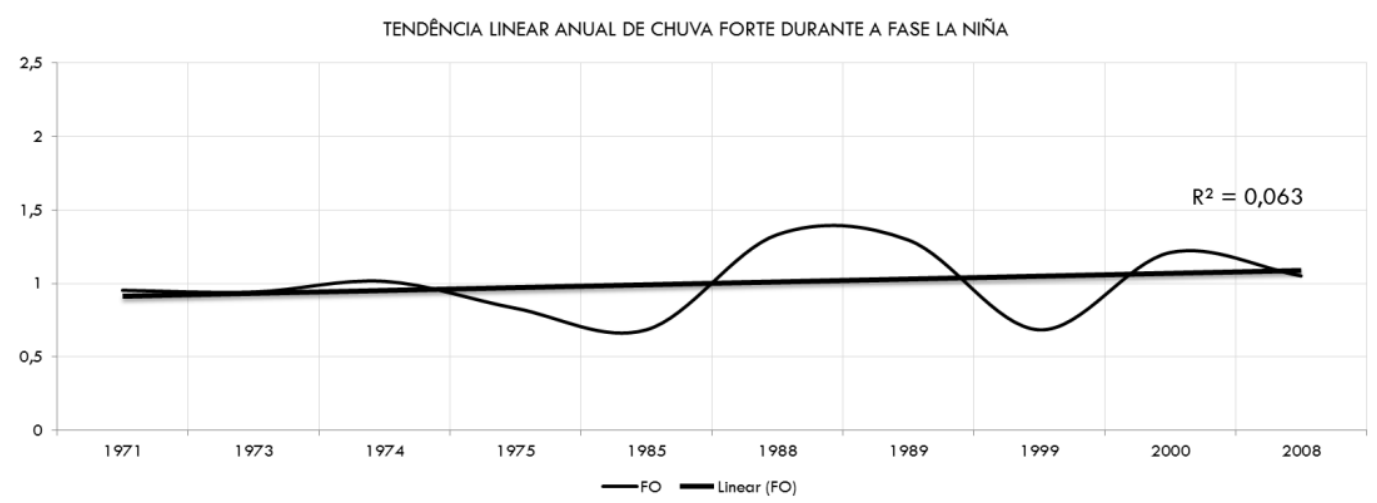

Figura 85 - Tendência Linear da Frequência Anual de Chuva Forte para a Fase, Neutra, ENOS, EN e LN, entre 1970-2009.

Os resultados observados através dos ajustes lineares positivos para a série anual revelam que as frequências analisadas no intervalo horário refletiram positivamente com os resultados das análises diárias realizadas por Cabral (2002).

Tabela 34 - Tendência Linear Anual de Chuva Forte e do ONI para o Período de 1970 a 2009. A Primeira Linha da Tabela indica a Tendência Linear de Todos os Dados Anuais e, as Demais Linhas indicam a Tendência Linear para cada Fase do ONI.

\begin{tabular}{|c|c|c|c|c|c|c|}
\hline${ }^{-A} A^{*}$ & TIPO DE CHUVA & TENDENCIA UNEAR & $" B$ & CATEGORIA & TENDENCIA UNEAR & CORRELAÇĀO UNEAR \\
\hline A1 & FO & POSITIVA & B1 & ONI & POSITIVA & POSITIVA \\
\hline A2 & FO & NEGATIVA & B2 & NEUTRO & POSITIVA & NEGATIVA \\
\hline A3 & FO & POSITIVA & B3 & ENOS & POSITIVA & POSITIVA \\
\hline A4 & FO & POSITIVA & B4 & EL NIÑO & NEGATIVA & NEGATIVA \\
\hline A5 & FO & POSITIVA & B5 & LA NIÑA & POSITIVA & POSITIVA \\
\hline
\end{tabular}

\subsubsection{3- Variação Cíclica de Chuva Forte}

A variação cíclica anual de Chuva Forte pode ser observada na Figura 86 . É possível notarmos a oscilção presente na série temporal completa, de 1970 a 2009, formada por 18 fases altas (esferas vermelhas) e 22 fases baixas (esferas azuis).

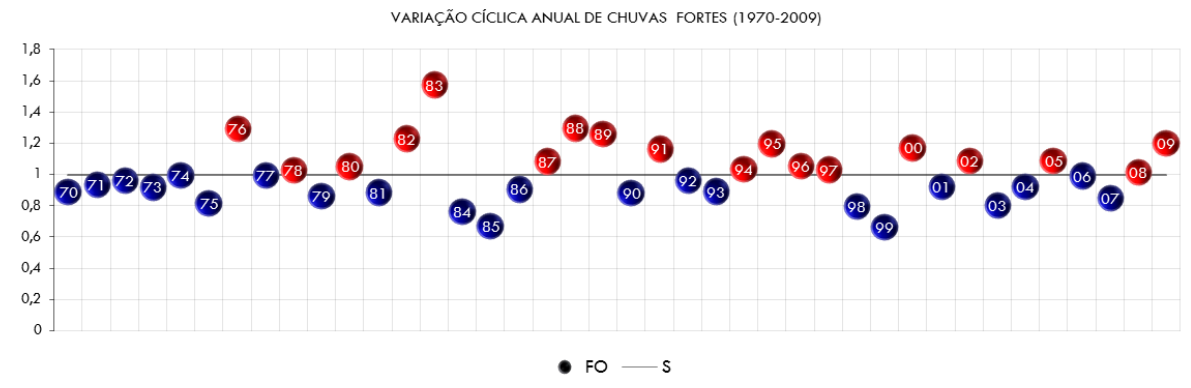

Figura 86 - Variação Cíclica Anual da Frequência de Chuva Forte entre 1970 e 2009. 


\subsubsection{4- Análise da Correlação Cíclica}

A partir dos resultados do teste de significância - t-"Student" - notamos que os resultados do cálculo de correlação linear, para as séries cíclicas, entre $\mathrm{ONI}$ e a frequência anual de Chuva Forte, nas fases, Neutra, ENOS e La Niña não foram significativos (Tabela 35). Por outro lado, observamos que a fase de EN (Tabela 35, linha 4) apresentou correlação linear significativa (Figura 87).

Tabela 35 - Correlação Linear entre a Anomalia de ONI e da Frequência Anual de Chuva Forte entre 1970 e 2009, sem Tendência Linear (Série Cíclica).

$\begin{array}{lccccc}\text { CICLO "A" } & & \text { CICLO "B" } & \text { CORRELAÇÃO CICUCA } & \text { TESTE T-STUDENT } \\ \text { A1 } & \text { FO } & \text { B1 } & \text { ONI } & 0,159 & \text { NÃO SIGNIFICATIVO } \\ \text { A2 } & \text { FO } & \text { B2 } & \text { NEUTRA } & 0,118 & \text { NÃO SIGNIFICATIVO } \\ \text { A3 } & \text { FO } & \text { B3 } & \text { ENOS } & 0,218 & \text { NÃO SIGNIFICATIVO } \\ \text { A4 } & \text { FO } & \text { B4 } & \text { EL NIÑO } & 0,771 & \text { SIGNFICATIVO } \\ \text { A5 } & \text { FO } & \text { B5 } & \text { LANINA } & 0,275 & \text { NÃO SIGNIFICATIVO }\end{array}$

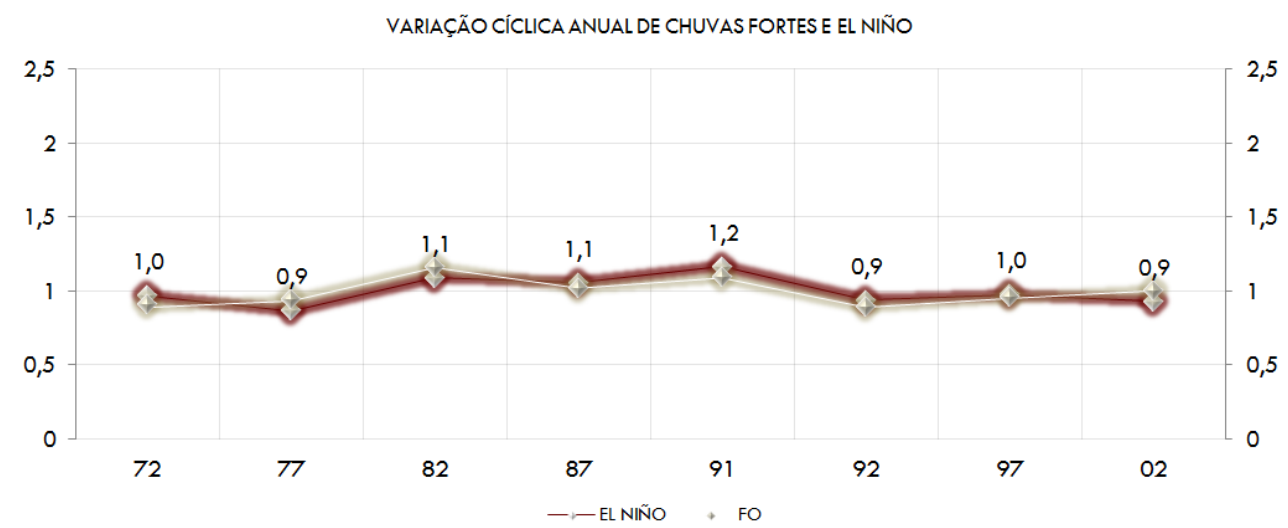

Figura 87 - Variações Cíclicas Anuais da Frequência de Chuva Forte, durante a Fase EN.

\subsubsection{5- Análise Específica do Ciclo de Chuva - FO}

Os resultados de tal análise revelam as possíveis correlações existentes entre as fases altas e baixas da frequência de Chuva Forte e do ONI. Neste caso, na Figura 88 identificamos a série específica através das fases altas $(\bar{x}>1)$ e baixas $(\bar{x}<1)$ da variação cíclica da frequência de chuva FO. 
AS FASES DA VARIAÇÃO CÍCLICA ANUAL DE CHUVAS FORTES E O OCEANIC NIÑO INDEX (1970-2009)

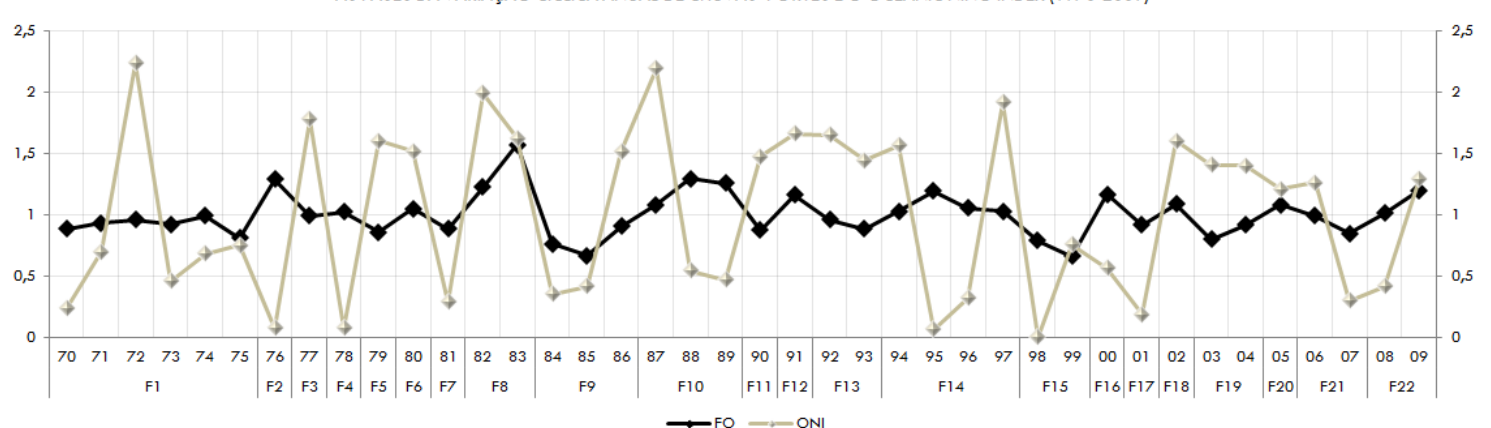

Figura 88 - Fases Específicas do Ciclo Anual de Chuva Forte. A linha Branca corresponde à variação cíclica do ONI e a linha Preta de Chuva FO, para o Período de 1970-2009.

A variação cíclica anual de Chuva Forte no período de 1970 a 2009 foi composta por 22 fases específicas (altas e baixas). No entanto, a partir do resultado positivo da correlação linear entre a tendência positiva de Chuva Forte e a tendência positiva da ONI, procuramos identificar as fases da oscilação que possivelmente estiveram associadas a tal comportamento. Neste caso, as fases altas estariam concomitantemente correlacionadas com a frequência de Chuva Forte e o ONI. Neste caso, foram identificadas 5 fases altas, positivamente correlacionadas, nos anos de 1980, 1991, 2002, 2005, 2008 e 2009. Tais fases refletem o resultado positivo relativo ao aumento das frequências de Chuva Forte em função do aquecimento na TSM, na região Niño3.4.

\subsubsection{6- Hipótese Inicial e a Conclusão Final - FO I}

A conclusão final para análise anual de Chuva Forte foi baseada a partir dos resultados envolvendo os três procedimentos aplicados. De modo geral, durante este período, os resultados sugerem que $\circ$ aquecimento observado na região Niño3.4 coincidiu com $\circ$ aumento na frequência de Chuva Forte. Foi também possível notar que não houve correlação cíclica e, desta forma, é insignificante a explicação da variância de Chuva Forte em função da ONI. Por último, foi observada a existência de uma correlação linear envolvendo as fases altas (anos) que poderiam ter refletido, pontualmente, os efeitos da correlação linear positiva. 
A partir dessas informações é possível concluir que possivelmente houve um reflexo linear na frequência de Chuva Forte proporcionado pelo aquecimento da TSM, na região Niño3.4, que por sua vez, não foi refletida, em um possível aumento das amplitudes do ciclo de Chuva Forte. Neste caso, há possibilidade dos reflexos terem ocorridos somente a partir de fases específicas. A quarta séria analisada é a fase El Niño. A partir dos seus resultados é possível concluir que possivelmente não houve um reflexo linear positivo, na frequência de Chuvas Fortes, que provavelmente estaria relacionado com o resfriamento da TSM na região Niño 3.4. Por outro lado, há correlação entre os ciclos, uma vez que é significante a explicação da variância de Chuva Forte em função do El Niño. A partir da conclusão de que os ciclos estão correlacionados, as possibilidades de correlações envolvendo as fases específicas aumentam. Neste caso, envolvendo as análises específicas, uma parte tende a estar relacionada à correlação positiva, das fases altas, com a frequência de Chuva Forte e outra parte tende a estar relacionado à correlação positiva, das fases baixas, com a série da fase El Niño. A Tabela 36 apresenta uma síntese dos resultados finais da correlação por fases específicas entre a frequência de Chuva Forte e o ONI, entre 1970 e 2009.

Tabela 36 - Correlação Anual em Fases Específicas. A Coluna "A" indica ○ Ajuste Linear da Chuva FO nas Séries Temporais "B" correspondente o ONI e suas Fases. A Última Coluna aponta os Possíveis Anos que estiveram Correlacionados com o Resultado da Correlação Linear do Ajuste "A" e "B".

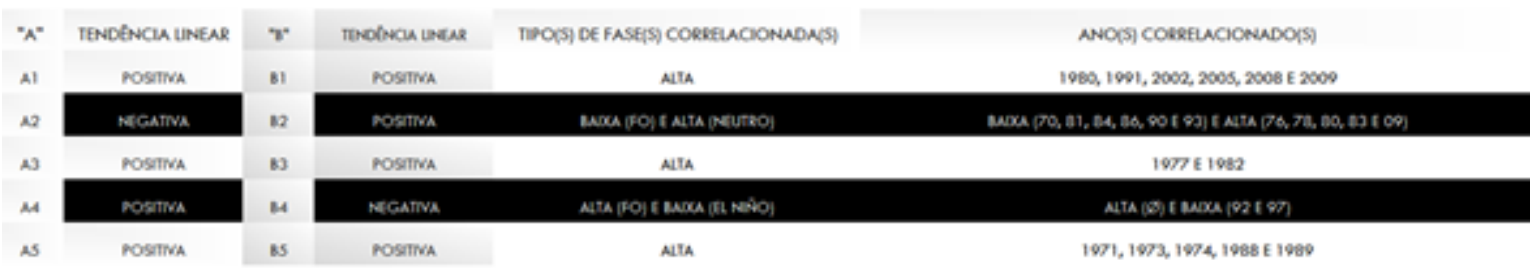

\subsection{2- Análise Trimestral}

A segunda análise envolve a relação trimestral entre a Chuva Forte e o Oceanic Niño Index. Trata-se de uma análise individualizada, envolvendo os procedimentos elementares adotados, que foram aplicados para as quatro estações climáticas do ano. 


\subsubsection{1 - Frequência Trimestral de Chuva Forte}

Os resultados das frequências trimestrais de Chuva Forte $\left(4,0\right.$ a $\left.16,0 \mathrm{~mm} \mathrm{~h}^{-1}\right)$ podem ser observados a partir da Figura 89. No outono a tendência linear de chuva FO, durante o período de 1970 a 2009, é negativa (Figura 90). Por outro lado, a tendência linear, deste tipo de chuva, para a estação de verão, inverno e primavera, pode ser considerada como sendo nulas ou estáveis.

FREQUÊNCIA TRIMESTRAL DE CHUVAS FORTES- VERÃO (1970-2009)

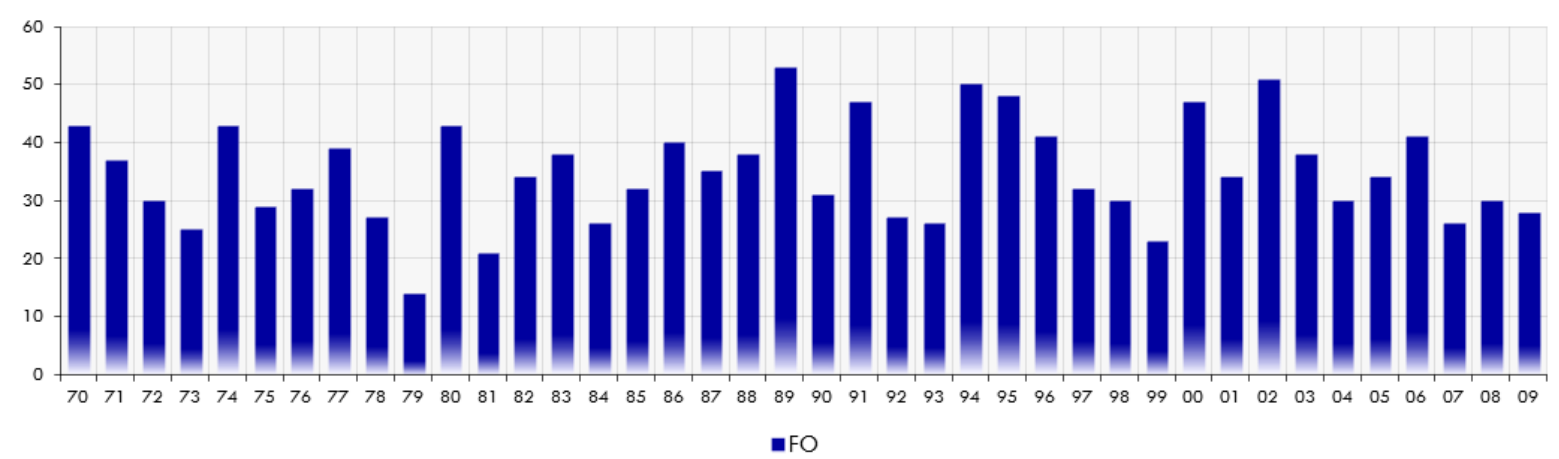

FREQUÊNCIA TRIMESTRAL DE CHUVAS FORTES - OUTONO (1970-2009)

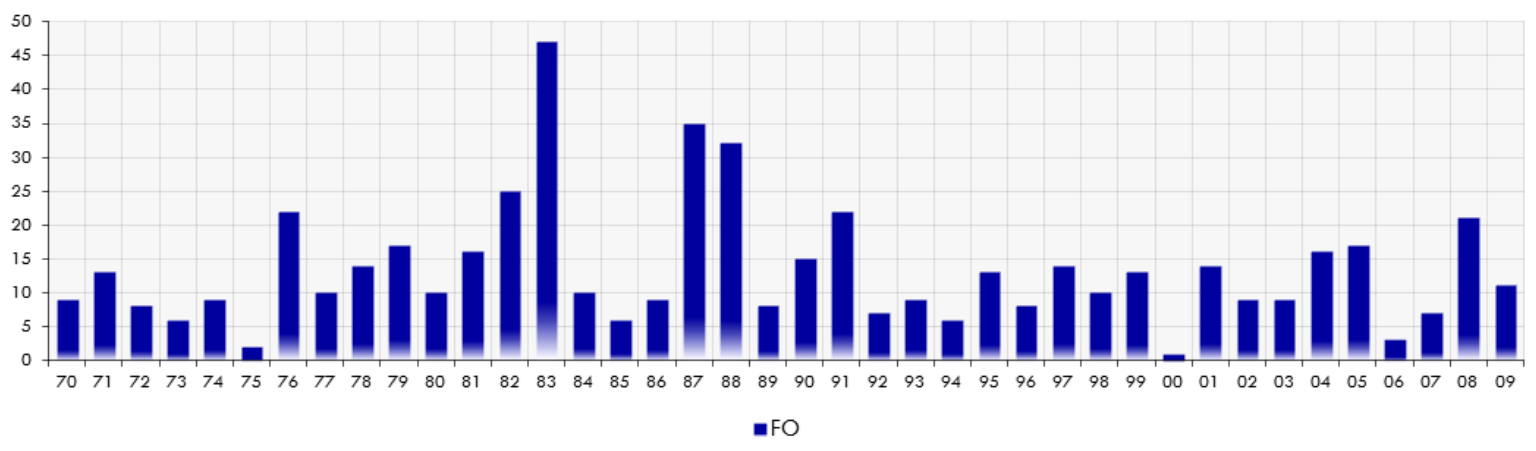

FREQUUÊNCIA TRIMESTRAL DE CHUVAS FORTES - INVERNO (1970-2009)

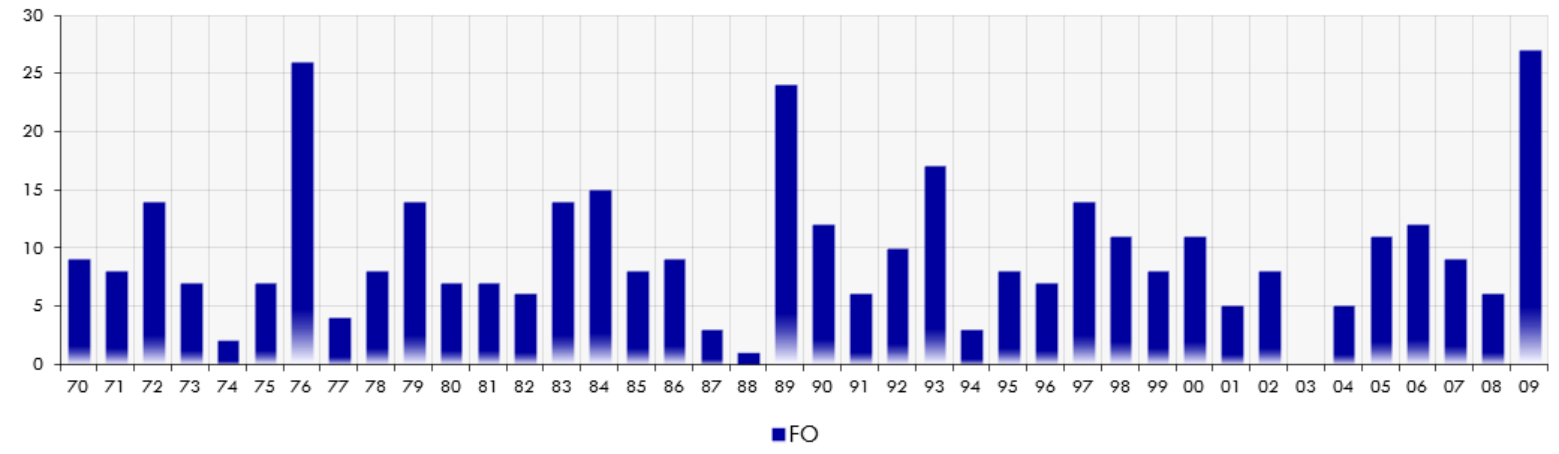


FREQUÊNCIA TRIMESTRAL DE CHUVAS FORTES - PRIMAVERA (1970-2009)

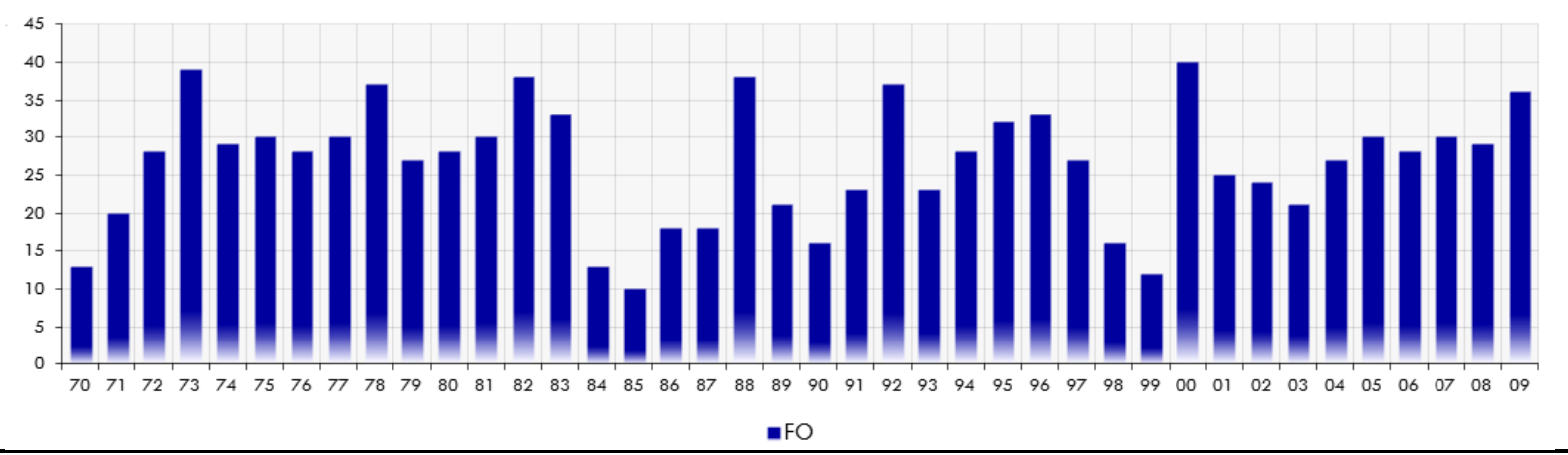

Figura 89 - Frequência Trimestral de Chuva Forte na Estação do IAG-USP durante o Verão, Outono, Inverno e Primavera para o Período de 1970 a 2009.

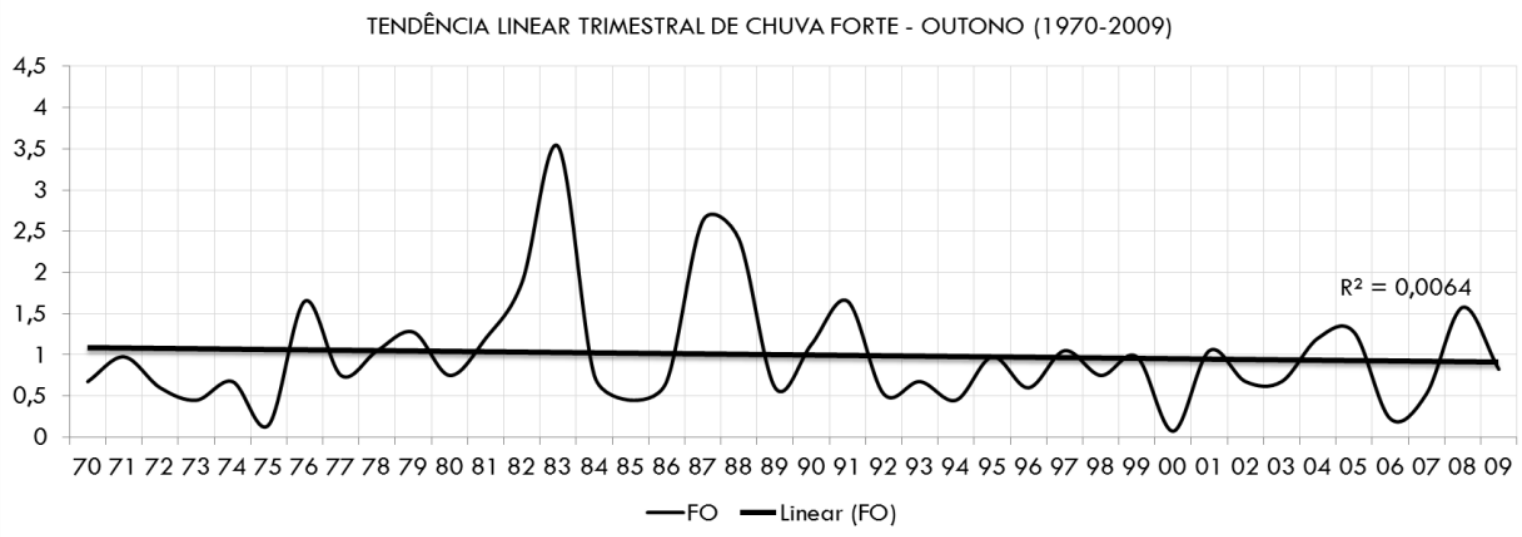

Figura 90 - Ajuste Linear Trimestral de Chuva Forte para a Estação de Outono, no Período de 1970 a 2009.

As séries temporais do ONI apresentarm tendências lineares equilibradas entre negativa e positiva, neste caso incluímos os ajustes lineares mais significativos nas Figuras 91 94. Nestas figuras observamos que durante a fase neutra, os ajustes foram negativos e identificados no outono e no inverno (Figura 91). Na fase ENOS ocorreu apenas um ajuste negativo que foi identificado no inverno (Figura 92). Na fase EN foram identificados dois ajustes positivos no verão e no inverno e, um negativo no outono (Figura 93). Na fase LN, os ajustes foram positivos e identificados no outono e no inverno (Figura 94). 

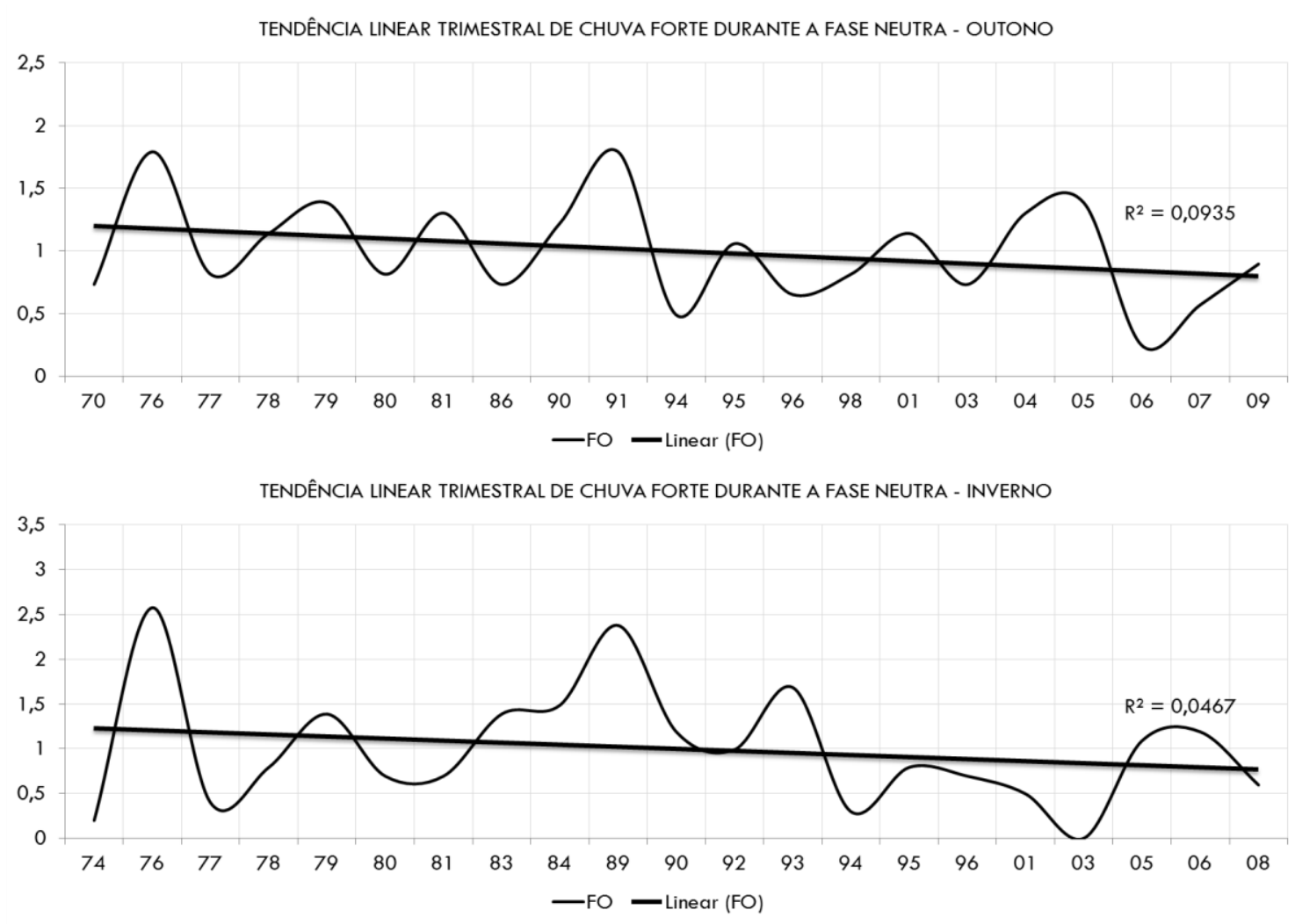

Figura 91 - Ajuste Linear Trimestral de Chuva Forte para as Estações de Outono e Inverno durante a fase Neutra.

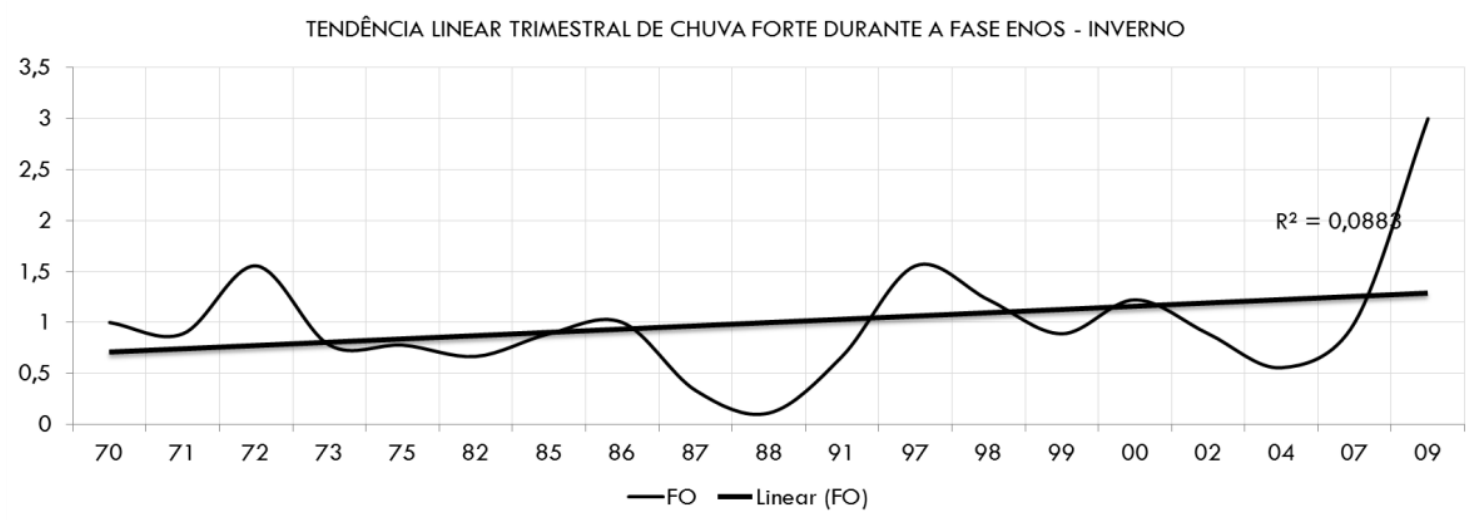

Figura 92 - Ajuste Linear Trimestral de Chuva Forte para a Estação de Inverno durante a fase ENOS.

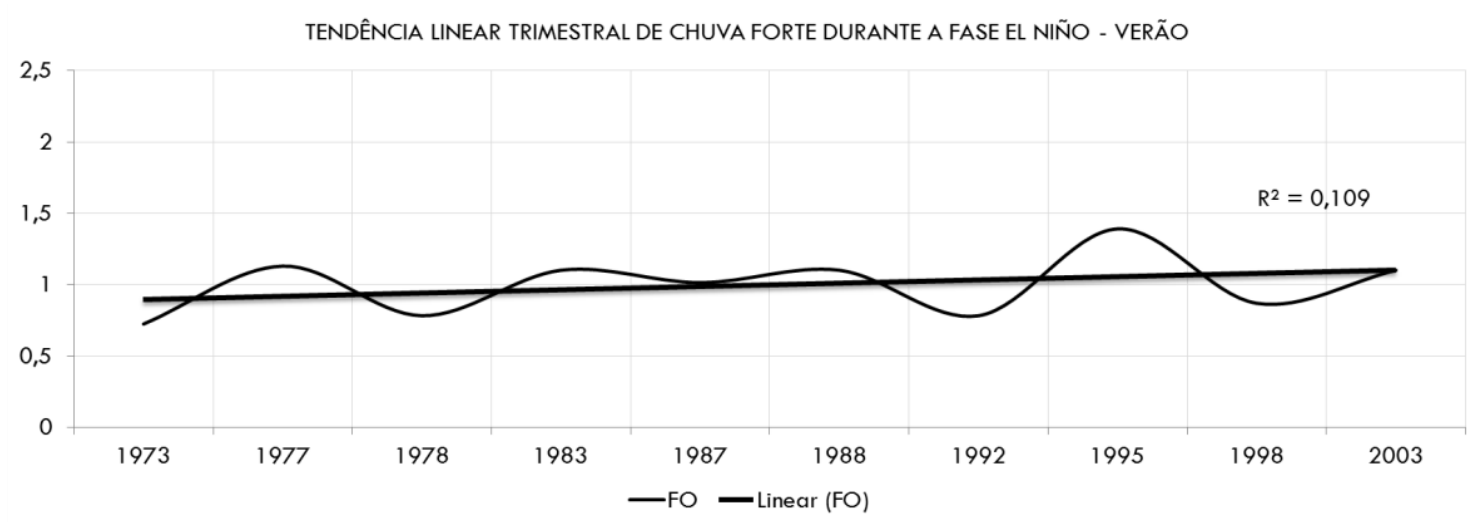



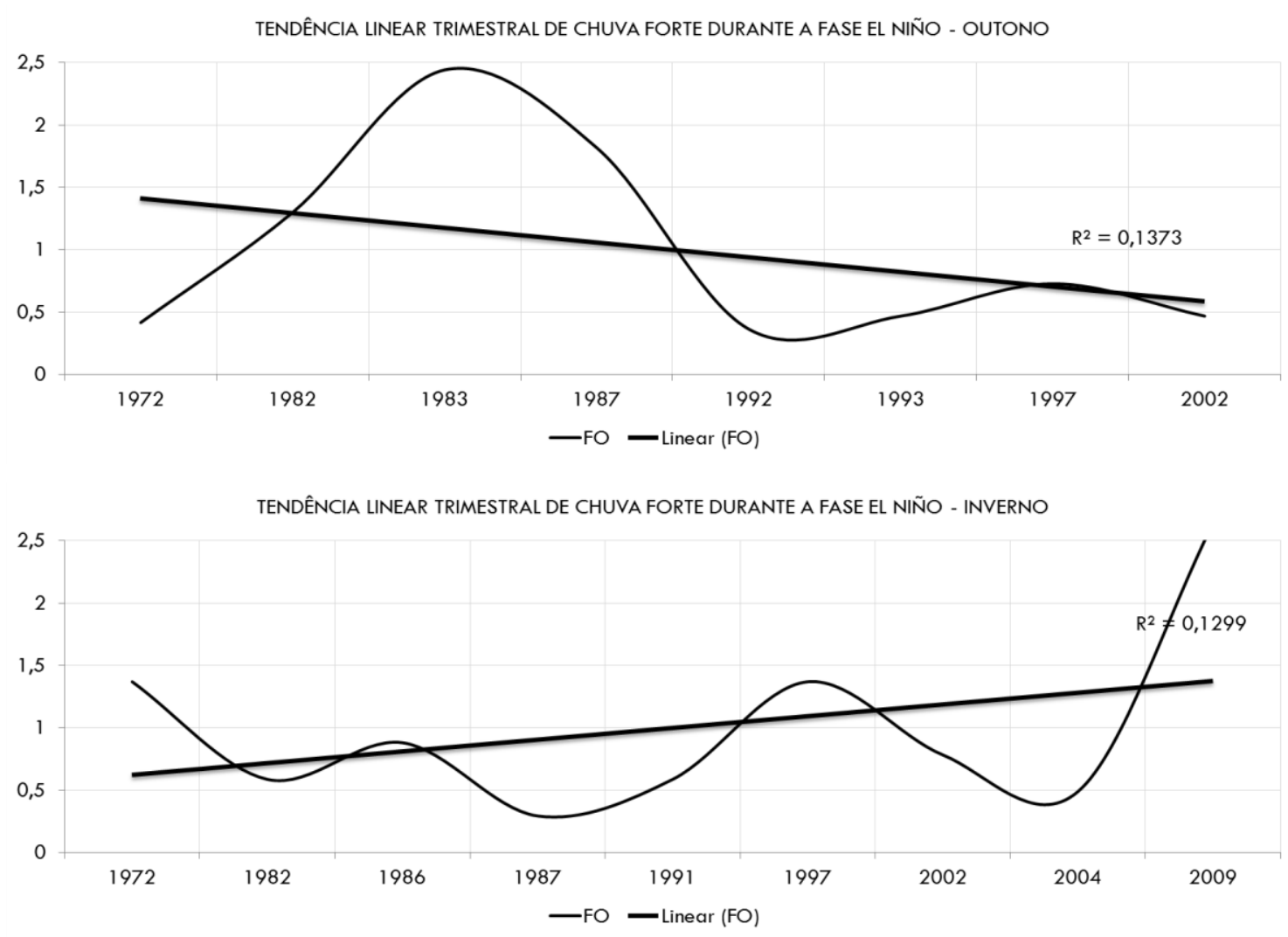

Figura 93 - Ajuste Linear Trimestral de Chuva Forte para as Estações de Verão, Outono e Inverno durante a fase El Niño.
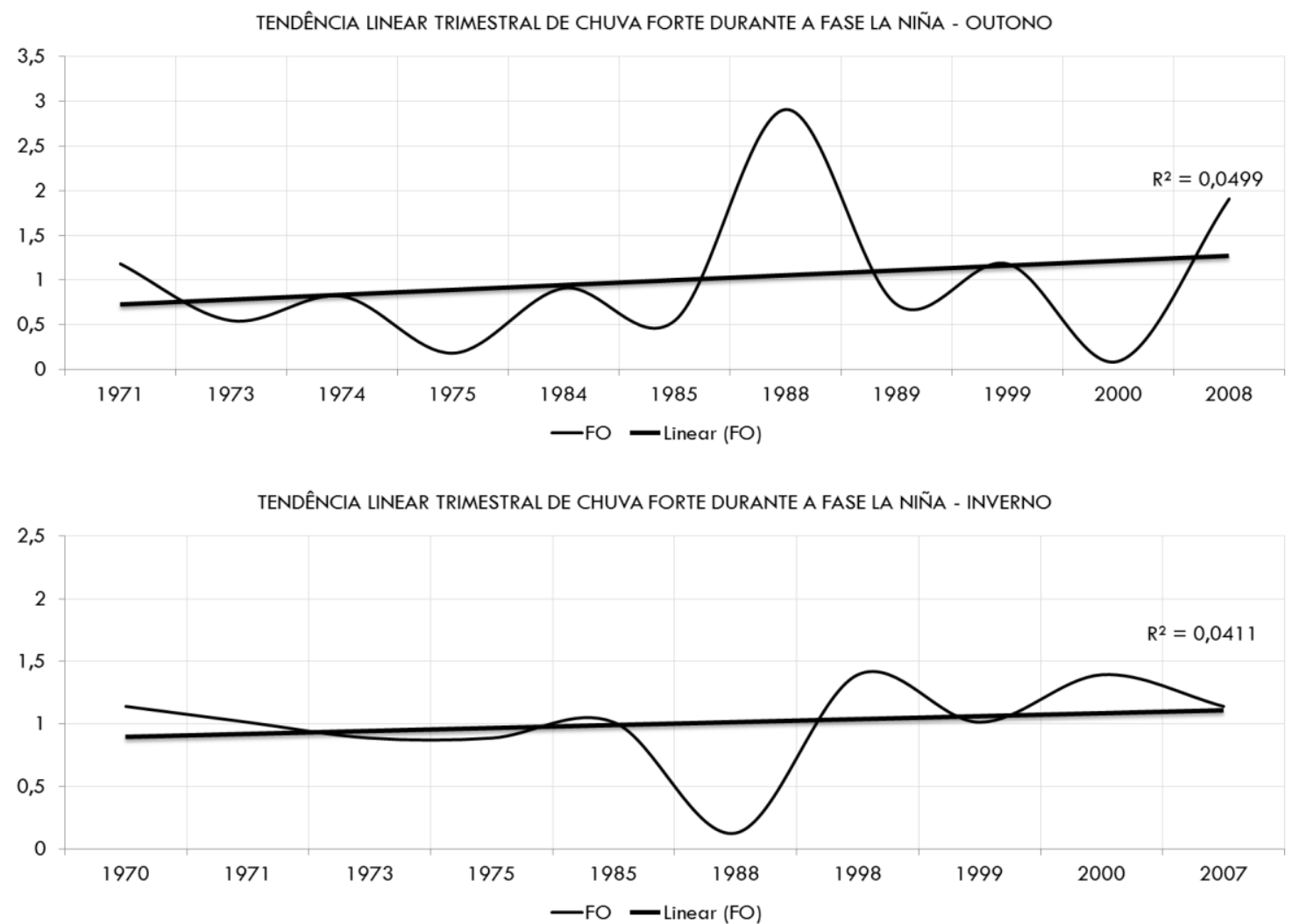


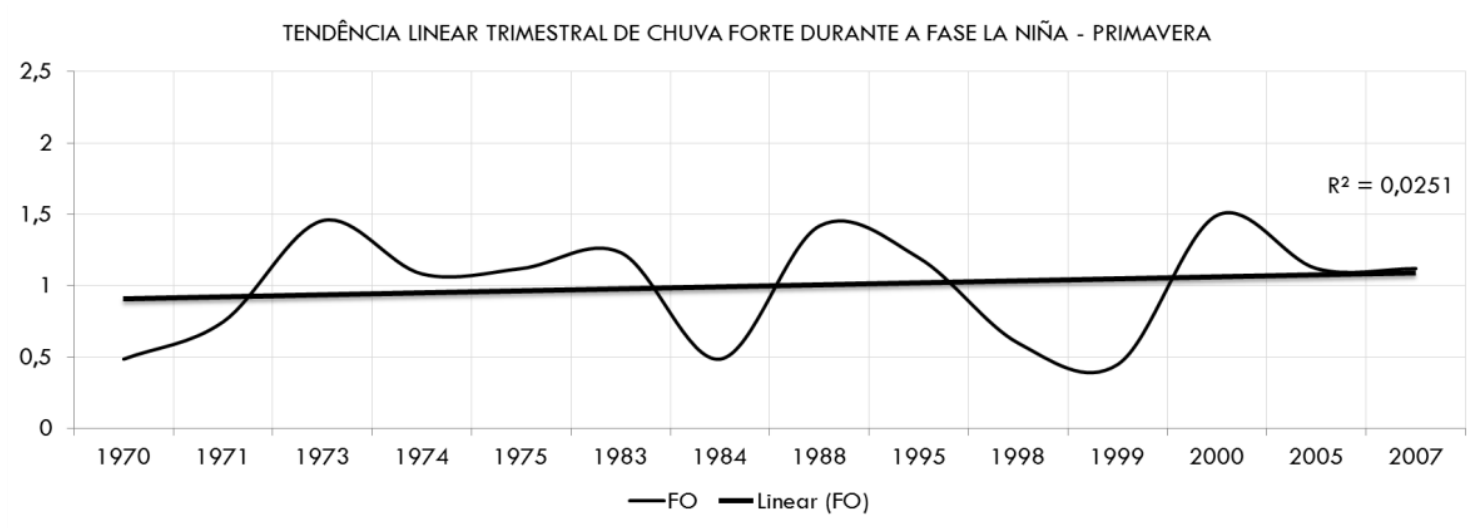

Figura 94 - Ajuste Linear Trimestral de Chuva Forte para as Estações de Outono, Inverno e Primavera durante a fase La Niña.

Os resultados trimestrais por fases especificam os resultados identificados no trabalho de Cabral (2002). Ou seja, em determinadas séries temporais específicas o padrão de aumento da frequência de chuvas mais intensas se manteve, por outro lado, foram encontradas séries que discordaram dessa generalização. De modo geral, a Tabela 37 indica que a metade dos casos envolvendo correlações lineares entre a chuva FO e ONI foram positivas $(+)$. No total foram 10 correlações positivas que apresentaram haver uma correlação estatística, em todas as estações climáticas do ano, entre as chuvas FO e a série temporal integral (ONI) e as séries temporais relativas (neutra, ENOS, EN e LN). As correlações lineares ocorreram com mais frequência durante o verão e outono.

Tabela 37 - Correlação Linear Trimestral entre a Tendência Linear Trimestral de Chuva Forte e a Tendência Linear Trimestral do ONI incluindo as Fases, Neutra, ENOS, EN e LN.

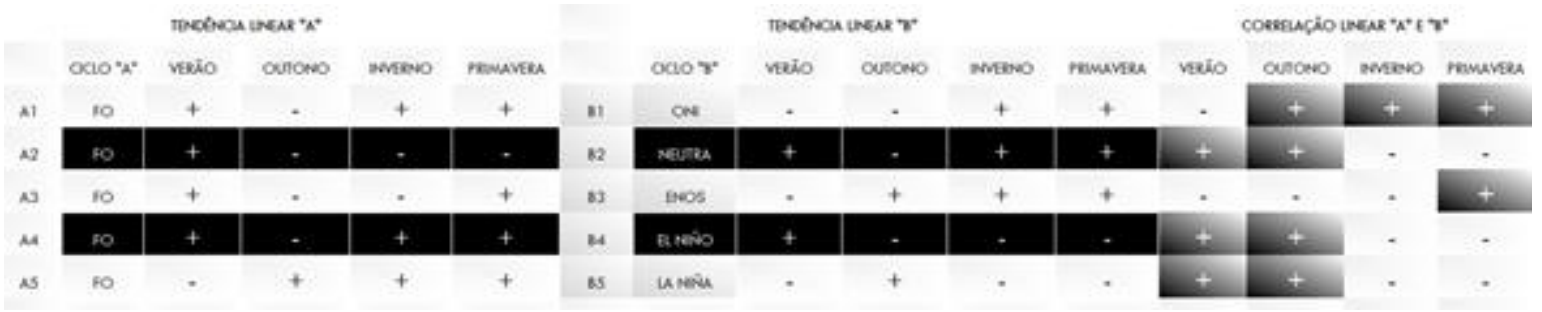

A frequência da chuva $F O$, durante o verão, diminui apenas durante a fase $L N$. Durante o outono, a frequência da chuva FO aumenta apenas durante a fase LN. No inverno, a frequência da chuva FO aumenta durante o ONI e, durante as fases de EN e LN. Na 
primavera, a frequência da chuva FO diminui apenas na fase Neutra (Tabela 37). Contudo, considerando todas as estações climáticas, no período de 1970 a 2009, verificamos que a frequência de chuva FO aumenta no decorrer do tempo, porém a tendência linear positiva identificada não é significativa. Por outro lado, justamente a única tendência linear negativa, indentificada no outono, pode ser considerada como sendo a mais significativa (Tabela 37).

\subsubsection{2- Variação Cíclica Trimestral de Chuva - FO}

A variação das anomalias da frequência de chuva FO para o período de 1970 a 2009, para as quatro estações do ano está ilustrada na Figura 95.

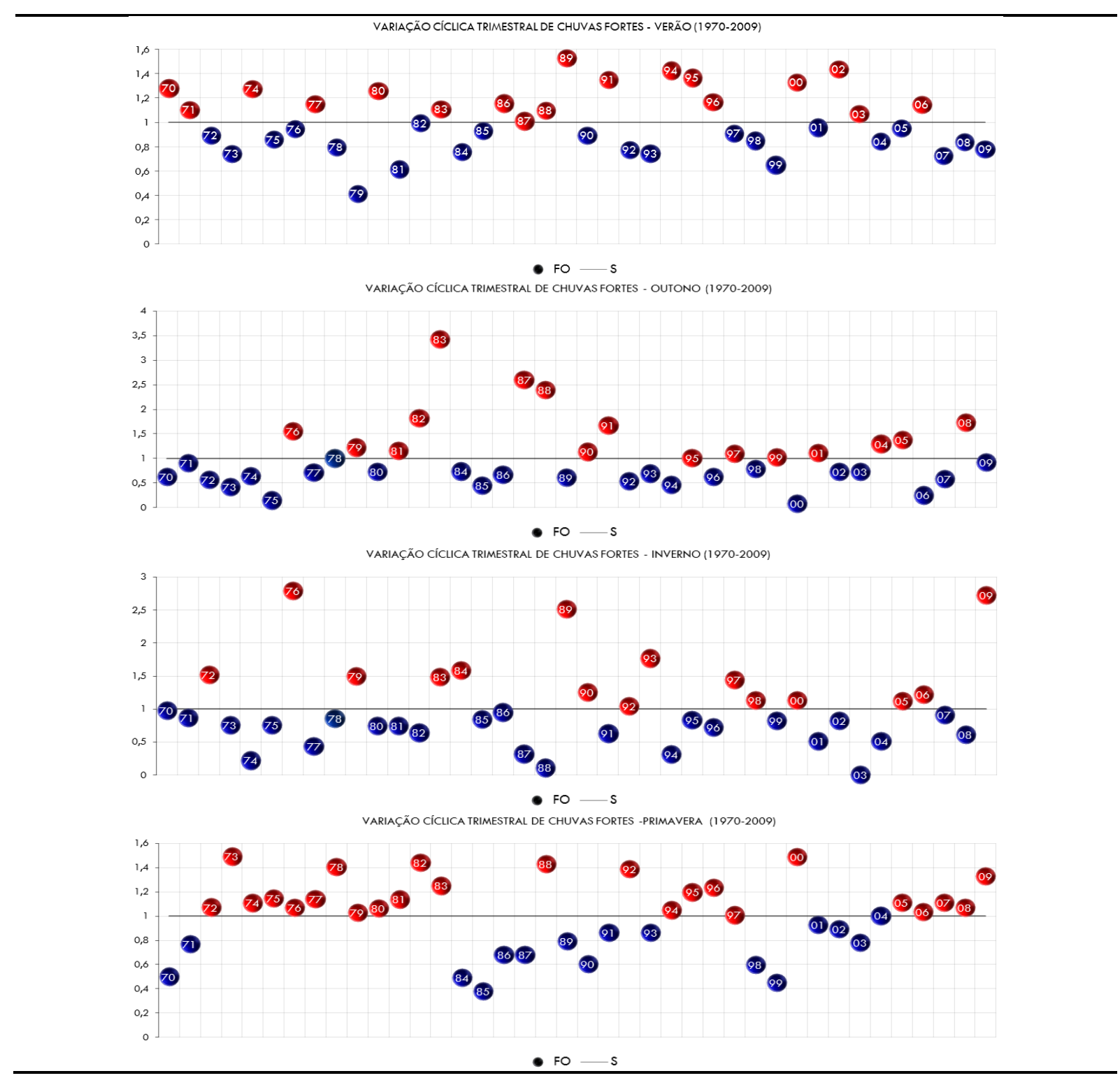

Figura 95 - Variação Cíclica Trimestral de Chuva Forte, entre 1970 e 2009. 


\subsubsection{3- Análise da Correlação Cíclica Trimestral}

De forma geral, separando a série temporal em estações do ano, observamos que a correlação linear entre as séries de $\mathrm{ONI}$ e frequência de chuva FO é positiva e significativa somente para o outono $(r=0,30)$, Figura 96. Ou seja, a frequência de chuva FO pode estar associada fisicamente aos valores de ONI durante o outono. A separação das séries temporais em eventos distintos quanto à TSM na região do Niño3.4 permitiu verificar que durante o verão, na fase $L N$, a correlação linear entre estas duas variáveis foi positiva e significativa $(r=0,61)$, Figura 97. A segunda correlação linear, significativa e positiva foi identificada no outono, na fase ENOS $(r=0,40)$, Figura 98. A terceira correlação linear, significativa, porém negativa foi identificada da primavera, na fase Neutra $(r=-0,52)$, Figura 99. Todos os demais resultados podem ser observados a partir da Tabela 38.

Tabela 38 - Correlação Cíclica entre a Frequência de Chuva Forte observada na Estação do IAG e os Valores de ONI para Cada Estação do Ano e, para Cada Condição de Anomalia na Região de Niño3.4 (Eventos Neutros, ENOS, EN e LN).

\begin{tabular}{|c|c|c|c|c|c|c|c|}
\hline VERÃO & OUICNO & INWERNO & PRLMAVERA & VEะ̃̃o & OUtCavo & ANERTNO & PRIMAVERA \\
\hline AI & A1 & A) & A1 & Coet & ONe & ONe & ONe \\
\hline $\mathbf{N}_{2}$ & $\wedge 2$ & $\mathrm{~N}^{2}$ & $N$ & NEUTRO & NEUTRO & NEUTRO & NEUTRO \\
\hline N & N & N & $\mathbf{N}$ & eros & enos & ENOS & enos \\
\hline M & $M$ & $\mu$ & $M$ & E NESO & E NENOO & fi NeASOO & EINENO \\
\hline is & as & As & N & unera & IANENA & UANER & unein \\
\hline \multicolumn{4}{|c|}{ CORRELAÇÄO CICUICA } & \multicolumn{4}{|c|}{ TESTE T - STUDENT } \\
\hline VERR̆O & OUTCNO & INWERNAO & PRIMAVERA & VERẼO & OUTCNO & RIVERTOO & PRIMAVERA \\
\hline 0,007 & $0,30 \%$ & 0,08 & 0,031 & NT̈O SIONEFCATIVO & SIONACATNO & NïO SROeEKCATNO & NIOO SLONEFCATMO \\
\hline$-2,038$ & 0,281 & 0,112 & $-0,524$ & MĨo SIGHERCATIVO & NIOO SIGNFACATINO & NḦO STGESTCATIVO & SSONERCATwO \\
\hline 0,00 & 0,401 & 0.122 & a,1is & NŔO SKCHEHCATINO & SACNACATINO & Nho SECNEICATINO & MÜO SIGNEFCATMO \\
\hline 0.317 & QA10 & 0,032 & 0.259 & Mä́ SCANERCATIVO & NHO SENERCATINO & Nío scceatcutro & Nho segmencatmo \\
\hline 0,012 & 0,002 & 0,538 & 0,219 & Scaeficativo & NÜO STCNARCATtio & 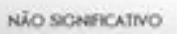 & NLIO SCNARCATMO \\
\hline
\end{tabular}

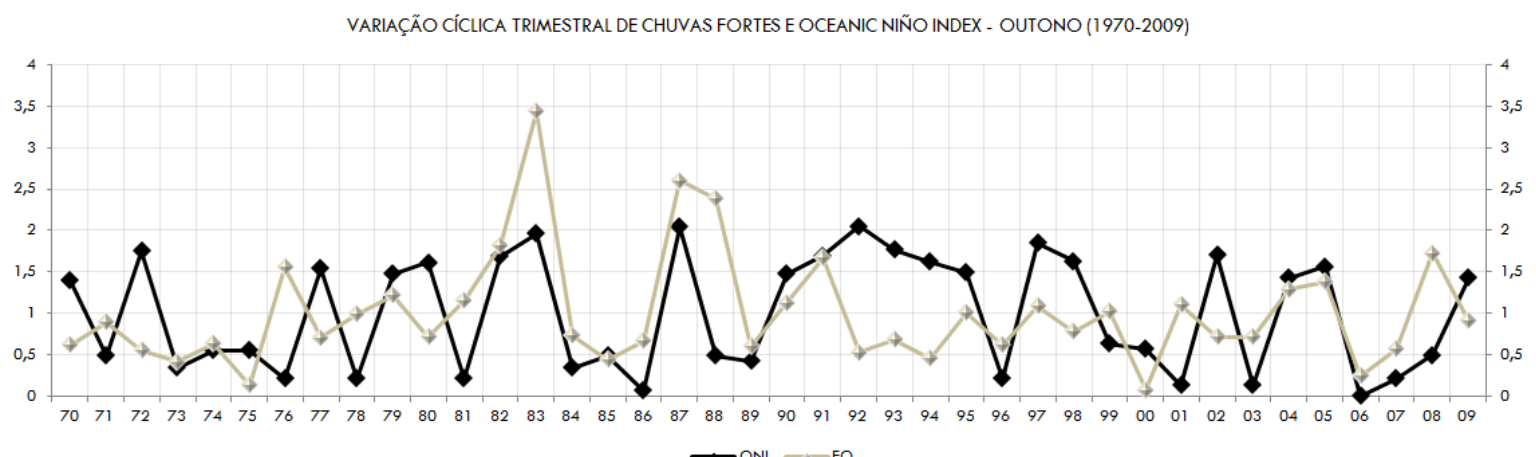

Figura 96 - Variação Cíclica de Chuva FO, no Outono, entre 1970 e 2009. 


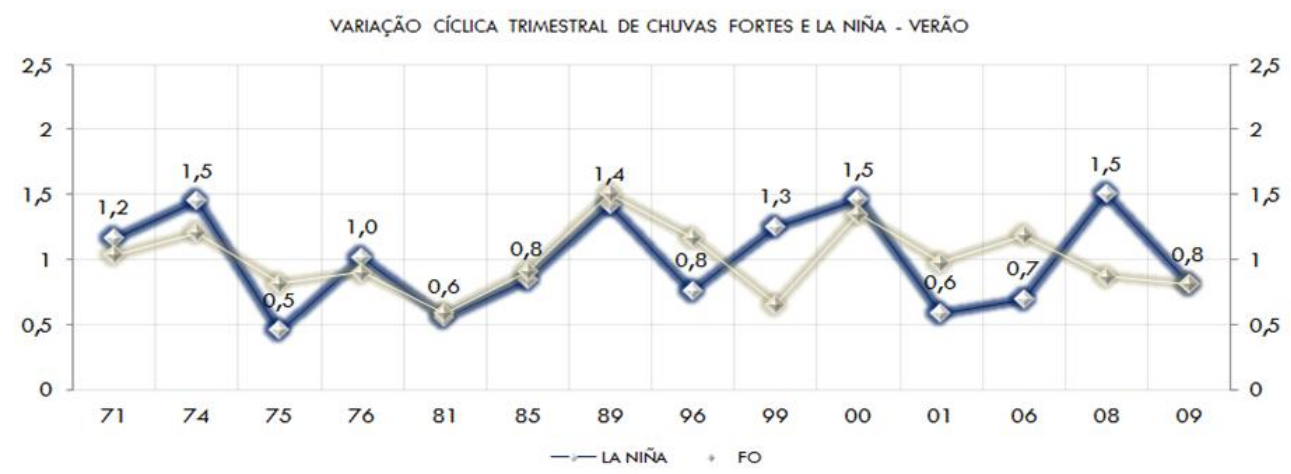

Figura 97 - Variação Cíclica de Chuva FO, no Verão, durante a Fase La Niña.

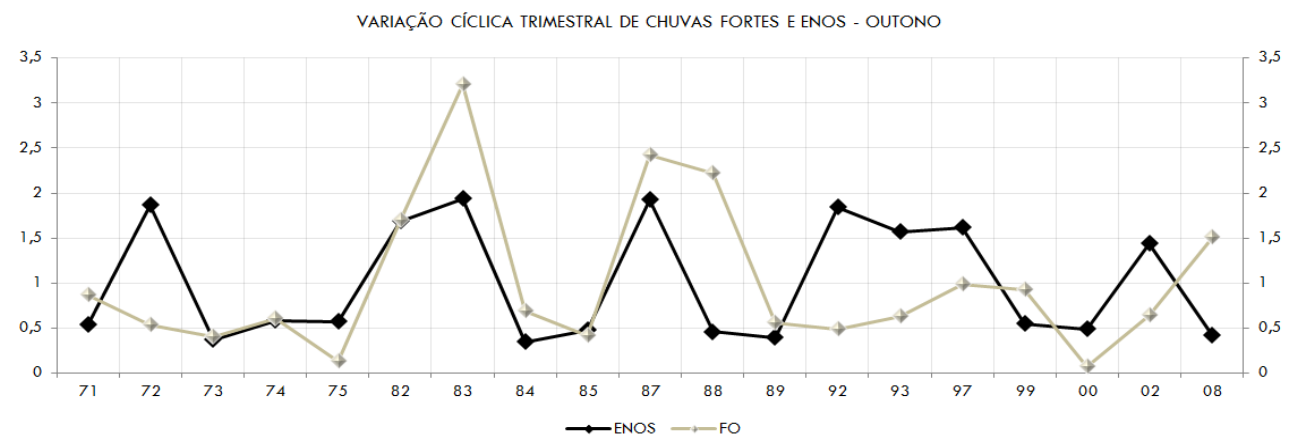

Figura 98 - Variação Cíclica de Chuva FO, no Outono, durante a Fase ENOS.

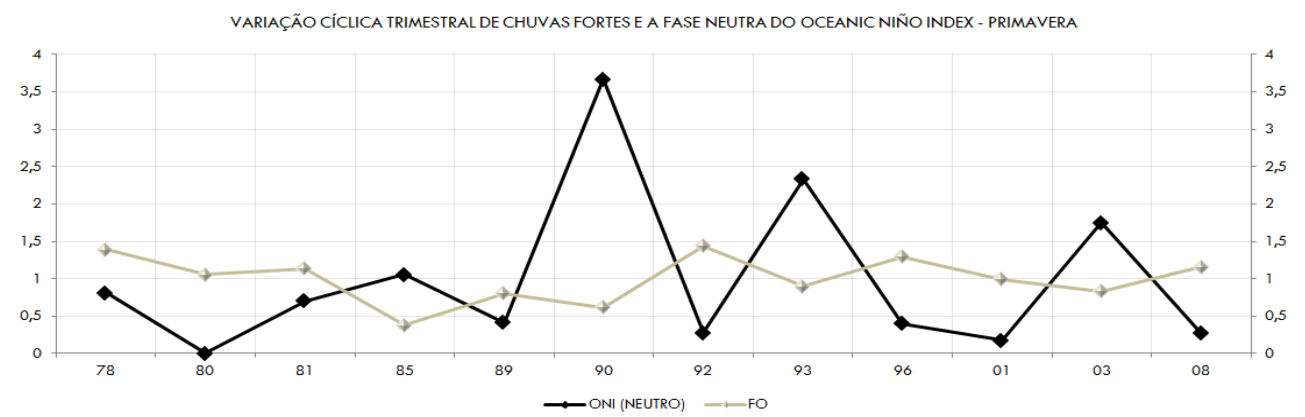

Figura 99 - Variação Cíclica de Chuva FO, na Primavera, durante a Fase Neutra.

\subsubsection{4- Análise Específica das Fases Trimestrais}

Os resultados de tal análise revelam as possíveis correlações existentes entre as fases altas e baixas da frequência de Chuva Forte e do ONI. Neste caso, identificamos à série específica através das fases altas $(\bar{x}>1)$ e baixas $(\bar{x}<1)$ da variação cíclica da frequência trimestral de chuva FO. A variação cíclica de chuva FO no período de 1970 a 2009 durante a estação de verão foi composta por 22 fases específicas. A partir do 
resultado negativo da correlação linear entre a tendência positiva de chuva FO e a tendência negativa do ONI, procuramos identificar as fases da oscilação que possivelmente estiveram associadas a tal comportamento. Neste caso, as fases altas estariam correlacionadas com a chuva FO e, as fases baixas correlacionadas com o ONI (Figura 100). Em função dessa probabilidade, identificamos nos anos $70,71,77,80,83,91,94,95$ e 96 as fases altas que estariam significativamente e positivamente correlacionadas com a chuva FO. Por outro lado, identificamos nos anos $75,76,78,79,84,85,92,93,01,04$ e 05 as fases baixas que estariam significativamente e positivamente correlacionadas com o ONI (Tabela 39). A variação cíclica de chuva FO no período de 1970 a 2009 durante a estação de outono foi composta por 22 fases específicas. A partir do resultado positivo da correlação linear entre a tendência negativa de chuva FO e a tendência negativa do ONI, procuramos identificar as fases da oscilação que possivelmente estiveram associadas a tal comportamento. Neste caso, deduzimos que somente as fases baixas estariam correlacionadas (Figura 100). Em função dessa probabilidade, identificamos nos anos $89,97,04$ e 05 as fases baixas que estariam significativamente e positivamente correlacionadas com a correlação positiva entre a chuva FO e o ONI (Tabela 39). A variação cíclica de chuva FO no período de 1970 a 2009 durante a estação de inverno foi composta por 22 fases específicas. A partir do resultado positivo da correlação linear entre a tendência positiva de chuva FO e a tendência positiva do ONI, procuramos identificar as fases da oscilação que possivelmente estiveram associadas a tal comportamento. Neste caso, deduzimos que somente as fases altas estariam correlacionadas (Figura 100). Em função dessa probabilidade, identificamos nos anos 72, 76, 79, 92, 97, 98, 05, 06 e 09 as fases altas que estariam significativamente e positivamente correlacionadas com a correlação positiva entre a chuva FO e o ONI (Tabela 39). A variação cíclica de chuva FO no período de 1970 a 2009 durante a estação da primavera foi composta por 12 fases específicas. A partir do resultado positivo da correlação linear entre a tendência positiva de chuva FO e a tendência positiva do ONI, procuramos identificar as fases da oscilação que possivelmente estiveram associadas a tal comportamento. Neste caso, deduzimos que somente 
as fases altas estariam correlacionadas (Figura 100). Em função dessa probabilidade, identificamos nos anos $88,05,06,07,08$ e 09 as fases altas que estiveram significativamente e positivamente correlacionadas com a correlação positiva encontrada entre a chuva FO e o ONI (Tabela 39).
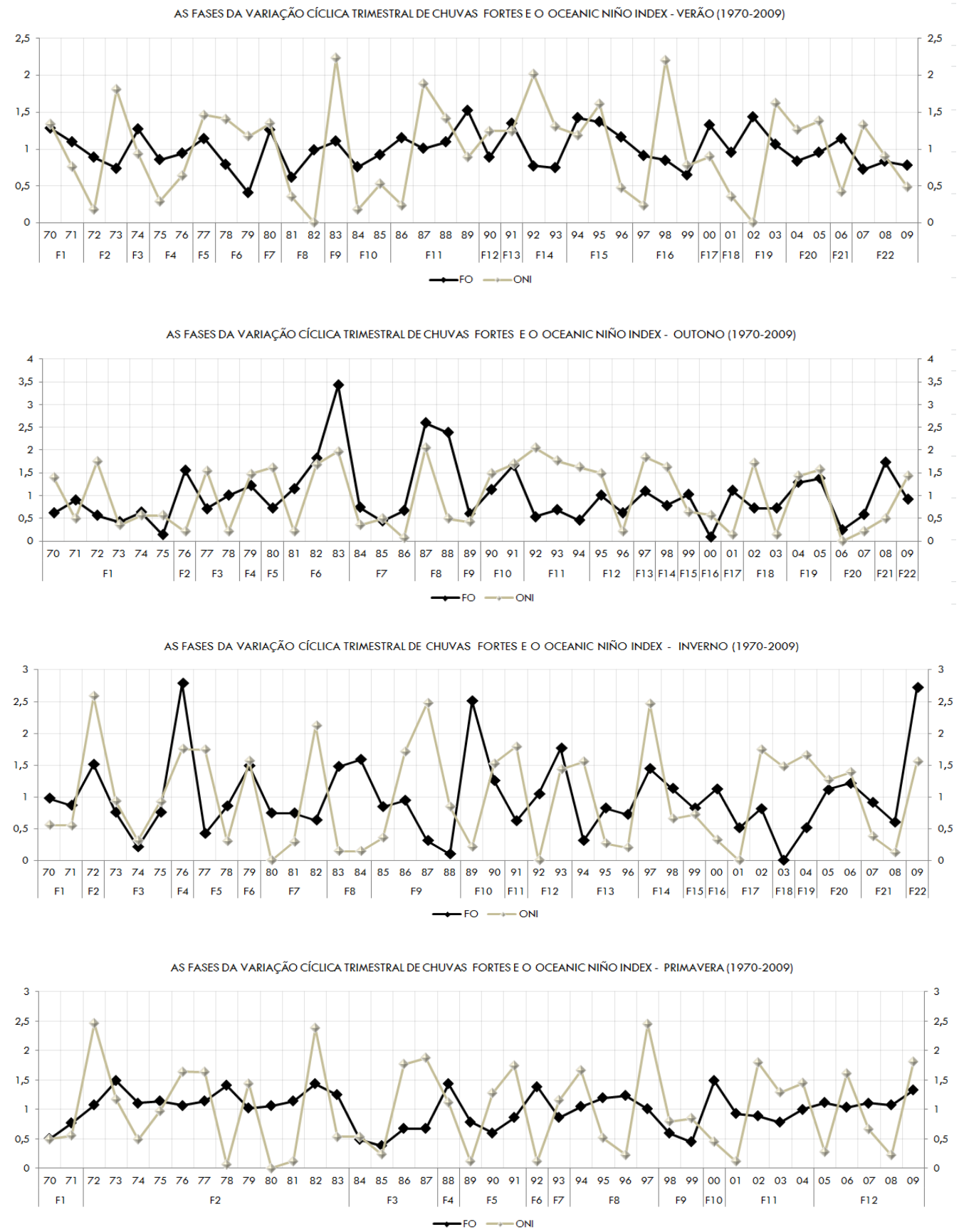

Figura 100 - Fases Específicas do Ciclo Trimestral de Chuva Forte, Verão, Outono, Inverno e Primavera. A linha Branca corresponde à variação cíclica do ONI e a linha Preta de Chuva FO, para o Período de 1970-2009. 
Tabela 39 - Correlação Linear entre a Frequência de Chuva Forte observada na Estação do IAG e os Valores de ONI para Cada Estação do Ano e, para Cada Condição de Anomalia na Região de Niño3.4 (Eventos Neutros, ENOS, EN e LN). "A" representa as Séries Temporais de Chuva FO relativa às Séries Temporais do ONI "B". Assim, B1 (ONI), B2 (Neutro), B3 (ENOS), B4 (EN) e B5 (LN). Correlação "A" são os Tipos Fases Correlacionadas com a Chuva FO e Correlação "B" são os Tipos Fases Correlacionadas com o ONI.

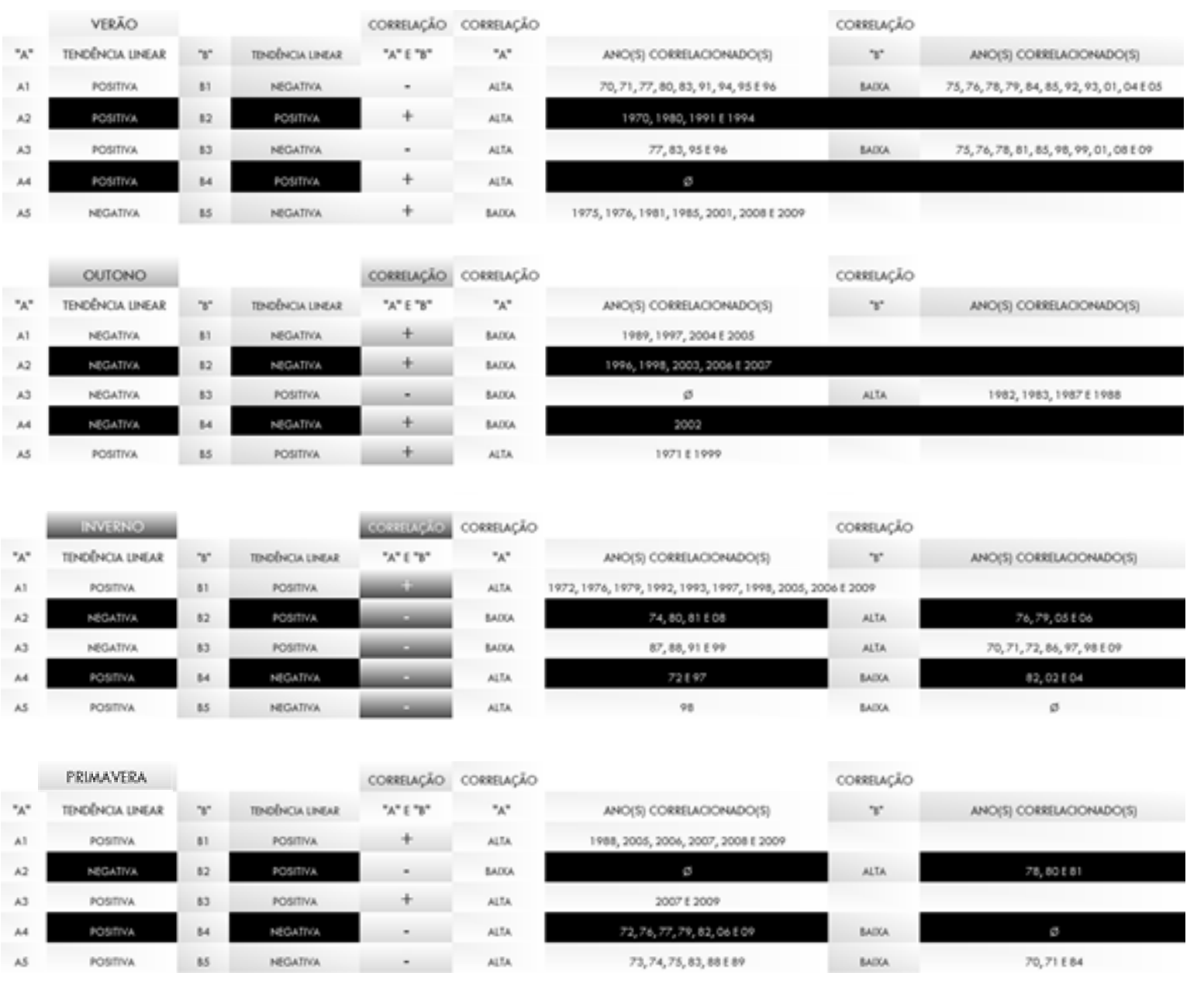

\subsubsection{5- A Hipótese Inicial e a Conclusão Final - FO II}

A conclusão final para análise trimestral de Chuva Forte parte das distintas correlações identificadas, para cada estação climática, envolvendo o ajuste linear dos índices do ONI na região Niño3.4 e a frequência de chuva FO. De modo geral, no outono, inverno e primavera observamos que o ajuste linear positivo (negativo) do ONI coincidiu positivamente com o ajuste de chuva FO. A exceção observada ocorreu na estação de verão, onde o ajuste linear positivo de chuva FO não coincidiu positivamente com o ajuste linear do ONI. A Tabela 39 apresenta os resultados das demais correlações realizadas para as séries temporais do 
ONI em cada estação climática do ano. Após identificarmos as respectivas correlações lineares trimestrais entre a chuva $\mathrm{FO}$ e $\circ \mathrm{ONI}$, analisamos os resultados das correlações cíclicas trimestrais. Neste caso, encontramos apenas quatro correlações cíclicas significativas, três positivas e uma negativa (Tabela 38). A primeira foi identificada no verão, durante a fase LN. A segunda e a terceira foram identificadas no outono, durante o ONI e a fase ENOS. A quarta foi identificada na primavera, durante o ONI.

A partir da combinação dos resultados observados durante a série temporal da fase LN, na estação de verão, onde identificamos uma correlação positiva envolvendo ajustes lineares negativos e uma correlação cíclica significativa, analisamos por dedução e correlação que seja muito provável que tenha ocorrido um enfraquecimento das variações cíclicas de chuva FO em função da diminuição das amplitudes dos seus ciclos ao longo do período da fase La Niña. Neste caso, é possível identificar consonância com a expectativa de Grimm et al (1999), ou seja, nota-se a influência de padrões de macroescala alterando a frequência de circulação que neste caso diminuiu suprimindo a precipitação. A mesma conclusão pode ser feita para o caso da variação cíclica de chuva FO na estação de outono, durante o período do ONI. Ainda, podemos identificar os possíveis reflexos das combinações observadas, em fases específicas, que podem ser visualizados através dos anos que estiveram correlacionados, de acordo com a Tabela 39.

\section{6- Chuva Muito Forte - 16,0 a $50,0 \mathrm{~mm} \mathrm{~h}-1$}

As chuvas definidas como sendo muito fortes e, que possivelmente estão associadas as "tempestades severas" atingem níveis pluviométricos equivalentes a $16,0-50,0 \mathrm{~mm} \mathrm{h-1}$. A partir da hipótese inicial deste estudo, a intenção ao analisar este tipo de chuva, é a de concluir para a série temporal de 1970-2009, a existência ou não de um nível de correlação aceitável, envolvendo o comportamento de sua frequência e as variações registradas na temperatura da superfície do mar na região Niño3.4. De acordo com tal hipótese, o estudo 
estabelece uma reflexão a partir de três possibilidades, que podem ou não atuar em conjunto. A reflexão teórica e quantitativa analisa a possibilidade de uma possível correlação, que pode ser ou não, isoladamente linear, cíclica e/ou especificamente por fases, altas ou baixas da variação cíclica. A cronologia das escalas de análise foi dividida em anuais e trimestrais. A intenção desta reflexão científica é a de presumir a partir dos resultados, a possibilidade de ter ocorrido uma intensificação ou enfraquecimento, nos quadros evolutivos das variações cíclicas de Chuva Muito Forte, a partir do aumento ou da diminuição das amplitudes dos seus respectivos ciclos, em função do aquecimento ou resfriamento, diagnosticado através dos registros da TSM, na região Niño3.4.

\subsection{1 - Análise Anual}

A análise anual possui a finalidade de apresentar uma conclusão obtida a partir da identificação do tipo de correlação existente na intenção de sugerir a possibilidade de haver uma relação anual envolvendo a Chuva Muito Forte (MFO) e o Oceanic Niño Index. Neste caso, também estão inclusos os resultados das correlações realizadas para as fases ENOS, Neutra, El Niño e La Niña.

\subsubsection{1 - Frequência Anual de Chuva Muito Forte}

A partir da frequência anual de Chuva Muito Forte $(16,0$ a $50,0 \mathrm{~mm} \mathrm{~h}-1)$, representada no gráfico da Figura 101, é possível identificar que a frequência máxima ocorreu no ano de 1996, relativo à contagem de 22 casos horários.

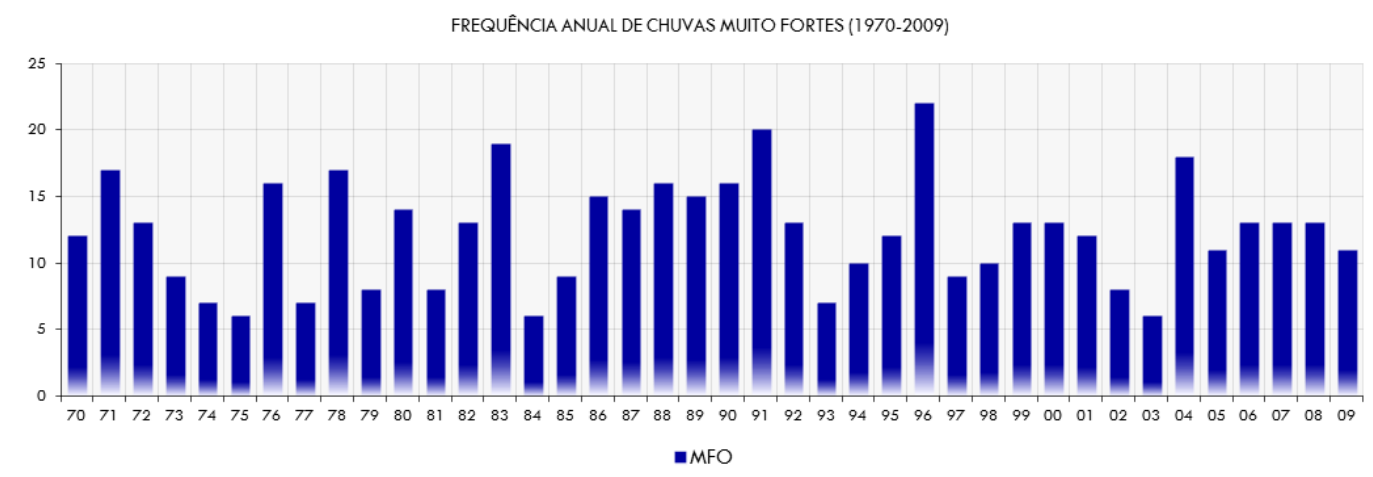

Figura 101 - Frequência Anual de Chuva Muito Forte entre 1970-2009. 


\subsubsection{2- Análise do Ajuste Linear}

O ajuste linear da frequência anual de Chuva Muito Forte no município de São Paulo indica tendência linear positiva nula ao longo da série temporal analisada, de 1970 a 2009, tal como ilustrada na Figura 102. A análise realizada para as fases, neutra, ENOS, El Niño e La Niña, separadamente, mostra que, em todos os casos, a frequência anual de Chuva Muito Forte aumenta com o tempo, exceto na fase Neutra e El Niño (Figura 103). A comparação entre a tendência linear da frequência de Chuva Muito Forte e do ONI indica que enquanto o ONI assume valores cada vez mais intensos, no decorrer da série temporal, a frequência de Chuva Muito Forte aumenta, tal como indicado na Tabela 40. A exceção ocorre no caso de eventos de EN que apresenta tendência negativa nula de TSM, ao longo do período analisado, concomitantemente com a tendência negativa da frequência de Chuva Muito Forte (ver tabela $X X$, linha 4).

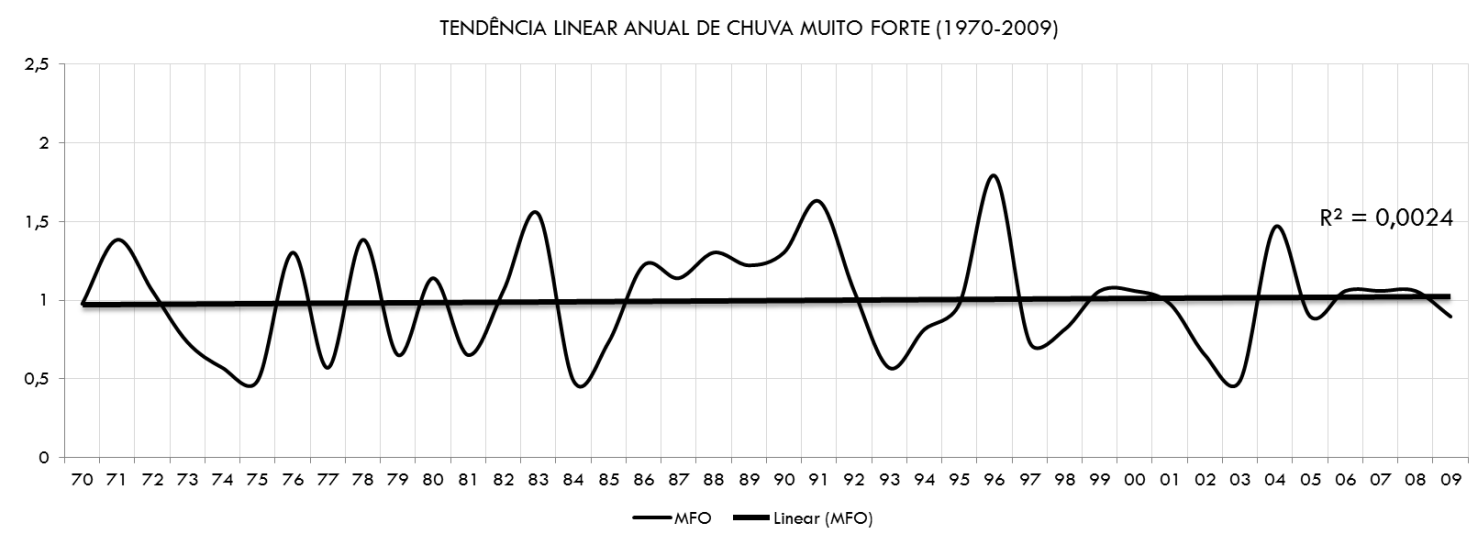

Figura 102 - Ajuste Linear da Frequência Anual de Chuva Muito Forte entre 1970-2009.

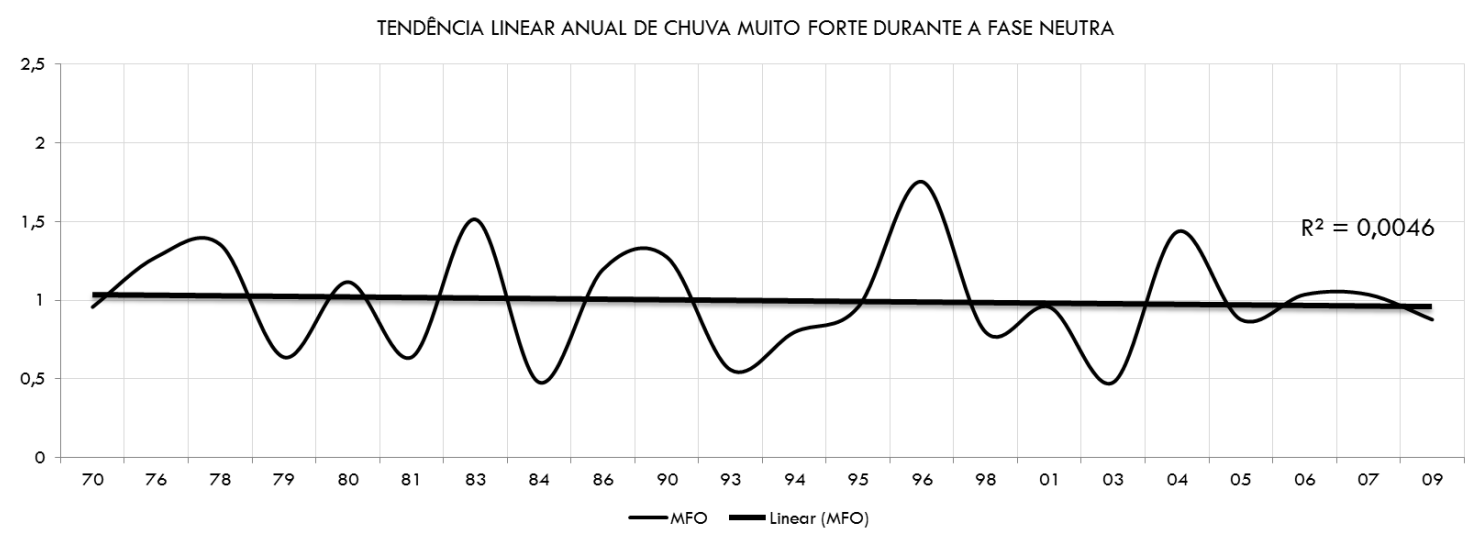



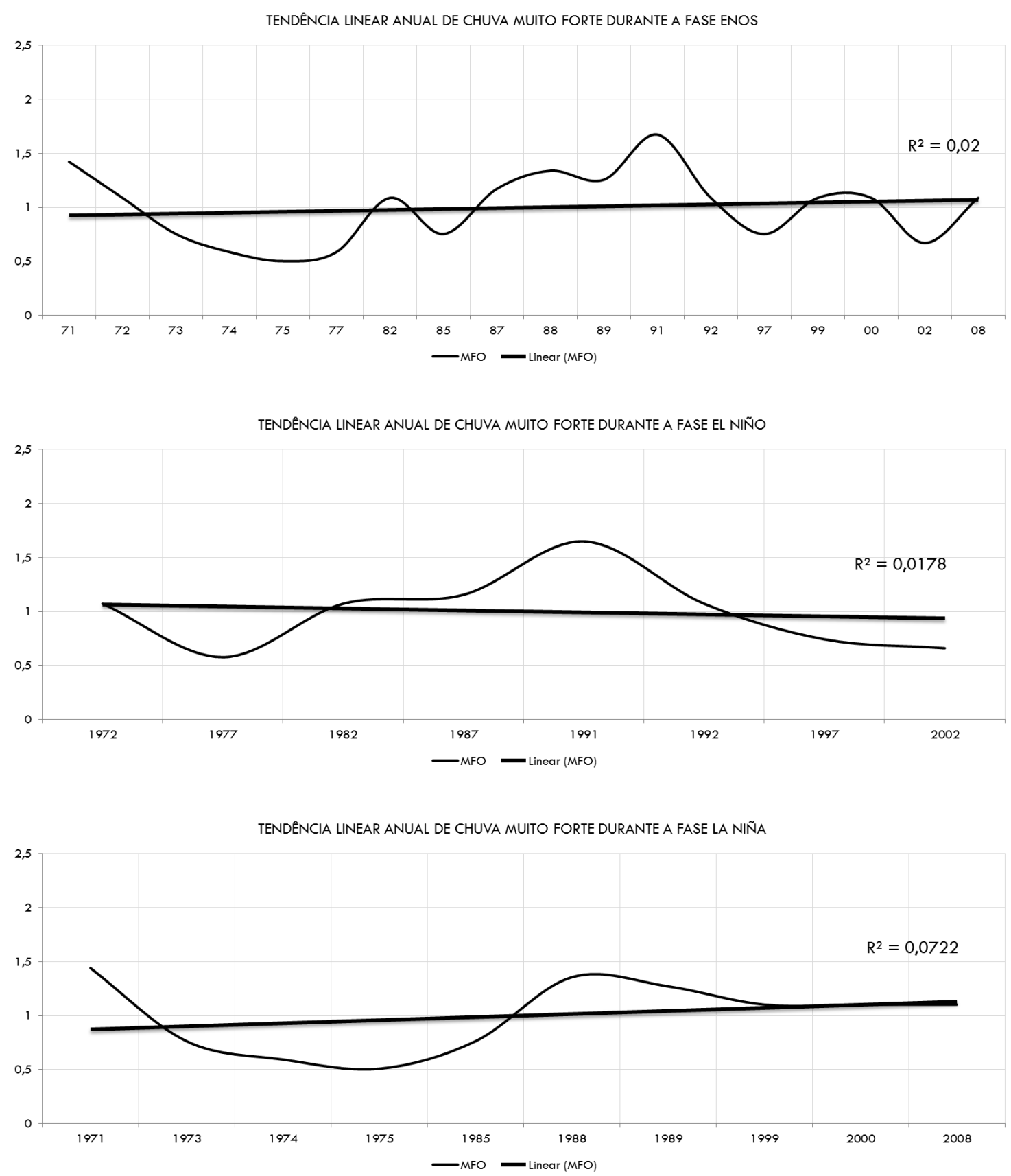

Figura 103 - Tendência Linear da Frequência Anual de Chuva Muito Forte para a Fase, Neutra, ENOS, EN e LN, entre 1970-2009.

Os resultados observados através dos ajustes lineares para a série anual revelam que as frequências analisadas no intervalo horário refletiram positivamente com os resultados das análises diárias realizadas por Cabral (2002), Sugahara et al (2009) e Freitas et al (2013), porém ocorrem algumas exceções quando são analisadas algumas fases específicas. 
Tabela 40 - Tendência Linear Anual de Chuva Muito Forte e do ONI para o Período de 1970 a 2009. A Primeira Linha da Tabela indica a Tendência Linear de Todos os Dados Anuais e, as Demais Linhas indicam a Tendência Linear para cada Fase do ONI.

\begin{tabular}{|c|c|c|c|c|c|c|}
\hline$" A{ }^{-}$ & TIPO DE CHUVA & TENDENCIA UINEAR & "B" & CATEGORIA & TENDENCIA UINEAR & CORRELAÇÃO UNEAR \\
\hline Al & MFO & POSITIVA & B1 & ONI & POSITIVA & POSITIVA \\
\hline A2 & MFO & NEGATIVA & B2 & NEUTRO & POSITIVA & NEGATIVA \\
\hline A3 & MFO & POSITIVA & B3 & ENOS & POSITIVA & POSITIVA \\
\hline A4 & MFO & NEGATIVA & B4 & EL NIÑO & NEGATIVA & POSITIVA \\
\hline A5 & MFO & POSITIVA & B5 & LA NIÑA & POSITIVA & POSITIVA \\
\hline
\end{tabular}

\subsubsection{3- Variação Cíclica de Chuva Muito Forte}

A variação cíclica anual de Chuva Muito Forte pode ser observada na Figura 104. É possível notarmos a oscilção presente na série temporal completa, de 1970 a 2009, formada por 22 fases altas (esferas vermelhas) e 18 fases baixas (esferas azuis).

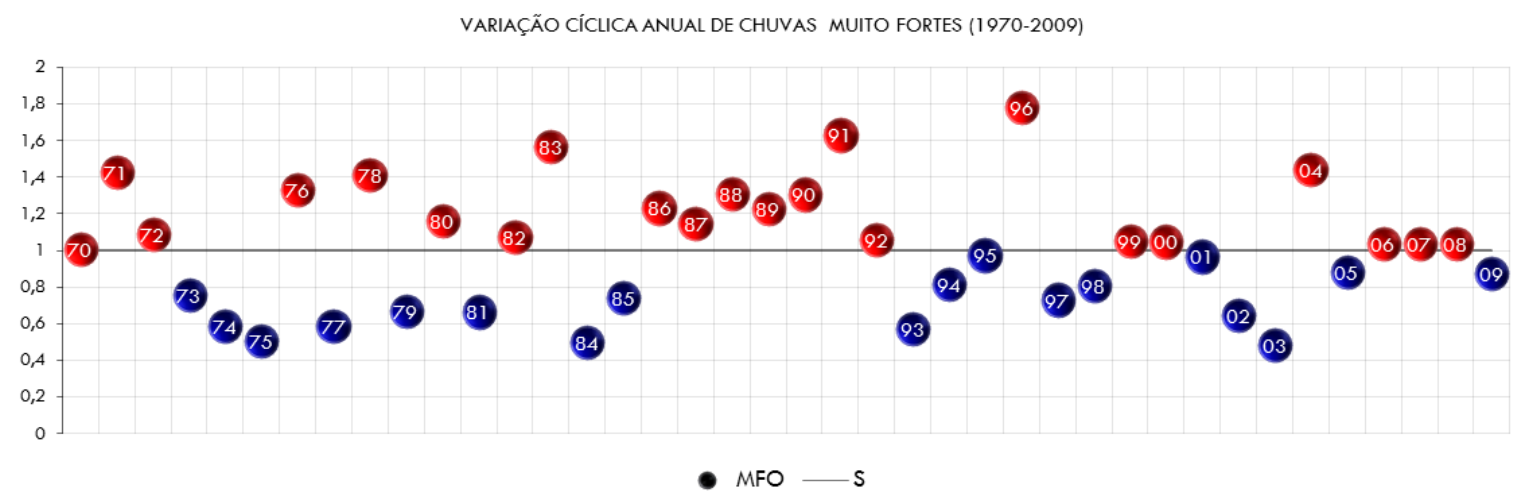

Figura 104 - Variação Cíclica Anual da Frequência de Chuva Muito Forte entre 1970 e 2009.

\subsubsection{4- Análise da Correlação Cíclica}

A partir dos resultados do teste de significância - t-"Student" - notamos que os resultados do cálculo de correlação linear, para as séries cíclicas, entre ONI e a frequência anual de Chuva Muito Forte, nas fases, Neutra, ENOS e La Niña não foram significativos (Tabela 41). Por outro lado, observamos que a fase de EN (Tabela 41, linha 4) apresentou correlação linear significativa (Figura 105). 
Tabela 41 - Correlação Linear entre a Anomalia de ONI e da Frequência Anual de Chuva Muito Forte entre 1970 e 2009, sem Tendência Linear (Série Cíclica).

\begin{tabular}{|c|c|c|c|c|c|}
\hline & CICLO "A" & & CICIO "B" & CORRELAÇĀO CICUICA & TESTE T-STUDENT \\
\hline Al & MFO & B1 & ONI & $-0,022$ & NĀO SIGNIFICATIVO \\
\hline A2 & MFO & B2 & NEUTRA & $-0,041$ & NĀO SIGNIFICATIVO \\
\hline A3 & MFO & B3 & ENOS & 0,058 & NÃO SIGNIFICATIVO \\
\hline A4 & MFO & B4 & EL NIÑO & 0,864 & SIGNIFICATIVO \\
\hline A5 & MFO & B5 & LANINA & 0,821 & NÄO SIGNIFICATIVO \\
\hline
\end{tabular}

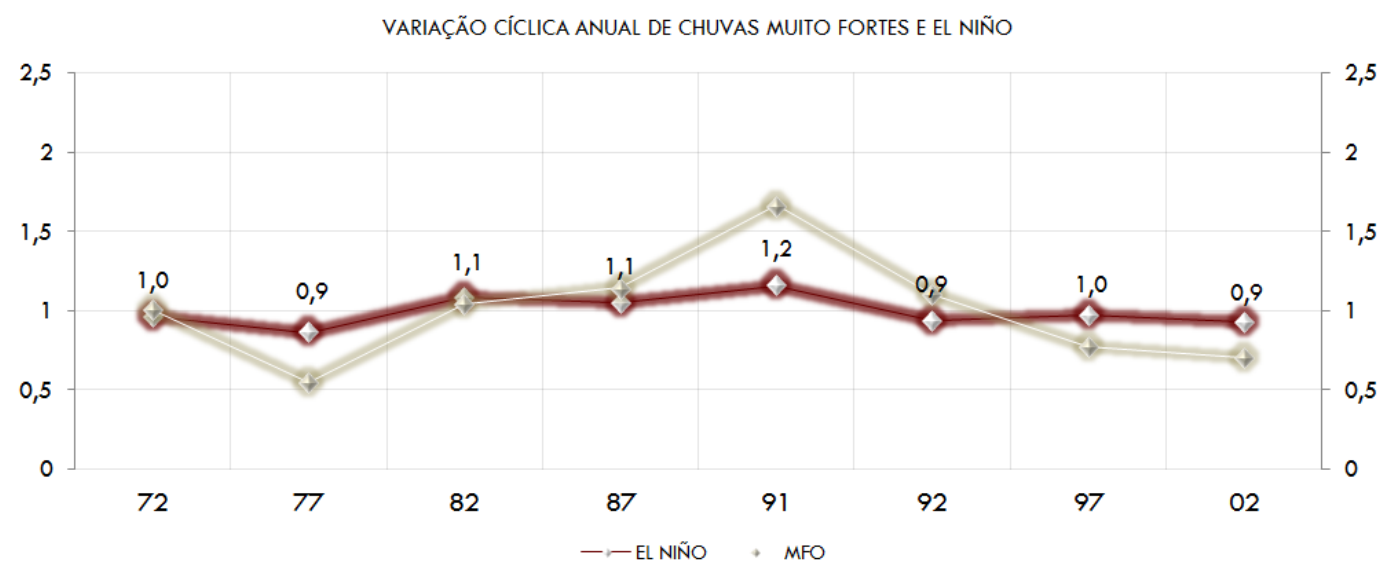

Figura 105 - Variações Cíclicas Anuais da Fase EL Niño e de Frequência de Chuva Muito Forte, entre 1970 e 2009.

\subsubsection{5- Análise Específica do Ciclo de Chuva - MFO}

Os resultados de tal análise revelam as possíveis correlações existentes entre as fases altas e baixas da frequência de Chuva Muito Forte e do ONI. Neste caso, na Figura 106 identificamos a série específica através das fases altas $(\bar{x}>1)$ e baixas $(\bar{x}<1)$ da variação cíclica da frequência de chuva MFO.

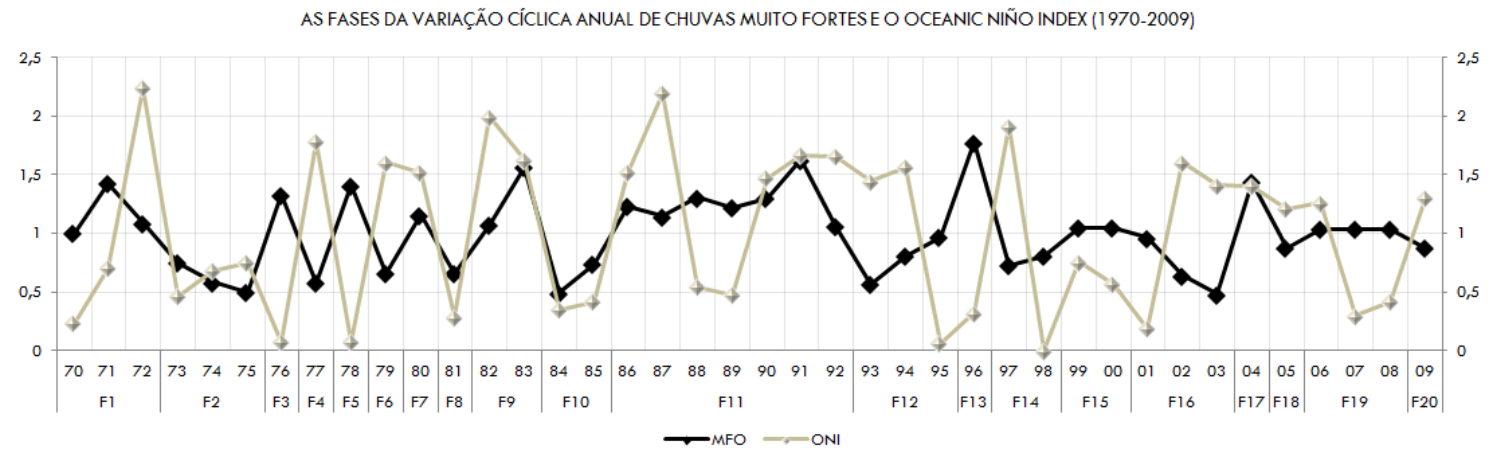

Figura 106 - Fases Específicas do Ciclo Anual de Chuva Muito Forte. A linha Branca corresponde à variação cíclica do ONI e a linha Preta de Chuva MFO, para o Período de 1970-2009. 
A variação cíclica anual de Chuva Muito Forte no período de 1970 a 2009 foi composta por 20 fases específicas (altas e baixas). No entanto, a partir do resultado positivo da correlação linear entre a tendência positiva de Chuva Muito Forte e a tendência positiva da ONI, procuramos identificar as fases da oscilação que possivelmente estiveram associadas a tal comportamento. Neste caso, as fases altas estariam concomitantemente correlacionadas com a frequência de Chuva Forte e o ONI. A partir dessa possibilidade foram identificadas, 4 fases altas, significativamente e positivamente correlacionadas, nos anos de 1980, 1999, 2000, 2004, 2006, 2007 e 2008.

\subsubsection{6- A Hipótese Inicial e a Conclusão Final - MFO I}

A conclusão final para análise anual de Chuva Muito Forte nos sugere que o aquecimento observado na região Niño3.4 coincidiu com o aumento na frequência de Chuva Muito Forte, com exceção da Fase Neutra. A mesma situação, porém invertida pode ser observada para a fase El Niño. Nas correlações cíclicas, notamos que a fase El Niño esteve significativamente correlacionada. Por último, é possível sugerir que os reflexos do resultado do ajuste linear possam ter ocorrido, pontualmente, em fases e anos específicos. Desta forma, para os quatros casos de correlação linear positiva, aqueles, que envolveram ajustes positivos (ONI, ENOS e La Niña), possivelmente podem ser identificados a partir das fases altas, quando significativamente e positivamente correlacionados. Por outro lado, no caso da fase El Niño, onde envolveu ajustes negativos, possivelmente, podem ser identificados a partir das fases baixas, quando estas, estiverem significativamente e positivamente correlacionados (Figura 107). Neste caso, a combinação deste resultado com o resultado da significância da correlação cíclica, reforçaria a justificativa de ter ocorrido a tal possibilidade. Por último, é possível constatar que durante esta mesma fase ocorreu o enfraquecimento das variações cíclicas em função da diminuição de suas respectivas amplitudes ao longo da série. Neste caso, é possível identificar consonância com a expectativa de Grimm et al (1999), ou seja, 
nota-se a influência de padrões de macroescala alterando a frequência de circulação, que neste caso diminuiu suprimindo a precipitação.

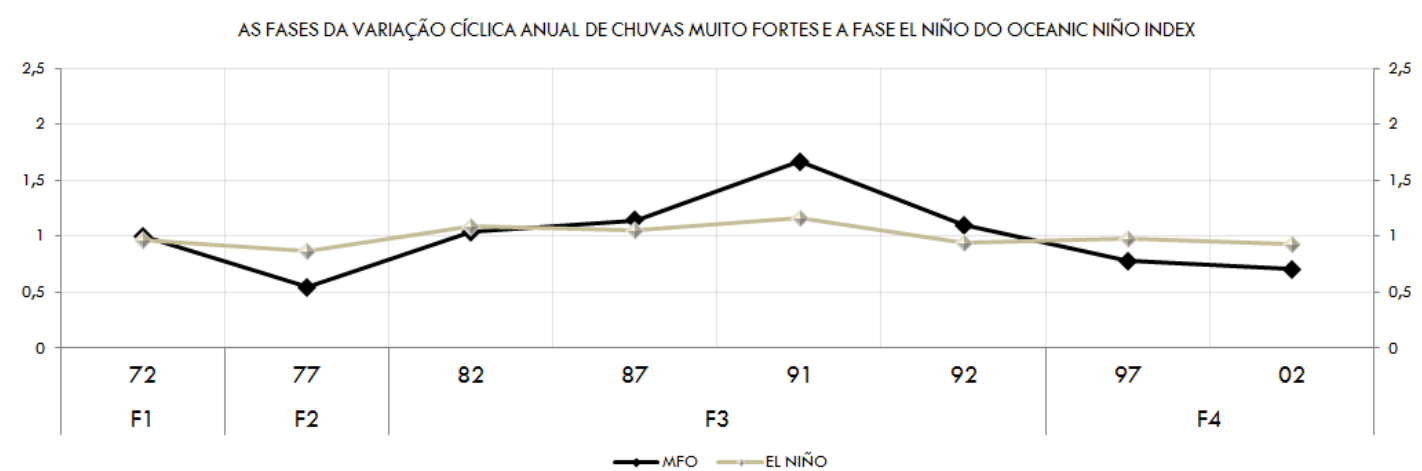

Figura 107 - Fases Específicas do Ciclo Anual de Chuva MFO durante a Série Temporal de EN. A linha branca corresponde à variação cíclica do EN e a linha cinza de Chuva MFA.

A Tabela 42 apresenta uma síntese dos resultados finais da correlação por fases específicas entre a frequência de Chuva Muito Forte e o ONI, entre 1970 e 2009.

Tabela 42 - Correlação Anual em Fases Específicas. A Coluna "A" indica ○ Ajuste Linear da Chuva MFO nas Séries Temporais "B" correspondente o ONI e suas Fases. A Última Coluna aponta os Possíveis Anos que estiveram Correlacionados com o Resultado da Correlação Linear do Ajuste "A" e "B".

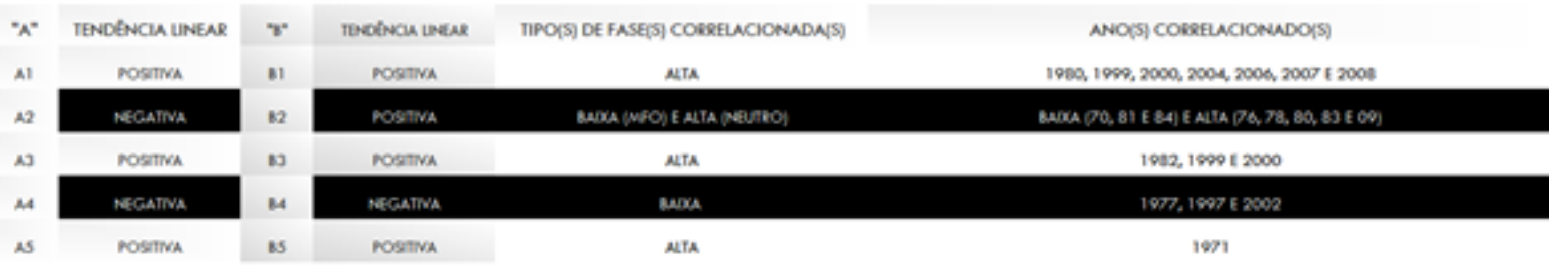

\subsection{2- Análise Trimestral}

A segunda análise envolve a relação trimestral entre a Chuva Muito Forte e o Oceanic Niño Index. Nestas análises estão incluídas as séries temporais, definidas como relativas, ou seja, períodos específicos da série integral, classificadas como ENOS, Fase Neutra, El Niño e La Niña. Trata-se de uma análise individualizada, envolvendo os três procedimentos elementares adotados, que foram aplicados para as quatro estações climáticas do ano, ou seja, verão, outono, inverno e primavera. 


\subsubsection{1 - Frequência Trimestral de Chuva Muito Forte}

Os resultados das frequências trimestrais de Chuva Muito Forte $\left(16,0\right.$ a 50,0 $\left.\mathrm{mm} \mathrm{h}^{-1}\right)$ podem ser observados a partir da Figura 108. No verão e outono a tendência linear de chuva MFO, durante o período de 1970 a 2009, é negativa (Figuras 109). Por outro lado, a tendência linear, deste tipo de chuva, para a estação de inverno e primavera é positiva.

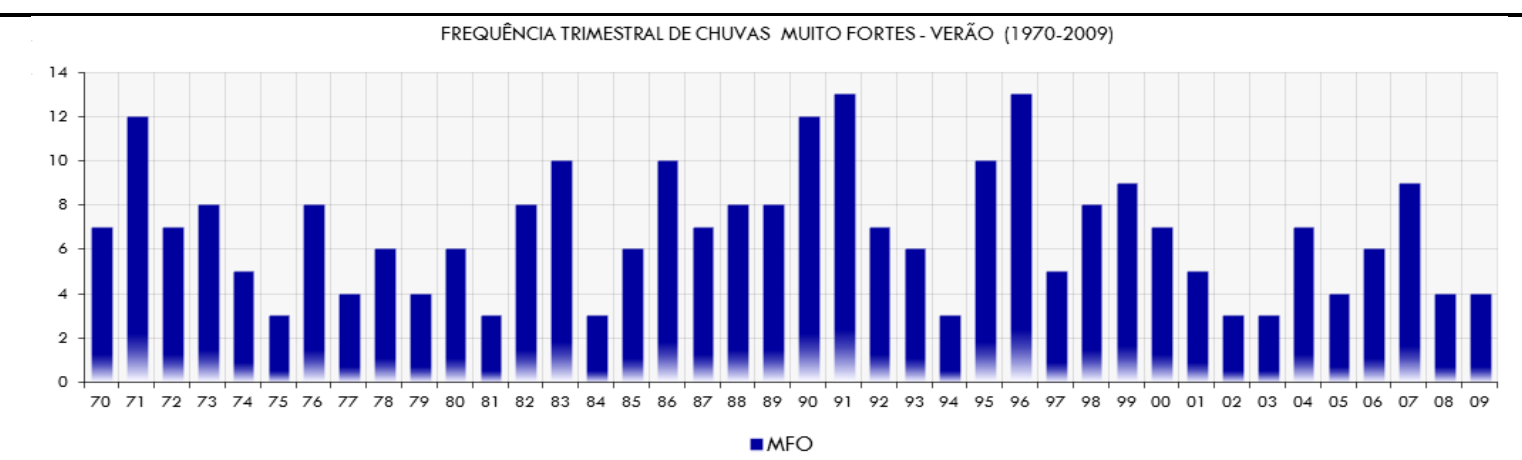

FREQUÊNCIA TRIMESTRAL DE CHUVAS MUITO FORTES - OUTONO (1970-2009)

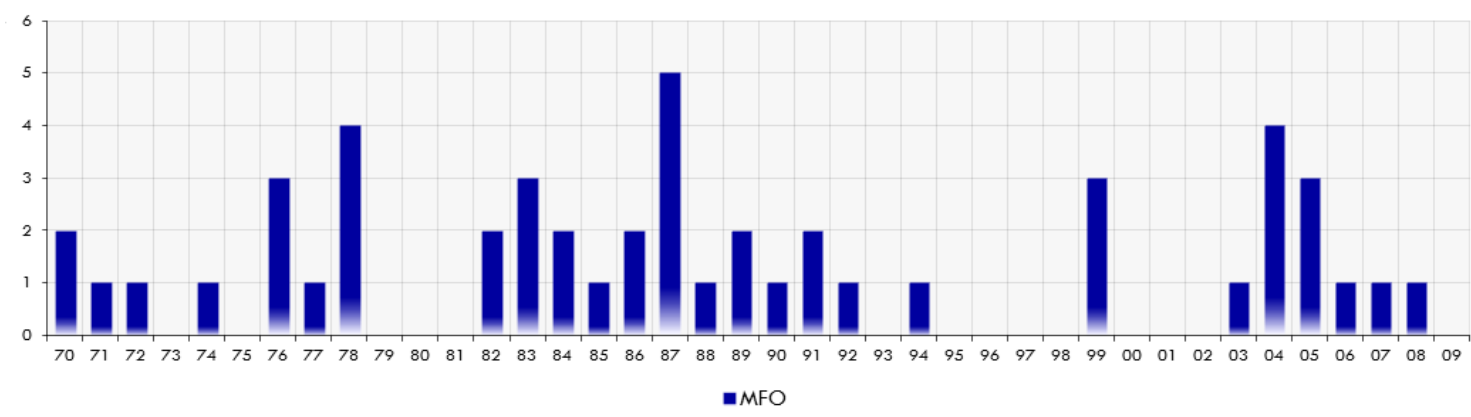

FREQUÊNCIA TRIMESTRAL DE CHUVAS MUITO FORTES - INVERNO (1970-2009)

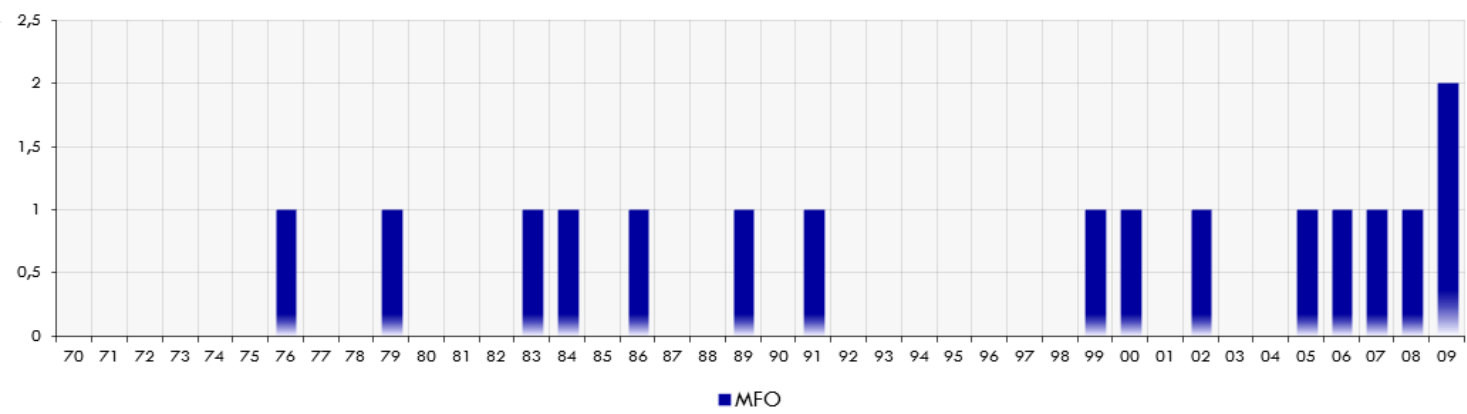

FREQUÊNCIA TRIMESTRAL DE CHUVAS MUITO FORTES - PRIMAVERA (1970-2009

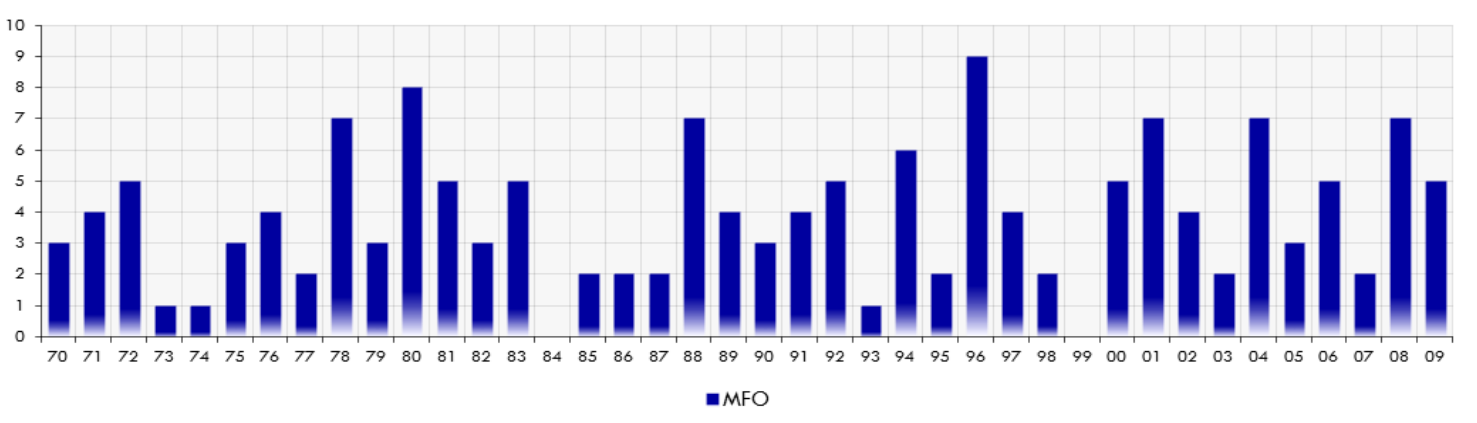

Figura 108 - Frequência Trimestral de Chuva Muito Forte na Estação do IAG-USP durante o Verão, Outono, Inverno e Primavera para o Período de 1970 a 2009. 

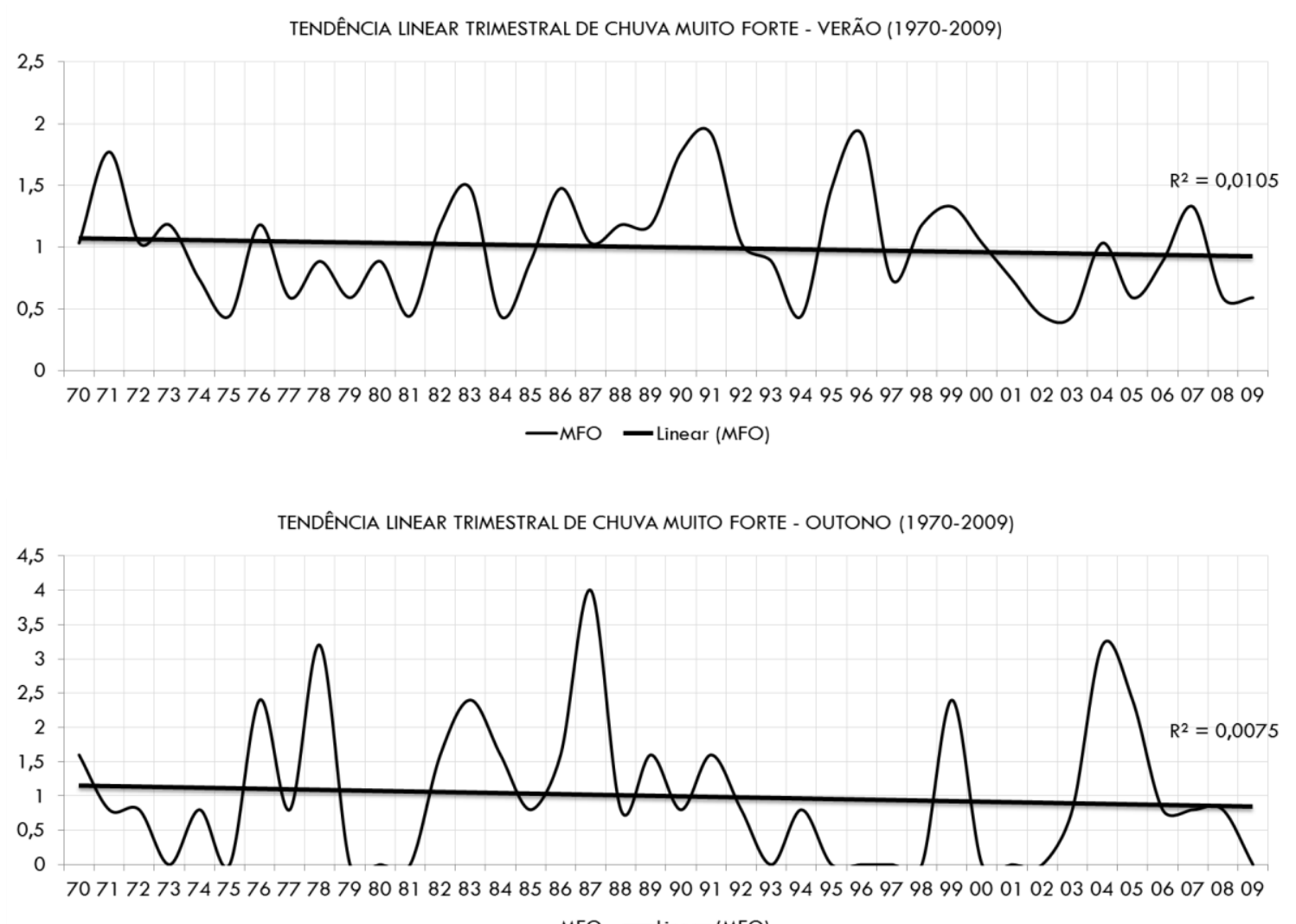

$$
\text { -MFO 一 Linear (MFO) }
$$
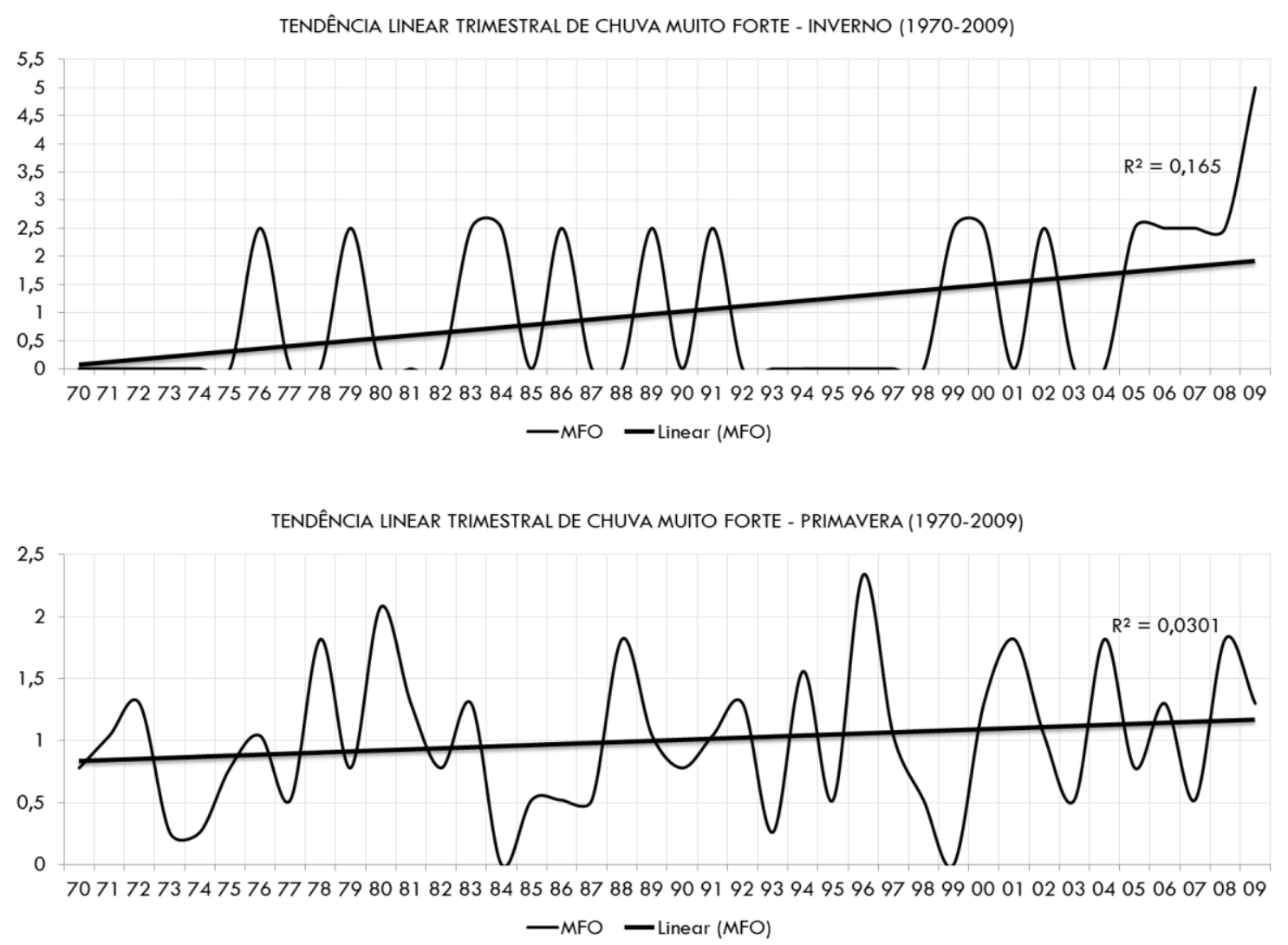

Figura 109 - Ajuste Linear Trimestral de Chuva Muito Forte para as Estações de Verão, Outono, Inverno e Primavera, no Período de 1970 a 2009. 
As séries temporais do ONI apresentarm tendências lineares equilibradas entre negativa e positiva, neste caso incluímos os ajustes lineares mais significativos nas Figuras 110 113. Nestas figuras observamos que durante a fase neutra, o ajuste linear identificado foi positivo e ocorreu no inverno (Figura 110). Na fase ENOS ocorreram dois ajustes positivos e dois negativos. Os negativos foram identificados no verão e no outono e, os positivos no inverno e na primavera (Figura 111). Na fase EN foram identificados dois ajustes lineares, um positivo e outro negativo. O positivo foi identificado no inverno e o negativo no outono (Figura 112). Na fase $L N$ também ocorreram dois ajustes lineares, o positivo no inverno e o negativo no verão (Figura 113 ).

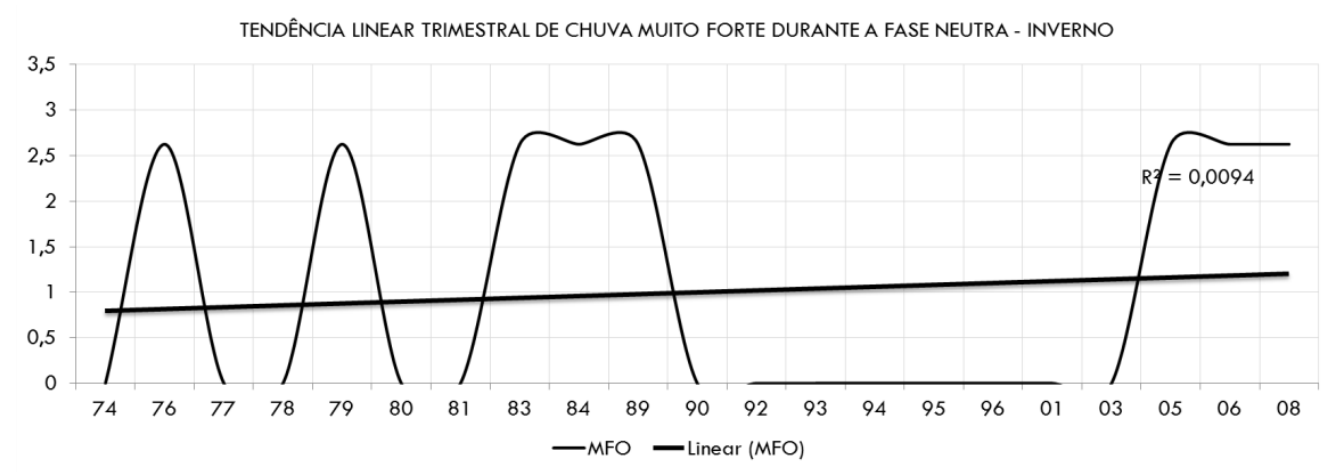

Figura 110 - Ajuste Linear Trimestral de Chuva Muito Forte para a Estação de Inverno durante a fase Neutra.
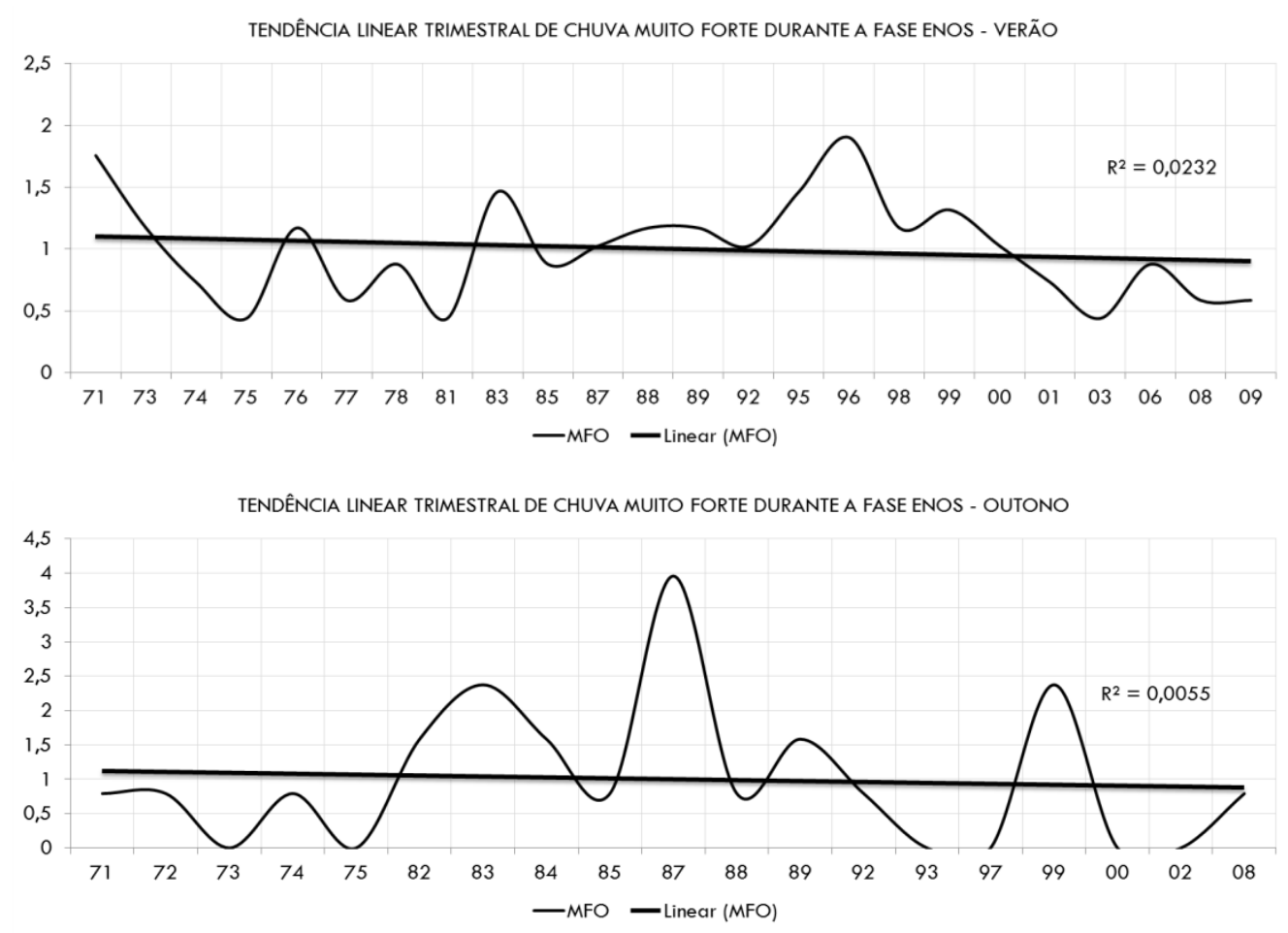

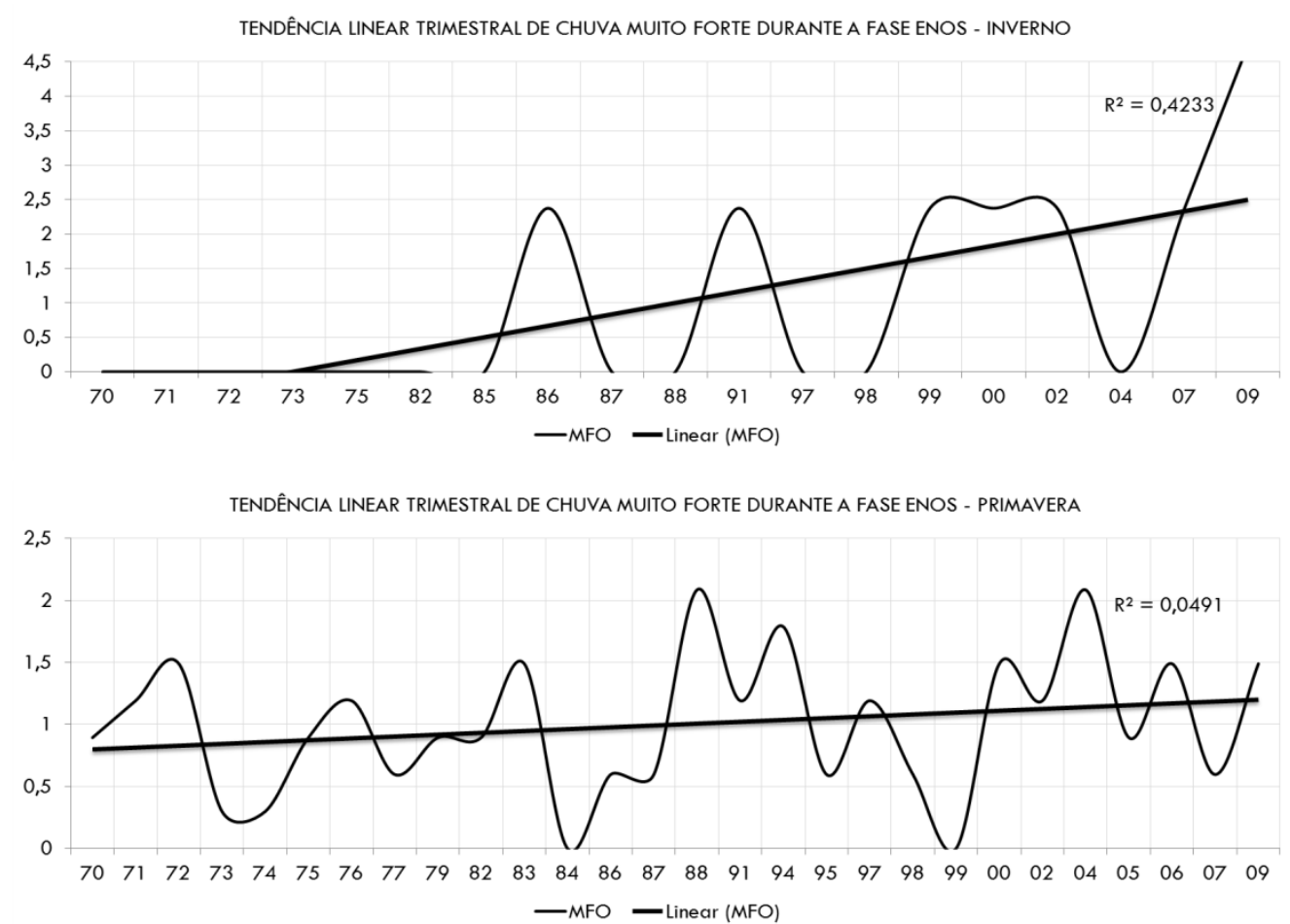

Figura 111 - Ajuste Linear Trimestral de Chuva Muito Forte para as Estações de Verão, Outono, Inverno e Primavera durante a fase ENOS.
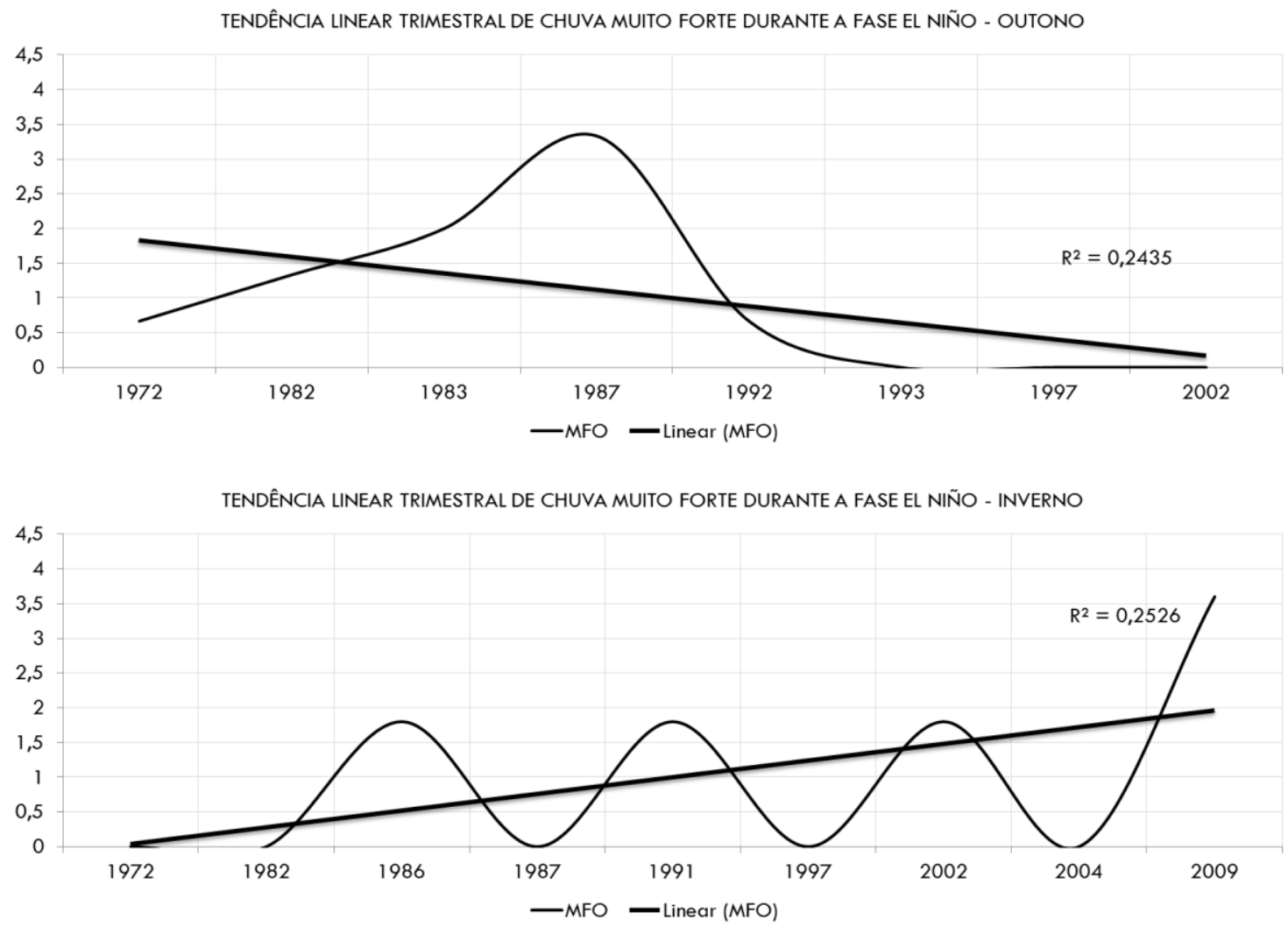

Figura 112 - Ajuste Linear Trimestral de Chuva Muito Forte para as Estações de Outono e Inverno durante a fase El Niño. 

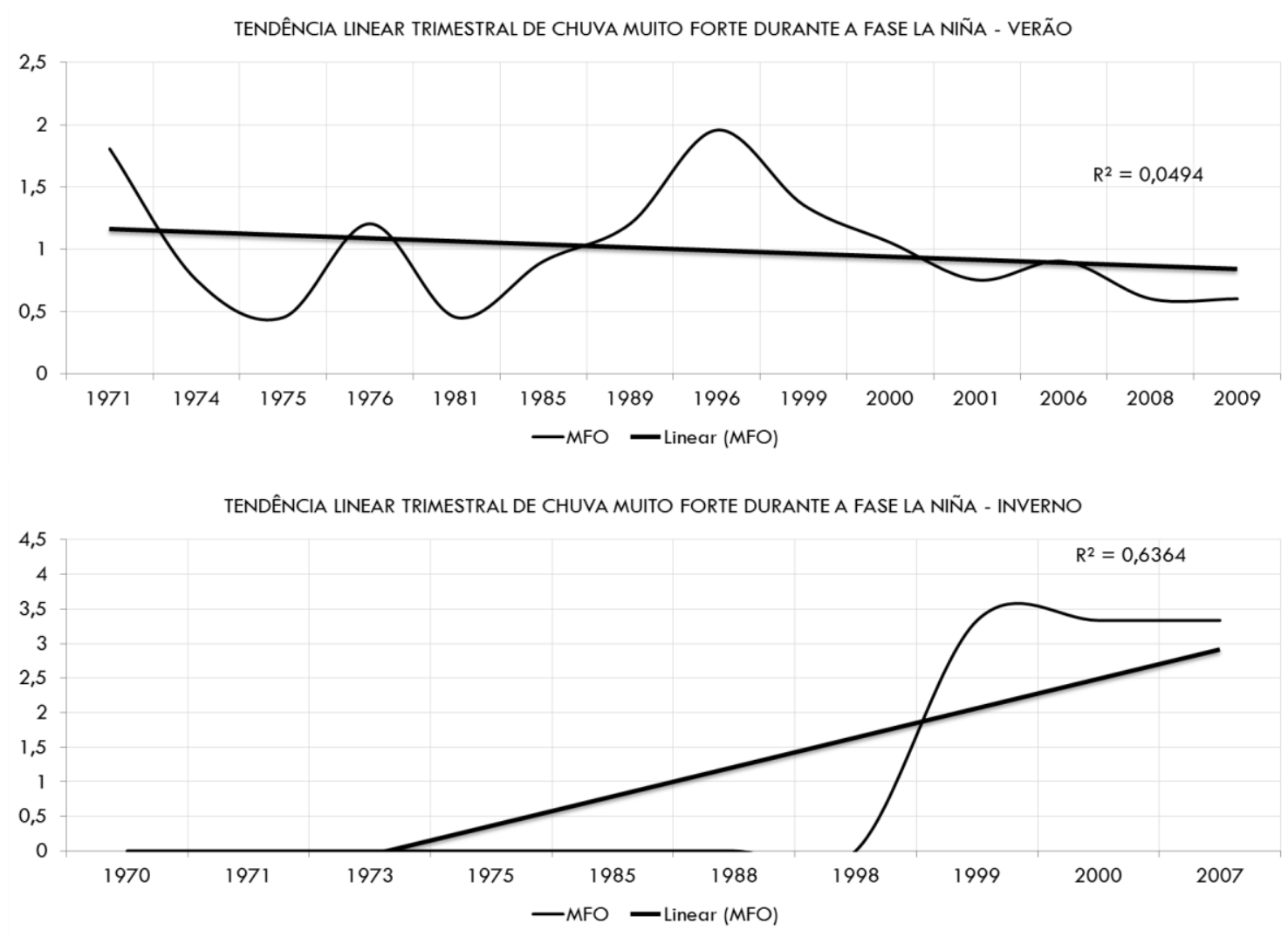

Figura 113 - Ajuste Linear Trimestral de Chuva Muito Forte para as Estações de Verão e Primavera durante a fase La Niña.

Os resultados trimestrais por fases permitem estabelecer uma reflexão mais especifica a respeito dos resultados encontrados nos trabalhos de Cabral (2002), Sugahara et al (2009) e Freitas et al (2013). No caso, dois resultados trimestrais estão assimétricos, por exemplo, os ajustes lineares, mais próximos de negativo, identificados no verão e outono. Por outro lado, as fases específicas também revelam novos resultados que em determinadas fases estão simétricos e outras assimétricos. Desta forma, observa-se que quando analisado particulamente amostras de períodos específicos, o comportamento da frequência de chuvas mais intensas apresentam resultados distintos. De modo geral, a Tabela XX indica que a maioria dos casos envolvendo correlações lineares entre a chuva MFO e ONI foram positivas (+). No total foram 13 correlações positivas que apresentaram haver uma correlação estatística, em todas as estações climáticas do ano, entre as chuvas MFO e a série temporal integral (ONI) e as séries temporais relativas (neutra, ENOS, EN e LN). As correlações lineares 
ocorreram com mais frequência durante a primavera. $O$ destaque é a série do ONI que apresentou correlações positivas em todas as estações.

Tabela 43 - Correlação Linear Trimestral entre a Tendência Linear Trimestral de Chuva Muito Forte e a Tendência Linear Trimestral do ONI incluindo as Fases, Neutra, ENOS, EN e LN.

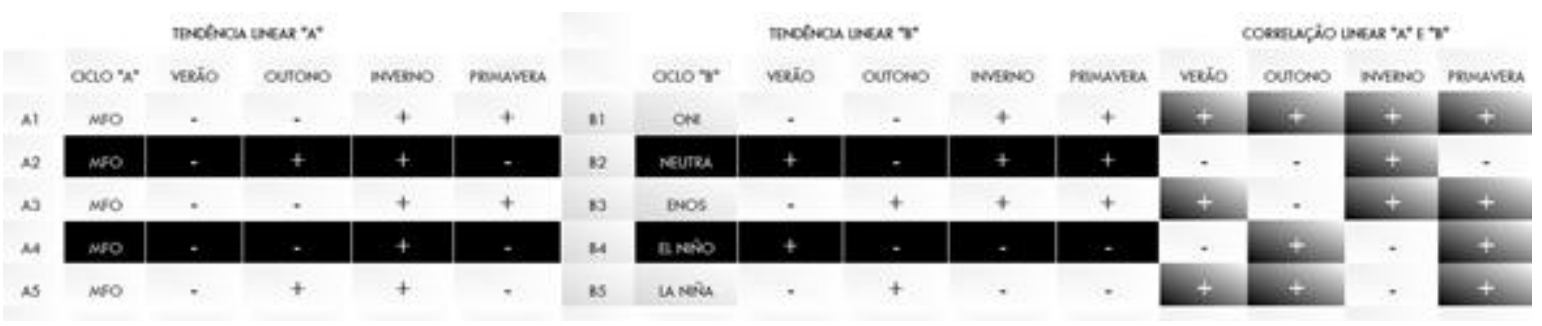

A frequência da chuva MFO, durante o verão, diminui durante todas as fases ou séries temporais. Durante o outono, a frequência da chuva MFO aumenta apenas durante a fase Neutra e LN. No inverno, a frequência da chuva MFO aumenta durante todas as fases. Na primavera, a frequência da chuva MFO aumenta apenas durante o ONI e a fase ENOS (Tabela 43). Contudo, considerando todas as estações climáticas, no período de 1970 a 2009, verificamos que a frequência de chuva MFO diminuiu durante o verão e o outono e, por outro lado aumentou durante o inverno e a primavera (Tabela 43 ).

\subsubsection{2- Variação Cíclica Trimestral de Chuva - MFO}

A variação das anomalias da frequência de chuva MFO para o período de 1970 a 2009, para as quatro estações do ano está ilustrada na Figura 114.

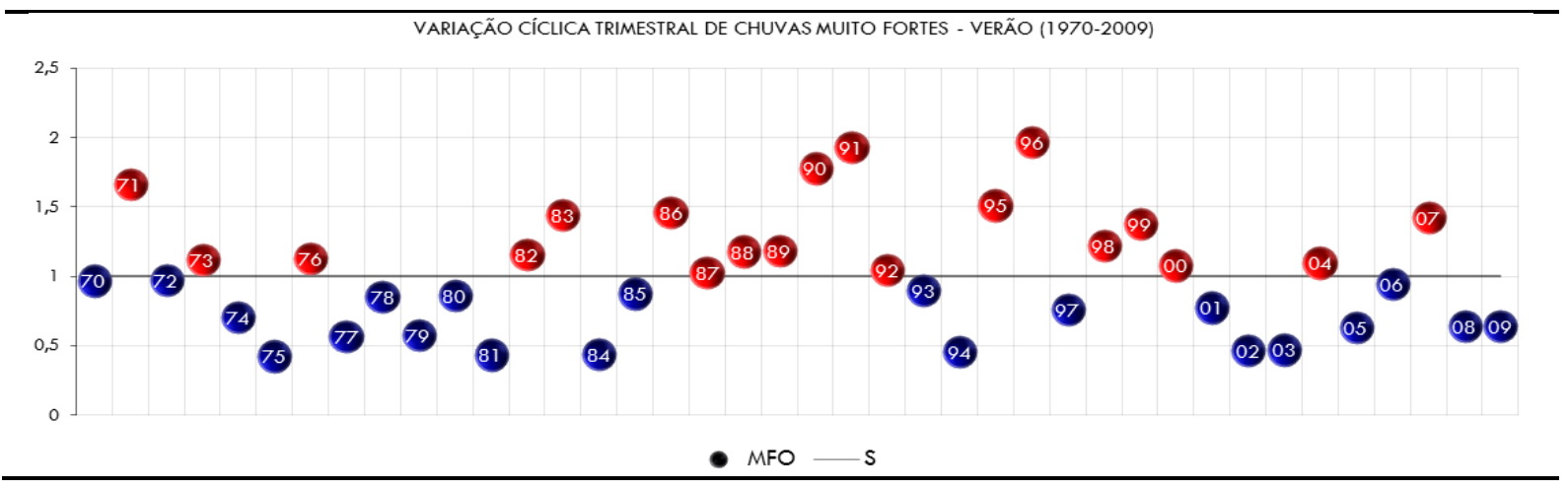




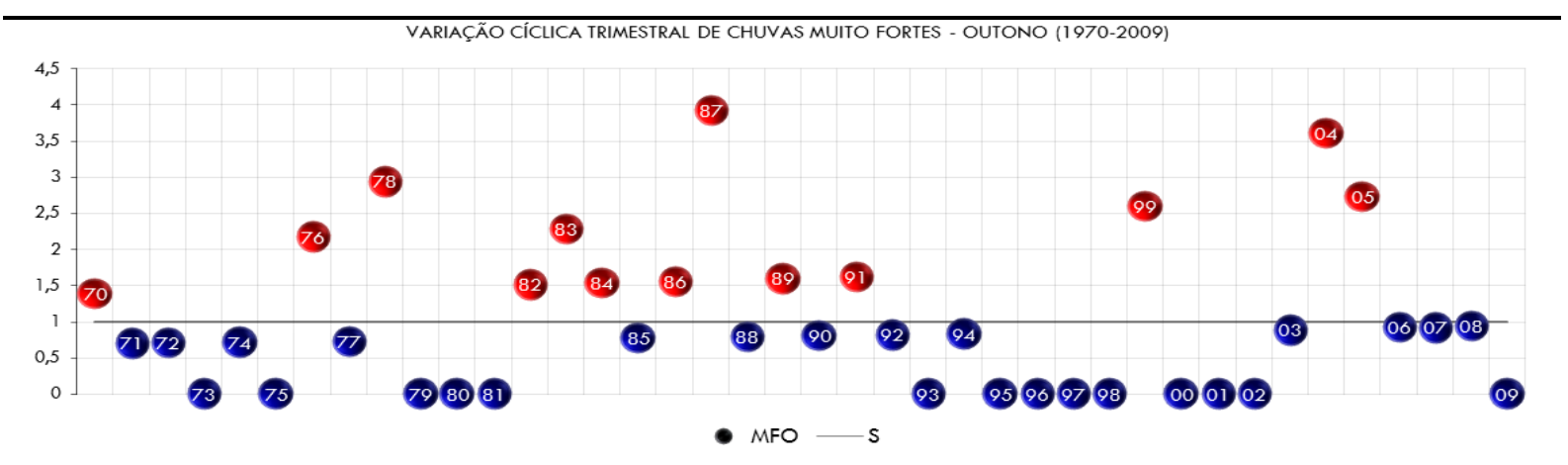

VARIAÇÃO CÍCLICA TRIMESTRAL DE CHUVAS MUITO FORTES - INVERNO (1970-2009)

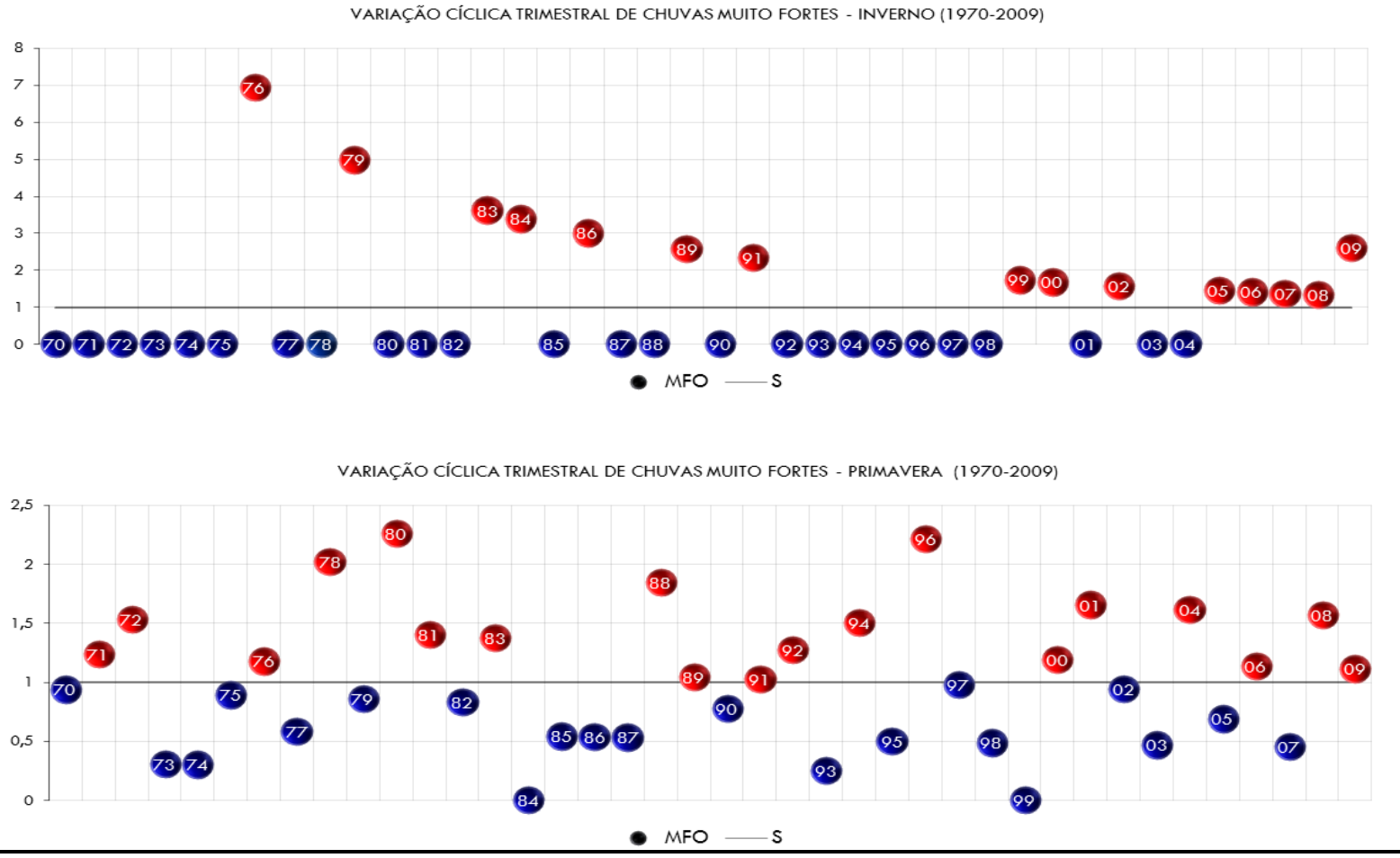

Figura 114 - Variação Cíclica Trimestral de Chuva Muito Forte, entre 1970 e 2009.

\subsubsection{3- Análise da Correlação Cíclica Trimestral}

De forma geral, separando a série temporal em estações do ano, observamos que não houve correlação linear entre as séries de ONI e frequência de chuva MFO. Ou seja, a frequência de chuva MFO pode não estar associada fisicamente aos valores de ONI durante cada estação climática. A separação das séries temporais em eventos distintos quanto à TSM na região do Niño3.4 permitiu verificar que durante o outono, na fase EN, a correlação linear entre estas duas variáveis foi positiva e significativa $(r=0,85)$, Figura 115. A segunda e a 
terceira correlações lineares significativas, porém negativas foram identificadas no inverno e na primavera, durante a fase EN $(r=-0,69)$, Figura 116 e durante a fase Neutra $(r=-0,67)$, Figura 117. Todos os demais resultados podem ser observados a partir da Tabela 44.

Tabela 44 - Correlação Cíclica entre a Frequência de Chuva Muito Forte observada na Estação do IAG e os Valores de ONI para Cada Estação do Ano e, para Cada Condição de Anomalia na Região de Niño3.4 (Eventos Neutros, ENOS, EN e LN).

\begin{tabular}{|c|c|c|c|c|c|c|c|}
\hline VERĀO & OUTONO & INVERNO & PRIMAVERA & VERĂO & OUTONO & INVERNO & PRIMAVERA \\
\hline A1 & A1 & A) & A) & ONd & ONd & Coet & One \\
\hline 12 & $\mathrm{~A}^{2}$ & $A 2$ & $A^{2}$ & NEUTRO & NEUTRO & NeUtro & NEUIRO \\
\hline$A 3$ & A 3 & N3 & $A^{3}$ & ENOS & evos & ENOS & ENOS \\
\hline MA & MA & M & M & E IEÑO & EI NANOO & EI NANOO & E. NENOO \\
\hline NS & AS & NS & AS & LA NERA & UANEAT & LANERA & LANERA \\
\hline \multicolumn{4}{|c|}{ CORRELAÇÄO CICLICA } & \multicolumn{4}{|c|}{ TESTE T - STUDENT } \\
\hline VERÄO & OUTONO & INVERNO & PRIMAVERA & VERĀO & OUTONO & ENVERNO & PRUMAVERA \\
\hline 0,204 & $0,0,72$ & 0,079 & 0,193 & NÄO SGONAFCAINO & NÁO SICNAFCATINO & NÄO SIGAERICATIVO & NÄO SICNUFCAINO \\
\hline 0,181 & $-0,006$ & 0,112 & $-0,0,7$ & NİO SEGNAFCATIVO & NÃO SICNENCATMO & NH̄o siGveICATIVO & sictencativo \\
\hline 0,187 & 0,232 & 0,135 & 0.295 & NÜO SIOREFCATIVO & NIIO SIONFECATNO & NÄO SIGMEFICATIVO & Nä́ SICNeACATIVO \\
\hline 0,05 & 0.85 & asss & 0,052 & MR̈o signafcalmo & SCGNEACATINO & sicenacativo & NüO SICNAICAIVO \\
\hline 0,242 & 0,0004 & 0,318 & 0,03 & NȞO SICNUFACATIVO & NḦO SKCNFACATNO & NẄO SIGNEFICATIVO & NüO SIGNencativo \\
\hline
\end{tabular}

VARIAÇÃO CÍCLICA TRIMESTRAL DE CHUVAS MUITO FORTES E EL NIÑO - OUTONO

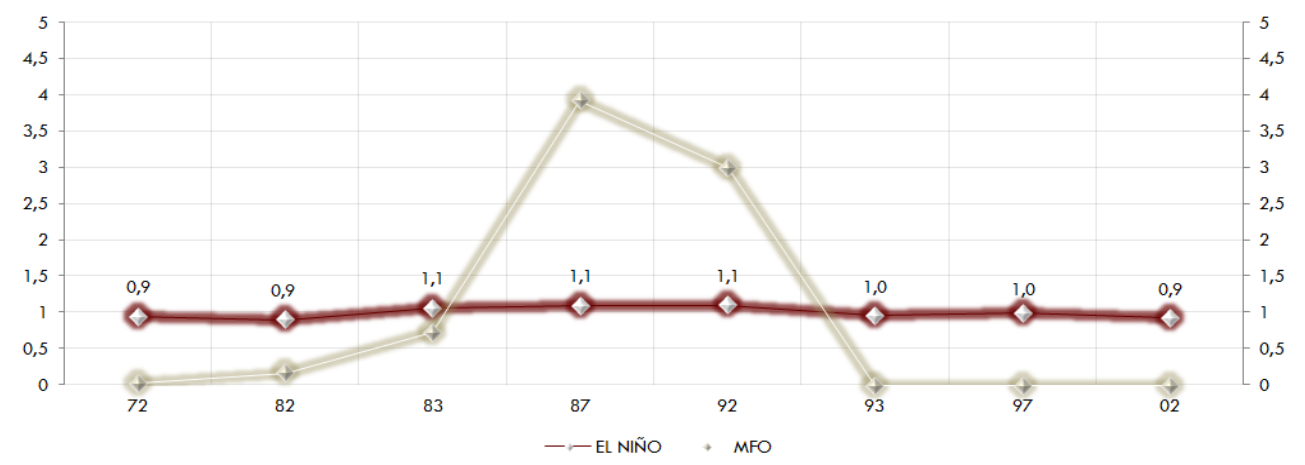

Figura 115 - Variação Cíclica de Chuva MFO, no Outono, durante a Fase El Niño.

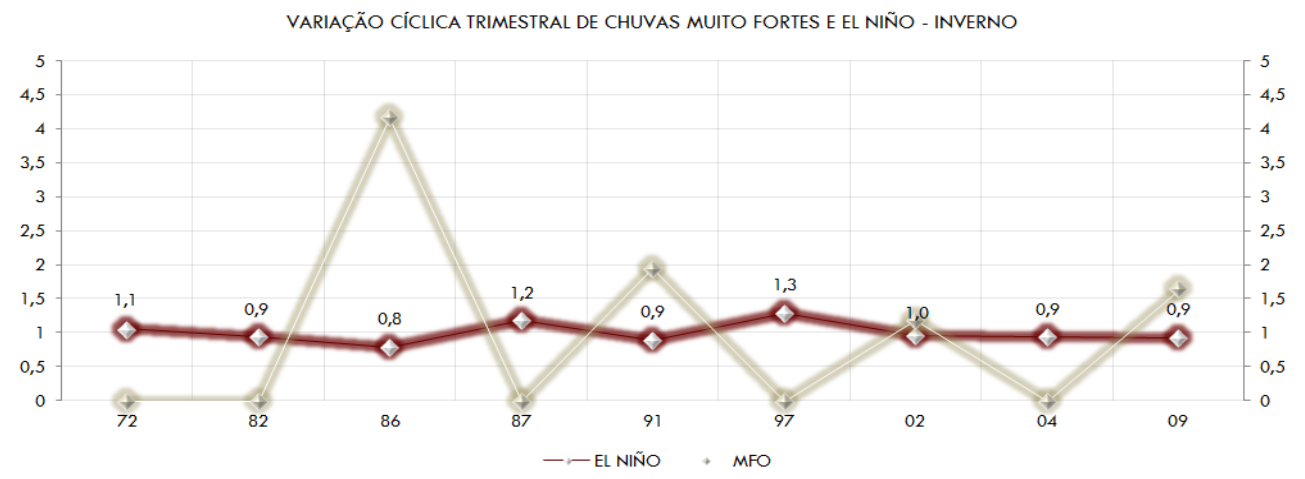

Figura 116 - Variação Cíclica de Chuva MFO, no Inverno, durante a Fase El Niño. 


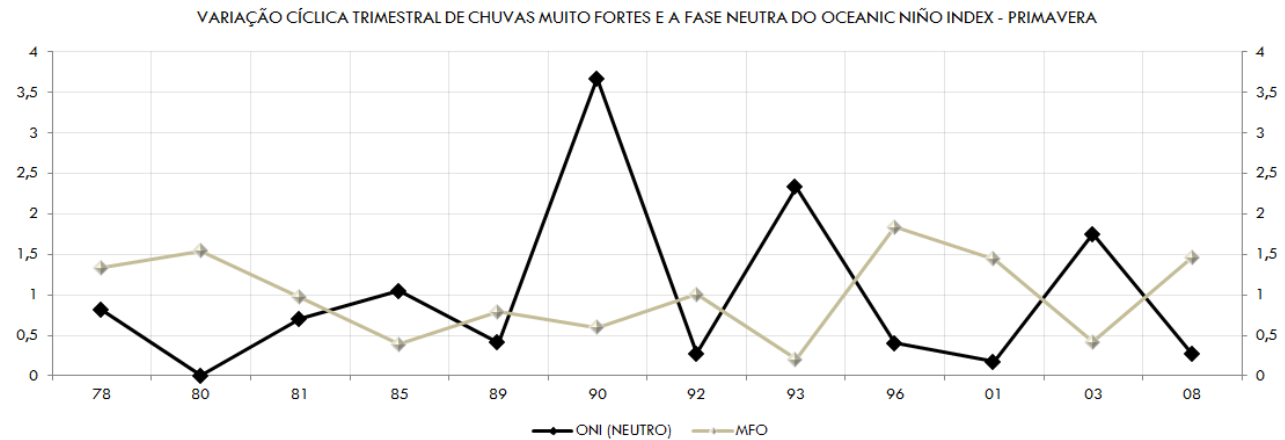

Figura 117 - Variação Cíclica de Chuva MFO, na Primavera, durante a Fase Neutra.

\subsubsection{4- Análise Específica das Fases Trimestrais}

Os resultados de tal análise revelam as possíveis correlações existentes entre as fases altas e baixas da frequência de Chuva Muito Forte e do ONI. Neste caso, identificamos à série específica através das fases altas $(\bar{x}>1)$ e baixas $(\bar{x}<1)$ da variação cíclica da frequência trimestral de chuva MFO. A variação cíclica de chuva MFO no período de 1970 a 2009 durante a estação de verão foi composta por 19 fases específicas. A partir do resultado positivo da correlação linear entre a tendência negativa de chuva MFO e a tendência negativa do $\mathrm{ONI}$, procuramos identificar as fases da oscilação que possivelmente estiveram associadas a tal comportamento. Neste caso, deduzimos que somente as fases baixas estariam correlacionadas (Figura 118). Em função dessa probabilidade, identificamos nos anos $72,74,75,77,78,79,80,81,84,85,93,94$ e 97 as fases baixas que estariam significativamente e positivamente correlacionadas com a correlação positiva entre a chuva MFO e o ONI (Tabela 45). A variação cíclica de chuva MFO no período de 1970 a 2009 durante a estação de outono foi composta por 18 fases específicas. A partir do resultado positivo da correlação linear entre a tendência negativa de chuva MFO e a tendência negativa do ONI, procuramos identificar as fases da oscilação que possivelmente estiveram associadas a tal comportamento. Neste caso, deduzimos que somente as fases baixas estariam correlacionadas (Figura 118). Em função dessa probabilidade, identificamos nos 
anos 85 e 88 as fases baixas que estariam significativamente e positivamente correlacionadas com a correlação positiva entre a chuva MFO e o ONI (Tabela 45). A variação cíclica de chuva MFO no período de 1970 a 2009 durante a estação de inverno foi composta por 18 fases específicas. A partir do resultado positivo da correlação linear entre a tendência positiva de chuva MFO e a tendência positiva do ONI, procuramos identificar as fases da oscilação que possivelmente estiveram associadas a tal comportamento. Neste caso, deduzimos que somente as fases altas estariam correlacionadas (Figura 118). Em função dessa probabilidade, identificamos nos anos 76, 79, 83, 84, 86, 91, 99, 00, 02, 05, 05, 07, 08 e 09 as fases altas que estariam significativamente e positivamente correlacionadas com a correlação positiva entre a chuva MFO e o ONI (Tabela 45). A variação cíclica de chuva MFO no período de 1970 a 2009 durante a estação de primavera foi composta por 26 fases específicas. A partir do resultado positivo da correlação linear entre a tendência positiva de chuva MFO e a tendência positiva do ONI, procuramos identificar as fases da oscilação que possivelmente estiveram associadas a tal comportamento. Neste caso, deduzimos que somente as fases altas estariam correlacionadas (Figura 118). Em função dessa probabilidade, identificamos nos anos 71, 72, 76, 88, 89, 94, 04 e 06 as fases altas que estariam significativamente e positivamente correlacionadas com a correlação positiva entre a chuva MFO e o ONI (Tabela 45).
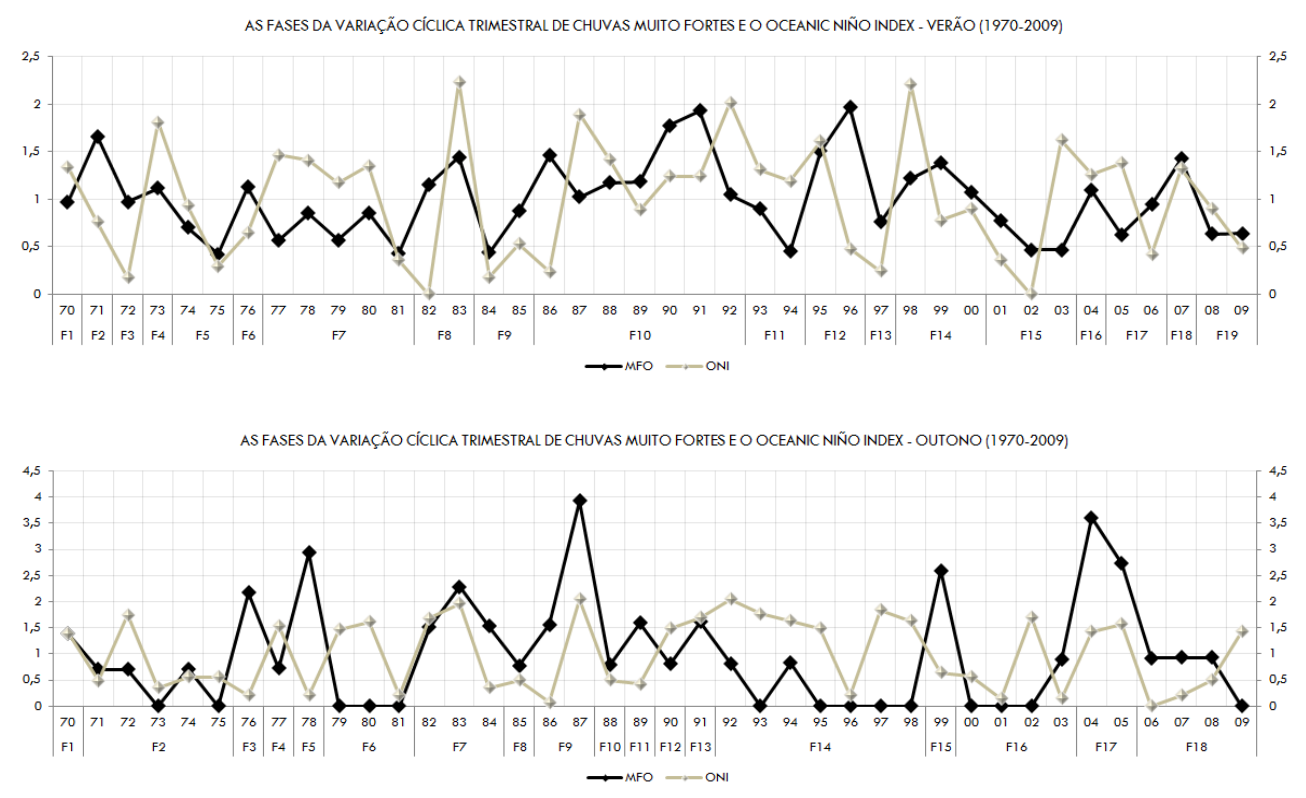

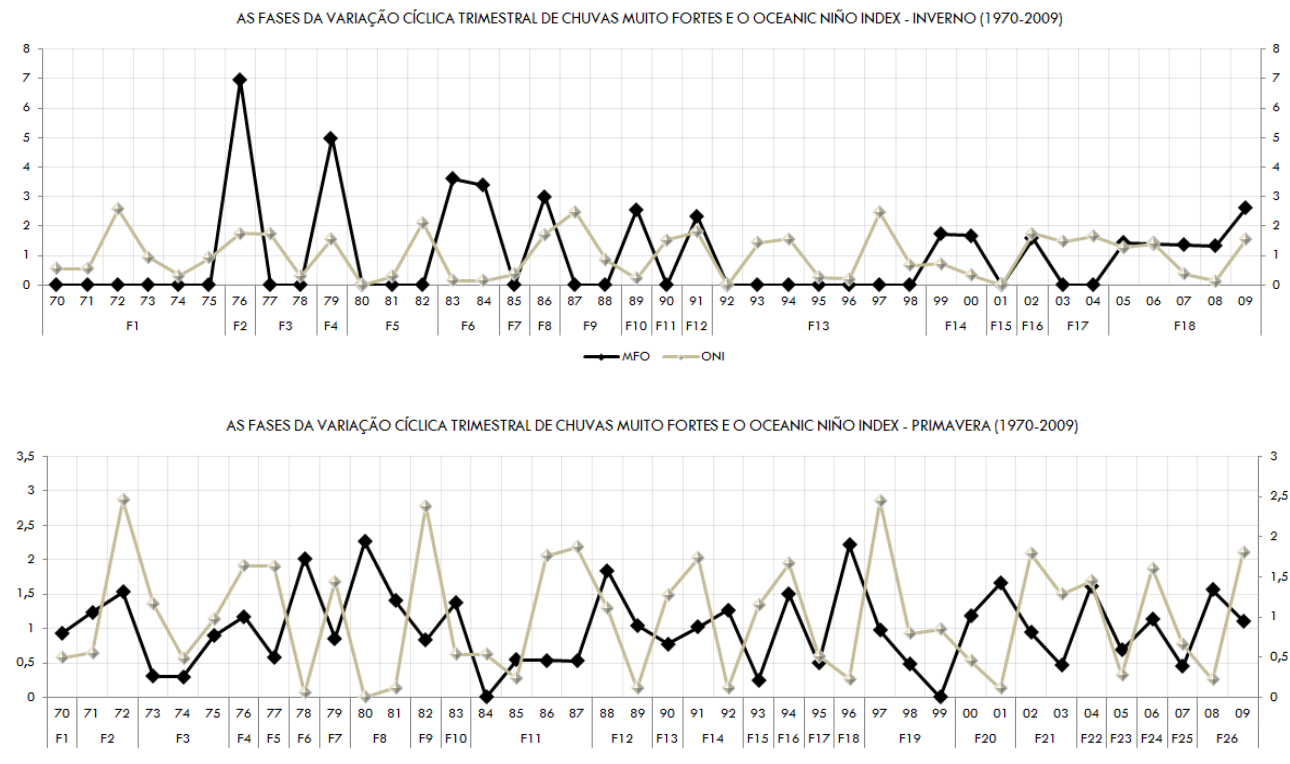

Figura 118 - Fases Específicas do Ciclo Trimestral de Chuva Muito Forte, Verão, Outono, Inverno e Primavera. A linha Branca corresponde à variação cíclica do ONI e a linha Preta de Chuva MFO, para o Período de 1970-2009.

Tabela 45 - Correlação Linear entre a Frequência de Chuva Muito Forte observada na Estação do IAG e os Valores de ONI para Cada Estação do Ano e, para Cada Condição de Anomalia na Região de Niño3.4 (Eventos Neutros, ENOS, EN e LN). "A" representa as Séries Temporais de Chuva MFO relativa às Séries Temporais do ONI "B". Assim, B1 (ONI), B2 (Neutro), B3 (ENOS), B4 (EN) e B5 (LN). Correlação "A" são os Tipos Fases Correlacionadas com a Chuva MFO e Correlação "B" são os Tipos Fases Correlacionadas com o ONI.

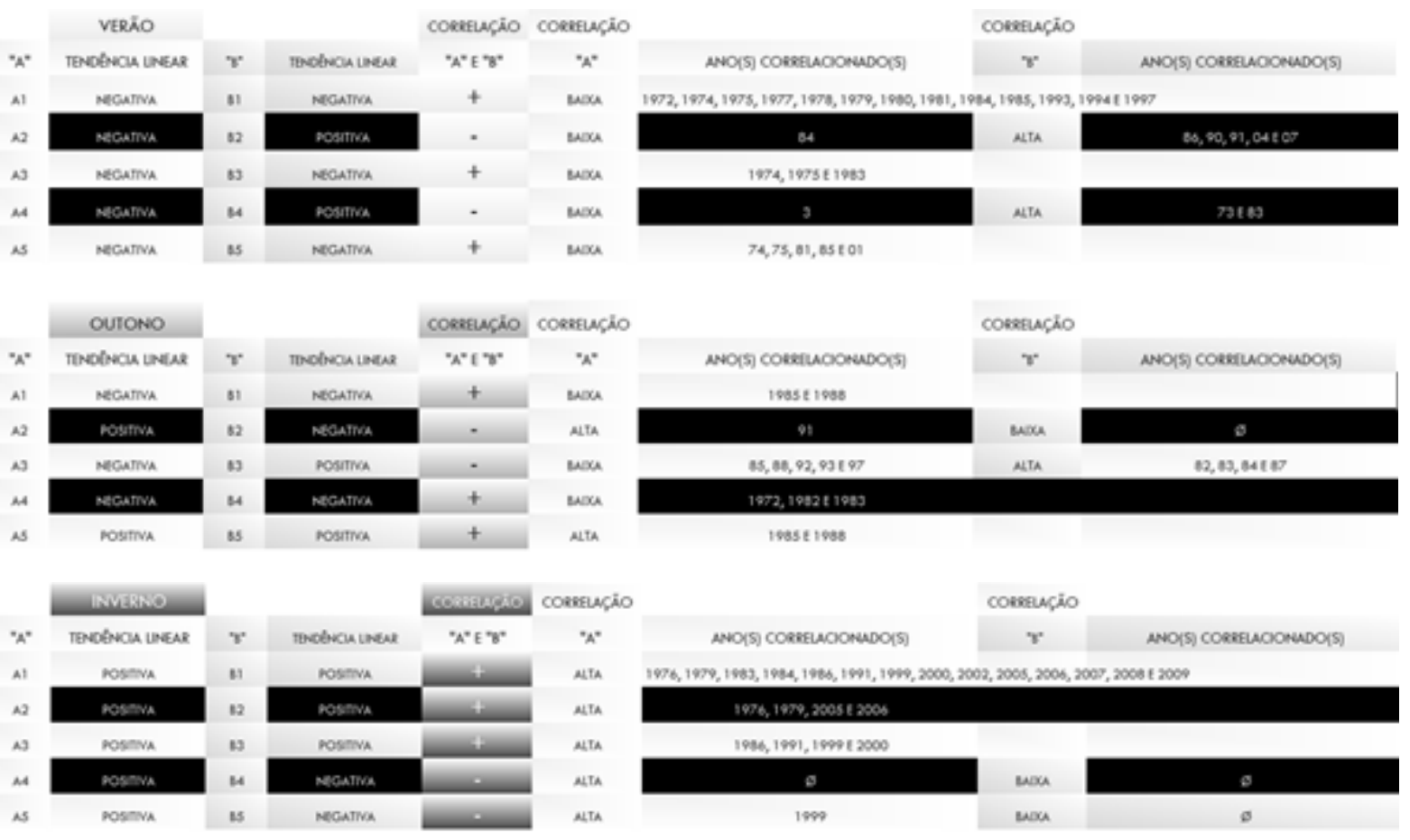




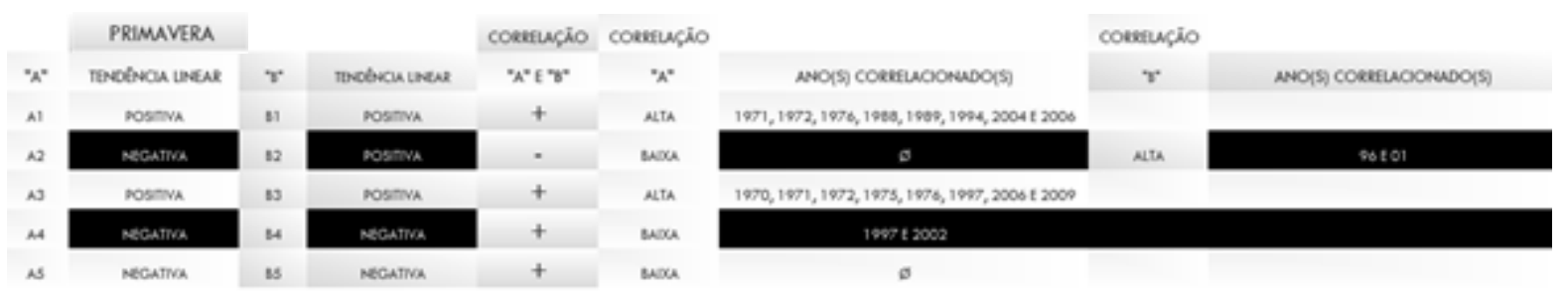

\subsubsection{5- A Hipótese Inicial e a Conclusão Final - MFO II}

A conclusão final para análise trimestral de Chuva Muito Forte parte das distintas correlações identificadas, para cada estação climática, envolvendo o ajuste linear dos índices do ONI na região Niño3.4 e a frequência de chuva MFO. De modo geral, em todas as estações climáticas observamos que o ajuste linear positivo (negativo) do ONI coincidiu positivamente com o ajuste de chuva MFO. A Tabela 45 apresenta os resultados das demais correlações realizadas para as séries temporais do ONI em cada estação climática do ano. Após identificarmos as respectivas correlações lineares trimestrais entre a chuva MFO e o ONI, analisamos os resultados das correlações cíclicas trimestrais. Neste caso, encontramos apenas três correlações cíclicas significativas, uma positiva e duas negativas (Tabela 44). A primeira foi identificada no outono, durante a fase EN. A segunda foi identificada no inverno, durante a fase EN. A terceira foi identificada na primavera, durante fase Neutra.

A partir da combinação dos resultados observados durante a série temporal da fase EN, na estação de outono, onde identificamos uma correlação positiva envolvendo ajustes lineares positivos e uma correlação cíclica significativa, analisamos por dedução e correlação que seja muito provável que tenha ocorrido uma intensificação das variações cíclicas de chuva MFO em função do aumento das amplitudes dos seus ciclos ao longo do período da fase El Niño. Neste caso, é possível identificar consonância com a expectativa de Grimm et al (1999), ou seja, nota-se a influência de padrões de macroescala alterando a frequência de circulação, que neste caso aumentou intensificando a frequência de precipitação para este tipo de chuva. Ainda, podemos identificar o possível reflexo da combinação observada, em 
fases específicas, que podem ser visualizados através dos anos que estiveram correlacionados, de acordo com a Tabela 45.

\section{7- Chuva Intensa}

As chuvas definidas como sendo intensas são aquelas que quando quantificadas excedem um limite mínimo estipulado para cada duração. Tais limites, que partem dos resultados dos cálculos realizados por Pfafstetter (1957), são padrões reconhecidos na identificação das alturas (em $\mathrm{mm}$ ) e das intensidades médias $\left(\mathrm{em} \mathrm{mm} \mathrm{h}^{-1}\right.$ ) de precipitação para qualquer intervalo de tempo entre cinco minutos e 24 horas. Ao identificar este tipo de chuva, este estudo, destacará a potência do episódio em uma escala temporal que pode variar a cada cinco minutos, num intervalo máximo de uma hora.

A partir da hipótese inicial deste estudo, a intenção ao analisar este tipo de chuva, é a de concluir para a série temporal de 1970-2009, a existência ou não de um nível de correlação aceitável, envolvendo o comportamento de sua frequência e as variações registradas na temperatura da superfície do mar localizada na região Niño3.4. De acordo com tal hipótese, o estudo estabelece uma reflexão a partir de três possibilidades, que podem ou não estarem atuando em conjunto. A reflexão, teórico-quantitativa, analisa a possibilidade de uma possível correlação, que pode ser ou não, isoladamente linear, cíclica e/ou especificamente por fases, altas ou baixas. A cronologia das escalas de análise foi dividida em anuais e trimestrais. A intenção desta reflexão científica é a de presumir a partir dos resultados, a possibilidade de ter ocorrido uma intensificação ou enfraquecimento, nos quadros evolutivos das variações cíclicas de Chuvas Intensas, a partir do aumento ou da diminuição das amplitudes dos seus respectivos ciclos, em função do aquecimento ou resfriamento, diagnosticado através dos registros da TSM, na região Niño3.4. 


\subsection{1 - Análise Anual}

A análise anual possui a finalidade de apresentar uma conclusão obtida a partir da identificação do tipo de correlação existente na intenção de sugerir a possibilidade de haver uma relação anual envolvendo a Chuva Intensa $(\mathrm{Cl})$ e o Oceanic Niño Index. Neste caso, também estão inclusos os resultados das correlações realizadas para as fases ENOS, Neutra, El Niño e La Niña.

\subsubsection{1 - Frequência Anual de Chuva Intensa}

A partir da frequência anual de Chuva Intensa representada no gráfico da Figura 119, é possível identificar que a frequência máxima ocorreu no ano de 1996, relativo à contagem de 13 casos horários.

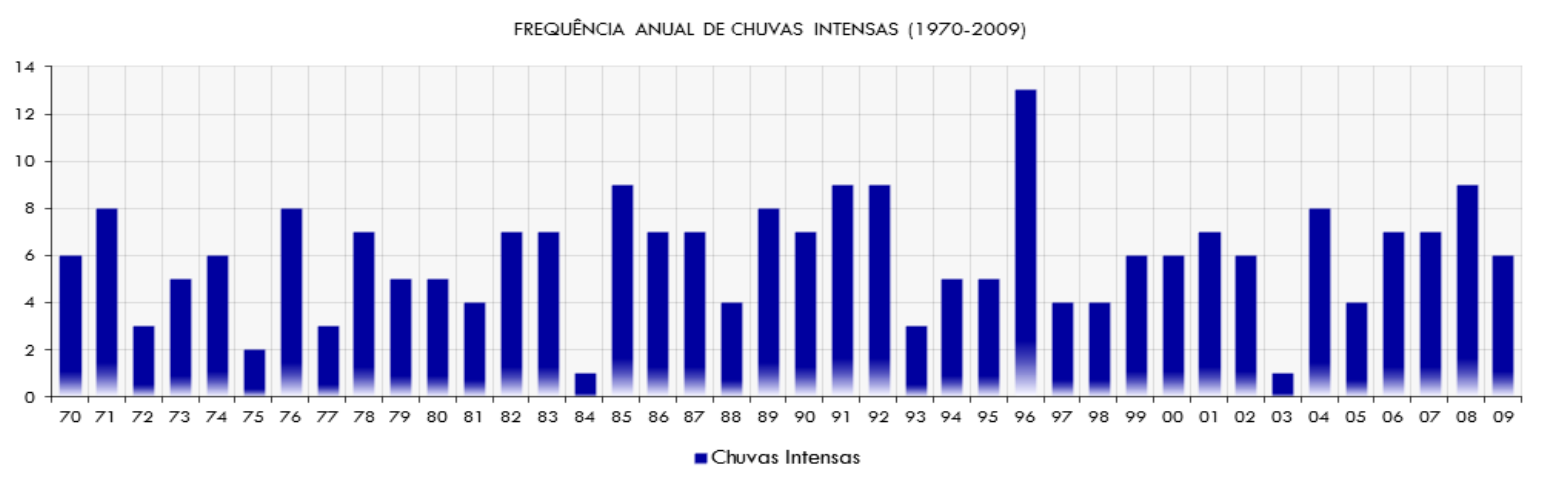

Figura 119 - Frequência Anual de Chuvas Intensas entre 1970-2009.

\subsubsection{2- Análise do Ajuste Linear}

O ajuste linear da frequência anual de Chuva Intensa no município de São Paulo indica a diminuição desta frequência ao longo da série temporal analisada, de 1970 a 2009, tal como ilustrada na Figura 120. A análise realizada para as fases, neutra, ENOS, El Niño e La Niña, separadamente, mostra que, em todos os casos, a frequência anual de Chuva Intensa aumenta com o tempo (Figura 121 e Tabela 46). A comparação entre a tendência linear da 
frequência de Chuva Intensa e do ONI indica que enquanto o ONI assume valores cada vez mais intensos, no decorrer da série temporal, a frequência de Chuva Intensa aumenta, tal como indicado na Tabela 46. A exceção ocorre no caso de eventos de EN que apresenta tendência negativa nula (estabilidade) de TSM, ao longo do período analisado, que diverge com a tendência positiva nula (estável) da frequência de Chuva Intensa (tabela 46, linha 4).

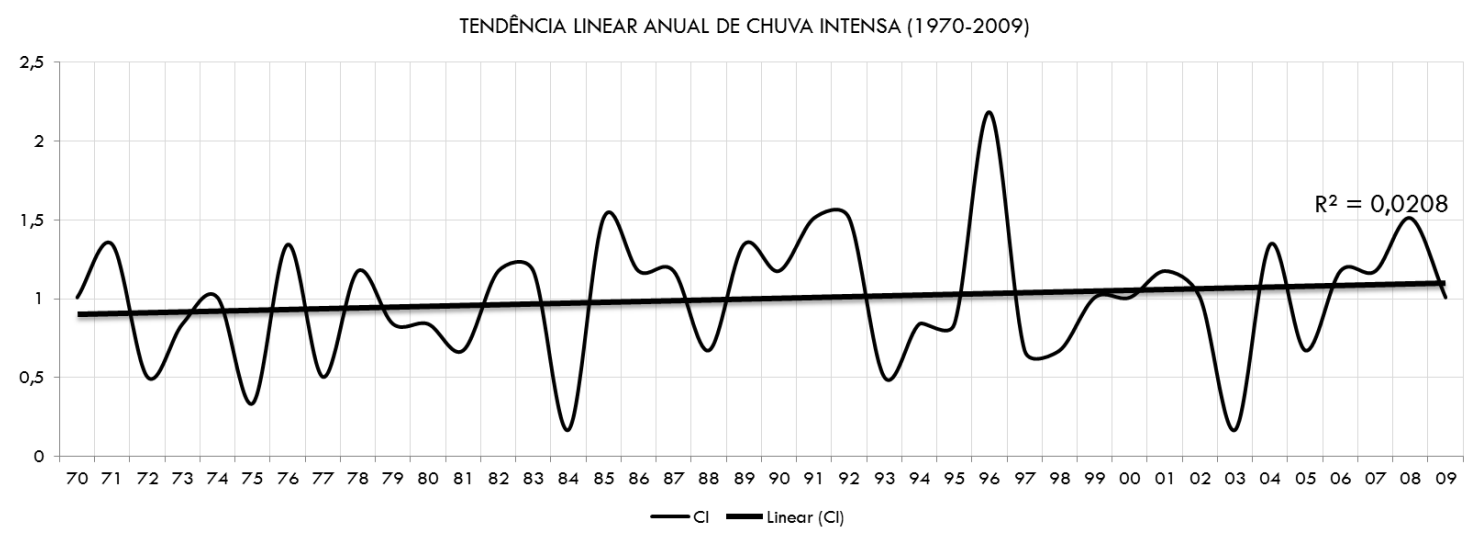

Figura 120 - Ajuste Linear da Frequência Anual de Chuva Intensa entre 1970-2009.
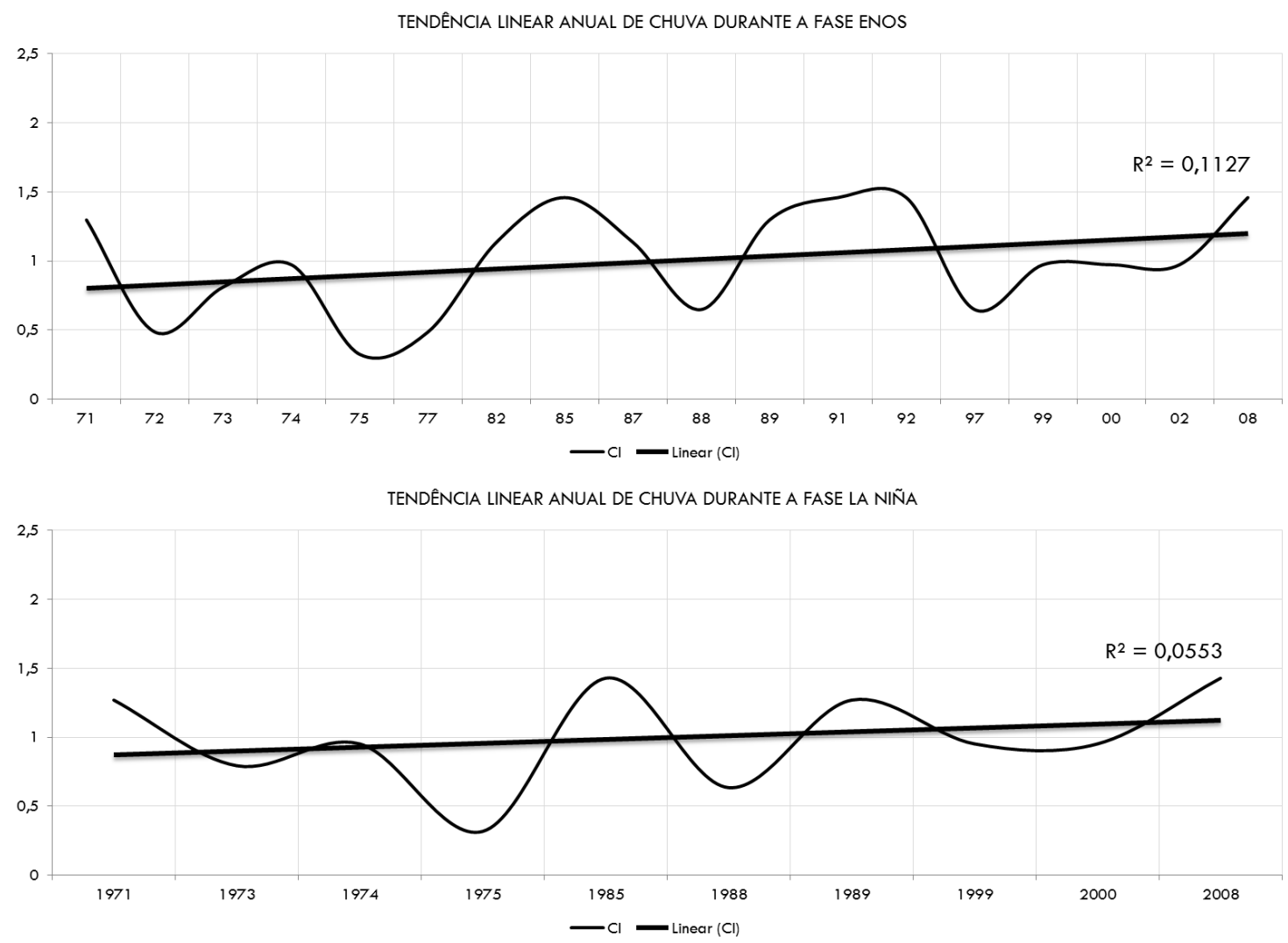

Figura 121 - Tendência Linear da Frequência Anual de Chuva Intensa para as Fases ENOS e LN, entre 1970-2009, para Ajustes Lineares mais Significativos. 
Os resultados observados através dos ajustes lineares positivos para a série anual revelam que as frequências analisadas no intervalo horário refletiram positivamente com os resultados obtidos das análises diárias realizadas por Cabral (2002), Sugahara et al (2009) e Freitas et al (2013).

Tabela 46 - Tendência Linear Anual de Chuva Intensa e do ONI para o Período de 1970 a 2009. A Primeira Linha da Tabela indica a Tendência Linear de Todos os Dados Anuais e, as Demais Linhas indicam a Tendência Linear para cada Fase do ONI.

\begin{tabular}{|c|c|c|c|c|c|c|}
\hline${ }^{\circ} A^{*}$ & TIPO DE CHUVA & TENDENCIA UINEAR & "B" & CATEGORIA & TENDÉNCIA UINEAR & CORRELAÇÄO UNEARR \\
\hline Al & a & POSITIVA & B1 & ONI & POSITIVA & POSIIIVA \\
\hline A2 & a & POSITIVA & B2 & NEUTRO & POSITIVA & POSIIIVA \\
\hline A3 & a & POSIIIVA & B3 & ENOS & POSITIVA & POSIIIVA \\
\hline A4 & $a$ & POSITIVA & B4 & EL NIÑNO & NEGATIVA & NEGATIVA \\
\hline A5 & $\mathrm{a}$ & POSITIVA & B5 & LA NIÑA & POSITIVA & POSIIIVA \\
\hline
\end{tabular}

\subsubsection{3- Variação Cíclica de Chuva Intensa}

A variação cíclica anual de Chuva Intensa pode ser observada na Figura 122. É possível notarmos a oscilção presente na série temporal completa, de 1970 a 2009, formada por 20 fases altas (esferas vermelhas) e 20 fases baixas (esferas azuis).

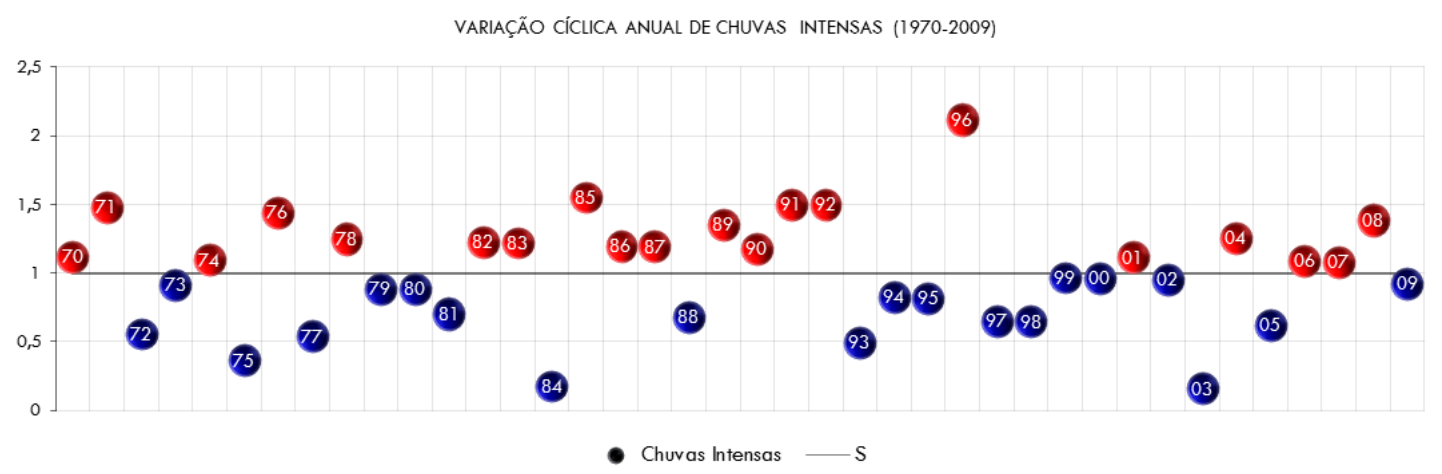

Figura 122 - Variação Cíclica Anual da Frequência de Chuva Intensa entre 1970 e 2009.

\subsubsection{4- Análise da Correlação Cíclica}

A partir dos resultados do teste de significância - t-"Student" - notamos que os resultados do cálculo de correlação linear, para todas as séries temporais cíclicas, entre ONI e a frequência anual de Chuva Intensa não foram significativos (Tabela 47). 
Tabela 47 - Correlação Linear entre a Anomalia de ONI e da Frequência Anual de Chuva Intensa entre 1970 e 2009, sem Tendência Linear (Série Cíclica).

\begin{tabular}{|c|c|c|c|c|c|}
\hline & CICIO "A" & & CACIO ${ }^{\circ}$ " & CORRELAÇ̄ó CICULA & TESTE T-STUDENT \\
\hline Al & $a$ & B1 & ONI & $-0,141$ & NĀO SIGNIFICATIVO \\
\hline A2 & a & B2 & NEUTRA & $-0,141$ & NĀO SIGNIFICATIVO \\
\hline$A 3$ & $a$ & B3 & ENOS & $-0,183$ & NĀO SIGNIFICAIIVO \\
\hline A4 & $a$ & B4 & EL NIÑO & $-0,099$ & NÄO SIGNIFICATIVO \\
\hline A5 & a & B5 & LANENA & 0,213 & NÄO SIGNIFICATIVO \\
\hline
\end{tabular}

\subsubsection{5- Análise Específica do Ciclo de Chuva Intensa}

Os resultados de tal análise revelam as possíveis correlações existentes entre as fases altas e baixas da frequência de Chuva Intensa e do ONI. Neste caso, identificamos a série específica através das fases altas $(\bar{x}>1)$ e baixas $(\bar{x}<1)$ da variação cíclica da frequência de Chuva Intensa. O ciclo anual da frequência de Chuvas Intensas durante o período de 1970 a 2009 foi composto por 22 fases específicas, de acordo com a Figura 123. No entanto, a partir do resultado positivo da correlação linear, envolvendo por um lado, a tendência positiva de Chuva Intensa, e por outro, a tendência positiva da ONI, analisamos as fases da oscilação que estiveram associadas a tal comportamento. Neste caso, as fases altas seriam as mais prováveis. A partir dessa possibilidade, identificamos três fases altas, significativamente e positivamente correlacionadas, nos anos 70, 71, 82, 83 e 04 .

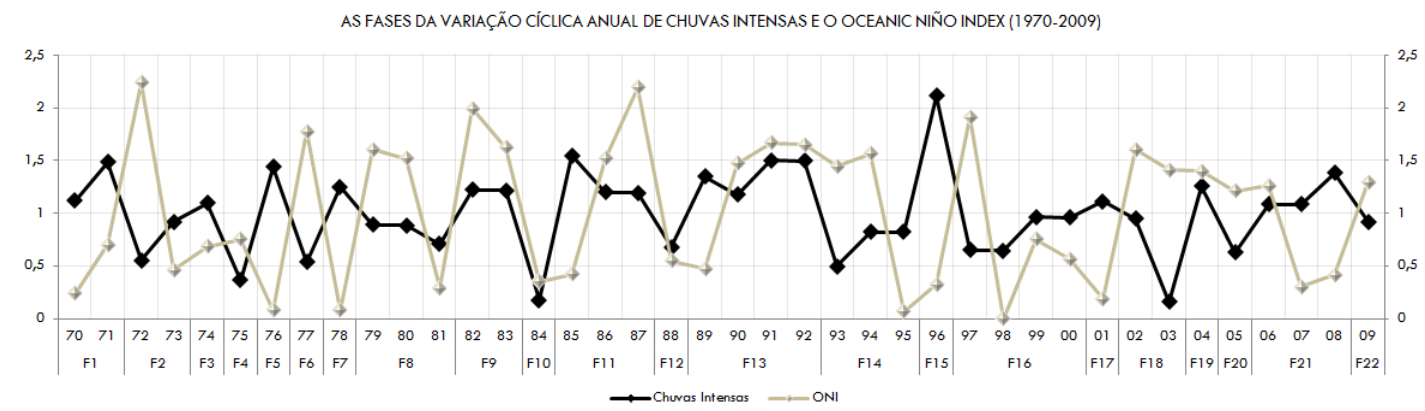

Figura 123 - Fases Específicas do Ciclo Anual de Chuva Intensa. A linha Branca corresponde à variação cíclica do ONI e a linha Preta de Chuva Intensa, para o Período de 1970-2009.

\subsubsection{6- A Hipótese Inicial e a Conclusão Final - Cl I}

A conclusão final para análise anual de Chuva Intensa foi baseada a partir dos resultados envolvendo os três procedimentos aplicados. De modo geral, durante este período, 
os resultados indicam que o aquecimento observado na região Niño3.4 coincidiu com $\circ$ aumento na frequência de Chuva Intensa, com exceção da fase El Niño. Nesta fase foi possível observar que o aumento na frequência de Chuva Intensa divergiu com o resfriamento na TSM durante o período. A respeito dos resultados das correlações cíclicas foi possível notar que não houve correlações significativas entre a Chuva Intensa e o ONI, inclusive as suas séries temporais, Neutra, ENOS, EN e LN. Ou seja, não ocorre a explicação da variância de Chuva Intensa em função do ONI. Por último, é possível sugerir que os reflexos do resultado do ajuste linear possam ter ocorrido pontualmente em fases e anos específicos. Desta forma, para os quatros casos de correlação linear positiva (ONI, Fase Neutra, ENOS e La Niña) é provável que as fases altas quando significativamente e positivamente correlacionados estivessem associadas a tais ajustes lineares. A respeito da exceção observada, para o caso de correlação envolvendo a fase El Niño observamos que não ocorreu concomitantemente uma correlação linear e cíclica. Em função destes resultados, concluímos que não houve nenhum caso na contagem da frequência anual de Chuvas Intensas que apontasse a possibilidade de enfraquecimento ou intensificação das amplitudes dos ciclos deste tipo de chuva ao longo do período de 1970 a 2009. No entanto, identificamos na Tabela 48 que as fases altas $(\bar{x}>1)$ provavelmente refletiriam a correlação linear positiva entre os ajustes positivos da Chuva Intensa e do ONI.

Tabela 48 - Correlação Anual em Fases Específicas. A Coluna "A" indica ○ Ajuste Linear da Chuva Intensa nas Séries Temporais "B" correspondente o ONI e suas Fases. A Última Coluna aponta os Possíveis Anos que estiveram Correlacionados com o Resultado da Correlação Linear do Ajuste "A" e "B".

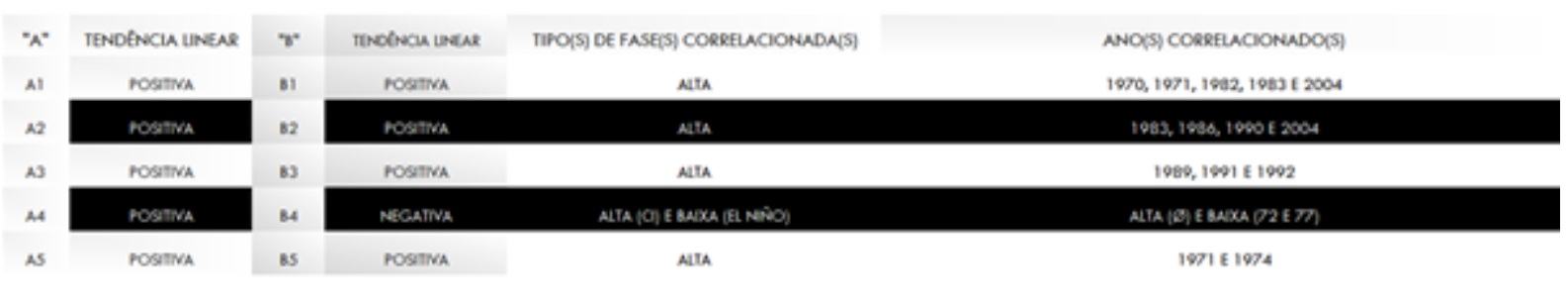




\subsection{2- Análise Trimestral}

A segunda análise envolve a relação trimestral entre a Chuva Intensa e o Oceanic Niño Index. Nestas análises estão incluídas as séries temporais, definidas como relativas, ou seja, períodos específicos da série integral, classificadas como ENOS, fase Neutra, El Niño e La Niña. Trata-se de uma análise individualizada, envolvendo os três procedimentos elementares adotados, que foram aplicados para as quatro estações climáticas do ano, ou seja, verão, outono, inverno e primavera.

\subsubsection{1 - A Frequência Trimestral de Chuva Intensa}

Os resultados das frequências trimestrais de Chuva Intensa podem ser observados a partir da Figura 124. No inverno e primavera, a tendência linear de Chuva Intensa é positiva durante o período de 1970 a 2009 (Figuras 124 e 125). Por outro lado, a tendência linear deste tipo de chuva para o verão e outono pode ser considerada nula ou estável.

FREQUÊNCIA TRIMESTRAL DE CHUVAS INTENSAS - VERÃO (1970-2009)

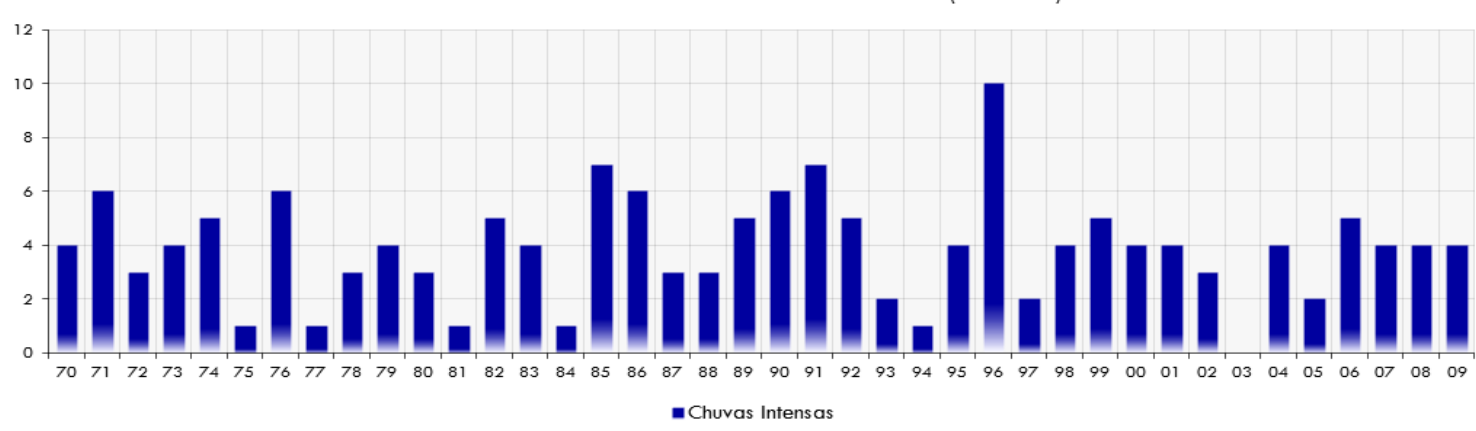

FREQUÊNCIA TRIMESTRAL DE CHUVAS INTENSAS - OUTONO (1970-2009)

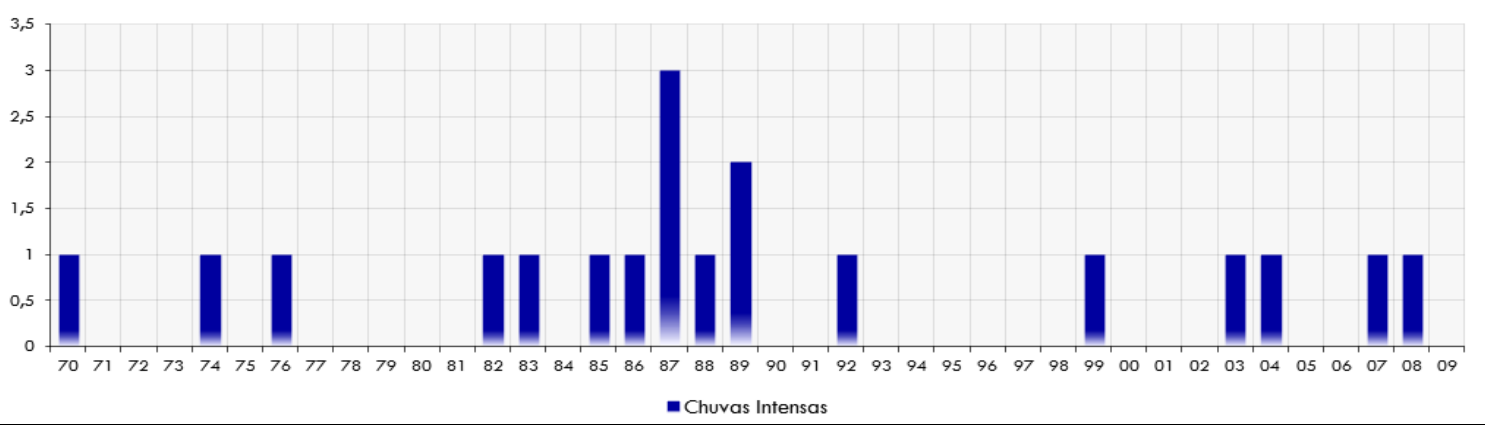




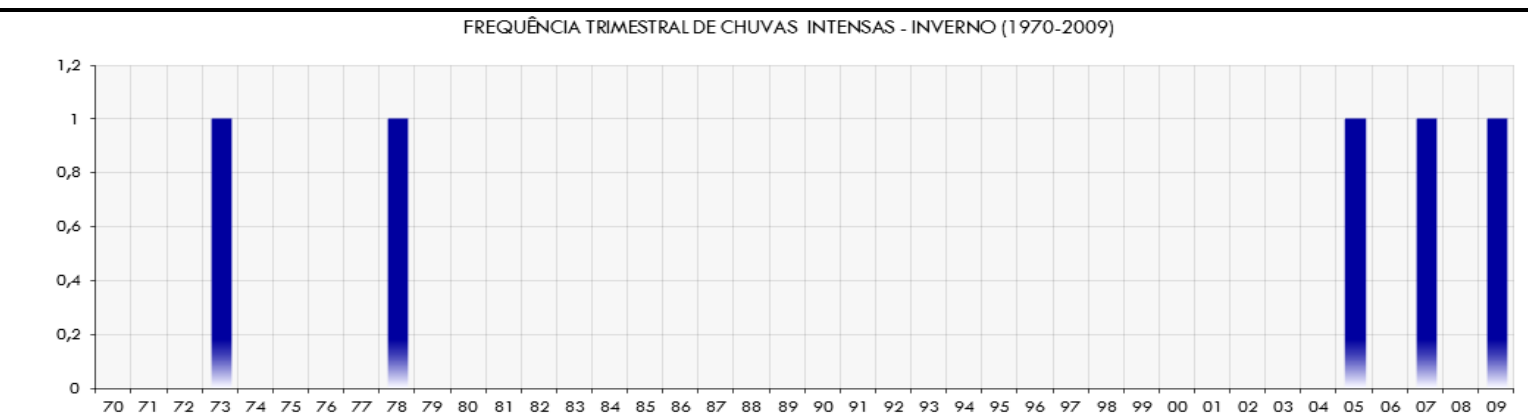

- Chuvas Intensas

FREQUÊNCIA TRIMESTRAL DE CHUVAS INTENSAS -PRIMAVERA (1970-2009)

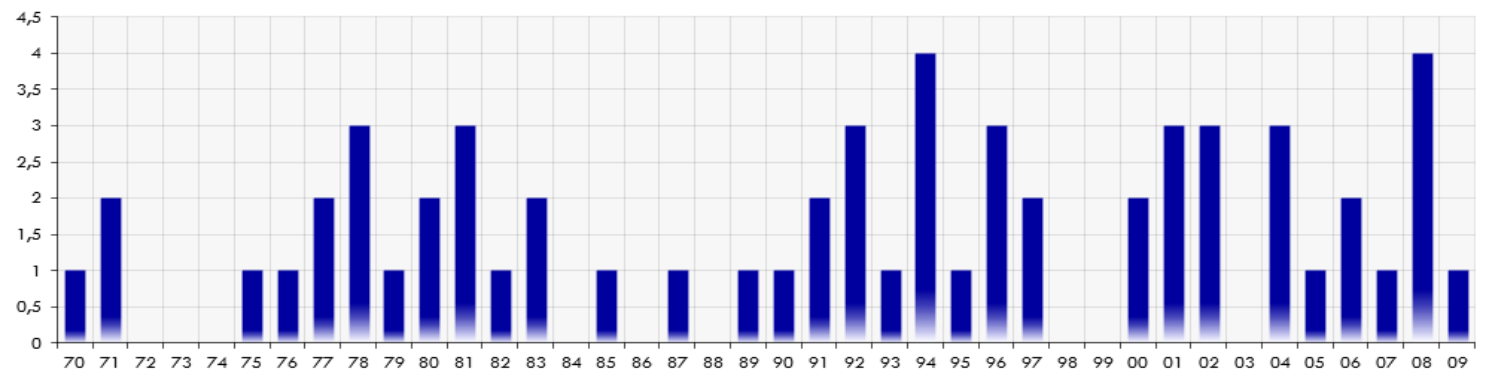

- Chuvas Intensas

Figura 124 - Frequência Trimestral de Chuva Intensa na Estação do IAG-USP durante o Verão, Outono, Inverno e Primavera para o Período de 1970 a 2009.

TENDÊNCIA LINEAR TRIMESTRAL DE CHUVA INTENSA - INVERNO

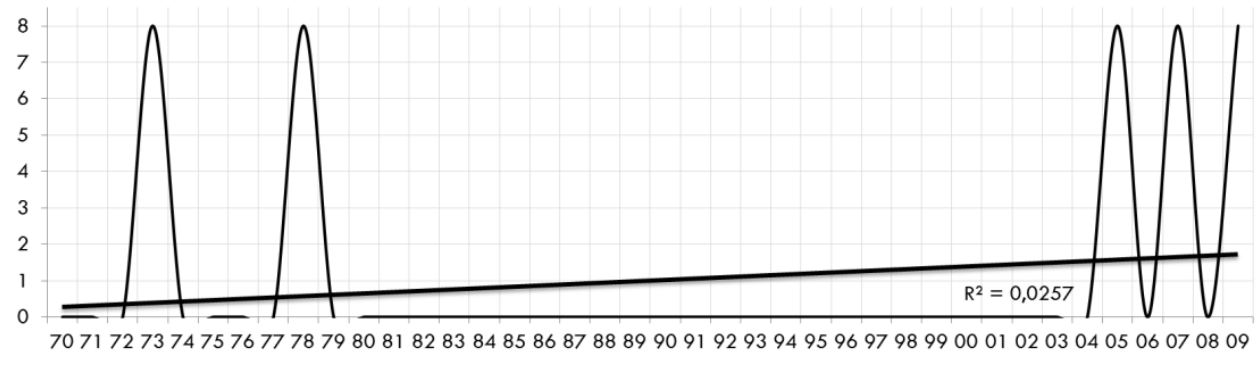

$$
\text { - } \mathrm{Cl} \text { - Linear (Cl) }
$$

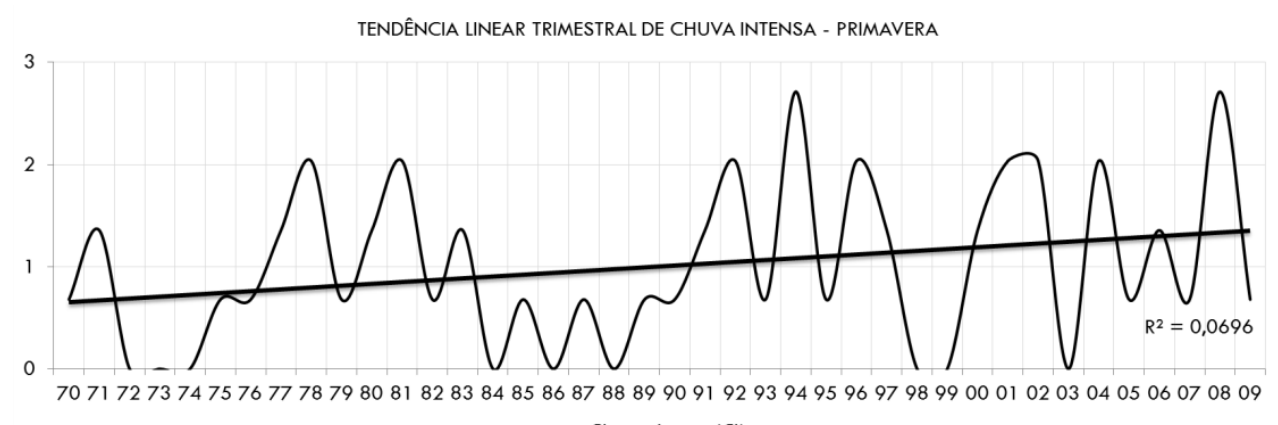

$$
\text { - Cl - Linear (Cl) }
$$

Figura 125 - Ajuste Linear Trimestral de Chuva Intensa para as Estações de Inverno e Primavera, no Período de 1970 a 2009.

As séries temporais do ONI que apresentaram tendências lineares positivas foram identificadas na fase ENOS, Figura 127, no inverno e na primavera da fase EN, Figura 128 e, 
na LN, Figura 129 . Por outro lado, as séries temporais que apresentaram tendências lineares negativas foram identificadas na fase Neutra, Figura 126 e, no outono da fase EN. Nas Figuras $125-129$ são apresentadas somente os ajustes lineares mais significativos.

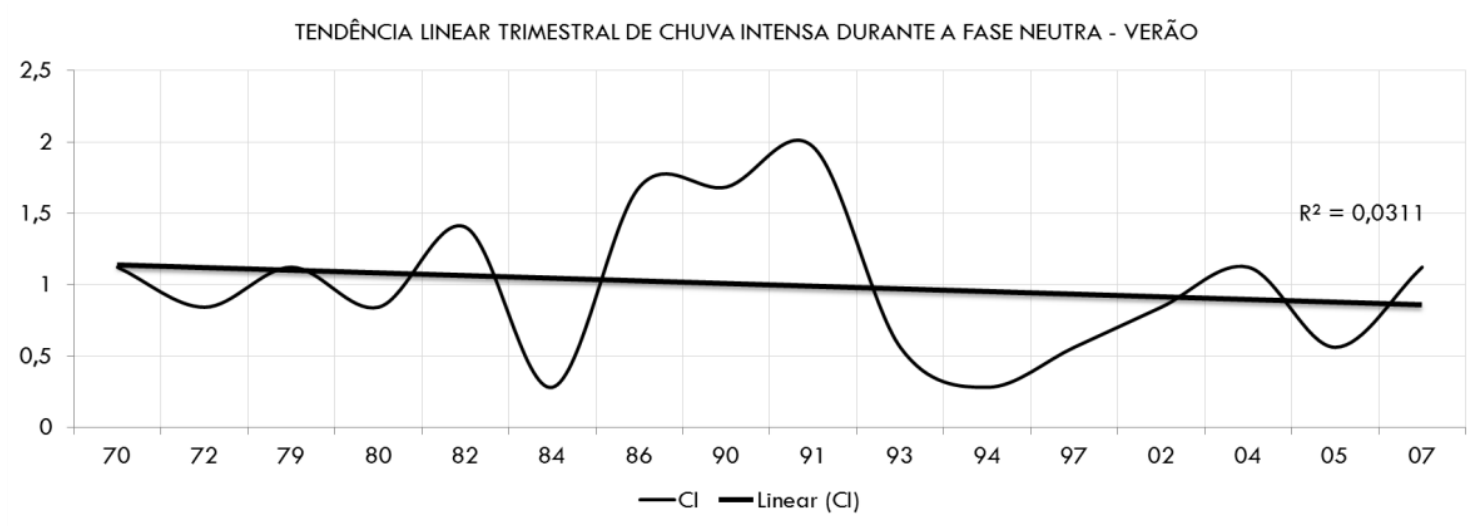

Figura 126 - Ajuste Linear Trimestral de Chuva Intensa para a Estação de Verão durante a fase Neutra.
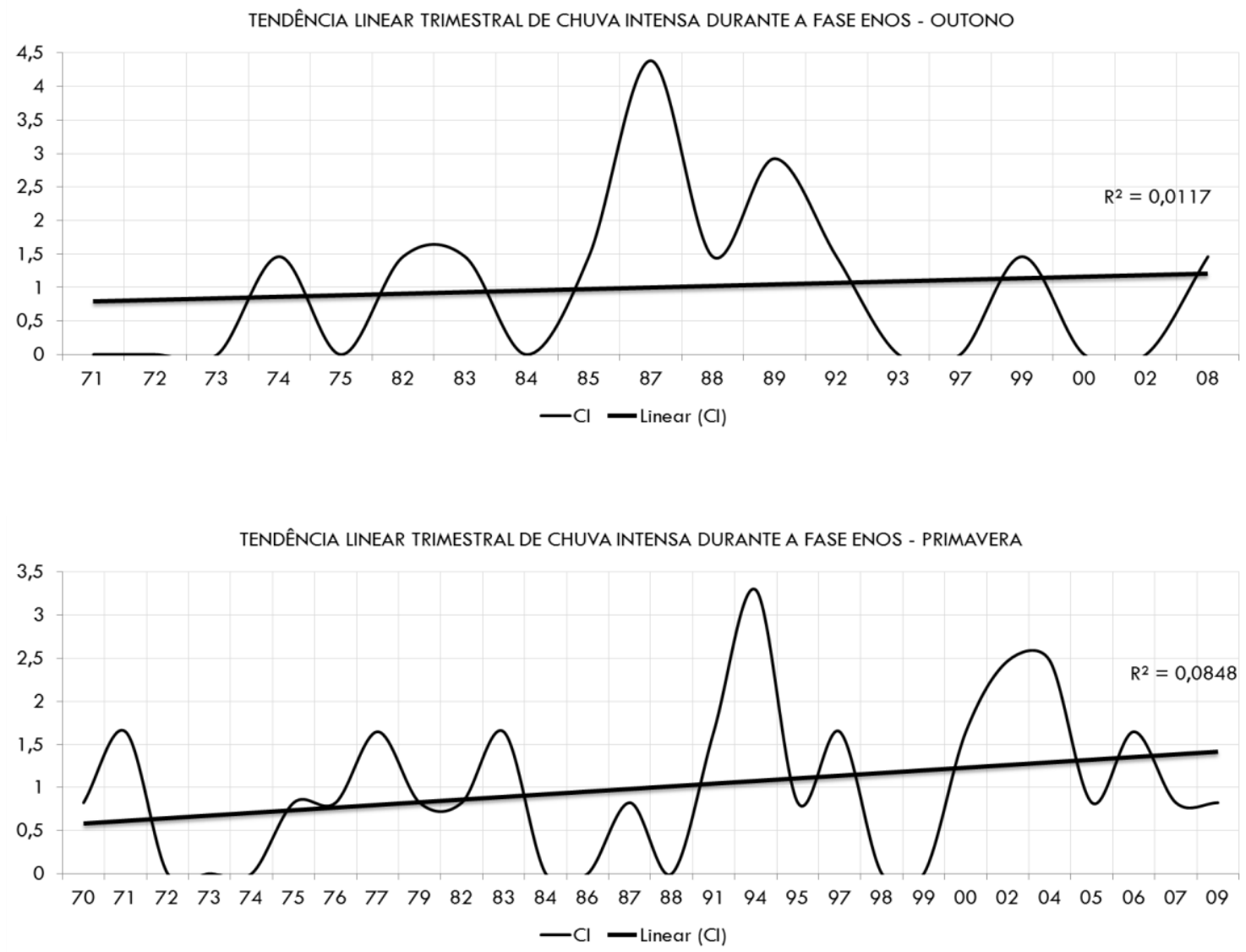

Figura 127 - Ajuste Linear Trimestral de Chuva Intensa para as Estações de Outono e Primavera durante a fase ENOS. 

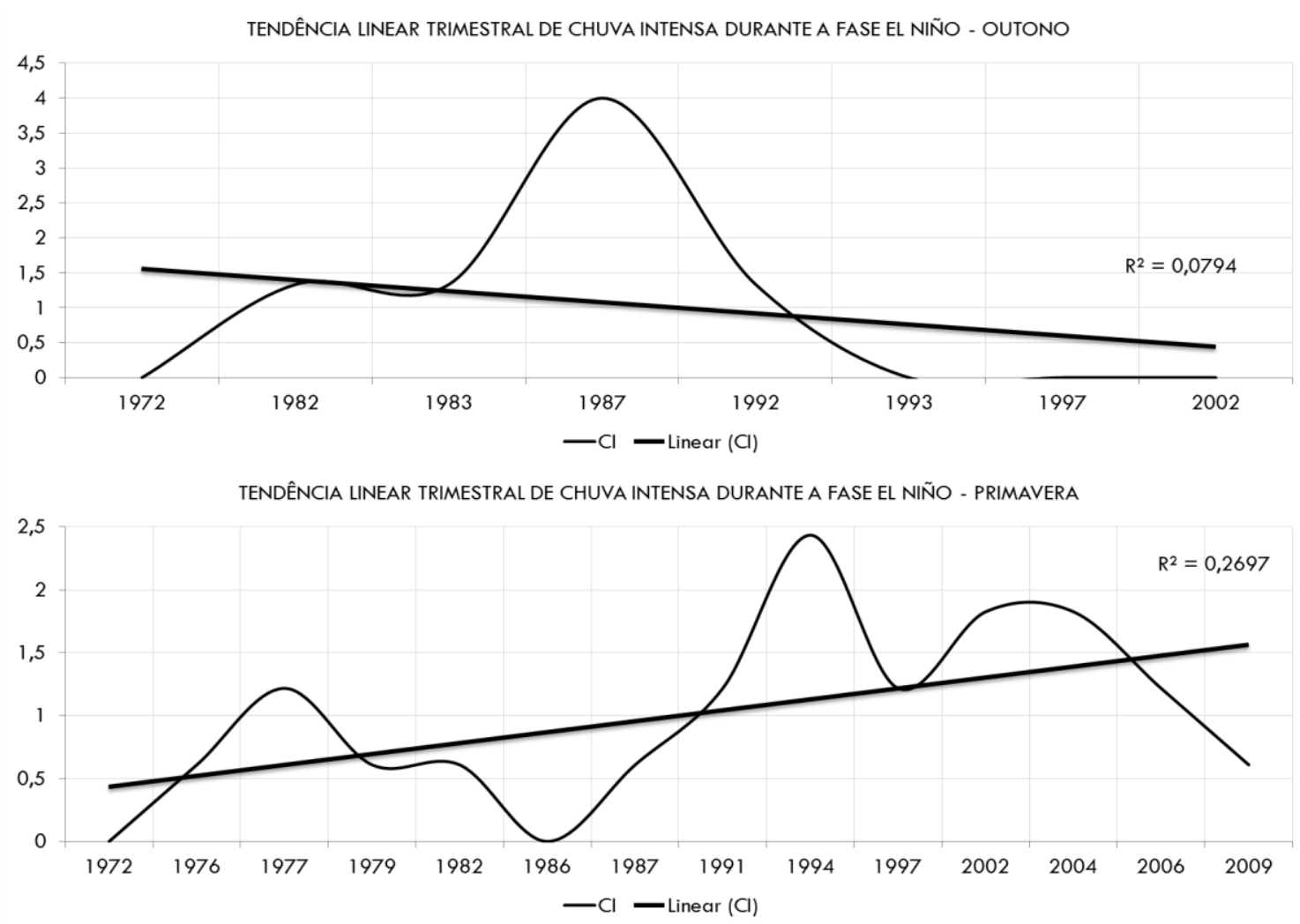

Figura 128 - Ajuste Linear Trimestral de Chuva Intensa para as Estações de Outono e Primavera durante a fase El Niño.

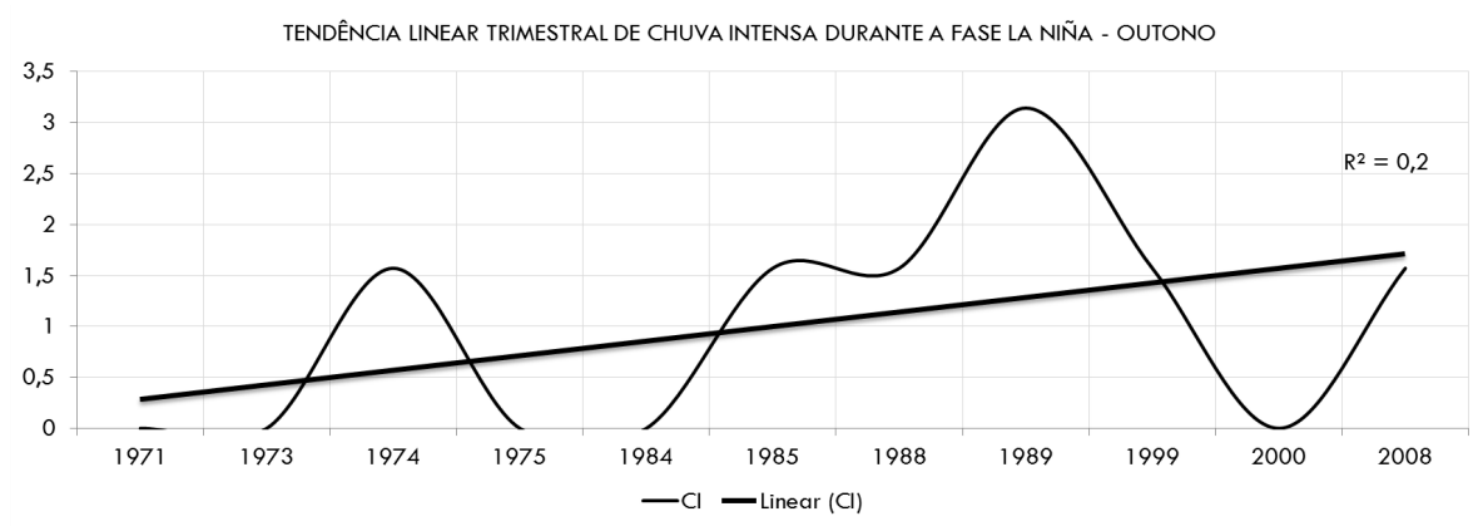

Figura 129 - Ajuste Linear Trimestral de Chuva Intensa para as Estações de Outono durante a fase La Niña.

Os resultados trimestrais por fases envolvendo ajustes lineares positivos também coincidem com os resultados identificados no trabalho de Cabral (2002), Sugahara et al (2009) e Freitas et al (2013). No entanto, há algumas assimetrias sazonais e em fases específicas que indicam alteração de comportamento quando analisado amostras dentro da série completa. De modo geral, a Tabela 49 indica que na maioria dos casos envolvendo correlações lineares entre a Chuva Intensa e ONI foram positivas (+). No total foram 13 
correlações positivas que apresentaram haver uma correlação estatística, em todas as estações climáticas do ano, entre a Chuva Intensa e a série temporal do ONI, incluindo as séries temporais relativas (neutra, ENOS, EN e LN). As correlações lineares ocorreram com mais frequência durante o outono.

Tabela 49 - Correlação Linear Trimestral entre a Tendência Linear Trimestral de Chuva Intensa e a Tendência Linear Trimestral do ONI, incluindo as Fases, Neutra, ENOS, EN e LN.

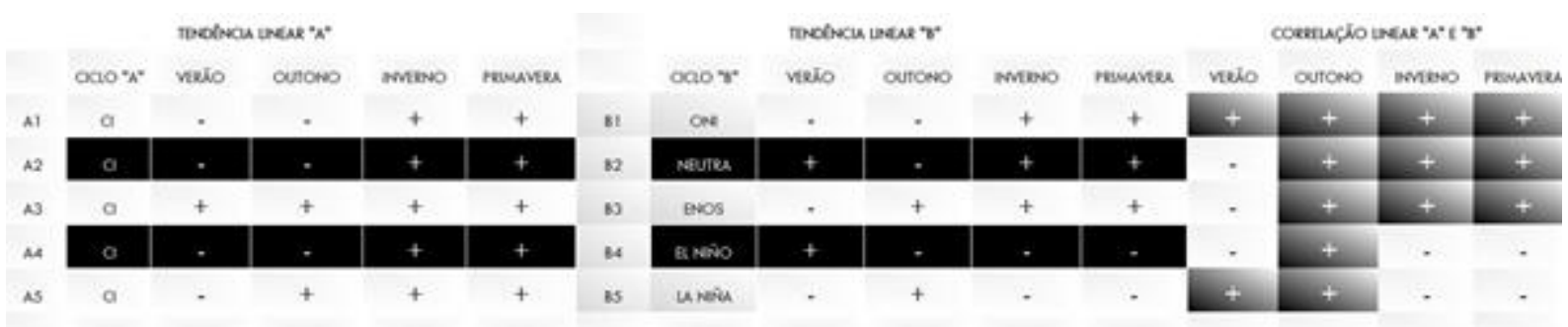

A frequência da Chuva Intensa, durante o verão, diminui em todos os casos, exceto para a série temporal constituída por eventos de ENOS. Durante o inverno e primavera, a frequência da Chuva Intensa aumenta em todos os casos. Para a estação de outono, a frequência da Chuva Intensa aumenta em apenas dois caso, ENOS e La Niña, (Tabela 49). Contudo, considerando todas as estações climáticas, no período de 1970 a 2009, verificamos que a frequência de Chuva intensa aumenta no decorrer do tempo, exceto no verão e no outono, porém a tendência linear negativa está mais próxima de ser estável do que significativa (Tabela 49).

\subsubsection{2- Variação Cíclica Trimestral de Chuva Intensa}

A variação das anomalias da frequência de Chuva Intensa para o período de 1970 a 2009, durante as quatro estações do ano está ilustrada na Figura 130.

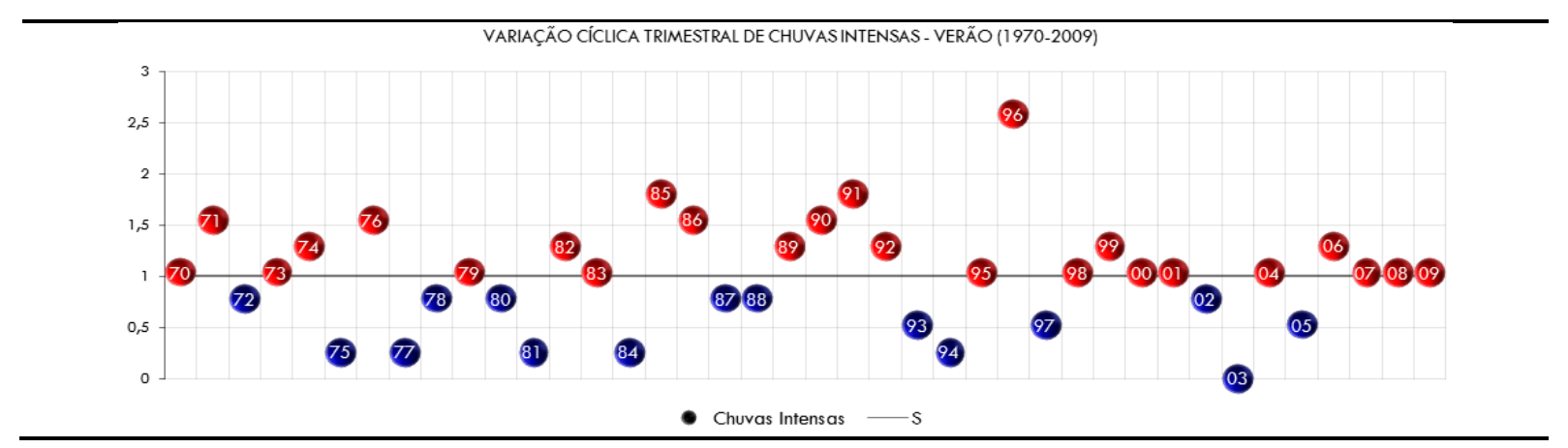




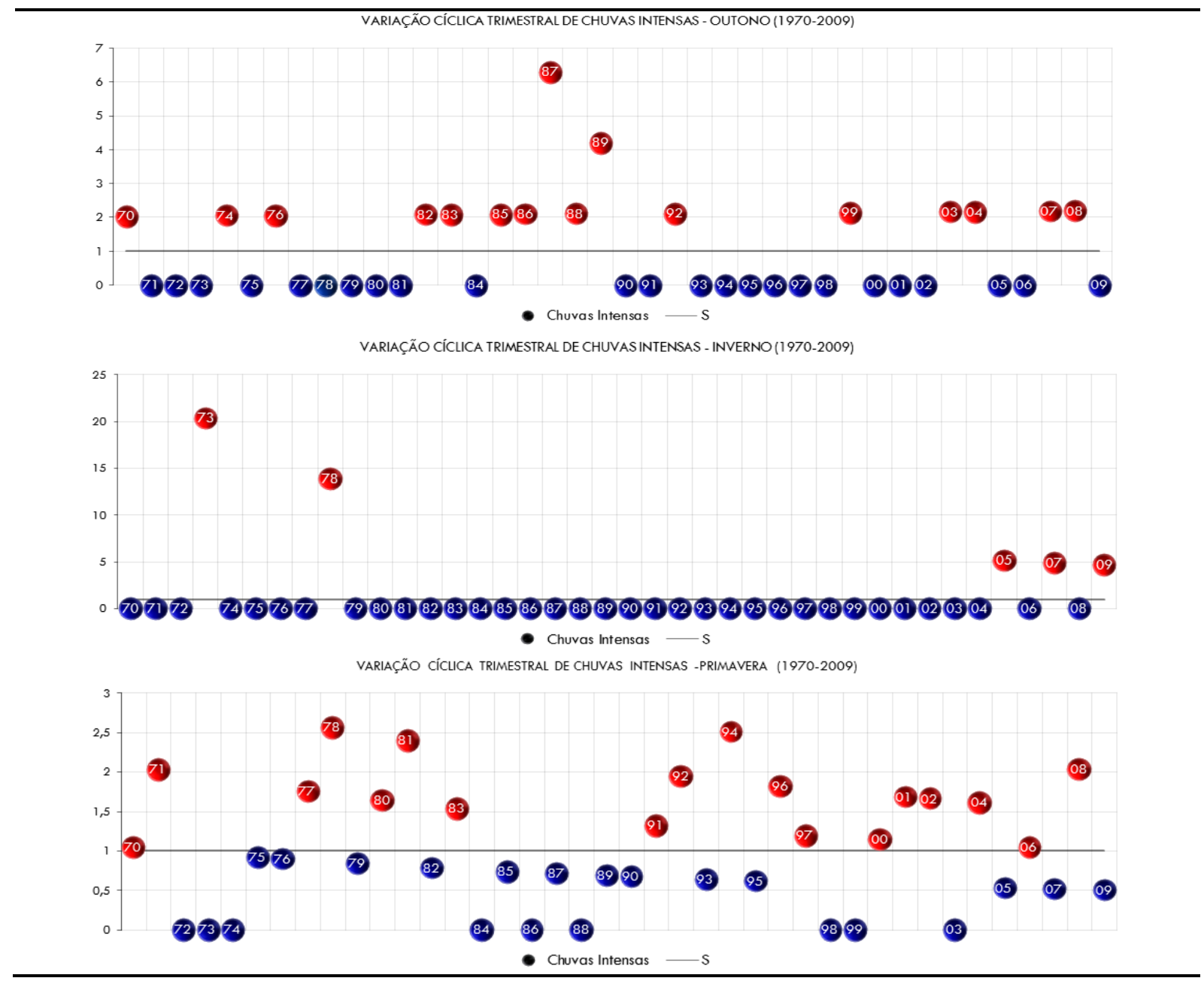

Figura 130 - Variação Cíclica Trimestral de Chuva Intensa, entre 1970 e 2009.

\subsubsection{3- Análise da Correlação Cíclica Trimestral}

De forma geral, separando a série temporal em estações do ano, observamos que a correlação linear entre as séries de ONI e frequência de Chuva Intensa é negativa e significativa para a primavera $(r=-0,25)$, Figura 131 . Ou seja, a frequência de Chuva Intensa pode estar associada fisicamente aos valores de ONI durante a primavera. A separação das séries temporais em eventos distintos quanto à TSM na região do Niño3.4 permitiu verificar que durante a primavera, na fase Neutra, a correlação linear entre estas duas variáveis continua significativa, embora negativa durante a fase neutra $(r=-0,61)$, Figura 132. No outono, durante a fase El Niño, identificamos uma correlação positiva e significativa $(r=0,71)$, Figura 133. Todos os demais resultados podem ser observados a partir da Tabela 50. 
Tabela 50 - Correlação Cíclica entre a Frequência de Chuva Intensa observada na Estação do IAG e os Valores de ONI para Cada Estação do Ano e, para Cada Condição de Anomalia na Região de Niño3.4 (Eventos Neutros, ENOS, EN e LN).

\begin{tabular}{|c|c|c|c|c|c|c|c|}
\hline VERÃO & OUTONO & INVERNO & PRIMAVERA & vERĀO & OUIONO & INVERNO & PRimuVERa \\
\hline A1 & Al & A) & A) & ONe & ONe & One & Onet \\
\hline $\mathrm{A}^{2}$ & A2 & A2 & A2 & NEUTRO & NEUTRO & Neutro & Neutro \\
\hline A3 & A3 & A3 & A3 & enOS & ENOS & enOS & enos \\
\hline M & $M 4$ & M & M & E NE⿱乛龰O & E NENOO & E NEATO & A nấo \\
\hline is & NS & is & AS & U VINA & Uneria & LANËA & u reina \\
\hline \multicolumn{4}{|c|}{ CORRELAÇÄO CICUCA } & \multicolumn{4}{|c|}{ TESTE T - STUDENT } \\
\hline VERÃO & OUTONO & INVERNO & PRIMAVERA & VERÃO & OUTONO & INVERNO & PRIMAVERA \\
\hline$-0,104$ & .0013 & .0084 & .0 .259 & NÜO SIGERACAIIVO & NḦO SIGNEFICAIIVO & NÄO SDGNEFCAIINO & SGGESACAINO \\
\hline 0,105 & $-0,339$ & 0 & 0,012 & NËO SICREACATIVO & MÜO SICNEFICATIVO & NÁO SICNEFCATINO & SIGNEACAIMO \\
\hline$-0,243$ & 0,178 & $-0,187$ & 0,111 & NËO SICREFCATIVO & NÄO SIGNEACATIVO & NÄO SSGNEACATIVO & NḦO SIGEAPCATIVO \\
\hline 0,507 & 0,716 & $-0,173$ & $-0,30$ & NHOO STGAAPCATIVO & SIGNEACATMO & NÜO SGNEACATMO & NïO SGGEACATIVO \\
\hline 0,2007 & 0,104 & 0,25 & 0,519 & NḦO SIGERACATIVO & NÜO SIGEEFCATVO & NÄO SOGNEACATIVO & NHO SIGEACAIVOO \\
\hline
\end{tabular}

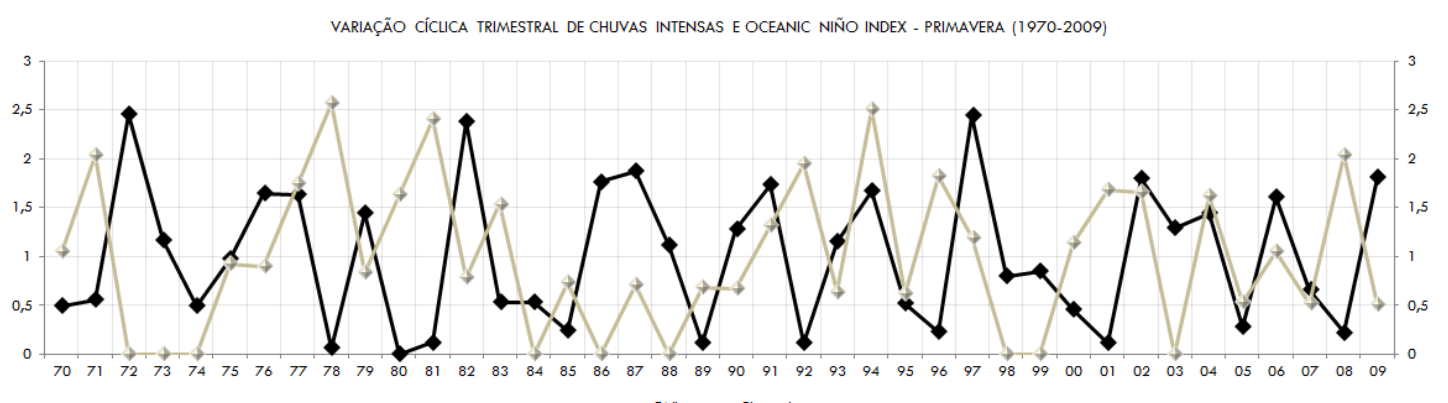

Figura 131 - Variação Cíclica de Chuva Intensa, na Primavera, entre 1970 e 2009.

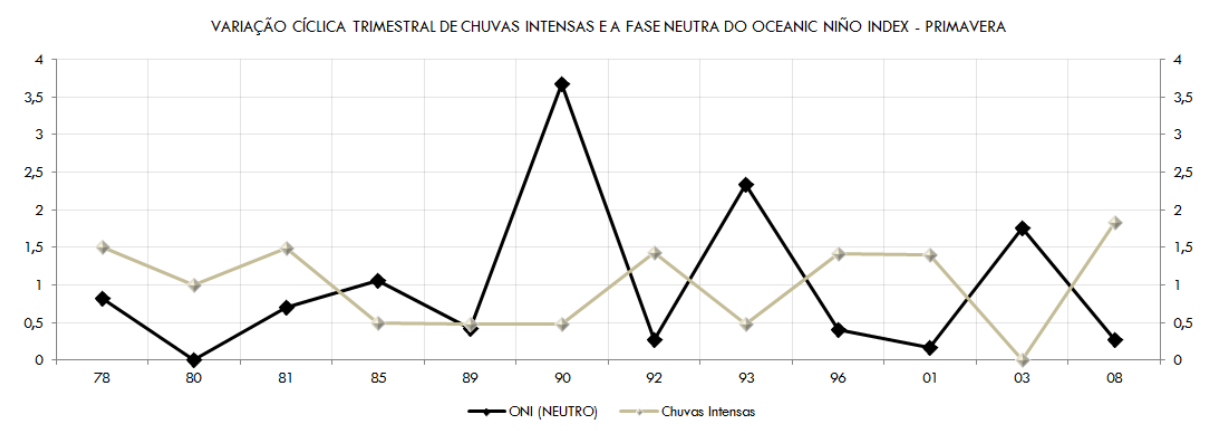

Figura 132 - Variação Cíclica de Chuva Intensa, na Primavera, durante a Fase Neutra.

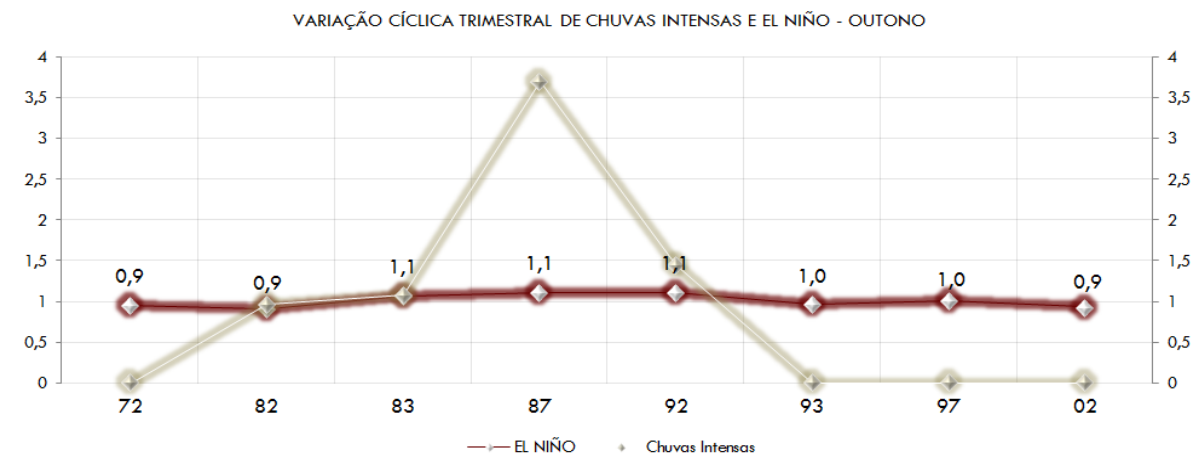

Figura 133 - Variação Cíclica de Chuva Intensa, no Outono, durante a Fase El Niño. 


\subsubsection{4- Análise Específica das Fases Trimestrais}

Os resultados de tal análise revelam as possíveis correlações existentes entre as fases altas e baixas da frequência de Chuva Intensa e do ONI. Neste caso, identificamos a série específica através das fases altas $(\bar{x}>1)$ e baixas $(\bar{x}<1)$ da variação cíclica da frequência trimestral de Chuva Intensa. A variação cíclica de Chuva Intensa no período de 1970 a 2009 durante a estação de verão foi composta por 22 fases específicas. A partir do resultado positivo da correlação linear entre a tendência negativa de Chuva Intensa e a tendência negativa do ONI, procuramos identificar as fases da oscilação que possivelmente estiveram associadas a tal comportamento. Neste caso, deduzimos que somente as fases baixas estariam correlacionadas (Figura 134). Em função dessa probabilidade, identificamos nos anos $72,75,80,81,84,85,86,93,94,97$ e 04 as fases baixas que estariam significativamente e positivamente correlacionadas com a correlação positiva entre a Chuva Intensa e o ONI (Tabela 51). A variação cíclica de Chuva Intensa no período de 1970 a 2009 durante a estação de outono foi composta por 18 fases específicas. A partir do resultado positivo da correlação linear entre a tendência negativa de Chuva Intensa e a tendência negativa do ONI, procuramos identificar as fases da oscilação que possivelmente estiveram associadas a tal comportamento. Neste caso, deduzimos que somente as fases baixas estariam correlacionadas, no entanto, não foram identificadas fases baixas que estariam significativamente e positivamente correlacionadas com a correlação positiva entre a Chuva Intensa e o ONI (Tabela 51). A variação cíclica de Chuva Intensa no período de 1970 a 2009 durante a estação de inverno foi composta por 10 fases específicas. A partir do resultado positivo da correlação linear entre a tendência positiva de Chuva Intensa e a tendência positiva do ONI, procuramos identificar as fases da oscilação que possivelmente estiveram associadas a tal comportamento. Neste caso, deduzimos que somente as fases altas estariam correlacionadas (Figura 134). Em função dessa probabilidade, identificamos no ano de 2005 a única fase baixa que esteve significativamente e positivamente correlacionada 
com a correlação positiva entre a Chuva Intensa e o ONI (Tabela 51). A variação cíclica de Chuva Intensa no período de 1970 a 2009 durante a estação de primavera foi composta por 28 fases específicas. A partir do resultado positivo da correlação linear entre a tendência positiva de Chuva Intensa e a tendência positiva do ONI, procuramos identificar as fases da oscilação que possivelmente estiveram associadas a tal comportamento. Neste caso, deduzimos que somente as fases altas estariam correlacionadas (Figura 134). Em função dessa probabilidade, identificamos nos anos $70,71,80,81,94,04$ e 06 as fases altas que estariam significativamente e positivamente correlacionadas com a correlação positiva entre a Chuva Intensa e o ONI (Tabela 51).
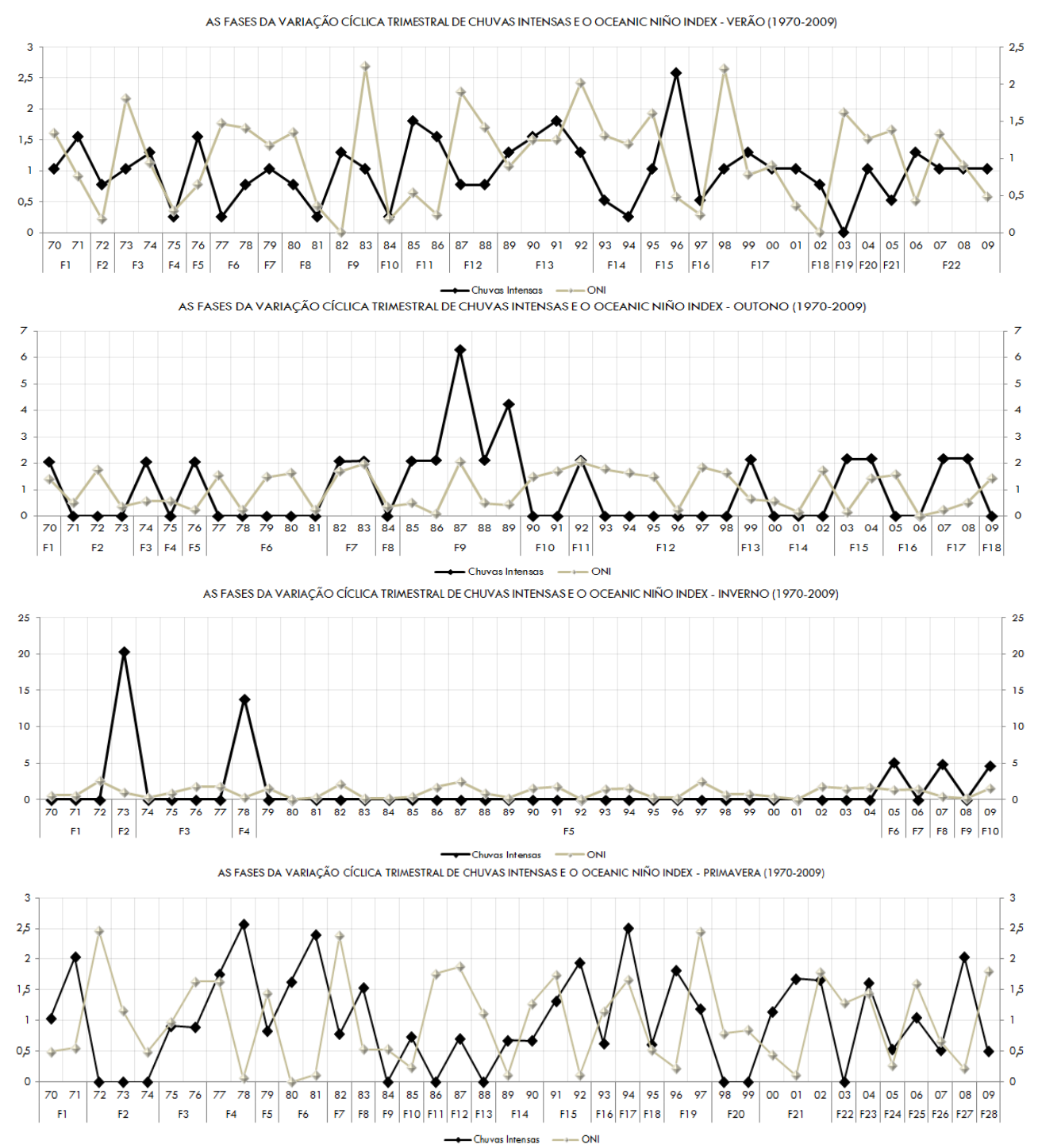

Figura 134 - Fases Específicas do Ciclo Trimestral de Chuva Intensa, Verão, Outono, Inverno e Primavera. A linha Branca corresponde à variação cíclica do ONI e a linha Preta de Chuva Intensa, para o Período de 1970-2009. 
Tabela 51 - Correlação Linear entre a Frequência de Chuva Muito Fraca observada na Estação do IAG e os Valores de ONI para Cada Estação do Ano e, para Cada Condição de Anomalia na Região de Niño3.4 (Eventos Neutros, ENOS, EN e LN). "A" representa as Séries Temporais de Chuva MFA relativa às Séries Temporais do ONI "B". Assim, B1 (ONI), B2 (Neutro), B3 (ENOS), B4 (EN) e B5 (LN). Correlação "A" são os Tipos Fases Correlacionadas com a Chuva MFA e Correlação "B" são os Tipos Fases Correlacionadas com o ONI.

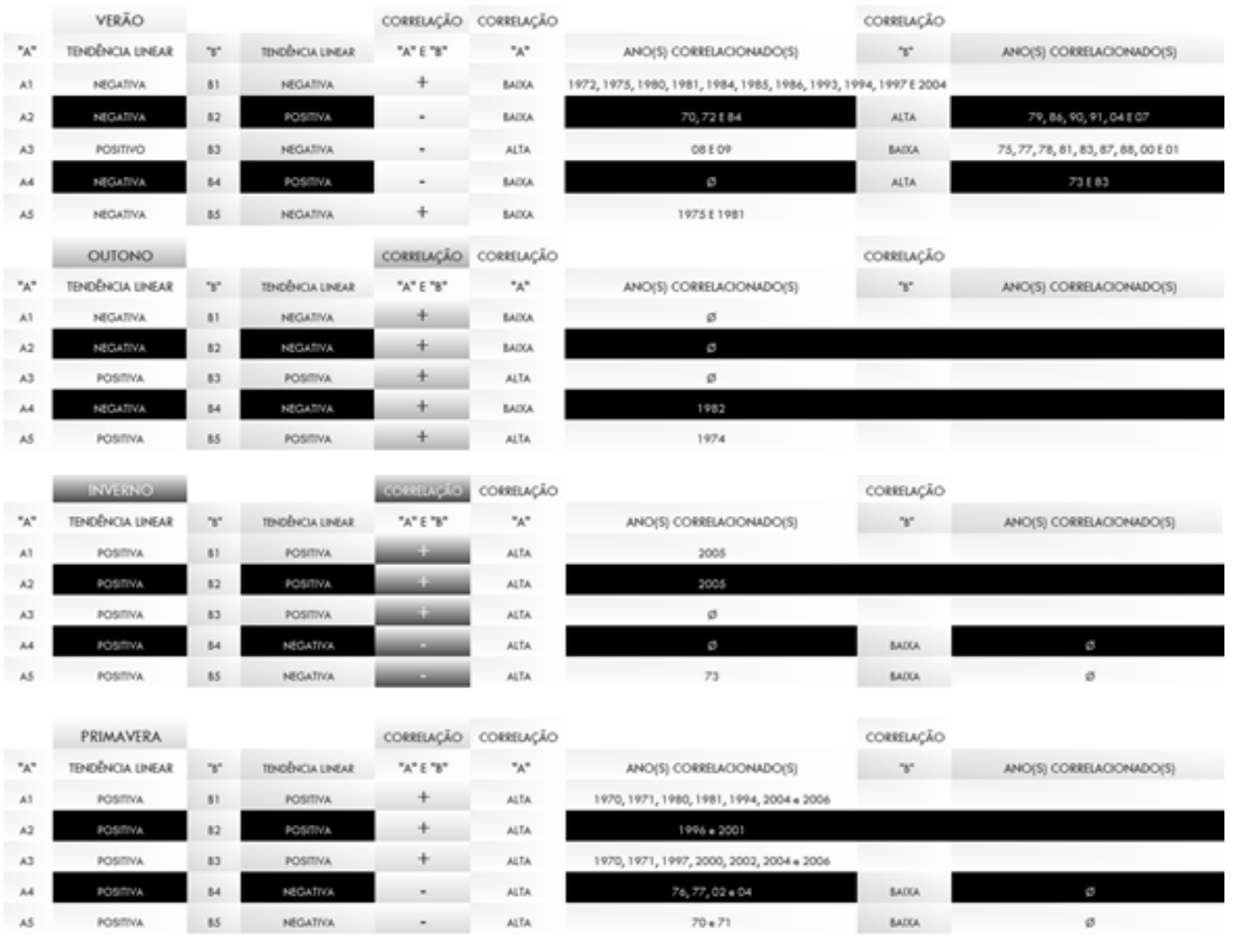

\subsubsection{5- A Hipótese Inicial e a Conclusão Final - Cl II}

A conclusão final para análise trimestral de Chuva Intensa parte das distintas correlações identificadas, para cada estação climática, envolvendo o ajuste linear dos índices do ONI na região Niño3.4 e a frequência de chuva intensa. De modo geral, no verão e no outono, observamos que o ajuste linear negativo do ONI coincidiu positivamente com o ajuste negativo de Chuva Intensa. O mesmo ocorreu durante o inverno e a primavera, no entanto, neste período a correlação positiva ocorreu em função dos ajustes lineares positivos do $\mathrm{ONI}$ e da Chuva Intensa. A Tabela 51 apresenta os resultados das demais correlações realizadas para as séries temporais do $\mathrm{ONI}$ em cada estação climática do ano. Após identificarmos as 
respectivas correlações lineares trimestrais entre a Chuva Intensa e ○ ONI, analisamos os resultados das correlações cíclicas trimestrais. Neste caso, encontramos apenas três correlações cíclicas significativas de acordo com a Tabela 50. A primeira e única correlação significativa e positiva foi identificada no outono, durante a série temporal da fase El Niño. A segunda e a terceira correlação significativa foram negativas, identificadas na primavera, durante $\circ \mathrm{ONI}$ e a fase neutra. A partir da combinação dos resultados observados durante o outono relativo à identificação de correlação negativa envolvendo ajustes negativos e a identificação de uma significativa de correlação cíclica, analisamos por dedução e correlação que seja muito provável que tenha ocorrido um enfraquecimento das variações cíclicas de Chuva Intensa em função da diminuição das amplitudes dos seus ciclos durante a fase do El Niño. Neste caso, é possível identificar consonância com a expectativa de Grimm et al (1999), ou seja, nota-se a influência de padrões de macroescala alterando a frequência de circulação, que neste caso diminuiu suprimindo a precipitação. Ainda, podemos identificar os possíveis reflexos da combinação observada, em fases específicas, que podem ser visualizados através dos anos que estiveram correlacionados, de acordo com a Tabela 51.

\section{8- Amostra de Chuva $\geq 10 \mathrm{~mm} \mathrm{h-1}$}

A amostra de chuva $\geq 10 \mathrm{~mm} \mathrm{~h}^{-1}$ é formada por chuvas que atingem níveis pluviométricos maiores e iguais a 10 milímetros no intervalo de uma hora. A partir da hipótese inicial deste estudo, a intenção ao analisar uma determinada amostra, é a de concluir para a série temporal de 1970-2009, a existência ou não de um nível de correlação aceitável, envolvendo classes estatísticas mais representativas, com a intenção de avaliar o nível de explicação para o comportamento de sua frequência, em função das variações registradas na temperatura da superfície do mar na região Niño 3.4. A amostra de chuva $\geq 10 \mathrm{~mm} \mathrm{~h}^{-1}$ é identificada pela sigla "A10". 


\subsection{1 - Análise Anual}

A análise anual possui a finalidade de apresentar uma conclusão obtida a partir da identificação do tipo de correlação existente na intenção de sugerir a possibilidade de haver uma relação anual envolvendo a chuva A10 e o Oceanic Niño Index. A partir dos dados da estação do IAG-USP, calculamos a frequência anual de chuva A10 ( $\geq 10 \mathrm{~mm} \mathrm{~h}^{-1}$ ), representada no gráfico da Figura 135, onde identificamos a frequência máxima no ano de 1996 através da contagem de 50 casos horários.

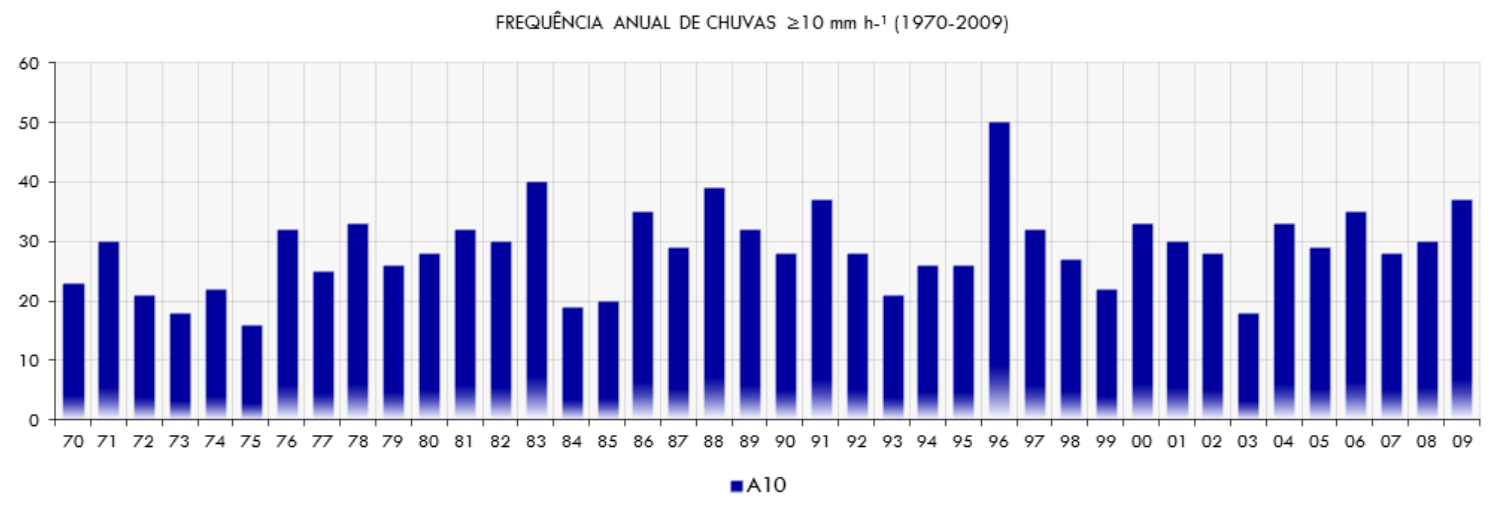

Figura 135 - Frequência Anual de Chuva $\geq 10 \mathrm{~mm} \mathrm{~h}^{-1}$ entre 1970-2009.

\subsubsection{1 - Análise do Ajuste Linear}

O ajuste linear da frequência anual de chuva A10 no município de São Paulo indica aumento desta frequência ao longo da série temporal analisada, de 1970 a 2009, tal como ilustrada na Figura 136. A análise realizada para as fases, neutra, ENOS, El Niño e La Niña, separadamente, mostra que, em todos os casos, a frequência anual de chuva A10 aumenta com o tempo (Figura 137). A comparação entre a tendência linear da frequência de chuva A10 e do ONI indica que enquanto o ONI assume valores cada vez mais intensos, no decorrer da série temporal, a frequência de chuva A10 aumenta, tal como indicado na Tabela 52. A exceção ocorre no caso de eventos de EN que apresenta tendência negativa nula de TSM, ao longo do período analisado que diverge com a tendência positiva de frequência de chuva A10 (ver tabela 52, linha 4). 
TENDÊNCIA LINEAR ANUAL DE CHUVA $\geq 10 \mathrm{~mm} \mathrm{~h}$-1 $^{-1970-2009)}$

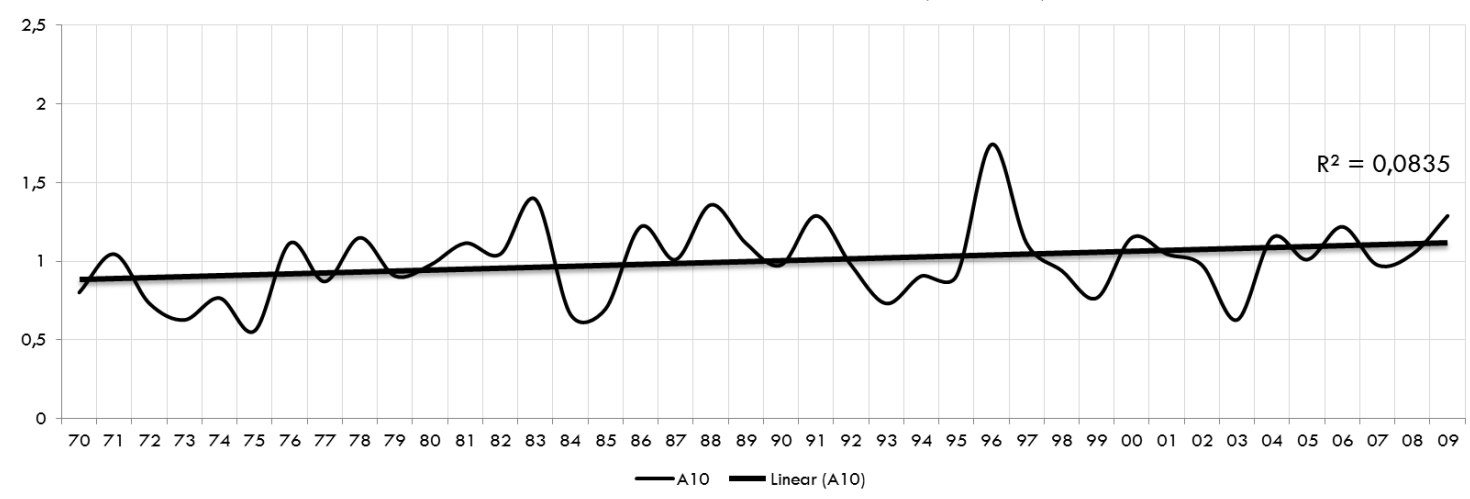

Tabela 136 - Ajuste Linear Anual de Chuva $\geq 10 \mathrm{~mm} \mathrm{~h}-1^{-1}$

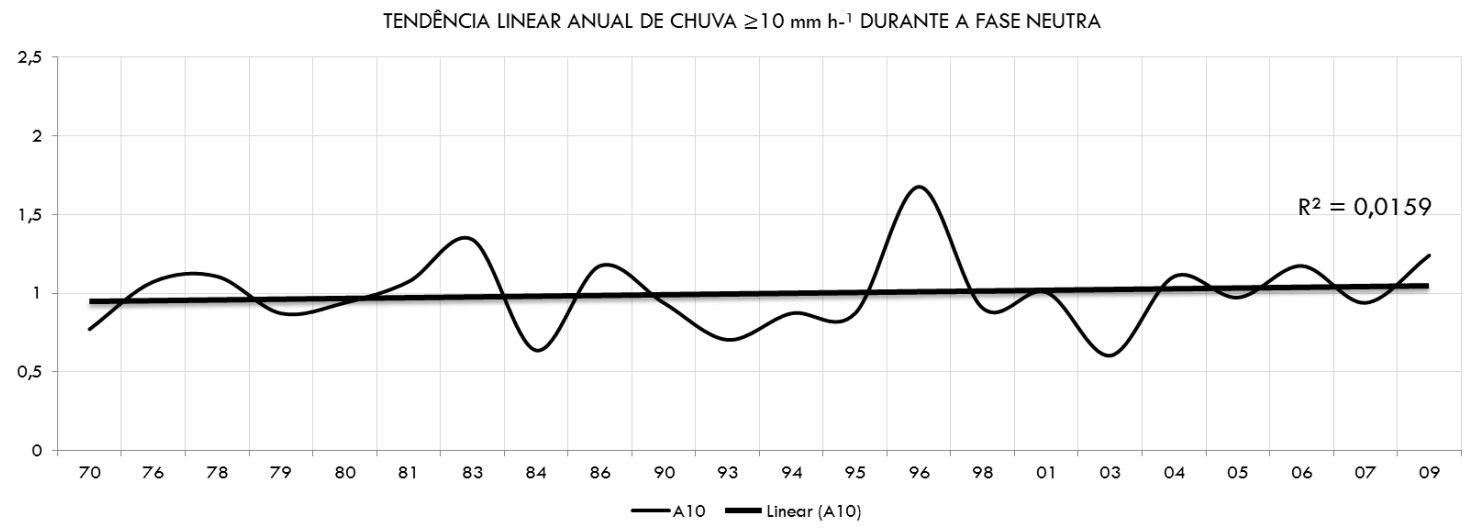

TENDÊNCIA LINEAR ANUAL DE CHUVA $\geq 10 \mathrm{~mm} \mathrm{h-1} \mathrm{DURANTE} \mathrm{A} \mathrm{FASE} \mathrm{ENOS}$

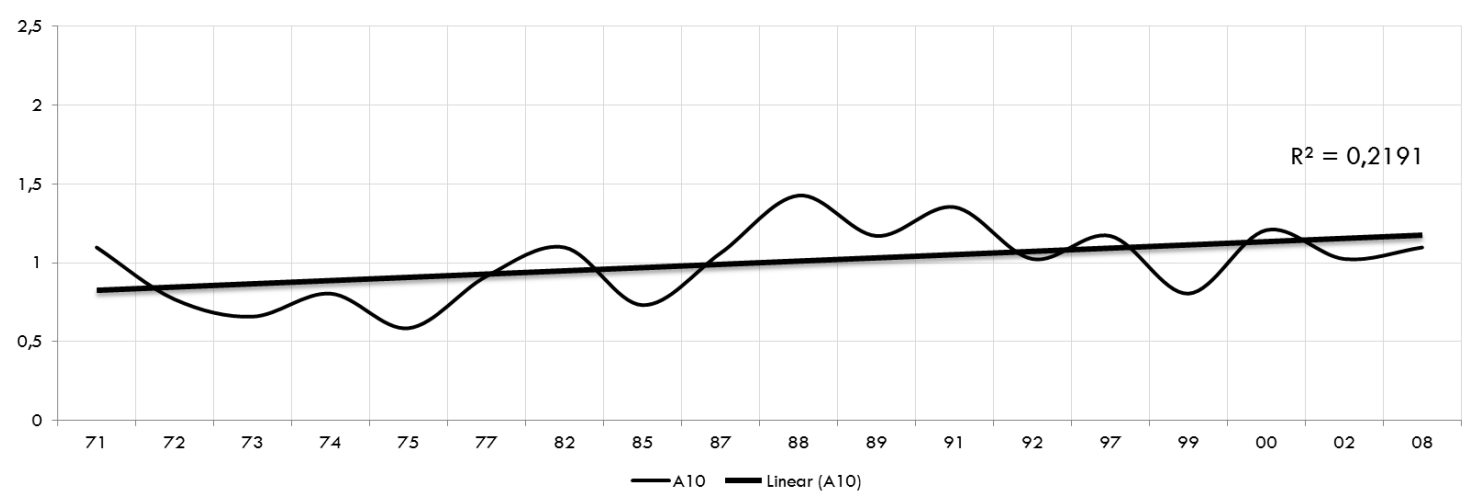

TENDÊNCIA LINEAR ANUAL DE CHUVA $\geq 10 \mathrm{~mm} \mathrm{h-1} \mathrm{DURANTE} \mathrm{A} \mathrm{FASE} \mathrm{EL} \mathrm{NIÑO}$

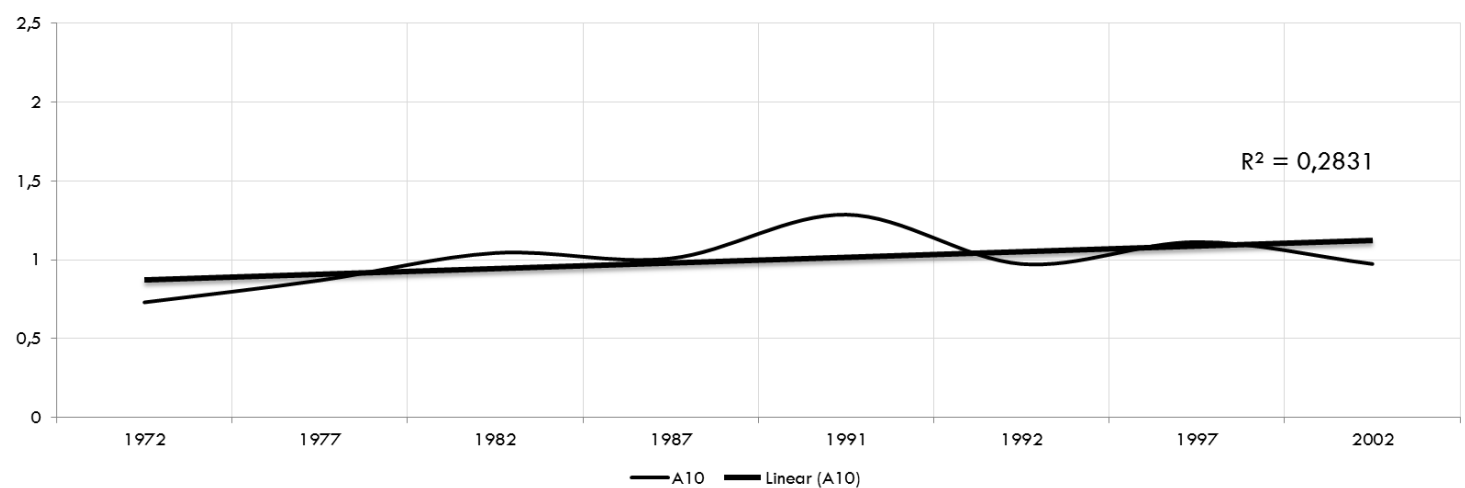




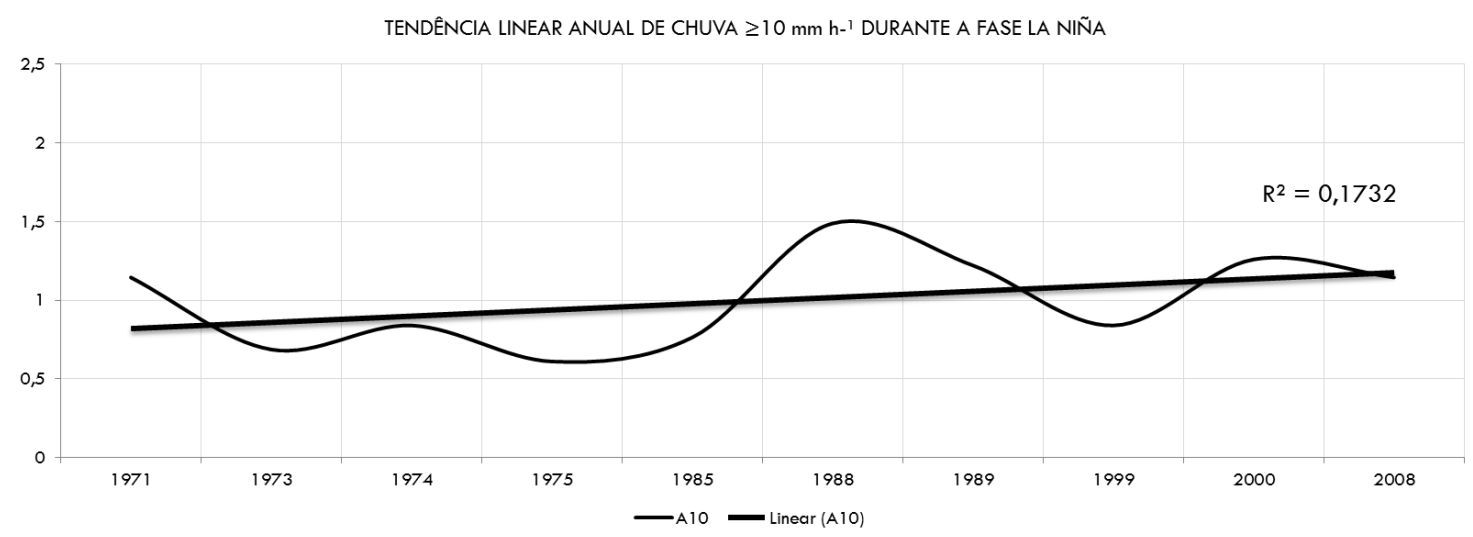

Figura 137 - Tendência Linear da Frequência Anual de Chuva $\geq 10 \mathrm{~mm} \mathrm{~h}{ }^{1}$ para a Fase, Neutra, ENOS, EN e LN, entre 1970-2009.

Os resultados observados através dos ajustes lineares positivos para a série anual revelam que as frequências analisadas no intervalo horário refletiram positivamente com os resultados obtidos das análises diárias realizadas por Cabral (2002), Sugahara et al (2009) e Freitas et al (2013).

Tabela 52 - Tendência Linear Anual de Chuva A10 e do ONI para o Período de 1970 a 2009. A Primeira Linha da Tabela indica a Tendência Linear de Todos os Dados Anuais e, as Demais Linhas indicam a Tendência Linear para cada Fase do ONI.

\begin{tabular}{|c|c|c|c|c|c|c|}
\hline${ }^{*}$ & HPO DE CHUVA & TENDENCLA UINEAR & $*$ & CATEGOSA & TENDENECIA UINEAR & CORRELAÇÃO UNEAR \\
\hline A & A10 & POSITIVA & 81 & ONa & POSITIVA & POSIIIVA \\
\hline 12 & A10 & positva & 12 & NeUtho & Postiva & POSITIVA \\
\hline As & A10 & POSITIVA & B3 & ENOS & POSITIVA & POSITIVA \\
\hline A & Alo & postiva & 84 & A ANETO & NeCoAtiva & NEGATIVA \\
\hline as & A10 & POSITIVA & BS & UANIRA & POSITIVA & POSITIVA \\
\hline
\end{tabular}

\subsubsection{2- Variação Cíclica da Amostra A10}

A variação cíclica anual de chuva A10 pode ser observada na Figura 138. É possível notarmos a oscilção presente na série temporal completa, de 1970 a 2009, formada por 18 fases altas (esferas vermelhas) e 22 fases baixas (esferas azuis). 
VARIAÇÃO CÍCLICA ANUAL DE CHUVAS $\geq 10 \mathrm{~mm} \mathrm{~h}^{-1}$ (1970-2009)

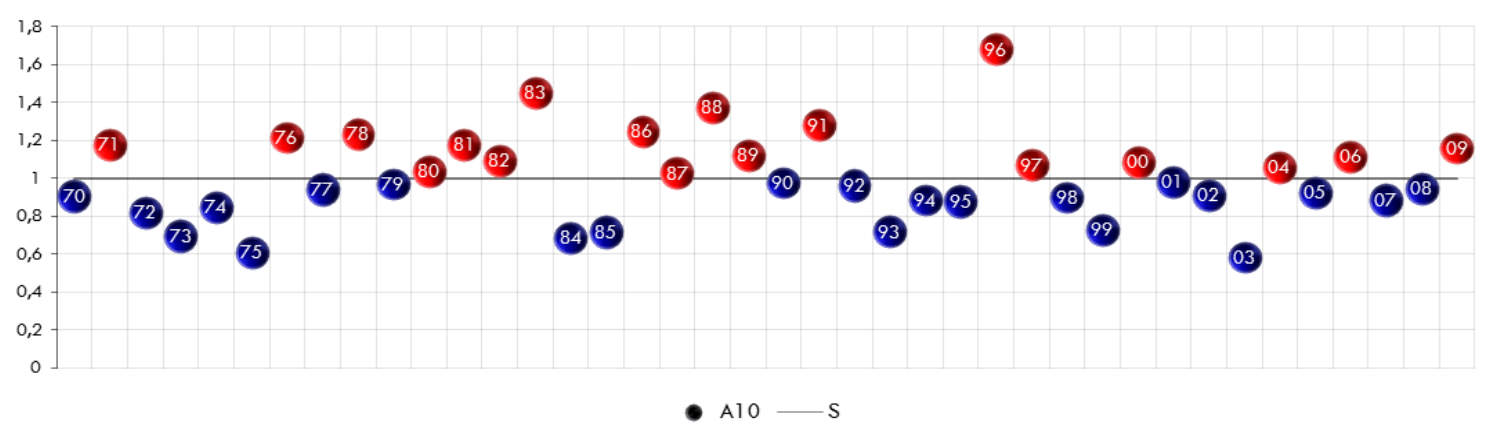

Figura 138 - Variação Cíclica Anual da Frequência de chuva A10 entre 1970 e 2009.

A partir dos resultados do teste de significância - t-"Student" - notamos que os resultados do cálculo de correlação linear, para as séries cíclicas, entre $\mathrm{ONI}$ e a frequência anual de chuva A10 não foram significativos (Tabela 53).

Tabela 53 - Correlação Linear entre a Anomalia de ONI e da Frequência Anual de chuva A10 entre 1970 e 2009, sem Tendência Linear (Série Cíclica).

$\begin{array}{lccccc}\text { A1 } & \text { CICLO "A* } & \text { CICLO "B" } & \text { CORRELAÇÄO CICUCA } & \text { TESTE T-STUDENT } \\ \text { A1 } & \text { A10 } & \text { B1 } & \text { ONI } & -0,002 & \text { NÃO SIGNIFICATIVO } \\ \text { A2 } & \text { A10 } & \text { B2 } & \text { NEUTRA } & -0,04 & \text { NÃO SIGNIFICATIVO } \\ \text { A3 } & \text { A10 } & \text { B3 } & \text { ENOS } & 0,159 & \text { NÃO SIGNIFICATIVO } \\ \text { A4 } & \text { A10 } & \text { B4 } & \text { EL NIÑO } & -0,043 & \text { NÃO SIGNIFICATIVO } \\ \text { A5 } & \text { A10 } & \text { B5 } & \text { LANINA } & 0,62 & \text { NÃO SIGNIFICATIVO }\end{array}$

\subsubsection{3- Análise Específica do Ciclo de Chuva - A10}

Os resultados de tal análise revelam as possíveis correlações existentes entre as fases altas e baixas da frequência de chuva A10 e do ONI. Neste caso, na Figura 139 identificamos a série específica através das fases altas $(\bar{x}>1)$ e baixas $(\bar{x}<1)$ da variação cíclica da frequência de chuva A10.

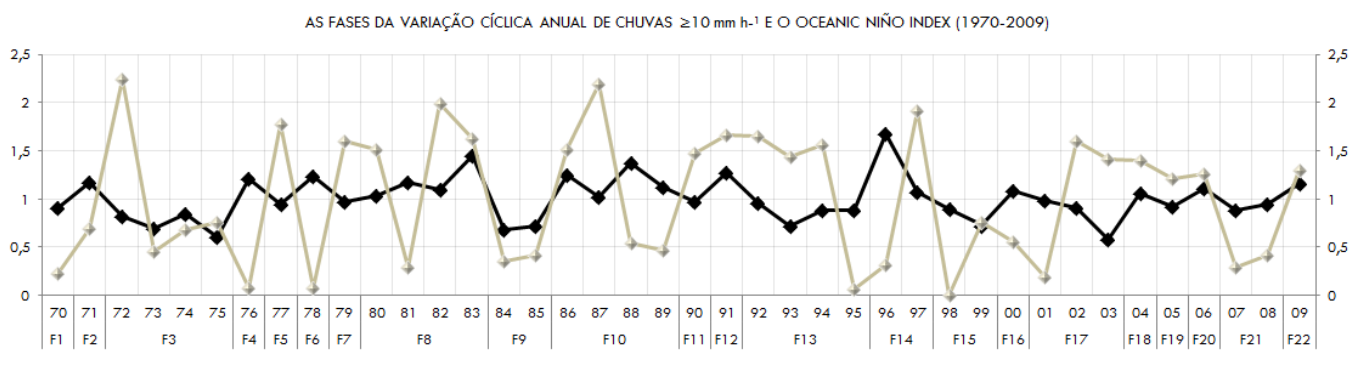

Figura 139 - Fases Específicas do Ciclo Anual de Chuva A10. A linha Branca corresponde à variação cíclica do ONI e a linha Preta de Chuva A10, para o Período de 1970-2009. 
A variação cíclica anual de chuva A10 no período de 1970 a 2009 foi composta por 22 fases específicas (altas e baixas). No entanto, a partir do resultado positivo da correlação linear entre a tendência positiva de chuva $\mathrm{A} 10$ e a tendência positiva da ONI, procuramos identificar as fases da oscilação que possivelmente estiveram associadas a tal comportamento. Neste caso, as fases altas estariam concomitantemente correlacionadas com a frequência de chuva A10 e o ONI. Neste caso, identificamos nos anos 91, 04, 06 e 09 as fases que estiveram positivamente e significativamente correlacionados. Tais fases refletem o resultado positivo relativo ao aumento das frequências de chuva Al0 em função do aquecimento na TSM, na região Niño3.4.

\subsubsection{4- A Hipótese Inicial e a Conclusão Final - A10 I}

A conclusão final para análise anual de chuva A10 parte das distintas correlações identificadas, para cada estação climática, envolvendo o ajuste linear dos índices do ONI na região Niño3.4 e a frequência de chuva A10. De modo geral, observamos que o ajuste linear positivo do ONI coincidiu positivamente com o ajuste de chuva A10. A exceção observada ocorreu na estação durante o EN, onde o ajuste linear positivo de chuva A10 não coincidiu positivamente com o ajuste linear do EN. A Tabela 54 apresenta os resultados das demais correlações realizadas para as séries temporais do ONI. Após identificarmos as respectivas correlações lineares anuais entre a chuva A10 e o ONI, analisamos os resultados das correlações cíclicas anuais e, notamos que não houve correlações significativas (Tabela 53).

Tabela 54 - Correlação Anual em Fases Específicas. A Coluna "A" indica ○ Ajuste Linear da Chuva A10 nas Séries Temporais "B" correspondente o ONI e suas Fases. A Última Coluna aponta os Possíveis Anos que estiveram Correlacionados com o Resultado da Correlação Linear do Ajuste "A" e "B".

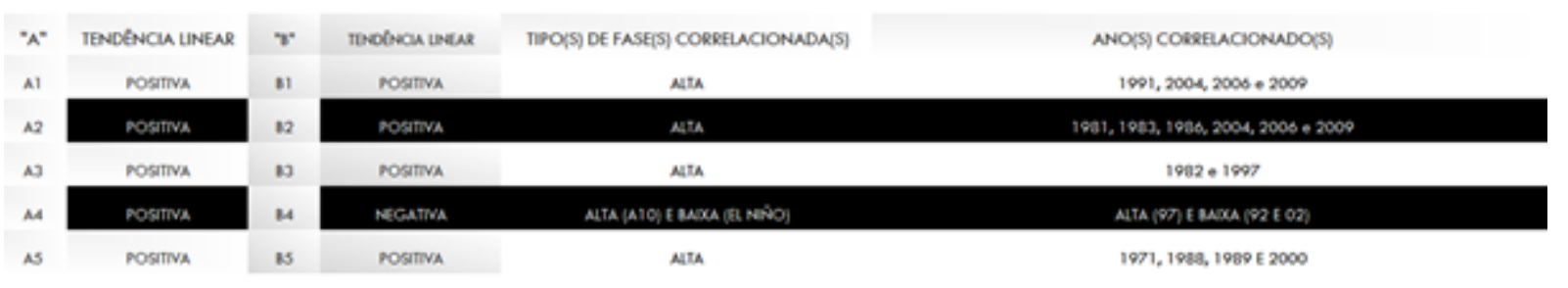




\subsection{2- Análise Trimestral}

A segunda análise envolve a relação trimestral entre a chuva A10 e o Oceanic Niño Index. Trata-se de uma análise individualizada, envolvendo os procedimentos elementares adotados, que foram aplicados para estações climáticas quentes, verão e primavera. Os resultados das frequências trimestrais de chuva $A 10\left(\geq 10 \mathrm{~mm} \mathrm{~h}^{-1}\right)$ podem ser observados a partir da Figura 140 e Tabela 55. Nas duas estações analisadas, verão e primavera, identificamos uma tendência linear positiva, de chuva A10, durante o período de 1970 a 2009 (Figura 141).
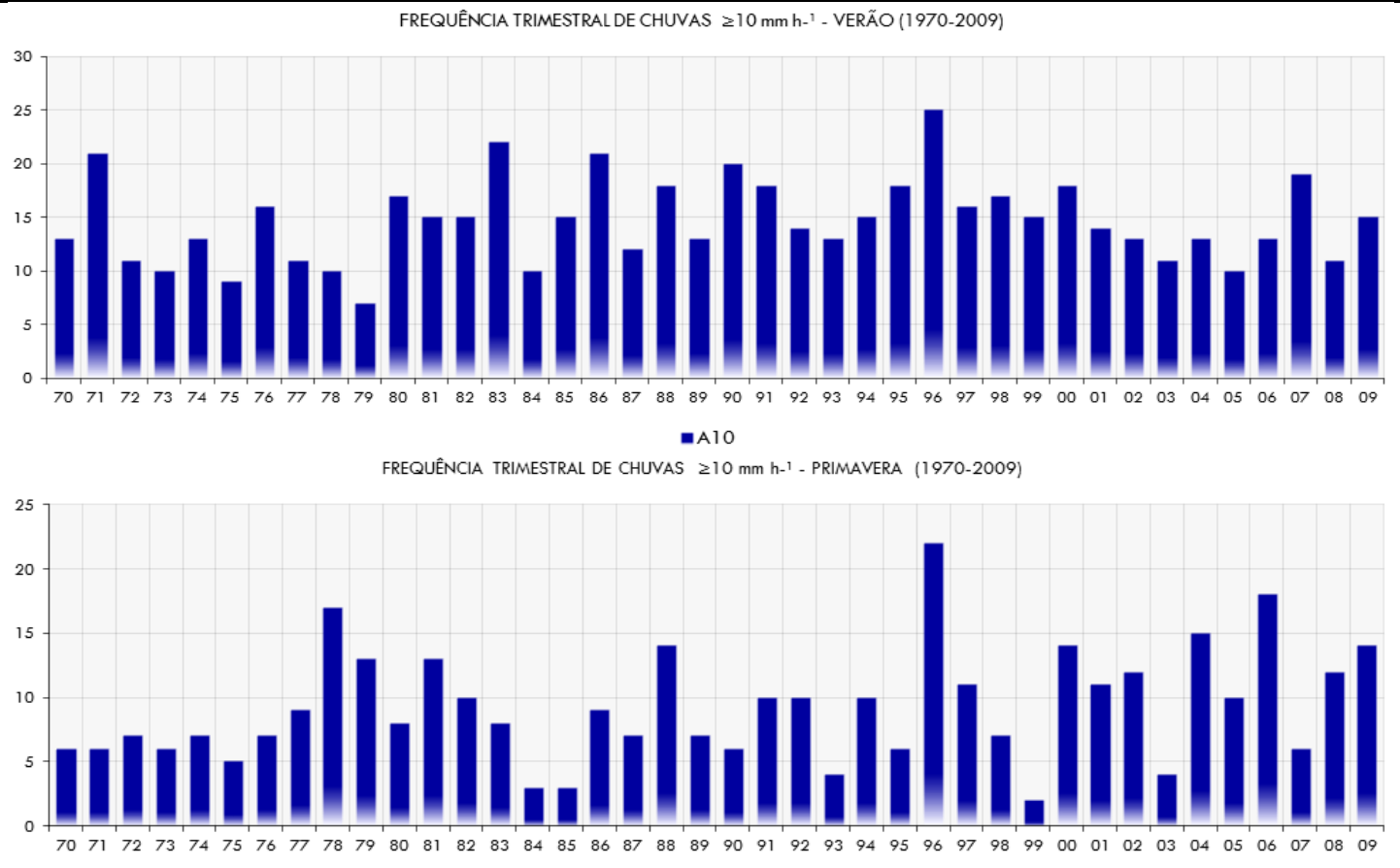

$=\mathrm{A} 10$

Figura 140 - Frequência Trimestral de chuva A10 na Estação do IAG-USP durante o Verão e Primavera para o Período de 1970 a 2009.

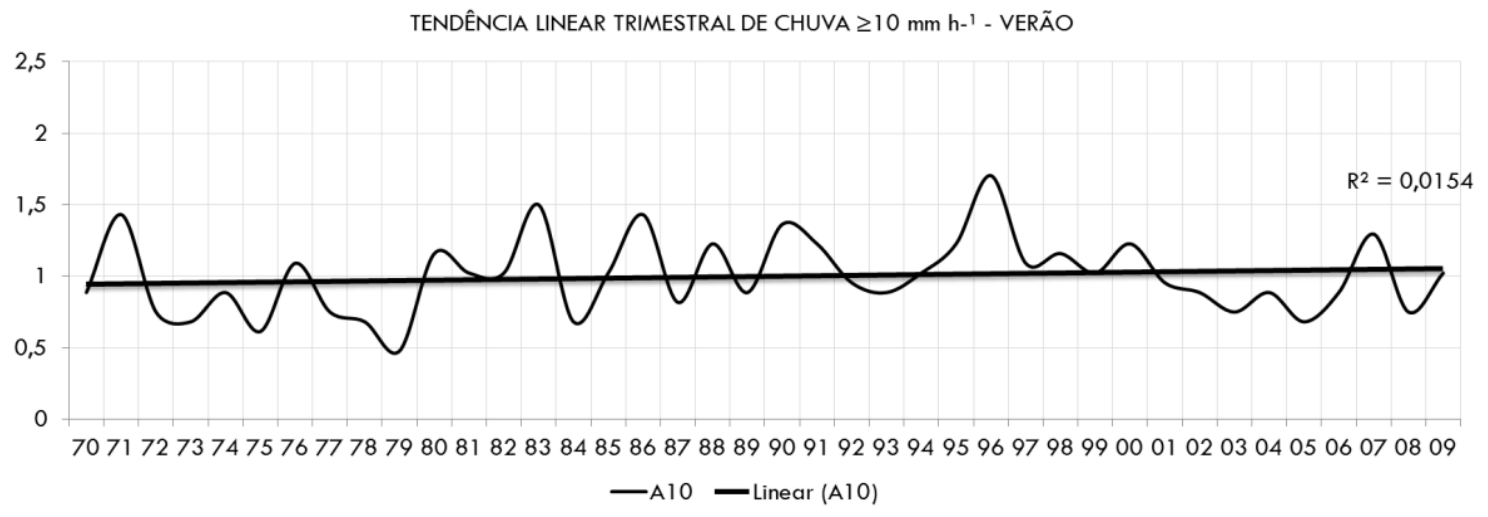




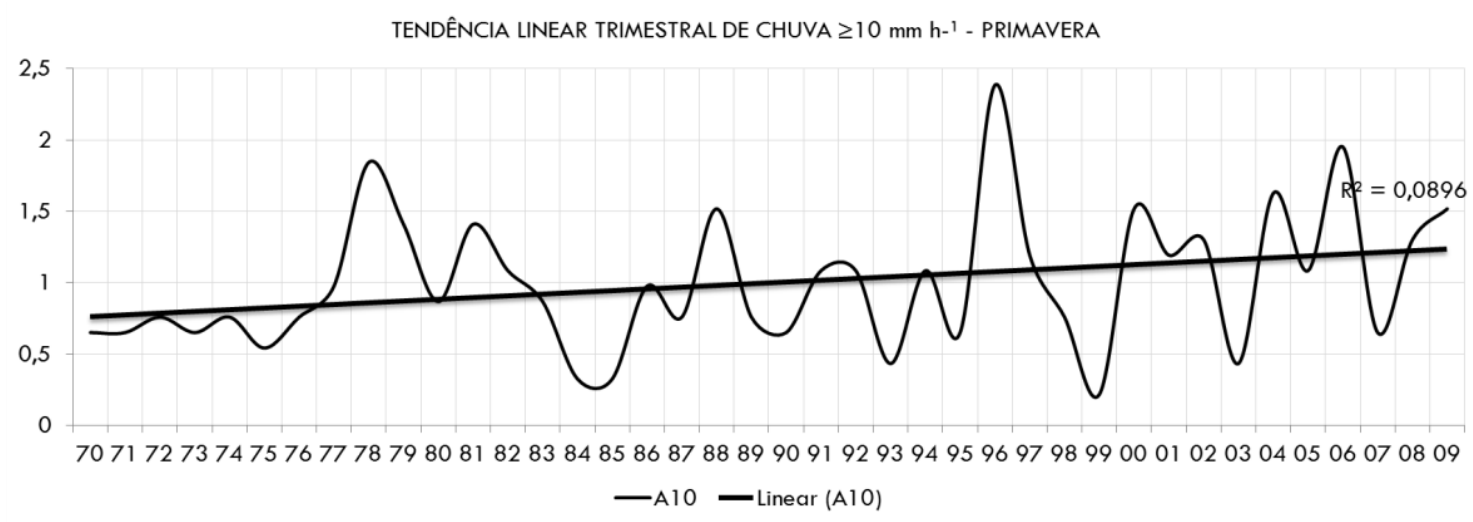

Figura 141 - Ajuste Linear Trimestral de chuva A10 para as Estações de Verão e Primavera, no Período de 1970 a 2009.

As fases do ONI apresentarm tendências lineares positivas, neste caso, analisamos os ajustes lineares mais significativos nas Figuras 142-145 e Tabela 55.

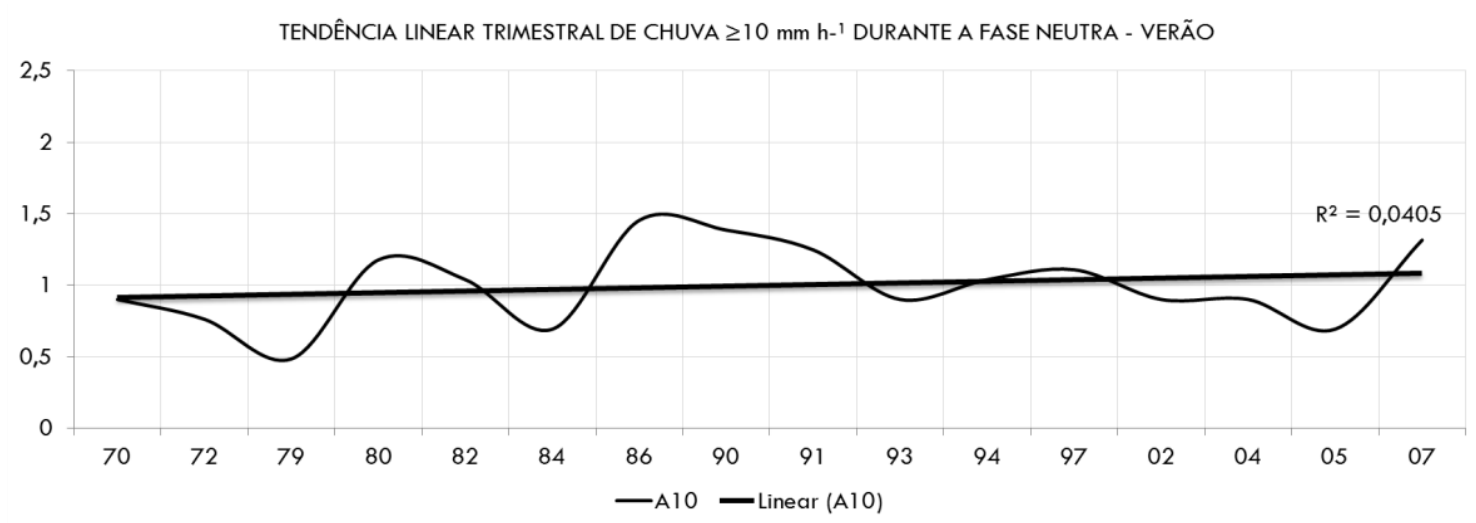

Figura 142 - Ajuste Linear Trimestral de chuva A10 para a Estação de Verão, durante a Fase Neutra.

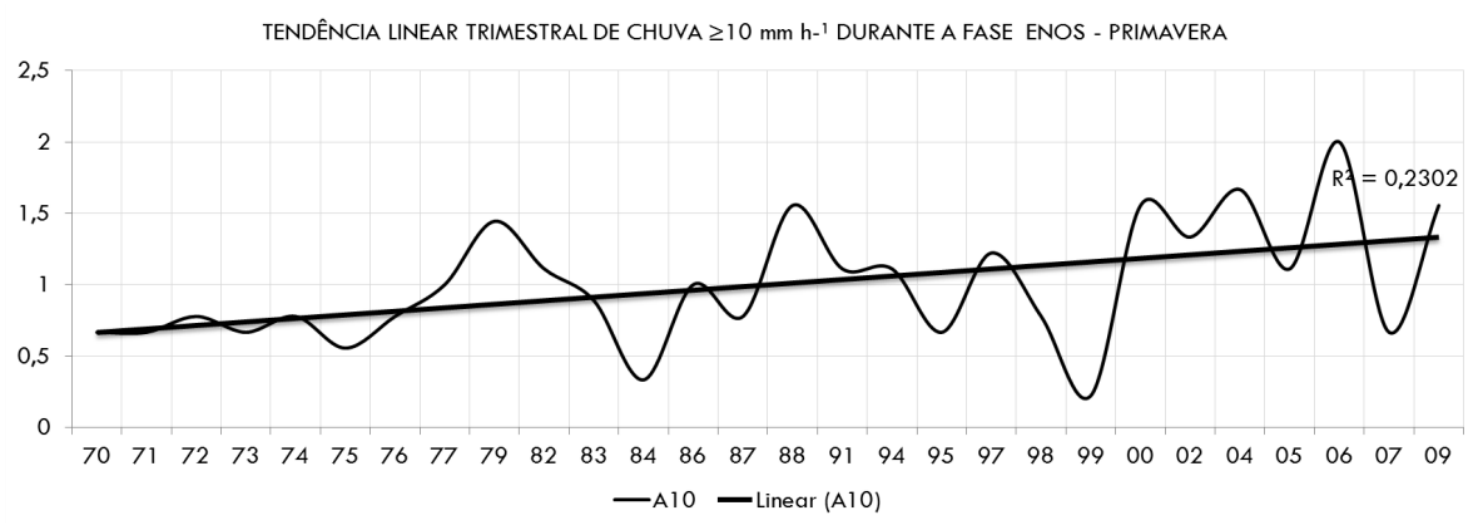

Figura 143 - Ajuste Linear Trimestral de chuva A10 para a Estação de Primavera, durante a Fase ENOS. 

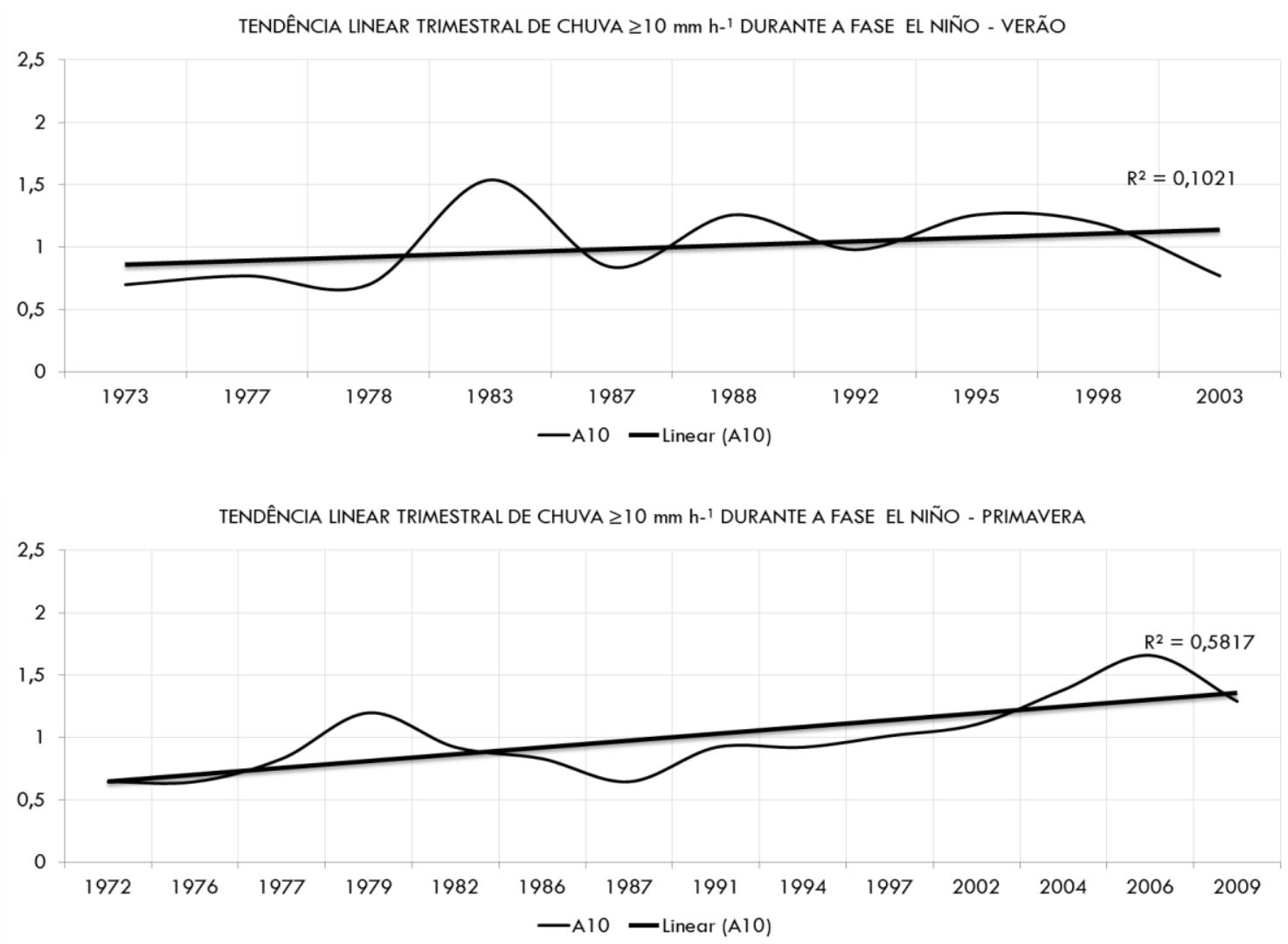

Figura 144 - Ajuste Linear Trimestral de chuva A10 para as Estações de Verão e Primavera, durante a Fase EN.

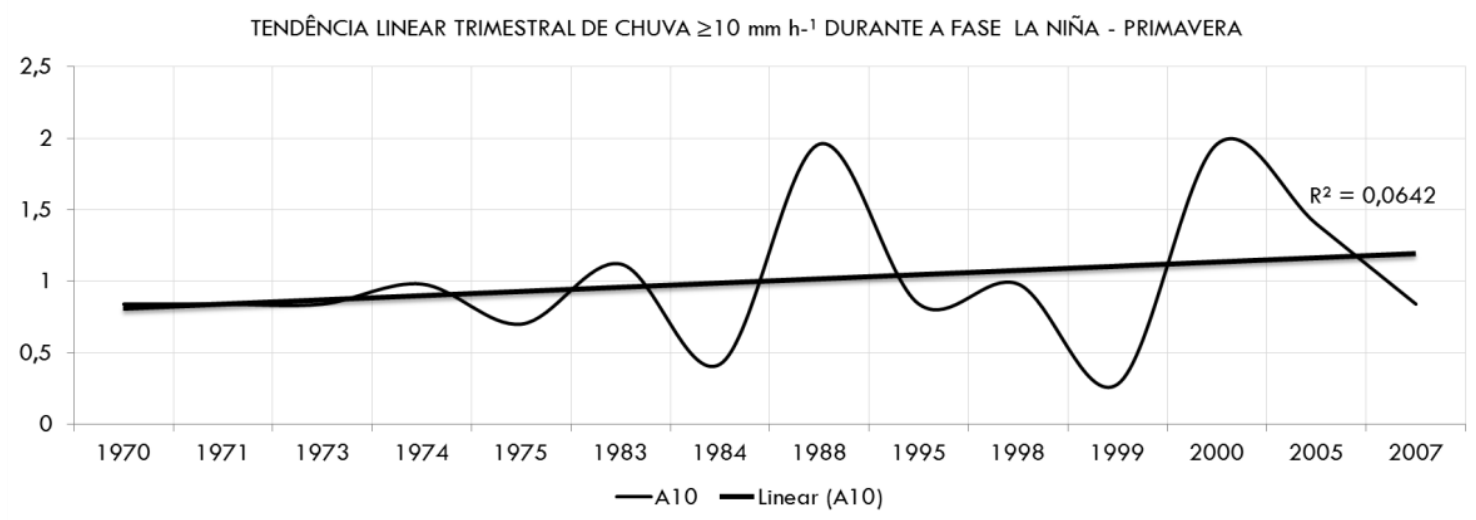

Figura 145 - Ajuste Linear Trimestral de chuva A10 para a Estação de Primavera, durante a Fase $\mathrm{LN}$.

Os resultados trimestrais por fases também coincidem com os resultados identificados no trabalho de Cabral (2002), Sugahara et al (2009) e Freitas et al (2013). Ou seja, mesmo me séries temporais específicas o padrão de aumento da frequência de chuvas mais intensas se manteve. 
Tabela 55 - Correlação Linear Trimestral entre a Tendência Linear Trimestral de Chuva A10 e a Tendência Linear Trimestral do ONI incluindo as Fases, Neutra, ENOS, EN e LN.

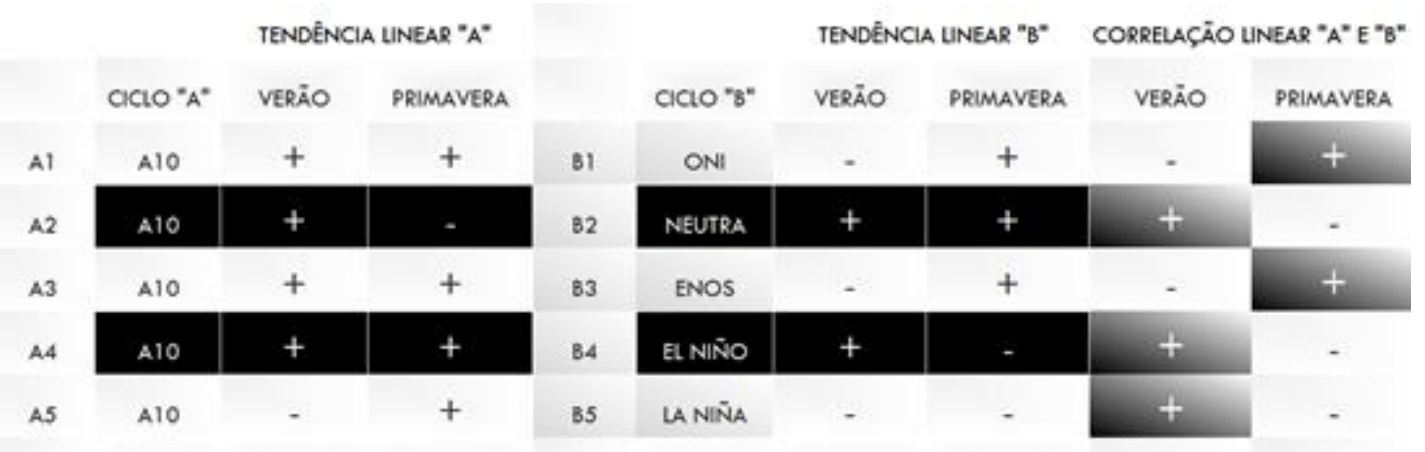

\subsubsection{1 - Variação Cíclica Trimestral de Chuva - A10}

A variação das anomalias da frequência de chuva A10 para o período de 1970 a 2009, para as quatro estações do ano está ilustrada na Figura 146.
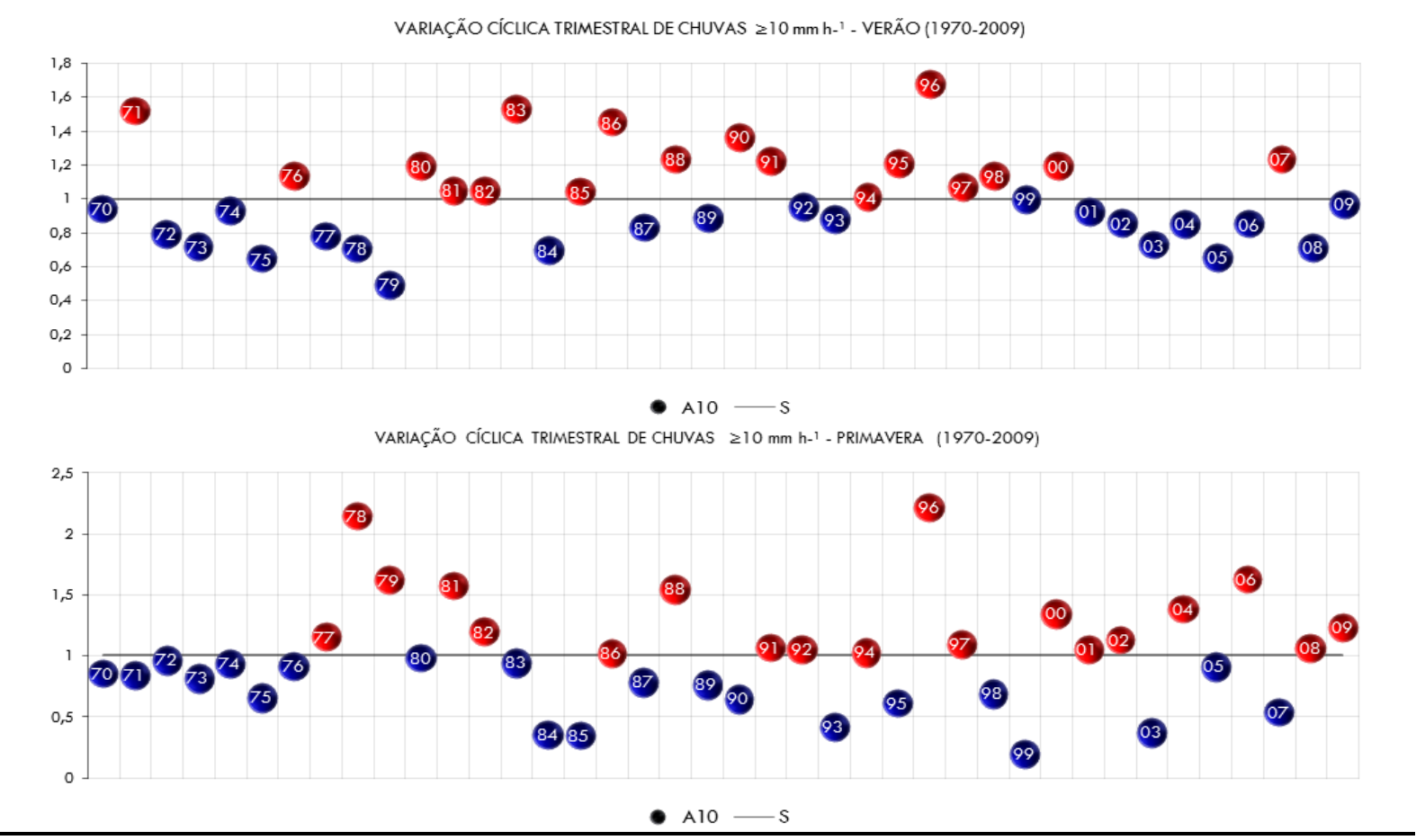

Figura 146 - Variação Cíclica Trimestral de Chuva A10, entre 1970 e 2009.

De forma geral, separando a série temporal em estações do ano, observamos que não há correlação linear significativa entre as séries de ONI e frequência de chuva A10. Por outro lado, a separação das séries temporais em eventos distintos quanto à TSM na região do 
Niño3.4 permitiu verificar que durante a primavera, na fase ENOS, a correlação linear entre estas duas variáveis foi positiva e significativa $(r=0,4)$, Figura 147. Todos os demais resultados podem ser observados a partir da Tabela 56.

Tabela 56 - Correlação Cíclica entre a Frequência de Chuva A20 observada na Estação do IAG e os Valores de ONI para Cada Estação do Ano e, para Cada Condição de Anomalia na Região de Niño3.4 (Eventos Neutros, ENOS, EN e LN).

\begin{tabular}{|c|c|c|c|c|c|c|c|}
\hline VERÃO & PRUMAVERA & VERĀO & PRLMAVERA & VERĀO & PRIMAVERA & VERĀO & PRIMAVERA \\
\hline A1 & AI & ONI & ONat & 0,025 & 0,004 & NäO SIGAaficativo & NR̈́ STCAEICATIVO \\
\hline$\wedge 2$ & 12 & NEUTRO & NeUtro & 0,014 & $-0,400$ & NG̈O sigraficatrvo & Nǘ signeracativo \\
\hline$A 3$ & $A 3$ & ENCS & enos & 0,004 & 0,4 & NÄO SIGEAFCATIVO & SIGNAFICATVO \\
\hline M & M & E NINOO & A NIÑO & 0,442 & 0,958 & Nüo sicreficalivo & Nǘ SUCNEACATIVO \\
\hline As & As & UANIRU & UNIRA & 0,023 & $-0,013$ & N"̈o sigraficatrvo & N"̈́ SicheICATIVO \\
\hline
\end{tabular}

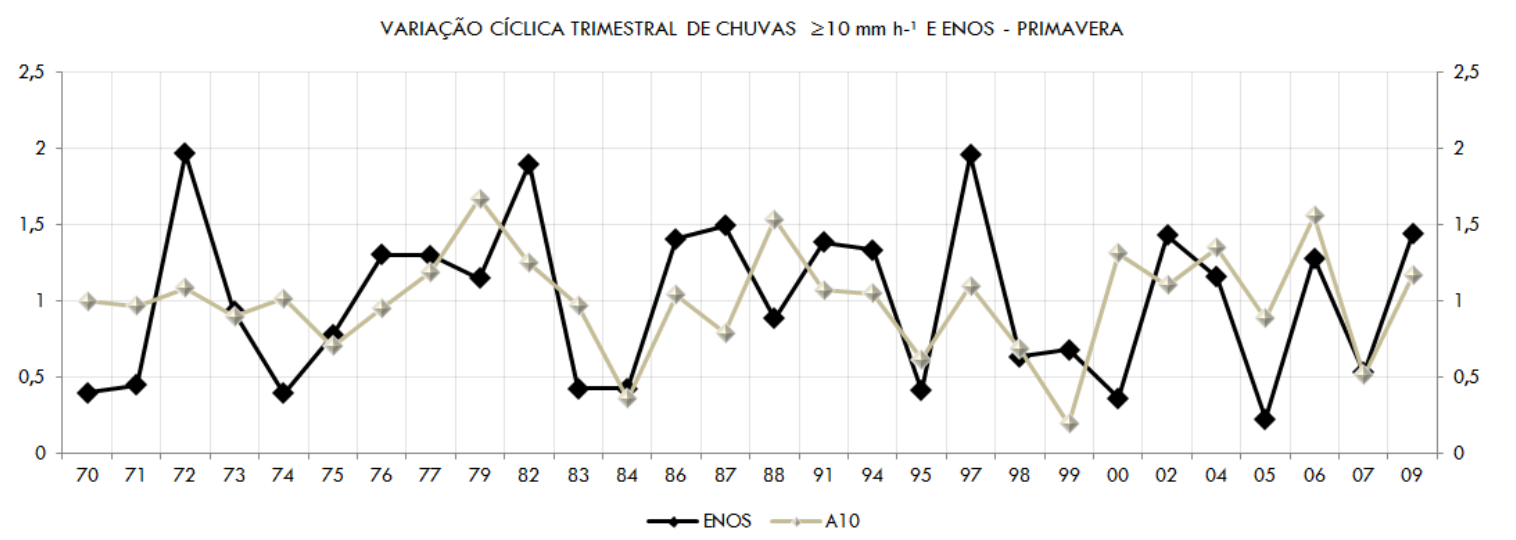

Figura 147 - Variação Cíclica de Chuva A10, na Primavera, durante a Fase ENOS.

\subsubsection{2- Análise Específica das Fases Trimestrais}

Os resultados de tal análise revelam as possíveis correlações existentes entre as fases altas e baixas da frequência de Chuva A10 e do ONI. Neste caso, identificamos à série específica através das fases altas $(\bar{x}>1)$ e baixas $(\bar{x}<1)$ da variação cíclica da frequência trimestral de chuva A10. A variação cíclica de chuva A10 no período de 1970 a 2009 durante a estação de verão foi composta por 19 fases específicas. A partir do resultado negativo da correlação linear entre a tendência positiva de chuva Alo e a tendência negativa do ONI, procuramos identificar as fases da oscilação que possivelmente estiveram associadas a tal comportamento. Neste caso, as fases altas estariam correlacionadas com a 
chuva A10 e, as fases baixas correlacionadas com ○ ONI (Figura 148). Em função dessa probabilidade, identificamos nos anos $80,81,82,83,88$ e 07 as fases altas que estariam significativamente e positivamente correlacionadas com a chuva A10. Por outro lado, identificamos nos anos $77,78,79,84,89,92,93$ e 99 as fases baixas que estariam significativamente e positivamente correlacionadas com o ONI (Tabela 57). A variação cíclica de chuva A10 no período de 1970 a 2009 durante a estação da primavera foi composta por 22 fases específicas. A partir do resultado positivo da correlação linear entre a tendência positiva de chuva $\mathrm{A} 10$ e a tendência positiva do ONI, procuramos identificar as fases da oscilação que possivelmente estiveram associadas a tal comportamento. Neste caso, deduzimos que somente as fases altas estariam correlacionadas (Figura 148). Em função dessa probabilidade, identificamos nos anos $86,88,91,92,94,04,06,08$ e 09 as fases altas que estiveram significativamente e positivamente correlacionadas com a correlação positiva encontrada entre a chuva A10 e o ONI (Tabela 57).
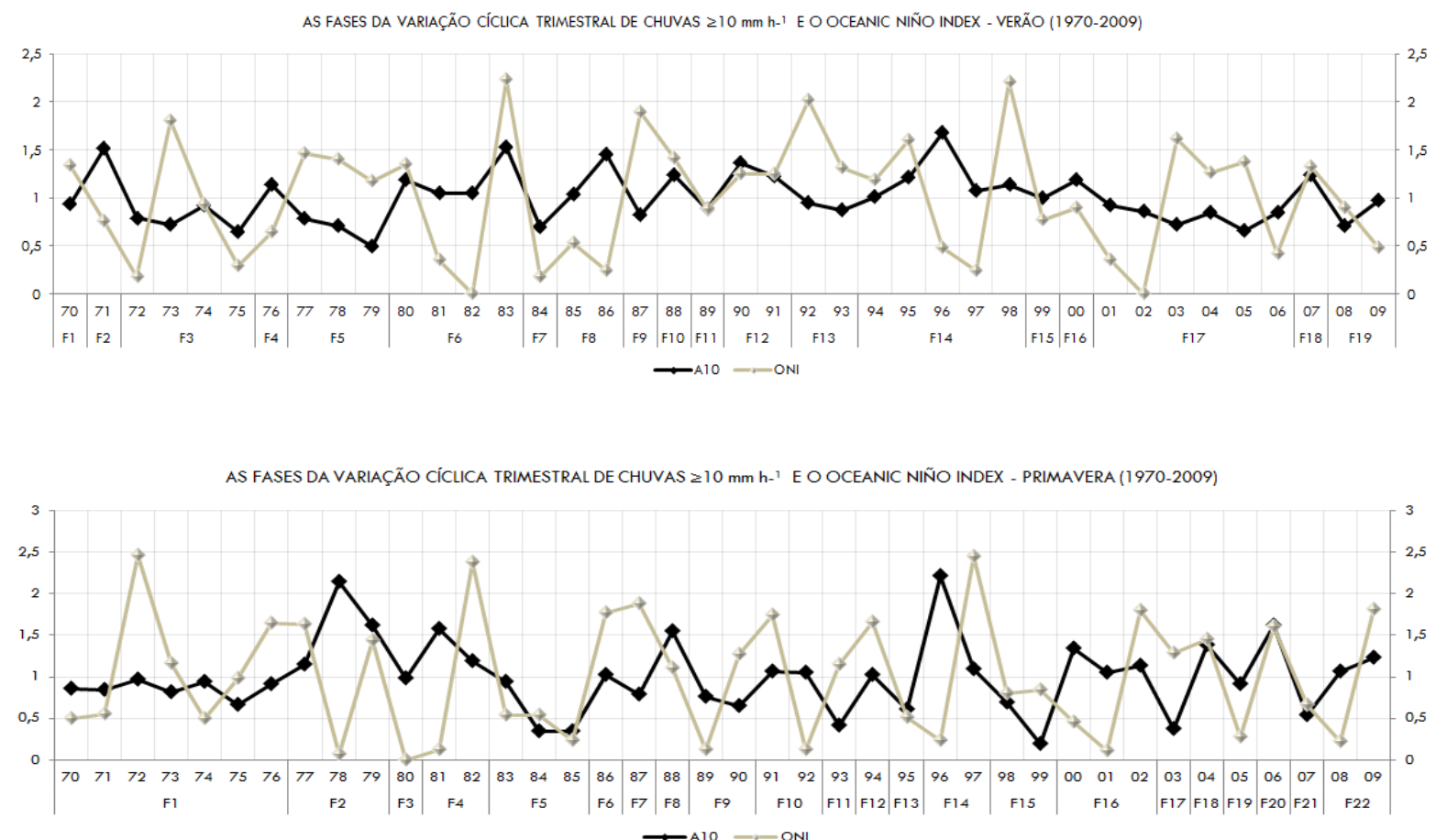

Figura 148 - Fases Específicas do Ciclo Trimestral de Chuva A10, Verão e Primavera. A linha Branca corresponde à variação cíclica do ONI e a linha Preta de Chuva A10, para o Período de 1970-2009. 
Tabela 57 - Correlação Linear entre a Frequência de Chuva A10 observada na Estação do IAG e os Valores de ONI para Cada Estação do Ano e, para Cada Condição de Anomalia na Região de Niño3.4 (Eventos Neutros, ENOS, EN e LN). "A" representa as Séries Temporais de Chuva A10 relativa às Séries Temporais do ONI "B". Assim, B1 (ONI), B2 (Neutro), B3 (ENOS), B4 (EN) e B5 (LN). Correlação "A" são os Tipos Fases Correlacionadas com a Chuva A10 e Correlação "B" são os Tipos Fases Correlacionadas com o ONI.

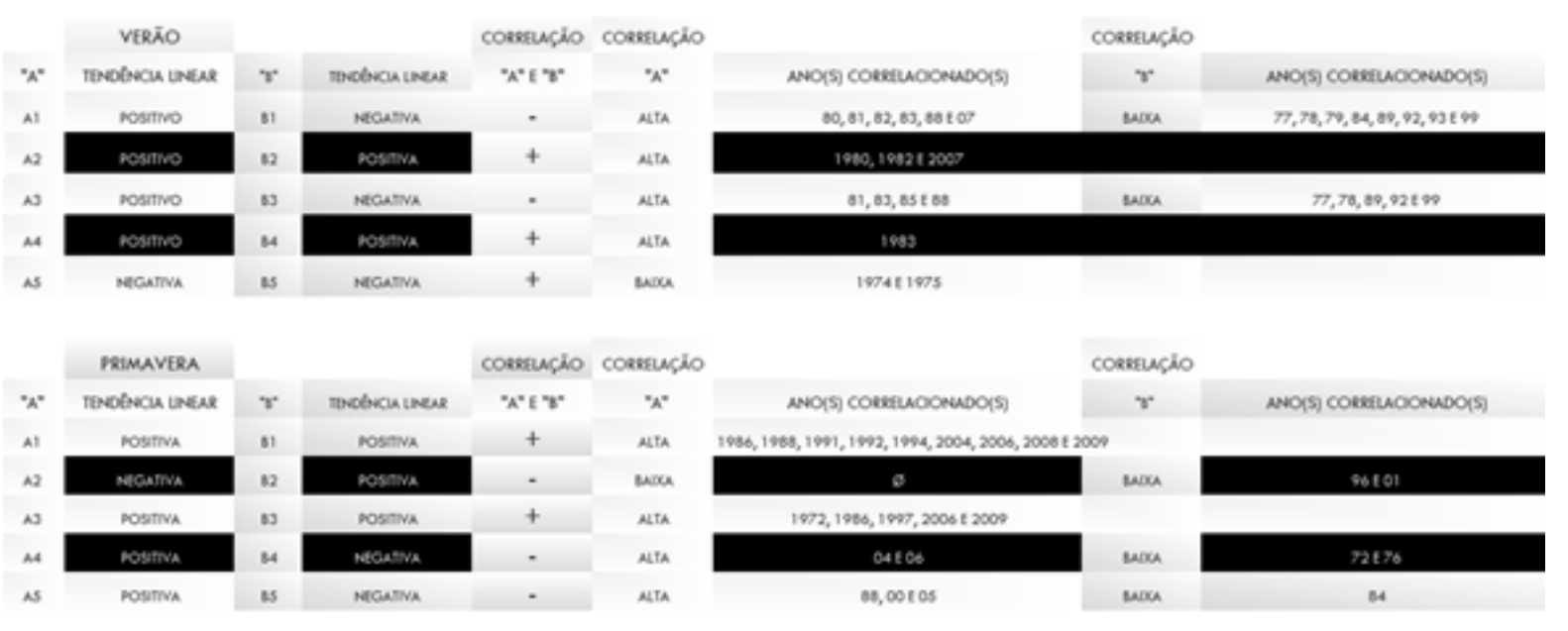

\subsubsection{3- A Hipótese Inicial e a Conclusão Final - A10 II}

A conclusão final para análise trimestral de chuva A10 parte das distintas correlações identificadas, para cada estação climática, envolvendo o ajuste linear dos índices do ONI na região Niño3.4 e a frequência de chuva A10. No verão, observamos que o ajuste linear negativo do ONI não coincidiu positivamente com o ajuste linear de chuva $\mathrm{A} 10$. Na primavera, observamos que $\circ$ ajuste linear positivo do $\mathrm{ONI}$ coincidiu positivamente com $\circ$ ajuste linear de chuva A10. A Tabela 57 apresenta os resultados das demais correlações realizadas para as séries temporais do ONI em cada estação climática do ano. Após identificarmos as respectivas correlações lineares trimestrais entre a chuva A10 e o ONI, analisamos os resultados das correlações cíclicas trimestrais. Neste caso, encontramos apenas uma correlação cíclica significativa (Tabela 56). A única correlação significativa foi identificada na primavera, durante a fase ENOS.

A partir da combinação dos resultados observados durante a série temporal da fase ENOS, na estação de primavera, onde identificamos uma correlação positiva envolvendo ajustes lineares positivos e uma correlação cíclica significativa, analisamos por dedução e 
correlação que seja muito provável que tenha ocorrido uma intensificação das variações cíclicas de chuva A10 em função do aumento das amplitudes dos seus ciclos ao longo do período da fase ENOS. Neste caso, é possível identificar consonância com a expectativa de Grimm et al (1999), ou seja, nota-se a influência de padrões de macroescala alterando a frequência de circulação, que neste caso aumentou intensificando a frequência de chuva.

\section{9- Amostra de Chuva $\geq 20 \mathrm{~mm} \mathrm{~h}-1^{1}$}

A amostra de chuva $\geq 20 \mathrm{~mm} \mathrm{~h}^{-1}$ é formada por chuvas que atingem níveis pluviométricos maiores e iguais a 20 milímetros no intervalo de uma hora. A partir da hipótese inicial deste estudo, a intenção ao analisar uma determinada amostra, é a de concluir para a série temporal de 1970-2009, a existência ou não de um nível de correlação aceitável, envolvendo classes estatísticas mais representativas, com a intenção de avaliar o nível de explicação para o comportamento de sua frequência, em função das variações registradas na temperatura da superfície do mar na região Niño 3.4. A amostra de chuva $\geq 20 \mathrm{~mm} \mathrm{~h}^{-1}$ é identificada pela sigla "A20".

\subsection{1 - Análise Anual}

A análise anual possui a finalidade de apresentar uma conclusão obtida a partir da identificação do tipo de correlação existente na intenção de sugerir a possibilidade de haver uma relação anual envolvendo a chuva A20 e o Oceanic Niño Index. A partir dos dados da estação do IAG-USP, calculamos a frequência anual de chuva A20 ( $\geq 20 \mathrm{~mm} \mathrm{h-1}$ ), representada no gráfico da Figura 149, onde identificamos a frequência máxima nos anos de 1991 e 1996 através da contagem de 17 casos horários. 
FREQUÊNCIA ANUAL DE CHUVAS $\geq 20 \mathrm{~mm} \mathrm{~h}^{-1}(1970-2009)$

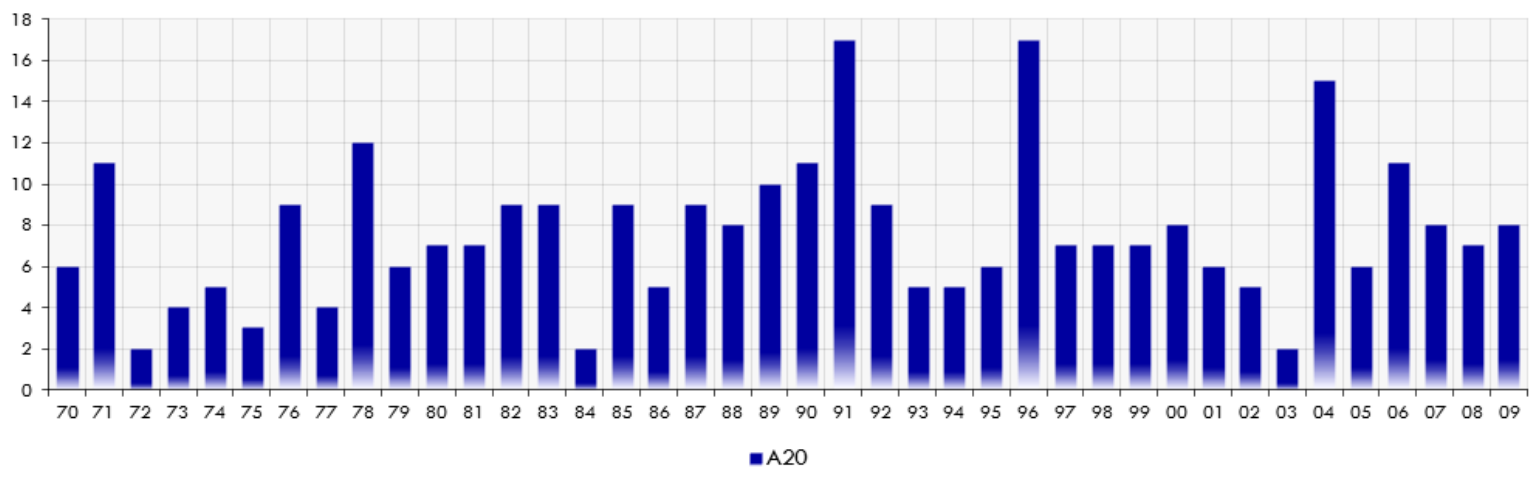

Figura 149 - Frequência Anual de Chuva $\geq 20 \mathrm{~mm} \mathrm{~h}^{-1}$ entre 1970-2009.

\subsubsection{1 - Análise do Ajuste Linear}

O ajuste linear da frequência anual de chuva A20 no município de São Paulo indica aumento desta frequência ao longo da série temporal analisada, de 1970 a 2009, tal como ilustrada na Figura 150. A análise realizada para as fases, neutra, ENOS, El Niño e La Niña, separadamente, mostra que, em todos os casos, a frequência anual de chuva A20 aumenta com o tempo (Figura 151). A comparação entre a tendência linear da frequência de chuva A20 e do ONI indica que enquanto o ONI assume valores cada vez mais intensos, no decorrer da série temporal, a frequência de chuva A20 aumenta, tal como indicado na Tabela 58. A exceção ocorre no caso de eventos de EN que apresenta tendência negativa nula de TSM, ao longo do período analisado que diverge com a tendência positiva de frequência de chuva A20 (ver tabela 58, linha 4).

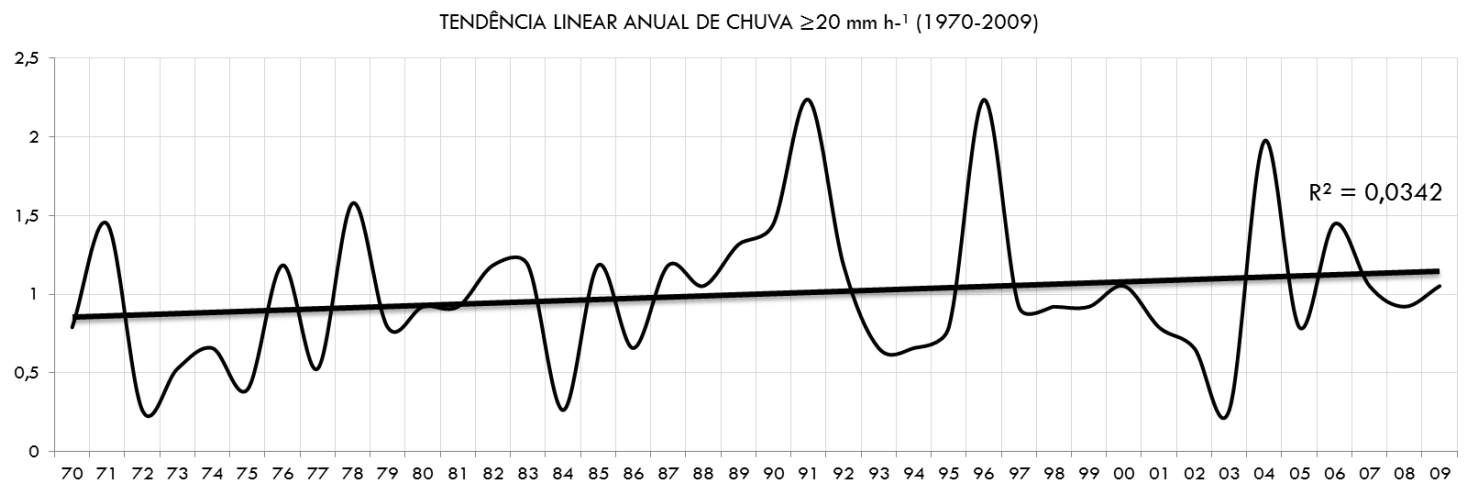

Tabela 150 - Ajuste Linear Anual de Chuva $\geq 20 \mathrm{~mm} \mathrm{~h}^{-1}$. 
TENDÊNCIA LINEAR ANUAL DE CHUVA $\geq 20 \mathrm{~mm} \mathrm{h-1} \mathrm{DURANTE} \mathrm{A} \mathrm{FASE} \mathrm{NEUTRA}$

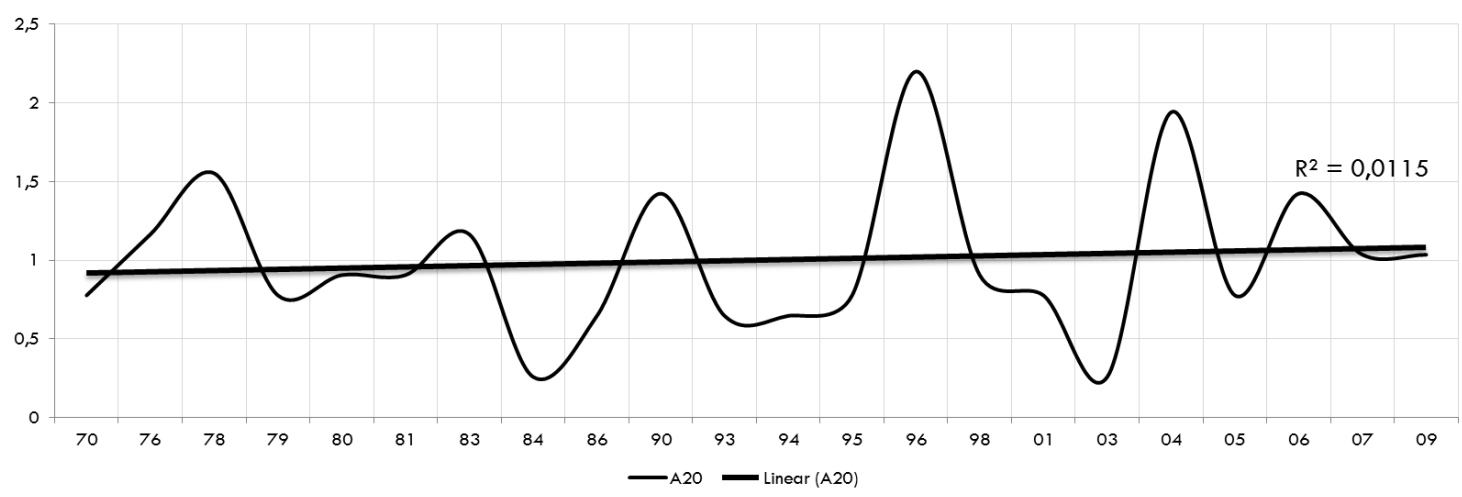

TENDÊNCIA LINEAR ANUAL DE CHUVA $\geq 20 \mathrm{~mm} \mathrm{h-1}$ DURANTE A FASE ENOS

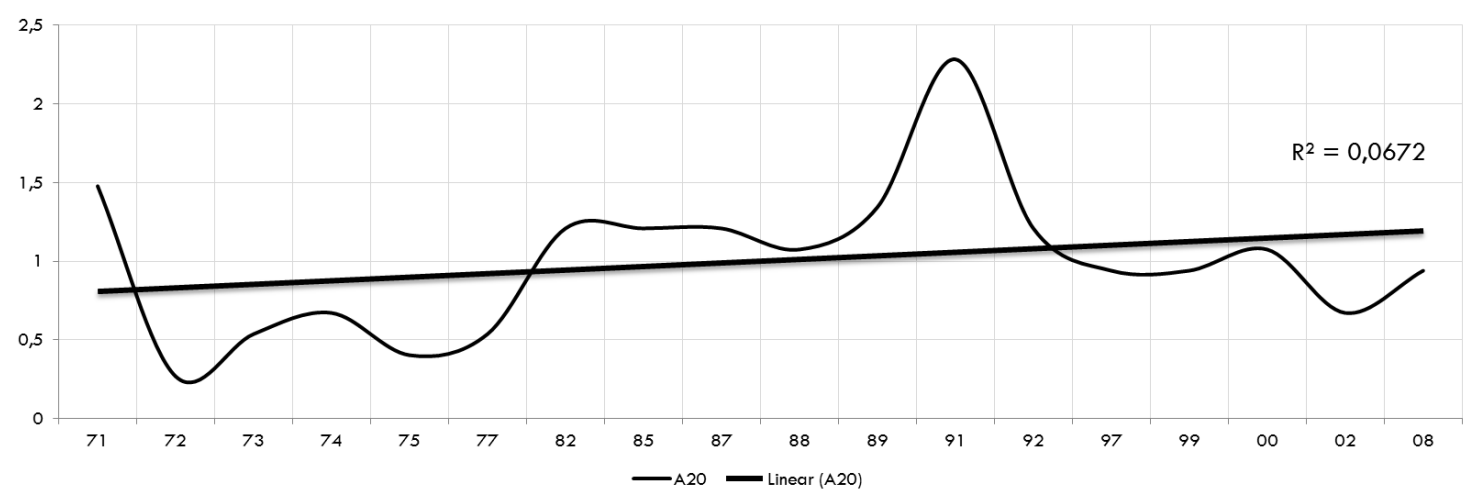

TENDÊNCIA LINEAR ANUAL DE CHUVA $\geq 20 \mathrm{~mm} \mathrm{~h}^{-1}$ DURANTE A FASE EL NIÑO

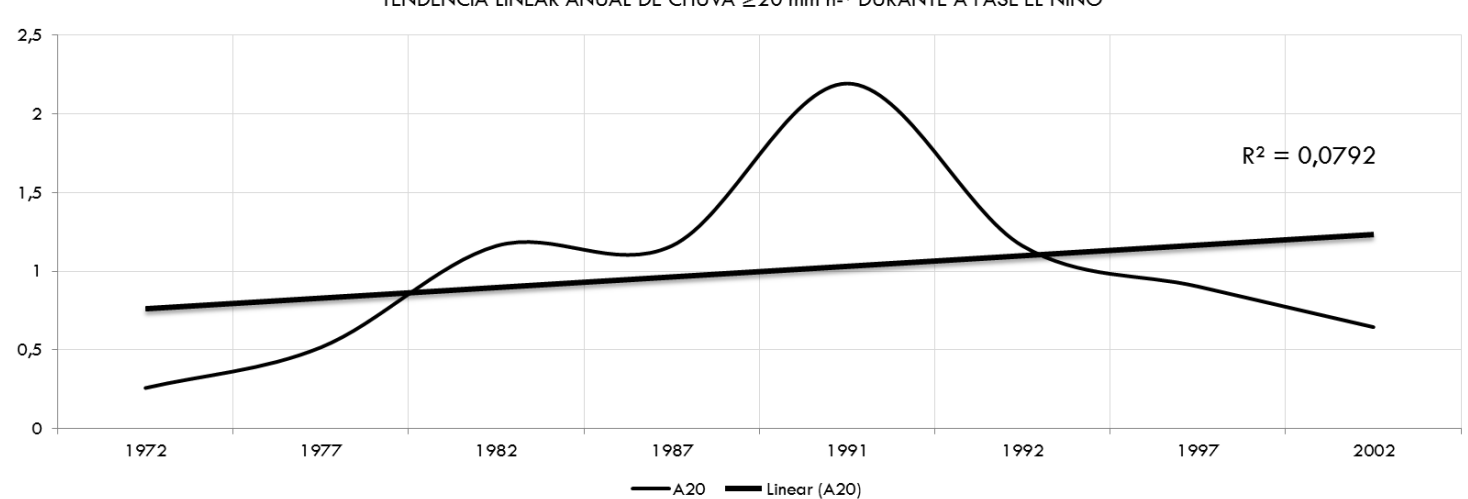

TENDÊNCIA LINEAR ANUAL DE CHUVA $\geq 20 \mathrm{~mm} \mathrm{h-1}$ DURANTE A FASE LA NIÑA

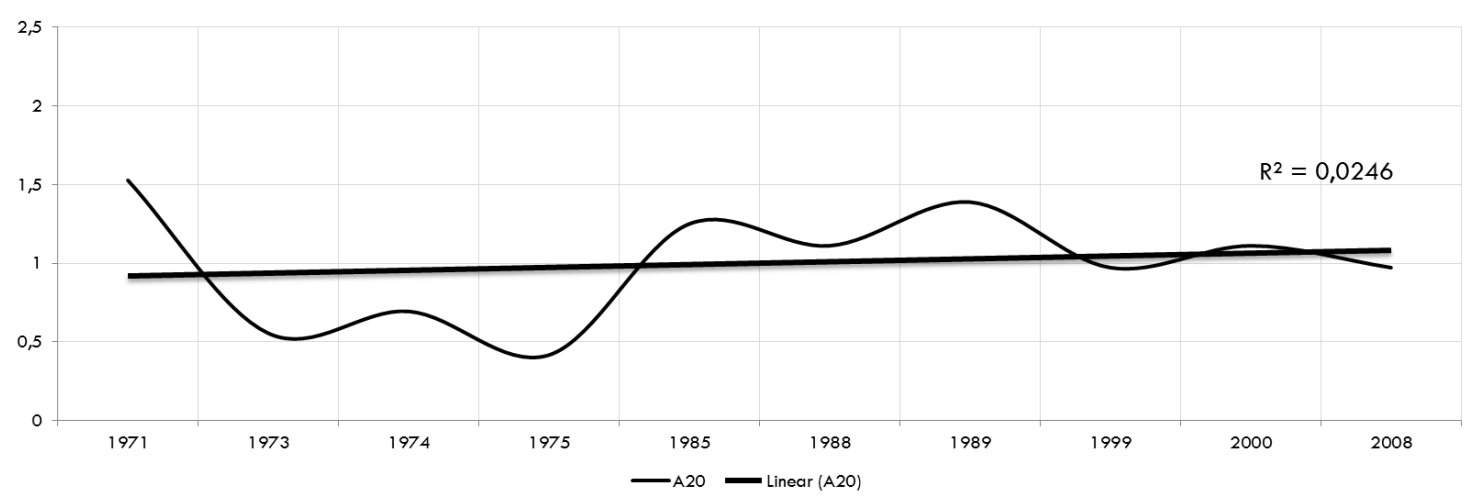

Figura 151 - Tendência Linear da Frequência Anual de Chuva $\geq 20 \mathrm{~mm} \mathrm{~h}^{-1}$ para a Fase, Neutra, ENOS, EN e LN, entre 1970-2009. 
Os resultados observados através dos ajustes lineares positivos para a série anual revelam que as frequências analisadas no intervalo horário refletiram positivamente com os resultados obtidos das análises diárias realizadas por Cabral (2002), Sugahara et al (2009) e Freitas et al (2013).

Tabela 58 - Tendência Linear Anual de Chuva A20 e do ONI para o Período de 1970 a 2009. A Primeira Linha da Tabela indica a Tendência Linear de Todos os Dados Anuais e, as Demais Linhas indicam a Tendência Linear para cada Fase do ONI.

\begin{tabular}{|c|c|c|c|c|c|c|}
\hline$x^{*}$ & MPO DE CHUVA & TENDENCLA UNEAR & $\boldsymbol{*}$ & CAttgons & TENDENNCIA UINEAR & CORRELAÇĀO UNEAR \\
\hline A1 & $\wedge 20$ & POSITIVA & B1 & Cond & POSITIVA & POSITIVA \\
\hline 12 & $\wedge 20$ & POSIITIA & 12 & Neutno & posinva & POSITIVA \\
\hline A & $\wedge 20$ & POSITIVA & B3 & ENOS & POSITIVA & POSITIVA \\
\hline M & $\wedge 20$ & positrva & BA & E1 NENO & NEOAIIVA & NEGATIVA \\
\hline as & $\wedge 20$ & POSITIVA & as & UNIRA & POSITIVA & POSITIVA \\
\hline
\end{tabular}

\subsubsection{2- Variação Cíclica da Amostra A20}

A variação cíclica anual de chuva A20 pode ser observada na Figura 152. É possível notarmos a oscilção presente na série temporal completa, de 1970 a 2009, formada por 15 fases altas (esferas vermelhas) e 25 fases baixas (esferas azuis).

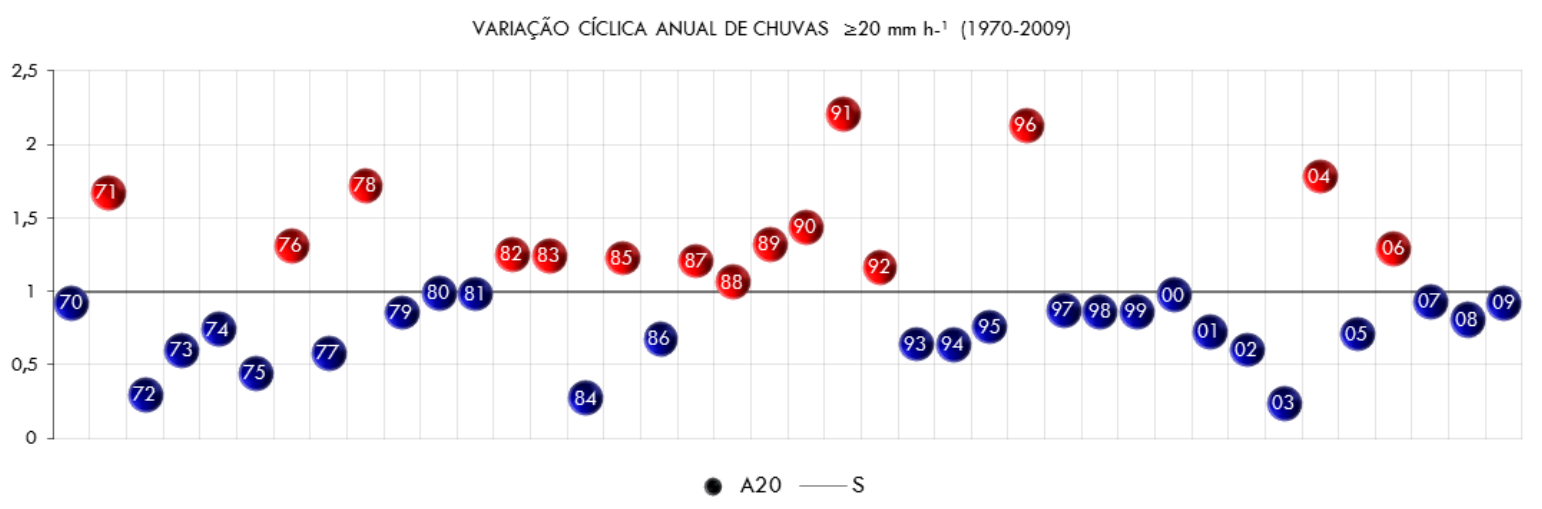

Figura 152 - Variação Cíclica Anual da Frequência de chuva A20 entre 1970 e 2009.

A partir dos resultados do teste de significância - t-"Student" - notamos que os resultados do cálculo de correlação linear, para as séries cíclicas, entre $\mathrm{ONI}$ e a frequência anual de chuva A20 não foram significativos (Tabela 59). 
Tabela 59 - Correlação Linear entre a Anomalia de ONI e da Frequência Anual de chuva A20 entre 1970 e 2009, sem Tendência Linear (Série Cíclica).

\begin{tabular}{|c|c|c|c|c|c|}
\hline & CICLO "A" & & CACLO "B" & CORRELAÇĀO CICLICA & TESTE T-STUDENT \\
\hline Al & A20 & B1 & ONI & $-0,074$ & NÄO SIGNIFICATIVO \\
\hline A2 & A20 & B2 & NEUTRA & $-0,121$ & NÃO SIGNIFICATIVO \\
\hline A3 & A20 & B3 & ENOS & $-0,01$ & NÃO SIGNIFICATIVO \\
\hline A4 & A20 & B4 & EL NIÑO & $-0,114$ & NÄO SIGNIFICATIVO \\
\hline A5 & A20 & B5 & LANINA & 0,464 & NÃO SIGNIFICATIVO \\
\hline
\end{tabular}

\subsubsection{3- Análise Específica do Ciclo de Chuva - A20}

Os resultados de tal análise revelam as possíveis correlações existentes entre as fases altas e baixas da frequência de chuva A20 e do ONI. Neste caso, na Figura 153 identificamos a série específica através das fases altas $(\bar{x}>1)$ e baixas $(\bar{x}<1)$ da variação cíclica da frequência de chuva A20.

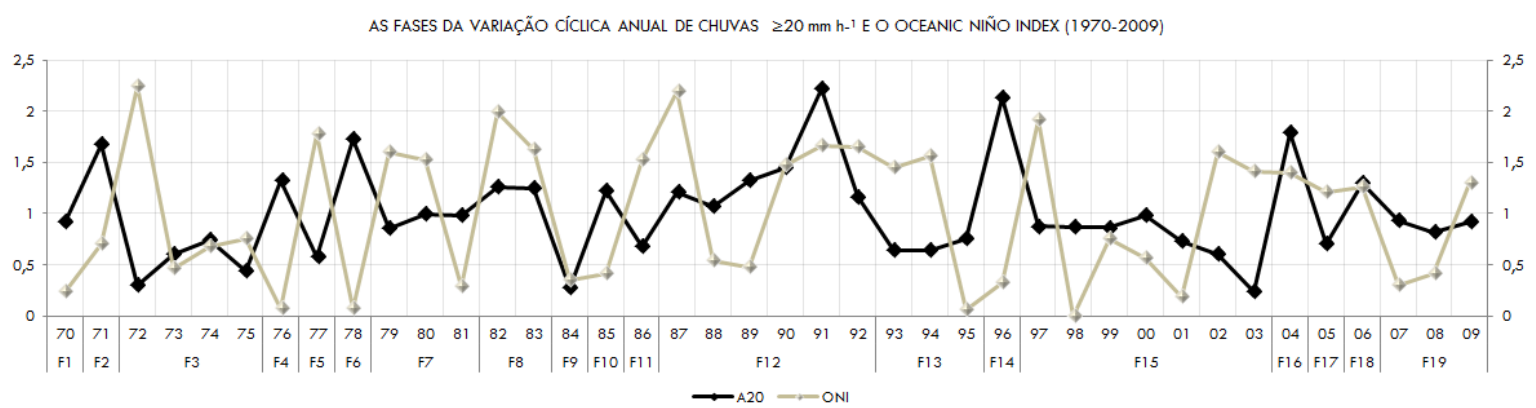

Figura 153 - Fases Específicas do Ciclo Anual de Chuva A20. A linha Branca corresponde à variação cíclica do ONI e a linha Preta de Chuva A20, para o Período de 1970-2009.

A variação cíclica anual de chuva A20 no período de 1970 a 2009 foi composta por 19 fases específicas (altas e baixas). No entanto, a partir do resultado positivo da correlação linear entre a tendência positiva de chuva $\mathrm{A} 20$ e a tendência positiva da $\mathrm{ONI}$, procuramos identificar as fases da oscilação que possivelmente estiveram associadas a tal comportamento. Neste caso, as fases altas estariam concomitantemente correlacionadas com a frequência de chuva A20 e o ONI. Neste caso, identificamos nos anos 82, 83, 04 e 06 as fases que estiveram positivamente e significativamente correlacionados. Tais fases refletem o resultado 
positivo relativo ao aumento das frequências de chuva $A 20$ em função do aquecimento na TSM, na região Niño3.4.

\subsubsection{4- A Hipótese Inicial e a Conclusão Final - A20 I}

A conclusão final para análise anual de chuva A20 parte das distintas correlações identificadas, para cada estação climática, envolvendo o ajuste linear dos índices do ONI na região Niño3.4 e a frequência de chuva A20. De modo geral, observamos que o ajuste linear positivo do ONI coincidiu positivamente com o ajuste de chuva A20. A exceção observada ocorreu na estação durante o EN, onde o ajuste linear positivo de chuva A20 não coincidiu positivamente com o ajuste linear do EN. A Tabela 60 apresenta os resultados das demais correlações realizadas para as séries temporais do ONI. Após identificarmos as respectivas correlações lineares anuais entre a chuva A20 e o ONI, analisamos os resultados das correlações cíclicas anuais e, notamos que não houve correlações significativas (Tabela 59).

Tabela 60 - Correlação Anual em Fases Específicas. A Coluna "A" indica ○ Ajuste Linear da Chuva A20 nas Séries Temporais "B" correspondente o ONI e suas Fases. A Última Coluna aponta os Possíveis Anos que estiveram Correlacionados com o Resultado da Correlação Linear do Ajuste "A" e "B".

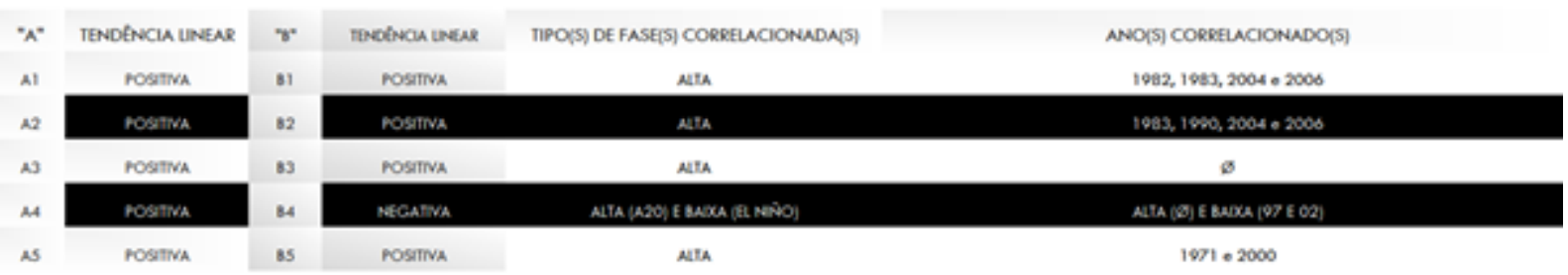

\subsection{2- Análise Trimestral}

A segunda análise envolve a relação trimestral entre a chuva A20 e o Oceanic Niño Index. Trata-se de uma análise individualizada, envolvendo os procedimentos elementares adotados, que foram aplicados para estações climáticas quentes, verão e primavera.

Os resultados das frequências trimestrais de chuva A20 ( $\left.\geq 20 \mathrm{~mm} \mathrm{~h}^{-1}\right)$ podem ser observados a partir da Figura 154 e Tabela 61. Na estação de verão identificamos uma 
tendência linear negativa nula (estável) e, na primavera, uma tendência linear positiva, de chuva A20, durante o período de 1970 a 2009 (Figura 155).

FREQUÊNCIA TRIMESTRAL DE CHUVAS $\geq 20 \mathrm{~mm} \mathrm{~h}^{-1}$ - VERÃO (1970-2009)

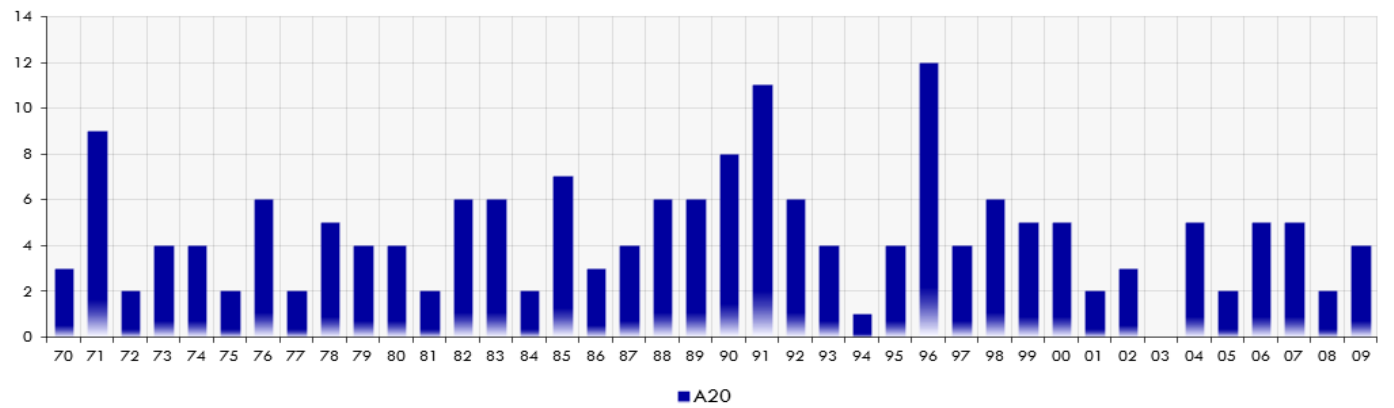

FREQUÊNCIA TRIMESTRAL DE CHUVAS $220 \mathrm{~mm}$ h-1 - PRIMAVERA (1970-2009)

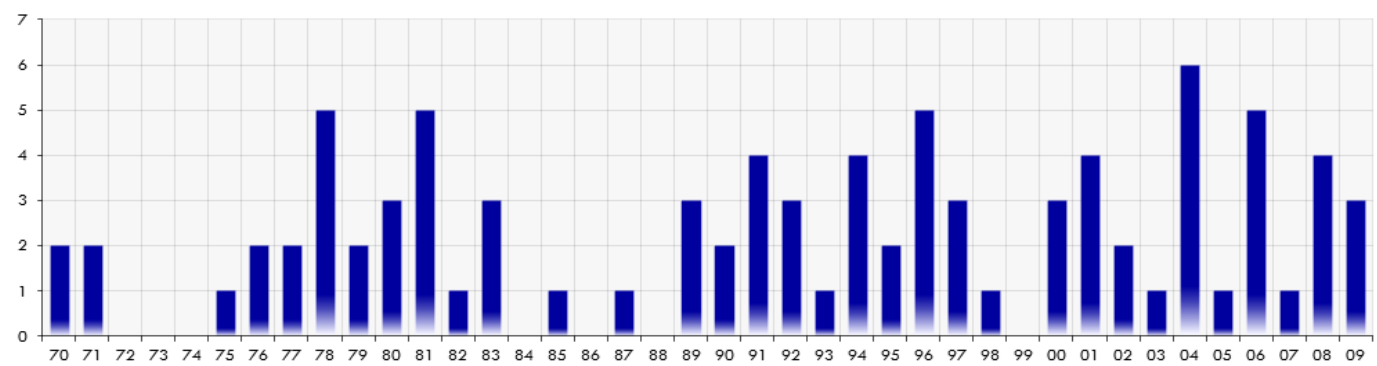
$=\mathrm{A} 20$

Figura 154 - Frequência Trimestral de chuva A20 na Estação do IAG-USP durante o Verão e Primavera para o Período de 1970 a 2009.

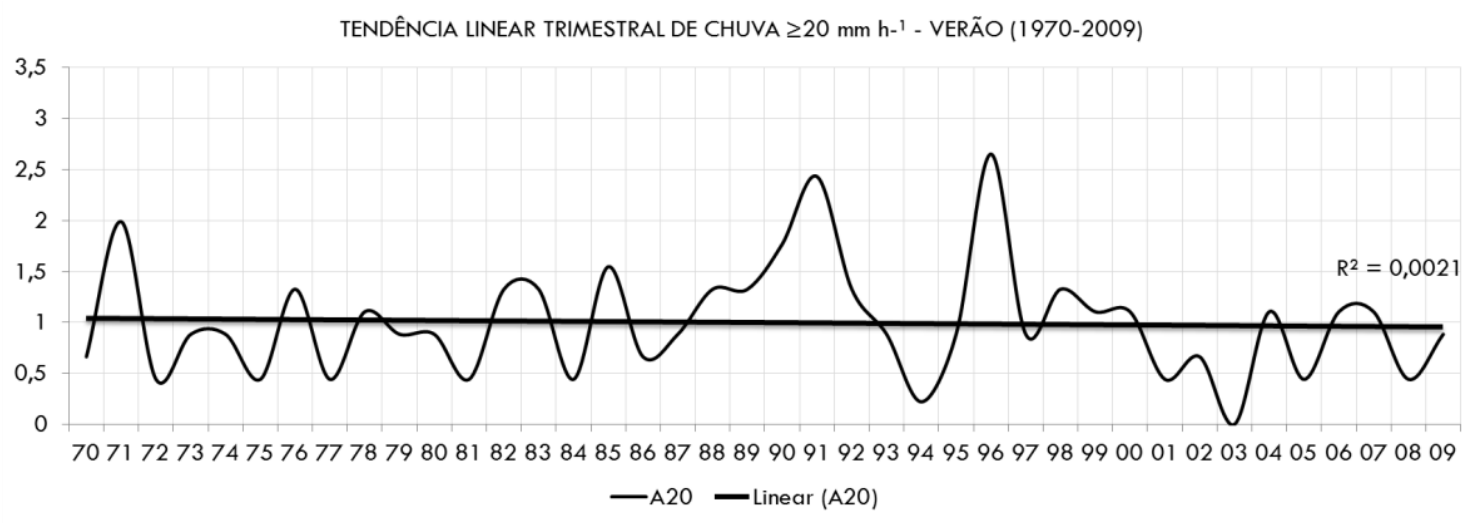

TENDÊNCIA LINEAR TRIMESTRAL DE CHUVA $\geq 20$ mm h-1 - PRIMAVERA (1970-2009)

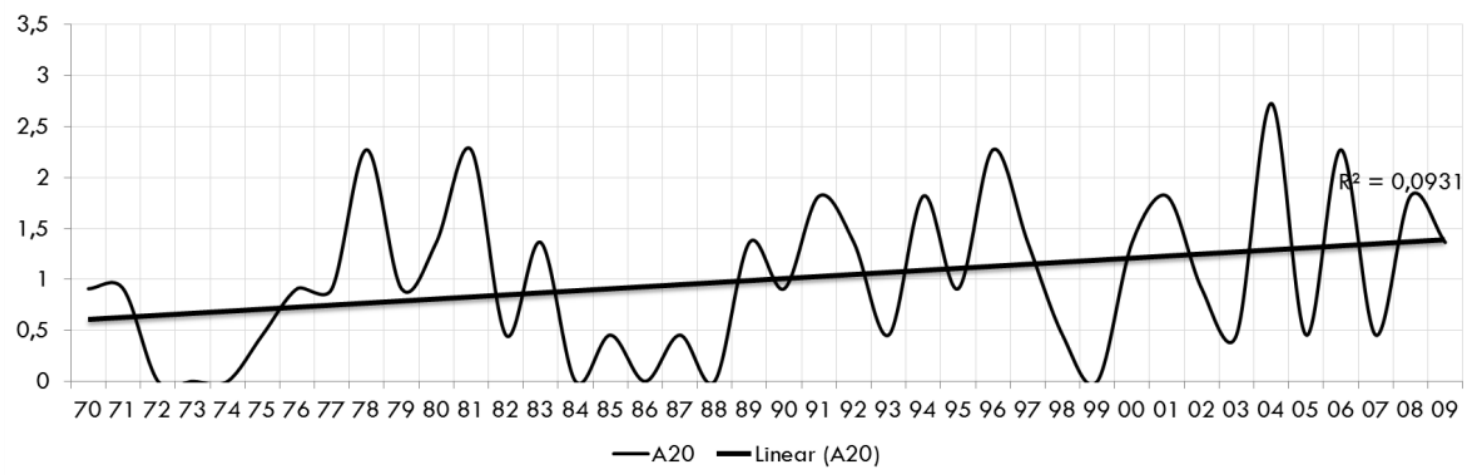

Figura 155 - Ajuste Linear Trimestral de chuva A20 para as Estações de Verão e Primavera, no Período de 1970 a 2009. 
De modo geral, os ajustes lineares mais significativos (inclinados) das fases do ONI foram negativos. O único caso de tendência linear positivo foi identificado durante a fase EN da estação de primavera (Figuras 156-159 e Tabela 61).

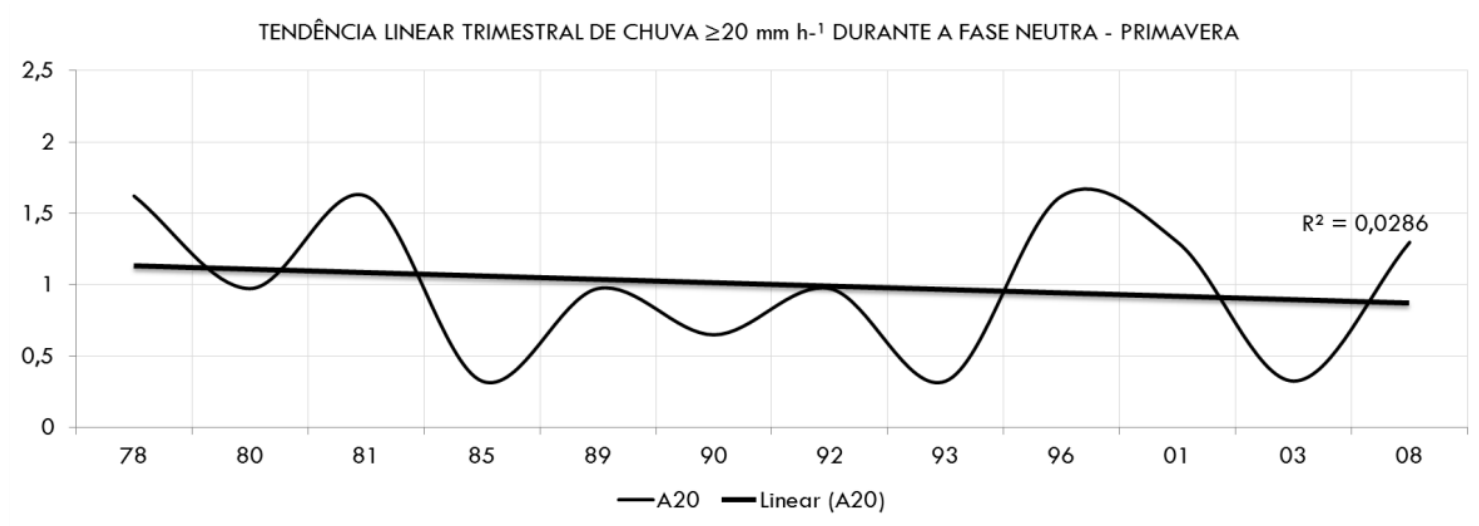

Figura 156 - Ajuste Linear Trimestral de chuva A20 para a Estação da Primavera, durante a Fase Neutra.
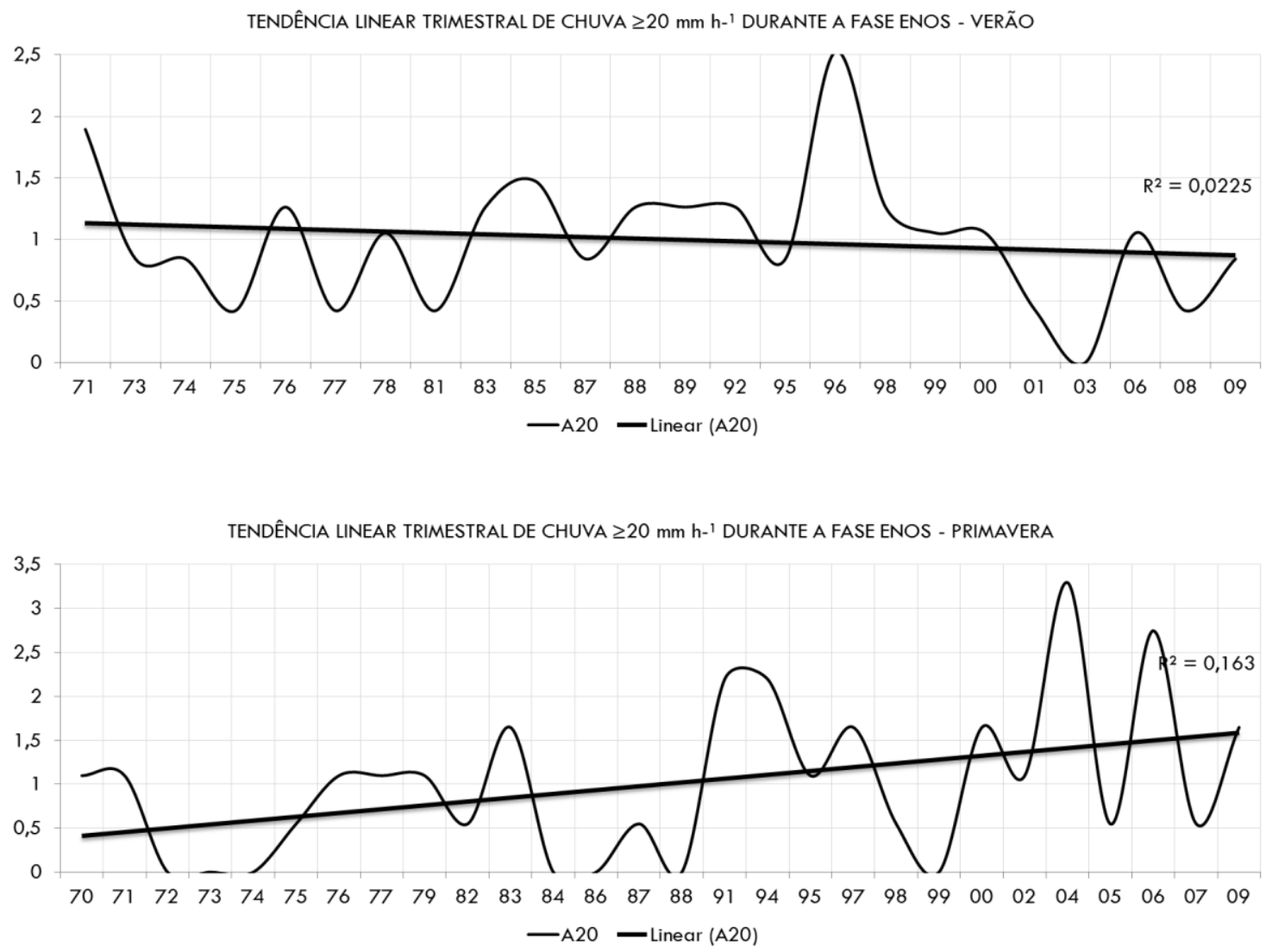

Figura 157 - Ajuste Linear Trimestral de chuva A20 para as Estações de Verão e Primavera, durante a Fase ENOS. 


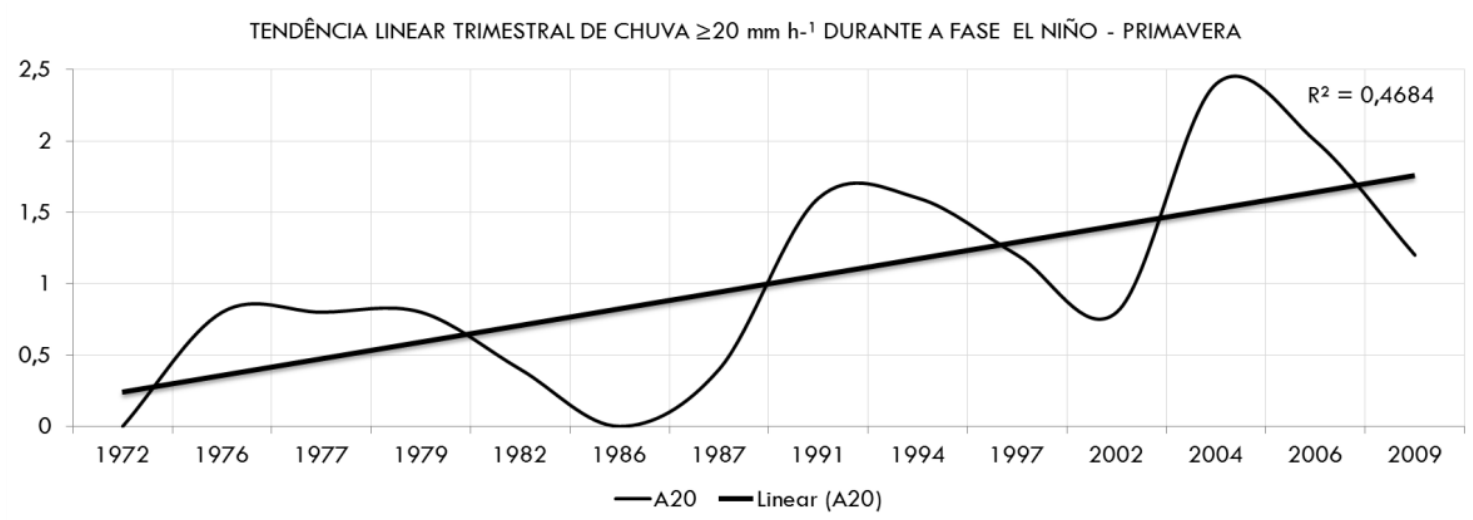

Figura 158 - Ajuste Linear Trimestral de chuva A20 para a Estação de Primavera, durante a Fase EN.

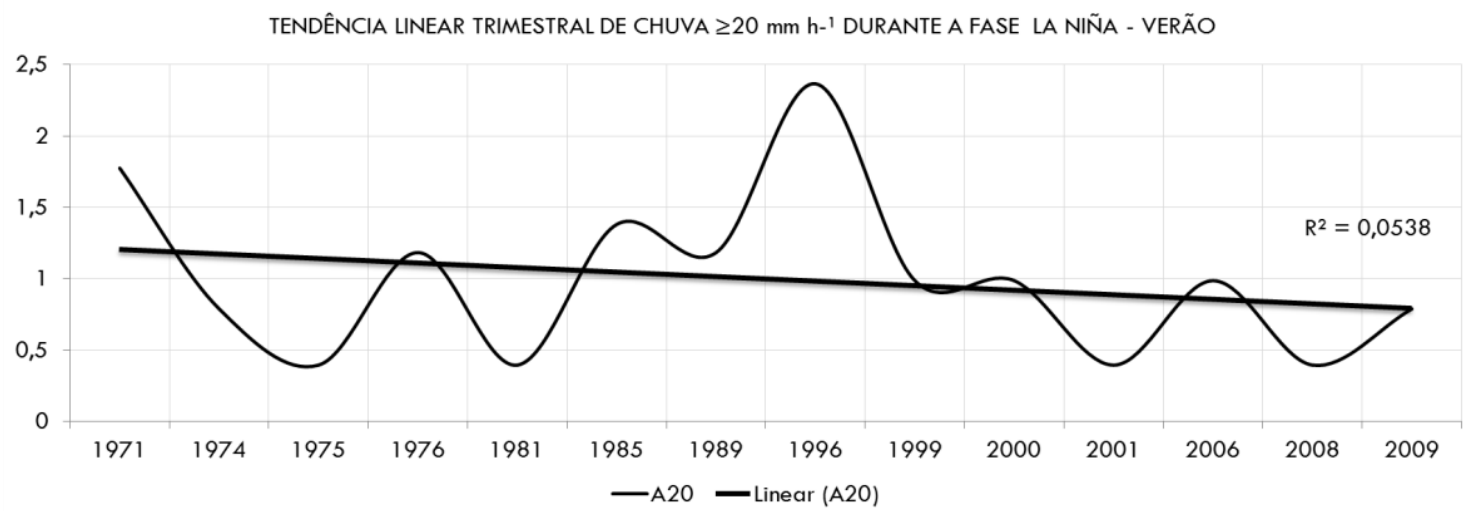

Figura 159 - Ajuste Linear Trimestral de chuva A20 para a Estação de Verão, durante a Fase LN.

Os resultados trimestrais relativos aos ajustes lineares apresentam assimetrias em relação aos trabalhos de Cabral (2002), Sugahara et al (2009) e Freitas et al (2013). Ou seja, é possível notar que há séries temporais específicas onde ocorre a diminuição da frequência de chuvas mais intensas.

Tabela 61 - Correlação Linear Trimestral entre a Tendência Linear Trimestral de Chuva A20 e a Tendência Linear Trimestral do ONI incluindo as Fases, Neutra, ENOS, EN e LN.

\begin{tabular}{|c|c|c|c|c|c|c|c|c|c|}
\hline & \multirow[b]{2}{*}{$\operatorname{acio}^{\circ} \mathrm{A}^{*}$} & \multicolumn{2}{|c|}{ TENDÊNCIA UNEAR "A" } & & & \multicolumn{2}{|c|}{ TENDÊNCLA UNEAR "B" } & \multicolumn{2}{|c|}{ CORRELAÇĀO UNEAR "A" E "B" } \\
\hline & & VERĀO & PRIMAVERA & & CICIO "B" & VERÃO & PRIMAVERA & VERĀO & PRIMAVERA \\
\hline Al & A.20 & - & + & B1 & ONI & - & + & + & + \\
\hline A2 & $A 20$ & + & - & $B 2$ & NEUTRA & + & + & + & - \\
\hline $\mathrm{A} 3$ & A.20 & - & - & B3 & ENOS & - & + & + & - \\
\hline A.4 & $\mathrm{A} 20$ & $=$ & + & BA & a NIÑO & + & - & - & - \\
\hline AS & A20 & - & NULA & B5 & LANIÑA & - & - & + & NULA \\
\hline
\end{tabular}




\subsubsection{1 - Variação Cíclica Trimestral}

A variação das anomalias da frequência de chuva A20 para o período de 1970 a 2009, para as quatro estações do ano está ilustrada na Figura 160.

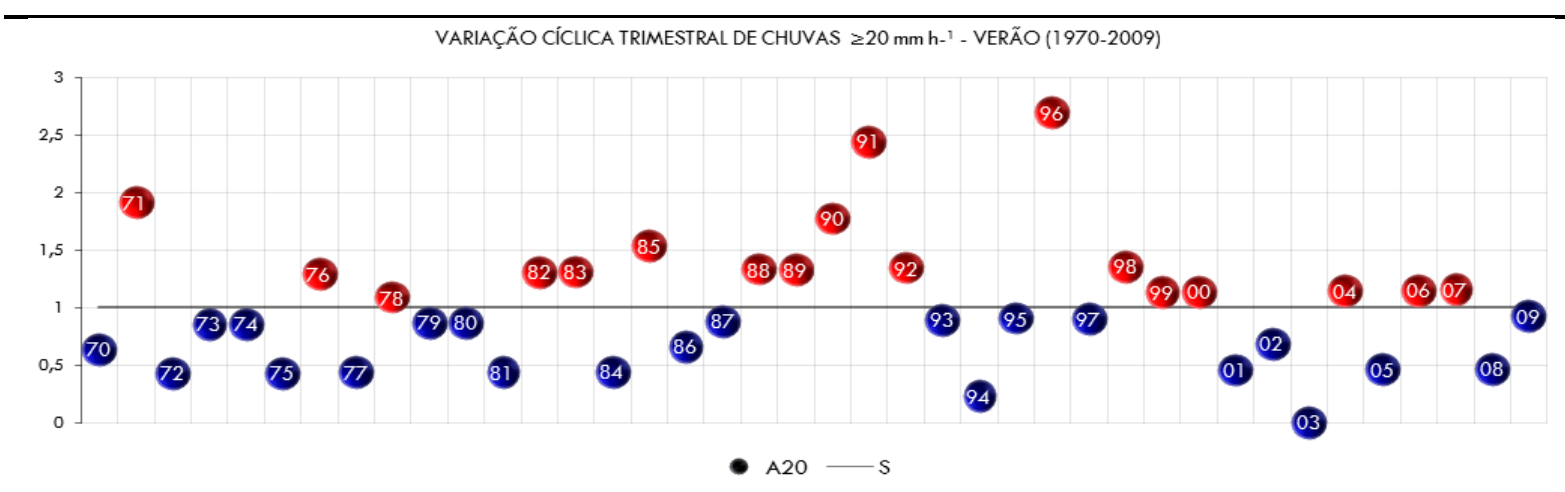

VARIAÇÃO CÍCLICA TRIMESTRAL DE CHUVAS $\geq 20 \mathrm{~mm}$ h-1 - PRIMAVERA (1970-2009)

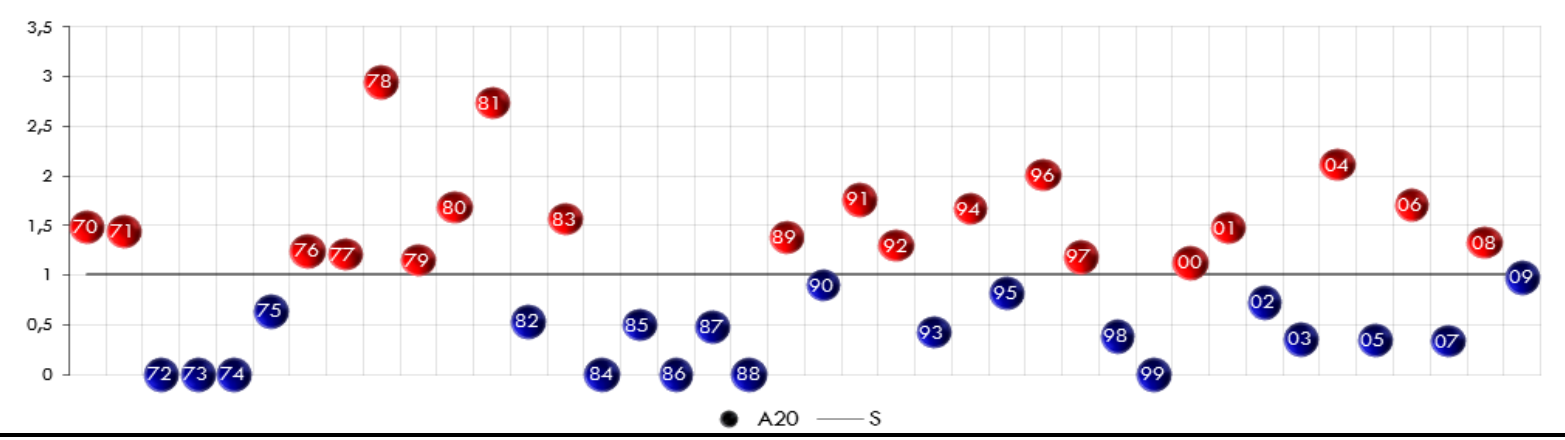

Figura 160 - Variação Cíclica Trimestral de Chuva A20, entre 1970 e 2009.

De forma geral, separando a série temporal em estações do ano, observamos que a correlação linear entre as séries de ONI e frequência de chuva A20 é negativa e significativa somente para a primavera $(r=-0,27)$, Figura 161. Ou seja, a frequência de chuva A20 pode não estar associada fisicamente aos valores de ONI durante a primavera. A separação das séries temporais em eventos distintos quanto à TSM na região do Niño3.4 permitiu verificar que durante a primavera, na fase EN, a correlação linear entre estas duas variáveis foi negativa e significativa $(r=-0,59)$, Figura 162. Todos os demais resultados podem ser observados a partir da Tabela 62. 
Tabela 62 - Correlação Cíclica entre a Frequência de Chuva A20 observada na Estação do IAG e os Valores de ONI para Cada Estação do Ano e, para Cada Condição de Anomalia na Região de Niño3.4 (Eventos Neutros, ENOS, EN e LN).

\begin{tabular}{|c|c|c|c|c|c|c|c|}
\hline 시 & AI & onet & ONI & 0,008 & $-0,278$ & NüO SICNERICATIVO & SIONAFICAIINO \\
\hline N & $A 3$ & beos & ENOS & 0,000 & 0,040 & Nh̆O SIGREICATIVO & 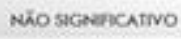 \\
\hline$M$ & $M$ & al natio & El natio & 0,401 & $.0,503$ & NäOSIGNeFicatTVO & SICNIFACATIVO \\
\hline
\end{tabular}

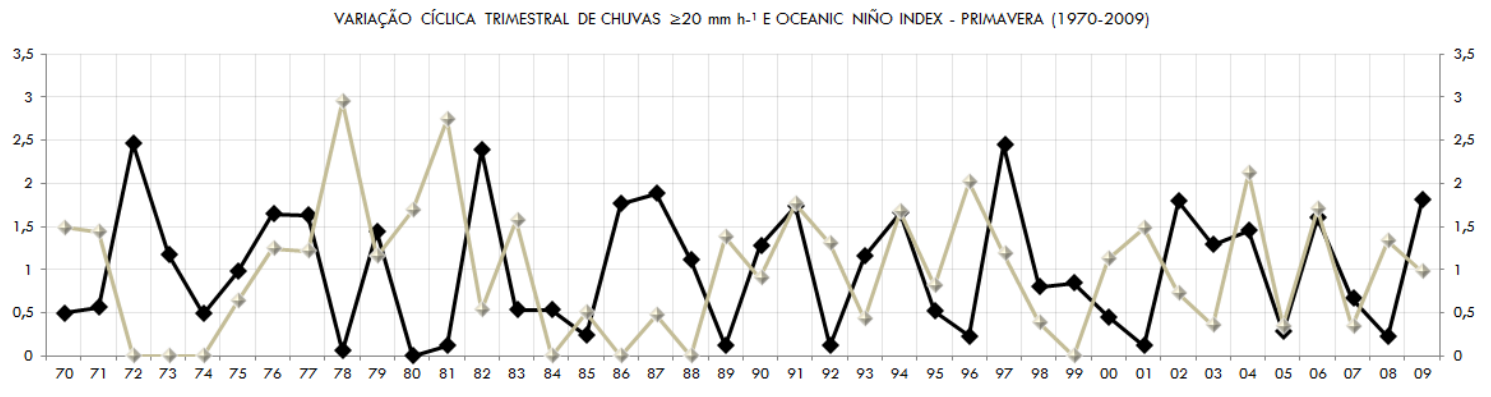

$\longrightarrow \mathrm{ONI}=-\mathrm{A} 2 \mathrm{O}$

Figura 161 - Variação Cíclica de Chuva A20, na Primavera, entre 1970 e 2009.

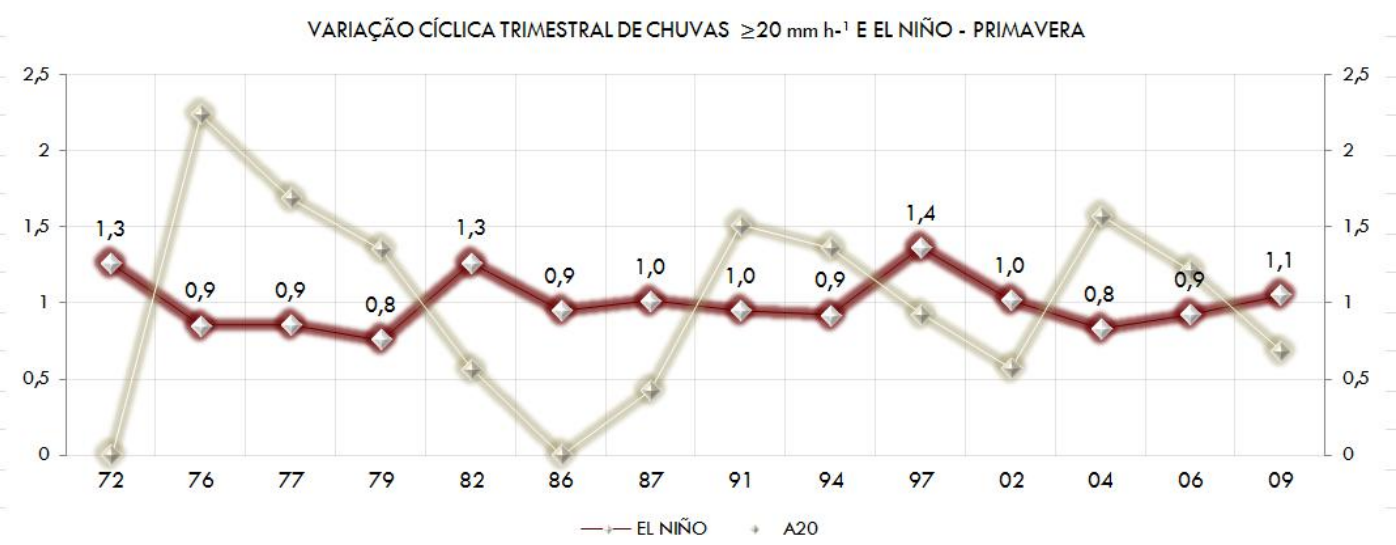

Figura 162 - Variação Cíclica de Chuva A20, na Primavera, durante a Fase El Niño.

\subsubsection{2- Análise Específica das Fases Trimestrais}

Os resultados de tal análise revelam as possíveis correlações existentes entre as fases altas e baixas da frequência de Chuva A20 e do ONI. Neste caso, identificamos à série específica através das fases altas $(\bar{x}>1)$ e baixas $(\bar{x}<1)$ da variação cíclica da frequência trimestral de chuva A20. A variação cíclica de chuva A20 no período de 1970 a 2009 
durante a estação de verão foi composta por 19 fases específicas. A partir do resultado positivo da correlação linear entre a tendência negativa de chuva A20 e a tendência negativa do ONI, procuramos identificar as fases da oscilação que possivelmente estiveram associadas a tal comportamento. Neste caso, deduzimos que somente as fases baixas estariam correlacionadas (Figura 163). Em função dessa probabilidade, identificamos nos anos $72,73,74,75,79,80,81,84,86,87,93,94,95,97,04,06$ e 07 as fases altas que estariam significativamente e positivamente correlacionadas com a chuva A20 (Tabela 63).

A variação cíclica de chuva A20 no período de 1970 a 2009 durante a estação da primavera foi composta por 28 fases específicas. A partir do resultado positivo da correlação linear entre a tendência positiva de chuva A20 e a tendência positiva do ONI, procuramos identificar as fases da oscilação que possivelmente estiveram associadas a tal comportamento. Neste caso, deduzimos que somente as fases altas estariam correlacionadas (Figura 163). Em função dessa probabilidade, identificamos nos anos $75,91,92,94,04$ e 06 as fases altas que estiveram significativamente e positivamente correlacionadas com a correlação positiva encontrada entre a chuva A20 e o ONI (Tabela 63).
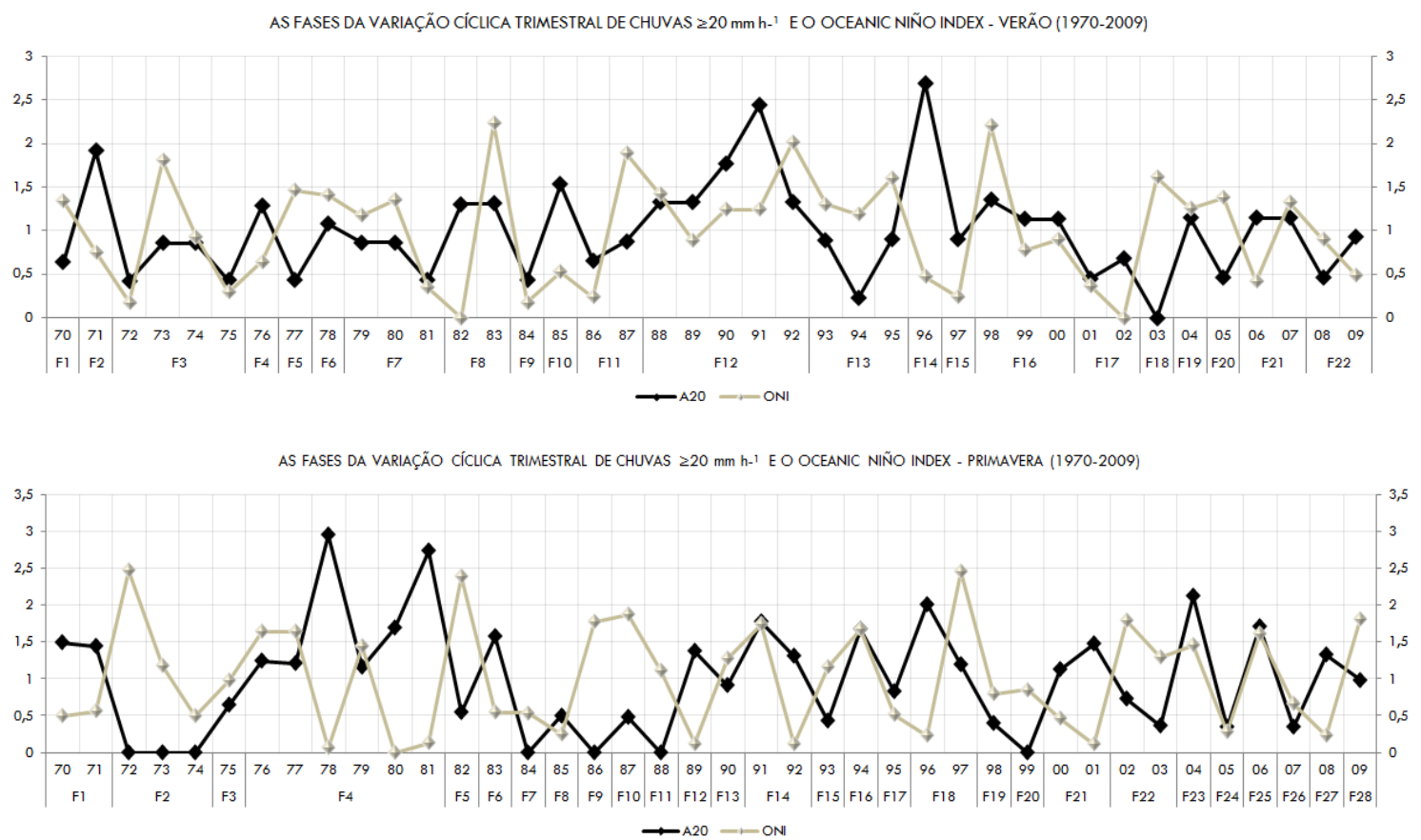

Figura 163 - Fases Específicas do Ciclo Trimestral de Chuva A20, Verão e Primavera. A linha Branca corresponde à variação cíclica do ONI e a linha Preta de Chuva A20, para o Período de 1970-2009. 
Tabela 63 - Correlação Linear entre a Frequência de Chuva A20 observada na Estação do IAG e os Valores de ONI para Cada Estação do Ano e, para Cada Condição de Anomalia na Região de Niño3.4 (Eventos Neutros, ENOS, EN e LN). "A" representa as Séries Temporais de Chuva A20 relativa às Séries Temporais do ONI "B". Assim, B1 (ONI), B2 (Neutro), B3 (ENOS), B4 (EN) e B5 (LN). Correlação "A" são os Tipos Fases Correlacionadas com a Chuva A20 e Correlação "B" são os Tipos Fases Correlacionadas com o ONI.

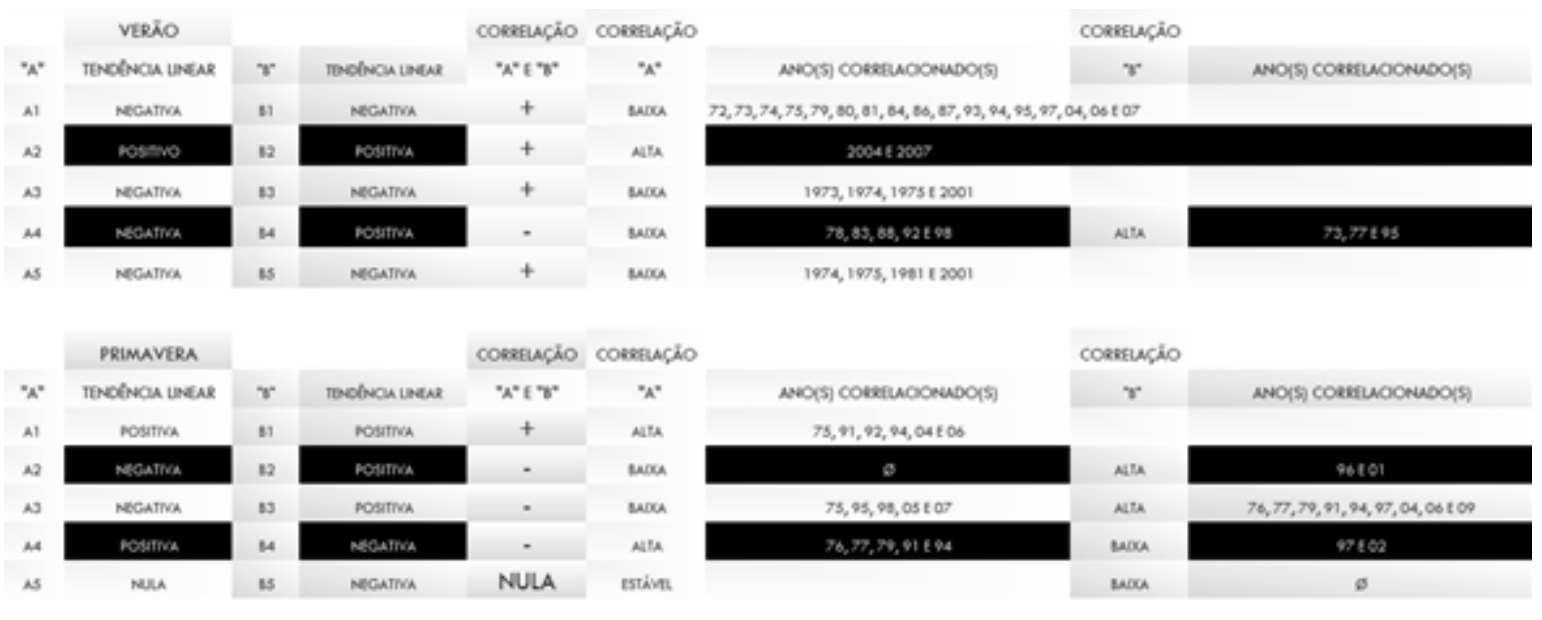

\subsubsection{3- A Hipótese Inicial e a Conclusão Final - A20 II}

A conclusão final para análise trimestral de chuva A20 parte das correlações identificadas, para as estações climáticas de verão e primavera, envolvendo o ajuste linear dos índices do ONI na região Niño3.4 e a frequência de chuva A20. Tanto no verão, quanto na primavera observamos que o ajuste linear positivo do ONI coincidiu positivamente com $\circ$ ajuste linear de chuva A20. A Tabela 63 apresenta os resultados das demais correlações realizadas para as séries temporais do ONI em cada estação climática do ano. Após identificarmos as respectivas correlações lineares trimestrais entre a chuva A20 e o ONI, analisamos os resultados das correlações cíclicas trimestrais. Neste caso, encontramos apenas duas correlações cíclicas significativas e negativas na primavera (Tabela 62). A primeira correlação significativa foi identificada durante o ONI e a segunda durante a fase El Niño. Em função do fator negativo das correlações significativas encontradas, não foi possível realizar uma possível combinação de resultados e, assim deduzimos que o mais provável é que tenham ocorrido alterações isoladas e lineares na frequência de chuva A20. 


\subsection{0- Amostra de Chuva $\geq 30 \mathrm{~mm} \mathrm{~h}-1^{1}$}

A amostra de chuva $\geq 30 \mathrm{~mm} \mathrm{~h}^{-1}$ é formada por chuvas que atingem níveis pluviométricos maiores e iguais a 30 milímetros no intervalo de uma hora. A partir da hipótese inicial deste estudo, a intenção ao analisar uma determinada amostra, é a de concluir para a série temporal de 1970-2009, a existência ou não de um nível de correlação aceitável, envolvendo classes estatísticas mais representativas, com a intenção de avaliar o nível de explicação para o comportamento de sua frequência, em função das variações registradas na temperatura da superfície do mar na região Niño 3.4. A amostra de chuva $\geq 30 \mathrm{~mm} \mathrm{~h}^{-1}$ é identificada pela sigla "A30".

\subsection{1 - Análise Anual}

A análise anual possui a finalidade de apresentar uma conclusão obtida a partir da identificação do tipo de correlação existente na intenção de sugerir a possibilidade de haver uma relação anual envolvendo a chuva A30 e o Oceanic Niño Index. A partir dos dados da estação do IAG-USP, calculamos a frequência anual de chuva A30 ( $\geq 30 \mathrm{~mm} \mathrm{h-1}$ ), representada no gráfico da Figura 164, onde identificamos a frequência máxima nos anos de 1976 e 2004 através da contagem de 6 casos horários.

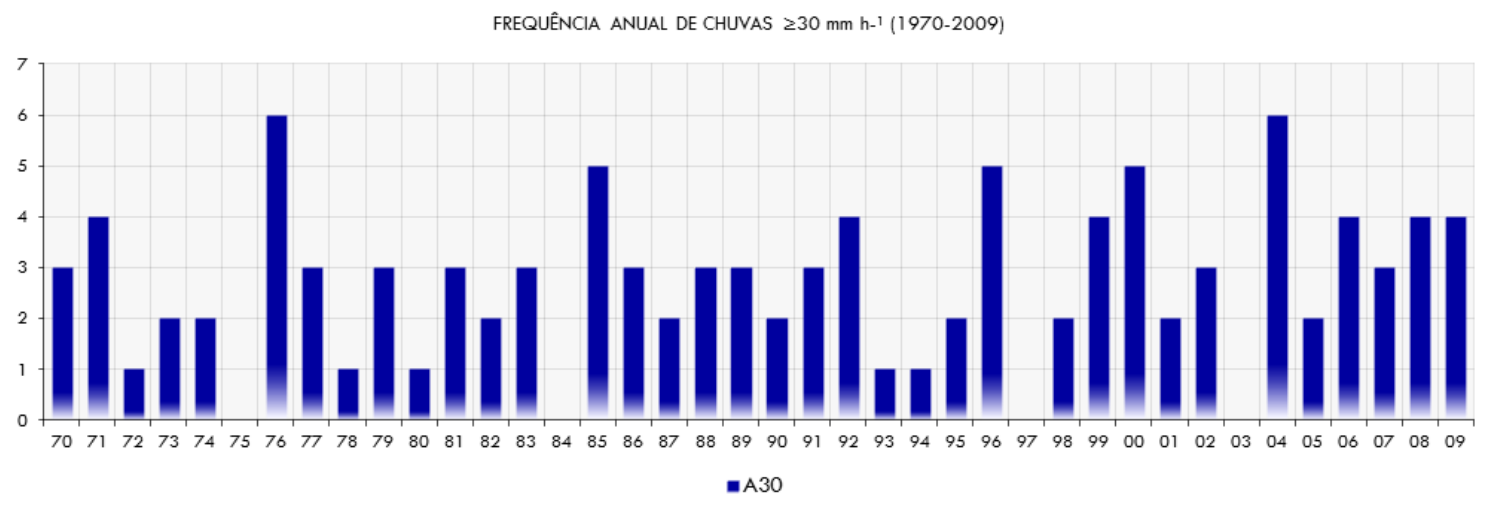

Figura 164 - Frequência Anual de Chuva $\geq 30 \mathrm{~mm} \mathrm{~h}^{-1}$ entre 1970-2009. 


\subsubsection{1 - Análise do Ajuste Linear}

O ajuste linear da frequência anual de chuva A30 no município de São Paulo indica aumento desta frequência ao longo da série temporal analisada, de 1970 a 2009, tal como ilustrada na Figura 165. A análise realizada para as fases, neutra, ENOS, El Niño e La Niña, separadamente, mostra que, em todos os casos, a frequência anual de chuva A30 aumenta com o tempo, exceto para o caso do período de El Niño onde o ajuste positivo pode ser considerado nulo (Figura 166). A comparação entre a tendência linear da frequência de chuva $\mathrm{A} 30$ e do $\mathrm{ONI}$ indica que enquanto o ONI assume valores cada vez mais intensos, no decorrer da série temporal, a frequência de chuva A30 aumenta, tal como indicado na Tabela 64.

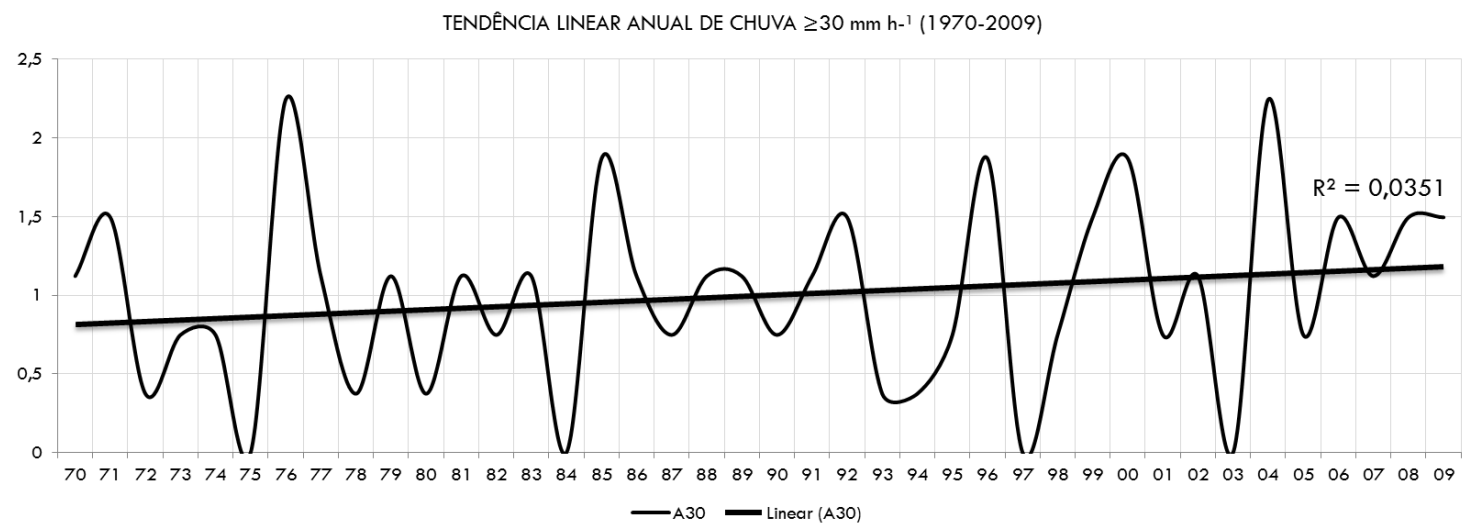

Tabela 165 - Ajuste Linear Anual de Chuva $\geq 30 \mathrm{~mm} \mathrm{~h}-^{1}$.

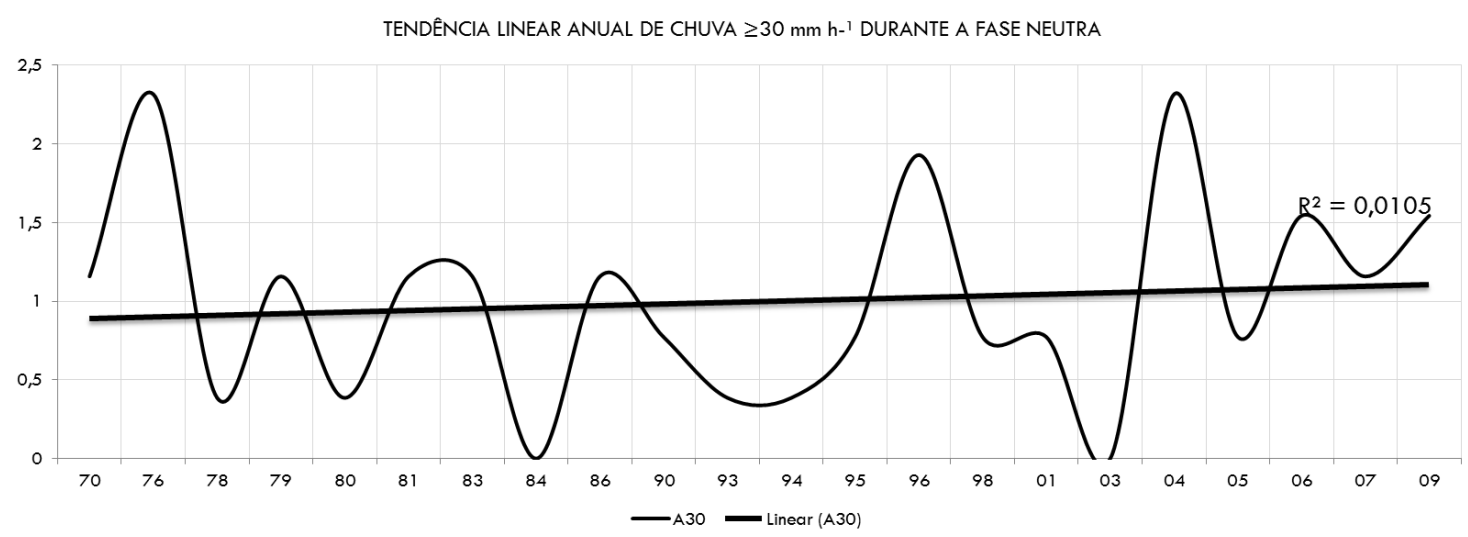



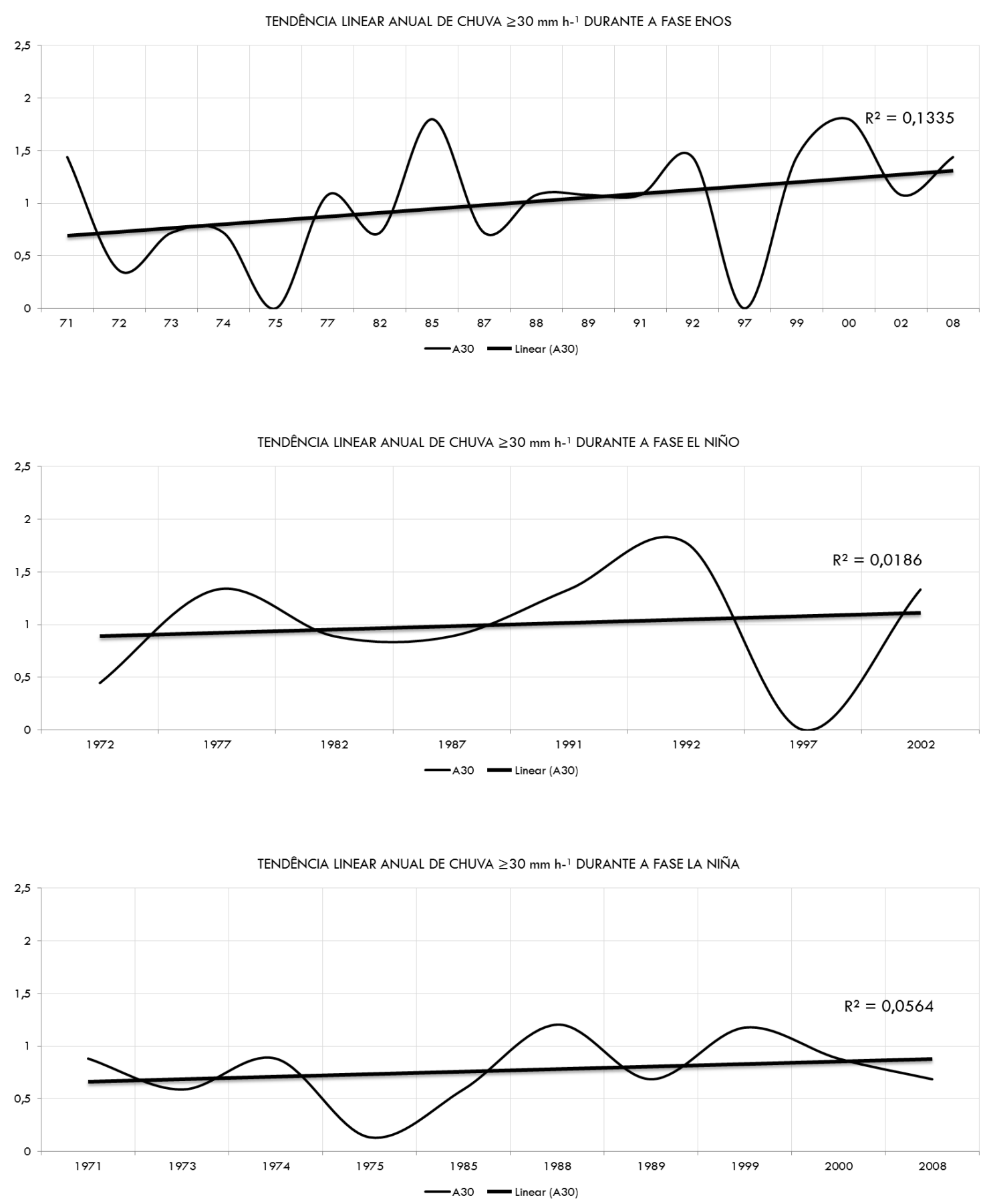

Figura 166 - Tendência Linear da Frequência Anual de Chuva $\geq 30 \mathrm{~mm} \mathrm{~h}{ }^{1}$ para a Fase, Neutra, ENOS, EN e LN, entre 1970-2009.

Os resultados observados através dos ajustes lineares positivos para a série anual revelam que as frequências analisadas no intervalo horário refletiram positivamente com os resultados obtidos das análises diárias realizadas por Cabral (2002), Sugahara et al (2009) e Freitas et al (2013). 
Tabela 64 - Tendência Linear Anual de Chuva A30 e do ONI para o Período de 1970 a 2009. A Primeira Linha da Tabela indica a Tendência Linear de Todos os Dados Anuais e, as Demais Linhas indicam a Tendência Linear para cada Fase do ONI.

\begin{tabular}{|c|c|c|c|c|c|c|}
\hline$A^{*}$ & THPO DE CHUNA & TENDENCLA UNEAR & $\mathrm{r}^{*}$ & CATEOOEA & TENDENCIA LINEAR & CORRELAÇĂO UINEAR \\
\hline AI & $A>0$ & POSITIVA & 81 & Oed & POSITIVA & POSITIVA \\
\hline 12 & $\wedge=0$ & POSIINA & 12 & Neutso & Positiva & POSIIIVA \\
\hline N & $\wedge>0$ & POSITIVA & 63 & ENOS & POSITIVA & POSITIVA \\
\hline$\mu$ & $A>0$ & positiva & B4 & A Natio & MECAMIVA & NEGATIVA \\
\hline AS & $A 30$ & POSITIVA & es & UANESA & POSITIVA & POSITIVA \\
\hline
\end{tabular}

\subsubsection{2- Variação Cíclica da Amostra A30}

A variação cíclica anual de chuva $A 30$ pode ser observada na Figura 167. É possível notarmos a oscilção presente na série temporal completa, de 1970 a 2009, formada por 21 fases altas (esferas vermelhas) e 19 fases baixas (esferas azuis).

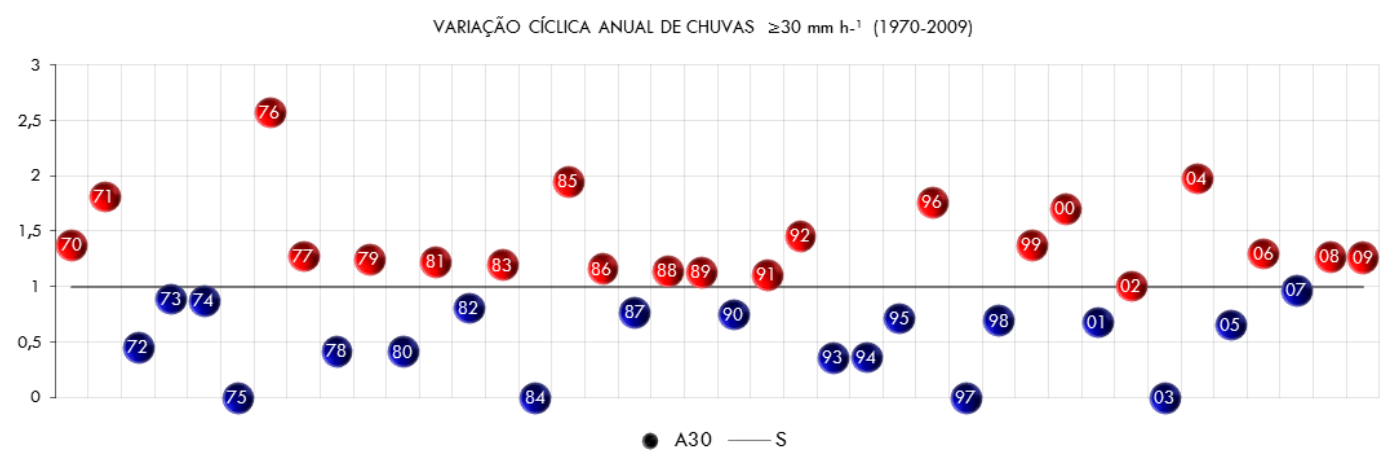

Figura 167 - Variação Cíclica Anual da Frequência de chuva A30 entre 1970 e 2009.

A partir dos resultados do teste de significância - t-"Student" - notamos que os resultados do cálculo de correlação linear entre ONI e a frequência anual de chuva $\mathrm{A} 30$ foi considerado como sendo significativo (Figura 168 e Tabela 65).

Tabela 65 - Correlação Linear entre a Anomalia de ONI e da Frequência Anual de chuva A30 entre 1970 e 2009, sem Tendência Linear (Série Cíclica).

\begin{tabular}{|c|c|c|c|c|c|}
\hline & CIClO "A" & & CIClO "B" & CORRELAÇÃO CICLICA & TESTE T-STUDENT \\
\hline Al & A30 & B1 & ONI & $-0,23.4$ & SIGNIFICATIVO \\
\hline A2 & A 30 & B2 & NEUTRA & $-0,128$ & NĀO SIGNEFICATIVO \\
\hline A3 & A30 & B3 & ENOS & $-0,435$ & SIGNIFICATIVO \\
\hline A4 & A30 & B4 & EL NIÑO & $-0,754$ & SIGNIFICATIVO \\
\hline A5 & A 30 & B5 & LA NINA A & 0,518 & NÄO SIGNEFICATIVO \\
\hline
\end{tabular}


De forma geral, separando a série temporal em fases, observamos que houve correlações lineares significativas, porém negativas envolvendo duas séries do ONI e a frequência de chuva A30. A primeira foi durante a fase ENOS $(r=-0,43)$, Figura 169 e, a segunda durante a fase EN $(r=-0,75)$, Figura 170. Todos os demais resultados podem ser observados a partir da Tabela 65.

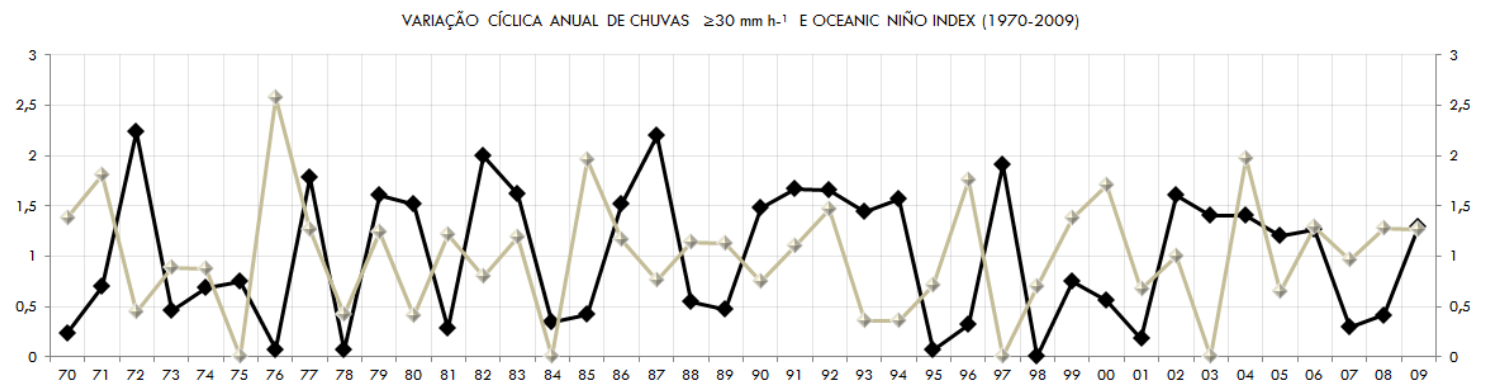

Figura 168 - Variações Cíclicas Anuais do ONI e da Frequência de chuva A30, entre 1970 e 2009.

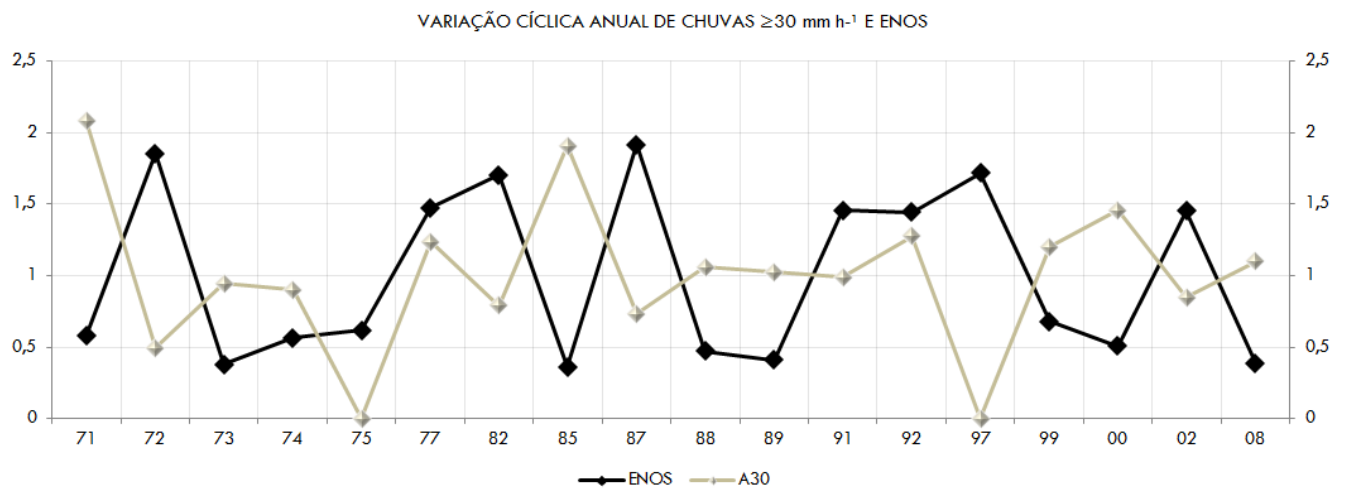

Figura 169 - Variações Cíclicas Anuais da Frequência de chuva A30, durante a Fase Neutra.

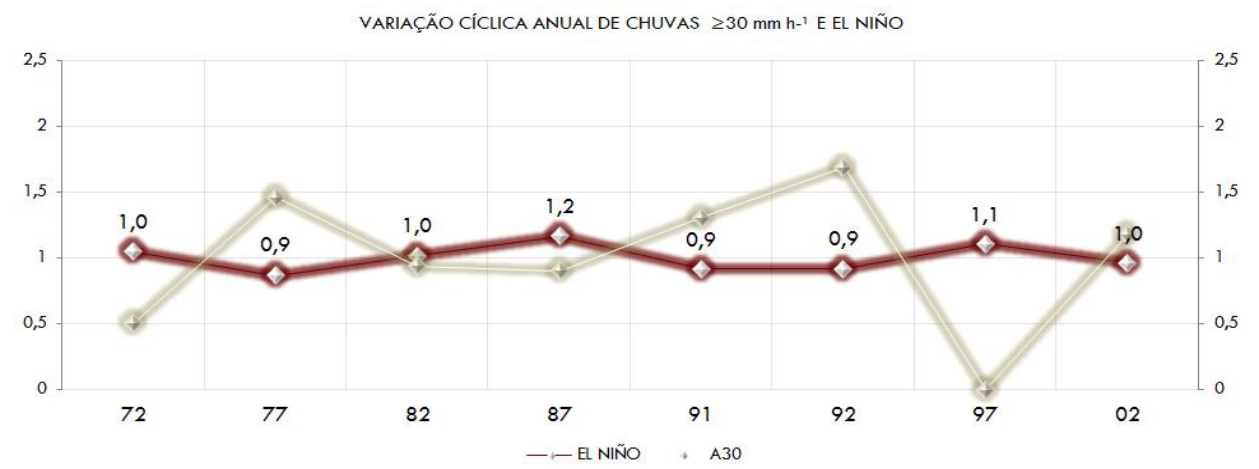

Figura 170 - Variações Cíclicas Anuais da Frequência de chuva A30, durante a Fase EN. 


\subsubsection{3- Análise Específica Ciclo de Chuva - A30}

Os resultados de tal análise revelam as possíveis correlações existentes entre as fases altas e baixas da frequência de chuva A20 e do ONI. Neste caso, na Figura 171 identificamos a série específica através das fases altas $(\bar{x}>1)$ e baixas $(\bar{x}<1)$ da variação cíclica da frequência de chuva A20.

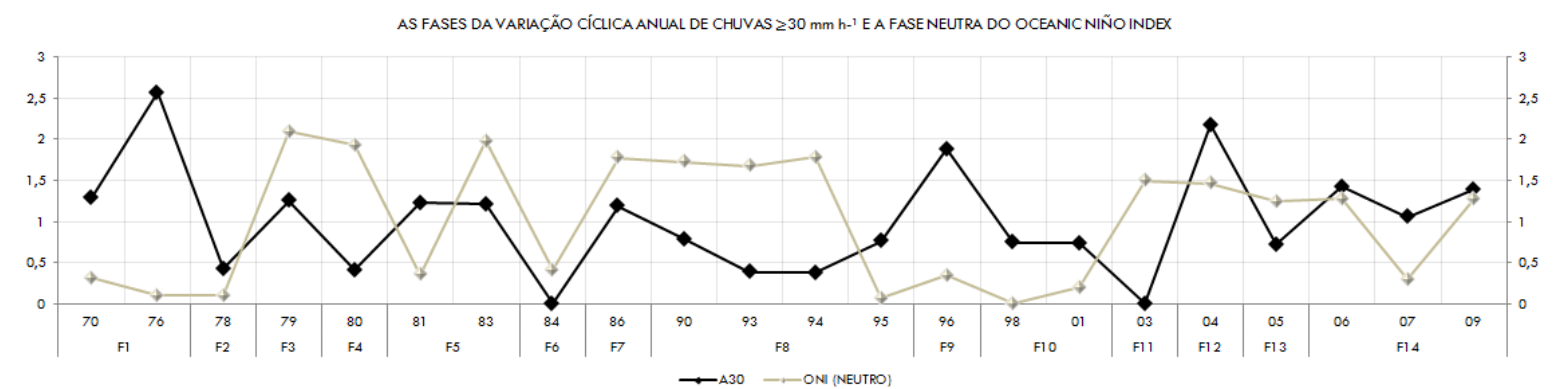

Figura 171 - Fases Específicas do Ciclo Anual de Chuva A30. A linha Branca corresponde à variação cíclica do ONI e a linha Preta de Chuva A30, para o Período de 1970-2009.

A variação cíclica anual de chuva A30 no período de 1970 a 2009 foi composta por 19 fases específicas (altas e baixas). No entanto, a partir do resultado positivo da correlação linear entre a tendência positiva de chuva $\mathrm{A} 30$ e a tendência positiva da $\mathrm{ONI}$, procuramos identificar as fases da oscilação que possivelmente estiveram associadas a tal comportamento. Neste caso, as fases altas estariam concomitantemente correlacionadas com a frequência de chuva A30 e o ONI. Neste caso, identificamos nos anos 70, 71, 79, 83, 88, 89, 02,04 e 06 as fases que estiveram positivamente e significativamente correlacionados. Tais fases refletem o resultado positivo relativo ao aumento das frequências de chuva $A 30$ em função do aquecimento na TSM, na região Niño3.4.

\subsubsection{4- A Hipótese Inicial e a Conclusão Final - A30 I}

A conclusão final para análise anual de chuva A30 parte das distintas correlações identificadas, para cada estação climática, envolvendo o ajuste linear dos índices do ONI na região Niño3.4 e a frequência de chuva A30. De modo geral, observamos que o ajuste linear 
positivo do ONI coincidiu positivamente com o ajuste de chuva A30. A exceção observada ocorreu na estação durante o $\mathrm{EN}$, onde o ajuste linear positivo de chuva $\mathrm{A} 30$ não coincidiu positivamente com o ajuste linear do EN. A Tabela 66 apresenta os resultados das demais correlações realizadas para as séries temporais do ONI. Após identificarmos as respectivas correlações lineares anuais entre a chuva $\mathrm{A} 30$ e $\circ \mathrm{ONI}$, analisamos os resultados das correlações cíclicas anuais e, notamos que houve três correlações significativas e negativas. A primeira foi identificada no período do ONI, a segunda, na fase ENOS e, a terceira, na fase EN, de acordo com a Tabela 65. Nestes casos, constatamos que as alterações na frequência de chuva A30 ocorreram em um processo contínuo e evolutivo e, que as oscilações das variações cíclicas de chuva A30, não estiveram associadas em períodos específicos e nem durante período de 1970 a 2009.

Tabela 66 - Correlação Anual em Fases Específicas. A Coluna "A" indica ○ Ajuste Linear da Chuva A30 nas Séries Temporais "B" correspondente o ONI e suas Fases. A Última Coluna aponta os Possíveis Anos que estiveram Correlacionados com o Resultado da Correlação Linear do Ajuste "A" e "B".

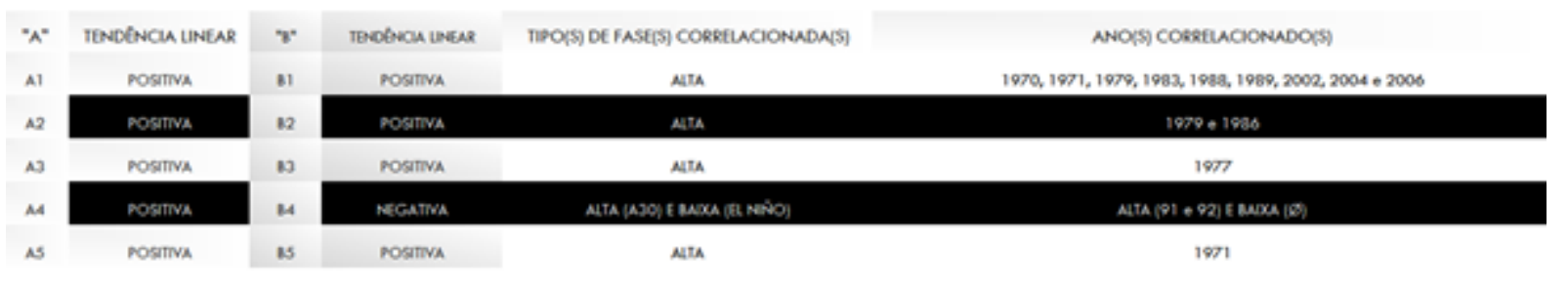

\subsection{2- Análise Trimestral}

A segunda análise envolve a relação trimestral entre a chuva A30 e o Oceanic Niño Index. Trata-se de uma análise individualizada, envolvendo os procedimentos elementares adotados, que foram aplicados para estações climáticas quentes, verão e primavera. Os resultados das frequências trimestrais de chuva $A 30\left(\geq 30 \mathrm{~mm} \mathrm{~h}^{-1}\right)$ podem ser observados a partir das Figuras 172 e Tabela 67. Nas estações, verão e primavera, identificamos um ajuste linear positiva, de chuva A30, durante o período de 1970 a 2009 (Figuras 173). 


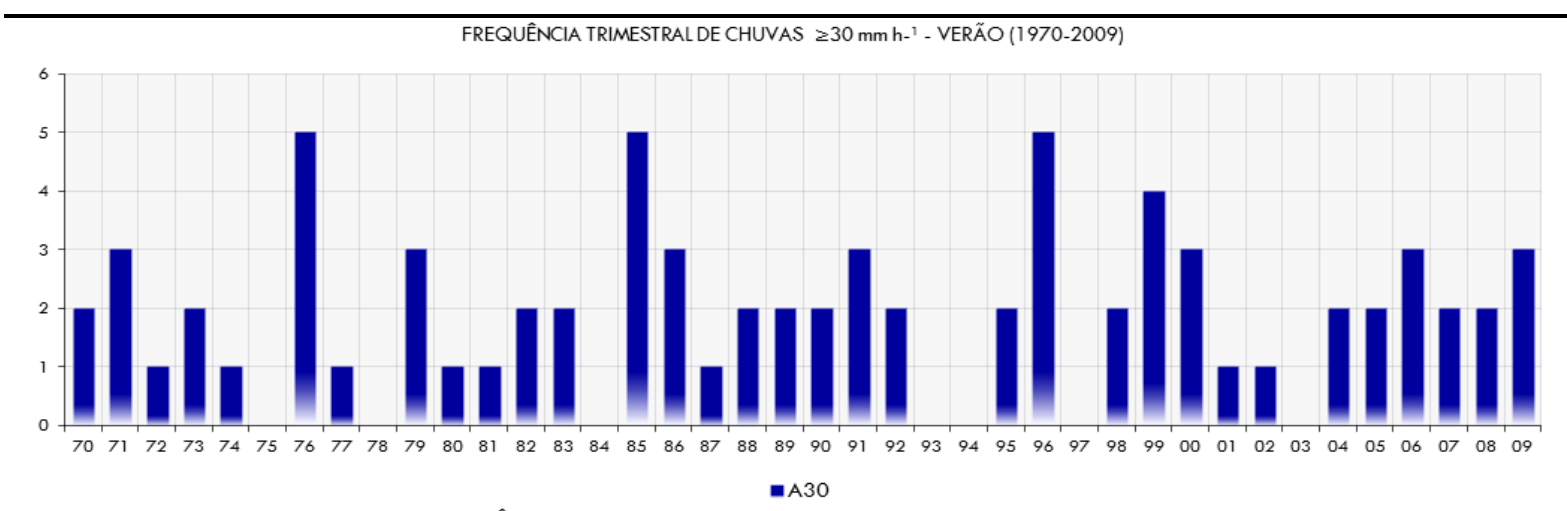

FREQUÊNCIA TRIMESTRAL DE CHUVAS $\geq 30 \mathrm{~mm} \mathrm{h-1}$ - PRIMAVERA (1970-2009)

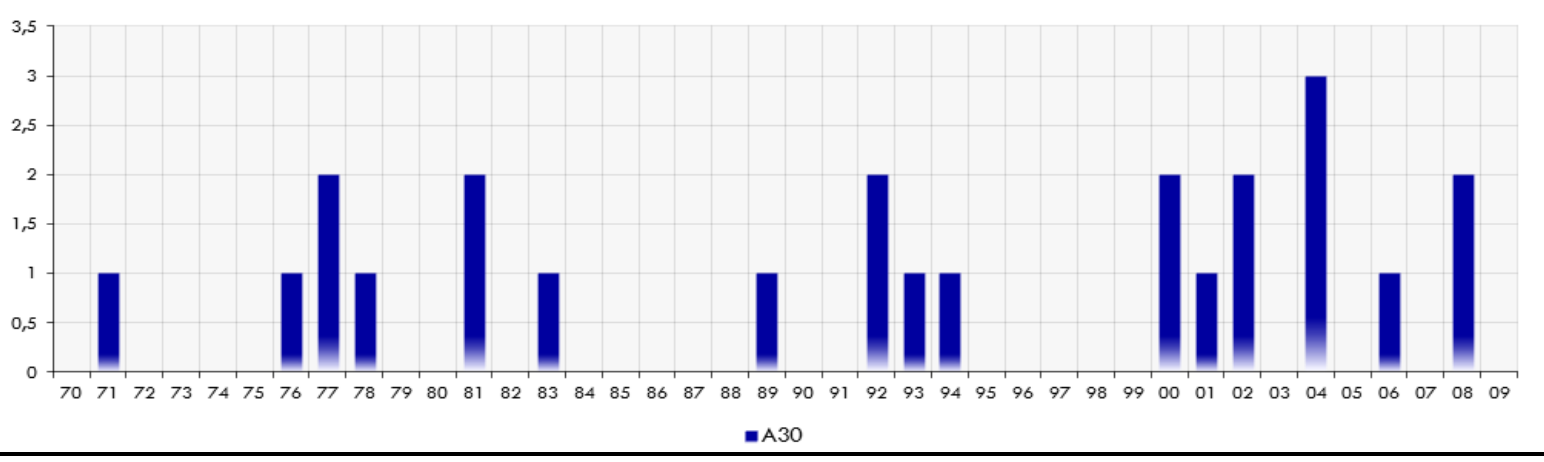

Figura 172 - Frequência Trimestral de chuva A30 na Estação do IAG-USP durante o Verão e Primavera para o Período de 1970 a 2009.
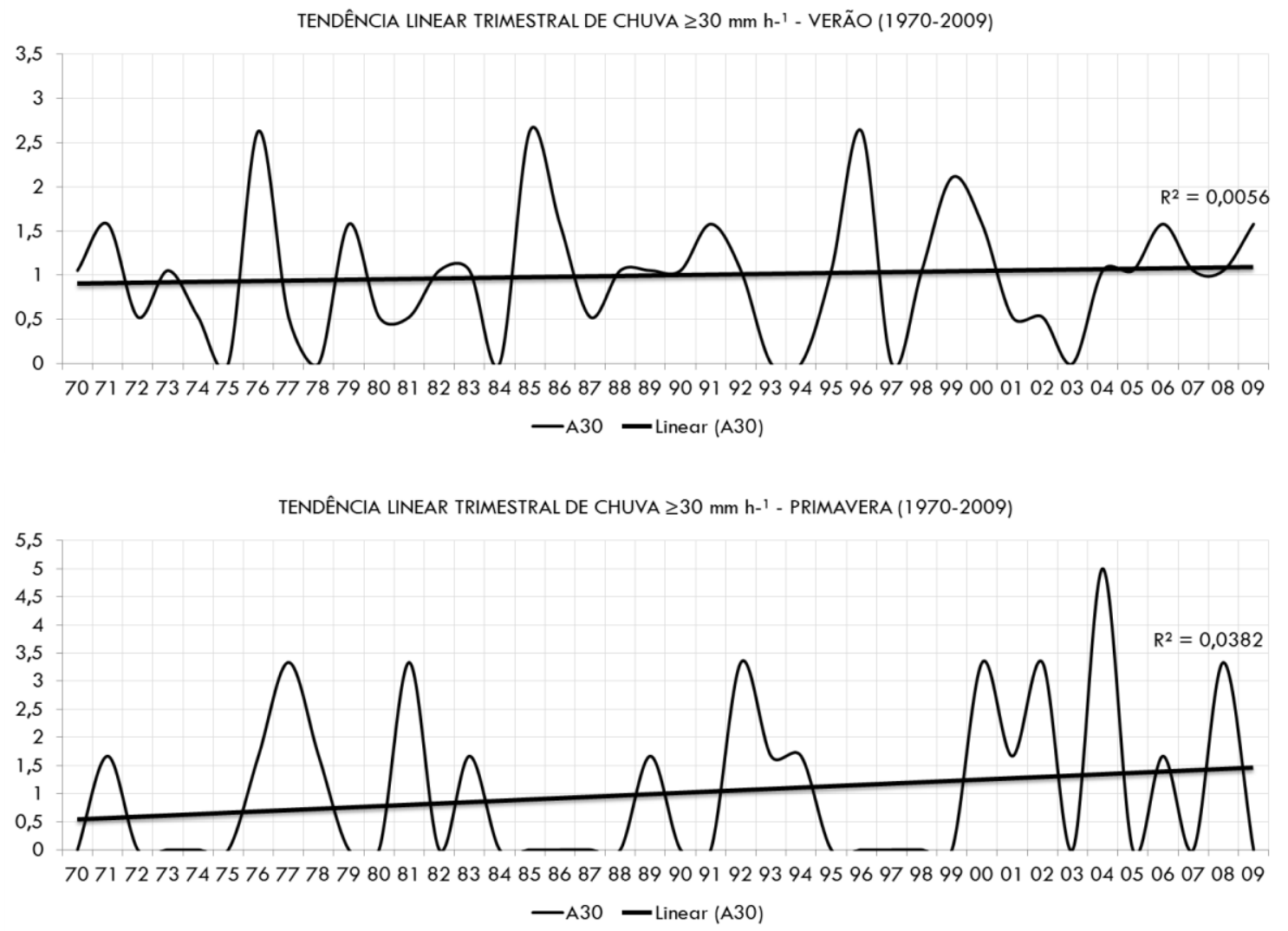

Figura 173 - Ajuste Linear Trimestral de chuva A30 para as Estações de Verão e Primavera, no Período de 1970 a 2009. 
De modo geral, os ajustes lineares mais significativos (inclinados) das fases do ONI foram positivos. O único caso de tendência linear negativo identificado foi durante a fase Neutra da estação de verão (Figura 174-177).
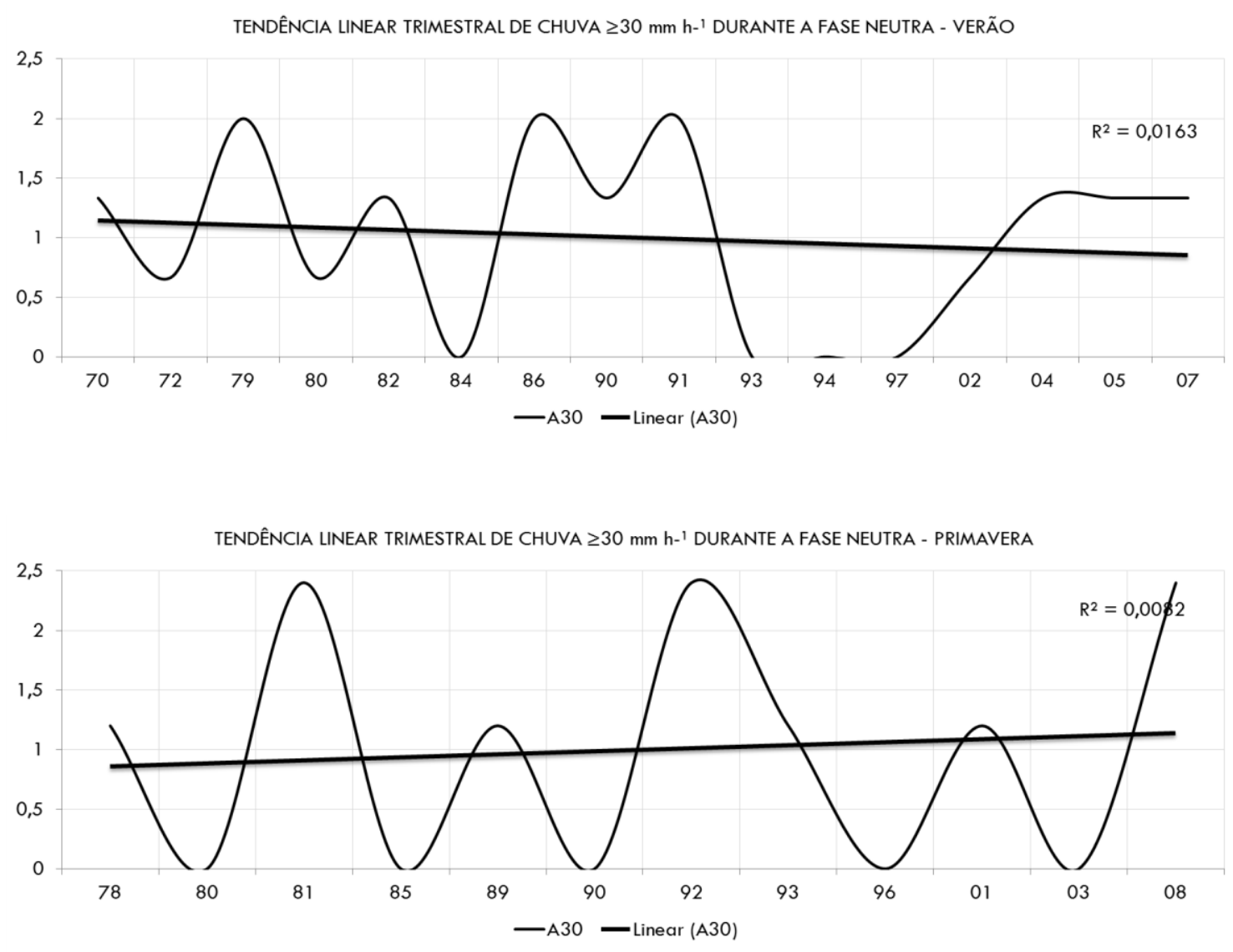

Figura 174 - Ajuste Linear Trimestral de chuva A30 para as Estações de Verão e Primavera, durante a Fase Neutra.

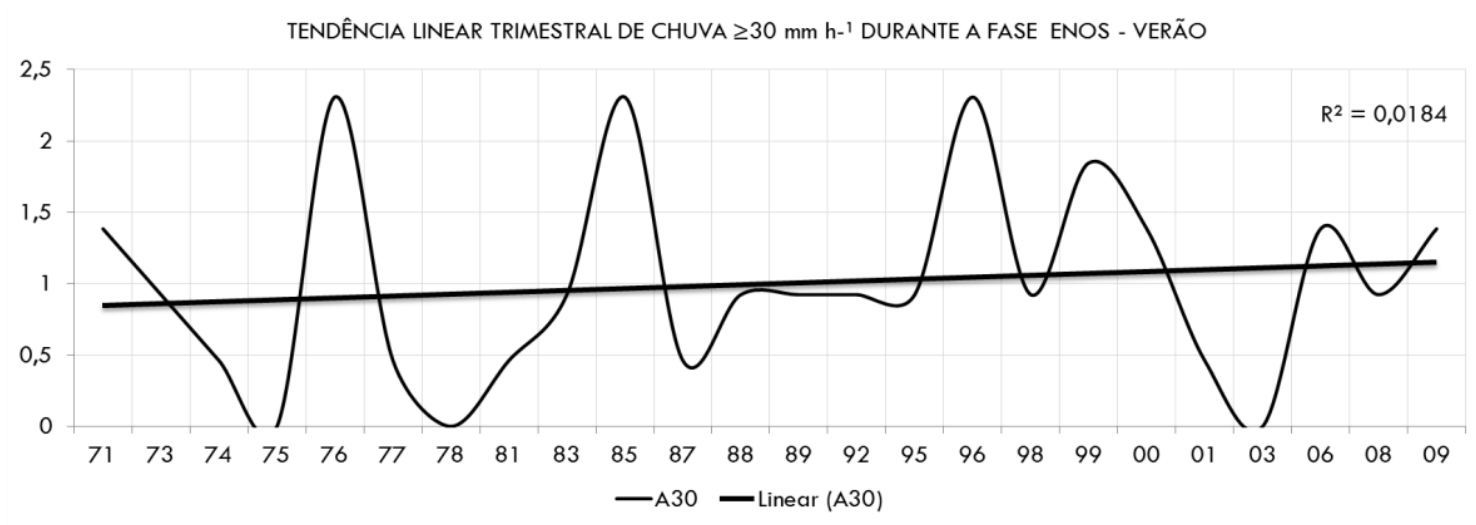

Figura 175 - Ajuste Linear Trimestral de chuva A30 para a Estação de Verão, durante a Fase ENOS. 


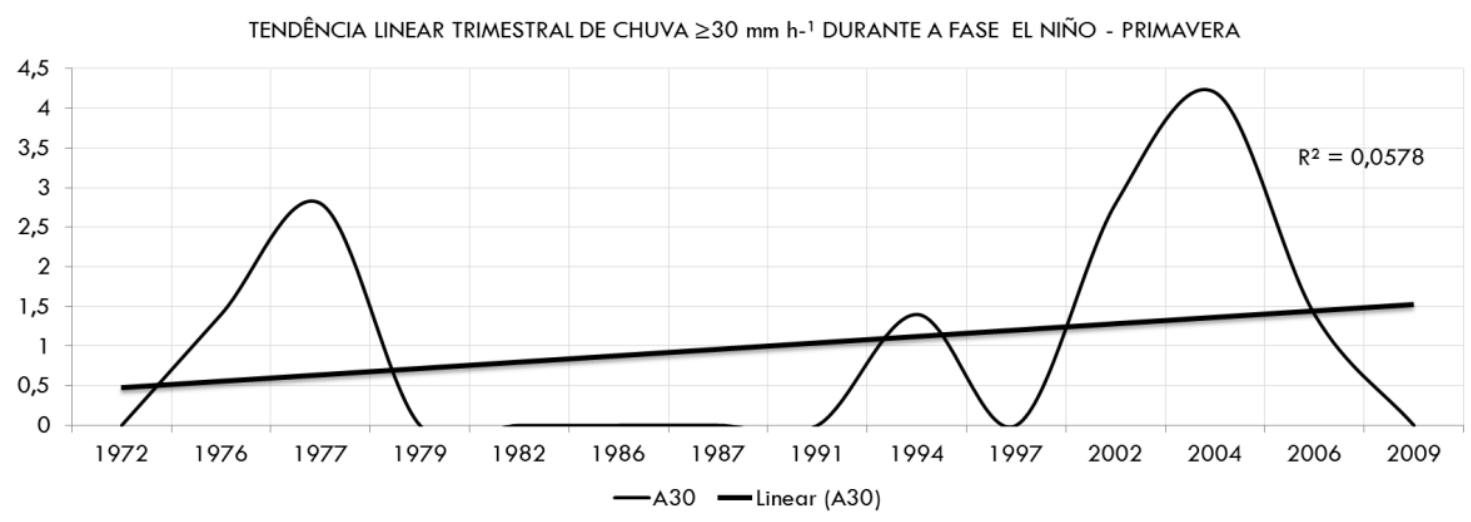

Figura 176 - Ajuste Linear Trimestral de chuva A30 para a Estação de Primavera, durante a Fase EN.
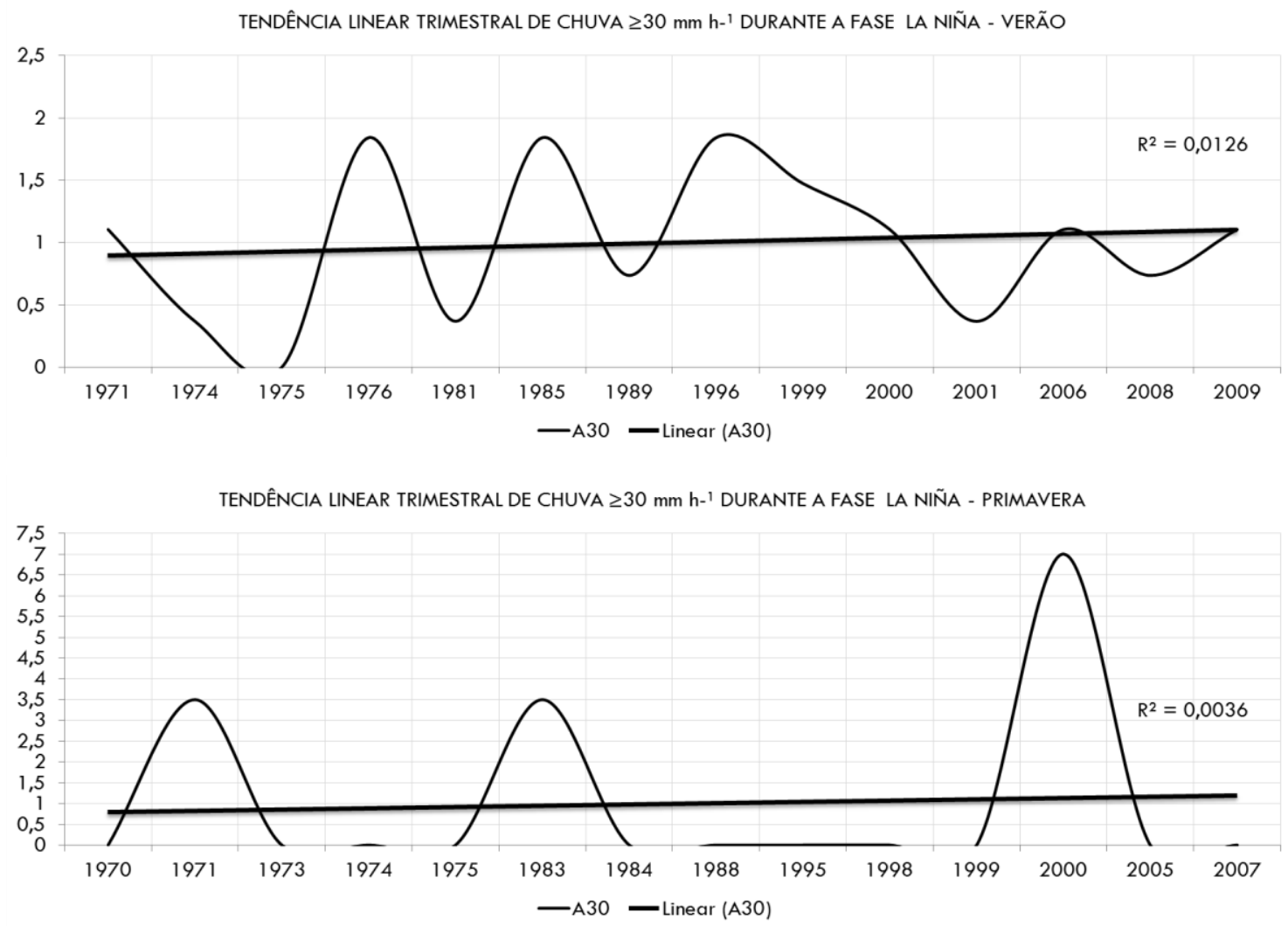

Figura 177 - Ajuste Linear Trimestral de chuva A30 para a Estação de Verão e Primavera, durante a Fase $L N$.

De modo geral, os ajustes lineares trimestrais positivos por fases também coincidem com os resultados identificados no trabalho de Cabral (2002), Sugahara et al (2009) e Freitas et al (2013). Ou seja, mesmo me séries temporais específicas o padrão de aumento da frequência de chuvas mais intensas se manteve. 
Tabela 67 - Correlação Linear Trimestral entre a Tendência Linear Trimestral de Chuva A30 e a Tendência Linear Trimestral do ONI incluindo as Fases, Neutra, ENOS, EN e LN.

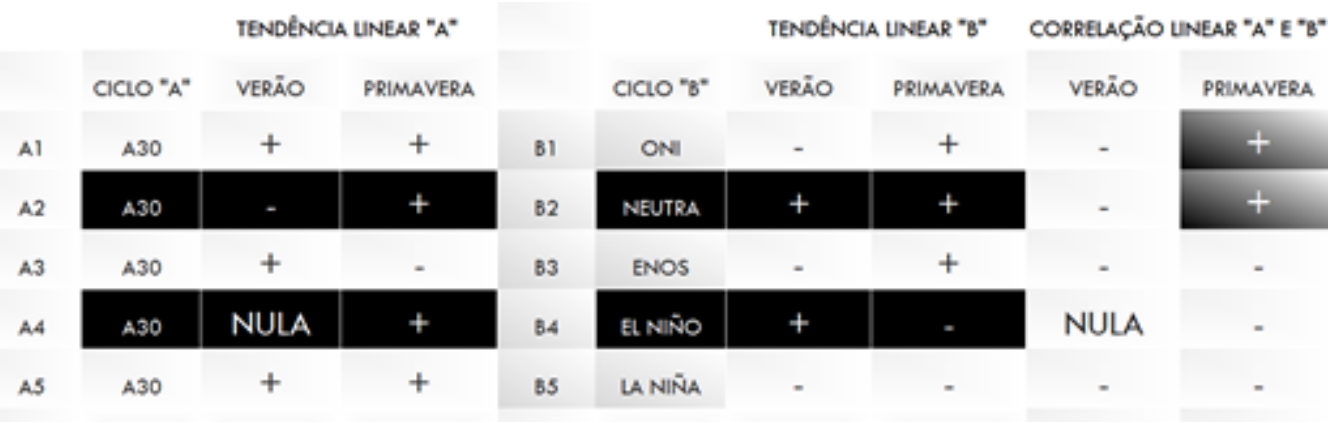

\subsubsection{1 - Variação Cíclica Trimestral}

A variação das anomalias da frequência de chuva A30 para o período de 1970 a 2009, para as quatro estações do ano está ilustrada na Figura 178.

VARIAÇÃO CÍCLICA TRIMESTRAL DE CHUVAS $\geq 30 \mathrm{~mm} \mathrm{~h}^{-1}$ - VERÃO (1970-2009)
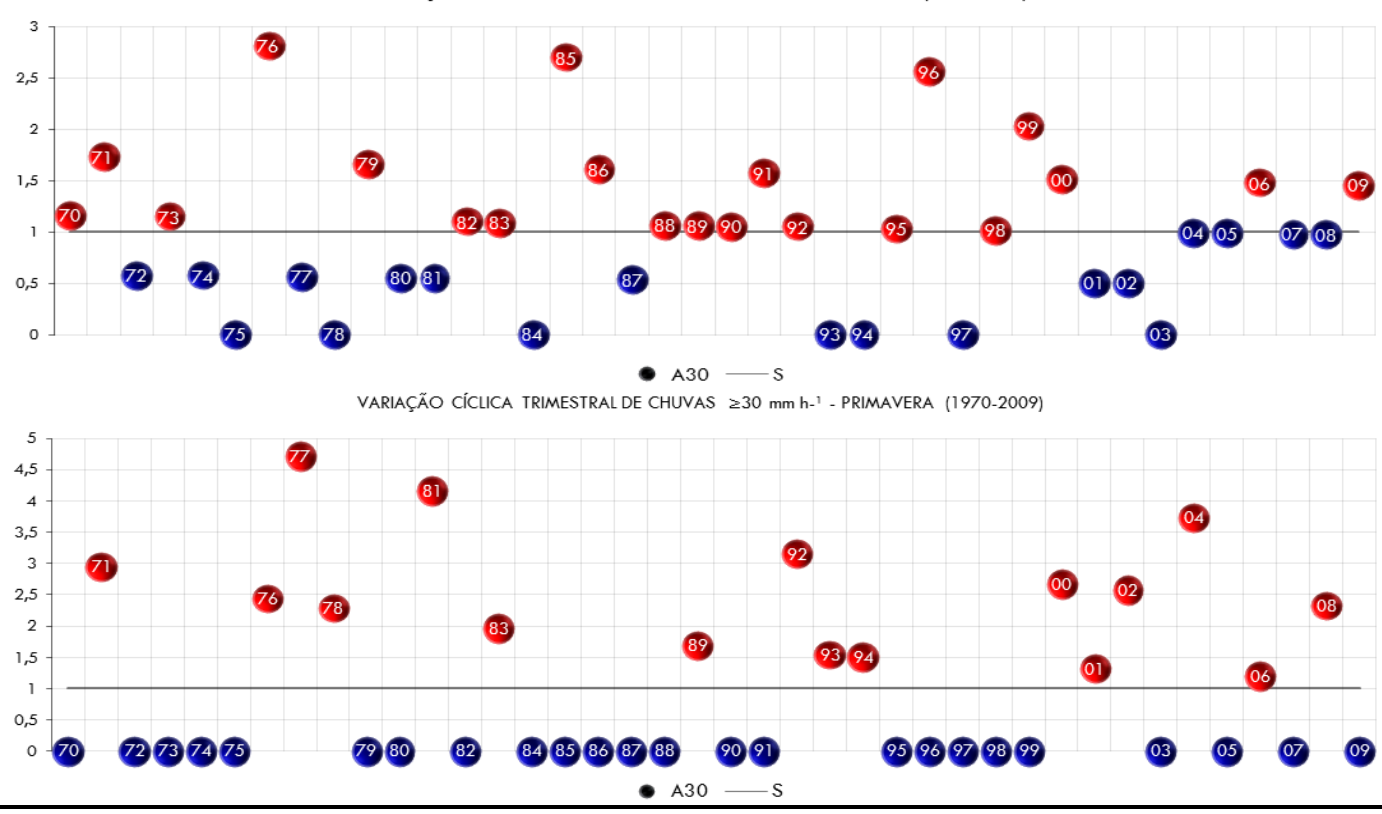

Figura 178 - Variação Cíclica Trimestral de Chuva A30, entre 1970 e 2009.

De forma geral, separando a série temporal em estações do ano, observamos que não correlação linear significativa entre as séries de ONI e frequência de chuva A30. A separação das séries temporais em eventos distintos quanto à TSM na região do Niño3.4 permitiu verificar que também não houve correlação linear entre estas duas variáveis durante oscilações específicas do ONI. 
Tabela 68 - Correlação Cíclica entre a Frequência de Chuva A30 observada na Estação do IAG e os Valores de ONI para Cada Estação do Ano e, para Cada Condição de Anomalia na Região de Niño3.4 (Eventos Neutros, ENOS, EN e LN).

\begin{tabular}{|c|c|c|c|c|c|c|c|}
\hline VERÄO & PELMAVEeA & VERÃo & PRLMAVERA & VERÄO & PRIMAVERA & VERÄO & PRIMAVERA \\
\hline A) & A] & CNa & ONd & $-0,004$ & $-0,104$ & NR̈O SIGNUFICATIVO & NüO SHCAUEACAIIVO \\
\hline 12 & 12 & Neutro & Neutbo & 0,243 & 0,354 & Mäo signaficativo & NẄO SGGAEICATIVO \\
\hline A 3 & $A^{3}$ & envos & ENOS & $-0,3$ & $-0,0020$ & NïO SHGNaFicativo & NÄO SIGANEACATIVO \\
\hline As & MS & A MANOO & EL NETOO & 0,518 & $-0,496$ & NÄO SIGNAFCATIVO & NÄO HCEUPCAIIVO \\
\hline As & as & UNEKA & uneria & 0,132 & 0,342 & NẌO STGMARCATVO & NR̈O SIGNEICATIVO \\
\hline
\end{tabular}

\subsubsection{2- Análise Específica das Fases Trimestrais}

Os resultados de tal análise revelam as possíveis correlações existentes entre as fases altas e baixas da frequência de Chuva A30 e do ONI. Neste caso, identificamos à série específica através das fases altas $(\bar{x}>1)$ e baixas $(\bar{x}<1)$ da variação cíclica da frequência trimestral de chuva A30. A variação cíclica de chuva A30 no período de 1970 a 2009 durante a estação de verão foi composta por 25 fases específicas. A partir do resultado negativo da correlação linear entre a tendência positiva de chuva A30 e a tendência negativa do ONI, procuramos identificar as fases da oscilação que possivelmente estiveram associadas a tal comportamento. Neste caso, deduzimos que somente as fases altas estariam correlacionadas com a chuva A30 e, fases baixas com o ONI (Figura 179). Em função dessa probabilidade, identificamos nos anos $73,79,85$ e 86 as fases altas que estariam significativamente e positivamente correlacionadas com a chuva $A 30$ e, nos anos 72, 74, 80, $81,01,02,07$ e 08 as fases baixas que estariam significativamente e positivamente correlacionadas com o ONI (Tabela 69). A variação cíclica de chuva A30 no período de 1970 a 2009 durante a estação da primavera foi composta por 28 fases específicas. A partir do resultado positivo da correlação linear entre a tendência positiva de chuva A30 e a tendência positiva do ONI, procuramos identificar as fases da oscilação que possivelmente estiveram associadas a tal comportamento. Neste caso, deduzimos que somente as fases altas estariam correlacionadas (Figura 179). Em função dessa probabilidade, identificamos nos anos 76, 77, 
$78,00,01,02,04$ e 06 as fases altas que estiveram significativamente e positivamente correlacionadas com a correlação positiva entre a chuva A30 e o ONI (Tabela 69).
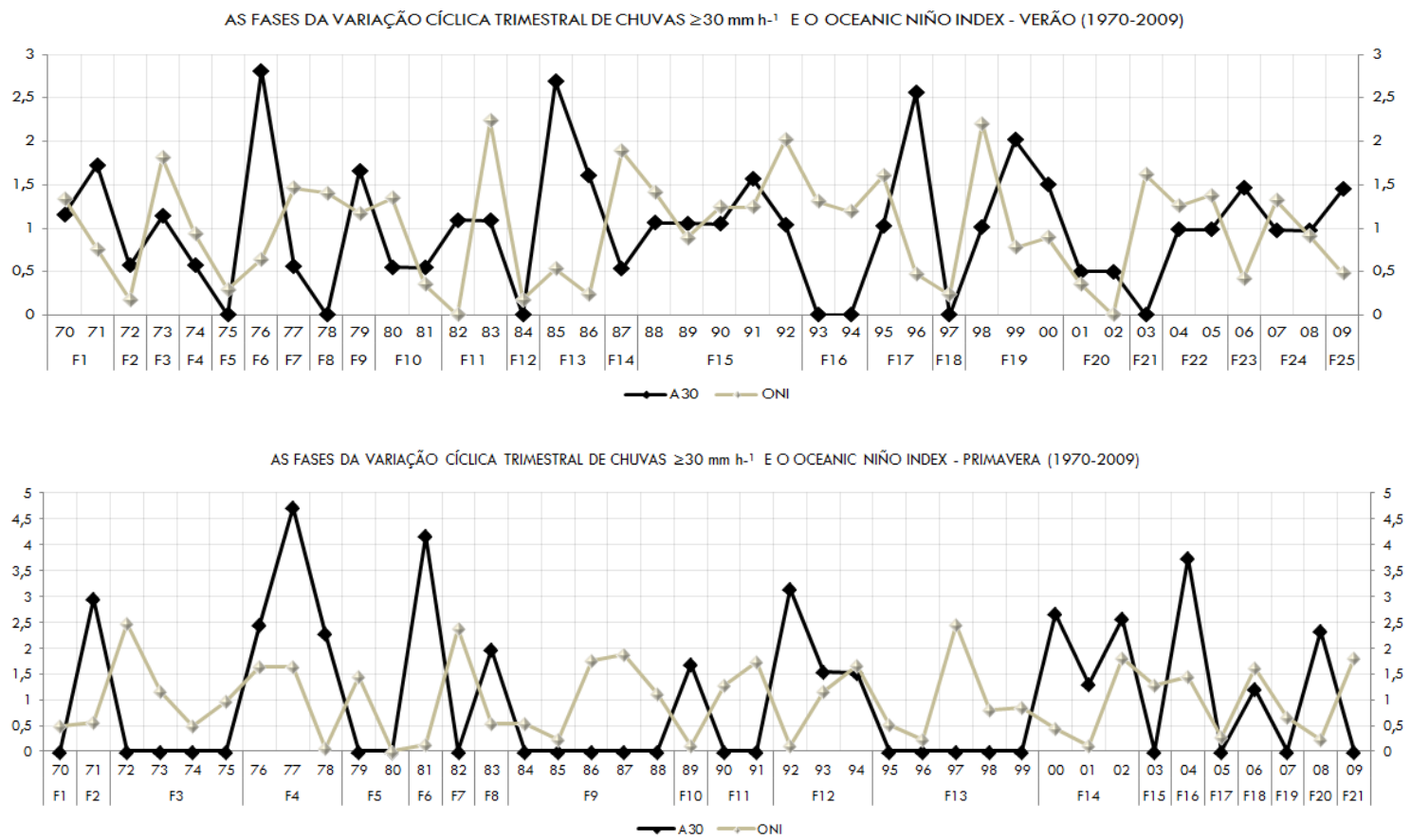

Figura 179 - Fases Específicas do Ciclo Trimestral de Chuva A30, Verão e Primavera. A linha Branca corresponde à variação cíclica do ONI e a linha Preta de Chuva A30, para o Período de 1970-2009. Na tabela, a direita do gráfico, a cor azul indica às fases baixas e a cor vermelha as fases altas.

Tabela 69 - Correlação Linear entre a Frequência de Chuva A30 observada na Estação do IAG e os Valores de ONI para Cada Estação do Ano e, para Cada Condição de Anomalia na Região de Niño3.4 (Eventos Neutros, ENOS, EN e LN). "A" representa as Séries Temporais de Chuva A30 relativa às Séries Temporais do ONI "B". Assim, B1 (ONI), B2 (Neutro), B3 (ENOS), B4 (EN) e B5 (LN). Correlação "A" são os Tipos Fases Correlacionadas com a Chuva A30 e Correlação "B" são os Tipos Fases Correlacionadas com o ONI.

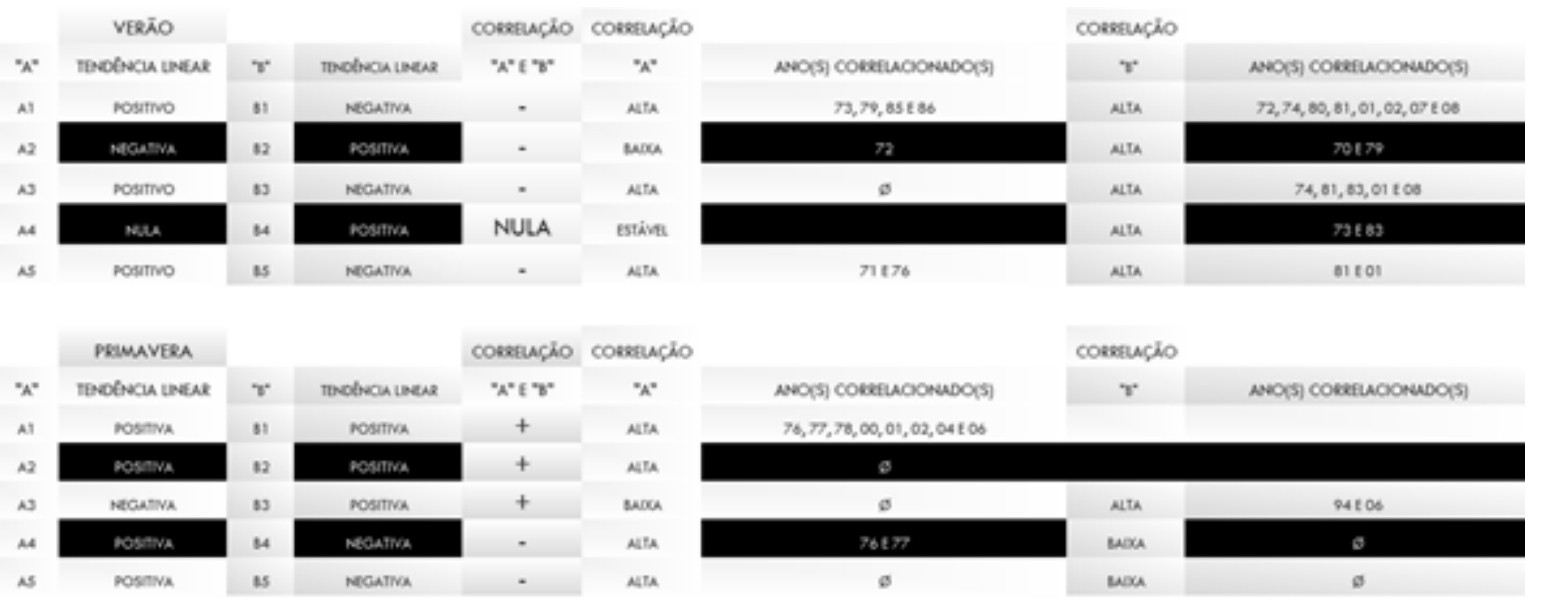




\subsubsection{3- A Hipótese Inicial e a Conclusão Final - A30 II}

A conclusão final para análise trimestral de chuva A30 parte das distintas correlações identificadas, para cada estação climática, envolvendo o ajuste linear dos índices do ONI na região Niño3.4 e a frequência de chuva A30. No verão, observamos que o ajuste linear negativo do ONI não coincidiu positivamente com o ajuste linear de chuva A10. Na primavera, observamos que $\circ$ ajuste linear positivo do ONI coincidiu positivamente com $\circ$ ajuste linear de chuva A30. A Tabela 69 apresenta os resultados das demais correlações realizadas para as séries temporais do ONI em cada estação climática do ano. Após identificarmos as respectivas correlações lineares trimestrais entre a chuva A30 e o ONI, analisamos os resultados das correlações cíclicas trimestrais. Neste caso, não encontramos nenhuma correlação cíclica significativa (Tabela 68). Em função da ausência de correlações significativas nas variações cíclicas, não foi possível realizar uma possível combinação de resultados e, assim deduzimos que o mais provável é que tenham ocorrido alterações isoladas e lineares na frequência de chuva A30.

\subsection{1- Chuva Extrema}

As chuvas definidas como sendo extremas e que possivelmente são produzidas a partir de sistemas atmosféricos do tipo "Multicélula", normalmente proporcionam tempestades severas que serão responsáveis por precipitações superiores ao limite inferior de $50 \mathrm{~mm} \mathrm{~h}^{-1}$. Ao analisar este tipo de chuva a intenção é a de concluirmos para a série temporal de 1970 2009, a existência ou não, de uma evolução no quadro de suas frequências. Nestas análises também incluímos a identificação os períodos e os horários de suas ocorrências. Neste caso, especificamente, esta sendo levada em consideração, apenas, a realização da análise de correlação de caráter qualitativo, na intenção de apresentar os possíveis feedbacks de acordo com a hipótese inicial deste estudo. De acordo com tal hipótese, o estudo estabelece para este caso, uma reflexão a partir da possibilidade de haver uma influência, analisada a partir 
da observação de uma coincidência envolvendo a combinação de dois fatores climáticos. No caso, tais fatores seriam os períodos mais aquecidos da Oscilação Decadal do Pacífico e do Oceanic Niño Index. Para compreender a razão de tal correlação é preciso compreender a contextualização na qual as frequências de Chuva Extrema estão associadas. Ou seja, a Chuva Extrema está associada a fenômenos e não a fatos. Desta forma, o estudo leva em consideração, em suas análises, que os fenômenos são raros e os fatos corriqueiros. Assim, análises dos comportamentos lineares não foram à prioridade, uma vez que ao identificar um fenômeno foi necessários avaliar o grau de combinação envolvendo os fatores atuantes (ODP e ONI) e, assim apresentar argumentos que possam contribuir para a busca do mais próximo possível do que seria a verdade científica.

\subsection{1 - Frequência Anual e a os Limites Extremos}

De modo geral, apesar do ângulo de inclinação obtida a partir do ajuste linear, a frequência anual de Chuva Extrema (CE) indicou o aumento nas intensidades máximas ao longo do período de 1970 e 2009. Apesar da insignificância estatística, analisou-se o resultado consciente da característica da variável calculada. Desta forma avaliou-se a frequência a partir da contagem do número de casos por década e calculou-se a média dos limites máximos destes períodos em função da diferença entre as quantidades obtidas. $O$ resultado observado na (Figura 180) revela que a maioria dos casos de Chuva Extrema ocorreu na década de 2000. O aumento do limite máximo obtida a partir da diferença entre as médias das décadas anteriores e a de 2000 foi de aproximadamente $8 \mathrm{~mm} \mathrm{~h}^{-1}$.

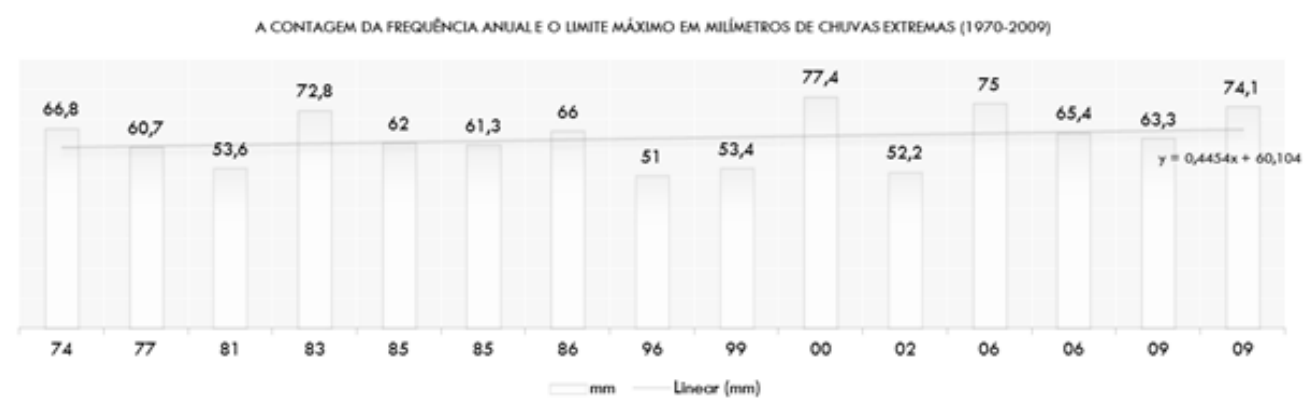

Figura 180 - Frequência Anual de Chuva Extrema e os Limites Máximos (mm) obtidos a partir da Estação do IAG-USP, no Período de 1970 a 2009. 
Analisando especificamente cada ano em relação aos respectivos comportamentos da ODP e da ONI foi possível notar os anos de 1981, 1983, 1985, 1986 e 1996 coincidiu com as fases altas $(\geq 0,5)$ da ODP e, por outro lado, os anos de 1977 e 2002 com a fase El Niño da ONI. No caso, não houve combinação dos fatores climáticos (ONI e ODP). No entanto, foi possível observar todos os casos da década de 80 coincidiram com os respectivos períodos mais aquecidos da ODP.

\subsection{2- Frequência Trimestral}

De modo geral foi possível notar na Figura 181 que as frequências de Chuva Extrema estiveram praticamente concentradas nos três primeiros meses do ano, ou seja, no trimestre de verão. Neste caso, aproximamos a série temporal com os episódios de ocorrência deste tipo de chuva, onde deduzimos que a correlação estabelecida anualmente, no tópico anterior, quando analisadas em uma escala trimestral, nos revelou que houve um aumento de anos correlacionados com a ODP. No caso, os anos $77,81,83,85,86,96$ e 06 . Por outro lado, em relação à ONI, observamos dois anos correlacionados, o de 77 e o de 83.

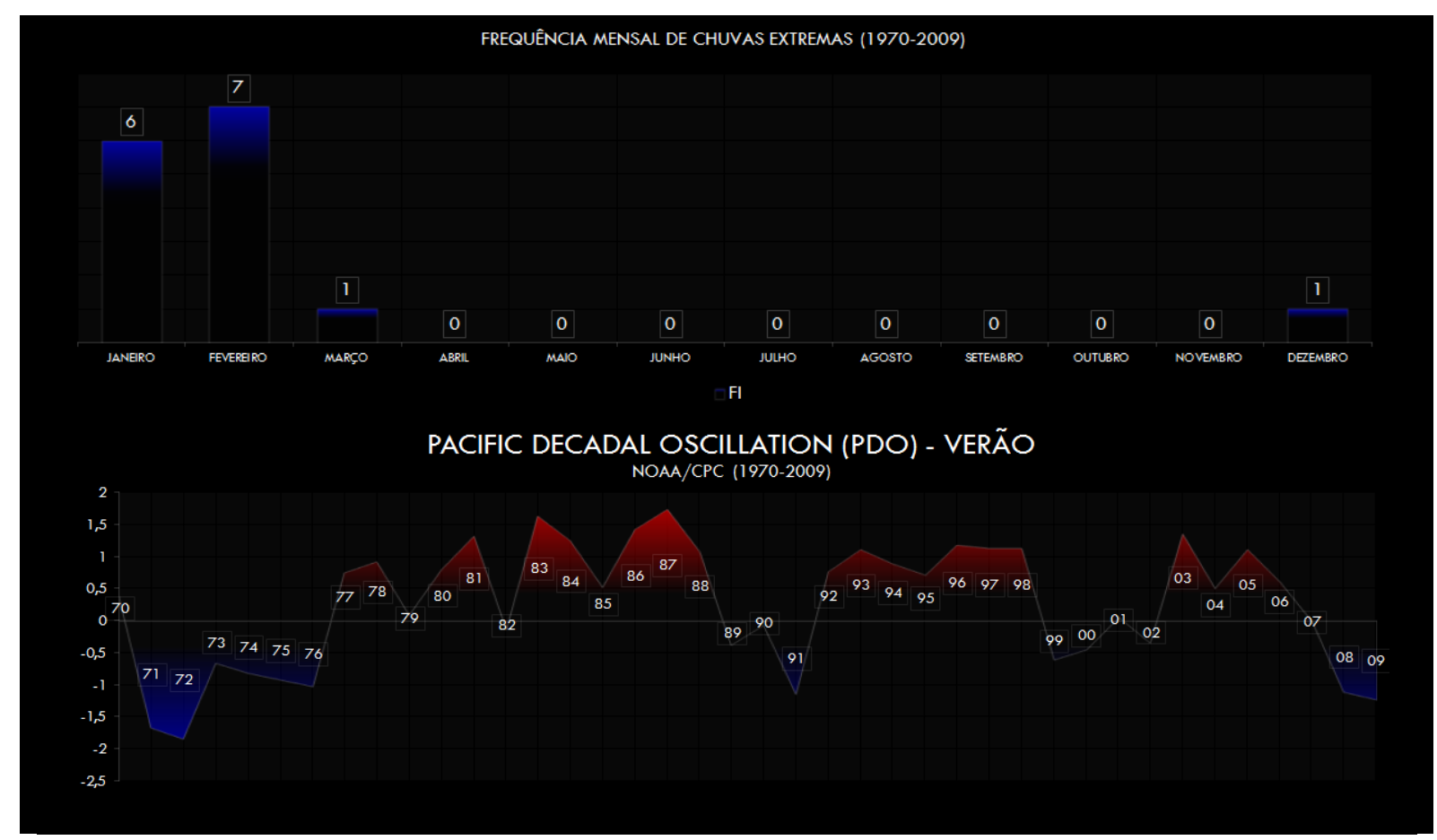




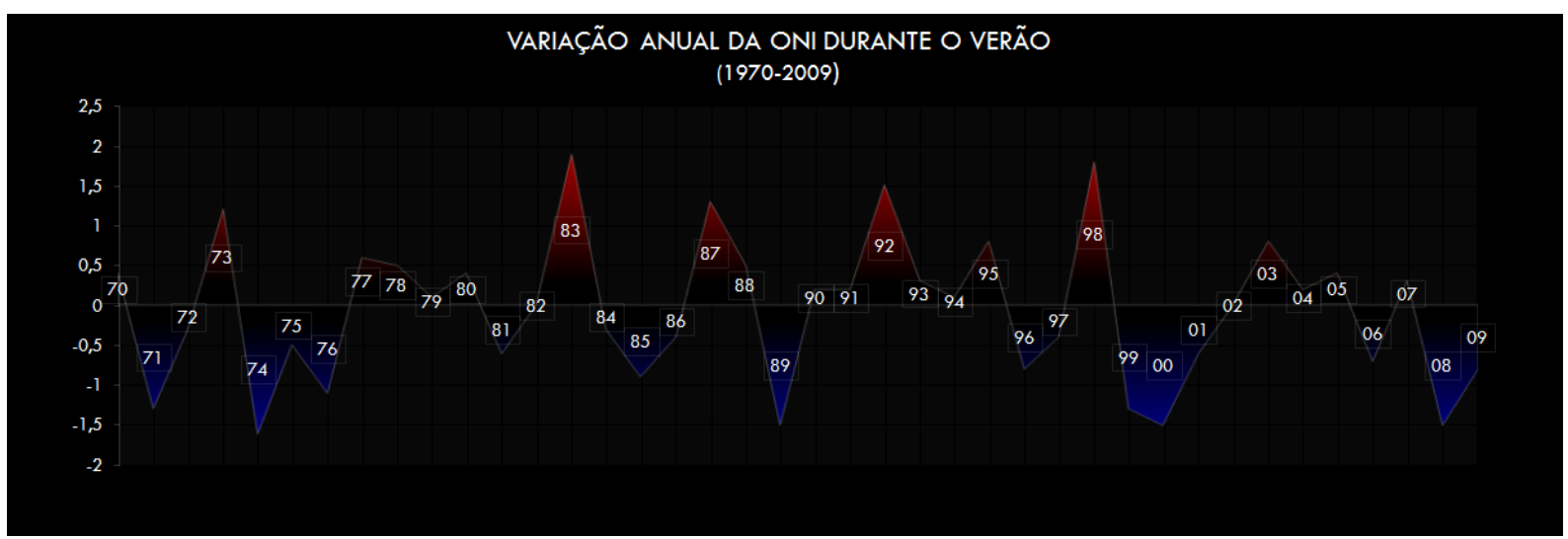

Figura 181 - Frequência Mensal de Chuva Extrema e os Índices de Verão da ODP e ONI, no Período de 1970 a 2009.

\subsection{3- Frequência Mensal}

De modo geral foi possível notar que até o momento, a Chuva Extrema de 1983, esta sendo o principal destaque em todas as correlações realizadas, uma vez que neste ano coincidiram na escala temporal anual e trimestral, os dois fatores climáticos analisados (ONI e ODP). O segundo ano identificado com maior probabilidade foi o de 1977 que apresentou as mesmas condições, porém os valores da ONI e ODP foram menos intensos. A análise da frequência mensal realizada a partir da data de ocorrência de cada episódio, de acordo com a Tabela 70 e a Figura 182 apresentou uma conclusão definitiva e, compreendida como sendo o terceiro argumento utilizado para justificar a possível existência da hipótese inicial apresentado na introdução deste tópico.

Tabela 70 - Cronologia de Episódios de Chuva Extrema no Período de 1970 a 2009.

\begin{tabular}{|ccccccccc|}
\hline & 74 & 77 & 81 & 83 & 85 & 85 & 86 \\
$\mathrm{~mm}$ & 66,8 & 60,7 & 53,6 & 72,8 & 62 & 61,3 & 66 \\
$\mathrm{~min}$ & 53 & 48 & 60 & 60 & 52 & 60 & 45 \\
Data & $19 / 01 / 1974$ & $01 / 01 / 1977$ & $10 / 02 / 1981$ & $12 / 02 / 1983$ & $17 / 02 / 1985$ & $18 / 02 / 1985$ & $08 / 01 / 1986$ \\
Hora & $15: 00$ & $17: 00$ & $15: 00$ & $16: 00$ & $13: 00$ & $16: 00$ & $14: 00$ \\
\hline Intensidade & 1,260377358 & 1,26458333 & 0,89333333 & 1,21333333 & 1,19230769 & 1,02166667 & 1,46666667 \\
96 & 99 & 00 & 02 & 06 & 06 & 09 & 09 \\
51 & 53,4 & 77,4 & 52,2 & 75 & 65,4 & 63,3 & 74,1 \\
60 & 60 & 60 & 60 & 45 & 45 & 60 & 60 \\
$27 / 01 / 1996$ & $26 / 02 / 1999$ & $12 / 01 / 2000$ & $28 / 01 / 2002$ & $08 / 02 / 2006$ & $31 / 12 / 2006$ & $07 / 02 / 2009$ & $17 / 03 / 2009$ \\
$18: 00$ & $17: 00$ & $17: 00$ & $20: 00$ & $15: 00$ & $15: 00$ & $17: 00$ & $15: 00$ \\
0,85 & 0,89 & 1,29 & 0,87 & 1,66666667 & 1,45333333 & 1,055 & 1,235 \\
\hline
\end{tabular}


EVOLUÇÃO ANUAL DOS DIAS E HORÁRIOS DAS OCORRÊNCIAS DE CHUVAS EXTREMAS (1970-2009)

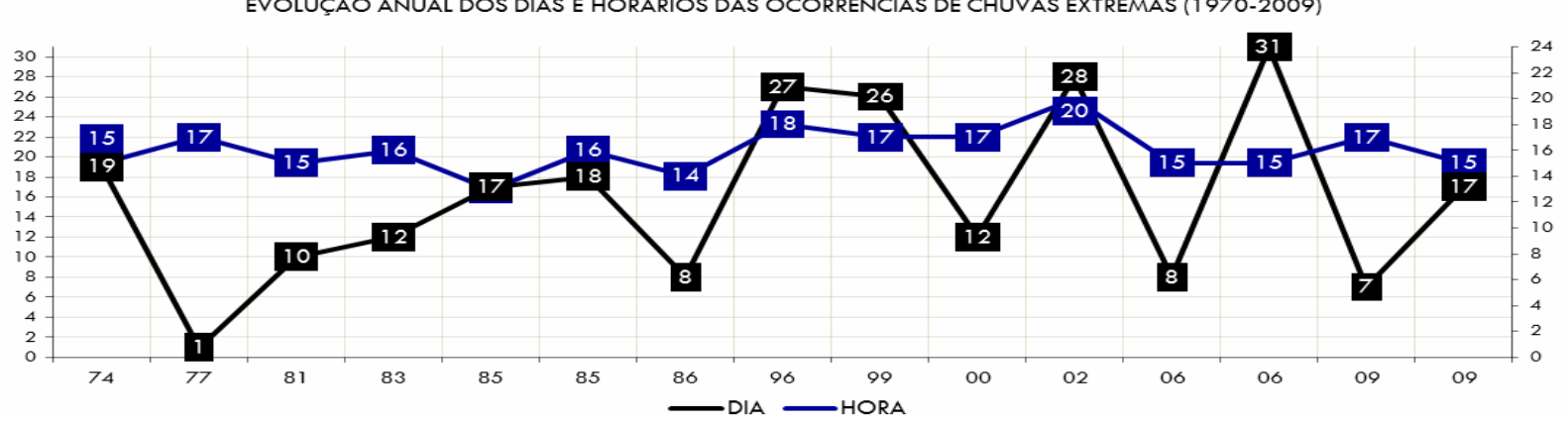

Figura 182 - Cronologia de Episódios de Chuva Extrema no Período de 1970 a 2009. O Horário da Ocorrência (Linha Azul) e o Dia (Linha Preta).

O primeiro mês analisado foi o de janeiro. A Figura 183 apresentou, para este mês, - gráfico da variação cíclica da ODP e da ONI ao longo da série temporal. Neste caso, foram analisados os anos de 1974, 1977, 1986, 1996, 2000 e 2002.

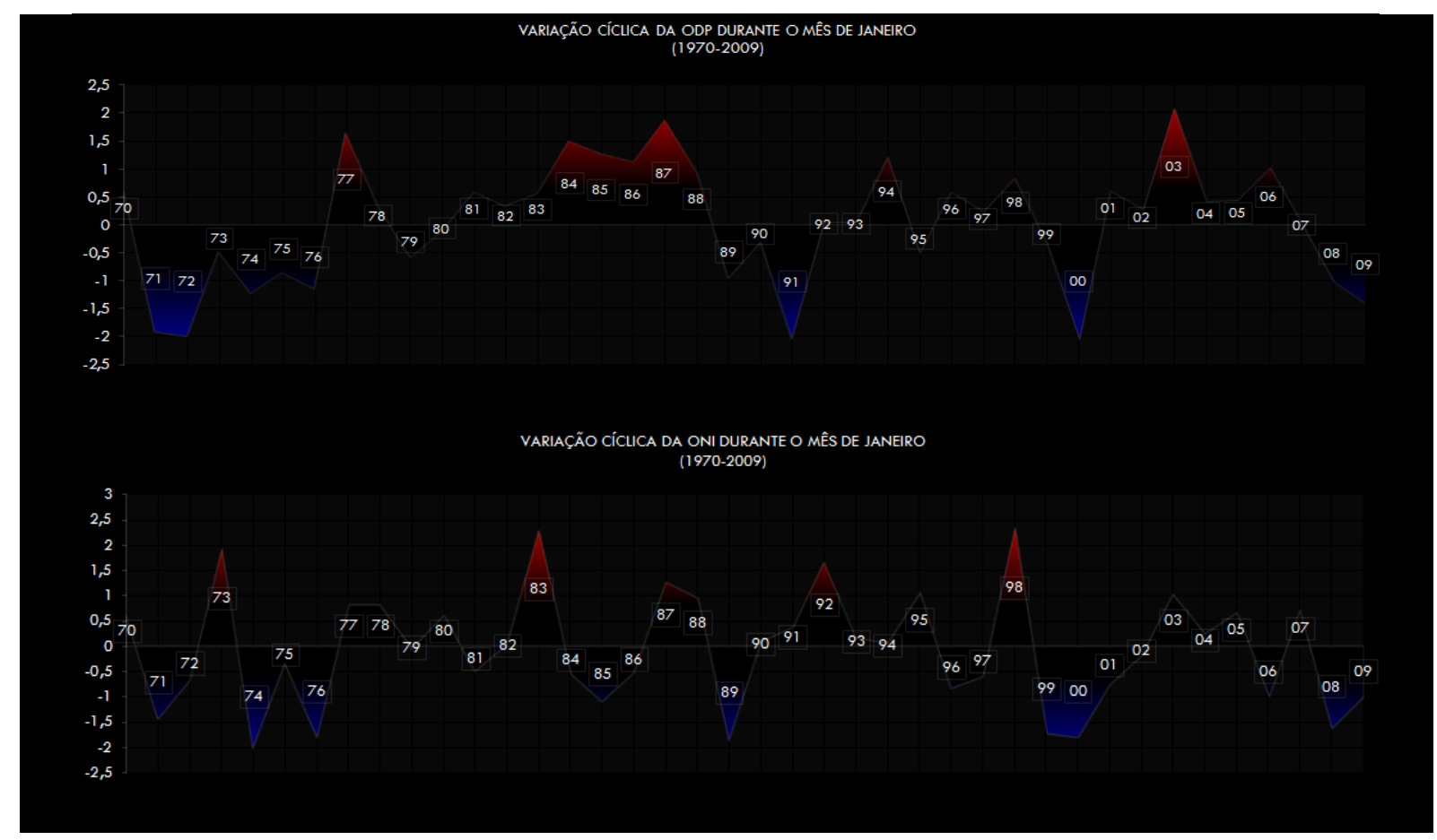

Figura 183 - Variação Cíclica da ODP e da ONI durante o Mês de Janeiro, no Período de 1970 a 2009.

A conclusão final constatou que a partir de todos os resultados envolvendo cada escala temporal analisada que, muito provavelmente em função de coincidir em todos os casos a combinação dos fatores climáticos da ODP e do ONI que o episódio de Chuva Extrema 
ocorrido no ano de 1977 esteve positivamente correlacionado com as alterações de temperatura na TSM, da região Niño 3.4.

O segundo mês analisado foi o de fevereiro. A Figura 184 apresentou, para este mês, o gráfico da variação cíclica da ODP e da ONI ao longo da série temporal. Neste caso, avaliamos os anos de 1981, 1983, 1985, 1999, 2006 e 2009.

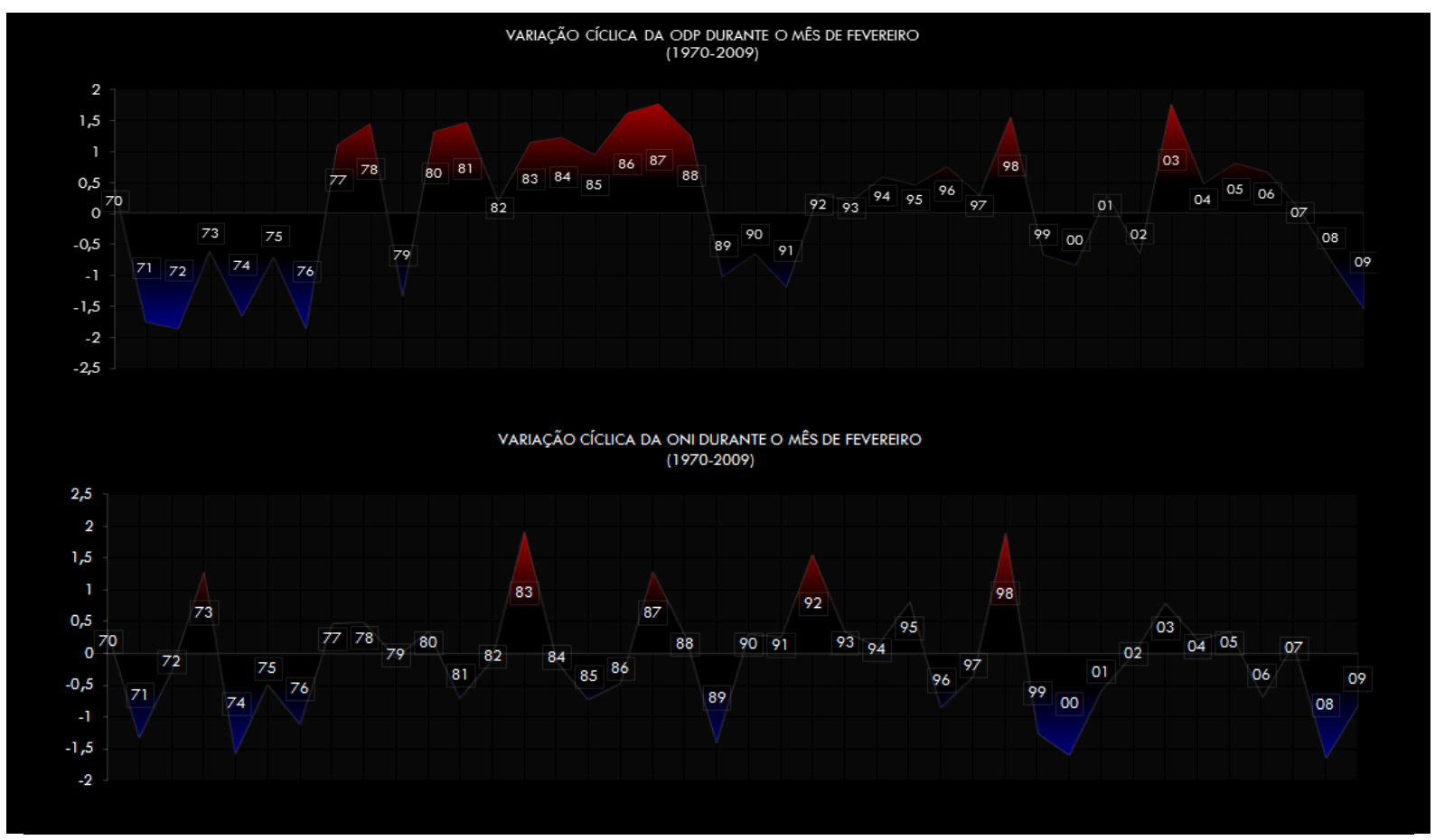

Figura 184 - Variação Cíclica da ODP e da ONI durante o Mês de Fevereiro, no Período de 1970 a 2009.

A segunda conclusão final constatou que a partir de todos os resultados envolvendo cada escala temporal analisada que, muito provavelmente em função de coincidir em todos os casos a combinação dos fatores climáticos da ODP e da ONI que os dois episódios de Chuva Extrema no ano de 1983 estiveram positivamente correlacionados com as alterações de temperatura na TSM, da região Niño 3.4.

O terceiro e o último mês analisado foi o de dezembro. A Figura 185 apresentou, para este mês, o gráfico da variação cíclica da ODP e da ONI ao longo da série temporal. Neste caso, o único ano avaliado foi o de 2006. 


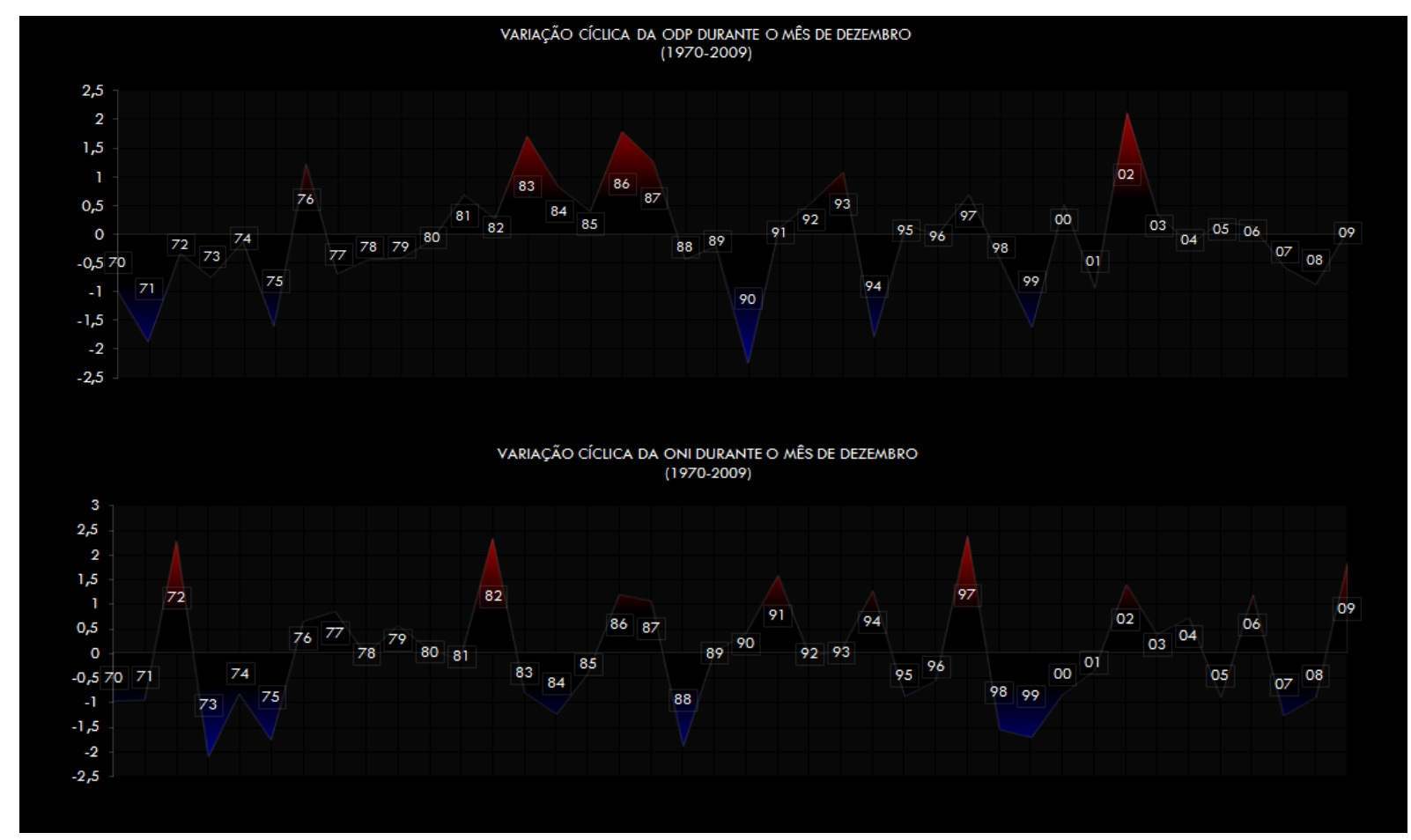

Figura 185 - Variação Cíclica da ODP e da ONI durante o Mês de Dezembro, no Período de 1970 a 2009.

A conclusão final constatou a partir de todos os resultados envolvendo cada escala temporal analisada quando correlacionados anualmente e trimestralmente com a ODP que, a presença da combinação dos fatores climáticos na escala mensal contribuiu para deduzirmos que o episódio de Chuva Extrema ocorrido no ano de 2006 sofreu de alguma forma a influência das alterações na temperatura da TSM, na região Niño 3.4. 


\section{V - CONCLUSÕES E CONSIDERAÇÕES FINAIS}

O estudo realizado, denominado de -Análise Estatística de uma Série Histórica de Precipitação Horária na Cidade de São Pauloll, permitiu verificar a tendência linear da frequência de precipitação horária para os limiares 0,1 a 0,25 mm h-1, 0,25 a 1,0 mm h-1, 1,0 a $4,0 \mathrm{~mm} \mathrm{~h}-1,4,0$ a $16,0 \mathrm{~mm} \mathrm{~h}-1,16,0$ a $50,0 \mathrm{~mm} \mathrm{~h}-1$, incluindo amostras de chuvas maiores e iguais a $10,0 \mathrm{~mm} \mathrm{~h}^{-1}, 20,0 \mathrm{~mm} \mathrm{~h}^{-1}$ e $30,0 \mathrm{~mm} \mathrm{~h}-1$, Chuvas Extremas superiores a $50,0 \mathrm{~mm} \mathrm{h-1}$ e Chuvas Intensas. A partir desta classificação da intensidade da chuva horária foram estabelecidas correlações lineares entre o índice ENOS, Oceanic Niño Index - ONI, e as séries da frequência da precipitação observada na estação meteorológica do IAG-USP, nas escalas sazonal e anual. Toda a análise ateve-se ao período de 1970 a 2009 . Este estudo baseou-se nos resultados relativos ao aumento da frequência de chuva intensa na região sudeste da América do Sul como mostrado por Liebmann et al. (2004), Pereira Filho e Xavier (2010), Cabral (2012), Machado (1993), Marengo (2012), Soares e Dias (1986) e França (1945), além de basear-se em resultados sobre a relação entre a ocorrência da precipitação na América do Sul e eventos ENOS, como indicado em Grimm (2000), Ambrizzi (2011) e Zilli (2007). A análise particularizada para as quatro estações do ano propõe mais precisão à análise com valores anuais. Supôs-se que a correlação linear entre a frequência de vários tipos de chuva e o ONI, em suas diferentes fases, pudesse prover novas informações sobre as possíveis associações entre a variabilidade da TSM do Pacífico Equatorial e a da precipitação na região sudeste do Brasil.

O ONI anual apresenta tendência geral positiva ao longo da série temporal analisada, de 1970 a 2009. A análise para os vários tipos de fases do ENOS evidencia que a série dos valores anuais formada apenas por eventos EN apresenta tendência linear baixa, levemente negativa; a série formada apenas por eventos ENOS apresenta tendência linear baixa e positiva; as séries formadas por eventos neutros e $L N$ apresentam tendência linear positiva com ordem de grandeza igual. Considerando todas as fases do ENOS, verificamos 
que a tendência linear da TSM no Pacífico Equatorial para o período considerado é positiva. Em relação aos resultados trimestrais, verifica-se que o ONI das estações de verão e outono apresenta pequena tendência linear negativa. Por outro lado, os valores de ONI nos meses de inverno e primavera apresentam tendência linear positiva, sendo que a tendência durante o inverno é o dobro da observada durante a primavera. A subdivisão da série temporal de ONI em períodos caracterizados por fases distintas de ENOS para cada estação do ano permitiu novas conclusões. Nas estações de inverno e primavera, caracterizadas por tendências lineares positivas de ONI, os anos que contribuem para este fato são os classificados como Neutros e ENOS.

A respeito dos resultados do ajuste linear feito para cada tipo de chuva considerado, identificou-se que, para o período de 1970 a 2009, os tipos de chuva definidos como Chuva Muito Fraca (MFA), Chuva Fraca (FA) e Moderada (MO) apresentam tendências lineares negativas e, por outro lado, os tipos Chuva Forte (FO), Chuva Muito Forte (MFO) e Chuva Extrema (CE) apresentam tendência linear baixa, mas positiva. Ou seja, a frequência das chuvas forte tende a aumentar enquanto que a frequência da chuva fraca tende a diminuir no município de São Paulo. Por último, os tipos de Chuva Intensa (Cl), Chuva superior a $10 \mathrm{~mm} \mathrm{h-1}$ (A10), Chuva superior a $20 \mathrm{~mm} \mathrm{~h}^{-1}$ (A20) e Chuva superior a $30 \mathrm{~mm} \mathrm{~h}^{-1}$ (A30) apresentaram tendências lineares positivas. Esta última conclusão foi obtida uma vez que todas estas classes, chuva superior a 10, 20 e 30 mm, são classificadas como chuva forte para o intervalo de uma hora. A frequência da Chuva Fraca tem diminuído em todas as estações do ano, exceto no verão. Durantes a fase Neutra dos eventos ENOS, a tendência à diminuição é observada também em todas as estações, exceto no verão. O aumento da frequência da Chuva Moderada é observado somente durante o verão. A frequência da Chuva Forte aumenta em todas as classes de ENSO, exceto no caso dos anos caracterizados por EN.

A cidade de São Paulo apresenta uma evolução urbana constante ao longo do tempo, assume-se que a ilha de calor associada a esta expansão se intensifica. Além da expansão urbana, entende-se que qualquer localidade está sujeita à variabilidade natural do 
clima. O aquecimento global, tal como citado nos relatórios do IPCC (2001, 2007), também pode estar associado às alterações climáticas observadas localmente. De forma contrária, podemos considerar que as alterações ocorridas localmente possam também influenciar o aquecimento global. De qualquer forma, a tendência positiva observada para chuva horária superior à Forte, superior a 4,0-16,0 milímetros, está associada aos três processos acima citados. Desta forma, consideramos que está em curso à redistribuição das chuvas no município de São Paulo quanto à sua intensidade, com a ocorrência de chuvas mais fortes e a diminuição de chuvas mais fracas nas últimas décadas. Outro aspecto importante obtido nesta análise é a alteração da frequência de cada tipo de chuva nas estações do ano. De modo geral, a frequência de chuvas mais fortes tem aumentado nas estações de verão, inverno e, principalmente, na primavera, enquanto que na estação de outono, a frequência tem diminuído ao longo do período considerado. Por outro lado, a frequência das chuvas mais fracas tem diminuído nas estações de outono, inverno e primavera. Na estação de verão não foi observada alteração significativa para o caso de chuva mais fraca.

Na perspectiva climática, a associação de chuvas mais intensas pode ser estudada ainda em relação a eventos diferentes de ENOS e o comportamento do Oceano Indico. Com o intuito de se investigar a associação de eventos severos de precipitação na região sudeste de São Paulo, estudos de caso podem ser analisados em relação ao sinal e intensidade de índices climáticos do Pacífico e Indico. O aumento da precipitação intensa na região sudeste do Brasil tem impacto direto nas enchentes urbanas e no movimento de massa na vertente oceânica da Serra do Mar, produzindo impacto na condição de moradia da população em várias áreas ocupadas. 


\section{VI - REFERÊNCIAS BIBLIOGRÁFICAS}

AMBRIZZI, T. O clima da terra. Processos, Mudanças e Impactos. Instituto de Astronomia, Geofísica e Ciências Atmosféricas. Departamento de Ciências Atmosféricas, Universidade de São Paulo. São Paulo, 2011.

AZEVEVEDO, T.R. Precipitação na cidade de São Paulo em função da atividade urbana. Universidade de São Paulo: Laboratório de Climatologia. Faculdade de Filosofia, Letras e Ciências humanas. USP, 2003.

AZEVEVEDO, T.R. Chove todo dia em São Paulo? Universidade de São Paulo: Laboratório de Climatologia. Faculdade de Filosofia, Letras e Ciências humanas. USP, 2003.

BARROS, M.T.L.; ZAMBON, R.C. Aula 4: Precipitação I. PHD 2308 - Hidrologia Ambiental. Escola Politécnica, Departamento de Engenharia Hidráulica e Ambiental, Universidade de São Paulo. São Paulo, 2012.

BASTOS, C.C; FERREIRA, N.J. Análise climatológica da alta subtropical do atlântico sul. Instituto Nacional de Pesquisas Espaciais - INPE. São José dos Campos, São Paulo, 2012.

BEIGUELMAN, B. Curso Prático de Bioestatística - 4a ed. rev. Sociedade Brasileira de Genética, Ribeirão Preto, 1996.

CABRAL, E. Tendências e variabilidade do fenômeno pluvial na região metropolitana de São Paulo e possíveis vinculações com o processo de urbanização. 2002. 182f. Tese (Doutorado em Geografia Física) - Departamento de Geografia, Universidade de São Paulo, São Paulo. 2002.

CATALUNHA, M.J. Avaliação de cinco funções densidade de probabilidade a séries de precipitação pluvial no estado de Minas Gerais. Departamento de Eng. Agrícola, Universidade Federal de Viçosa. Minas Gerais, 2003.

COELHO C.A.S., A.R.M. DRUMOND, T. AMBRIZZI, e G. Sampaio, 1999: Estudo Climatológico Sazonal da Precipitação sobre o Brasil em Episódios Extremos da Oscilação Sul. Rev.Bras.Meteo., 14(1), 49-65.

CONDE, F.C; DIAS, M.A.F.S; Caracterização das condições atmosféricas durante a ocorrência de Nevoeiro em São Paulo: um estudo de caso. Instituto de Astronomia, Geofísica e Ciências Atmosféricas. Departamento de Ciências Atmosféricas, Universidade de São Paulo. São Paulo, 1999.

CONTI, J.B. Aquecimento Global: Visão Apocalíptica ou Fenômeno Natural. Jornal de Opinião. Belo Horizonte, Minas Gerais. 2012.

COSTA, K.M.S. Variabilidade Oceânica Associada à Variabilidade Climática da Vazão na Bacia do Rio São Francisco. 2012. 163 f. Dissertação (Mestrado) - Faculdade de Filosofia Letras e Ciências Humanas, Universidade de São Paulo, 2012. 
DIAS, M.A.F.S. Efeito estufa e mudanças climáticas regionais. Departamento de Ciências Atmosféricas do Instituto de Astronomia, Geofísica e Ciências Atmosféricas, Universidade de São Paulo. São Paulo, 2006.

DIAS, M.A.F.S et al. Changes in extreme daily rainfall for São Paulo, Brazil. Climatic Change. no prelo. 2012.

DOMINGUES, L.M; DEGOLA, T.S.D. Veranicos no estado de São Paulo: rastreamento e correlação com as variáveis meteorológicas. Instituto de Astronomia, Geofísica e Ciências Atmosféricas. Departamento de Ciências Atmosféricas, Universidade de São Paulo. São Paulo, 2010.

ESTEVES, E. Introdução à Estatística Aplicada e Estatística Descritiva. Departamento de Engenharia Alimentar, Instituto Superior de Engenharia da Universidade do Algarve. Faro, Portugal. 2009.

FILHO, A.J.P. Evolução do tempo e do clima na região metropolitana de São Paulo. Organização de Augusto José Pereira Filho, Paulo Marques dos Santos e Terezinha de Maria Bezerra Sampaio Xavier - São Paulo: Linear B; IAG/USP, 2007. 282p.

FILHO, A.J.P. Chuvas de verão e as enchentes na grande São Paulo: El niño, brisa marítima e ilha de calor. Departamento de Ciências Atmosféricas do Instituto de Astronomia, Geofísica e Ciências Atmosféricas, Universidade de São Paulo. São Paulo, 2000.

FRANÇA, A. Estudo sobre o Clima da Bacia de São Paulo. 1945. 52f. Tese (Doutorado em Geografia) - Departamento de Geografia, Universidade de São Paulo, São Paulo. 1946.

FARIAS, A.M.L. Variáveis Aleatórias. Algumas Distribuições Discretas e Contínuas. Instituto de Matemática. Departamento de estatística, Universidade Federal Fluminense. Rio de Janeiro, 2008.

FREDIANI, M.E.B. Tempestades Severas. Departamento de Ciências Atmosféricas, Universidade de São Paulo. São Paulo, 2012.

FREITAS, E. D, SILVA DIAS, Maria A. F., DIAS, Juliana., CARVALHO, Leila M. V., SILVA DIAS, Pedro L. . Changes in extreme daily rainfall for São Paulo, Brazil. Climatic Change, v. 116, p. 705-722, 2013.

GRIMM, A.M., V.R. BARROS, AND M.E. DOYLE, 2000: Climate Variability in Southern South America Associated with El Niño and La Niña Events. J. Climate, 13, 35-58.

GALVANI, E. Tipos de Chuva: Frontal, convectiva e orográfica. FLG 0253 - Climatologia I. Departamento de Geografia, Universidade de São Paulo. São Paulo, 2012.

GIACOMELLO, C.P. Probabilidade e Estatística. Centro de Ciências Exatas, da Natureza e de Tecnologia, Universidade de Caxias do Sul. Rio Grande do Sul, 2012.

JÚNIOR, G.L.S. Econometria. Secretaria de Estado de Planejamento de Desenvolvimento Econômico. Centro de Educação Tecnológica do Amazonas. Amazonas, 2012.

KRÜGER, C.M.; DZIEDZIC, M. Drenagem Urbana. Prefeitura Municipal de Curitiba, Instituto Municipal de Administração Pública/IMAP. Plano de Desenvolvimento de Competências. Curitiba, 2010. 
LEITE, M.L.; ADACHESKI, P.A.; FILHO, J.S.V. Análise da frequência e da intensidade das chuvas em Ponta Grossa, Estado do Paraná, no período entre 1954 E 2001. Acta Scientiarum. Technology. Maringá, v. 33, n. 1, p. 57-64, 2011.

LIEBMANN, B. et al. An Observed Trend in Central South American Precipitation. Accepted. Journal of Climate, 2004.

MONTEIRO, C.A.F. Teoria e Clima Urbano. São Paulo: IGEO/USP.1976, 181 p. (Série Teses e Monografias, 25).

MONTEIRO, C.A.F.; MENDONÇA, F. Clima Urbano. São Paulo: Contexto, 2003.

MAGRIN, G., C. GAY GARCÍA, D. CRUZ CHOQUE, J.C. GIMÉNEZ, A.R. MORENO, G.J. NAGY, C. NOBRE AND A. VILLAMIZAR, 2007: Latin America. Climate Change 2007: Impacts, Adaptation and Vulnerability. Contribution of Working Group II to the Fourth Assessment Report of the Intergovernmental Panel on Climate Change, M.L. Parry, O.F. Canziani, J.P. Palutikof, P.J. van der Linden and C.E. Hanson, Eds., Cambridge University Press, Cambridge, UK, 581-615.

MACHADO, M.A. As Circulações Locais Associadas à Formação de Nevoeiro na Grande São Paulo. Dissertação de Mestrado, ACA/IAG/USP, 1993.

MARENGO, J.A. Mudanças Climáticas Globais e Efeitos sobre a Biodiversidade. Caracterização do clima atual e definição das alterações climáticas para o território brasileiro ao longo do Século XXI. Relatório No. 1. Caracterização do clima no Século XX e Cenários Climáticos no Brasil e na América do Sul para o Século XXI derivados dos Modelos Globais de Clima do IPCC. Ministério do meio ambiente. Secretaria de biodiversidade e florestas. Diretoria de conservação da biodiversidade. CPTEC/INPE. São Paulo, 2007.

MARENGO, J. A. et al. The climate in future: projections of changes in rainfall extremes for the Metropolitan Area of São Paulo (Masp). Climate Research. no prelo. 2012.

MARENGO, J. A. Água e mudanças climáticas. In: Estudos Avançados. 22 (63), p.83-96. 2008.

MET OFFICE. National Meteorological Library and Archive. Fact sheet No. 3 - Water in the atmosphere. United Kingdom, 2011.

MOLION, L.C.B, 2007: Aquecimento Global, El Niños, Manchas Solares, Vulcões e Oscilação Decadal do Pacífico. Departamento de Meteorologia, Universidade Federal de Alagoas, UFAL.

MELLO, C. R.; FERREIRA, D. F.; SILVA, A. M.; LIMA, J. M. Análise de modelos matemáticos aplicados ao estudo de chuvas Intensas. Revista Brasileira de Ciência do Solo, vol. 25, núm. 3, 2001, pp. 693-698 Sociedade Brasileira de Ciência do Solo Viçosa, Brasil.

NUNES, L.H. Distribuição espaço-temporal da pluviosidade no estado de São Paulo: Variabilidade, Tendências, processos intervenientes. 1997. 192f. Tese (Doutorado em Engenharia) - Escola Politécnica, Universidade de São Paulo, São Paulo. 1997.

NATIONAL OCEANIC AND ATMOSPHERIC ADMINISTRATION (NOAA). Climate prediction center (NCEP). ENSO Cycle: Recent Evolution, Current Status and Predictions. United States, 2012. 
PFAFSTETTER, O. Chuvas Intensas do Brasil. Rio de Janeiro, Departamento Nacional de Obras e Saneamento, 1956.

ROBERTSON, A.W.; E MECHOSO, C.R, 2000: Interannual and Interdecadal Variability of the South Atlantic Convergence Zone. Department of Atmospheric Sciences, University of California, Los Angeles, Los Angeles, California.

SANTOS, A.F.P. Probabilidade e estatística. Regressão Linear. Aula 8 de Estatística. Instituto de Matemática e Estatística, Universidade de São Paulo. São Paulo, 2012.

SANTOS, P.M. et al. Evolução Climática na Região Metropolitana de São Paulo. Instituto de Astronomia, Geofísica e Ciências Atmosféricas. Departamento de Ciências Atmosféricas, Universidade de São Paulo. São Paulo, 2003.

SUMNER, G.N. Precipitation: process and analysis. J. Wiley \& Sons, Chichester, UK, 1988.

SOARES, J. R.; DIAS, M. A. F. S. Probabilidade de ocorrência de alguns eventos meteorológicos Valores Extremos na cidade de São Paulo. Revista Brasileira de Meteorologia, São Paulo, v.2, n. 1, p.67-75, 1986.

SENTELHAS, P.C.; CRUCIANI, D.E.; PEREIRA, A.S.; VILLA NOVA, N.A. Distribuição horária de chuvas intensas de curta duração: um subsídio ao dimensionamento de projetos de drenagem superficial. Revista Brasileira de Meteorologia, Jaboticabal, v.13, n.1, p.45-52, 1998.

SILVEIRA, A.L.L. Provável efeito urbano nas relações IDF das chuvas de Porto Alegre. Revista Brasileira de Recursos Hídricos, Porto Alegre, v.2, n.2, p.93-107, 1997.

SALES, C. Teste t-student. Notas de Aula. Universidade Autónoma de Lisboa, UAL. Portugal, 2012.

SHIMAKURA, S.E.; E JUNIOR, P.J.R. Estatística. Departamento de Estatística, Universidade Federal do Paraná. Curitiba, 2004.

SILVA, C.B. Variabilidade Climática nos Oceanos e a Vazão Fluvial no Pantanal Brasileiro. 2012. 2001 f. Dissertação (Mestrado) - Faculdade de Filosofia Letras e Ciências Humanas, Universidade de São Paulo, 2012.

SUGAHARA, S., ROCHA, R.P., SILVEIRA, R., 2008. Non-stationary frequency analysis of extreme daily rainfall in São Paulo, Brazil, Int. J. Climate, DOI: 10.1002/joc. 1760.

TARIFA, J.T.; AZEVEDO, T.R. Os climas na cidade de São Paulo: Teoria e Prática. São Paulo: PróReitoria de Cultura e Extensão. Universidade de São Paulo: Laboratório de Climatologia. Faculdade de Filosofia, Letras e Ciências humanas. USP, 2001.

XAVIER, T.M.B.S., XAVIER, A.F.S. E DIAS, M.A.F.S, 1994: Evolução da precipitação diária num ambiente urbano: o caso da Cida de São Paulo. RBMET, 9(1): 44-53.

XAVIER, T.M.B.S., XAVIER, A.F.S. E DIAS, M.A.F.S, 1994: Evolução da precipitação diária num ambiente urbano: o caso da Cida de São Paulo. RBMET, 9(1): 44-53.

WILKEN, P.S. Engenharia de Drenagem Superficial. CETESB - Cia. de Tecnologia de Saneamento Ambiental, São Paulo, 1978. 
ZILLI, M.T. Variabilidade interanual da precipitação de primavera e verão na América do Sul, suas interconexões e seu impacto nos principais aproveitamentos hidrelétricos brasileiros Curitiba, 2007. 213 f.: il., tabs, grafs.

NATIONAL OCEANIC AND ATMOSPHERIC ADMINISTRATION (NOAA)

Disponível em < $\underline{\text { http: } / / \text { www.noaa.gov/> }}$

AMERICAN METEOROLOGICAL SOCIETY (AMS)

Disponível em <http://www.ametsoc.org/>

INTERGOVERNMENTAL PANEL ON CLIMATE CHANGE (IPCC)

Disponível em <http://www.ipcc.ch/>

CENTRO DE PREVISÃO DE TEMPO E ESTUdOS CLIMÁTICOS (CPTEC/INPE)

Disponível em $<\underline{w w w . c p t e c . i n p e . b r}>$

WORLD METEOROLOGICAL ORGANIZATION (WMO)

Disponível em <http://www.wmo.int/pages/index en.html>

OCEANIC NIÑO INDEX (ONI)

Disponível em <http://ggweather.com/enso/oni.html>

PREFEITURA DE SÃO PAULO

Disponível em <http://smdu.prefeitura.sp.gov.br/historico demografico/>

ESTAÇÃO METEOROLÓGICA DO IAG-USP

Disponível em <http://www.estacao.iag.usp.br/>

INSTITUTO BRASILEIRO DE GEOGRAFIA E ESTATÍSTICA (IBGE)

Disponível em <http://www.ibge.gov.br/home/> 


\section{OBRAS CITADAS}

DESCARTES, R. Discours de la Méthode. In: Oeuvres et Lettres. Paris: Gallimard, 1953 [1637].

EINSTEIN, A. "My Future Plans" an essay written at age 17 for school exam (18 September 1896) The Collected Papers of Albert Einstein Vol. 1 (1987) Doc. 22.

IPCC, 2001: Climate Change 2001: Impacts, Adaptation, and Vulnerability. Contribution of Working Group II to the Third Assessment Report of the Intergovernmental Panel on Climate Change, J.J. McCarthy, O.F. Canziani, N.A. Leary, D.J. Dokken and K.S. White, Eds., Cambridge University Press, Cambridge,1032 pp.

LLOYD P. GERSON, Knowing Persons: A Study in Plato. Oxford: Oxford University Press, 2003. Pp. 308. ISBN 0-19-925763-9.

NEWTON, ISAAC. Philosophiae Naturalis Principia Mathematica: Facsimile of third edition (1726) with variant readings; Vols. 1 and 2. In Latin.

SANTOS, M. O Intelectual e o dever da crítica. São Paulo: Humanitas. FFLCH/USP, 1998.

VAREJÃO, M. A. Meteorologia e Climatologia. Recife: Versão digital, 2006. 